DEPARTAMENTO DE DIDÁCTICA DE LA MATEMÁTICA Y DE LAS CIENCIAS EXPERIMENTALES UNIVERSIDAD DE SALAMANCA

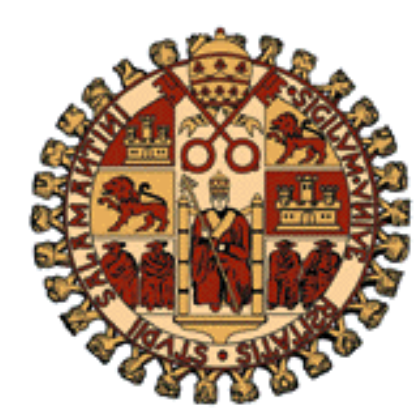

\title{
CONOCIMIENTO DIDÁCTICO DEL CONTENIDO SOBRE LA REPRESENTACIÓN DE DATOS ESTADÍSTICOS: ESTUDIOS DE CASOS CON PROFESORES DE ESTADÍSTICA EN CARRERAS DE PSICOLOGÍA Y EDUCACIÓN
}

\author{
Tesis doctoral de \\ Jesús Enrique Pinto Sosa \\ Realizado bajo la dirección de \\ Dra. María Teresa González Astudillo
}

Salamanca, 2010 

DEPARTAMENTO DE DIDÁCTICA DE LA MATEMÁTICA Y DE LAS CIENCIAS EXPERIMENTALES UNIVERSIDAD DE SALAMANCA

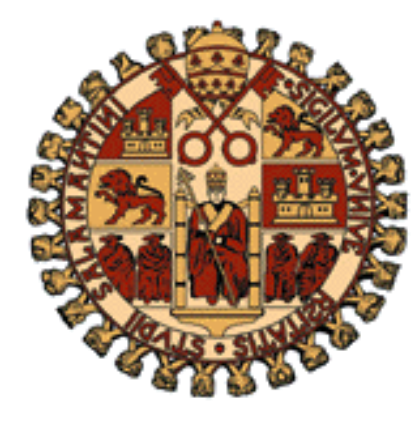

CONOCIMIENTO DIDÁCTICO DEL CONTENIDO SOBRE LA REPRESENTACIÓN DE DATOS ESTADÍSTICOS: ESTUDIOS DE CASOS CON PROFESORES DE ESTADÍSTICA EN CARRERAS DE PSICOLOGÍA Y EDUCACIÓN

TESIS DOCTORAL

Jesús Enrique Pinto Sosa

Salamanca, 2010 
DEPARTAMENTO DE DIDÁCTICA DE LA MATEMÁTICA Y DE LAS CIENCIAS EXPERIMENTALES UNIVERSIDAD DE SALAMANCA

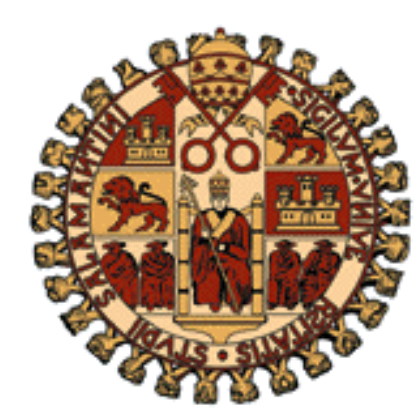

\title{
CONOCIMIENTO DIDÁCTICO DEL CONTENIDO SOBRE LA REPRESENTACIÓN DE DATOS ESTADÍSTICOS: ESTUDIOS DE CASOS CON PROFESORES DE ESTADÍSTICA EN CARRERAS DE PSICOLOGÍA Y EDUCACIÓN
}

\author{
Tesis doctoral de \\ Jesús Enrique Pinto Sosa \\ Realizado bajo la dirección de \\ Dra. María Teresa González Astudillo
}

Salamanca, 2010 


\section{DSALAMANCA}

VNIVERSIDAD

Dra. María Teresa González Astudillo, Profesora Titular de Universidad del Departamento de Didáctica de la Matemática y Didáctica de las Ciencias Experimentales de la Universidad de Salamanca

\section{HAGO CONSTAR:}

Que la presente memoria titulada Conocimiento didáctico del contenido sobre la representación de datos estadísticos: estudios de casos con profesores de Estadística en carreras de Psicología y Educación, ha sido realizada bajo mi dirección por Jesús Enrique Pinto Sosa y constituye su tesis para optar al grado de doctor.

Y para que conste y tenga los efectos oportunos ante el Departamento de Didáctica de la Matemática y de las Ciencias Experimentales de la Universidad de Salamanca, firmo el presente documento.

Salamanca a de de dos mil diez.

Fdo: 



\title{
Resumen
}

\section{Conocimiento didáctico del contenido sobre la representación de datos estadísticos: estudios de casos con profesores de Estadística en carreras de Psicología y Educación}

\author{
por \\ Jesús Enrique Pinto Sosa
}

Desde el trabajo pionero de Lee Shulman a mediados de los 80 s, el conocimiento didáctico del contenido (CDC) ha suscitado un gran interés como modelo para mejorar la formación de profesores y como objeto de estudio. Si bien el CDC en educación matemática ha tenido bastante interés en los últimos años, ha sido un constructo teórico poco explorado en la educación estadística, sobre todo en el contexto de México. La investigación explora el CDC de dos profesores noveles (uno con formación matemática y otro psicólogo) que enseñan Estadística a estudiantes de Educación y Psicología, respectivamente. El estudio tuvo como objetivos describir las concepciones que tienen los profesores sobre la Estadística, su enseñanza y aprendizaje y, más concretamente, sobre la representación gráfica, así como el conocimiento que tienen del tópico, de las estrategias y representaciones instruccionales y del conocimiento del estudiante sobre la representación gráfica en Estadística. El análisis se centró en comprender la cognición del profesor, constituida por lo que conoce y hace y las razones por las que actúa.

Con base en una revisión conceptual y metodológica de las investigaciones del CDC en educación matemática y estadística sobre el conocimiento profesional del profesor y de un análisis del contenido utilizando una aproximación empírica, inductivo - deductiva, se determinó un Sistema de Dimensiones e Indicadores (SDI) del CDC correspondientes a tres categorías: el conocimiento del contenido de la disciplina a enseñar, el conocimiento de estrategias y representaciones instruccionales y el conocimiento del estudiante. Se definieron los objetivos de aprendizaje específicos de la representación gráfica al nivel de pensamiento estadístico, los cuales junto con el SDI del CDC ayudaron a delimitar y definir la instrumentación necesaria para el estudio.

Desde una perspectiva cualitativa se solicitó a los profesores proporcionen información a través de diferentes técnicas: a) entrevista contextual, biográfica y sobre la planeación de las clases sobre representación gráfica, b) cuestionario didáctico sobre representación gráfica (el cual consistió en cuatro situaciones-problemas sobre su enseñanza y aprendizaje), c) entrevista en profundidad respecto de las respuestas al cuestionario, y d) análisis de materiales para la enseñanza de la representación gráfica (ej. programa y notas de curso, ejercicios, exámenes, libros de texto y libretas de los estudiantes).

Los resultados de este estudio revelan que el CDC de cada profesor está influenciado por su concepción hacia la matemática y la estadística, la formación que recibió como estudiante y la experiencia que tiene en investigar en contextos diferentes a la matemática. Se encontró que se utiliza un repertorio reducido de estrategias para la enseñanza de la representación gráfica y que exclusivamente se estudia al nivel de lectura de gráficos. Esto es atribuible tanto al CDC de cada profesor como al currículo escolar cuyo objetivo es sólo revisar los 
gráficos más usuales (ej. barras, circular, histograma) exclusivamente para la construcción y la presentación de resultados de investigación.

Se confirman algunas relaciones significativas, como la relación entre las concepciones de la Estadística y la RG, su enseñanza y aprendizaje y el CDC, así como entre las características del CDC y la formación inicial del profesor, las experiencias previas como estudiante, el contexto escolar, la actitud positiva del profesor hacia su formación permanente como docente, y el conocimiento del contenido a enseñar, destacando la experiencia docente del profesor como elemento diferenciador en algunos aspectos relativos a la práctica docente.

Los resultados nos permitieron también darnos cuenta que los profesores sostienen una concepción diferente sobre la Estadística que sobre la RG, su aprendizaje y enseñanza. Asimismo, presentan algunas dificultades relacionadas con la adquisición del conocimiento de algún(os) dominio(s) del CDC o de su integración como son: relacionar el conocimiento del contenido a enseñar con las representaciones instruccionales y el conocimiento del proceso de aprendizaje del estudiante; utilizar una variedad de recursos y materiales para la enseñanza de la representación gráfica; y conocer el contenido y estudio de la representación gráfica, más allá de la construcción de gráficos.

La investigación sustenta la necesidad de planificar, desarrollar, implementar y evaluar programas de formación de profesores con enfoques diferentes a los actuales, a la luz de la educación estadística, centrados en el desarrollo del CDC en Estadística. Asimismo, se sugiere revisar y modificar el currículo de la enseñanza de la Estadística en las áreas sociales, así como adquirir bibliografía más reciente que aborde el estudio de los diferentes tópicos a partir de las reformas y tendencias de la educación estadística. 


\section{DEDICATORIA}

A mi hijo Diego Iván

-iii- 


\section{AGRADECIMIENTOS}

A Dios, por su infinita bondad, amor y compañía en mi vida.

A mi directora de tesis, la Dra. María Teresa González Astudillo, que siempre tuvo a bien encontrar la forma apropiada de guiarme en la elaboración de la investigación. Gracias por haber estado siempre al pendiente de mis avances, por darme siempre ánimos, por ayudarme a construir una tesis doctoral de calidad y sobretodo por la amistad cultivada en estos años.

A los profesores que han colaborado en la revisión y asesoría en las diferentes fases de la tesis, en especial al Dr. Salvador Llinares, a la Dra. Angustias Vallecillos, a la Dra. Mar Moreno, la Dra. Carmen Batanero y al Dr. Lorenzo Blanco. Gracias por sus aportaciones y contagiarme el entusiasmo por la investigación.

A la Mtra. María Elena Barrera Bustillos, decana de la Facultad de Educación de la Universidad Autónoma de Yucatán, por su siempre decido apoyo a lo largo de mi formación doctoral. Gracias porque a través suyo, siempre obtuve la ayuda financiera necesaria para desarrollar y finalizar mis estudios de doctorado.

A la Universidad Autónoma de Yucatán, institución de donde provengo y laboro, que a través del Dr. Raúl Godoy Montañez y al MVZ. M. Phil. Alfredo Dájer Abimerhi, quienes como rectores apuestan por la formación de doctores en la universidad.

A Alicia y Luis, quienes de manera voluntaria y decidida colaboraron en la investigación como profesores en los estudios de casos.

A la Dra. Guadalupe Moreno Bayardo, mi madrina, quien me ayudó a comprender día a día lo que implicaba obtener un doctorado. Gracias por escuchar, por sus palabras de aliento y sobretodo por compartir sus experiencias, abrirme las puertas de su hogar y nutrir durante estos años una bonita amistad.

No puedo olvidar un agradecimiento muy especial a mis padres y hermanos, quienes siempre encontraron la forma de motivarme en cada momento. Gracias por los detalles, por los abrazos y por creer en mi.

A Verónica, mi esposa, por comprender este proceso y sobre todo apoyarme en la parte final de la tesis. Eres parte de este sueño.

A todos mis amigos que me han apoyado y acompañado a lo largo de estos años. Gracias por siempre encontrar la manera de sentirme querido, apoyado, motivado y confiado para terminar el doctorado. 


\section{CONTENIDO}

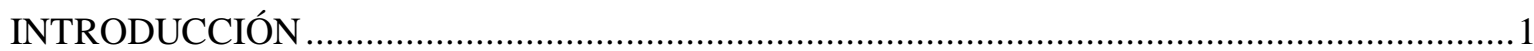

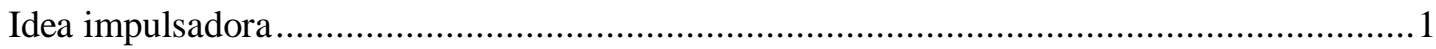

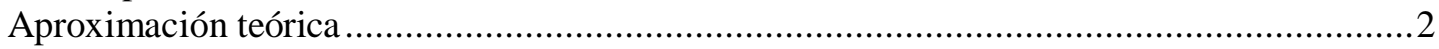

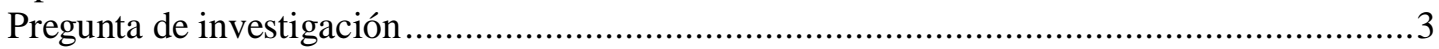

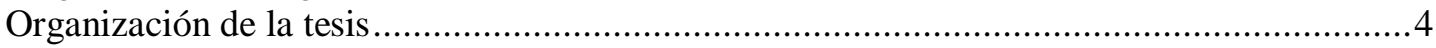

CAPÍTULO 1: Marco teórico del Conocimiento Didáctico del Contenido .....................................7

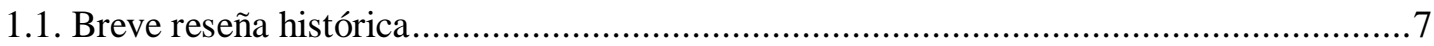

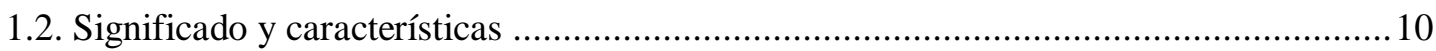

1.3. Importancia e implicaciones .................................................................................... 13

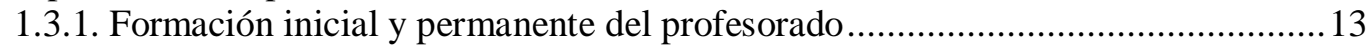

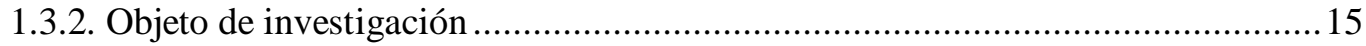

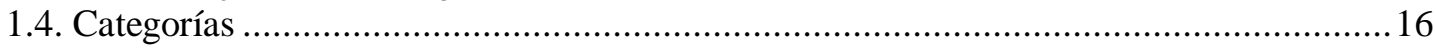

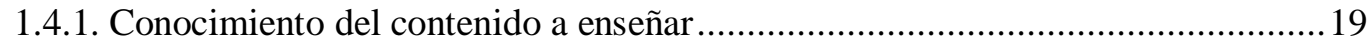

1.4.2. Conocimiento de las estrategias y representaciones instruccionales .....................24

1.4.3. Conocimiento de los procesos de aprendizaje del alumno .................................31

1.5. Investigaciones sobre el conocimiento didáctico del contenido del profesor de

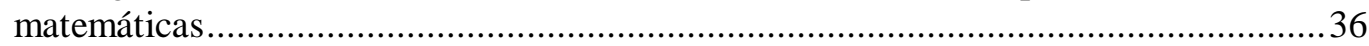

1.5.1. Caracterización del CDC, su significado y asociación con otros constructos .......37

1.5.2. Estudios sobre el conocimiento del contenido a enseñar ....................................44

1.5.3. Estudios sobre el conocimiento de las representaciones instruccionales .............49

1.5.4. Estudios sobre conocimiento del estudiante ...................................................50

1.5.5. Estudios para desarrollar el CDC en profesores de matemáticas........................54

1.5.6. Estudios relacionados con las actitudes del profesor ........................................56

1.5.7. Investigaciones en el campo de la enseñanza de las ciencias ............................57

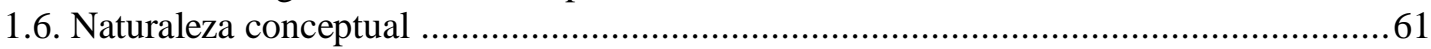

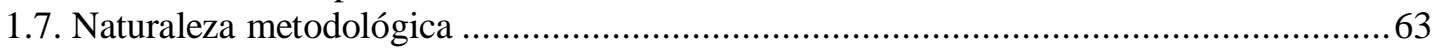

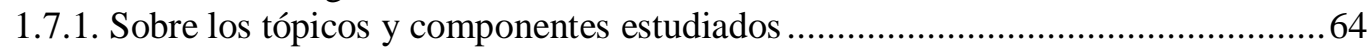

1.7.2. Sobre el CDC de los profesores de matemáticas ...............................................64

1.7.3. De los diseños y sujetos de investigación..........................................................65

1.7.4. De los instrumentos y procedimientos de recolección de datos .............................66

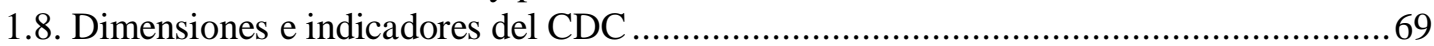

1.8.1. Fase I. Generación de preguntas clave .......................................................... 70

1.8.2. Fase II. Determinación de los constructos o conceptos a estudiar por

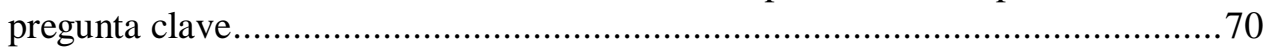

1.8.3. Fase III. Construcción de mapas conceptuales ............................................. 70

1.8.4. Fase IV. Primera versión de las dimensiones e indicadores .............................71

1.8.5. Fase V. Análisis a priori de las dimensiones e indicadores ............................... 72

1.8.6. Fase VI. Dimensiones e indicadores del CDC ................................................72

1.9. Análisis de las investigaciones sobre CDC a partir de las dimensiones e indicadores ... 75

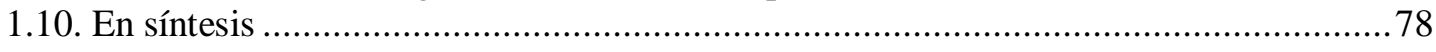

CAPÍTULO 2: Marco teórico del estudio de la representación gráfica en Estadística ....................81

2.1. La investigación en educación estadística y el conocimiento didáctico del contenido del profesor

2.1.1. Antecedentes del estudio del conocimiento didáctico del contenido

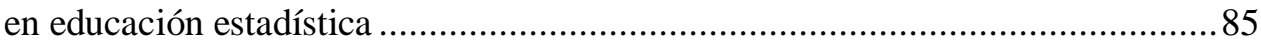

2.1.2. El estudio del conocimiento didáctico del contenido en Estadística ...................90

2.2. La representación gráfica como línea de investigación ............................................97 
2.3. El estudio de la representación gráfica en Estadística..... 103

2.3.1. Investigaciones sobre el estudio de las concepciones, errores y dificultades

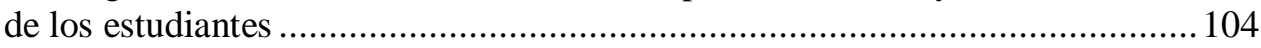

2.3.2. Materiales y estudios para aprender y desarrollar la comprensión gráfica ..........107

2.3.3. Desarrollo de instrumentos para medir la comprensión gráfica.......................... 109

2.3.4. Estudios teóricos sobre la representación gráfica en Estadística ....................... 110

2.3.5. Investigaciones sobre las concepciones y la comprensión conceptual de los estudiantes para profesor y los profesores sobre la representación gráfica .........114

2.3.6. Estudios sobre la formación de profesores en la enseñanza de la representación gráfica

2.4. Perspectivas cognitivas del desarrollo de la representación gráfica en Estadística ........119

2.4.1. Niveles cognitivos de la comprensión gráfica ............................................... 120

2.4.2. Tópicos de estudio de la representación de datos ......................................... 125

2.4.3. Diseño, instrumentos e ítems que estudian la representación gráfica ................. 128

2.4.3.1. Localización y análisis de los diseños e instrumentos de investigación 128

2.4.3.2. Análisis de los ítems que exploran la representación gráfica................ 131

2.5. La representación gráfica en educación superior: el pensamiento estadístico ............... 133

2.5.1. Objetivos sobre representación gráfica, por nivel cognitivo .............................. 133

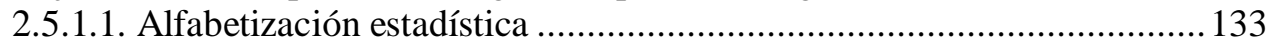

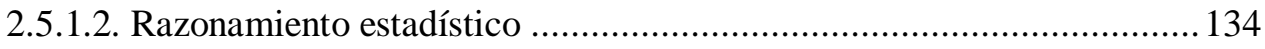

2.5.1.3. Pensamiento estadístico ............................................................ 134

2.5.2. Objetivos de aprendizaje específicos sobre representación gráfica

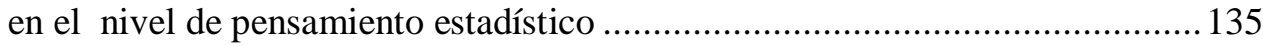

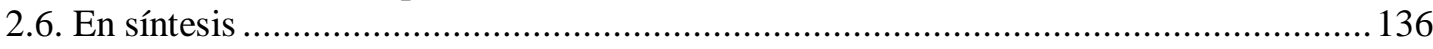

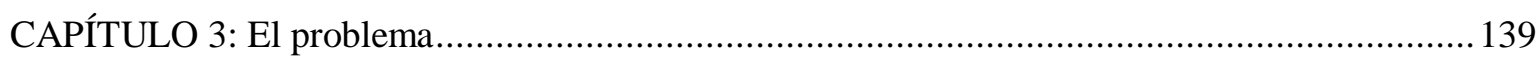

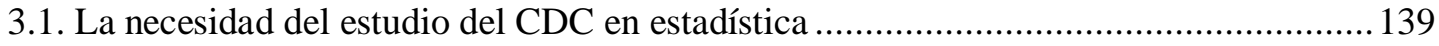

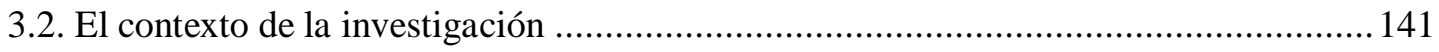

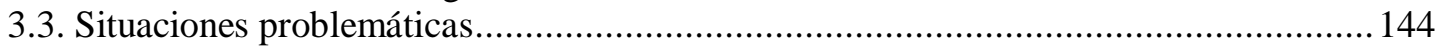

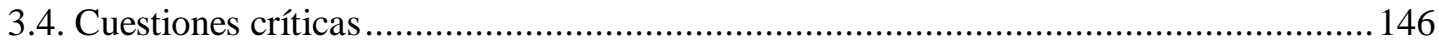

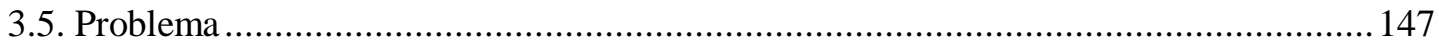

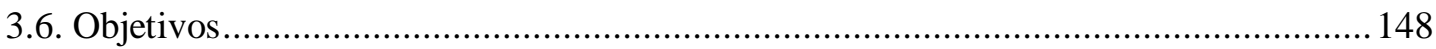

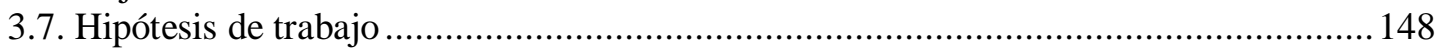

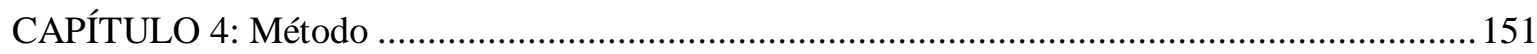

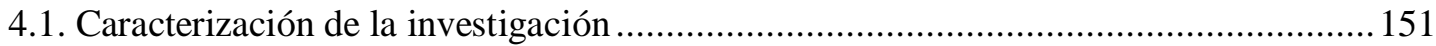

4.1.1. Línea de investigación: conocimiento profesional del profesor ....................... 151

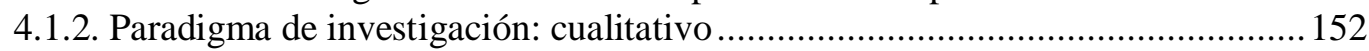

4.1.3. Diseño: estudio de casos........................................................................... 153

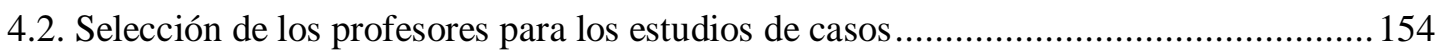

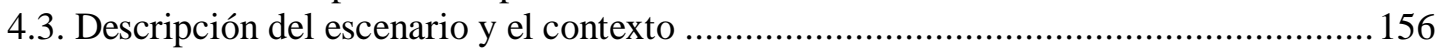

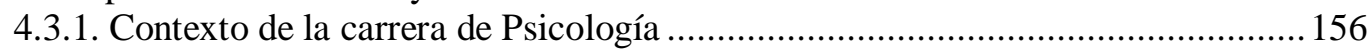

4.3.2. Contexto de la carrera de Educación .................................................................. 157

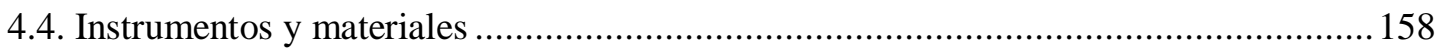

4.4.1. Programas de los cursos de Estadística ....................................................... 159

4.4.2. Guión de entrevista contextual, biográfica y sobre la planificación

de las clases del tema de RG .................................................................. 160

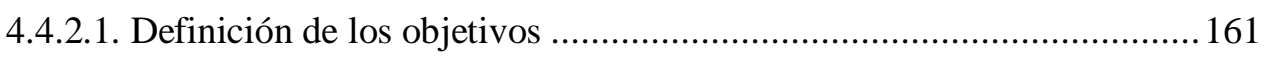

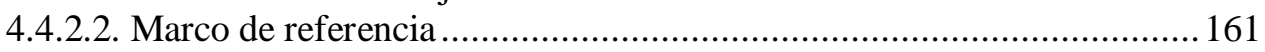

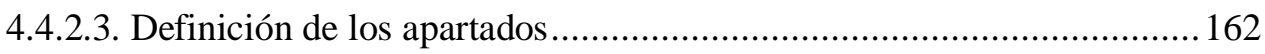

4.4.2.4. Revisión de los lineamientos metodológicos ..................................... 162 


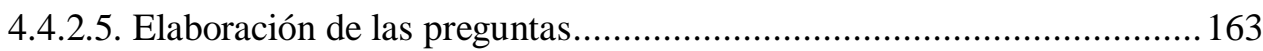

4.4.2.6. Clasificación y propósito de cada pregunta ........................................ 163

4.4.2.7. Análisis de jueces expertos y prueba piloto ....................................... 163

4.4.2.8. Versión definitiva del guión de entrevista ......................................... 164

4.4.3. Cuestionario didáctico sobre representación gráfica ....................................... 164

4.4.3.1. Preguntas orientadoras para explorar el CDC................................. 165

4.4.3.2. Cuestionario diagnóstico sobre representación gráfica. ....................... 166

4.4.3.3. Análisis del cuestionario diagnóstico. ............................................. 167

4.4.3.4. Versión definitiva del cuestionario didáctico sobre

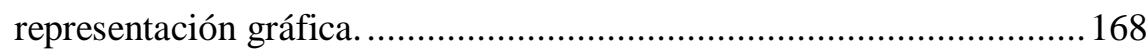

4.4.4. Entrevista en profundidad respecto de las respuestas al cuestionario ................. 177

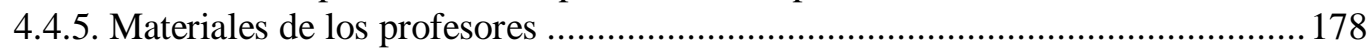

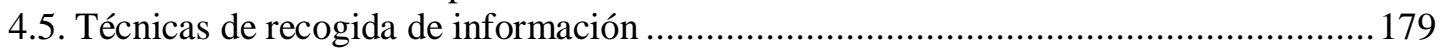

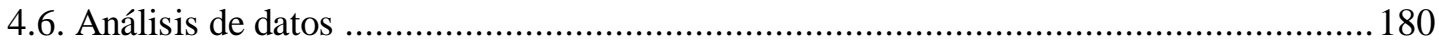

4.6.1. Transcripción y análisis de las entrevistas.................................................... 180

4.6.2. Método de análisis cuestionario didáctico sobre representación gráfica ............. 184

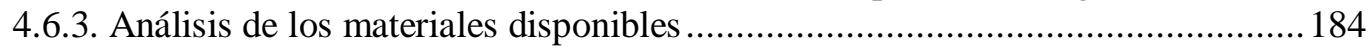

4.6.4. Análisis de las concepciones, creencias, errores y dificultades .......................... 185

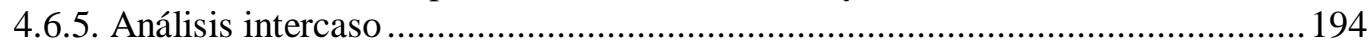

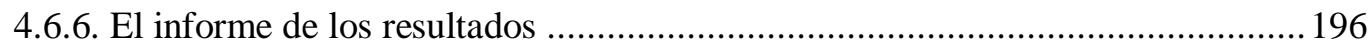

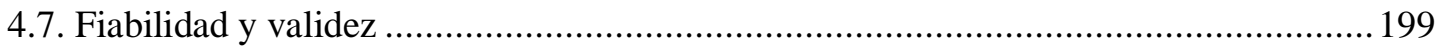

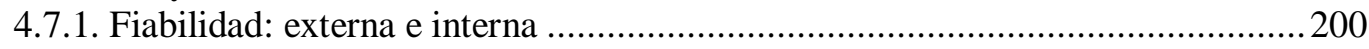

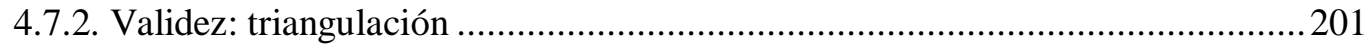

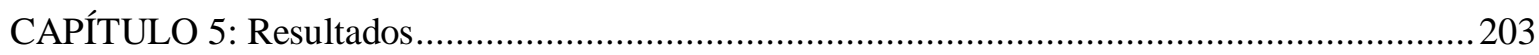

5.1. El caso de Alicia: aprender a enseñar estadística a futuros educadores.......................203

5.1.1. Formación profesional, interés y motivación como profesora.............................204

5.1.2. Origen y desarrollo del conocimiento de Alicia .............................................206

5.1.3. Concepciones sobre Estadística, su aprendizaje y enseñanza............................208

5.1.4. Concepciones sobre la representación gráfica, su aprendizaje y enseñanza.......2215

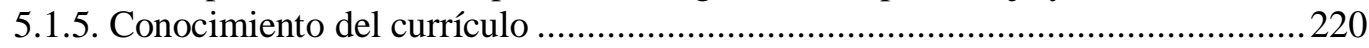

5.1.5.1. Del programa de la asignatura de Estadística ....................................220

5.1.5.2. De los objetivos y contenido de aprendizaje de la

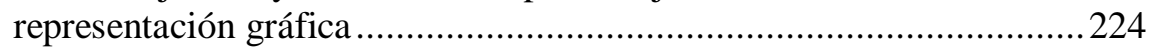

5.1.6. Conocimiento de las estrategias y representaciones instruccionales ................. 232

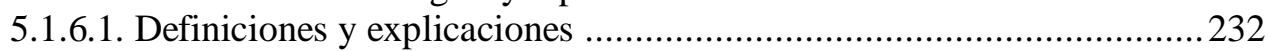

5.1.6.2. Preguntas .......................................................................... 234

5.1.6.3. Ejemplos y ejercicios........................................................ 237

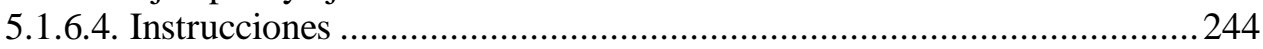

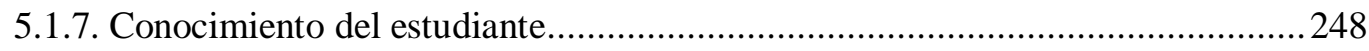

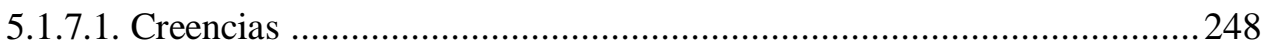

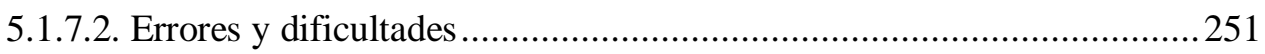

5.1.8. Identificación y diagnóstico del conocimiento del estudiante ...........................264

5.1.9. Estrategias específicas para corregir errores y dificultades ............................. 266

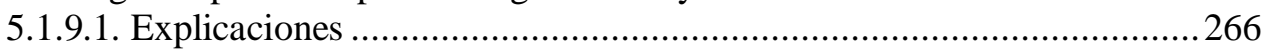

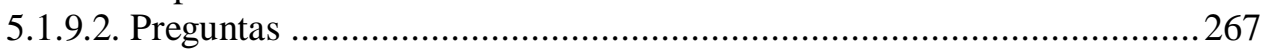

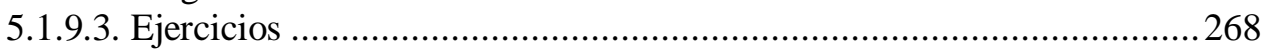

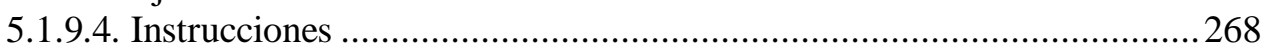

5.1.10. Dificultades para enseñar................................................................ 271

5.1.11. En síntesis: el conocimiento didáctico del contenido de Alicia ......................2274 
5.2. El caso de Luis: disfrutar enseñando Estadística a partir de investigaciones

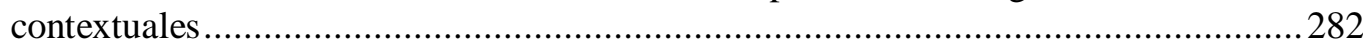

5.2.1. Formación profesional, interés y motivación como profesor ..........................2282

5.2.2. Origen y desarrollo del conocimiento de Luis ...............................................2. 286

5.2.3. Concepciones sobre la Estadística, su aprendizaje y enseñanza ........................292

5.2.4. Concepciones sobre la representación gráfica, su aprendizaje y enseñanza........ 307

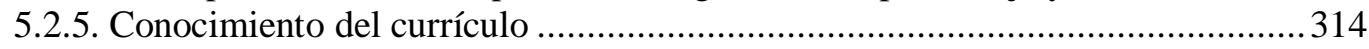

5.2.5.1. Del programa de la asignatura de Estadística .................................... 314

5.2.5.2. De los objetivos y contenidos de aprendizaje de la

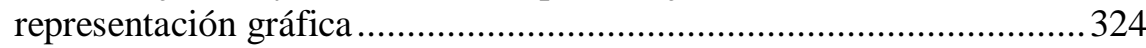

5.2.6. Conocimiento de las estrategias y representaciones instruccionales...................336

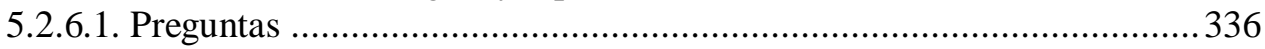

5.2.6.2. Manipulación de datos y gráficos................................................. 340

5.2.6.3. Proyectos de investigación............................................................. 341

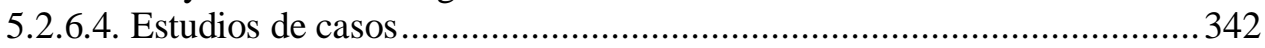

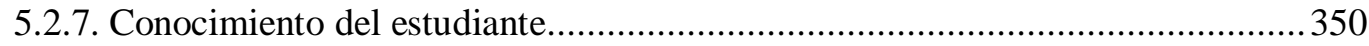

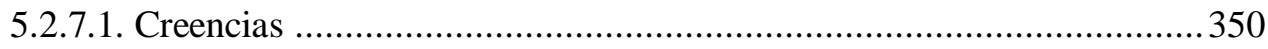

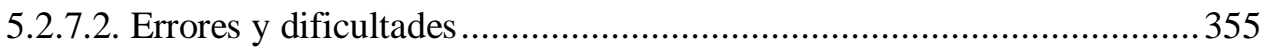

5.2.8. Identificación y diagnóstico del conocimiento del estudiante ........................... 366

5.2.9. Estrategias específicas para corregir errores y dificultades ….............................366

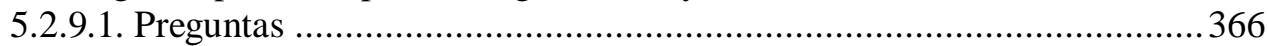

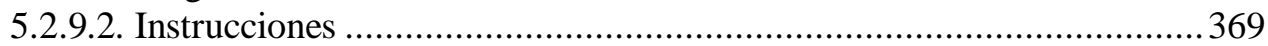

5.2.10. En síntesis: el conocimiento didáctico del contenido de Luis.......................... 372

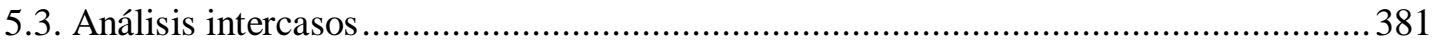

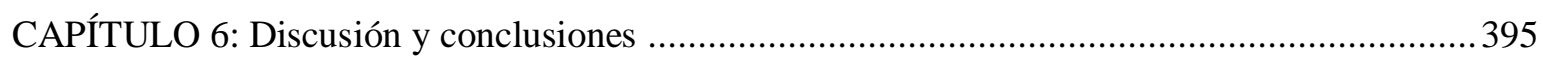

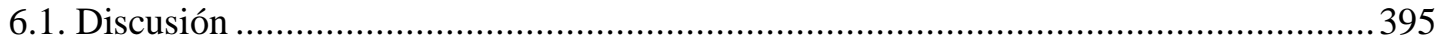

6.2. Consecución de los objetivos de investigación .........................................................400

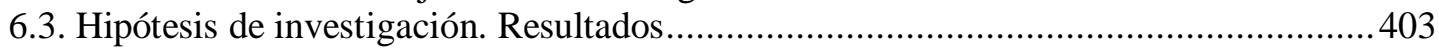

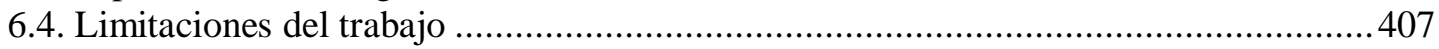

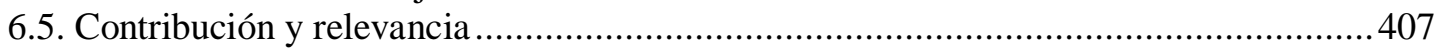

6.6. Implicaciones para futuras investigaciones y para la enseñanza .............................. 410

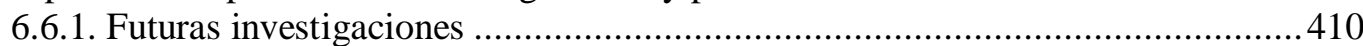

6.6.2. Enseñanza de la Estadística y de la representación gráfica ............................. 411

REFERENCIAS

APÉNDICES (CD-ROM)

A. Análisis de componentes y categorías del CDC para la generación de dimensiones e indicadores del CDC

B. Análisis curricular de los programas de estadística de Psicología y Educación

C. Programas de la asignatura de Estadística

D. Protocolo para la valoración de la validez de contenido del guión de entrevista por jueces expertos

E. Guión de entrevista contextual, biográfica y sobre la planeación de las clases del tema de representación gráfica

F. Preguntas orientadoras para explorar el CDC

G. Cuestionario didáctico sobre representación gráfica

H. Protocolos de entrevistas en profundidad

I. Carta de consentimiento

J. Transcripciones de las entrevistas. Caso Alicia

K. Transcripciones de las entrevistas. Caso Luis 


\section{TABLAS}

Tabla 1.1. Matriz de las propuestas de categorías del CDC según diversos autores ...................18

Tabla 1.2. Componentes del conocimiento del contenido matemático a enseñar ......................23

Tabla 1.3. Componentes del conocimiento de las estrategias y representaciones instruccionales de las matemáticas

Tabla 1.4. Componentes del conocimiento de los procesos de aprendizaje del estudiante sobre el contenido matemático 35

Tabla 1.5. Categorías para describir los cuatro aspectos de las preguntas sobre enseñanza del CDC, según An, Kulm y Wu (2004, pp.154-155).

Tabla 1.6. Tópicos y énfasis sobre el o los componentes estudiados del CDC en el campo de la educación matemática

Tabla 1.7. Resumen de los diseños de investigación, sujetos seleccionados y criterios de selección para estudios de casos en el estudio del CDC

Tabla 1.8. Tipos de instrumentos y formas de recolección utilizados en estudios sobre CDC......68

Tabla 1.9. Dimensiones e Indicadores de los componentes del CDC ....................................74

Tabla 1.10. Ejemplo de preguntas y clasificación según el SDI del CDC del Problema 1 sobre el Cuestionario sobre Enseñanza de las Fracciones, por An, Kulm, Wu (2004, p.152). .77

Tabla 1.11. Clasificación de 79 preguntas (en 24 problemas) según el SDI del CDC .77

Tabla 2.1. Taxonomía de habilidades requeridas para la comprensión gráfica según Curcio (1987) y Friel, Curcio y Brigth (2001).

Tabla 2.2. Taxonomía de las demandas cognitivas de aprendizaje matemático, según Porter y Smithson (2001) y Porter (2002 en Sorto, 2004) ....

Tabla 2.3. Taxonomía sobre los resultados esperados de aprendizaje en Estadística según Garfield (2002) y Garfield, delMas y Chance (2003)....

Tabla 2.4. Tareas específicas que demanda la representación gráfica según Sorto (2004) con base en la clasificación de delMas (2002) y Garfield (2002)

Tabla 2.5. Tareas que pueden distinguir el tipo de preguntas para los niveles de comprensión del aprendizaje estadístico, en delMas (2002) y Garfield, delMas y Chance (2003) . 125

Tabla 2.6. Objetivos de aprendizaje del Estándar de Estadística, según NCTM (1991 y 2003) en EEUU

Tabla 2.7. Matriz de los diseños e instrumentos de investigación sobre representación gráfica.....

Tabla 4.1. Resumen de los datos demográficos y de formación inicial de profesores de Estadística en carreras de Psicología y Educación, curso 2005-2006 ....

Tabla 4.2. Análisis del tema de la representación gráfica según los programas de Estadística de Psicología y Educación que imparten Alicia y Luis

Tabla 4.3. Clasificación de las preguntas del Cuestionario Didáctico sobre Representación Gráfica según el SDI del CDC. 168 
Tabla 4.4. Distribución de las preguntas del Caso 1 por SDI del CDC y los niveles cognitivos de pensamiento estadístico de la representación gráfica

Tabla 4.5. Distribución de las preguntas del Caso 2 por el SDI del CDC y los niveles cognitivos de pensamiento estadístico de la representación gráfica

Tabla 4.6. Distribución de las preguntas del Caso 3 por el SDI del CDC y los niveles cognitivos de pensamiento estadístico de la representación gráfica

Tabla 4.7. Distribución de las preguntas del Caso 4 por el SDI del CDC y los niveles cognitivos de pensamiento estadístico de la representación gráfica

Tabla 4.8. Clasificación de los ítems del cuestionario didáctico sobre representación gráfica según los niveles de pensamiento estadístico.

Tabla 4.9. Resultados de las concepciones sobre la Estadística, según Reid y Petocz (2002). .. 187

Tabla 4.10. Relación entre las categorías utilizadas para presentar los resultados de la investigación y el SDI del CDC

Tabla 5.1. Preguntas elaboradas por Alicia como estrategia para responder a casos del cuestionario didáctico sobre representación gráfica....

Tabla 5.2. Afirmaciones que confirman que Alicia no hace actividades similares a los casos del cuestionario

Tabla 5.3. Relación del tipo de creencias y las atribuciones que Alicia conoce de los estudiantes

Tabla 5.4. Relación del tipo de errores y dificultades y las atribuciones que conoce Alicia de los estudiantes a partir del cuestionario

Tabla 5.5. Resumen de las estrategias y propósito de aprendizaje sugeridas por Alicia a partir de las preguntas del cuestionario.

Tabla 5.6. Ejemplos de las dificultades expresadas por Alicia para enseñar

Tabla 5.7. Preguntas elaboradas por Luis como estrategia para responder a casos del cuestionario didáctico sobre representación gráfica.

Tabla 5.8. Relación del tipo de creencias y las atribuciones que Luis conoce de los estudiantes

Tabla 5.9. Relación del tipo de errores y dificultades y las atribuciones que conoce Luis de los estudiantes a partir del cuestionario.

Tabla 5.10. Resumen de las estrategias y propósito de aprendizaje sugeridas por Luis a partir de las preguntas del cuestionario 


\section{FIGURAS}

Figura 1.1. Estructura de CDC en quinto grado, sobre equivalencia de fracciones.

Fuente: Marks (1989, Fig. 2, p.11)...

Figura 1.2. Subcategorías de CDC en quinto grado, sobre equivalencia de fracciones.

Fuente: Marks (1990b, Fig.1, p.5).....

Figura 1.3. Ejemplo de ítems del cuestionario de Even (1993).

Figura 2.1. Componentes del conocimiento del profesor en relación al pensamiento estadístico y de investigación (Burgess, 2006). .88

Figura 2.2. Perfil del conocimiento estadístico para la enseñanza de Linda, según Burgess (2008)

Figura 2.3. Ejemplo del tipo de análisis hecho por cada ítem que estudia la representación gráfica.

Figura 4.1. Ejemplo del ejercicio 1, utilizado en el cuestionario diagnóstico sobre representación gráfica dirigido a estudiante de Psicología y Educación 167

Figura 4.2. Ejemplo de tabla discursiva en la entrevista contextual y biográfica de Alicia 182

Figura 5.1. Forma habitual de la clase de Alicia. 212

Figura 5.2. Concepciones de Alicia sobre la Estadística, su aprendizaje y su enseñanza, con base en Reid y Petocz (2002) y Petocz y Reid (2002).... 215

Figura 5.3. Concepciones de Alicia sobre la representación gráfica, su aprendizaje y su enseñanza .....

Figura 5.4. Ejemplo del tipo de ejercicios en los exámenes de Alicia (Eje.CA.01) ...................223

Figura 5.5. Ejemplo de definición utilizado por Alicia del tema de gráfico circular 233

Figura 5.6. Ejemplo representativo del tipo de ejercicios que utiliza Alicia en el tema de la RG

Figura 5.7. Ejemplo utilizado por Alicia para que los alumnos comprendan la importancia del uso de la escala en los ejes.....

Figura 5.8. Ejemplo de ejercicio que utiliza Alicia donde solicita el cálculo de valores estadísticos.

Figura 5.9. Ejemplo del tipo de ejercicio centrado en la interpretación de la RG .... 243

Figura 5.10. Forma habitual de la clase de Luis 303

Figura 5.11. Concepciones de Luis sobre la Estadística, su aprendizaje y su enseñanza, con base en Reid y Petocz (2002) y Petocz y Reid (2002)

Figura 5.12. Concepciones de Luis sobre la representación gráfica, su aprendizaje y su enseñanza

Figura 5.13. Ejemplo de ejercicio de carácter rutinario o mecánico que utiliza Luis 319

Figura 5.14. Ejemplo de ejercicio colaborativo para desarrollar la habilidad para elaborar hipótesis 
Figura 5.15. Ejemplo de un cuestionario elaborado por un grupo de estudiantes sobre el tema de satisfacción marital

Figura 5.16. Ejemplo de ejercicio elaborado por un estudiante a partir de un ejercicio con el SPSS. 334

Figura 5.17. Ejemplo del índice de un proyecto de investigación ........................................... 342

Figura 5.18. Ejemplo del estudio de casos: el efecto Mozart. ................................................. 344

Figura 5.19. Ejemplo del estudio de casos: el efecto Mozart (continuación). ................................345

Figura 5.20. Rasgos característicos de la dimensión concepciones sobre la enseñanza y aprendizaje de la Estadística del CDC de Alicia

Figura 5.21. Rasgos característicos de la dimensión concepciones sobre la enseñanza y aprendizaje de la Estadística del CDC de Luis 384

Figura 5.22. Rasgos característicos de la dimensión conocimiento del currículo del CDC de Alicia

Figura 5.23. Rasgos característicos de la dimensión conocimiento del currículo del CDC de Luis.

Figura 5.24. Rasgos característicos de la dimensión conocimiento de las estrategias de enseñanza específicas del CDC de Alicia

Figura 5.25. Rasgos característicos de la dimensión conocimiento de las estrategias de enseñanza específicas del CDC de Luis.

Figura 5.26. Rasgos característicos de la dimensión conocimiento de las creencias, errores y dificultades en el estudiante del CDC de Alicia

Figura 5.27. Rasgos característicos de la dimensión conocimiento de las creencias, errores y dificultades en el estudiante del CDC de Luis

Figura 5.28. Rasgos característicos de la dimensión conocimiento de las estrategias para ayudar al estudiante del CDC de Alicia

Figura 5.29. Rasgos característicos de la dimensión conocimiento de las estrategias para ayudar al estudiante del CDC de Luis..... 


\section{SIGLAS Y ABREVIATURAS}

ARTIST

APA

ASA

$\mathrm{Bib}$

CA

CAOS

CAP

$\mathrm{CC}$

CDC

CE

CER

CINVESTAV-

IPN

CL

CLAME

CONACYT

$\mathrm{Cu}$

C-1, C-2, C-3, C-4

E

E1

E2

EDA

EGB

Eje

ELEE

ENSY

EPPs

Exa

FMUADY
Assessment Resource Tools for Improving Statistical Thinking

American Psychological Association

American Stadistical Association

Bibliografía del programa

Caso Alicia

Comprehensive Assessment of Outcomes in Statistics

Curso de Aptitud Pedagógica

Conocimiento del contenido a enseñar

Conocimiento didáctico del contenido

Conocimiento del estudiante sobre el contenido a estudiar

Conocimiento de las estrategias y representaciones

instruccionales

Centro de Investigación y de Estudios Avanzados del Instituto

Politécnico Nacional

Caso Luis

Comité Latinoamericano de Matemática Educativa

Consejo Nacional de Ciencia y Tecnología

Cuestionario didáctico sobre la representación gráfica

Caso 1, 2, 3 y 4 del cuestionario didáctico sobre representación gráfica

Guión de entrevista

Entrevista contextual y biográfica

Entrevista en profundidad

Exploratory Data Analysis

Educación General Básica

Ejercicios que utiliza el profesor

Encuentro Latinoamericano de Educación Estadística

Escuela Normal Superior de Yucatán

Estudiantes para profesores

Exámenes del profesor

Facultad de Matemáticas de la Universidad Autónoma de Yucatán 
GAEDS

GAISE

IASE

ICME

ICMI

ICOTS

INSPIRE

ISI

ITESM

LD

LED

$\mathrm{Lib}$

LMD

Mat

MKT

NCTM

$\mathrm{Ncu}$

ND

OCDE

PCK

PCM

PISA

Pre

Pro

RG

RIQ

SCAS

SDI

SOLO

SPSS

SRTL

TOGS

TUSG
Guide to Analyse and Evaluate the Didactial Suitability, Guidelines for Assessment and Instruction in Statistics Education International Association for Statistical Education International Congress on Mathematical Education International Commission on Mathematical Instruction International Conference on the Teaching of Statistics Insight into Statistical Practice, Instruction and Reasoning International Statistical Institute

Instituto Tecnológico de Estudios Superiores de Monterrey Leer datos

Leer entre Datos

Libreta del estudiante

Leer más allá de los datos

Materiales de lectura o de apoyo del profesor

Mathematical Knowledge for Teaching

National Council of Teachers of Mathematics

Notas de curso del profesor

No disponible

Organización para la Cooperación y Desarrollo Económico

Pedagogical Content Knowledge

Parcial Credit Model

Programa Internacional para la Evaluación de Estudiantes

Presentaciones (diapositivas) utilizadas por el profesor

Programa de curso de Estadística en extenso

Representación Gráfica

Rango Intercuartílico

STARC-CHANCE Abbreviated Scale

Sistema de Dimensiones e Indicadores

The Structure of Observed Learning Outcomes

Statistical Package for the Social Sciences

Statistical Reasoning, Thinking and Literacy

Test of Graphing in Science

Test of students' Understanding os Statistical Graph 
Gráfico de Tallo y Hoja

USG

Understanding of Statistical Graph

-XV- 



\section{INTRODUCCIÓN}

\section{IDEA IMPULSADORA}

En el Estado de Yucatán, México, existen muchas instituciones de educación superior, como por ejemplo: la Universidad Autónoma de Yucatán, la Universidad del Mayab, la Universidad Modelo, la Universidad Marista, la Universidad Mesoamericana de San Agustín, el Instituto Tecnológico de Mérida, la Normal Superior de Yucatán, entre otros. En estas instituciones se ofrece una diversidad de carreras del área de Humanidades y Ciencias de la Conducta: Psicología, Educación, Derecho, Economía, Ciencias de la Familia, Filosofía, Lingüística y Antropología, por citar algunas.

Del análisis de los planes de estudios de estas carreras, se puede identificar que en la mayoría se ofrece la asignatura de Estadística. Del mismo modo, se aprecia que en los posgrados se incluye la enseñanza de ésta como prerrequisito para el análisis, estudio y desarrollo de proyectos de investigación con mayor rigor metodológico; así en los programas de doctorado, la Estadística se incluye como una herramienta importante en el desarrollo de habilidades de investigación. Esto demuestra el valor que tiene la Estadística en la formación de los alumnos que estudian una carrera del área de Humanidades y Ciencias de la Conducta en dichas universidades, con el propósito principal de adquirir los conocimientos y competencias para la organización, análisis y elaboración de reportes de su práctica profesional y/o de investigación. Batanero (2000 y 2001a) enuncia de manera clara los fines principales de la enseñanza de la estadística en la formación de los alumnos: a) que lleguen a comprender y a apreciar el papel de la estadística en la sociedad conociendo sus diferentes campos de aplicación y el modo en que la estadística ha contribuido a su desarrollo, y b) que lleguen a comprender y a valorar el método estadístico, es decir, lo que la estadística puede responder y la forma básica de razonamiento, su potencia y limitaciones.

El interés hacia el tema de la tesis se origina de la experiencia del autor: profesor de estadística en la carrera de Educación, investigador de la Facultad de Educación de la Universidad Autónoma de Yucatán, con un interés genuino hacia la formación de profesores de matemáticas. Los resultados de algunos estudios hechos en el campo de la educación matemática, la opinión de estudiantes para profesor y profesores en ejercicio y de investigadores en educación matemática, representaron una fuente de inspiración 
invaluable en la identificación del tema de tesis. Todos estos elementos, en conjunción con el análisis del contexto y de una exploración preliminar de la literatura sobre el tema durante los estudios de doctorado, dieron origen a la necesidad de centrarse en un área desatendida como objeto de estudio: la formación del profesor que enseña estadística en carreras del área de Humanidades y Ciencias de la Conducta; más específicamente, de las carreras de Psicología y Educación.

De manera específica, llama particularmente la atención la falta de contextualización de una Estadística dirigida a profesionales de las áreas sociales, es decir, la preocupación por entender lo que ocurre en el aula cuando un profesor enseña Estadística a estos estudiantes, los problemas o situaciones que enfrenta y cómo los resuelve, del tal modo que permita identificar sus necesidades de formación o actualización en el campo de la educación estadística.

Esta investigación se centra en el Conocimiento Didáctico del Contenido (CDC, o bien PCK, Pedagogical Content Knowledge, por sus siglas en inglés) que tienen estos profesores y sobre todo, los procesos cognitivos que subyacen en su práctica cuando trabajan con estudiantes de Psicología y Educación, que no tienen una formación matemática y cuyo interés está muy ligado con su área profesional de la carrera. Este interés sobre el CDC surgió a partir de un curso impartido por el Dr. Salvador Llinares, del pleno reconocimiento de su trascendencia en la preparación de profesores, de una perspectiva ignorada (missing paradigm, según Shulman, 1986b) tanto como objeto de estudio como modelo de formación de estudiantes para profesor y profesores en ejercicio en México (González y Pinto, 2006).

Hasta el momento, en Yucatán, no hay constancia de estudios que estén enfocados sobre la perspectiva de investigación didáctica del conocimiento del profesor de matemáticas y mucho menos, en estadística; y los pocos estudios encontrados, investigan al profesor a partir de la opinión del alumno y a la luz de la didáctica general, o bien, estudian el conocimiento del profesor sobre un tópico concreto (ej. límite, derivada, ecuaciones diferenciales). Esta tesis se centra en estudiar el CDC del profesor que enseña Estadística en carreras como Psicología y Educación, en un tópico específico: la representación gráfica. Se desarrolla a partir de un marco teórico y metodológico de la educación matemática y de estadística y explora el conocimiento del profesor desde su propia práctica.

Por último, mención especial tiene un elemento adicional como parte inherente de la motivación hacia el tema de tesis: la pasión, compromiso y entrega de investigadores que han sabido contagiar con sus ideas, consejos y su firme convicción de que a partir de la investigación científica y del estudio sobre el pensamiento y conocimiento del profesor se contribuye, primero a comprender su naturaleza cognitiva y segundo, a presentar más alternativas de formación que coadyuven en el mejoramiento de su enseñanza.

\section{APROXIMACIÓN TEÓRICA}

Tres principios teóricos de la investigación didáctica orientaron la elaboración de la tesis: el conocimiento profesional del profesor, el paradigma cualitativo y el pensamiento estadístico de la representación gráfica. 
El conocimiento profesional del profesor, cuyo precursor fue Lee Shulman, tiene como finalidad básica el análisis del conocimiento de los profesores. Desde su perspectiva teórica denominada el conocimiento base para la enseñanza emerge el CDC, el cual permite una visión específica sobre el conocimiento de la didáctica del contenido específico, que incorpora según Shulman (1986b), Grossman, Wilson y Shulman (1989) y Llinares y Sánchez (1990), por lo menos, tres componentes básicos: el conocimiento del contenido de la disciplina a enseñar, el conocimiento de la didáctica específica (representaciones o estrategias instruccionales para la enseñanza del tópico) y el conocimiento del estudiante (Pinto y González, 2006). La tesis explora la cognición del profesor de estadística a la luz del CDC, centrado en dos de sus componentes: el conocimiento de las estrategias y representaciones instruccionales y el conocimiento del estudiante.

El enfoque cualitativo, como paradigma metodológico de investigación, permitió indagar sobre la comprensión de los significados que tiene para el profesor el CDC. A través de dos estudios de casos, el enfoque cualitativo permitió por un lado, examinar de manera detallada, comprehensiva, sistemática y a profundidad el pensamiento y conocimiento del profesor de estadística; y por otro, abarcar la complejidad como un todo (Rodríguez, Gil y García, 1999).

El pensamiento estadístico, junto con la alfabetización y razonamiento estadístico, son áreas que representan aprendizajes importantes a desarrollar como metas de la instrucción estadística. El estudio se basó en las aportaciones de Garfield (2002), delMas (2002) y Garfield, delMas y Chance (2003) respecto al pensamiento estadístico de la representación gráfica. Su perspectiva teórica presenta una clasificación originada a partir de estudios en educación estadística y enfocada al aprendizaje de la estadística a nivel licenciatura (educación superior) y sobre diferentes tópicos de la disciplina (como puede ser la representación gráfica). Asimismo, los estudios de Curcio (1987 y 1989), Friel, Curcio y Bright (2001) y Sorto (2004), contribuyeron a ampliar el conocimiento sobre los resultados de aprendizaje o niveles cognitivos de la comprensión gráfica exclusivamente.

\section{PREGUNTA DE INVESTIGACIÓN}

El estudio exploró la manera en que dos profesores interpretan e implementan el currículo, cómo comprenden y enseñan la representación gráfica y cómo reconocen las creencias, errores y dificultades del aprendizaje de sus estudiantes. Aporta elementos que reivindican la profesionalización de la enseñanza de la Estadística, explora el CDC que tienen los profesores de estadística de las carreras de Psicología y Educación; permitió conocer qué elementos pueden estar asociados a su práctica y las concepciones que tienen acerca de los procesos de aprendizaje de sus estudiantes, qué conocimientos tienen y utilizan a partir de los marcos teóricos propios de la didáctica de la matemática y la estadística.

Con base en la revisión de la literatura en educación estadística y del contexto, se detectaron por lo menos seis focos-problemas que condujeron hacia la necesidad de una investigación de esta naturaleza: (a) el predominio del uso la estadística de forma procesal, (b) las pocas o nulas aplicaciones encontrados en los libros de textos, realmente propias de 
la actividad estadística, (c) el uso y manejo incorrecto de la estadística, (d) la falta de contextualización y aplicación de la estadística dirigida a profesionales de áreas diferentes a las matemáticas, (e) la diversidad en los perfiles de la formación inicial y continua de los profesores de estadística, y (f) la falta de estudios e investigaciones sobre el conocimiento, las concepciones de la estadística y de la representación de datos en profesores (México) y en idioma castellano.

Específicamente en Yucatán, México, aunque hay programas y cursos de formación continua a profesores, no hay investigación sobre formación de profesores de matemáticas a la luz de los marcos conceptuales, teóricos y metodológicos de la educación matemática. Asimismo, según se ha constatado en entrevistas realizadas a profesionales vinculados con la enseñanza de la Estadística en México, ésta se ha reducido a una visión superficial o no verla en los diferentes grados escolares. La educación superior no es la excepción, incluso para los programas de formación de profesores de matemáticas, en donde se observa que los planes de estudios contemplan poco o nada sobre el estudio de la didáctica de la estadística. El problema llega a ser más acuciante, cuando se carece del conocimiento de la didáctica de la estadística en áreas diferentes a la matemática. Este estudio pretende contribuir a este conocimiento, trabajando directamente con los profesores de estadística en ejercicio.

La investigación se centra en el tema de la representación de datos estadísticos, específicamente la representación gráfica, que es uno de los primeros tópicos de un curso introductorio de Estadística en cualquier nivel escolar, así como el punto de partida del proceso estadístico del análisis de un conjunto de datos y como el primer elemento fundamental del pensamiento estadístico (Pfannkuch y Rubick, 2002).

La pregunta central que dirigió este estudio fue:

¿Cuál es el conocimiento didáctico del contenido que sobre la representación gráfica tienen los profesores de Estadística?

\section{ORGANIZACIÓN DE LA TESIS}

El documento está organizado en siete capítulos.

El Capítulo 1, sobre el marco teórico del conocimiento didáctico del contenido se presentan los fundamentos de la teoría que dieron origen a su creación, hasta llegar al CDC, su significado y características. Se describe la importancia e implicaciones que tiene en la formación inicial y permanente del profesorado, así como en las investigaciones que se han desarrollado en educación matemática. Se analiza su naturaleza conceptual y metodológica y desde una aproximación empírica, inductivo - deductiva y de la teoría del análisis de contenido se determinó un sistema de dimensiones e indicadores con los cuales se organizaron y estructuraron las características y conceptos de los componentes del CDC.

El Capítulo 2, sobre el marco teórico de la representación gráfica se presenta en primer lugar los antecedentes de la relación del CDC y la educación estadística. Luego se describe la importancia de investigar sobre la representación gráfica para después presentar la revisión de los principales autores que han investigado sobre el tema, sus contribuciones 
y su relación con el problema de investigación. Después se analizan los niveles cognitivos de comprensión gráfica surgidos de diferentes autores, los tópicos que comprende el estudio de la representación gráfica; seguido de un análisis y caracterización de los diseños e instrumentos utilizados para su estudio. Al final del capítulo se sintetizan los aspectos teóricos relevantes sobre la representación gráfica que enmarcaron y justificaron la construcción de los instrumentos de investigación y definieron los elementos del CDC que se estudiaron.

El Capítulo 3 describe la necesidad de estudiar el CDC en educación estadística y detalla el contexto del estudio, las situaciones problemáticas, las cuestiones críticas, el planteamiento del problema, los objetivos y las hipótesis de trabajo.

El Capítulo 4 se centra en la descripción de la metodología de investigación. El lector encontrará las perspectivas teóricas y metodológicas en que se sustenta el trabajo, una descripción del escenario y contexto donde se desarrolló, así como los criterios y justificación de la selección de los dos profesores que participaron para los estudios de casos. Se describe brevemente la biografía académica de cada uno. Después se detallan los instrumentos de recogida de información, así como los materiales que sirvieron para analizar el CDC sobre la representación gráfica de los profesores. El capítulo finaliza con la descripción de las técnicas de recogida de información y del análisis que se realizó para validar la información y generar los resultados del estudio.

El Capítulo 5 presenta los resultados y análisis de la información a partir de los dos estudios de casos. El análisis se centró sobre las siguientes categorías, a partir del SDI del CDC y del análisis de la información: 1) formación profesional, interés y motivación del profesor(a), 2) origen y desarrollo del conocimiento , 3) concepciones sobre la Estadística, su aprendizaje y enseñanza, 4) concepciones sobre la RG, su aprendizaje y enseñanza, 5) conocimiento del currículo, 6) conocimiento de las estrategias y representaciones instruccionales, 7) conocimiento del estudiante, 8) identificación y diagnóstico del conocimiento del estudiante, 9) estrategias específicas para corregir errores y dificultades y 10) dificultades para enseñar. Al final de cada caso se hace una síntesis donde se analiza el conocimiento del profesor a la luz del marco teórico de la RG y del CDC. Posteriormente, se presenta el análisis intercasos que nos permitió comparar los resultados de cada profesor como un criterio más para comprender las diferencias en sus concepciones y conocimientos.

El Capítulo 6 y último, examina y discute los resultados y expone las principales conclusiones y recomendaciones e implicaciones para la enseñanza de la RG y futuras investigaciones.

Después del capítulo de discusión se encuentran las Referencias de las citas bibliográficas.

En el índice de contenido se podrá apreciar la relación de Apéndices mencionados dentro del documento, los cuales podrán consultarse en el CD-ROM que se encuentra en la cubierta posterior de la tesis. 
6 Conocimiento didáctico del contenido sobre la representación de datos: estudios de casos

Jesús Enrique Pinto Sosa 


\section{CAPÍTULO 1: Marco teórico del Conocimiento Didáctico del Contenido}

Este capítulo presenta en primer lugar, cómo surge la perspectiva teórica "El conocimiento base para la enseñanza" cuyo precursor es Lee Shulman. Se presentan los fundamentos de la teoría que dieron origen a su creación, hasta llegar al Conocimiento Didáctico del Contenido (CDC), su significado y características. Aunque se ha procurado establecer estas características para cualquier materia, se particulariza en relación con la enseñanza de las matemáticas por ser éste el área de conocimiento en el que se inscribe esta tesis doctoral. Se describe la importancia e implicaciones que ha tenido y tiene en la formación inicial y permanente del profesorado, así como en las investigaciones, particularmente en la educación matemática.

La parte central del capítulo comprende los componentes del CDC. A partir de las investigaciones que diversos autores han realizado con este marco teórico, se analizan sus características generales y específicas y describen los tres componentes del CDC: conocimiento del contenido a enseñar, conocimiento de las estrategias y representaciones instruccionales y conocimiento de los procesos de aprendizaje de los alumnos.

Posteriormente, se analizó su naturaleza conceptual y metodológica y, desde una aproximación empírica, inductivo - deductiva, se desarrolló un procedimiento para la definición de qué elementos conceptuales era posible estudiar. Se utilizó el análisis de contenido con el que se determinó un sistema de dimensiones e indicadores con los cuales se organizaron y estructuraron las características y los componentes del CDC.

Al final, se sintetizan los principales aspectos abordados, estableciendo las posiciones teóricas y metodológicas que se asumieron para este trabajo.

\subsection{BREVE RESEÑA HISTÓRICA}

Dos artículos dieron origen a la teoría de la enseñanza propuesta por Shulman. El primero, Those who understand: knowledge growth in teaching (1986b) y posteriormente, Knowledge and teaching: foundations of new reform (1987). Del análisis de éstos, se articula un conjunto de principios, hechos, reflexiones, estudios y/o exploraciones que dan cuenta del surgimiento del CDC: 
$1^{\circ}$. La necesidad de profesionalizar la enseñanza. Era indignante e insultante (a principios de los 80s) para la profesión de enseñar, que todavía hubiera profesores que se dedicaban a esta labor, sin tener idea del significado de la profesión y de lo que implicaba enseñar.

$2^{\circ}$. El énfasis entre 1875-1900 hacia el contenido como criterio esencial para enseñar una asignatura; elemento limitativo e insuficiente.

$3^{\circ}$. Las críticas recibidas a la corriente didáctica del profesor denominada procesoproducto (surgida en los 70s y duramente criticada en los 80s) debido principalmente a su limitada conceptuación de "profesor eficaz", a describir acríticamente las conductas de un determinado profesor, a dejar de lado otros elementos del contexto (ej. concepciones, creencias y procesos de aprendizaje del alumno), a su concepción lineal y simple de aprendizaje, a no tener en cuenta el contenido y reducirlo todo a un conjunto de conductas observables y tener como hipótesis central que el docente es la causa exclusiva, única y directa de un buen rendimiento de los alumnos (López, 1999).

$4^{\circ}$. Las críticas recibidas a la corriente didáctica del profesor denominada pensamiento del profesor (surgida a mediados de los 70s, en la que Shulman aparece como uno de sus precursores), debido principalmente a que ignora casi por completo la reflexión del profesor sobre la acción, presta escasa atención a su razonamiento pedagógico, al cambio y evolución del mismo; tiene un marcado carácter psicologista, los resultados de investigación padecen de una excesiva generalidad, se olvida el resto de los elementos del sistema-aula (es decir, alumnos, contexto y currículo), por su exclusiva preocupación por los procesos cognitivos, manteniendo una relación lineal y unidireccional de la teoría y la práctica, y dejando de lado el análisis del contenido vinculado con la didáctica (López, 1999).

$5^{\circ}$. Los paradigmas proceso-producto y pensamiento del profesor, favorecieron un mayor énfasis (sobre todo a finales de los 70s hasta mediados de los 80s) en los procesos de evaluación y acreditación y selección de profesores basado en lo pedagógico (casi exclusivamente), asumiendo que el contenido está cubierto por el hecho de tener una licenciatura en la disciplina correspondiente. Esto redundó en la escasez de investigaciones sobre cómo la materia específica debería ser transformada en conocimiento del profesor dentro de un contenido de instrucción. A este vacío, Shulman le denominó el "paradigma ignorado" (Missing Paradigm).

$6^{\circ}$. Recuperar y asignarle el justo valor al conocimiento del contenido. A principios de los 80s, Shulman y colaboradores (ver Shulman y Sykes, 1986; y Wilson, Shulman y Richert, 1987) crearon un programa de investigación denominado "Desarrollo del conocimiento para la enseñanza" (Knowledge Growth in Teaching). Sin intentar restar importancia al contenido pedagógico y los métodos o técnicas en la formación de habilidades docentes, Shulman y colaboradores buscaban recuperar y asignarle el lugar justo al conocimiento del 
contenido y además, crear un modelo que integrara el conocimiento del contenido con el conocimiento pedagógico. Como producto de este programa realizaron:

- una investigación cuyo objetivo fue estudiar cómo aprenden a enseñar profesores de secundaria de inglés, biología, matemáticas y estudios sociales (ver Shulman, 1986b);

- una experiencia de formación de profesores (a partir de la investigación anterior);

- un análisis de contenidos de las investigaciones sobre el profesor (ej. Fenstermacher, 1978; Smith, 1980 y Schwab, 1983, citados en Shulman, 1986a);

- la observación de episodios de enseñanza hecha por Shulman y sus colaboradores y el análisis sobre éstos hecho por otros autores;

- la reforma a mediados de los 80s en Estados Unidos, de la que surgió de manera recurrente (en sus diferentes textos) la necesidad de elevar la enseñanza a la categoría de una ocupación más respetada partiendo de un supuesto básico y esencial: que existe una "conocimiento base para enseñar";

- el estudio de informes generados ad hoc para el análisis de la reforma (ej. los del Grupo Colmes y Carnegie Task Force); y

- la creación de una Junta Nacional para la Enseñanza (dirigida por Shulman a mediados de los 80s) para la reforma de la profesión docente (en Estados Unidos).

De este modo surge la corriente de investigación que Shulman denominó "el conocimiento base para la enseñanza", cuya finalidad básica es el análisis del conocimiento profesional del profesor. No deja de lado los avances y la perspectiva teórica del pensamiento del profesor, sino que incluye y destaca el rol central que ocupa en la enseñanza la comprensión de los contenidos curriculares por parte del docente y los alumnos (López, 1999). Representa, desde sus orígenes, un cambio conceptual sobre los procesos de enseñanza y aprendizaje de la materia que ha de influir en las concepciones y creencias de los profesores (Prawat, 1992, en López, 1999). López (1999) resume en tres las características esenciales de esta perspectiva teórica:

a. refleja una naturaleza más bien didáctica (y no psicológica),

b. el saber profesional de los profesores debiera integrar las proposiciones teóricas con los procedimientos técnicos que implican y que pueden optimizar su actuación en el aula, y

c. tanto el conocimiento de la disciplina, como el conocimiento de los fundamentos psicopedagógicos, tienen mucho que aportar a la mejora de la práctica de la enseñanza de una materia escolar concreta.

En un primer momento, Shulman (1986b) propuso tres categorías iniciales con las cuales se podría pensar y estudiar acerca del conocimiento que se desarrolla en las mentes de los profesores con especial énfasis sobre el contenido: conocimiento del contenido de la materia específica, conocimiento didáctico del contenido y conocimiento curricular. 
Un año más tarde, Shulman $(1987$, p.8) reconoce otras categorías de conocimiento y establece con ello, un cuerpo de conocimientos como base para la enseñanza. Los organiza como saberes o conocimientos indispensables, que todo profesor debe saber como mínimo:

a. conocimiento de la materia impartida;

b. conocimientos pedagógicos generales, teniendo en cuenta especialmente aquellos principios y estrategias generales de manejo y organización de la clase que trascienden el ámbito de la asignatura;

c. conocimiento del currículo, con un especial dominio de los materiales y los programas que sirven como "herramientas para el oficio" del docente;

d. conocimiento pedagógico de la materia (conocimiento didáctico del contenido): esa especial amalgama entre materia y pedagogía que constituye una esfera exclusiva de los maestros, su propia forma especial de comprensión profesional;

e. conocimiento de los educandos y de sus características;

f. conocimiento de los contextos educacionales, que abarcan desde el funcionamiento del grupo o de la clase, o la gestión y el financiamiento de los distritos escolares, hasta el carácter de las comunidades y culturas; y

g. conocimiento de los objetivos, las finalidades y los valores educacionales, y de sus fundamentos filosóficos e históricos.

\subsection{SIGNIFICADO Y CARACTERÍSTICAS}

Entre las categorías citadas por Shulman, el Conocimiento Didáctico del Contenido (CDC) adquiere particular interés porque identifica los diferentes bagajes de conocimientos para la enseñanza.

Representa la mezcla entre materia y pedagogía por la que se llega a una comprensión de cómo determinados temas y problemas se organizan, se representan y se adaptan a los diversos intereses y capacidades de los alumnos, y se exponen para su enseñanza. El conocimiento pedagógico de la materia es la categoría que con mayor probabilidad permite distinguir entre la comprensión del especialista en un área del saber y la comprensión del pedagogo (Shulman, 1987, p.8).

Denominado también como conocimiento del contenido pedagógico (Llinares, 1998), conocimiento sobre didáctica de la asignatura (Bromme, 1994), o bien, conocimiento didáctico específico (Martín del Pozo, 1994 en López, 1999, pp.78-79); representa la intersección entre conocimiento de la materia per se, y los principios generales de pedagogía, surgiendo así a la defensa de la eficacia de la enseñanza (Shulman, 1993). Sin embargo, va más allá del conocimiento de la materia específica ya que debe encarnar los aspectos del contenido más relevantes y necesarios para su escolaridad; con ello se refiere a los contenidos específicos enseñables.

Shulman (1986b) define y caracteriza el CDC de la siguiente manera:

las formas más útiles de representación de estas ideas, las analogías, ilustraciones, ejemplos, explicaciones y demostraciones más poderosas - en una palabra, las formas de representación y formulación de la materia que hacen a ésta comprensible a otros... incluye un conocimiento [o comprensión] de lo que hace que el 
aprendizaje de un tópico específico sea fácil o difícil: las concepciones y creencias que los estudiantes de diferentes edades y experiencias, traen consigo al aprender estos tópicos y lecciones frecuentemente enseñados con anterioridad (p.9).

Estas formas de representación son "formas de expresar, exponer, escenificar o de representar de otra manera ideas, de suerte que los que no saben puedan llegar a saber, los que no entienden puedan comprender y discernir, y los inexpertos puedan convertirse en expertos" (Shulman, 1987, p.7), es decir, las estrategias de enseñanza a la luz del tópico específico, o bien, la didáctica del contenido específico. Así pues, el proceso de enseñanza se inicia si el maestro comprende aquello que se ha de aprender y cómo se debe enseñar, con lo cual el profesor debe tener un amplio repertorio de formas alternativas de representación, algunas de las cuales derivan de la investigación mientras que otras se originan de la práctica. El CDC trata de cómo el contenido específico puede ser interpretado en una situación de enseñanza (Cooney, 1994). Tiene que ver con la forma como los profesores piensan que hay que ayudar a los alumnos a comprender un determinado contenido (Marcelo, 2007). En este sentido, Shulman esboza lo que sería el papel del profesor a partir del dominio del CDC:

El profesor debe de algún modo ser fiel, por un lado, a los posibles significados dentro de la materia y, por otro, a las comprensiones que sus estudiantes son capaces de alcanzar. El profesor debe construir puentes entre los significados inherentes al contenido curricular y las construcciones de significados que los estudiantes pueden inventar, idear o discernir (Shulman, 1993, p. 58).

A partir del surgimiento del constructo del CDC, se han desarrollado muchos estudios al respecto. Todos éstos basan sus investigaciones en el trabajo de Shulman: Tamir, 1988; Smith y Neale, 1989; Marks, 1990b; Even, 1990 y 1993; Rovegno, 1992; Llinares, 1993 y 1998, Marcelo, 1993; Fernández-Balboa y Stiehl, 1995; Blanco, Mellado y Ruiz, 1995; Mellado, Blanco, y Ruiz, 1999; García, 1997; Cooney, 1999; Graeber, 1999; Barnett y Hodson, 2001; Val Driel, De Jong y Verloop, 2002; Appleton, 2003; Badillo, 2003; An, Kulm y Wu, 2004; Bolivar, 2005; Md, Hamzah, Ismail, Husain e Ismail, 2006; Ponte y Chapman, 2006; Attorps, 2006; Sorto, 2007; Burgess, 2008; son algunas de ellas. Sin embargo, varios expertos han propuesto diferentes conceptualizaciones del CDC, en términos de las características que incluyen o integran como parte del constructo. Estas conceptualizaciones o características se resumen a continuación:

a. es por definición contextualizado con respecto tanto al contenido como a la instrucción; en este sentido, CDC en matemáticas, pertenece más al profesor de matemáticas, que al matemático o al profesor (Marks, 1989, p.2);

b. requiere de características especiales de tal forma que permitan transformarlo en materia de enseñanza (Llinares y Sánchez, 1990);

c. es diferente del conocimiento de las matemáticas como disciplina (Llinares y Sánchez, 1990);

d. requiere de dos transformaciones para la enseñanza y el aprendizaje: del contenido disciplinar a contenido a enseñar y del contenido para enseñar a contenido aprendido (Llinares y Sánchez, 1990), es decir, "una transposición 
didáctica del contenido para que sea objeto de enseñanza y aprendizaje en el contexto escolar" (Martín del Pozo, 1994, en López, 1999, p.77);

e. consiste en la habilidad de transferir la asignatura desde un conocimiento particular a otro conocimiento. No significa que todos los alumnos conozcan la asignatura a través del mismo patrón (o modelo), ni tampoco que sea un cuerpo mezclado de conocimiento, pero si una habilidad que puede ser desarrollada a través de la reflexión y aplicación (Fernández-Balboa y Stiehl, 1995). En otras palabras, es parecido a los compuestos químicos: es más que la suma de sus partes; y los elementos en combinación, forman un compuesto, una nueva entidad, con características impredecibles por una simple unión de los componentes (Marks, 1989);

f. consiste en "la comprensión de cómo determinados temas, principios, estrategias, en determinadas materias, se comprenden o se comprenden mal, se aprenden o tienden a olvidarse" (Castro y Castro, 1996, p.119);

g. tiene vinculación en cómo pueden ser interpretados los contenidos específicos en situaciones de enseñanza (García, 1997), a partir de ideas acerca de las matemáticas y de su enseñanza y aprendizaje (Cooney, 1994);

h. la integración de matemática y psicología es un primer paso para definir el CDC (García, 1997);

i. una de las fuentes para la generación del CDC de matemáticas, es el conocimiento originado por las investigaciones centradas en enseñanza y aprendizaje de nociones matemáticas concretas (García, 1997);

j. es necesario centrarse en el estudio de las potencialidades y limitaciones de los diferentes modos de representación del contenido matemático por parte del profesor, como medios para hacer comprensible a los estudiantes el contenido matemático y en el conocimiento de las dificultades y errores más comunes de los alumnos en relación a un contenido específico (Llinares, 1998, p.161);

k. consiste en la transformación de varios tipos de conocimiento para la enseñanza (Magnusson, Krajcik y Borko, 1999 en Van Driel, De Jong y Verloop, 2002);

1. se centra en el conocimiento y las habilidades específicas que afectan a la enseñanza de una asignatura concreta (Putnam y Borko, 2000); e

m. impacta y se basa en la naturaleza misma de la materia (Barnett y Hodson, 2001).

Estas características pueden agruparse en cuatro aspectos: (1) el CDC es contextualizado, tanto con base en la naturaleza del contenido de la asignatura, como de la instrucción; (2) consiste en la transformación, transferencia o transposición didáctica del contenido para la enseñanza (o al ámbito escolar), (3) es diferente al conocimiento de la materia y no es una simple conjunción o mezcla de pedagogía y contenido ni tampoco un modelo único de desarrollo, por lo cual requiere de características especiales para su formación y estudio con los profesores; y (4) para la formación de los profesores, se requiere la reflexión y aplicación sobre la acción, la integración de psicología y contenido, la investigación en didáctica de la disciplina y el estudio de los diferentes modos de representar el contenido a enseñar. Características que explican con mayor profundidad y que amplían la comprensión del significado del CDC. 
Por su parte, Shulman (1993, p.56) desarrolló tres particularidades y concepciones importantes (interrelacionadas) que hay que considerar en el estudio e implementación del CDC en programas de investigación o de formación de profesores:

1. el CDC es una forma de comprender o conocer lo que los profesores poseen (o deberían poseer) que distingue su pensamiento y razonamiento de las meras características de un experto en la materia en cuestión, siendo éste un ejemplo de "sabiduría de los practicantes", con lo cual diferencia al matemático y al educador, del profesor de matemáticas,

2. el CDC es una parte del conocimiento base para la enseñanza, un cuerpo de conocimientos, habilidades y - para algunos- una disposición, que distingue a la enseñanza como una profesión y que incluye aspectos como técnicas racionales y capacidades de juicio, improvisación e intuición; lo que Schön (1983) denominó como "reflexión-en-la-acción" y "reflexión-sobre-la-acción”, con lo cual justifica su naturaleza, su interrelación con otros dominios de conocimiento y su metodología para la formación, y

3. el CDC es un proceso de razonamiento pedagógico y acción a través del cual los profesores crean sus conocimientos cuando se enfrentan a problemas de enseñanza en contextos particulares, expresando sus planes y corrigiendo espontáneamente incluso improvisando ante los inevitables momentos impredecibles que surgen de la enseñanza, con lo cual estos profesores desarrollan nuevos conocimientos, intuiciones y disposiciones (Shulman, 1987).

\subsection{IMPORTANCIA E IMPLICACIONES}

La perspectiva teórica del CDC ha recibido bastante atención en los últimos años (Even, 1993; Llinares, Sánchez y García, 1994; Even y Tirosh, 1995; Fernández-Balboa y Stiehl, 1995; Gess-Newsome y Lederman, 1999; Van Driel, De Jong y Verloop, 2002; An, Kulm y Wu, 2004; Attorps, 2006; Sorto, 2007; Burgess, 2008). El CDC ha tenido diferentes implicaciones, las cuales se clasifican en dos vertientes: aquellas relacionadas con la formación inicial y permanente del profesor y aquellas que lo tienen como objeto de estudio o de investigación.

\subsubsection{Formación inicial y permanente del profesorado}

Shulman, en 1999, describe cómo la noción del CDC ha sido la causa de subsecuentes iniciativas. La primera de ellas fue a través de la National Board of Professional Teaching Standards (Cámara Nacional de Estándares para la Profesionalización de la Enseñanza), la cual optó (a finales de los 80s) por una estructura que utiliza dominios de certificación por áreas de contenido, así como niveles de desarrollo para los estudiantes. Esto implicó que muchas instituciones (americanas e inglesas, principalmente) incorporaran dentro de sus estándares de acreditación y certificación, el CDC. Esta importante incorporación puede observarse a través de los programas o sistemas escolares que prevalecen en las universidades e institutos de educación superior y formadoras de profesores. Ejemplos son la Southern Utah University, la Longwood University, la Michigan State University y la King College, entre otras.

Universidad de Salamanca 
Como consecuencia de lo anterior, es posible observar diferentes institutos y universidades, de educación superior y responsables de la formación de profesores, que incorporan como parte de sus programas alguna(s) asignatura(s), módulo, o seminario sobre el CDC específico de la disciplina a enseñar, o bien, proyectos de desarrollo de formación de profesores a través del CDC. Ejemplos son la University of California, la University of Vermont, la Central Connecticut State University, Escuela de Educación y Estudios Profesionales y la State University of New York, entre otras.

Otra de las importantes implicaciones de la perspectiva teórica de la base para la enseñanza es la creación de asociaciones, fundaciones y organizaciones que pretenden ayudar en la formación de los profesores. Tal es el caso de La Fundación Carnegie para el Mejoramiento de la Enseñanza (The Carnegie Foundation for de Advancement of Teaching, en http://www.carnegiefoundation.org/index.htm), fundada desde 1906 por Andrew Carnegie en Stanford, California (Estados Unidos). Dirigida actualmente por Lee Shulman, es un centro de formación e investigación independiente cuya misión principal es "hacer y desarrollar todo lo necesario para estimular, elevar y dignificar la profesión de ser profesor y por consiguiente la educación superior" (en http://www.carnegiefoundation.org/ ).

Otra consecuencia, según el mismo Shulman (1999), fue un inesperado desarrollo del interés sobre el CDC en el mundo de la educación superior, que a principios de los noventa fue muy incipiente. Esto contribuyó al reconocimiento gradual de que la visión de la calidad de enseñanza no tiene nada que ver con la calidad del dominio en una disciplina; es decir, con el dominio de contenido de un área específica (pp.x-xi). Esto ha llevado a que en los últimos años, en el nivel de la educación superior, exista mayor interés de explorar y estudiar el CDC en dicho sistema. Más aún, actualmente, la Fundación Carnegie incorpora recomendaciones y proyectos específicos para el desarrollo de programas de formación de profesores en ese nivel.

Por otro lado, cada vez más, se reconoce la importancia y relevancia de incorporar la perspectiva teórica del CDC como elemento esencial de la formación del profesorado. Tal es el caso, por ejemplo, de Gess-Newsome y Lederman (1999) quienes afirman que, sobre el modelo y el marco de investigación de una enseñanza específica, los profesores necesitan desarrollar el conocimiento de todos los aspectos del CDC en todos los tópicos que enseñan. Marks (1990b), en un sentido práctico, expresa que el CDC representa una clase de conocimiento que es central para el trabajo de los profesores y que podría no ser sostenido típicamente por personas expertas o por profesores que conocen poco de la materia: "en este sentido el concepto es muy significativo y muy útil, ayudando a los formadores de profesores sobre lo que los profesores deberían conocer y cómo ellos pueden aprender esto" (p.9).

$\mathrm{Su}$ inclusión como un elemento esencial en la formación de profesores ha significado la conceptuación y creación de una Red de Conocimiento didáctico del contenido (Network of Pedagogical Content Knowledge) que abarca los diferentes componentes, características, dimensiones e indicadores del contenido disciplinario a enseñar (An, Kulm y Wu, 2004). Según estos autores, esta red debe poseer además del conocimiento del contenido, un profundo y amplio conocimiento de enseñanza y currículo o un profundo CDC. Con este conocimiento, los profesores serán capaces de conectar su 
conocimiento de contenido, currículo y enseñanza en una red sostenida. En esta red, interactúan los tres tipos de conocimiento unos con otros y son capaces de hacer transformaciones alrededor de la tarea central de la enseñanza (An, Kulm y Wu, 2004).

El uso, estudio e implementación del CDC como modelo de formación de profesores plantea todavía grandes retos o desafíos, y el primero es, que las instituciones formadoras conozcan su existencia, reconozcan su necesidad y emprendan la tarea de incluirlo en su sistema de formación. Por eso es necesario tener particular cuidado y atención a las conexiones que existan o puedan existir entre el conocimiento de los profesores y las consecuencias últimas en el aprendizaje y desarrollo de los estudiantes (Shulman, 1999).

\subsubsection{Objeto de investigación}

Como consecuencia del impacto que el CDC ha tenido en la formación de profesores se ha incrementado de igual modo los estudios sobre éste. Ejemplo de este interés es el congreso de 2004 de la National Science Teachers Association (en http://www.nsta.org/ncse2004 recuperado en octubre de 2004), el cual incluyó dentro de los seis grupos de discusión el de "El profesor altamente cualificado y el Conocimiento didáctico del contenido" (The Highly Qualified Teacher and Pedagogical Content Knowledge). La National Council of Teachers of Mathematics (NCTM, 2000), estableció la necesidad de desarrollo de investigación en los siguiente términos: "la efectividad de la enseñanza requiere conocer y comprender las matemáticas, los estudiantes como aprendices y de estrategias de aprendizaje" (p. 17).

Respecto a los aspectos particulares a investigar del CDC, son varios los trabajos que tratan de comprender su naturaleza conceptual y metodológica, centrándose más hacia el conocimiento del contenido a enseñar (ej. Even, 1993; Chinnappan y Lawson, 2005) y al conocimiento del estudiante (ej. Even y Tirosh, 1995; An, Kulm y Wu, 2004) y menos al conocimiento de las estrategias y representaciones instruccionales (ej. Llinares, Sánchez y García, 1994).

Autores como Marks (1990b) afirman que en el futuro las investigaciones deben centrarse en otras áreas curriculares y en los diferentes niveles de enseñanza, y utilizar diversos métodos de investigación (Marks, 1990b). Los estudios deben, según afirma Marks (1990b) "ayudar a comprender más las diferencias y aspectos comunes entre materias o áreas $\mathrm{y}$, con ellos, esforzarnos en construir el conocimiento base para la enseñanza y mejorar la calidad de nuestros programas de formación de profesores" (p.11) y a determinar las necesidades que los profesores tienen para enseñar un tópico específico de matemáticas (Even, 1990).

A pesar del incremento en la atención que ha recibido el CDC, todavía hay una relativa ausencia de investigación que usen situaciones de aprendizaje para profundizar en el CDC (Van, Driel, De Jong y Verloop, 2002), es decir, prevalecen estudios que investigan el conocimiento del profesor desde la perspectiva proceso-producto o pensamiento del profesor, centrados exclusivamente en el contenido pedagógico, dejando de lado los demás aspectos del CDC. 
Por otro lado, como señalan Marks (1989), Even (1990) y Shulman (1999), es necesario desarrollar más investigación sobre los diferentes componentes, categorías, características, dimensiones e indicadores del CDC, para seguir generando un cuerpo de conocimientos que fundamente y oriente la formación de los programas de formación inicial y permanente y subsecuentes investigaciones. Es indispensable lograr la conexión entre la investigación didáctica del conocimiento del profesor (a través del CDC) y los programas de formación de profesores. El desarrollo de la investigación sobre el CDC permitirá acercarnos a las bases teóricas y prácticas que requieren los programas de formación, conocer cómo se desarrolla u opera en la realidad escolar, clarificar su comprensión y significado, y generar un repertorio de estrategias o representaciones instruccionales. Como señalan Cooney (1994) y García (1997): "el futuro de la investigación sobre el profesor está en las cogniciones de éste y el contexto en el que se construyen. Estos serán aspectos sobre los que se basarán las investigaciones en formación del profesorado de matemáticas" (p.100).

\subsection{CATEGORÍAS}

Existe una diversidad de investigadores que proponen o describen los dominios, componentes, elementos o categorías de conocimiento del CDC. En primer lugar se presentan las categorías que se identifican y son reconocidas por Shulman, y en segundo lugar, se presenta una síntesis de las propuestas generadas a partir de otros autores.

Al analizar la definición de Shulman (1986b, p.9) se identifican ciertas expresiones de las cuales se derivan las categorías del CDC:

1. "de un tópico específico" y "aprender estos tópicos y lecciones",

2. "las formas más útiles de representación de estas ideas", y

3. "las concepciones y creencias que los estudiantes de diferentes edades y experiencias".

En el inciso (a) hace referencia al contenido o al tópico específico que se trate, es decir, el contenido a enseñar. En el inciso (b) a las formas de representación, es decir, a las estrategias específicas de dicho contenido. Finalmente, en el inciso (c) a las concepciones y creencias de los estudiantes, es decir, a los conocimientos sobre el proceso de aprendizaje de los estudiantes respecto del contenido que enseña. Así, Shulman (1986b) estableció y propuso tres componentes esenciales como parte del CDC:

1. el conocimiento del contenido enseñable (más relevante a ser enseñado según el sistema escolar), es decir, el conocimiento de la materia específica para enseñar,

2. formas de representación (estrategias) para enseñar el área específica, y el

3. conocimiento del aprendizaje del estudiante (que incluye las estrategias con las que los profesores ayudan al alumno).

Shulman deja entrever (y reconoce) el conocimiento pedagógico de la enseñanza como parte inmersa dentro del constructo, pero no lo hace de manera explícita como los tres componentes antes mencionados (Shulman, 1986b). No obstante, Shulman y 
colaboradores incluyen el conocimiento de la pedagogía general dentro de la perspectiva teórica de la base del conocimiento para la enseñanza.

Muchos son los autores que han estudiado, analizado, complementado, propuesto o modificado las categorías del CDC de Shulman (ej. Tamir, 1988; Smith y Neale, 1989; Grossman, 1990; Cooney, 1994; Fernández-Balboa y Stiehl, 1995; Graeber, 1999; An, Kulm y Wu, 2004; entre otros). La Tabla 1.1 presenta una matriz con las diferentes categorías que se han propuesto como elementos del $\mathrm{CDC}^{1}$. El hecho de etiquetar algunas como "no lo contempla como tal", es que explícitamente no hace referencia a esa clasificación pero no por ello debe entenderse que lo suprimen. Por otra parte, la etiqueta "se reconocen como subcategorías" es porque los autores explícitamente las incorporan dentro de algunas de sus principales categorías que proponen.

Las categorías del CDC tienen su origen en las principales publicaciones de Shulman y colaboradores; algunas de ellas citadas cronológicamente en diferentes momentos, como es el caso de Shulman (1986b), Shulman (1987) y Wilson, Shulman y Richert (1987). No se contraponen, pero sí se complementan. Probablemente a esto se debe que algunos autores asuman ciertas categorías y el resto otras; o bien, otros las incorporan dentro de alguna otra. Otra razón es que algunos elementos del CDC están íntimamente relacionados con la base del conocimiento para la enseñanza. Por ejemplo, Grossman (1990, en López, 1999) propuso como elementos el conocimiento de la materia, el conocimiento pedagógico general, el conocimiento didáctico del contenido y el conocimiento del contexto; e incluye en el conocimiento didáctico del contenido otros tres: conocimiento de los propósitos de enseñanza, conocimiento curricular y conocimiento de estrategias de enseñanza y aprendizaje.

Lo que sí es común, es que la mayoría de los que han estudiado el CDC, basan su clasificación en los principales trabajos publicados por Shulman y colaboradores. Las propuestas adicionales surgen con base en estas publicaciones y en la interpretación particular de los componentes, en el énfasis personal que cada autor confiere a cada elemento o bien, en la perspectiva teórica del autor sobre la educación (su enseñanza, aprendizaje o ambas), sus concepciones de la disciplina de que se trate y de los resultados de investigación obtenidos. Algunos asumen literalmente los elementos del CDC y otros los integran o desglosan en subcategorías enfatizando algún(os) elemento(s). Sin embargo, aunque se observe que un autor no expone una categoría no significa que lo excluya, sino que muy probablemente lo agrega en una de las categorías que hizo explícitas. Por ejemplo, Graeber (1999) incorpora el conocimiento de la materia como parte del conocimiento de las representaciones del contenido a enseñar; y An, Kulm y Wu (2004) incorporan dentro del conocimiento de las estrategias de enseñanza todo lo relacionado con la detección de los errores conceptuales de los estudiantes, atraer en los estudiantes el aprendizaje matemático, promover el conocimiento del pensamiento del estudiantes y la construcción de las ideas matemáticas del estudiante.

\footnotetext{
1 Otros autores incorporan algunos elementos o variantes del CDC, como es el caso de Fernández-Balboa y Stiehl (1995) que hablan de CDC genérico y CDC específico, o Barnett y Hodson (2001) que proponen el Conocimiento del Contexto Pedagógico (pedagogical context knowledge).
} 
Tabla 1.1. Matriz de las propuestas de categorías del CDC según diversos autores

\begin{tabular}{|c|c|c|c|c|c|c|c|c|c|}
\hline Categorías & 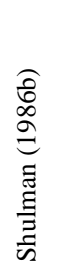 & 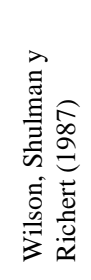 & 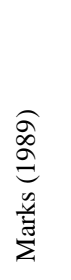 & 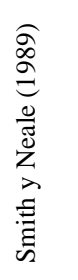 & 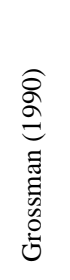 & 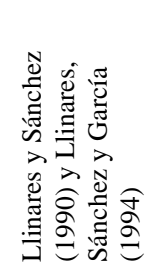 & 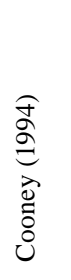 & 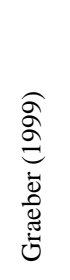 & 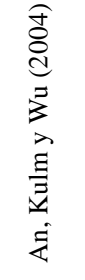 \\
\hline $\begin{array}{l}\text { Conocimiento de la } \\
\text { materia enseñable }\end{array}$ & $\bullet$ & $\bullet$ & $\bullet$ & $\mathrm{X}$ & $\bullet$ & • & $\bullet$ & $\mathrm{X}$ & - \\
\hline $\begin{array}{l}\text { Conocimiento de las } \\
\text { formas de } \\
\text { representación del } \\
\text { contenido a enseñar }\end{array}$ & $\bullet$ & $\mathrm{X}$ & $\mathrm{X}$ & $\bullet$ & $\bullet$ & $\bullet$ & $\bullet$ & $\bullet$ & $\mathrm{X}$ \\
\hline $\begin{array}{l}\text { Conocimientos de los } \\
\text { procesos de } \\
\text { aprendizaje del alumno } \\
\text { sobre el contenido a } \\
\text { enseñar }\end{array}$ & $\bullet$ & $\mathrm{X}$ & $\bullet$ & $\bullet$ & $\bullet$ & $\bullet$ & $\bullet$ & $\bullet$ & $\diamond$ \\
\hline $\begin{array}{l}\text { Conocimiento } \\
\text { pedagógico general }\end{array}$ & $\mathrm{X}$ & $\bullet$ & $\mathrm{X}$ & $\mathrm{X}$ & $\mathrm{X}$ & $\bullet$ & $\mathrm{X}$ & $\mathrm{X}$ & $\mathrm{X}$ \\
\hline $\begin{array}{l}\text { Conocimiento de los } \\
\text { objetivos o propósitos } \\
\text { de la enseñanza. } \\
\text { General }\end{array}$ & $\mathrm{X}$ & $\bullet$ & $\mathrm{X}$ & $\mathrm{X}$ & $\diamond$ & $\bullet$ & $\mathrm{X}$ & $\mathrm{X}$ & $\mathrm{X}$ \\
\hline $\begin{array}{l}\text { Conocimiento } \\
\text { curricular }\end{array}$ & $\mathrm{X}$ & $\mathrm{X}$ & $\mathrm{X}$ & $\bullet$ & $\diamond$ & $\mathrm{X}$ & $\mathrm{X}$ & $\mathrm{X}$ & • \\
\hline $\begin{array}{l}\text { Conocimiento de } \\
\text { estrategias de } \\
\text { enseñanza y } \\
\text { aprendizaje. } \\
\text { Estrategias y medios } \\
\text { instruccionales }\end{array}$ & $\mathrm{X}$ & $\mathrm{X}$ & $\bullet$ & $\mathrm{X}$ & $\diamond$ & $\mathrm{X}$ & $\mathrm{X}$ & $\mathrm{X}$ & $\bullet$ \\
\hline $\begin{array}{l}\text { Conocimiento del } \\
\text { contexto }\end{array}$ & $\mathrm{X}$ & $\mathrm{X}$ & $\mathrm{X}$ & $\mathrm{X}$ & $\bullet$ & $\mathrm{X}$ & $\mathrm{X}$ & $\mathrm{X}$ & $\mathrm{X}$ \\
\hline
\end{tabular}

Nota $: \mathrm{x}=$ no lo contempla como tal, $\bullet=$ si lo contempla explícitamente, $\diamond=$ se reconoce como subcategorías

Para este trabajo se asumirán, como punto de partida, las categorías presentadas por Shulman (1986b). Estas categorías además de apoyarse en la concepción original de Shulman muestran el mayor número de coincidencias entre los diferentes autores que han estudiado el CDC. A lo largo de este trabajo, las tres categorías identificadas por Shulman del CDC se denominarán: conocimiento del contenido a enseñar (para referirse al conocimiento del contenido enseñable), conocimiento de las estrategias y representaciones instruccionales (para referirse a las formas de representación del contenido a enseñar) y conocimiento de los procesos de aprendizaje del alumno sobre el contenido a enseñar (para 
referirse al conocimiento de las creencias y concepciones de los estudiantes). A continuación se explicará el significado y las características conceptuales de cada categoría.

\subsubsection{Conocimiento del contenido a enseñar}

Shulman (1986b) define este primer nivel de conocimiento como la "cantidad y organización de conocimiento per se en la mente del profesor" (p.9). Como elemento esencial, y previo a su labor de enseñar, el profesor deber tener un nivel mínimo de dominio del contenido que se propone a enseñar. Él mismo plantea la necesidad de que:

El profesor necesita no únicamente conocer o comprender qué, sino que además saber por qué esto es así, sobre qué supuestos estas justificaciones pueden ser ciertas y bajo qué circunstancias nuestras creencias en estas justificaciones pueden ser débiles y aún denegadas (Shulman, 1986b, p.9)

Muchos son los expertos que opinan que los profesores necesitan tener un sólido conocimiento de la materia para la enseñanza (ej. Shulman, 1986b, Even, 1990; Llinares, 1993; García, 1997; López, 1999; entre otros). Conocer bien el contenido de una lección incrementa la capacidad del profesor en implementar actividades diferentes en el aula, coordinar y dirigir las intervenciones y preguntas de los estudiantes, generar un cúmulo de estrategias de enseñanza vinculadas con el contenido y profundizar en el por qué y el para qué de la asignatura. No conocer bien el contenido es limitativo para desarrollar muchas de estas capacidades o habilidades (López, 1999 y McDiarmid, Ball y Anderson, 1989).

Para enseñar no basta con saber la asignatura (López, 1999). Como elemento del CDC, el conocimiento del contenido a enseñar es únicamente un componente del conocimiento de la preparación de un buen profesor. Autores como Shulman (1986b y 1987), Smith y Neale (1989), Even (1990) y López (1999) coinciden que el conocimiento de la materia es una condición necesaria aunque; sin embargo, no suficiente para la enseñanza y el aprendizaje del contenido.

Particularmente en la didáctica de las matemáticas, el estudio del conocimiento del contenido matemático es una rama que se orienta a analizar su naturaleza conceptual y epistemológica, sus componentes, características y el grado de conocimiento matemático (genérico o específico) que tienen los profesores; así como sus relaciones con la enseñanza y el aprendizaje y con otros dominios de conocimiento. Even (1990, 1993), Even y Tirosh (1995) y Baturo y Nason (1996), son ejemplos de algunos investigadores que trabajan en esta línea. Según An, Kulm y Wu (2004), consiste en un amplio conocimiento de las matemáticas tanto en cuanto conocimiento del contenido específico matemático, como del grado o nivel en que se enseña.

Como parte del conocimiento del contenido enseñable, muchos otros autores (ej. Tamir, 1988; Smith y Neale, 1989; Marks, 1989 y 1990b; Llinares y Sánchez, 1990; Even, 1990; Llinares, 1993; Even y Tirosh, 1995; García, 1997; Llinares, 1998; López, 1999; entre otros) han estudiado la naturaleza de ese contenido (genérico o específico de las matemáticas), su diferenciación con el conocimiento del contenido matemático en sí mismo, sus componentes y caracterización y se ha concluido que requiere de elementos como son:

Universidad de Salamanca 
a. la habilidad para usar este conocimiento para conducir discusiones, proporcionar ejemplos y explicaciones y generar soluciones de problemas y aplicaciones, es decir, la traslación e interpretación dentro de la enseñanza (Smith y Neale, 1989);

b. dominio y comprensión de los postulados y procedimientos básicos de la disciplina, ámbito o área de conocimiento que enseña (López, 1999, y Baturo y Nason, 1996);

c. conocimiento de la transformación del contenido como disciplina científica a contenido para enseñar (que algunas veces se le propone al profesor directamente a través de los libros de texto) y del contenido para enseñar un contenido aprendido (Llinares y Sánchez, 1990, p.87);

d. conocimiento declarativo y procedimental que los estudiantes traen consigo cuando van a aprender un tópico concreto (Llinares y Sánchez, 1990);

e. conocimiento de las características de aprendizaje, métodos instruccionales específicos y creencias epistemológicas de la materia que enseña (Llinares y Sánchez 1990);

f. conocimiento de y sobre las matemáticas, conocimiento de y sobre la actividad matemática y conocimiento sobre el currículo matemático (Llinares, 1993);

g. conocimiento acerca de la cultura matemática y sociedad (Baturo y Nason, 1996); y

h. disposición hacia la materia (Baturo y Nason, 1986).

Al hablar de esta categoría es necesario hacer referencia a cuatro autores que han orientado su trabajo al estudio del conocimiento del contenido enseñable de forma más exhaustiva y que merecen la pena mencionar y describir por separado. Por un lado están los trabajos de Tamir (1988) y López (1999), quienes a partir de análisis de contenidos y de una revisión de artículos de investigación, presentan los componentes del conocimiento del contenido a enseñar a la luz del contenido de cualquier disciplina. Por otra parte, Marks (1989) y Even (1990) presentan sus propuestas de dominios de conocimiento del contenido enseñable a la luz de la didáctica de las matemáticas, a partir de la naturaleza de la matemática, de su enseñanza, de una revisión de los marcos teóricos existentes y los resultados y experiencias de investigación desarrolladas.

Tamir (1988) menciona que, como parte de su conocimiento de la materia, el profesor debe conocer las teorías, modelos, conceptos y hechos y formas, significados y procesos; comprensión y conocimiento de todos los niveles de la materia a enseñar para ser capaz de presentar una imagen balanceada a sus estudiantes; debe conocer la naturaleza de las explicaciones, de la heurística y de los valores histórico-filosófico; así como las interrelaciones entre la vida científica y otras materias (tanto exactas como sociales); y aspectos controversiales: ética, valores morales y estética.

Por su parte, López (1999, pp.80-81), con base en Shulman (1986b y 1987), Gimeno (1988), McDiarmid, Ball y Anderson (1989), entre otros; propone como elementos mínimos del conocimiento del contenido enseñable:

a. conocimiento de las diferentes posturas o escuelas filosóficas en relación a cómo se crea y se construye el saber científico básico y las consiguientes reglas tecnológicas que se derivan y que dan lugar a las denominadas ciencias aplicadas;

b. conocimiento de la historia de la disciplina (definir una serie progresiva de niveles de formulación de un concepto dado); comprender el contexto histórico, 
sociocultural e ideológico en el que se elaboró y definieron los principales problemas, hechos, principios y nociones de la disciplina particular;

c. comprensión de aquellos conceptos, principios, hechos y teorías principales de la disciplina en cuestión, así como las posibles interrelaciones que pueden establecerse entre los mismos (conocimiento sustantivo, según Schwab, 1978);

d. conocimiento sintáctico de la disciplina (según Schwab, 1978); es decir, conjunto de procedimientos que sirven de base para que el conocimiento de las misma progrese y avance, esto es, la comprensión de cómo el conocimiento es descubierto, organizado y evaluado, así como debates, principales perspectivas o escuelas que han contribuido a su desarrollo a través del tiempo; y

e. conocimiento de cómo enseñar la disciplina a otras personas, en esta dimensión del saber profesional debiera estar presente una perspectiva socio-cultural, de las diferentes materias que componen el currículo escolar.

Dado que Tamir y López parten de referentes teóricos tanto genéricos como específicos, sus propuestas son útiles para cualquier disciplina. Pueden considerarse como el referente teórico, epistemológico y procedimental que todo profesor debe tener de la actividad propia de su disciplina.

Por otra parte, Even (1990) conceptúa el conocimiento del contenido enseñable como conocimiento de la materia del profesor (Teachers' subject matter knowledge) acerca de un tópico específico, el cual debe integrar cuatro aspectos: a) el rol e importancia del tópico en matemáticas y en el currículo matemático, b) investigación y marco teórico sobre el aprendizaje, c) conocimiento y comprensión de conceptos matemáticos en general y, en particular, del tópico específico, e d) investigación y marco teórico sobre el conocimiento de la materia del profesor y su rol en la enseñanza. Por ello propone siete dominios o principales elementos que debe tener el conocimiento de la materia del profesor acerca de un tópico específico en matemáticas:

a. características esenciales, correspondencia entre idea mental y concepto matemático, imagen del concepto, atributos críticos del concepto, ejemplos prototipos, distinción entre ejemplos concretos y no-ejemplos, actualización del cambio en el concepto;

b. diferentes representaciones, comprender los conceptos en diferentes representaciones, trasladar y formar conexiones entre éstos;

c. formas alternativas de aproximación, familiarización con las principales alternativas de aproximación del concepto, sus usos en las diferentes ramas de la matemática, en otras disciplinas y en la vida diaria, así como el estudio de las posibles adecuaciones de estas aproximaciones a ciertas situaciones;

d. la fuerza del concepto, aspectos que originan los nuevos conceptos, características únicas del concepto y sus propiedades relevantes, relaciones con otros conceptos, subtópicos o subcomponentes; todo visto desde una manera multidireccional e integral;

e. repertorio básico, conocer y tener fácil acceso a familias de ejemplos específicos, ejemplos potentes que ilustran principios importantes, propiedades, teoremas, etc., aspectos prácticos en la escuela que se incluyen en el currículo; 
f. conocimiento y comprensión del concepto, conocimiento conceptual y procedimental del concepto, y las relaciones de éstos; y

g. conocimiento acerca de las matemáticas, conocimiento acerca de la naturaleza de las matemáticas, formas del significado y procesos.

Estos dominios, se refieren a un tópico específico de la matemática, es decir, al conocimiento que se debe tener por cada concepto matemático (ej. función, límite, derivada, media, varianza, etc.). Even, por lo tanto, incorpora una propuesta específica como parte del conocimiento de y sobre la matemática que el profesor debe estudiar.

Marks (1989) hace una propuesta a partir de las opiniones y práctica del profesor de matemáticas. Su clasificación de dominios del conocimiento sobre la materia se relaciona estrechamente con la instrucción. Estos son:

1. conocer los propósitos de la instrucción matemática en general, para referirse principalmente a tres aspectos: la importancia de las matemáticas en la escuela, el significado de aprenderla y el valor de cada uno de los contenidos dentro del ámbito escolar;

2. conocer las justificaciones para aprender un tópico dado, que consiste en conocer y utilizar una variedad de formas específicas para justificar los tópicos específicos (ej. la importancia del contenido, la vinculación con otros contenidos u otras disciplinas, la matemática en la sociedad, la utilidad, el interés o diversión) y con ello motivar a los alumnos para aprender;

3. conocer las ideas importantes para enseñar un tópico dado, que son aquellas que los alumnos necesitan aprender acerca de estos tópicos, como son los procesos, conceptos del currículo, la capacidad y esfuerzo del estudiante, formas intuitivas de representación del tópico, entre otros;

4. conocer los prerrequisitos de conocimiento para un tópico dado en los diferentes momentos del ciclo didáctico y estudio del tópico (ej. tópico dentro del mismo currículo, tópico y herramientas conceptuales y procedimentales previas, experiencia en el manejo del tópico o concepto y experiencia en procesos de pensamiento similares); y

5. conocer los problemas típicos de la "escuela matemática", que muestre una familiaridad con problemas típicamente encontrados en la instrucción matemática.

A diferencia de Even, Marks (1989) propone elementos vinculados directamente con el currículo matemático.

Con base en Tamir (1988), Marks (1989), Even (1990), López (1999), y otros (ej. Llinares, 1993 y Baturo y Nason, 1996) los conocimientos del contenido matemático a enseñar pueden agruparse en tres grandes componentes (ver Tabla 1.2): (a) conocimiento sobre la actividad matemática general, (b) conocimientos por tópico específico matemático y (c) conocimientos sobre el currículo matemático. 
Tabla 1.2. Componentes del conocimiento del contenido matemático a enseñar

\section{Componentes del conocimiento / breve descripción}

(a) Conocimientos sobre la actividad matemática general

- conocimiento de la historia de la disciplina, evolución, principales problemas y cambios en las nociones o conceptos, la naturaleza de las explicaciones, de la heurística y de los valores histórico-filosóficos,

- conocimiento de las diferentes posturas o escuelas filosóficas en relación a cómo se crea y se construye el saber científico básico,

- comprensión de aquellos conceptos, principios, hechos y teorías principales de la disciplina en cuestión, así como las posibles interrelaciones que pueden establecerse entre los mismos,

- conocimiento del conjunto de procedimientos que sirven de base para que el conocimiento de los mismos progrese y avance, principales perspectivas o escuelas en el campo, cómo el campo se ha desarrollado a través del tiempo y quiénes han contribuido a ese desarrollo,

- conocimiento de la disciplina para enseñar a otras personas, desde una perspectiva sociocultural, de las diferentes materias que componen el currículo escolar,

- conocimientos de la ética y valores morales y estéticos del contenido a enseñar, acerca de la cultura matemática y sociedad.

(b) Conocimientos por tópico específico matemático

- características esenciales (correspondencia entre idea mental y concepto matemático, imagen del concepto, atributos críticos del concepto, ejemplos prototipos, distinción entre ejemplos concretos y no-ejemplos, actualización del cambio en el concepto),

- diferentes representaciones (comprender los conceptos en diferentes representaciones, trasladar y formar conexiones entre éstos),

- formas alternativas de aproximación (familiarización con las principales alternativas de aproximación del concepto, sus usos en las diferentes ramas de la matemática, en otras disciplinas y en la vida diaria, así como el estudio de las posibles adecuaciones de estas aproximaciones a ciertas situaciones),

- la fuerza del concepto (nuevas oportunidades que originan nuevos conceptos, características únicas y propiedades relevantes del concepto, relación con otros conceptos, subtópicos o subcomponentes, visto desde una manera multidireccional e integral),

- repertorio básico (conocer y tener fácil acceso a familias de ejemplos específicos, ejemplos potentes que ilustran principios importantes, propiedades, teoremas, etc., aspectos prácticos en la escuela que se incluyen en el currículo),

- conocimiento y comprensión del concepto, (conocimiento conceptual y procedimental del concepto, y las relaciones de éstos),

- conocimiento acerca de las matemáticas (conocimiento acerca de la naturaleza de las matemáticas, formas del significado y procesos).

(c ) Conocimientos sobre el currículo matemático

- conocimiento de los propósitos de la instrucción matemática en general, para referirse principalmente a tres aspectos: la importancia de las matemáticas en la escuela, el significado de aprenderla y el valor de cada uno de los contenidos dentro del ámbito escolar,

- conocimiento de las justificaciones para aprender un tópico dado, que consiste en conocer y utilizar una variedad de formas específicas para la materia, para justificar los tópicos específicos y con ello motivar a los estudiantes para aprender,

- conocimiento de las ideas importantes para enseñar un tópico dado, que son aquellas que los alumnos necesitan aprender acerca de estos tópicos, como son los procesos, conceptos del currículo, la capacidad y esfuerzo del estudiante, formas intuitivas de representación y otros,

- conocimiento de los prerrequisitos de conocimiento para un tópico dado, en los diferentes momentos del ciclo didáctico y estudio del tópico (ej. tópico dentro del mismo currículo, tópico y herramientas conceptuales y procedimentales previas, experiencia en el manejo del tópico o concepto y experiencia en procesos de pensamiento similares),

- conocimiento de los problemas típicos de la "escuela matemática", que muestre una familiaridad con problemas típicamente encontrados en la instrucción matemática. 
El primero comprende el estudio del surgimiento de la matemática como disciplina y como objeto de estudio en la escuela, su evolución, sus conceptos, principios, hechos y teorías, las posturas filosóficas en que se sustenta, y los valores éticos, morales y estéticos que vislumbra. El segundo componente, considera dominios de conocimientos a estudiar por cada tópico específico de las matemáticas. Finalmente, el tercer componente, está formado por los elementos del contenido vinculado con el currículo escolar, como son el rol e importancia del tópico en matemáticas, su relación con otras disciplinas, el programa matemático escolar, los problemas típicos a enfrentar y los antecedentes académicos vinculados con otros contenidos matemáticos.

Dentro de esta agrupación no se contemplan aquellas relacionadas con las habilidades para conducir discusiones, ayudar al estudiante, utilizar diferentes métodos instruccionales (como señalan autores como Smith y Neale, 1989), las cuales, para fines de este documento, se incorporan en las siguientes categorías del CDC.

Esta agrupación (los componentes y sus correspondientes categorías) permiten darle un justo valor a la base del conocimiento del contenido enseñable y demuestra la importancia tanto del conocimiento del contenido matemático como de aspectos vinculados con el currículo. Aspectos que es menester que todo profesor tenga en cuenta. Además, permiten identificar aquellos aspectos que los programas de formación inicial o permanente pueden incorporar en sus planes de desarrollo y establecer una gama de opciones o líneas de investigación sobre el conocimiento del contenido enseñable por parte del profesor.

Como objeto de estudio, el conocimiento del contenido a enseñar, incluye además, el estudio de las creencias (ej. dilemas y cambio), concepciones de y sobre la matemática (Shulman, 1986b, Llinares y Sánchez, 1990, Even y Tirosh, 1995) y el estudio sobre los diferentes conceptos matemáticos; es decir, las formas en que los profesores (o estudiantes para profesor) comprenden un determinado contenido matemático (qué conocen y cómo lo conocen) (Llinares, 1998), que involucra también la exploración sobre cómo se origina y obtiene dicho conocimiento en el profesor, cómo se comprende la estructura (definida por los expertos) de la materia a enseñar, cómo se aprende y cómo se traduce (traslada o transpone) el contenido matemático a contenido matemático enseñable.

\subsubsection{Conocimiento de las estrategias y representaciones instruccionales}

Shulman (1986b y 1987) y Barnett y Hodson (2001) afirman que los profesores no sólo tienen o deben conocer y comprender el contenido de su materia, sino también cómo enseñar ese contenido de forma efectiva, es decir, conocer lo que parece ser más fácil o difícil para los estudiantes, cómo organizar, secuenciar y presentar el contenido para promover el interés y habilidades del estudiantes. Para ello, se debe tener un conocimiento pedagógico (de métodos de enseñanza y aprendizaje) adaptado al contexto específico de la materia, es decir, el conocimiento de la didáctica específica.

Este conocimiento de la didáctica específica se define como:

las formas más útiles de representación de estas ideas, las analogías, ilustraciones, ejemplos, explicaciones y demostraciones más poderosas - en una palabra, las 
formas de representación y formulación de la materia que hacen a ésta comprensible a otros (Shulman, 1986b, p.9).

En el conocimiento de la didáctica específica se conjugan dos elementos centrales del constructo $\mathrm{CDC}$, que son, el conocimiento de las representaciones de la materia en cuestión y las estrategias instruccionales, incorporando estas representaciones, por un lado, en un área de contenido específico a enseñar y por otro, la comprensión de las concepciones específicas del estudiante y sus dificultades de aprendizaje (Van Driel, De Jong y Verloop, 2002). Según estos autores, estos dos elementos están entrelazados y deberían ser usados de una manera flexible: la mayoría de las representaciones y estrategias están dispuestas dentro de un cierto dominio, y tienen relación tanto con la forma de comprender el proceso de aprendizaje de los estudiantes como con las formas más efectivas de enseñanza en ese dominio.

Grossman (1990, en Putnam y Borko, 2000) al referirse a las cuatro categorías del CDC, señala la denominación "conocimiento de estrategias y representaciones de instrucción" como similar o equivalente a las "representaciones" a que hace mención Shulman (1986b). De este modo, al hablar de representaciones de la materia en cuestión es permisible pensar en estrategias instruccionales o en representaciones instruccionales en un área de contenido específico.

Las representaciones instruccionales son elementos utilizados por el profesor para ayudar en la generación del conocimiento por parte de los alumnos (Llinares, Sánchez y García, 1994) y a construir y establecer relaciones (Graeber, 1999), lo que significa que no es un relación lineal y unidireccional, o una simple exposición de modelos o métodos didácticos particulares, sino un conjunto de estrategias específicas vinculadas con el contenido, donde se conjugan y relacionan las formas de representación instruccionales, con el conocimiento del contenido y el conocimiento del proceso del aprendizaje del estudiante y otros elementos del contexto o del sistema (ej. el currículo).

McDiarmid, Ball y Anderson (1989) denominan representación instruccional a "un amplio rango de modelos que pueden comunicar alguna cosa relativa a la materia a los aprendices: actividades, preguntas, modelos y analogías, por ejemplo”. Según estos autores, las representaciones toman diferentes formas para diferentes disciplinas. Aunque reconocen que existen algunas representaciones que pueden ser comunes entre algunas disciplinas, afirman la necesidad de que el profesor de matemáticas estudie las representaciones que están más directamente relacionadas con el conocimiento sustantivo y sintáctico de cada contenido (referido por Schwab, 1978, en López, 1999). Los autores aseveran que dos son las fuentes de las que se derivan las representaciones instruccionales: aquellas que se originan del propio profesor y aquellas que se originan del exterior. En la primera expresan que los profesores crean unidades de instrucción, hacen hojas de trabajo, diseñan actividades, desarrollan explicaciones, piensan en preguntas y responden a sus alumnos. Algunas veces son ideas modificadas de otras representaciones, y otras, son invenciones originales de ellos. El segundo grupo de representaciones se deriva de los materiales curriculares (ej. libros de texto, guía para el profesor, equipos, programas por computadora, películas, vídeos), cursos o talleres para profesores, estudios académicos dirigidos por los 
mismos profesores, de experiencias compartidas por colegas y el medio ambiente (contexto) escolar.

Por su parte, Even y Tirosh (1995) incorporan dos fuentes como elementos para estudiar las representaciones del profesor de matemáticas: la materia en cuestión y el conocimiento acerca del estudiante. Es decir, el conocimiento de las representaciones del profesor de matemáticas se puede estudiar a partir de la forma como adquiere y aprende el conocimiento de la materia y del conocimiento de los procesos de aprendizaje de los estudiantes. En ambos dominios, el profesor pone en juego una variedad de formas o representaciones instruccionales que hacen fácil o difícil la comprensión o el aprendizaje del contenido, o bien, lo hacen comprensible a otros.

Respecto al tipo y diferentes formas de representación, Shulman (1986b) menciona algunas: analogías, ilustraciones, ejemplos, explicaciones y demostraciones. Llinares, Sánchez y García (1994) sugieren adicionalmente los dibujos y las representaciones gráficas que aparecen en los libros o los realizados por el profesor en la pizarra. Even y Tirosh (1995) presentan como ejemplos de representaciones, las preguntas, actividades y discusiones vinculados con el contenido matemático. McDiarmid, Ball y Anderson (1989) hablan también de exposiciones verbales, diagramas, simulaciones, dramatizaciones y análisis de contenido; y destacan las representaciones verbales, simbólicas, gráficas o concretas, como inherentes al contenido matemático. Putnam y Borko (2000) nombran otras: modelos y metáforas. Estas representaciones o estrategias instruccionales específicas pueden variar según el contenido o tópico específico que se trate, a la luz de la investigación de la didáctica de la disciplina y de la propia práctica profesional del profesor.

Shulman (1986b) afirma que un profesor debería usar y/o seleccionar un amplio repertorio de sólidas representaciones apropiadas al contenido específico de que se trate, con lo cual resalta la importancia del conocimiento sobre las representaciones instruccionales del profesor vinculadas a los tópicos relativos a la labor de enseñar, y el modo de usarlas por parte del profesor (Llinares, Sánchez y García, 1994).

¿Qué elementos integran el conocimiento de las estrategias y representaciones instruccionales? ¿cuáles son las formas, representaciones o estrategias instruccionales específicas para el profesor de matemáticas? Para responder a estas dos preguntas, es preciso retomar algunos elementos de análisis hechos anteriormente $\mathrm{y}$, de forma particular, el conocimiento del currículo y las fuentes de las que se derivan las representaciones instruccionales.

El conocimiento del currículo es reconocido por Shulman (1986b y 1987) como uno de los dominios del conocimiento base para la enseñanza. En la sección sobre las categorías, se analizó y observó que diferentes autores (ej. Grossman, 1990 y An, Kulm y Wu, 2004) lo incorporan como parte del CDC. Para An, Kulm y Wu (2004), y basado en la publicación de la NCTM (2000), el conocimiento del currículo incluye la selección y uso adecuado de materiales curriculares, conocimiento completo de las metas e ideas claves de los libros de texto y del currículo, relacionado con el tópico específico. Para Shulman (1986b): 
El currículo es representado por un rango amplio de programas diseñados para la enseñanza de una materia particular y los tópicos a un nivel dado, la variedad de materiales instruccionales disponibles en relación a estos programas y el conjunto de características que atiende, así como las indicaciones y contraindicaciones para el uso del currículo particular o materiales de programas en circunstancias particulares (p.10).

En otras palabras, el currículo y sus materiales asociados, son la materia médica de la pedagogía, la farmacopea de la cual el profesor obtiene las herramientas de la enseñanza que presenta o los ejemplos sobre los contenidos particulares y los remedios a las dificultades de los alumnos o las valoraciones de la adecuación de la habilidad del estudiante (Shulman, 1986b). Así, el conocimiento del currículo es una parte esencial dentro del conocimiento de la didáctica específica. Hablar de representaciones instruccionales conlleva necesariamente estudiar no sólo las estrategias didácticas específicas sino también las tareas de fundamentación, planificación, implementación y evaluación curricular que el profesor utiliza como herramienta inherente de su labor de y la selección de los materiales curriculares.

Para Shulman (1986b), el conocimiento del currículo incluye un buen conocimiento de los materiales para la instrucción, sus características, los textos alternativos, software, programas, materiales visuales, películas de y sobre conceptos o tópicos, demostraciones en laboratorios o "invitaciones para investigar". Supone que los profesores conozcan el mayor número de formas para tratar un contenido y que esté familiarizado, incluso, con los materiales curriculares que sus estudiantes tienen en otras materias.

Hecha esta observación, se aborda lo correspondiente a los elementos del conocimiento, las estrategias y representaciones instruccionales particularmente de la didáctica de las matemáticas. Varios son los autores que proponen ciertos elementos o características como parte de este dominio de conocimiento. Este trabajo presenta aquellos (ej. Shulman, 1986b; Marks, 1989; McDiarmid, Ball y Anderson, 1989; Smith y Neale, 1989; y Llinares y Sánchez, 1990) que han incidido con mayor fuerza en la didáctica de las disciplinas.

Smith y Neale (1989) plantean dos elementos: las estrategias de contenido a enseñar y la formación y elaboración del contenido. En el primero incorporan el conocimiento de estrategias de enseñanza particulares (del contenido) que permite que el profesor progrese en el conocimiento conceptual del contenido de que se trate. En el segundo, que conozca y use ejemplos, explicaciones, metáforas, analogías y representaciones que sirvan para hacer que el estudiante para profesor aprenda dicho conocimiento.

Por su parte, Llinares y Sánchez (1990) reconocen como elementos esenciales: (a) el conocimiento de los materiales curriculares alternativos para una determinada noción (tópico o concepto), (b) el conocimiento del currículo de otras disciplinas escolares (para diseñar aplicaciones vinculadas con el contexto real) y (c) el conocimiento del currículo matemático de los cursos anteriores y siguientes. De igual modo consideran que se debe prestar atención al conocimiento pedagógico general y al conocimiento de las metas y objetivos de la educación. Con estos elementos se identifican las formas en que las 
nociones matemáticas están organizadas y relacionadas dentro del currículo. El conocimiento del currículo afirman que "se constituye en una de las características diferenciadoras y específicas al hablar del conocimiento profesional del profesor" (p.89). Posteriormente, Llinares (1993), bajo la denominación de "conocimiento del proceso instructivo" reconoce también otros dominios: (1) conocimiento sobre la planificación de la enseñanza, (2) conocimiento sobre las representaciones y recursos instruccionales, (3) conocimiento sobre la rutinas instruccionales, (4) conocimiento de las características de las interacciones didácticas y (5) conocimiento sobre las tareas académicas.

A partir de los trabajos de Llinares, se observa un reconocimiento de diferentes elementos propios del CDC, y específicamente del conocimiento de la didáctica específica. Reconoce la relación entre conocimiento curricular y las representaciones instruccionales afirmando que muchas veces el significado dado de una noción curricular viene caracterizado por las condiciones de la representación utilizada. Y que la representación de un tópico concreto tiene relación con el tipo de actividad planteada y el uso que hace de ella el profesor o el alumno (Llinares, Sánchez y García, 1994). De este modo, Llinares entrelaza conocimiento de las representaciones con el conocimiento de los materiales curriculares y el contexto en el que se usan.

McDiarmid, Ball y Anderson (1989) sostienen, en cuanto a las representaciones instruccionales, que los profesores deben:

a. desarrollar, seleccionar y usar apropiadas representaciones;

b. tener un amplio y apropiado repertorio de representaciones de la materia que enseñan;

c. desarrollar estándares mediante los cuales evalúen las adecuaciones de las representaciones de la materia en cuestión;

d. comprender el contenido específico que subyace en las representaciones que utilizan, las formas de pensamiento disciplinario y el conocimiento asociado con este contenido y las características de los alumnos a los que enseñan, los cuales traen consigo una diversidad de conocimiento, experiencia, expectativas y valores;

e. desarrollar un conocimiento flexible, pensado y conceptual de su materia que permita crear o seleccionar representaciones que capaciten a los alumnos en el desarrollo de un conocimiento similar; y

f. conocer acerca de los aprendices - tanto de forma específica y genérica, como sus propios alumnos y de los aprendices en general - y acerca de su proceso de aprendizaje (genérico y relacionado con el contenido).

Para McDiarmid, Ball y Anderson (1989) poseer un conocimiento "flexible" implica que los profesores necesitan conocer cómo un fenómeno o evento es relacionado con otro fenómeno o hecho, tanto dentro de su campo disciplinario como fuera de éste. El conocimiento de tales relaciones capacita a los profesores a representar ideas, información o procedimientos. Adquirir un conocimiento "Pensado" (thoughtful) significa que el profesor debe comprender cómo el conocimiento es generado en su campo y debe ser consciente de las ideas que han sido desarrolladas para explicar las relaciones observadas. Tener un conocimiento "Conceptual" implica que el profesor comprenda las ideas fundamentales y relaciones que subyacen en las interpretaciones de fenómenos o eventos 
particulares. Estas características del conocimiento de las representaciones están estrechamente relacionadas tanto como sea posible con el conocimiento acerca de la materia en cuestión como con el conocimiento del proceso de aprendizaje del alumno, con lo cual muestra una vez más, la sinergia de las categorías del CDC a que hizo referencia Shulman (1986b).

Marks (1989) incorpora bajo la denominación de "medios para la instrucción en la materia en cuestión" elementos útiles como parte de la didáctica específica del contenido (matemático). Plantea la necesidad de que el profesor debe:

1. conocer el tratamiento de los textos de la materia en cuestión, consistente en el conocimiento y análisis de los elementos que se eligen en un texto a partir del contenido enseñable;

2. conocer las organización razonada de tópicos del texto, su secuenciación, la graduación de la dificultad de los problemas, su extensión, entre otros aspectos;

3. conocer las actividades y problemas de los textos, su tipificación, las omisiones o errores en las definiciones, procesos o respuestas; la evaluación de la dificultad de los problemas, usando diferentes criterios (ej. tamaño de los números, grado de orientación), la evaluación de la utilidad de las actividades y problemas;

4. conocer los efectos de los materiales sobre el aprendizaje del estudiante, cuándo el uso de los materiales tiene impacto; los beneficios que tiene, las conexiones y relaciones, su utilidad (en otros contenidos o en la creación de modelos de representación de ideas matemáticas), así como las formas en las cuales los materiales pueden causar dificultades para los estudiantes (ej. trucos inapropiados o engañosos, poner atención o apoyarse en información equivocada y los efectos contradictorios en el uso o abuso de materiales o herramientas de simplificación);

5. conocer la relación entre materiales y contenido, lo cual incluye el estudio de los materiales y en qué medida favorecen o interfieren en los procesos de adquisición conceptual; las limitaciones para representar ideas matemáticas, la selección y uso de materiales sobre los aspectos más prácticos de la matemática (ej. para análisis conceptual, para practicar ejercicios rutinarios, para inducir conceptos, su flexibilidad en el manejo de determinados problemas, variedad, entre otros);

6. conocer la relación entre materiales y estudiantes, para discernir los más apropiados según el grado y nivel particular de matemáticas que se enseña; y

7. conocer la relación entre materiales y texto, que consiste en el estudio y discusión de los libros de texto y otros materiales para la enseñanza de las matemáticas, sus relaciones e interrelaciones con los diferentes medios instruccionales, e incluso, el análisis de textos y materiales que pueden ser incompatibles en alguna forma, y en su caso, la forma de adaptarlo para la enseñanza y el aprendizaje.

Marks (1989), a diferencia de McDiarmid, Ball y Anderson (1989), no sólo hace una propuesta específica sobre el conocimiento de las estrategias instruccionales específicas de las matemáticas, sino que considera que ésta surge a partir de la práctica de los profesores. El autor establece la apremiante necesidad de la relación entre las estrategias instruccionales con el conocimiento de los materiales de instrucción. 


\section{Tabla 1.3. Componentes del conocimiento de las estrategias y representaciones instruccionales de las matemáticas}

\section{Componentes del conocimiento / breve descripción}

(a) Conocimientos sobre las representaciones instruccionales

- comprender el contenido específico que subyace en las representaciones, las relaciones con otras representaciones o conceptos de la misma disciplina y con otros campos de conocimiento, conocer el origen y fundamento de las representaciones, así como las relaciones que subyacen y los procedimientos de verificación y su relación con el conocimiento del proceso de aprendizaje del alumno;

- criterios para desarrollar, evaluar, seleccionar y usar apropiadas representaciones instruccionales; que implica el conocimiento de los estándares de calidad que evalúan las adecuaciones de las representaciones de la materia en cuestión;

- $\quad$ amplio repertorio de representaciones de la materia que enseñan; que incluye, el estudio de la relación entre las representaciones y recursos instruccionales específicos para la disciplina; así como de analogías, ilustraciones, modelos, metáforas, ejemplos, explicaciones, demostraciones, dibujos, preguntas, actividades, discusiones, exposiciones verbales, diagramas, simulaciones, dramatizaciones y análisis de contenido, así como representaciones verbales, simbólicas, gráficas o concretas, etc.,

- conocimiento sobre las rutinas instruccionales, que implica, estrategias, métodos o técnicas específicas al contenido matemático vinculado con los materiales de instrucción y el conocimiento de las características de las interacciones didácticas, así como de las dificultades cognitivas que implica para su enseñanza y aprendizaje y las alternativas para afrontarlas.

(b) Conocimientos los materiales curriculares

- de los materiales para la instrucción del contenido matemático o para una determinación noción, sus características, los textos y materiales básicos y alternativos, software, calculadoras, programas específicos, problemas, ejercicios, guías, proyectos, ilustraciones, casos, materiales visuales, películas de y sobre conceptos o tópicos, demostraciones en laboratorios, programas o simuladores on-line, recursos en Internet, etc., y de los materiales curriculares que los estudiantes tienen en otras materias;

- del tratamiento y evaluación de los textos y materiales de la materia en cuestión, su organización razonada de tópicos, las actividades y problemas que presentan, sus efectos en el aprendizaje del estudiante, de la relación con el contenido y las estrategias instruccionales que proponen y sobre los criterios de uso, selección y adecuación para la enseñanza o aprendizaje de un tópico matemático.

(c ) Conocimiento sobre el currículo matemático

- conocimiento sobre la planificación de la enseñanza del contenido matemático, que incluye el conocimiento del diseño, evaluación y modificación del programa escolar, de las características del currículo matemático (según el grado y nivel de enseñanza), de las relaciones con otros contenidos matemáticos y de las tendencias curriculares específicas de la educación matemática;

- conocimiento del currículo de otras disciplinas escolares, que incluye la revisión de programas, textos, materiales y recursos con el objeto de establecer con éstas una mayor vinculación con la matemática y el tópico específico que se trate;

- del diseño e implementación de nuevos materiales de la materia en cuestión, que implica el conocimiento teórico y práctico del estudio del diseño y evaluación de materiales curriculares de contenido matemático. 
A partir de las ideas anteriores, los conocimientos de la didáctica de la matemática pueden agruparse en tres grandes componentes (ver Tabla 1.3): (a) conocimiento sobre las representaciones instruccionales, (b) conocimiento de los materiales curriculares y (c) conocimiento sobre el currículo matemático. El primero, comprende el estudio, comprensión, origen de las representaciones instruccionales de un tópico específico, así como los elementos para su desarrollo, evaluación, selección e implementación en el aula. El segundo grupo, es el estudio y caracterización del amplio conjunto de materiales curriculares diseñados a partir de la investigación en educación matemática; y el tercero, comprende aspectos relacionados con la actividad del diseño, planificación, implementación y evaluación del programa matemático en el aula, y su relación con el contenido y la didáctica específica.

Cabe observar que tanto en la tabla anterior (Tabla 1.2) como en ésta (Tabla 1.3), se identifica un elemento común: el conocimiento sobre el currículo matemático. En ambos casos tiene relación con el contenido matemático, sólo que en el primero, se refiere a los propósitos, importancia e ideas primordiales para enseñar las matemáticas en la escuela, así como los prerrequisitos y los problemas típicos del contenido a enseñar; mientras que en el segundo, se refiere más a la labor de diseñador y evaluador del currículo del contenido matemático y del conocimiento de otros currículos y su relación con el de las matemáticas.

\subsubsection{Conocimiento de los procesos de aprendizaje del alumno}

En su modelo de CDC, Shulman resalta otra categoría inherente al conocimiento que el profesor de una disciplina específica debe tener: el conocimiento de los procesos de aprendizaje del alumno sobre el contenido que desea enseñar. Hawkins (s.f. en Smith y Neale, 1989) define este dominio de conocimiento como la habilidad de hacer "penetrable" el contenido a los estudiantes. Consiste en que el profesor conozca los errores típicos del estudiante y la trayectoria del estudiante a lo largo de su progreso.

Shulman (1986b) afirma la apremiante necesidad de que el profesor incorpore e integre a su bagaje de conocimientos el del estudio de errores, creencias y concepciones de los estudiantes y de las condiciones instruccionales necesarias para lograr transformar estas concepciones de manera adecuada y correcta. Para Shulman y sus colaboradores, este conocimiento redundaría en una mejor comprensión, no sólo por parte de los estudiantes, sino también del nivel de CDC por parte del profesor, sobre el tópico específico que se trate.

Diferentes autores (ej. Shulman, 1986b; Marks, 1989; McDiarmid, Ball y Anderson, 1989; López, 1999, entre otros) insisten en la necesidad, no sólo de conocer los aspectos genéricos del proceso de pensamiento del alumno sobre su forma de aprender, sino además, cómo aprenden un tópico específico. De este modo, es indispensable que también se conozca el origen y evolución del proceso cognitivo del estudiante (según edad, grado, experiencia y escolaridad), las motivaciones (intrínsecas y extrínsecas), expectativas e intereses, formas de aprender, creencias, concepciones y dificultades bajo la perspectiva del aprendizaje de las matemáticas y del tópico específico matemático. 
Particularmente en la didáctica de las matemáticas, una de las fuentes más importantes de este cuerpo de conocimientos ha sido como consecuencia de las dos últimas décadas la amplia investigación cognitiva sobre el aprendizaje del estudiante, lo cual ha generado muchos datos útiles sobre concepciones, errores, obstáculos y dificultades de los estudiantes y de su pensamiento matemático (Even y Tirosh, 1995).

Respecto a los elementos que comprende el conocimiento de los procesos de aprendizaje del alumno sobre el contenido a enseñar, Shulman (1986b) y otros (ej. Carpenter, Fennema, Peterson, Carey, 1988; Van Driel, De Jong y Verloop, 2002 y Appleton, 2003), señalan que es importante "el estudio de las creencias y concepciones inadecuadas o errores conceptuales y su influencia sobre subsecuentes aprendizajes" (p.9). Según Shulman, si estas creencias son equívocas, lo que a menudo sucede, los profesores necesitan conocer las estrategias que son más fructíferas para su reorganización con vistas a conseguir la comprensión de los alumnos.

De la misma forma, Carpenter, Fennema, Peterson y Carey (1988), Llinares y Sánchez (1990), y An, Kulm y Wu (2004) señalan que el CDC incluye además: (a) el conocimiento de los conceptos y procedimientos que los estudiantes traen sobre un tópico, (b) las etapas de comprensión de un concepto, o bien, las fases de aprendizaje de los conceptos, (c) el conocimiento de técnicas para medir la comprensión de los estudiantes y diagnosticar sus concepciones inadecuadas, (d) el conocimiento de las estrategias instruccionales (específicas) que pueden ser usadas para permitir que los estudiantes conecten lo que tienen que aprender con el conocimiento que ellos ya poseen, y (e) el conocimiento de estrategias instruccionales para eliminar las concepciones inadecuadas que puedan estar desarrollando. Llinares y Sánchez (1990) y An, Kulm y Wu (2004) añaden un elemento adicional: el conocimiento de las características del aprendizaje de tópicos concretos definidas por los errores de comprensión de los estudiantes. An, Kulm y Wu (2004) plantean como elemento preliminar, el conocimiento de las necesidades de los estudiantes.

Marks (1989), amplía la descripción de estos elementos del conocimiento de los procesos de aprendizaje sobre el contenido matemático, a la luz de la práctica del profesor de matemáticas, y obtiene como elementos mínimos que el profesor debe:

a. conocer los procesos de aprendizaje de los estudiantes, enfatizando los procesos de comprensión del concepto y las formas de justificación, partiendo de objetos concretos que representen ideas matemáticas, conociendo las diferencias individuales que puede haber en la forma de aprender de los alumnos (ej. algunos aprenden más con experiencias cinésicas, otros con experiencias concretas), las formas de conectar las ideas concretas con las abstractas de las matemáticas (con los correspondientes materiales de apoyo necesario), y de las formas de ir de lo simple a lo complejo;

b. conocer las formas en que la mayoría de los estudiantes comprende un tópico dado;

c. conocer la falta de recursos de los estudiantes, como son la falta de criterio para utilizar un procedimiento en una situación y que debe ser diferente para otra (especialmente cuando parecen similares), entre otros; 
d. conocer los aspectos que son difíciles o fáciles para los estudiantes, algunos aplicados a las matemáticas en general (ej. terminología), a los tópicos y procedimientos específicos de la matemáticas (ej. simplificar), a su concepción o forma de aprender (ej. memorizar reglas sin comprenderlas) y al por qué de estos aspectos; y

e. conocer los conocimientos particulares de los estudiantes a partir del estudio y observación de su desarrollo y desempeño en el aula sobre el contenido o tópico que aprende, con lo cual se estudian las diferentes formas de pensar y concebir el contenido matemático.

Graeber (1999), en su artículo Forms of knowing mathematics: what preservice teachers should learn, concibe que el CDC incluye dos grandes tipos de conocimientos: (1) aquellos que hacen comprensible un concepto particular fácil o difícil y las concepciones o creencias que los estudiantes comúnmente traen con frecuencia, y (2) aquellos que hacen referencia a las representaciones de tópicos enseñados (desarrollado en la anterior sección). Graeber responde a la pregunta ¿Qué ideas importantes deberían ser incluidas como formas de conocimiento en los programas de formación de profesores? La autora, a partir del marco teórico del conocimiento del profesor de Shulman (1986b), propone cinco grandes ideas (big ideas) que tienen implicaciones en la formación de profesores de matemáticas. Las primeras tres, según la autora, tienen relación con lo que hace fácil o difícil la materia y las creencias de los estudiantes. Las últimas dos ideas están relacionadas con hacer comprensible la materia a los aprendices, es decir, aspectos del conocimiento de la didáctica del contenido matemático, a partir del conocimiento del estudiante.

Graeber (1999) desarrolla, describe y caracteriza cada una de estas ideas, e incorpora un conjunto de pautas y recomendaciones sobre las estrategias, mecanismos y materiales que pueden ser útiles en la construcción de estas formas de conocimiento en los programas de formación de profesores. Para cada una de estas grandes ideas se identifican diferentes aspectos sobre el conocimiento de los procesos de aprendizaje del estudiante que el profesor debe saber:

1. la comprensión del conocimiento del estudiante es importante, consiste en reconocer la importancia del estudio del conocimiento del estudiante, de sus creencias, concepciones y errores conceptuales de las nociones matemáticas, así como de los argumentos de su razonamiento;

2. los estudiantes que poseen una forma de conocimiento no necesariamente poseen otra(s) forma de conocimiento, es decir, conocer los patrones o modelos generales del pensamiento matemático acerca de los diferentes conceptos y su diferenciación de lo que es fácil o difícil al alumno, y comprender que los estudiantes que poseen una forma de conocimiento no necesariamente poseen otra forma de conocimiento; implica que el profesor conozca las formas de adquisición más comunes del conocimiento matemático, tanto las formas de adquisición del conocimiento conceptual como el procesal; la selección o creación de tareas adecuadas o situaciones que permitan comprender o valorar tanto una forma de conocer como otra, y reconocer y enmendar conflictos, errores, o inconsistencias en los estudiantes; 
3. el conocimiento intuitivo es un recurso tan valioso como útil, es decir, conocer las intuiciones de los estudiantes y pensar que para algunos alumnos éstas, aunque sean erróneas, tienen una lógica; incluye el estudio del conocimiento intuitivo en matemáticas y el conocimiento de las diferentes formas estrategias para ayudar al estudiante a aprender a estudiar matemáticas a partir de sus propias intuiciones;

4. ciertas características instruccionales parecen promover la retención, lo que implica que el profesor debe conocer las diferentes formas y estrategias actuales de enseñanza de las matemáticas, para relacionar lo que ya saben los alumnos con lo que tienen que aprender, para incorporar formas novedosas y actuales de enseñanza propias de la didáctica de la matemática (ej. uso de la resolución de problemas para motivar a los estudiantes), así como conocer las estrategias de aprendizaje de los estudiantes para promover la adquisición, organización y almacenamiento del contenido, el recuerdo, la memorización y la comprensión; y conocer los contextos significativos de aprendizaje de los estudiantes, desde los más primitivos hasta los más sofisticados; y

5. las representaciones alternativas y el reconocimiento y análisis de métodos alternativos son importantes, es necesario conocer una variedad de representaciones (como son, modelos lógicos o experimentales; experiencias varias); diferenciarlas entre sí (según el pensamiento del estudiante, su escolaridad, experiencia y madurez, así como los alcances, limitaciones y tópicos para los cuales es potencialmente útil); y conocer la validez, generalización y eficacia de las propias soluciones (métodos) de los estudiantes (los cuales pueden no ser lo que el profesor espera).

A modo de síntesis, las categorías de conocimiento de los procesos de aprendizaje del estudiante sobre el contenido a enseñar se agrupan en tres grandes rubros (ver Tabla 1.4): (a) conocimiento del proceso cognitivo del estudiante en matemáticas, (b) conocimiento del diagnóstico del proceso cognitivo del estudiante y (c) el conocimiento de estrategias instruccionales. En el primer rubro se incorpora lo referente al estudio del conocimiento del estudiante vinculado con el aprendizaje del contenido matemático y de los tópicos específicos. El segundo, con la forma en que el profesor selecciona, usa y adecua procedimientos de diagnósticos del conocimiento de alumno y el tercero, sobre las estrategias instruccionales específicas (incluyendo los materiales curriculares) que utiliza para corregir o modificar las concepciones inadecuadas del estudiante.

Tanto en esta tabla como en las anteriores (Tabla 1.2 y 1.3) se observan elementos similares que muestran las intersecciones o relaciones entre los tres elementos. En la Tabla 1.4, por ejemplo, se aprecia que algunas componentes del conocimiento de los procesos cognitivos del estudiante en matemáticas tienen una clara relación con el conocimiento del contenido matemático, y que las estrategias instruccionales tienen relación con el componente de las representaciones instruccionales. Se percibe igual una estrecha relación de todos los componentes con aspectos del currículo matemático. 
Tabla 1.4. Componentes del conocimiento de los procesos de aprendizaje del estudiante sobre el contenido matemático

\section{Componentes del conocimiento / breve descripción}

(a) conocimiento del proceso cognitivo del estudiante en matemáticas

- conocer las necesidades y conocimientos particulares de los estudiantes, a partir del estudio y observación de su desarrollo (edad, experiencia, antecedentes y escolaridad) y desempeño en el aula, sobre el contenido matemático que aprende, y reconocer la importancia del estudio de las concepciones y dificultades del estudiante como parte inherente e indispensable para la enseñanza y aprendizaje de las matemáticas; conocer sus intereses, motivaciones y expectativas relacionados con las matemáticas y con los diferentes tópicos específicos;

- conocer los procesos de aprendizaje de los estudiantes en matemáticas, enfatizando los procesos de comprensión del concepto y las formas de justificación, partiendo de objetos concretos que representen ideas matemáticas, conociendo las diferencias individuales que puede haber en la forma de aprender de los alumnos, el conocimiento de las características del aprendizaje de tópicos concretos (más y menos comunes) y según niveles cognitivos de desarrollo (procesal o conceptual), las formas de conectar las ideas concretas con las abstractas de las matemáticas y de las formas de ir de lo simple a lo complejo; del conocimiento de las intuiciones y heurísticas de los estudiantes; formas de conectar unas ideas con otras; formas en que la mayoría comprende un tópico dado; es decir, algunos aplicados a las matemáticas en general (ej. terminología), a los tópicos y procedimientos específicos de la matemáticas (ej. simplificar), y otros a su concepción o forma de aprender (ej. memorizar reglas sin comprenderlas) y el porqué de estos aspectos; los fundamentos de razonamiento del estudiante; $\mathrm{y}$

- conocer las creencias y concepciones inadecuadas comunes de los estudiantes, así como sus interpretaciones, dificultades (o facilidades), obstáculos y errores de los estudiantes del contenido matemático o del tópico específico, como son, por ejemplo, la falta de juicio para utilizar un procedimiento en una situación y que es diferente para otra (especialmente cuando parecen similares); y conocer las atribuciones o causas de éstas.

(b) Conocimiento del diagnóstico del proceso cognitivo del estudiante

- conocimiento de técnicas para medir y diagnosticar sus concepciones inadecuadas, que incluye, el análisis de los criterios de selección, uso y adecuación de instrumentos o materiales (genéricos o específicos de la didáctica de las matemáticas) para el diagnóstico de las necesidades, formas de aprender, creencias, errores y dificultades en el aprendizaje del tópico matemático.

(c ) Conocimiento de estrategias instruccionales

- conocer las estrategias instruccionales específicas para corregir las creencias y concepciones inadecuadas, errores y dificultades, así como conocer las estrategias instruccionales específicas que pueden ser usadas para permitir que los estudiantes conecten lo que ellos aprenden al conocimiento que ellos ya poseen;

- conocer las estrategias de aprendizaje de los estudiantes para promover la adquisición, organización y almacenamiento del contenido matemático, que implica, conocer estrategias para promover el recuerdo, la memorización y la comprensión; y conocer los contextos significativos de aprendizaje de los estudiantes, desde los más primitivos hasta los más sofisticados;

- conocer los materiales curriculares, utilizados como parte de las estrategias instruccionales para corregir las dificultades y concepciones inadecuadas de los estudiantes.

Como objeto de investigación, el estudio de los conocimientos del estudiante ha tenido gran relevancia en los investigadores, quienes han desarrollado una cantidad considerable de información sobre las creencias, concepciones, errores y dificultades de los estudiantes en los diferentes contenidos matemáticos. Así se evidencia en la revisión de las 
revistas internacionales sobre investigación en didáctica de las matemáticas y de didáctica de los tópicos específicos. Sin embargo, si bien es importante el estudio del conocimiento del estudiante a la luz de la didáctica de las matemáticas, éste como CDC se centra esencialmente en el estudio sobre lo que el profesor conoce, cómo lo conoce y las atribuciones o causas de ese conocimiento (Even, 1990 y Even y Tirosh, 1995), es decir, incluye el análisis del conocimiento que tiene el profesor sobre los diferentes elementos del proceso cognitivo de aprendizaje del alumno de las matemáticas, particularmente sobre las concepciones y errores que logra identificar en sus alumnos, las formas de diagnosticar éstas y las estrategias instruccionales que utiliza para corregirlas.

\subsection{INVESTIGACIONES SOBRE EL CONOCIMIENTO DIDÁCTICO DEL CONTENIDO DEL PROFESOR DE MATEMÁTICAS}

El desarrollo de la investigación sobre el CDC en los últimos 20 años ha tenido un crecimiento asombroso y acelerado. Esto mismo imposibilita presentar una revisión exhaustiva al respecto. Esta sección nos permitirá tener un panorama global sobre un conjunto de estudios que han analizado el CDC en matemáticas ${ }^{2}$, con el propósito explorar sus características y significado, conocer el énfasis que han puesto los investigadores sobre algunas categorías, los diseños de investigación utilizados, los escenarios y sujetos de investigación, los instrumentos de recogida de datos y los principales resultados, discusiones y conclusiones obtenidos.

El análisis se concentró en investigaciones concluidas, las cuales permitieron identificar siete principales áreas donde se ha desarrollado la mayoría de la investigación sobre el CDC: (1) investigaciones que buscan conocer las características del CDC, su significado y la asociación que guarda con otros constructos o variables, (2) estudios sobre el conocimiento del contenido a enseñar, (3) estudios sobre el conocimiento de las representaciones instruccionales, (4) estudios sobre conocimiento del estudiante, (5) investigaciones que proponen y evalúan formas o estrategias para desarrollar el CDC en profesores de matemáticas, (6) trabajos que relacionan la actitud del profesor con el desarrollo del CDC, y (7) finalmente se analizan los avances de investigación del CDC en el campo de la enseñanza de las ciencias, con el objeto de ampliar el contexto de los estudios del CDC en otras disciplinas.

La clasificación no pretende ser excluyente, por lo que es posible identificar algunos trabajos en una o más categorías. Sin embargo, con base en los objetivos de cada trabajo se agrupó en una solamente, de tal modo que nos permitiera posteriormente valorar cierta tendencia sobre el tipo de investigación que se ha realizado. Por otro lado, la amplitud de la descripción de cada investigación dependió de contar con la información completa dependiendo de la fuente primaria donde se obtuvo (ej. artículo, resumen, tesis).

Por último, en esta sección sólo se presentan aquellos trabajos que hacen referencia exclusivamente a una o más categorías del CDC. No obstante, en la literatura sobre

${ }^{2}$ En el Capítulo 2 se presentan los estudios que relacionan el CDC y la educación estadística. 
conocimiento profesional también encontramos trabajos que abordan el estudio de las concepciones y creencias de los profesores, los cuales están estrechamente relacionados con el CDC. Ejemplo de estas investigaciones son los trabajos de Contreras (1998), Carrillo (1998), Mellado (1997), Blanco (1997 y 1998), Flores (1998), Gil (2000), Llinares (2000), Moreno (2000), entre otros.

\subsubsection{Caracterización del CDC, su significado y asociación con otros constructos}

Este primer grupo de investigación intenta caracterizar el CDC en matemáticas. Busca estudiar cuál es el CDC del profesor, definirlo y cómo éste se asocia a otros constructos o variables (ej. concepciones, creencias, dilemas, experiencia docente, conocimiento pedagógico, aprovechamiento escolar). Se sitúan en esta clasificación los trabajos de Carpenter, Fenemma, Peterson y Carey (1988), Marks (1990a y 1990b), Wallece (1990), Howald (1998), Llinares (2000), Sánchez y Llinares (2003).

Uno de los primeros estudios en educación matemática fue el de Carpenter, Fenemma, Peterson y Carey (1988), quienes estudiaron los conocimientos de los profesores acerca de las características de los diferentes tipos de problemas de suma y resta y acerca de las estrategias que los niños usan para resolverlos; analizaron si los profesores son capaces de predecir el éxito de sus estudiantes en la resolución de problemas y de identificar las estrategias usadas por los niños para resolverlos. Asimismo exploraron la relación que existe entre el CDC del profesor y el aprovechamiento de sus estudiantes. Estudiaron a 40 profesores de 1er. Grado de 27 escuelas (tres católicas y 24 públicas) de Madison, Wisconsin (EEUU) y cuatro pequeñas comunidades de Madison. Todos los profesores en servicio tenían un promedio de experiencia docente en primaria de 10.9 siendo de 5.62 años su media docente en primer grado. Treinta y cuatro profesores ya habían participado en diferentes cursos de actualización en los últimos tres años, de los cuales nueve habían participado en cursos específicos sobre matemáticas. Los 40 profesores usaban 11 libros de texto diferentes.

Los instrumentos de recogida de datos fueron: (a) cuestionario sobre distinción entre problemas tipo, donde se les solicitó que escribieran el enunciado de seis problemas, dándoles las operaciones (ej. 5+7=?, 6+?=11...); (b) prueba de dificultad relativa de problemas, donde se les proporcionó 16 pares de problemas y se les pidió identificar (y rusticar) cuáles de los problemas de cada par podría ser más difícil para los niños de 1er. Grado; (c) análisis de su conocimiento general de estrategias, en el cual se les mostró un vídeo de tres niños de 1er. Grado resolviendo diferentes problemas y se les solicitó a los profesores expresaran cómo éstos los resolverían. Posteriormente, al profesor se le solicitó describir cómo el niño podría responder a siete problemas que fueran similares a los 4 trabajados en el vídeo. Cada vídeo se repitió una vez más, antes de solicitarle al profesor explicar cómo el niño podría resolver otros problemas; y (d) análisis del conocimiento del profesor de sus propios estudiantes donde se les solicitó explicar cómo seis de sus alumnos, seleccionados aleatoriamente podrían resolver seis diferentes Word problem de suma y resta. Dos instrumentos estaban dirigidos a los estudiantes: (a) prueba de hechos numéricos, donde se les solicitó resolver 20 sumas y restas (10 con cifras menos de 10 y 10 sumas entre 10 y 18) con límite de tiempo para completarla; y (b) prueba de resolución de 
problemas; donde se les solicitó resolver 17 Word problem (nueve problemas tipo de suma y resta, cuatro incorporando varias operaciones, cuatro involucrando agrupaciones y particiones). Los números que debían utilizar en los problemas los alumnos eran menores de 20. Los problemas fueron leídos a los estudiantes y se les pidió no pasar a otro hasta terminar el anterior.

Los resultados indican que los profesores distinguieron algunas de las diferencias básicas entre los tipos más amplios de problemas de suma y resta. La mayor parte de ellos pudo enunciar problemas para representar diferentes situaciones de unir y separar. Sin embargo, la mayor parte no pareció tener un marco teórico coherente para argumentar lo que habían hecho los niños con los problemas. La mayor parte estaban familiarizados con el uso de estrategias para resolver problemas de suma y resta, y pudieron identificar estas estrategias cuando observaron a niños en el vídeo. Sin embargo, los profesores no lograron categorizar los problemas en términos de las estrategias que los niños podían usar para resolverlos. Los profesores no pudieron organizar sus conocimientos dentro de una red coherente que relacionara los tipos de problemas, la solución de los niños y las dificultades de los problemas.

Los investigadores no encontraron correlación significativa entre el conocimiento general de problemas que tiene el profesor, la dificultad de problemas y las estrategias de resolución, con el aprovechamiento del estudiante o con la habilidad del profesor para predecir también el éxito de sus propios estudiantes en la resolución de problemas. Sin embargo, los autores concluyen que los profesores tradicionalmente no toman decisiones instruccionales basadas en las estrategias que se usan para resolver diferentes problemas, pero sí basadas sobre sus mediciones de si los problemas podrían ser muy difíciles para sus estudiantes. Los resultados de este estudio confirmaron el hecho de que los profesores no tienen una base de conocimiento suficientemente rica como para planear la instrucción basada en una medición cuidadosa sobre lo que los estudiantes usan para resolver problemas.

En este mismo grupo quedan los trabajos publicados por Marks (1990a y 1990b y 1989). Se trata de estudios con un enfoque más cualitativo y centrados en el estudio del profesor; en su propia práctica docente. Estos estudios tienen como finalidad comprender de forma más profunda el CDC del profesor. Marks desarrolla una investigación pionera en este campo centrada en la naturaleza conceptual y metodológica del CDC del profesor sobre el tema de las fracciones y sus hallazgos representan un referente obligatorio para quien comienza a estudiar sobre este constructo en el campo de las matemáticas.

Marks (1990a), como parte de su tesis doctoral, se ocupó de explorar el significado del CDC a partir de la realidad o práctica del aula de los profesores de matemáticas. Su estudio estuvo dividido en tres fases: descripción, comparación y definición del CDC. Estas tres fases del estudio examinan el $\mathrm{CDC}$ en profundidad en un contexto limitado: la enseñanza de equivalencia de fracciones en quinto grado. En la fase de Descripción exploró en qué consiste el CDC en este contexto, incluyendo ejemplos, alcances y una subestructura significativa. En la fase de Comparación analizó cómo el CDC difiere entre profesores con alto y bajo conocimiento de la materia y con mucha o poca experiencia docente. En la fase de Definición, comparó el CDC, con el conocimiento de la materia y el conocimiento 
pedagógico general en este contexto y generalizó la naturaleza de estas formas de representación al conocimiento del profesor. Seleccionó ocho profesores, tanto de altos como de bajos niveles de conocimiento matemático, así como de diferente tipo de experiencia docente y cada uno fue sometido a cuatro entrevistas estructuradas para evaluar diversos aspectos de la enseñanza centrados sobre el CDC. Las entrevistas fueron transcritas y reducidas a 900 breves segmentos de datos verbales. Seguidamente fueron analizadas en varias fases recursivas, con lo cual se sintetizaron mediante estructuras categóricas que representaban formas de conocimiento del profesor. La fase de Descripción produjo una estructura general y un amplio catálogo de ejemplos del CDC en matemáticas elemental. En la fase de Comparación el CDC de los estudiantes para profesor con alto conocimiento matemático fue cercano al de un profesor experto, mientras que los veteranos con mucha experiencia docente pero poco conocimiento matemático mostraron poco CDC. La fase de Definición identificó varios rasgos característicos del CDC, por ejemplo, que se origina de varias fuentes y de la relación entre el conocimiento de la materia y del conocimiento pedagógico genérico. Marks sugirió, entre otras cosas, que los profesores de primaria necesitan adquirir un conocimiento de la materia en cuestión antes que puedan esperar desarrollar el CDC en ese dominio, y que los programas de formación de profesores deberían tener en cuenta tanto los aspectos relativos al contenido matemático como los de pedagogía general y de los fundamentos y construcciones derivadas de éste hacia el CDC.

En ese mismo año, Marks (1990b) publicó parte de los resultados de su tesis doctoral en el artículo denominado Pedagogical Content Knowledge. From a Mathematical Case to a Modified Conception con los propósitos de: (a) presentar una descripción del $\mathrm{CDC}$ en matemáticas a partir de las entrevistas con profesores de quinto grado, (b) sugerir modificaciones en la concepción general del CDC a partir de esta descripción, y (c) sugerir revisiones en la práctica de la formación de profesores para mejorar el conocimiento del profesor de CDC. Participaron en el estudio ocho profesores, seis con experiencia y dos novatos. Dos de los experimentados puntuaron bajo en una escala compuesta de conocimiento matemático, mientras que los otros seis puntuaron alto. Los instrumentos fueron ocho tareas-basadas en entrevistas de entre 45 y 90 minutos de duración. El estudio formó parte de uno más amplio: el Proyecto de Evaluación de Profesores (Teacher Assessment Project) de la Universidad de Stanford, 1986-89, dirigido por Shulman y patrocinado por la Corporación Carnegie. Las tareas estaban centradas en la enseñanza de la matemática de quinto grado e incluyeron planes de clase, análisis crítico de vídeos del salón de clases y diagnóstico de los errores y dificultades de los estudiantes y las correspondientes estrategias para corregirlos. Se desarrollaron dos conjuntos de cuatro entrevistas por cuatro informantes, audiograbadas durante todo el proyecto.

A partir de los resultados, Marks obtuvo inicialmente 12 categorías del CDC: materia en cuestión, estudiantes, administración en el salón de clases, contextos, libros de texto, materiales, currículo, estrategias instruccionales, explicaciones, evaluaciones, propósitos y valores y por último una categoría que denominó "indeterminados". Posteriormente, del análisis del contenido de los datos de las entrevistas surgió una estructura del CDC (Figura 1.1). 


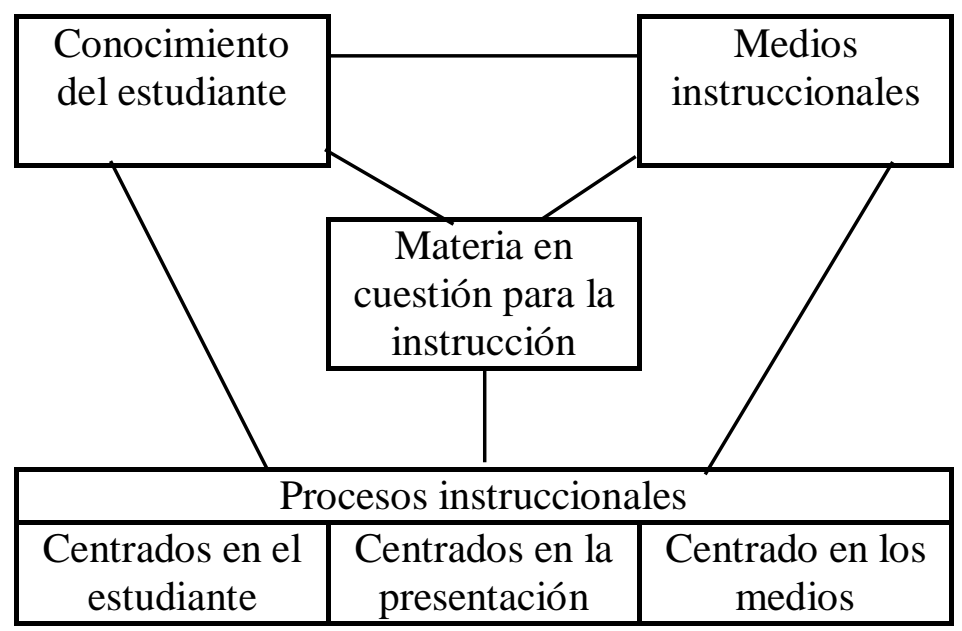

Figura 1.1. Estructura de CDC en quinto grado, sobre equivalencia de fracciones. Fuente: Marks (1989, Fig. 2, p.11).

Según Marks (1989 y 1990b) la particular disposición en la Figura 1.1, indica otra característica de la estructura del CDC. Las tres categorías superiores - materia en cuestión, conocimiento del estudiante y medios instruccionales - se refieren a la naturaleza de factores, mientras que los procesos instruccionales se refieren más a la naturaleza de las acciones. En este sentido, las tres primeras categorías pueden ser enseñadas como los ingredientes principales, y las últimas categorías como las técnicas para combinarlos.

Haciendo un análisis más detallado, Marks desglosa su modelo de CDC en subcategorías (Figura 1.2), a partir de la realidad y la práctica del profesor de matemáticas. Marks (1990b) concluye que:

$1^{\circ}$. El CDC tiene sus raíces en el conocimiento de la materia en cuestión. La transición del conocimiento de la materia en cuestión a CDC supone un proceso de interpretación, el contenido es examinado por su estructura y significado, entonces se transforma para hacerlo comprensible y propiciar el aprendizaje.

$2^{\circ}$. El CDC se deriva principalmente del conocimiento pedagógico general. Los futuros profesores, normalmente estudian los tópicos en términos genéricos y posteriormente, en su enseñanza, deben tratar de aplicar estas ideas para un contenido particular. El proceso con que tal conocimiento genérico engendra el CDC es la especificación, es decir, el uso apropiado de una idea amplia aplicable en un contexto particular.

$3^{\circ}$. El uso de construcciones previas de CDC influye en el nuevo CDC. Esto puede ser común en el diseño de actividades de aprendizaje, formulación de estrategias de enseñanza y conciencia de los errores conceptuales de los estudiantes. El conocimiento invocado para hacer alguna afirmación no es derivado primeramente del conocimiento de la materia o de la pedagogía general pero en cambio representa una síntesis de los tres tipos de conocimiento (conocimiento de la materia, conocimiento de la pedagogía general y conocimiento didáctico del contenido). 


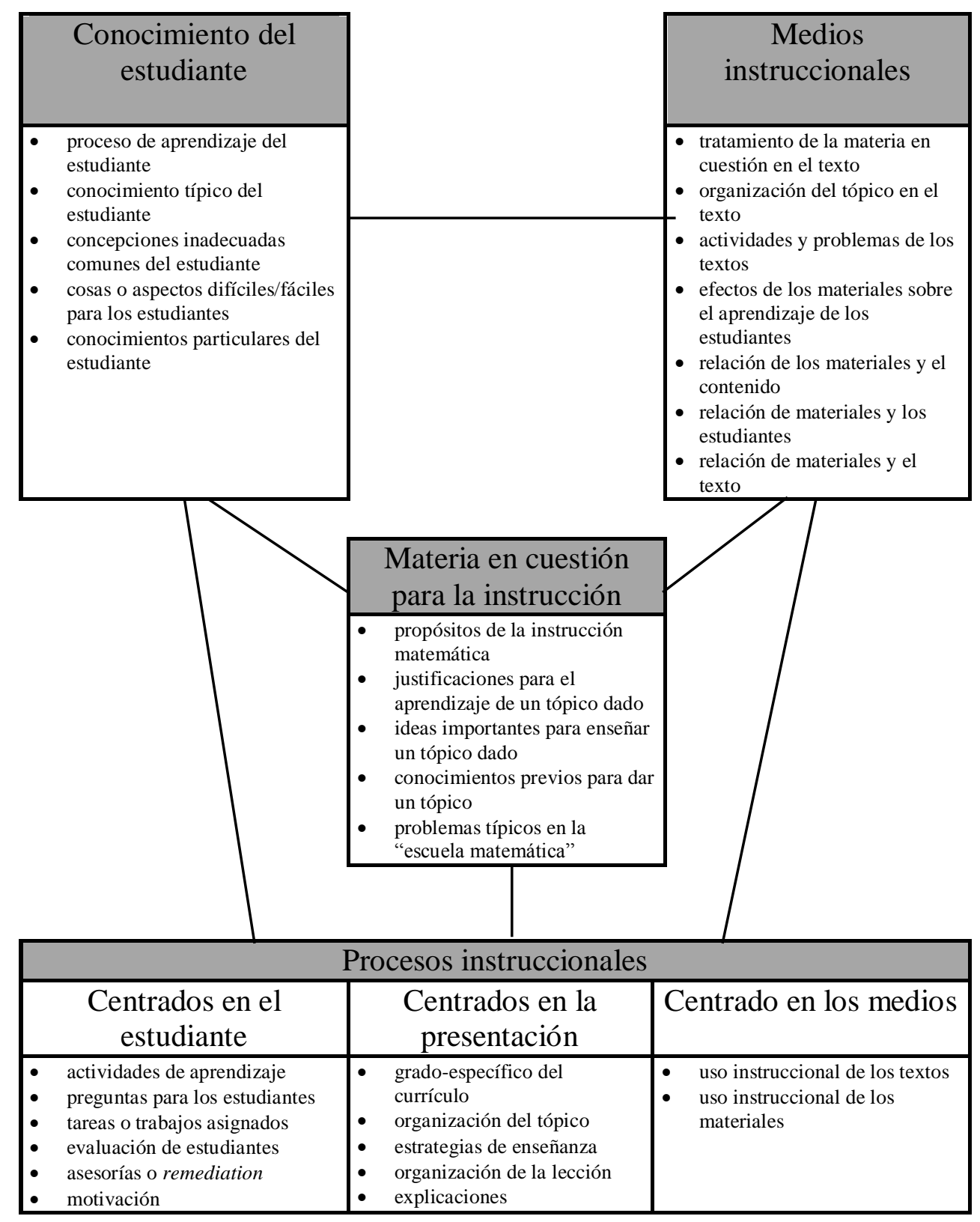

Figura 1.2. Subcategorías de CDC en quinto grado, sobre equivalencia de fracciones. Fuente: Marks (1990b, Fig.1, p.5).

Marks (1990b) recomienda hacer estudios similares con diferentes profesores, instrumentos, tópicos o áreas, y utilizar análisis de datos diferentes para clarificar más la naturaleza del CDC. La descripción del CDC, en su estudio, fue construida a partir de datos empíricos y únicamente con ocho profesores. Para Marks, la ampliación del estudio a más profesores podría revelar categorías adicionales y proporcionar mejores ejemplos. Propone, como estrategia, combinar el análisis teórico y el empírico para generar un bosquejo más completo del CDC fundamentado en la práctica del salón de clases. 
En 1990, Wallece bajo la perspectiva de investigación experto-novato realizó cuatro estudios de casos sobre el conocimiento de la geometría y el CDC de profesores de matemáticas en secundaria y la relación entre su conocimiento matemático y el CDC. Los sujetos fueron seleccionados en base a sus intereses, experiencia y desenvolvimiento profesional en la enseñanza de la geometría. Cada profesor fue observado durante dos semanas en el salón de clases y respondió a siete entrevistas y tareas diseñadas para obtener información acerca del contenido y organización de la materia en cuestión y del CDC de geometría. Las tareas incluyeron la construcción de un mapa conceptual, la planificación de una unidad de enseñanza simulada, y la clasificación de problemas geométricos con base en las relaciones y dificultades percibidas por los estudiantes. Wallece encontró que el conocimiento de la materia y el CDC parecen estar interrelacionados en las mentes de los profesores del estudio. Las fuentes del conocimiento del contenido de la geometría, consideradas por los profesores fueron numerosas e incluyeron a colegas, talleres y otras actividades en ejercicio y amplias lecturas. Cada profesor aprendió algunos aspectos del CDC durante su formación inicial como profesor de secundaria o en la Facultad de Matemáticas, pero ninguno atribuyó tales conocimientos a un curso de métodos matemáticos (a nivel licenciatura).

Otro estudio es el de Swenson (1998), quien investigó el conocimiento de la materia y del CDC del tema de probabilidad de los profesores y sus relaciones con la enseñanza de la probabilidad. Exploró la naturaleza de las tareas instruccionales y el discurso usado en el salón de clases. A través de un estudio de casos, se examinó el conocimiento y práctica de cuatro profesores de escuela media en Estados Unidos. Mediante una entrevista previa a las observaciones se valoró el conocimiento acerca de la probabilidad y posteriormente se observó cómo enseñaban el tema. Entrevistas posteriores a las observaciones, exploraron el conocimiento del profesor y su relación con la práctica. Las fuentes de datos incluyeron entrevistas transcritas, notas de campo de las observaciones, documentos instruccionales escritos, vídeo y audio grabaciones de la instrucción en clases. Los estudios de casos individuales fueron escritos describiendo la experiencia del profesor y la forma de enseñar probabilidad. Los resultados indicaron que los profesores: (a) carecen de un conocimiento explícito y relacionado del contenido probabilístico, (b) sostienen una visión tradicional acerca de las matemáticas y su enseñanza-aprendizaje, (c) les falta una comprensión de las "grandes ideas" (ver Graeber, 1999) para ser enfatizadas en la clase de probabilidad, (d) les falta conocimiento de las posibles concepciones y conceptos erróneos de los estudiantes, (e) les falta conocimiento y habilidades necesarias para organizar el discurso en formas que promuevan niveles altos de aprendizaje en sus estudiantes, y (f) les falta una integración del conocimiento a partir de las reformas educativas propuestas. Aunque los estudiantes fueron involucrados activamente en la exploración del contenido probabilístico a través del uso de juegos, simulaciones y otras tareas instruccionales disponibles por parte del profesor, el nivel cognitivo de sus tareas y discurso fue limitado por la naturaleza de la instrucción. Los resultados del estudio tuvieron implicaciones para las reformas de la educación matemática, tanto para la formación inicial de los profesores como para los equipos de diseño y desarrollo curricular.

Howald (1998) por su parte, buscó caracterizar cómo es aplicado el conocimiento del profesor en el salón de clases y cómo influyen sus concepciones sobre el concepto de función. En la primera fase del estudio se recogieron datos de 20 profesores acerca del Jesús Enrique Pinto Sosa 
conocimiento matemático el CDC de funciones. Esto sirvió como antecedente para la fase dos, en la cual se realizó un estudio de dos participantes mediante observaciones en el salón de clases y entrevistas. Para lograr la triangulación de la información, se utilizó una variedad de instrumentos: (a) una encuesta sobre el conocimiento del concepto de función, (b) una encuesta sobre concepciones acerca de la matemáticas de los profesores, (c) dos tareas sobre mapas conceptuales, (d) una entrevista basada sobre los mapas conceptuales elaborados, incluyendo dos tareas de tarjetas-ordenadas, y (e) una entrevista sobre los instrumentos de la encuesta.

Los resultados mostraron que los profesores en ejercicio tienen un mejor conocimiento y comprensión de funciones que los estudiantes para profesor, pero el $20 \%$ de los profesores en ejercicio no mostraron una comprensión profunda del concepto de función a pesar de su considerable experiencia en la enseñanza del concepto. En la segunda fase del estudio se encontró, primero, que la imagen del concepto de los profesores influye en la enseñanza por las oportunidades de aprendizaje que el profesor ofrece a los estudiantes. Segundo, el uso de aplicaciones en la enseñanza depende de la disponibilidad de aplicaciones del mundo real, aunque la existencia de este conocimiento no asegura esta aplicación. Finalmente, las concepciones de matemáticas influyen en el uso del concepto y en el CDC del salón de clases. Una dimensión de una concepción particularmente prominente fue la relacionada con la utilidad de las matemáticas.

Llinares (2000) exploró las relaciones entre el CDC del profesor de matemáticas y los dilemas que posee cuando enseña el concepto de función. Específicamente se abocó a analizar las interrelaciones entre: (i) conocimiento del profesor acerca de la forma en la cual dirige a sus estudiantes a la comprensión del concepto de función y (ii) la generación de enseñanza de dilemas en su práctica docente (como una mezcla desarrollada entre conocimiento y creencias en contexto). Se trató de un estudio de caso con una profesora del nivel secundaria con 17 años de experiencia docente, experta en el campo y con dominio en el tema de funciones.

Diferentes aproximaciones fueron utilizadas para obtener la información: entrevista biográfica y contextual, clasificación y análisis de problemas tomados de libros de texto, análisis hipotético de situaciones-problema, entrevista sobre la planeación de las clases, grabación de algunas clases y entrevistas que permitieron el análisis de los incidentes críticos observados durante las clases.

Llinares (2000) concluye que los resultados hacen pensar que el conocimiento de la profesora acerca de sus estudiantes sobre el concepto de función influye en la organización y contenido de su enseñanza en dos sentidos: (1) integrar las perspectivas proceso y objeto para desarrollar el concepto de función (conocimiento de la materia en cuestión) y (2) subrayar el rol que juegan los diferentes modos de representación y la interpretación entre estos (CDC específico de las matemáticas). Sus resultados corroboran la conclusión de que el CDC específico de las matemáticas es la integración cognitiva de diferentes componentes: conocimiento de las matemáticas, conocimiento de los modos de representación y conocimiento acerca de los estudiantes. 
Posteriormente, Sánchez y Llinares (2003) estudiaron la influencia del conocimiento de la materia de los estudiantes para profesor sobre el razonamiento pedagógico. Esta influencia fue estudiada a través de las formas en las cuales el concepto de función es presentado a los estudiantes de secundaria en los libros de texto utilizados en la enseñanza. Cuatro estudiantes para profesor participaron en cuatro entrevistas diseñadas para obtener información acerca de sus conocimientos del concepto de función y sus imágenes del concepto, así como estudiar las relaciones entre los aspectos de función obtenidos y el modo de representación seleccionado.

En la primera entrevista, de tipo semi-estructurada, se recogió información respecto de su experiencia biográfica relacionada a la matemática y sus imágenes acerca de la matemática, enseñanza y aprendizaje. En la segunda entrevista se les solicitó a los estudiantes trabajar con tareas prácticas asociadas a problemas de libros de textos, con base en la literatura sobre comprensión de funciones. Cada problema fue escrito en una tarjeta para luego darle oportunidad al estudiante de clasificarla (ordenarla), escribiendo sobre la tarjeta los argumentos que expliquen su respuesta. Después analizaron 10 problemas (ver Sánchez y Llinares, 2002 y Llinares, 2000). Se pretendía obtener información acerca de las razones por las que los estudiantes para profesor usan un problema específico en su enseñanza y cómo piensan que un aprendiz (estudiante) puede resolverlo. En la tercera entrevista, se les solicitó usar los problemas de los libros de texto para la planeación de una secuencia hipotética de enseñanza para el concepto de función proporcionando argumentos que justificaran su decisión. El propósito fue identificar lo que estaba detrás de la representación del contenido matemático en la planeación preparada por cada estudiante para profesor; con la idea de obtener información sobre la fuente de su selección y decisión. Finalmente, en la cuarta entrevista, se les pidió que resolvieran cuatro situaciones hipotéticas (Casos) (ver Llinares, 2000, y Sánchez y Llinares, 2002).

Los resultados mostraron que los cuatro estudiantes para profesor difieren en su conocimiento de la materia sobre el tema de función tanto en los diferentes aspectos del concepto como en los diferentes modos de representación y uso de actividades de aprendizaje estructuradas. Sánchez y Llinares (2003) exploraron además la influencia de las imágenes de matemáticas en la organización de la asignatura para la enseñanza y aprendizaje del concepto de función. Afirman que cuando los estudiantes para profesor piensan acerca de los contenidos para la enseñanza, sus decisiones iniciales estarán estrechamente relacionadas a su forma de conocer el contenido matemático.

\subsubsection{Estudios sobre el conocimiento del contenido a enseñar}

Aquí se agrupan aquellas investigaciones que se focalizan sobre el estudio de un componente del CDC: el conocimiento de la materia a enseñar. Se trata de estudios cuyo principal interés es el estudio de las concepciones sobre un tópico matemático o bien, sobre el conocimiento de las ideas centrales o de la noción matemática y cómo el profesor transforma este contenido a contenido enseñable. Los trabajos de Even (1990 y 1993), Baturo y Nason (1996), Durand (2003), Attorps (2004 y 2006), Chinnappan y Lawson (2005) y Chee y Han (2006) pueden quedar en esta clasificación. 
Estos estudios se caracterizan por investigar el CDC a partir de un concepto o contenido matemático (ej. función, número racional, medida, geometría, cuadriláteros y ecuación), con particular énfasis en el conocimiento del contenido a enseñar. Buscan principalmente explorar qué conoce el profesor del tópico que enseña, su concepción sobre el concepto, qué marco teórico utiliza y qué conocen sobre la investigación de la enseñanza del concepto en el campo de la educación matemática. Se puede apreciar que en algunos estudios se indaga también el conocimiento que tienen los profesores del estudiante como estrategia metodológica para conocer su CDC.

Bajo esta perspectiva se ubica el trabajo de Even (1990) quien estudia el conocimiento de la materia a enseñar, concretamente en el tema de funciones. La autora analiza qué y cómo conoce el profesor acerca de determinados tópicos matemáticos, esto es, cómo construye y analiza el marco teórico del conocimiento de la materia para la enseñanza de un tópico específico en matemáticas. Exploró a 162 profesores de matemáticas de secundaria en la última etapa de su preparación para profesor, a través de un cuestionario que incluyó problemas matemáticos no estandarizados sobre los siete aspectos del conocimiento de la materia del profesor del concepto de función, (ver sección 1.4.1. de este capítulo). A los profesores se les solicitó, además, evaluar y comentar algunas situaciones resueltas por los estudiantes (ej. situaciones que contenían concepciones inadecuadas o errores relacionados con la función). En una segunda fase, entrevistó a 10 de los participantes para conocer los argumentos de sus respuestas.

Even (1990) encontró que el conocimiento de los profesores sobre función es limitado y que no se puede asumir que éstos tengan una comprensión bien articulada del conocimiento de las matemáticas que enseñan. Sugirió que se deben modificar los cursos de formación de profesores de matemáticas para mejorar la comprensión del conocimiento de la materia a enseñar y que deberían estar construidos bajo los siete aspectos del conocimiento de la materia del profesor que propone.

Con los referentes teóricos de 1990, Even (1993) se centró nuevamente en el estudio de las características esenciales del concepto de función con el propósito de analizar la relación que existe entre el conocimiento de la materia y el CDC. En la primera fase de investigación administró un cuestionario (ver ejemplo en la Figura 1.3) a los mismos profesores de su estudio previo. Incluyó dos tipos de ítems: nueve problemas no estandarizados sobre diferentes aspectos del conocimiento de la materia y seis soluciones erróneas o incomprensiones de estudiantes. Ambos tipos de ítems se basaron en concepciones acerca del límite de una función que tienen los estudiantes, así como los errores descritos en la literatura o conocimientos previos sobre los estudiantes. La entrevista se desarrolló en dos partes. En la primera se incluyeron algunas preguntas similares pero que requirieron de respuestas más amplias y meditadas. Además, se incluyeron aspectos no manifestados por el profesor pero sí descritos en la revisión de la literatura sobre investigación de funciones. En la segunda parte se reflexionó sobre el pensamiento de cada profesor, para lo cual se les solicitó explicar y clarificar las respuestas dadas en el cuestionario. 
1. a) Proporcione una definición de una función.

b) Un estudiante dice que no comprende esta definición. Proporcione una versión alternativa que pueda ayudar al estudiante a comprenderla.

2. ¿Cómo se relacionan las funciones con las ecuaciones?

3. A un estudiante se le solicitó dar un ejemplo de una gráfica de una función que pase a través de los puntos A y B (Ver Fig. 1)

El estudiante dio la siguiente respuesta (ver Fig. 2)

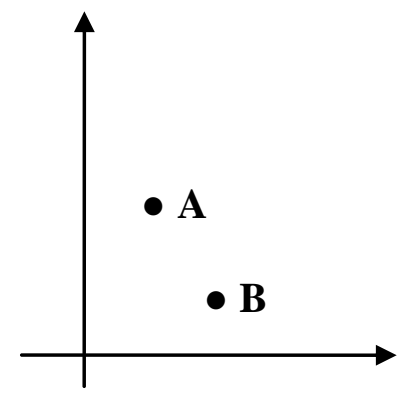

Figura 1

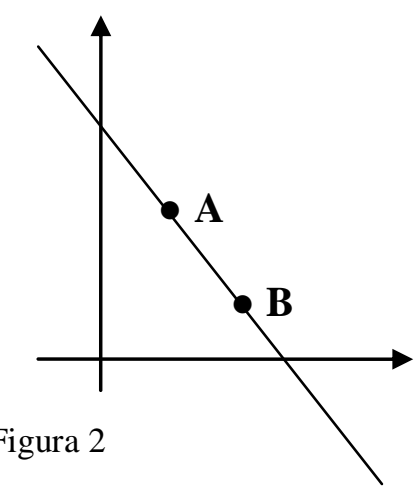

Cuando se le solicitó al estudiante si existe otra respuesta, contestó: "No"

a. ¿Piensa que el estudiante está en lo correcto? Explique por qué.

b. ¿Piensa que el estudiante está equivocado? ¿Cuántas funciones se pueden hallar que satisfagan la condición dada? Explique por favor.

Figura 1.3. Ejemplo de ítems del cuestionario de Even (1993).

Los resultados de Even (1993) demuestran que los futuros profesores tienen una imagen del concepto "función" limitada, similar a una definición del siglo XVIII, lo cual representa un problema. La autora encontró que las decisiones pedagógicas del profesor (preguntas que ellos hacen, actividades que diseñan, sugerencias que siguen de sus estudiantes) están basadas, en parte, en el conocimiento de la materia; por consiguiente, es importante que los profesores desarrollen una imagen del concepto de función moderna.

Otro estudio, similar y relacionado con el CDC en algunas de sus características, es el de Baturo y Nason (1996) que investigaron sobre el conocimiento sustantivo, el conocimiento del discurso, el conocimiento de la cultura matemática y las disposiciones de estudiantes para profesores de primaria de la Queenslan University Technology en el dominio de la medida. Seleccionaron a trece estudiantes del primer año de licenciatura en educación primaria a partir de sus calificaciones en la prueba de admisión de matemáticas en la universidad que valoraba el conocimiento del profesor sobre el contenido de matemáticas de $7^{\circ}$. Grado: siete profesores con altos puntajes y 6 con bajos puntajes. El instrumento (diseñado con base en las categorías de Leinhardt, 1988: conocimiento 
concreto, computacional y principios conceptuales), consistió en ocho tareas con preguntas sobre el conocimiento matemático desglosado en los elementos descritos con anterioridad. Posteriormente, se realizó una entrevista para profundizar sobre las diferentes tareas resueltas en el cuestionario y valorar cuestiones adicionales.

Los resultados afirman que el conocimiento sobre medida era pobre. Su conocimiento sustantivo fue incorrecto o bien incompleto y, a menudo, inconexo. La habilidad de los estudiantes en la traducción de una forma de representación a otra forma fue muy limitada. Su conocimiento acerca de la naturaleza y discurso matemático y acerca de la matemática en la cultura y sociedad fue similarmente alarmante. Según Baturo y Nason (1996) estos resultados permiten suponer que para los profesores: (1) los contenidos de matemáticas son una colección arbitraria de hechos y reglas, de tal modo que prevalece una concepción de naturaleza computacional, en donde lo central del conocimiento matemático es conocer "cómo hacer esto", (2) la mayoría de las ideas matemáticas tienen poca o ninguna relación con contextos reales y por consiguiente son utilizados mediante una representación simbólica exclusivamente, y (3) el principal propósito del aprendizaje de la medida fue utilitario, se trata de que los alumnos sean capaces de calcular áreas de figura regulares aunque no posean el significado de este concepto. Parece ser que estos estudiantes para profesor habían sido pasivos durante su instrucción matemática. Concluyen que esta pobreza de conocimiento, podría extremadamente limitar su habilidad para ayudar a sus alumnos a aprender e integrar y comprender el significado de los conceptos y procesos; y tener dificultad para sus representaciones.

Durand (2003) examinó el conocimiento de la noción de número racional de estudiantes para profesor de matemáticas incluyendo conocimiento conceptual y procedimental. Inicialmente, quince profesores para secundaria tomaron un curso de métodos en matemáticas y posteriormente se les realizó una encuesta sobre Números Racionales y sus Representaciones para un análisis cuantitativo. Tres de estos profesores fueron seleccionados para completar una entrevista y poder determinar los niveles de conocimiento del profesor. Las entrevistas fueron transcritas y codificadas para un análisis cualitativo. El estudio encontró que los estudiantes para profesor mostraron un alto nivel de conocimiento procesal de operaciones con números racionales así como de sus representaciones, mientras que mostraron de moderado a alto nivel de conocimiento conceptual. Sin embargo, los profesores que participaron en el proceso de entrevistas mostraron un nivel moderado del conocimiento conceptual de los números racionales y un bajo nivel de CDC. Pudieron listar las concepciones inadecuadas que sus futuros estudiantes pueden tener, pero las principales estrategias para corregir estos errores o concepciones inadecuadas se referían a regresar al algoritmo estándar.

Chinnappan y Lawson (2005) desarrollan un marco teórico para describir y analizar la calidad del conocimiento del contenido para la enseñanza de los profesores en un tópico dentro del dominio de la geometría: el cuadrado. Se apoyaron en el uso de mapas conceptuales o gráficos similares de representación del conocimiento. En su artículo presentan un estudio de caso de un profesor, el cual cumplió por lo menos dos criterios: (1) tener por lo menos 15 años de experiencia docente en matemáticas a nivel secundaria, (2) fuera recomendado por sus pares o asociaciones de profesionales como profesor ejemplar. 
Se le solicitó tres entrevistas para proporcionar un buen estimador de su conocimiento de la geometría y su enseñanza. En la primera, se le solicitó hablar acerca de una lista de esquemas focales (focus schemas) de geometría, trigonometría y coordenadas geométricas que fueran relevantes para el currículo escolar y su enseñanza, por ejemplo, se le solicitó hablar acerca del concepto de cuadrado (esquema focal 1) y su conocimiento acerca de la enseñanza y aprendizaje de un cuadrado. Se le hizo preguntas como: "Dígame qué Conoce Ud. acerca del cuadrado" y "Dígame cómo podría enseñar Ud. el cuadrado a sus estudiantes". Posteriormente, se le invitó a usar diagramas para explicar sus pensamientos (si ellos deseaban hacerlo). Se le hicieron preguntas similares sobre otros 12 esquemas focales: cuadrado, rectángulo, línea, triángulos semejantes, triángulos rectángulos, paralela, área, coordenadas, triángulos, hexágono regular, octágono regular, círculo.

En la segunda entrevista, se les solicitó que resolvieran cuatro problemas en voz alta, de los cuales dos suponían el uso de conocimiento relacionado al esquema focal del cuadrado. Cuando el profesor indicó que había terminado de completar la solución, se le solicitó decir si el problema podría ser resuelto de otras formas y que especificara cualquier característica de su solución que podría estar relacionada con la forma en que sus estudiantes podrían resolver este problema. Por ejemplo, se le solicitó: “¿Cómo piensa/espera Ud. que sus estudiantes abordarían este problema?” o “¿Qué tipo de dificultades espera que sus estudiantes experimenten si a ellos se les da este problema? ¿por qué?”

La tercera entrevista, consistió en una serie de preguntas indagativas diseñadas para dar al profesor la oportunidad de tener acceso al conocimiento relevante que no había sido activado (iniciado, generado) en las dos anteriores entrevistas.

El análisis de los resultados, les permitió a Chinnappan y Lawson (2005) concluir que el profesor tiene un rico conjunto de conexiones con evidencia de diferentes esquemas complejos. En general, su conocimiento es integral y muestra evidencia de una bifurcación sustancial en ciertas áreas. Sugieren el uso de mapas conceptuales como procedimiento útil para propósitos donde se pretenda la caracterización sistemática del conocimiento geométrico de los profesores, así como la "problematización del contenido" como una estrategia para explorar el conocimiento disponible del profesor.

Por su parte, Attorps (2004 y 2006) exploró el CDC de 10 estudiantes (cinco novatos y cinco expertos) para profesor sobre el concepto de ecuación. La investigación preliminar incluyó 30 estudiantes para profesores. Con el apoyo de cuestionarios, entrevistas y grabaciones de vídeo de seis lecciones en matemáticas y observaciones y desde una aproximación fenomenográfica, Attorps (2004) encontró que la concepción de los profesores acerca del propósito de la enseñanza de las ecuaciones se centran en el conocimiento procedimental de los estudiantes más que en la comprensión conceptual de la noción matemática. Sin embargo, los profesores experimentados poseían un repertorio más rico de experimentos y explicaciones sobre el concepto de ecuación que los novatos. Además los profesores experimentados mostraron una mayor habilidad para construir situaciones y estrategias instruccionales que podrían ayudar al estudiante a superar las dificultades con ecuaciones. 
Attorps (2006) encontró que las ecuaciones no son aprehendidas de forma completa y como objetos estáticos. Las concepciones de los profesores están estrechamente relacionadas a los símbolos " $x$ " y " $y$ ", con su idea de la solución de problemas y parece estar basada en la experiencia de los profesores en la enseñanza de la aritmética, así como de su primera impresión de cómo se aprende a resolver ecuaciones. Asimismo, encontró que algunos profesores no tienen una clara concepción de lo que deberían lograr sus alumnos mediante el aprendizaje del álgebra.

Un último estudio que queda incluido en este grupo, es el de Chee y Han (2006), quienes exploraron el CDC acerca de la enseñanza de cuadriláteros de ocho profesores de matemáticas de primaria en una comunidad de Hong Kong. Con el apoyo de una entrevista semiestructurada y el uso de escenarios como herramienta clave exploraron: 1) el conocimiento de los profesores acerca de los cuadriláteros y la enseñanza y aprendizaje de éstos en el salón de clases y 2) las acciones del profesor en las situaciones presentadas en clases. Los resultados indican que los profesores mostraron una pobre comprensión de los cuadriláteros, una inadecuada comprensión de sus estudiantes y una inadecuada actualización del conocimiento del currículo.

\subsubsection{Estudios sobre el conocimiento de las representaciones instruccionales}

Otro grupo de investigaciones son aquellas que estudian el CDC centrando su atención en el conocimiento de las estrategias y representaciones instruccionales del profesor. Aquí se ubica el estudio de Llinares, Sánchez y García (1994). Se constató, con base en las investigaciones encontradas, que son escasos los trabajos que se focalizan sobre este dominio de conocimientos.

Llinares, Sánchez y García (1994) centran su atención en el estudio del CDC vinculado con las representaciones instruccionales de un tópico concreto. En un contexto de formación inicial de profesores asumen la concepción de Ball y McDiarmid (1990) de que las representaciones instruccionales, por parte de los estudiantes que quieren ser profesores, están vinculadas a su experiencia previa como estudiantes, es decir al currículo y a la forma en que fue desarrollado cuando eran aprendices de Matemáticas (Llinares, Sánchez y García, 1994, p. 201). Los autores presentan los resultados de un cuestionario sobre el conocimiento del concepto de fracción, así como los modos de representación utilizados. Para ello administraron un cuestionario de elección múltiple centrado en la interpretación "parte-todo" del concepto de fracción a 282 estudiantes para profesor de Primaria y Profesores de EGB (Educación General Básica, en España) que participaban en un curso de adaptación en la Facultad de Ciencias de la Educación y 73 estudiantes de Ciencias (Matemáticas y Biología).

El cuestionario consideró tres variables: (a) el modo de representación, para lo cual se utilizaron tres modos diferentes (dibujos de figuras geométricas, como círculos, rectángulos, figuras irregulares y triángulo; dibujos de fichas y segmentos); (b) la fracciones propias e impropias, siendo estas últimas fracciones unitarias, del tipo $1 / \mathrm{n}(1 / 3)$ o no (2/3); y (c) el tipo de tareas, como son la reconstrucción de la unidad, la fracción como operador y la fracción como una relación "parte-todo". 
Concluyeron que "la idea que subyace en el trabajo realizado es que los estudiantes que se preparan para ser profesores dotan de significado a la idea de fracción, cuando están en la escuela (6-12 años) como aprendices, mediante la realización de un determinado tipo de tareas y la utilización de determinados modos de representación" (Llinares, Sánchez y García, 1994, p.218). Sus resultados aportan dos nuevas perspectivas en relación a la docencia de las matemáticas en los primeros niveles: (1) el mero hecho de estar enseñando en un nivel o estar en contacto con un determinado contenido matemático, no implica necesariamente poseer la "recurrencia" [sic] al pensamiento que permita modelar los conceptos matemáticos conocidos en el nivel de símbolos, es decir, que doten de significado a la idea de fracción cuando están en la escuela como aprendices, y (2) el tener una formación matemática más específica parece no implicar tampoco la capacidad de pensamiento recurrente en relación con dicho concepto. De igual modo, los autores resaltan la poca influencia de la representación gráfica en el éxito frente a la tarea presentada en los distintos ítems, frente a las otras dos variables: tipo de tarea y magnitud de la fracción, por lo que hacen particular mención sobre las "citas preceptúales" como posibles distractores en el proceso de resolver una tarea planteada donde intervienen distintos modos de representación. Concluyen que es necesario articular el CDC alrededor de la comprensión de las relaciones entre los sistemas de representación y el significado de la noción que hay que enseñar, lo cual sería el núcleo de atención de los programas de formación de profesores de matemáticas (p.223).

\subsubsection{Estudios sobre conocimiento del estudiante}

Otro grupo de trabajos, son los estudios que buscan comprender el CDC a la luz del conocimiento acerca del estudiante. Los trabajos de Even y Tirosh (1995) y An, Kulm y Wu (2004) pueden quedar en esta clasificación.

En 1995, Even en colaboración con Tirosh, desarrolló un estudio que se centró sobre el CDC a partir del conocimiento de la materia y de los estudiantes. Las autoras presentan una revisión y análisis teórico sobre los elementos que subyacen en el conocimiento de la materia a enseñar y de los procesos de aprendizaje del estudiante, y exploran cómo los profesores seleccionan y utilizan las representaciones en el contexto de la enseñanza de las matemáticas en dos dominios: funciones y operaciones matemáticas indefinidas. Para el estudio del CDC de las funciones se basaron en la selección de sujetos, instrumentos y procedimientos del trabajo de Even (1990 y 1993). Para el estudio de las operaciones indefinidas trabajaron con 33 profesores de secundaria de Israel. A éstos se les proporcionó operaciones matemáticas indefinidas (ej. 4/0, 0/0, $0^{0}$ ). Se les solicitó responder primero a un cuestionario que incluía expresiones matemáticas definidas e indefinidas para proporcionar, si fuese posible, soluciones numéricas, y si no, explicar por qué no. Todos los sujetos fueron entrevistados y se les pidió describir sus reacciones dentro de la clase asumiendo el rol de estudiante y pensando que los ejercicios fueran resueltos por éstos. Como parte del marco teórico de su investigación, Even y Tirosh plantean la necesidad de incorporar al análisis y estudio del conocimiento del profesor aspectos como "¿Qué conoce?” ("Knowing that”) y “Por qué conoce?” ("Knowing why”). En el primer caso, se explora el conocimiento declarativo de reglas, algoritmos, procedimientos y conceptos relacionados al tópico específico de la matemática en el currículo escolar. En el segundo, planteado como elemento complementario e indispensable, mejora las decisiones 
pedagógicas. Afirman que el profesor debe ser capaz de comprender el razonamiento que hay detrás de las concepciones de los estudiantes y anticipar fuentes comunes de error, es decir, qué y por qué.

Las autoras hallaron que algunos profesores no conocen el qué (knowing that) de las definiciones, o bien, resuelven incorrectamente problemas. Encontraron que algunos saben por qué un caso específico fue resuelto de cierta forma pero no pueden explicar qué ocurre en casos diferentes o extremos. Los datos evidencian que muchos profesores no se plantean comprender el por qué de las respuestas de los estudiantes y tienen dificultades para explicar por qué reaccionan de una forma determinada. Claramente, los profesores no estudian de manera explícita las concepciones y formas de pensamiento de las matemáticas de sus estudiantes durante sus estudios como profesores de secundaria.

Finalmente, An, Kulm y Wu (2004) desarrollaron un estudio sobre el CDC del tópico fracción. Examinaron las diferencias entre el CDC de profesores de China y de Estados Unidos (EEUU) en matemáticas del nivel medio. Tomando como base los estudios de Shulman (1986b), proponen considerar el CDC como una red. Para ellos, el CDC se compone sustancialmente de tres componentes: el conocimiento del contenido a enseñar, el conocimiento de la enseñanza y el conocimiento del currículo; pero le dan mayor peso al segundo componente dado que a partir de éste se constituye el conocimiento del pensamiento del estudiante. Bajo esta perspectiva, exploraron cómo el profesor usa el conocimiento para comprender y desarrollar el pensamiento matemático de los estudiantes.

Estudiaron a 28 profesores de matemáticas de $5^{\circ}$ a $8^{\circ}$ grado, de 12 escuelas en cuatro distritos en una amplia área metropolitana en Texas y 33 profesores de $5^{\circ}$ a $8^{\circ}$ grado de 22 escuelas en cuatro distritos de la ciudad de Jiangsu, provincia al este de China. Todos los profesores de EEUU tenían el grado de licenciatura; tres tenían el grado de maestría. Impartían un promedio de 24 horas de cursos de matemáticas y poseían un promedio de 13 años en experiencia docente. Todos los profesores de China tenían tres años de formación en educación en las escuelas normales, después de noveno grado; 23 además tenían tres años de universidad, y 10 de ellos tenían su mayor experiencia en otro campo diferente de la matemática. El promedio del número de horas en cursos de matemáticas era de 15 y su experiencia docente era de 9 años.

Los datos fueron recogidos con: (a) un Cuestionario de Enseñanza Matemática, que consistió en cuatro problemas que fueron diseñados para examinar la profundidad del CDC en tópicos de fracción, razón y proporción; (b) un Cuestionario acerca de las creencias de los profesores sobre la Enseñanza y Aprendizaje de las Matemáticas; (c) observaciones de cinco profesores seleccionados de cada país para confirmar que las respuestas del cuestionario habían sido consistentes con su enseñanza y (d) entrevistas, con el propósito de examinar las creencias de los profesores acerca de las metas de la educación matemática, explorar la forma de enseñanza que ellos usan en clases, como preparan la instrucción y cómo diagnostican el pensamiento de sus estudiantes.

Mediante un análisis comparativo de los datos, An, Kulm y Wu (2004) desarrollaron 18 diferentes categorías, que se utilizaron para analizar las respuestas a los 
cuatro problemas que resolvieron los profesores. En la Tabla 1.5 se muestran estas categorías, agrupadas en cuatro aspectos del componente de enseñanza del CDC.

Los resultados de An, Kulm y Wu (2004) por cada uno de los cuatro aspectos que estudiaron del CDC de la enseñanza del concepto de fracción, se resumen como sigue:

a. Construyendo sobre las ideas matemáticas de los estudiantes (Building on students' math ideas). La estrategia que más utilizaron los profesores americanos fue "conectar con un modelo concreto" (93\%), mientras que los profesores chinos fue "usar reglas y procedimientos" (76\%). La estrategia que menos utilizan los profesores americanos fue "usar un concepto o definición" (29\%) y los chinos fue "conectar con el conocimiento previo" (27\%).

b. Dirigiendo los conceptos equivocados del estudiante (Addressing students' misconceptions). Las estrategias que más utilizaron los profesores americanos fueron "identificar los errores conceptuales de los estudiantes" (86\%) y "respuestas inteligibles" (79\%); mientras que los profesores chinos fueron "identificar los errores conceptuales de los estudiantes" (97\%) y "usar preguntas o tareas para corregir errores" (100\%). La estrategia que menos utilizaron los profesores americanos fue "usar reglas y procedimientos" (11\%) y los chinos fue "conectar con un modelo concreto" (12\%).

c. Atendiendo a los estudiantes en el aprendizaje de las matemáticas (Engaging students in math learging). La estrategia que más utilizaron los profesores americanos fue "usar una representación" (64\%), mientras que los profesores chinos fue "dar un ejemplo" (76\%). Las estrategias que menos utilizaron los profesores americanos fueron "dar un ejemplo" (4\%) y "conectar con los conocimientos previos" (7\%) y de los chinos fueron "actividades manipulativas" (18\%) y "usar una representación" (28\%).

d. Promoviendo el pensamiento de los estudiantes acerca de las matemáticas (Promoting students' thinking about mathematics). La estrategia que más utilizaron los profesores americanos fue "proporcionar actividades para centrarse sobre el pensamiento del estudiante" (68\%), mientras que los profesores chinos fueron "actividades para centrarse sobre el pensamiento del estudiante" (94\%) y "usar preguntas o tareas para ayudar al estudiante a progresar en sus ideas" (100\%). La estrategia que menos utilizaron los profesores tanto americanos como chinos fue "usar estimación" (4\% y 6\%, respectivamente). 
Tabla 1.5. Categorías para describir los cuatro aspectos de las preguntas sobre enseñanza del CDC, según An, Kulm y Wu (2004, pp.154-155).

Aspectos sobre las preguntas de enseñanza del CDC / Componentes y descripción

Construyendo sobre las ideas matemáticas del estudiante

1. Conectar con los conocimientos previos: conocer los antecedentes previos del estudiante y conectar éste con el nuevo conocimiento

2. Los estudiantes no comprenden los conocimientos previos: a los estudiantes les falta comprender el antecedente de conocimiento previo

3. Usar concepto o definición: usar un concepto o definición para promover la comprensión

4. Conectar con un modelo concreto: usar algún modelo concreto para demostrar ideas matemáticas

5. Usar reglas y procedimientos: centrarse sobre reglas o procedimientos para reforzar el conocimiento

6. Respuesta inteligible: proporcionar respuestas que no son relevantes a la pregunta

7. Respuesta incorrecta: proporcionar una respuesta equivocada

endo los conceptos equivocados del estudiante

1. Procurar dirigir los errores de los estudiantes: identificar los conceptos equivocados de los estudiantes

2. Usar preguntas o tareas para corregir los errores: plantear preguntas o proporcionar actividades para corregir errores

3. Usar reglas o procedimientos

4. Trazar un dibujo o tabla: usar el dibujo (figura) o tabla para mostrar una idea matemática

5. Conectar con un modelo concreto

6. Respuesta inteligible

7. Respuesta incorrecta

Atendiendo a los estudiantes en el aprendizaje de las matemáticas

1. Actividades manipulativas: proporcionar actividades disponibles para que los estudiantes aprendan matemáticas

2. Conectar con un modelo concreto

3. Usar una representación para ilustrar conceptos: aplicar la adición repetida para dirigir el significado de la multiplicación de fracciones, o usar el área para dirigir el significado geométrico de la multiplicación de fracciones

4. Usar ambas representaciones para ilustrar la multiplicación de fracciones: utilizar tanto la adición repetida como el área para dirigir el significado de multiplicación de fracciones

5. Dar ejemplos: dirigir una idea matemática a través de ejemplos

6. Conectar con los conocimientos previos

7. Respuesta inteligible

8. Respuesta incorrecta

Promoviendo el pensamiento de los estudiantes acerca de las matemáticas

1. Proporcionar actividades y ejemplos para centrarse en el pensamiento del estudiante: crear actividades y ejemplos para estimular la reflexión

2. Usar preguntas o tareas para ayudar al estudiante a progresar en sus ideas: plantear preguntar o proporcionar actividades para incrementar el nivel de comprensión de los estudiantes

3. Usar estimación: resolver problemas usando estimación

4. Trazar dibujos o tablas

5. Proporcionar oportunidades para pensar y responder: promover en el estudiante el razonamiento de problemas y darles oportunidad de responder preguntas

6. Respuesta inteligible

7. Respuesta incorrecta 
Los autores concluyen que el CDC de los profesores en los dos países difiere marcadamente y esto tiene un profundo impacto sobre la práctica de la enseñanza. El sistema chino enfatiza adquirir un conocimiento procedimental que ha obtenido resultados satisfactorios durante muchos años. El sistema de EEUU enfatiza una variedad de actividades diseñadas para promover creatividad e investigar el dominio conceptual desarrollado, pero a menudo les falta la relación entre el pensamiento manipulativo y el abstracto y entre la comprensión y el desarrollo procesal. Ambas aproximaciones muestran beneficios y limitaciones en la enseñanza y aprendizaje de las matemáticas, y además, ilustran las diferentes exigencias sobre el CDC del profesor.

\subsubsection{Estudios para desarrollar el CDC en profesores de matemáticas}

Se encontraron también trabajos cuyo propósito principal fue identificar, proponer, implementar y evaluar estrategias para desarrollar el CDC en profesores de matemáticas. Aquí se ubican las investigaciones de Hutchison (1992), Fan (1998), Wanko (2000), Ward, Anhalt y Vinson (2003) y el de Md, Hamzah, Ismail, Husain e Ismail (2006).

En su tesis doctoral, Hutchison (1992) hace una revisión de la literatura y concluye, a partir de ella, que los profesores de primaria tienen limitados conocimientos en matemáticas. Por tal motivo, bajo una aproximación constructivista, y a partir de los estándares del NCTM, Hutchison investigó ¿cómo el conocimiento previo de la materia afecta el aprendizaje del CDC en un curso de métodos matemáticos a estudiantes para profesor? La autora asume la definición de Skemp (1976) de conocimiento relacional e instrumental, para describir tanto el conocimiento de la materia como el CDC de fracciones. El conocimiento de los participantes de las fracciones y de su CDC fueron analizados cualitativamente a través de seis estudios de casos, usando entrevistas, observando las clases que imparten de matemáticas y las clases donde toman sus cursos de matemáticas. Cuatro estudiantes para profesor con un conocimiento instrumental inicial de matemáticas demostraron mejorar el conocimiento instrumental de la materia al final de la entrevista y uno demostró un conocimiento relacional de fracciones. Los participantes con un conocimiento instrumental de fracciones mejoraron su conocimiento de las fracciones dentro del curso de métodos. Sin embargo, no se mejoró tanto como se hubiese querido en el CDC de fracciones, por la simultaneidad de aprender tanto el conocimiento de la materia como del CDC. Estos resultados sugieren que los programas de formación inicial de profesores de matemáticas deberían considerar el tipo de conocimiento de la materia en cuestión poseído por los futuros profesores. El conocimiento conceptual de la materia en cuestión debería revisarse para que se adecue el CDC y éste pueda ser desarrollado. Además, los cursos deben considerar las creencias de los estudiantes acerca de las matemáticas y del aprendizaje de las mismas.

Por su parte, Fan, en 1998, exploró cómo los profesores de matemáticas desarrollan su conocimiento en el dominio de la pedagogía. Específicamente, dos fueron las preguntas de investigación: (1) ¿existen diferentes fuentes de conocimiento pedagógico del profesor? y (2) ¿cómo las diferentes fuentes contribuyen al desarrollo del conocimiento pedagógico del profesor? A partir de la descripción de la NCTM (1991), el estudio categorizó el conocimiento pedagógico en tres componentes: (a) conocimiento pedagógico curricular, como conocimiento de enseñanza de materiales y recursos, incluyendo tecnología; (b) 
conocimiento didáctico del contenido, como conocimiento de las formas para representar conceptos y procedimientos matemáticos; y (c) conocimiento pedagógico instruccional, como conocimiento de las estrategias de enseñanza y modelos de organización en el salón de clases. El estudio tomó en cuenta la formación completa de los profesores, incluyendo sus experiencias de aprendizaje, su formación dentro de su carrera, y las experiencias en ejercicio de su profesión, para investigar las fuentes desde las cuales el profesor desarrolla su conocimiento pedagógico.

Los sujetos de la investigación fueron 77 profesores de matemáticas en tres escuelas secundarias de alto rendimiento, seleccionadas a partir de una muestra estratificada de las 25 mejores escuelas de secundaria en el área metropolitana de Chicago, Estados Unidos. Los instrumentos incluyeron un cuestionario, observaciones en el salón de clases y entrevistas. Se emplearon tanto análisis cuantitativos y cualitativos para analizar los datos. Los resultados revelaron que existen varias fuentes desde las que el profesor desarrolla su conocimiento pedagógico. Dentro de las diferentes fuentes, el estudio encontró que en todos los profesores, "su propia experiencia docente y reflexión”, y "el intercambio diario con colegas" son dos de los más importantes fuentes que utilizan para desarrollar los tres componentes de conocimiento pedagógico. "La formación permanente" y "actividades profesionales organizadas" son otras dos fuentes relativamente importantes. Los profesores señalaron que "su experiencia como estudiantes", "formación de la carrera" y "lectura de revistas y libros profesionales" como fuentes menos importantes. Los resultados del estudio indican que estos resultados son necesarios que los conozcan los formadores de profesores, para diseñar la reforma de los programas de formación inicial; los administradores para promover el intercambio diario de profesores con sus colegas y buscar así el desarrollo profesional; y los profesores porque necesitan ser aprendices para toda la vida.

La tesis de Wanko (2000) examinó un área de investigación poco o nada examinada: el CDC de los formadores de profesores, especialmente sobre los elementos que permiten ayudarles a desarrollar su CDC. Conduce su estudio a través de la pregunta ¿puede el CDC ser un marco teórico útil para que un formador de profesores pueda diseñar y enseñar un curso de contenido matemático dirigido a estudiantes para profesor, y si es así, de qué forma? Wanko usó su propio grupo y salón de clases de profesores de nivel elemental para el desarrollo de la investigación. Examinó las formas en las cuales su propio CDC como formador de profesores influyó y fue influenciado por el trabajo con sus estudiantes. Los datos del estudio fueron proporcionados a partir de sus reportes de enseñanza, lecciones y unidades de planeación, trabajo del estudiante y audio grabaciones de las clases. Wanko presentó tres grandes hallazgos. Primero, puso de relieve dificultades y problemas de la noción de Shulman sobre representación, usada para definir el CDC. Según el autor, en matemáticas existen representaciones matemáticas y representaciones empíricas; clasificación que no es fácil de realizar usando la noción de representación de Shulman. Segundo, reconoce la importancia del diseño de las tareas como un proceso que es particularmente esencial en la enseñanza de las matemáticas, pero encontró que la noción del modelo de razonamiento pedagógico y de acción (Model of pedagogical reasoning and action, en Shulman, 1997) obscurece este significado. Y tercero, Wanko añade la noción de reflexión compartida, a este modelo de razonamiento pedagógico y de acción de Shulman cuando éste es aplicado a la formación de profesores. 
Ward, Anhalt y Vinson (2003) estudiaron a 31 futuros profesores de primaria inscritos en un curso elemental de métodos matemáticos, para investigar y documentar cómo representan las ideas matemáticas en formas que sean comprensibles para los estudiantes. El programa de formación, de un semestre de duración, consistió en una instrucción basada en el enfoque constructivista a partir de los estándares de la NCTM (1991 y 2000). Paralelamente participaron en un programa concreto para desarrollar el CDC en tópicos específicos: multiplicación y división de fracciones, área de un círculo, trapezoide y paralelogramo, perímetro de polígonos, suma y resta de números enteros y media. El propósito central fue desarrollar el conocimiento de las representaciones instruccionales tomando como referencia las cinco representaciones matemáticas definidas por Lesh, Post y Behr (1987): concreto (manipulativo), lenguaje, simbolismo (notación), semiconcreto (figura) y contextual (situaciones con palabras reales).

El estudio sustentó que un programa como éste, basado en la codificación y análisis de su planificación de las clases a la luz de las representaciones matemáticas, puede proporcionar a los futuros profesores una alternativa para desarrollar su CDC, así como observar su evolución durante su preparación como profesores. Los autores sugieren que no se debe centrar la atención en encontrar cuál representación es mejor que otra o las representaciones más óptimas sino que lo central e importante debe ser cómo es usada ésta y quién la usa.

Finalmente, encontramos el estudio hecho por Md, Hamzah, Ismail, Husain e Ismail (2006) a quienes les interesó explorar los modelos de formación de profesores de las instituciones a la luz del marco teórico del conocimiento del profesor de Shulman. Se trata de un estudio comparativo, tipo encuesta cuyo principal propósito fue caracterizar los programas de formación y con ello determinar el balance que hay entre los diferentes componentes de la perspectiva teórica de Shulman. Analizaron los programas de formación de cinco universidades de Malasia y uno de Singapur. La información fue recogida a través de entrevistas al personal directivo de cada universidad y se administraron 268 cuestionarios a estudiantes para profesor de matemáticas. Los resultados generales indican que prevalecen principalmente dos creencias para la formación de profesores de matemáticas, por un lado la formación de matemáticos para profesor y por otro, la formación de profesores de matemáticas. Respecto al CDC se encontró que no existe un modelo definitivo según la percepción de los directivos y los estudiantes para profesor.

\subsubsection{Estudios relacionados con las actitudes del profesor}

Se han realizado también algunos estudios que relaciona las actitudes del profesor y el desarrollo del CDC. En este grupo están los trabajos de Smith (2000) y Caballero y Blanco (2007).

En 2000, Smith encontró con base en la exploración de investigaciones sobre el CDC del profesor en matemáticas que los resultados, aunque inconclusos, han indicado que las actitudes de los profesores, la experiencia profesional en educación y la de experiencia personal influyen en el CDC. Smith, trabajó con profesores de estimulación temprana que participaron en conferencias, que contestaron a la Encuesta de Conocimiento didáctico del contenido en Estimulación Temprana en Matemáticas (The Survey of Pedagogical Content 
Knowledge in Early Chilhood Mathematics) y al Inventario de Actitudes hacia las Matemáticas (The Attitude Toward Mathematics Inventory). Recogió información demográfica respecto a la experiencia educativa y años de experiencia de los participantes en la investigación. Los resultados revelan una leve y simple relación significativa entre las dimensiones de la Encuesta y el Inventario de Actitudes. El análisis de esta relación sugirió que los profesores de estimulación temprana que tienen un alto puntaje de CDC sostienen actitudes positivas hacia las matemáticas y un bajo nivel de ansiedad hacia ellas. Finalmente, el estudio sugirió que los años de experiencia no sirven para predecir las dimensiones de la Encuesta de CDC en Estimulación Temprana en Matemáticas. Smith sugiere que los profesores de estimulación temprana necesitan mejorar su desarrollo profesional en el área de matemáticas.

Por su parte, Caballero y Blanco (2007) se interesaron en los factores afectivos de los estudiantes para profesores (EPPs) y su influencia en los alumnos y los logros de éstos, así como en la enseñanza y aprendizaje de la resolución de problemas. La investigación se centró en una muestra no probabilística por conveniencia de 249 EPPs, pertenecientes a los cursos de primero y tercero de las especialidades de Educación Primaria y Educación Especial de la Facultad de Educación de la Universidad de Extremadura; a quienes se les administró un cuestionario de 48 ítems (tipo likert) distribuidos en seis categorías: a) creencias acerca de la naturaleza de las matemáticas y de su enseñanza y aprendizaje, b) creencias acerca de uno mismo como aprendiz de matemáticas, c) creencias acerca del papel del profesorado de matemáticas, d) creencias suscitadas por el contexto sociofamiliar, e) actitudes y reacciones emocionales hacia las matemáticas, f) valoración de la formación recibida en los estudios de magisterio en relación a las matemáticas. Caballero y Blanco concluyen que los EPPs no manifiestan rechazo hacia las matemáticas puesto que manifiestan sentir curiosidad por la solución de problemas y una enorme satisfacción ante el éxito en la actividad matemática así como la sensación de fracaso en el caso de no encontrar dicha solución. Los autores afirman que la formación recibida por los EPPs de didáctica de las matemáticas les ha aportado otras formas de abordar los problemas matemáticos que antes desconocían y que las creencias, actitudes y emociones de los EPPs hacia las matemáticas influyen en el logro de sus alumnos, así como en las creencias y actitudes de éstos hacia la misma y la actualización y formación del contenido didáctico de la disciplina.

\subsubsection{Investigaciones en el campo de la enseñanza de las ciencias}

Últimamente se ha incrementado el número de estudios sobre el CDC en el área de enseñanza de las ciencias, particularmente en química, biología y educación (GessNewsome y Lederman, 1999). Para fines de este trabajo, sólo se citan brevemente algunos trabajos, que permiten darnos una idea sobre las concepciones, diseño de investigaciones, métodos y resultados genéricos del estudio del CDC en estas otras disciplinas científicas.

Rovegno (1992) describió qué y cómo siete profesores en formación aprenden durante un curso de métodos en educación física elemental con el propósito de determinar ¿qué conocimiento consideran los profesores como sobresalientes? y ¿cómo este conocimiento se desarrolla? Partiendo del CDC de Shulman (1986b) y de que según varios estudios, hay una fuerte relación entre el CDC y el aprovechamiento de los niños (ej. 
Wilson y Wineburg, 1988; en Rovegno, 1992) y que los profesores con un fuerte CDC, a diferencia de los que tenían un débil CDC, encuentran más representaciones de contenido de manera exacta (ej. Grossman y Richert, 1988; Hermann y Duffy, 1989; en Rovegno, 1992), desarrolla una investigación interpretativa y de observación participativa.

La autora seleccionó el curso de Métodos de Educación impartido a lo largo de un semestre. Se utilizaron observaciones de todas las clases y entrevistas en tres momentos (después de cuatro, ocho y 13 semanas de la observación) para explorar la experiencia en la disciplina (a las cuatro semanas) y analizar lo que fue sucediendo con la experiencia y el significado que le daban al curso (a las ocho y 13 semanas). Se les preguntó sobre qué y cómo aprendían acerca del aprendizaje de los niños y del contenido. Adicionalmente se les solicitaron documentos escritos, como son notas de clases, planes de clases, evaluaciones, planes de unidad, unidades de evaluación, entre otros.

Utilizando las categorías de Glaser y Strauss (1967) y mediante una aproximación ecológica para la percepción y acción en la interpretación de los datos, Rovergno encontró que el CDC funcionó como una herramienta y que fue usada en la percepción y la puesta en común en el aula. Los resultados ponen de relieve que el conocimiento del contenido para su enseñanza, adquirido en ambientes universitarios no es el mismo conocimiento para enseñar en las escuelas; es decir, sugiere la idea de que el conocimiento práctico del profesor es fundamentalmente experiencial. Rovegno concluye a partir de sus resultados, que "aunque el CDC es a menudo discutido en la literatura como conocimiento, el significado de este conocimiento para un profesor de enseñanza está en el uso de éste" (Rovegno, 1992, p.79). Propone el conocimiento del cómo, es decir, la idea de conocimiento funcional como una herramienta útil relacionada con la experiencia y práctica profesional del profesor y de la reflexión sobre la acción.

Fernández-Balboa y Stiehl (1995) por su parte, distinguen entre dos tipos de CDC: $\mathrm{CDC}_{\mathrm{e}}$ "específico" el cual es particular a la instrucción de una materia específica o área de contenido; y el CDC "genérico" el cual es común a la instrucción sobre todas las materias, contenidos o áreas. Según los autores, el CDC específico ha sido estudiado y discutido en diferentes áreas o materias como son inglés, historia, matemáticas, educación física, estudios sociales, lectura, escritura y ciencia, y aunque estos estudios han producido importante información, ninguno ha intentado analizar los componentes genéricos del CDC sobre las materias. Por tal motivo, desarrollan una investigación con profesores universitarios con el propósito de conocer ¿cómo los profesores trascienden sus estudios de "expertos de la materia" a "profesores de la materia"?, ¿cómo el profesor estructura e implementa el CDC genérico?, enfatizado en explorar la efectividad interior de los procesos metacognitivos del profesor acerca de las estrategias de su CDC.

El trabajo de Fernández-Balboa y Stiehl (1995) se basa en un estudio con 10 profesores de EEUU, recomendados por directores de cinco diferentes universidades (artes y ciencia; negocios; educación; salud y ciencia humana; visual y arte productivo); que contaban de una gran estima y reputación en la enseñanza de su materia. Los criterios usados por los directores fueron: evaluaciones de los estudiantes, revisión de pares y premios de enseñanza. De la lista de nombres recibidos fueron seleccionados dos profesores (un hombre y mujer) de cada escuela (10 en total). Todos los profesores tenían 
entre 15 a 31 años de experiencia docente y únicamente dos de ellos habían recibido preparación formal de enseñanza. Los datos fueron obtenidos a partir de entrevistas fenomenológicas personales. Cada entrevista fue audiograbada, duró un promedio de dos horas y, a lo largo de ésta, los investigadores escucharon activamente, tomaron notas y solicitaron que los participantes aclarasen o ampliasen sus puntos de vista sobre el CDC genérico.

Según los resultados del estudio de Fernández-Balboa y Stiehl (1995), los profesores construyen y usan el CDC genérico en formas similares. Concluyen, que su investigación proporcionó un análisis de los componentes del CDC genérico a través de varias disciplinas. Los resultados coincidieron con los de Grossman (1990), en que los principales componentes de los profesores de CDC genérico identificados para agregarse como parte del conocimiento son: la materia en cuestión, los estudiantes, las estrategias instruccionales, y el contexto de la enseñanza. Adicionalmente, otro componente que claramente emergió de los datos, fueron los propósitos de la enseñanza de los profesores.

Mellado, Blanco y Ruiz (1999) en su libro Aprender a enseñar Ciencias Experimentales en la formación inicial del profesorado, revisan primero las investigaciones sobre el profesorado de ciencias experimentales (ej. antecedentes, concepciones sobre la naturaleza de la ciencia, conocimiento científicos, conocimiento sobre didáctica de las ciencias y actitudes); segundo, formulan un marco de formación del profesorado, que desarrolle los conocimientos profesionales necesarios para ser profesor de ciencia; tercero, analizan los métodos de investigación cualitativos centrándose principalmente en cuatro estudios de casos; cuarto, analizan las grabaciones de las clases de estos profesores y finalmente editaron un video que sirva de material de enseñanza en la formación del profesorado de ciencias experimentales.

El trabajo de Mellado, Blanco y Ruiz (1999) es un referente para formar el CDC en profesores de ciencia del concepto de energía, con base en el análisis de sus concepciones, creencias, actitudes, conocimiento de la materia y práctica docente. Después de presentar una síntesis de las investigaciones consultadas, exploran el CDC de cuatros profesores de EGB (Educación General Básica), licenciados en Ciencias, que estaban realizando el CAP (Curso de Aptitud Pedagógica) en la Universidad de Extremadura. Los procedimientos de recogida de datos fueron un cuestionario, entrevistas semiestructuradas grabadas en audio, documentos personales, observaciones en el aula durante la realización de las prácticas de enseñanza grabadas en video y entrevistas de estimulación del recuerdo.

Los resultados mostraron que tres de los cuatro profesores comienzan la enseñanza de la energía a partir de la definición operacional de la capacidad para realizar trabajo mecánico. En estos tres profesores la tradición de la enseñanza del contenido parece superar los planteamientos didácticos, que no se transfieren al aula de forma automática. Sólo un profesor optó por un enfoque descriptivo alejado de la definición operacional de energía como la capacidad para realizar trabajo. Mellado, Blanco y Ruiz (1999) concluyen que aprender a enseñar ciencias experimentales va más allá que aprender conocimientos académicos de didáctica de las ciencias. Sugieren que hay que reforzar la componente dinámica (componente académica, conocimiento de sí mismo, reflexión personal, práctica de enseñanza) para el desarrollo profesional del CDC. La componente dinámica "se genera 
y evoluciona a partir de los propios conocimientos, creencias y actitudes, que requiere una implicación personal, y que evoluciona mediante un proceso dialéctico entre la teoría asimilada y la práctica desarrollada, todo ello en un proceso de reflexión-acción" (Blanco, Mellado y Ruiz, 1995, p. 433).

Añaden que las asignaturas de didáctica de las ciencias, estrechamente unidas a los períodos de prácticas de la enseñanza, deben jugar un papel integrador de los diferentes aspectos de la formación del profesorado a desarrollar el proceso específico de aprender a enseñar ciencias, reflexionando sobre sus propias concepciones y sobre su propia práctica de enseñanza. Los autores recopilan y presentan un conjunto de recomendaciones para aprender ciencias durante las prácticas de enseñanza y para la elaboración de video como material audiovisual para la formación del CDC.

Otro estudio que merece mención, es el de Van Driel, De Jong y Verloop (2002), quienes investigaron el desarrollo del CDC de un grupo de 12 estudiantes para profesor de química durante el primer semestre de su primer año de formación de profesores a nivel de posgrado (Maestría en Química). El estudio, de corte cualitativo, se centró en el CDC de las ciencias, en concreto en torno al tema de los fenómenos observables, como son las reacciones químicas o las propiedades macroscópicas entre otras y su interpretación en términos de características corpusculares (macro-micro). Como propósitos se planteó desde un punto de vista teórico obtener una mejor comprensión de los factores que promueven o dificultan el desarrollo del CDC y contribuir al diseño de los cursos de formación de profesores de ciencias.

La recogida de datos se hizo mediante dos cuestionarios escritos, entrevistas con cada estudiante para profesor y sus respectivos mentores y una audio grabación de una sección específica de un taller. El primer cuestionario constaba de nueve procesos químicos y el profesor debía contestar a dos preguntas (en Van Driel, De Jong y Verloop, 2002, Apéndice IA, p.588):

1. Describe cada proceso en términos tanto de fenómenos como de partículas

2. Expresa en cada proceso las dificultades de aprendizaje específicas o creencias que esperas encontrar en los estudiantes de este respectivo grado

El segundo cuestionario sirvió para comparar sus respuestas después del programa de formación. Fue el mismo cuestionario, agregándole lo siguiente a la segunda pregunta (en Van Driel, De Jong y Verloop, 2002, Apéndice IB, p.588):

Puedes hacer referencia a tu experiencia u observaciones durante las clases.

Posteriormente, cada profesor participó en una entrevista que consistió en seis preguntas (en Van Driel, De Jong y Verloop, 2002, Apéndice II, p.588):

1. ¿Cómo podría - como químico - describir la relación entre fenómenos macroscópicos y partículas microscópicas? Use ejemplos para clarificar su respuesta 
2. ¿Por qué es importante poner particular atención en estas relaciones: (a) durante las lecciones de química en la escuela secundaria, y (b) en los talleres institucionales de formación de profesores?

3. ¿En qué forma puede enseñar esta relación durante sus lecciones?

4. ¿Qué dificultades y concepciones de estudiantes observa durante estas lecciones?

5. ¿Qué aspectos específicos de la macro-micro relaciones halla difíicil de enseñar?

6. ¿En qué forma sus ideas acerca de esta relación han estado influenciadas por: (a) Lectura y discusión de la literatura (ej. Harrison y Treagust, 1996), (6) su experiencia durante las clases de enseñanza, (c) discusiones con el mentor y (d) otros factores?

Van Driel, De Jong y Verloop, realizaron una entrevista al mentor del estudiante para profesor con el propósito de analizar, desde su punto de vista, la manera en que el estudiante para profesor enseñó el tópico, la forma de diagnosticar las dificultades de aprendizaje, las dificultades de enseñanza que observó en el estudiante y el desempeño del estudiante en el programa de formación.

Los resultados resaltan la importancia que tiene para muchos estudiantes para profesor el uso cuidadoso y consciente de lenguaje. Para los autores, el incremento de CDC estuvo bastante influenciado por las experiencias docentes de los profesores. Concluyeron, que el taller contribuyó sustancialmente en la formación del CDC y que, para algunos estudiantes para profesor, su mentor tuvo una influencia significativa.

Por último, en México se encuentran los trabajos de Garritz ${ }^{3}$ (ver Garritz y Trinidad, 2004; Garritz, Nieto, Padilla, Reyes y Trinidad, 2008; y Padilla, Ponce-de-León, Rembado y Garritz, 2008) que estudia el CDC desde la enseñanza de la Química. Recientemente Garritz participó en el VIII Congreso Internacional sobre Investigación en Enseñanza de las Ciencias (del 7 al 9 de septiembre de 2009) en Barcelona, España; cuyo tema central fue "Avances iberoamericanos sobre el CDC". Algunas de las aportaciones actuales tratan de profundizar en relación a los dominios cognitivos y afectivos (concepciones, actituciones y emociones), asumiendo la dimensión afectiva como una referencia necesaria para la caracterización del CDC.

\subsection{NATURALEZA CONCEPTUAL}

Como se puede apreciar, diferentes autores que han estudiado el CDC en matemáticas (ej. Llinares, Sánchez y García, 1994; Even y Tirosh, 1995; Castro y Castro, 1996; Llinares, 1996; Even, 2003 y 1993; An, Kulm, Wu, 2004; Sorto, 2004 entre otros), incluso desde otras perspectivas teóricas acerca del profesor, han identificado y sustentado la relación que guardan todos los componentes y elementos del CDC.

${ }^{3}$ http://garritz.com/andoni_garritz_ruiz/, recuperado el 31 de diciembre de 2009.

Universidad de Salamanca 
A partir de los resultados de las investigaciones presentadas y de las implicaciones o relaciones obtenidas en los diferentes análisis hecho por los mismos investigadores, se conceptúa al CDC por un lado como un modelo teórico que reproduce, esquematiza, figura y presenta una perspectiva paradigmática y por otro como un recurso de conocimiento, interpretación o explicación de la formación de profesores y desarrollo de investigación sobre el profesor. Como modelo, el CDC está compuesto por elementos que se interrelacionan y se transforman en representaciones ideales para facilitar su comprensión, desarrollo e investigación, dentro de un continuo de modelos acerca del conocimiento del profesor que van de integrativos a transformativos (Gess-Newsome, 1999).

Según Pinto y González (2006) el modelo del CDC no se caracteriza por ser un reproducción única ni mucho menos simple, sino más bien, se caracteriza por ser un modelo:

a. cíclico, en cuanto que está compuesto por un conjunto de componentes descritos como las fases por las que se desarrolla la enseñanza de un tópico específico, que se vuelven a repetir, conjugar, reactivar y relacionar por cada tópico diferente a conocer y enseñar;

b. sinérgico, en cuanto que existe una interdependencia entre los tres componentes y una intrarrelación entre las categorías o elementos entre cada componente, con lo cual no es posible estudiar un componente sin contemplar los otros, o bien, el desarrollo de uno implica la activación o influencia conjunta de los otros;

c. integral, en cuanto a que está compuesto por un todo, en donde cada uno de los componentes son esenciales para la composición del dominio, y sin alguno (su reconocimiento, estudio o acción) de los componentes no puede subsistir;

d. flexible, en cuanto a la constitución de diferentes formas o maneras de enseñar un mismo tópico a partir de la conjugación de todos los componentes, basado también en la formación, experiencia, iniciativa y creatividad del profesor; y en cuanto a la posibilidad y disposición de adquirir, extender o profundizar el propio conocimiento, en diferentes momentos cronológicos dentro de los programas de formación de profesores, según las características de éstos (ej. experiencia e historial académico), acentuando su adquisición en algún(os) componentes e incorporando de forma gradual los restantes, así como incorporando elementos novedosos y actuales como consecuencia del desarrollo de la didáctica de la disciplina y los resultantes de la práctica del profesor y reconociendo la complejidad de la interacción con los elementos del contexto;

e. incluyente, en cuanto a que está circunscrito dentro de un conjunto compuesto por otros componentes, propios de el conocimiento base para la enseñanza, y reconoce e incorpora otros elementos esenciales para su perfeccionamiento (ej. conocimiento pedagógico general, el contexto y la investigación didáctica sobre el pensamiento del profesor); y finalmente, un modelo 
f. investigable, en cuanto que requiere y necesita de la investigación científica a la luz de las didácticas de la disciplina, con el objeto de validar su desarrollo, proveer de mayor significado a sus componentes, generar un repertorio de conocimientos, representaciones, ejemplos y recomendaciones dirigidas a perfeccionarse como modelo teórico del conocimiento del profesor, crear subsiguientes líneas y proyectos de investigación que sustenten su desarrollo, evolución y enriquecimiento en cada uno de sus componentes por cada contenido disciplinario y obtener información que impacte tanto en el desarrollo profesional del profesor como en la mejora en la adquisición del conocimiento disciplinario y habilidades de pensamiento por parte del alumno.

Las características del modelo, su desarrollo y mayor reconocimiento en las diferentes áreas o disciplinas científicas han generado un incremento de la investigación desde la perspectiva didáctica del profesor, teniendo como primer propósito comprender su naturaleza conceptual y posteriormente conocer cómo medir o evaluar el CDC del profesor. Sin embargo, esto último ha representado un desafío para los investigadores, dado que la cognición del profesor, como lo es el CDC, no puede ser observado directamente, ya que por definición, el CDC es particularmente un constructo interno (Baxter y Lederman, 1999). Estos autores afirman que la cognición del profesor se lleva a cabo inconscientemente, es decir, los maestros no siempre poseen el lenguaje para expresar sus pensamientos y creencias; lo que manifiesta que es un constructo altamente complejo, no fácil de medir o evaluar (Baxter y Lederman, 1999). Es un constructo constituido por lo que los profesores conocen, lo que los profesores hacen y las razones por las que los profesores actúan.

\subsection{NATURALEZA METODOLÓGICA}

El significado, caracterización y naturaleza conceptual del CDC, con base en los estudios revisados, pone de manifiesto la importancia de conocer, seleccionar y/o construir formas (o instrumentos) que intenten comprender su naturaleza metodológica. Preguntas sobre ¿cómo se ha estudiado el constructo?, ¿qué diseños de investigación se han utilizado?, ¿qué instrumentos examinan de mejor forma el CDC y qué criterios utilizaron los autores sobre qué investigar del constructo? intentaremos contestar a continuación.

Para ello, se realizó una segunda revisión y análisis de los diferentes trabajos publicados que han utilizado el CDC como teoría para explorar el conocimiento del profesor, con el objeto de caracterizar diferentes cuestiones metodológicas como los principales tópicos estudiados, sujetos participantes, diseños de investigación e instrumentos de recogida de datos. Se analizaron cerca de 40 investigaciones para este propósito, dentro de las cuales estuvieron: Thompson (1984); Carpenter, Fennema, Peterson y Carey (1988); Smith y Neal (1989); Even (1990); Marks (1990a y 1990b); Wallece (1990); Hutchison (1992); Rovegno (1992); Even (1993); Llinares, Sánchez y García (1994); Even y Tirosh (1995); Fernández-Balboa y Stielh (1995); Moreno (1995); Baturo y Nason (1996); Vallecillos (1996); Batanero, Godino y Navas (1997); Fan (1998); Howald (1998); Swenson (1998); Baxter y Lederman (1999); Contreras (1999); Llinares (1999b); Llinares (2000); Smith (2000); Wanko (2000); Sánchez y Llinares (2002); Van Driel, De Jong y Verloop (2002); Badillo (2003); Durand (2003); Gil y Rico (2003); 
Moreno y Azcárate (2003); Sánchez y Llinares (2003); An, Kulm y Wu (2004); Chen (2004); Chinnappan y Lawson (2005) y Llinares y Krainer (2006), entre otros.

Las principales conclusiones obtenidas de la revisión de esto trabajos se resumen a continuación:

\subsubsection{Sobre los tópicos y componentes estudiados}

La Tabla 1.6 presenta los trabajos citados, identificando el tópico y el énfasis sobre el o los componentes del CDC estudiados.

Se encontró que el mayor número de investigaciones ha sido sobre el conocimiento del contenido a enseñar (cerca del 88\%), mientras que menos de la mitad han estudiado el conocimiento de la didáctica específica del contenido o del conocimiento del proceso de aprendizaje del estudiante. Analizando aquellas investigaciones que mencionan o asumen única y exclusivamente una categoría del CDC, se obtuvo nuevamente un mayor número centradas sobre el conocimiento del contenido a enseñar. Sobre el tópico de las matemáticas, los temas que han sido más investigados fueron las fracciones y las funciones.

Tabla 1.6. Tópicos y énfasis sobre el o los componentes estudiados del CDC en el campo de la educación matemática

\begin{tabular}{lll}
\hline Autor(es)/año & Tópico & $\begin{array}{l}\text { Énfasis o componente del CDC } \\
\text { estudiado }^{\mathrm{a}}\end{array}$ \\
\hline $\begin{array}{l}\text { Carpenter, Fennema, Peterson y } \\
\text { Carey (1988) }\end{array}$ & $\begin{array}{l}\text { Resolución de problemas } \\
\text { aritméticos }\end{array}$ & CC, CER, CE \\
Wallece (1990) & Geometría & CC \\
Marks (1990a y 1990b) & Fracciones & CC, CER, CE \\
Even (1990) & Funciones & CC \\
Hutchison (1992) & Fracciones & CC \\
Even (1993) & Funciones & CC, CER \\
Llinares, Sánchez y García (1994) & Fracciones & CER \\
Even y Tirosh (1995) & Funciones y operaciones & CC, CER \\
& matemáticas indefinidas & \\
Baturo y Nason (1996) & Medición & CC \\
Swenson (1998) & Probabilidad & CC, CER, CE \\
Fan (1998) & Pedagogía en matemáticas & CC (currículo) \\
Howald (1998) & Funciones & CC \\
Smith (2000) & Matemáticas para estimulación & CC, CER, CE \\
& temprana & CC, CER, CE \\
Wanko (2000) & Matemáticas en general & CC, CER \\
Durand (2003) & Números racionales & CE \\
An, Kulm y Wu (2004) & Fracciones & \\
\hline${ }^{a}$ CC= conocimiento del contenido a enseñar, CER= conocimiento de las estrategias y representaciones \\
instruccionales, CE= conocimiento del estudiante sobre el contenido a estudiar.
\end{tabular}

\subsubsection{Sobre el CDC de los profesores de matemáticas}

Aun cuando los estudios sobre el CDC se circunscriben al contexto y naturaleza de cada investigación, de sus propósitos, metodologías de investigación, sujetos participantes y tópico específico, se identificaron algunos elementos comunes a la educación matemática, producto de los resultados reportados por los autores: 
(a) todavía prevalecen serios problemas en la adquisición, dominio y uso del conocimiento del contenido a enseñar por parte del profesor;

(b) los profesores tienen dificultades para establecer la relación entre el conocimiento del contenido a enseñar con las representaciones instruccionales y el conocimiento del proceso de aprendizaje del estudiante;

(c) se evidencia, a partir del pobre conocimiento del contenido a enseñar, limitado o nulo conocimiento de la didáctica específica y del conocimiento del estudiante;

(d) se evidencia la necesidad de planear, desarrollar, implementar y evaluar programas de formación de profesores con enfoques diferentes a los actuales, a la luz de la didáctica de las matemáticas;

(e) se recomienda como principales fuentes de formación del CDC, la investigación de la didáctica de las matemáticas, las creencias y concepciones de los profesores, la reflexión sobre y de la acción, la experiencia profesional y personal del docente, la interacción entre colegas, lecturas, entre otros; y

(f) se confirman algunas relaciones significativas, como son las concepciones de la matemática y su enseñanza y aprendizaje y el CDC, así como entre los niveles altos de CDC y la actitud positiva del profesor, y el conocimiento del contenido a enseñar vinculado con la experiencia docente del profesor como elementos diferenciadores del profesor con poca experiencia.

Si bien, en algunos casos existen resultados que se contraponen o difieren entre sí, estos hallazgos dan cuenta de que el estudio del CDC resulta todavía complejo como modelo teórico para la formación de profesores y como objeto de estudio.

\subsubsection{De los diseños y sujetos de investigación}

Según el análisis, la tendencia para estudiar el CDC es bajo un enfoque cualitativo, a través de estudios de casos o bien, de una combinación encuesta (cuestionario) y estudios de casos. Existen muy contados estudios en el campo de la educación matemática que fundamentan su trabajo bajo una perspectiva cuantitativa y exclusivamente encuesta (ver Tabla 1.7).

Respecto a los sujetos que participan en las diferentes investigaciones se aprecia una amplia diversidad en los criterios de selección, los cuales dependen de la naturaleza misma de la investigación, del escenario y del contexto en la cual se realiza. No obstante destaca, en este sentido, un número importante de investigaciones que han incorporado a profesores con formación inicial matemática y en ejercicio de la docencia (ya sea a nivel primaria, secundaria o universitario) o estudiantes para profesor. La disposición, colaboración, experiencia, preparación en el contenido o en algún posgrado, entre otros, son otros criterios que destacan como adicionales. 


\subsubsection{De los instrumentos y procedimientos de recolección de datos}

Tres aspectos son posibles destacar del análisis de los instrumentos (ver Tabla 1.8).

Primero, la tendencia a utilizar el cuestionario sobre situaciones-problema (o casos) como recurso para valorar ya sean las concepciones acerca de la matemática o de algún concepto, o bien, los conocimientos sobre los componentes del CDC. Las situacionesproblema, definidas como tareas o situaciones (casos), vinculados con el contenido matemático y algún hecho o realidad en el aula que el profesor debe resolver, resaltan la necesidad de investigar la didáctica del profesor (sobre su conocimiento) a través del contenido matemático mismo.

Un segundo aspecto a destacar sobre la exploración de los instrumentos, es el uso ineludible de la entrevista como recurso para profundizar sobre el pensamiento y conocimiento del profesor. Ha sido utilizada en diferentes momentos de las investigaciones, siendo su uso más común, primero como recurso para explorar información de la biografía del profesor, de sus concepciones genéricas, de su historial académico y profesional o de sus concepciones o decisiones sobre la planificación de la enseñanza; y segundo como técnica para ahondar sobre las respuestas del profesor a las las situaciones-problema, para confrontarlo con la realidad de la práctica, es decir, indagar sobre sus argumentos o justificaciones, dificultades y análisis metacognitivo de los diferentes aspectos del CDC vinculado con el contenido matemático.

El tercer aspecto a destacar tiene relación con la diversidad de otras fuentes de recogida de información, utilizadas principalmente como herramientas complementarias, de validación y confiabilidad de la investigación, es decir, como instrumentos para la triangulación del estudio. Tal es el caso de materiales de uso exclusivo del profesor para su labor docente, como son notas de clase, libretas de sus alumnos, exámenes, diapositivas, planes de clase, tareas (ejercicios o problemas), entre otros. 
Tabla 1.7. Resumen de los diseños de investigación, sujetos seleccionados y criterios de selección para estudios de casos en el estudio del CDC

\begin{tabular}{|c|c|c|}
\hline Criterios & $\mathrm{f}$ & $\begin{array}{l}\text { Observaciones expresas en los } \\
\text { estudios }\end{array}$ \\
\hline \multicolumn{3}{|l|}{ Diseño } \\
\hline Estudio de casos & 12 & \\
\hline Encuesta y estudio de casos & 5 & \\
\hline Encuesta & 1 & \\
\hline \multicolumn{3}{|l|}{ Sujetos } \\
\hline Profesores de nivel elemental, medio y secundaria & 11 & \\
\hline Formación inicial matemática & 9 & $\begin{array}{l}\text { Según el tópico que trató el } \\
\text { artículo }\end{array}$ \\
\hline Profesores universitarios & 6 & $\begin{array}{l}\text { Con alguna o ninguna formación } \\
\text { previa }\end{array}$ \\
\hline Estudiantes para profesor & 5 & $\begin{array}{l}\text { En los primeros años o el último } \\
\text { año de formación, o último año de } \\
\text { su carrera }\end{array}$ \\
\hline $\begin{array}{l}\text { Buena disposición, confianza con el investigador y } \\
\text { voluntarios }\end{array}$ & 4 & \\
\hline $\begin{array}{l}\text { Tengan docencia actualmente en un grado y nivel } \\
\text { determinado }\end{array}$ & 4 & \\
\hline Disposición de tiempo & 3 & \\
\hline Con experiencia en la enseñanza del tópico & 3 & $\begin{array}{l}\text { Experiencia docente en el tópico, } \\
\text { nivel o grado }\end{array}$ \\
\hline $\begin{array}{l}\text { Matriculados en algún curso, taller de formación para } \\
\text { profesor (ej. CAP) }\end{array}$ & 3 & \\
\hline Edad & 3 & $\begin{array}{l}\text { Al parecer más en el sentido de } \\
\text { reportar el dato }\end{array}$ \\
\hline Participación de cursos previos sobre matemáticas & 3 & En los últimos dos años \\
\hline Preparación de contenido & 2 & $\begin{array}{l}\text { Dominio de contenido } \\
\text { (previamente comprobado antes } \\
\text { del estudio) }\end{array}$ \\
\hline Profesores en ejercicio (expertos) & 2 & \\
\hline Grado de Maestría & 2 & En el contenido \\
\hline Expertos - novatos & 1 & \\
\hline Muestreo aleatorio & 1 & \\
\hline \multicolumn{3}{|l|}{ Selección de casos } \\
\hline Experiencia docente & 5 & $\begin{array}{l}\text { De entre 3-5, 6-9, 10-15 años, 22- } \\
28 \text { años, }\end{array}$ \\
\hline Mitad hombres y mujeres & 3 & \\
\hline Interés por colaborar & 2 & \\
\hline Mitad expertos y mitad novatos & 2 & \\
\hline Por sus errores y problemas de comprensión & 1 & \\
\hline Evaluados por sus estudiantes & 1 & \\
\hline Recomendación & 1 & \\
\hline Aplicación de cuestionario & 1 & \\
\hline $\begin{array}{l}\text { Calificación de aprovechamiento (en la escuela, o de } \\
\text { admisión a la universidad, sobre el tópico) }\end{array}$ & 1 & \\
\hline Observación & 1 & \\
\hline Estima y reputación en la materia & 1 & \\
\hline Evaluación de pares & 1 & \\
\hline $\begin{array}{l}\text { Profesores con alto puntaje de conocimiento previos de } \\
\text { la matemática y con bajo puntaje }\end{array}$ & 1 & \\
\hline
\end{tabular}


Tabla 1.8. Tipos de instrumentos y formas de recolección utilizados en estudios sobre CDC

Descripción

\section{Instrumentos}

Entrevistas (clínicas sobre las situaciones problemáticas sobre el contenido,

conocimiento del contenido y conocimiento de los estudiantes)

Cuestionarios sobre situaciones problemáticas (problemas, casos, ejercicio) de carácter

semiabierto o abierto, o de selección justificada

Entrevista (sobre planificación de las clases, de reflexión tipo autoevaluación,

antecedentes académicos, experiencia docente)

Materiales preparados para los estudiantes (tareas, problemas, ejercicios) 4

Programas de estudio oficiales

Referencias utilizadas en clases

Apuntes del profesor

Obtención de exámenes administrados

Cuestionario tipo Likert (sobre concepciones)

Cuestionario de tareas de enseñanza (tipo autoreporte para describir lo que hace en diferentes funciones como profesor)

Solicitud de mapas conceptuales

Entrevistas con problemas (donde el CDC surge a partir del profesor, obteniendo al final un modelo de CDC específico)

Currículo vitae de cada profesor

Antecedentes biográficos

Análisis de tareas sobre el tópico

Cuestionario abierto sobre concepciones (de carácter verbal, es decir sin situación-

problema)

Técnica Kelly

Análisis de contenido (como entrevistas e informes escritos)

Inventario de creencias pedagógicas y científicas (tipo Likert)

Dimensiones bipolares (diferencial semántico) sobre concepción matemática

Elaboración de problemas tipos

Prueba de dificultad relativa a problemas (identificación y justificación)

Cuestionario sobre conocimiento general de estrategias (a través de un vídeo que

presentaba la solución de un problema por parte del alumno)

Cuestionario sobre conocimiento del profesor de sus propios estudiantes (dado un

problema debería describir cómo $\mathrm{X}$ alumno lo solucionaría)

Prueba de hechos numéricos y de resolución de problemas (dirigido a estudiantes para contrastar lo que el profesor contestó en otros cuestionarios)

\section{Registro de información}

Observación

Audiograbación

Notas de observación y/o listas de cotejo 


\subsection{DIMENSIONES E INDICADORES DEL CDC}

Todo lo anterior permitió tomar algunas decisiones sobre cómo investigar el CDC. Sin embargo, quedaba pendiente ¿qué investigar del CDC? Para ello, con los referentes teóricos y metodológicos revisados, se diseñó un procedimiento, de carácter empírico, inductivo - deductivo, cuyas características principales fueron: que sea ordenado, sistemático y con rigor científico para finalmente establecer un conjunto de dimensiones e indicadores a estudiar del CDC.

El análisis se centró por lo tanto, en averiguar ¿qué aspectos de los diferentes componentes y características del CDC se han estudiado hasta la fecha? ¿qué aspectos específicos de estas características, ideas y conceptos que intervienen en el CDC, serán objeto de interés para el estudio que se propone? ¿tendrá algún énfasis la investigación sobre algún(os) componente(s) o características del CDC o asumirá el estudio completo de éste? ¿qué elementos y criterios se utilizarán para la construcción de los instrumentos sobre CDC? La generación de las dimensiones e indicadores del CDC sirvió para responder a estos cuestionamientos, establecer las características, ideas y conceptos específicos que se han estudiado y con ello ofrecer una alternativa para decidir y definir qué estudiar y construir los instrumentos de recogida de datos.

A diferencia de otros planteamientos (ej. Thompson, 1984 y 1992; Llinares y Sánchez, 1990; Even, 1993; García, 1997; An, Kulm y Wu, 2004) que asumen un interés hacia ciertos marcos teóricos y generan sus categorías de estudio a partir de sus posiciones teóricas, conceptuales y metodológicas, este trabajo ha seguido una aproximación empírica e inductivo-deductivo, que analizó las características y componentes, las segmentó o desagregó en partes específicas e identificó los aspectos más puntuales de investigación de cada uno, el cual presentó cierta similitud con Vallecillos (1996) y Gil (2000). A partir de la información existente, se determinó un sistema de dimensiones e indicadores (SDI) con los cuales se organizó y estructuró una variedad de características de los componentes del CDC. Se utilizó la teoría del análisis de contenido, como procedimiento para la categorización de datos verbales o de conducta con fines de clasificación, resumen y tabulación (Fox, 1981). Para este análisis, se asumieron las definiciones sobre dimensiones e indicadores por Villarruel (2003, pp.10-11); las cuales se adaptan para explicar cada una en el contexto del CDC, atendiendo a la terminología del diseño de la investigación cualitativa según Flick (2004):

Dimensiones: Formas en que se desagrega una categoría, dicho de otra manera, son los elementos que puede integrar a cada categoría de los componentes del CDC.

Indicadores: Características distintivas del fenómeno objeto de estudio (CDC), las cuales son susceptibles de segmentarse y codificarse en un plano global y específico del CDC, a partir de las cuales se obtienen los datos y fenómenos en forma de ideas y conceptos definidos como necesarios para el estudio del CDC.

El proceso de definición de las dimensiones e indicadores del CDC se desarrolló en seis fases: (I) generación de preguntas clave, (II) determinación de los constructos o conceptos por pregunta clave, (III) construcción de mapas conceptuales, (IV) primera 
versión de dimensiones e indicadores, (V) análisis a priori de las dimensiones e indicadores, y (VI) dimensiones e indicadores del CDC. A partir de la Fase I se decidió cuál fue la unidad de contenido que se analizó; las Fases II, III, IV, permitieron elaborar el conjunto de dimensiones e indicadores; y las Fases V y VI ejercieron una función de fundamentación y validación.

El Apéndice A presenta las tablas, mapas conceptuales y evidencia de cada una de las fases que se realizaron en la definición de las dimensiones e indicadores del CDC.

\subsubsection{Fase I. Generación de preguntas clave}

Consistió en la generación de un conjunto de preguntas relacionadas con la comprensión, significado y caracterización de los diferentes elementos del CDC y sus componentes. A partir de éstas, se realizó un primer acercamiento en la identificación de las dimensiones e indicadores.

Las fuentes principales para la redacción de las preguntas, fueron: (a) la revisión bibliográfica sobre el CDC (categorías, características, posiciones teóricas sobre su significado, tipologías, críticas, alcances y limitaciones, fuentes de conocimiento, líneas actuales de investigación, implicaciones para la formación de profesores, instrumentos y resultados de investigación) y (b) la exploración de preguntas expresadas por diferentes autores.

Como criterios de inclusión, se decidió por un lado plantear tantas preguntas como fuera necesario hasta que éstas sugirieran su correspondencia con las diferentes categorías de los componentes del CDC y que el estilo de redacción estuviera dirigido a que estas preguntas permitieran obtener respuestas a partir de la perspectiva teórica del conocimiento del profesor. La Tabla A1 muestra el listado de las preguntas clave.

\subsubsection{Fase II. Determinación de los constructos o conceptos a estudiar por pregunta clave}

La siguiente fase fue elaborar un primer documento donde se identificaron, recogieron, integraron y escribieron, con distintas formulaciones, los diferentes constructos o conceptos que subyacen en la respuesta y que representasen posibles aspectos a estudiar en el profesor. Las fuentes de obtención de éstos fueron: (a) las palabras o frases substanciales a que cada pregunta hacía referencia y (b) la correspondencia de las palabras o frases con la denominación usual que ésta tiene en el campo de la educación matemática. Ver Tablas A2, A3 y A4.

\subsubsection{Fase III. Construcción de mapas conceptuales}

Los mapas conceptuales se definen como "diagramas bidimensionales que muestran relaciones jerárquicas entre conceptos de una disciplina y que derivan su existencia de la propia estructura de la disciplina" (Moreira y Buchweitz, 1988 en Costamagna, 2001, p.310). Constituyen una herramienta eficaz para revelar la comprensión conceptual de las propiedades estructurales de los conceptos o conocimientos, sus relaciones (que pueden ir de la superordenación hasta la subordinación) dependiendo del contexto específico del 
conocimiento y el análisis e identificación de elementos (núcleos o conceptos) semánticos que están en juego (Moreira y Novak, 1988; Costamagna, 2001).

Mediante la elaboración de un mapa conceptual, es posible expresar la jerarquía de los conceptos, enmarcados en "nodos", haciendo gráficos de los diferentes niveles de inclusión, desde los más generales hasta los más específicos. Fundamentalmente, es posible, mediante los "enlaces cruzados", relacionar distintas ramas jerárquicas entre sí, estableciendo conexiones o "nexos" que den cuenta de qué tipo de relación existe entre los conceptos involucrados (“oraciones nucleares") (Costamagna, 2001, p.311).

Así, en esta fase se elaboraron tres mapas conceptuales (ver Figuras A1, A2 y A3), uno por cada componente del CDC, que fueron un medio para representar la relación entre los conceptos y su ramificación, así como de las estructuras proposicionales procedentes del marco teórico sobre el CDC. Estos sirvieron de igual modo, para identificar, reafirmar y/o modificar los constructos o conceptos planteados en la Fase II y suprimir aquellos que estuvieran contenidos en otros. Los mapas conceptuales constituyeron una herramienta eficaz para la optimización y definición de las dimensiones e indicadores de los componentes del CDC, para enriquecerlas (con la incorporación de otros constructos o conceptos) o bien redescubrir su ubicación y relación con otros.

En la construcción de cada mapa conceptual, no sólo se consideraron los constructos o conceptos originados de las preguntas sino que se sirvió de la revisión y análisis del marco teórico del CDC y de la investigación didáctica del conocimiento del profesor, que se expuso con anterioridad. La construcción de éstos fue con base en los criterios establecidos por Costamagna (2001):

a. se agruparon aquellos enunciados que a juicio del autor responden al mismo concepto;

b. se ordenaron los conceptos desde aspectos más generales e inclusivos hasta los menos generales, subordinados a aquéllos;

c. se establecieron las relaciones cruzadas, que muestran uniones entre conceptos pertenecientes a partes diferentes del mapa conceptual;

d. se utilizaron oraciones nodales apropiadas o palabras-enlace para aclarar los nexos en las proposiciones, constructos o conceptos relacionados;

e. se corrigió cada mapa conceptual (las veces que fuese necesario) hasta considerar la consistencia en la jerarquía e interrelación de cada concepto con los marcos teóricos de la educación matemática; y

f. se trató de incluir el mayor número de oraciones nucleares y expresar mediante ellas detalles y ejemplos que permitieran identificar contenidos secundarios o complementarios.

\subsubsection{Fase IV. Primera versión de las dimensiones e indicadores}

Las oraciones nucleares, sus relaciones y cruces en los mapas conceptuales, permitieron obtener una primera versión de las dimensiones e indicadores. Los criterios fueron los siguientes: 
a. incluir como dimensiones las oraciones o frases que se generaron directamente de la relación con el núcleo (el componente central del mapa conceptual) y que representan las formas en que se disgrega el componente a partir de sus características; e

b. incluir como indicadores, las oraciones o frases que se generaron a partir de cada una de las dimensiones y que caracterizan, explican, segmentan y codifican ésta en diferentes formas, ideas, expresiones o conceptos, definidos como atributos importantes de la dimensión y que son claros elementos de objeto de estudio de la investigación didáctica del conocimiento del profesor de matemáticas.

La Tabla A5 presenta esta versión de dimensiones e indicadores del CDC.

\subsubsection{Fase V. Análisis a priori de las dimensiones e indicadores}

En esta fase se contrasta las dimensiones e indicadores obtenidos del análisis de los mapas conceptuales, con el marco teórico del CDC en investigación en didáctica de la matemática. Aun cuando las dimensiones e indicadores parten o tienen su origen del marco teórico del CDC, el propósito fue constatar que los conceptos vertidos fueran relevantes (ej. si han sido estudiado por expertos en el campo en educación matemática), con lo cual se pretende fundamentar los constructos o conceptos obtenidos.

Los autores que se revisaron para esta fase fueron Thompson (1984 y 1992), Carpenter, Fenemma, Peterson y Carey (1988), Marks (1989 y 1990b), McDiarmid, Ball y Anderson (1989), Even (1990), Graeber (1990), Llinares y Sánchez (1990 y 1994), NCTM (1991), Llinares (1993), Cooney (1994 y 1999), Even y Tirsoh (1995), Batanero, Garfield, Ottaviani y Truran (2000), Gil (2000), Batanero (2002), Garfield, delMas y Chance (2003) y An, Kulm y Wu (2004).

De esta exploración y análisis, se corroboraron muchas de las dimensiones e indicadores, incorporando en algunos casos, cambios en denominaciones, y en otros la inclusión de elementos adicionales (como ejemplos o aclaraciones para describir mejor el concepto).

\subsubsection{Fase VI. Dimensiones e indicadores del CDC}

Con base en análisis a priori de los autores e investigadores en educación matemática, se refinaron las dimensiones e indicadores del CDC (ver Tabla 1.9).

Comparando esta versión con la primera (Tabla A5) se identifican algunos elementos que han sido introducidos.

En el componente A (conocimiento del contenido a enseñar), en la dimensión IV, del conocimiento del currículo se incluye un tercer indicador: el conocimiento de las matemáticas como disciplina escolar, el cual contiene lo relacionado con los propósitos de la instrucción matemática, los conocimientos previos matemáticos del estudiante, los problemas típicos y la importancia y fundamentación de las matemáticas en la escuela. 
En el componente $\mathrm{B}$ (conocimiento de las estrategias y representaciones instruccionales), en la dimensión $\mathrm{V}$, del conocimiento de las estrategias específicas de la educación matemática se incorporó un indicador: el conocimiento de la evaluación de los aprendizajes. Este mismo indicador se anexó igual a la dimensión VI del conocimiento y estudio de las dificultades de la labor docente. En años recientes, investigadores en educación matemática como Garfield, delMas y Chance (2003) y otros, han reconocido el conocimiento de los procesos de evaluación de los aprendizajes en matemáticas, como un campo fértil de estudio para el profesor e importante dentro del cúmulo de conocimientos a su labor así como objeto de investigación.

En el componente $\mathrm{C}$ (conocimiento del proceso de aprendizaje del estudiante del tópico específico), en la dimensión III, del conocimiento de las estrategias (para la resolver los errores y dificultades del aprendizaje de los estudiantes), en el indicador de "específicas" se añadieron algunos ejemplos a la luz de la educación matemática. Otra inclusión fue en la dimensión IV, conocimiento de los materiales (en el diagnóstico y las estrategias), donde se incorporó el indicador de Observaciones, como un recurso característico en educación matemática para la identificación de creencias, concepciones, errores y dificultades. 


\section{Tabla 1.9. Dimensiones e Indicadores de los componentes del CDC}

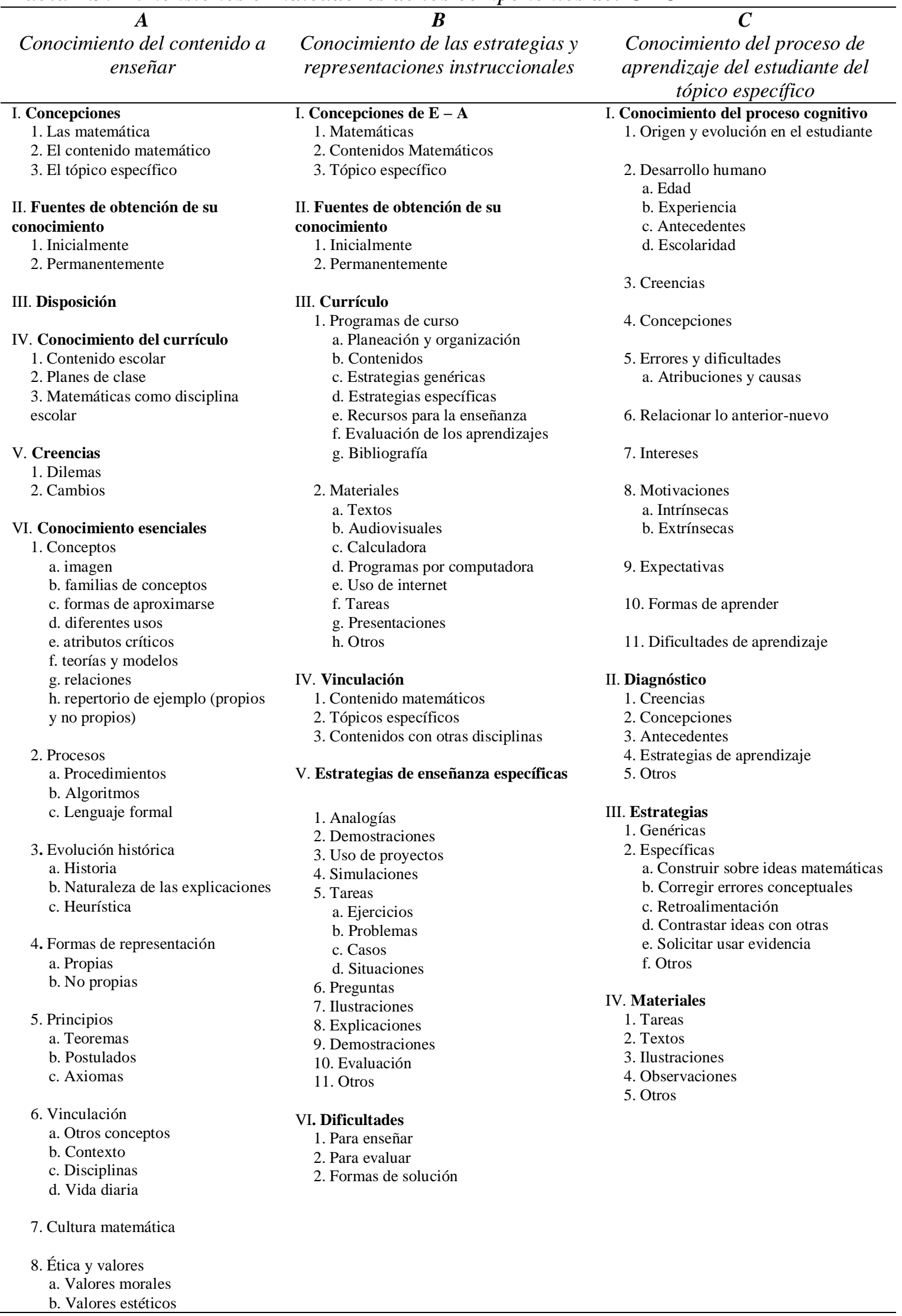

Jesús Enrique Pinto Sosa 
En síntesis, para el componente A se obtuvieron seis dimensiones con un total de 18 indicadores y 25 subindicadores. Para el componente B fueron seis dimensiones, con 24 indicadores y 19 subindicadores. Y para el componente $\mathrm{C}$, un total de cuatro dimensiones, con 23 indicadores y 13 subindicadores. Si bien, quizás no se logra completar con detalle todas las dimensiones e indicadores del CDC, sí da una idea suficientemente amplia y clara sobre la diversidad, ramificación, relaciones y objetos de estudio que se han realizado y pueden desarrollarse en el campo de la educación matemática. Por ejemplo, es posible encontrar a investigadores que su foco de atención es el estudio de los dilemas del profesor a la luz de sus propias creencias; aquellos que investigan sobre las concepciones sobre la matemática y sobre la enseñanza y aprendizaje de las matemáticas; aquellos que trabajan sobre las concepciones de un tópico específico; o aquellos que estudian las estrategias específicas para enseñar un tópico específico a partir del uso de las nuevas tecnologías (ej. Internet o software), entre muchos más.

Por otro lado, las dimensiones e indicadores del CDC muestran la diversidad y amplitud de conocimiento que el profesor de matemáticas puede aprender y que es deseable que así sea. Asimismo, la lista logra recoger e identificar muchos de los constructos y conceptos que se deben estudiar o que se están estudiando en el campo de la educación matemática; con lo cual, no sólo genera una aproximación a diferentes agendas de investigación, sino que también permite conocer el énfasis y las tendencias de investigación de los diferentes estudios que se han hecho en torno al CDC y así, identificar componentes, constructos o conceptos (de un tópico específico de las matemáticas) poco o nada estudiados a través de la investigación en didáctica del conocimiento del profesor de matemáticas. Vacíos que son necesarios llenar para la comprensión del significado de las características y componentes del CDC en matemáticas y del tópico específico y con ello, proporcionar información útil y valiosa tanto a la generación de más investigación, como para los programas de formación de profesores.

\subsection{ANÁLISIS DE LAS INVESTIGACIONES SOBRE CDC A PARTIR DE LAS DIMENSIONES E INDICADORES}

Este análisis consistió en la exploración de un conjunto de investigaciones en el campo de la educación matemática y de enseñanza de las ciencias (ej. química, biología o física). El propósito fue analizar el énfasis (sobre ciertos componentes y constructos) que han tenido las diferentes investigaciones sobre CDC y detectar posibles focos de interés para investigar, a través de los ítems o ejemplos de recogida de datos utilizados. La exploración sirvió también para justificar y validar las dimensiones e indicadores del CDC obtenidas a partir del análisis de contenido y tomar decisiones sobre qué estudiar del CDC.

El procedimiento fue el siguiente:

a. se seleccionaron aquellas investigaciones del campo de la educación matemática y/o de enseñanza de las ciencias (ej. Even, 1993; García, 1994; Even y Tirosh, 1995; Baturo y Nason, 1996; Llinares, 1996; Vallecillos, 1996; Cooney, 1999; Contreras, 1999; Sánchez y Llinares, 2002; Van Driel, De Jong y Verloop, 2002; Gil y Rico, 2003, Moreno y Azcárate, 2003, An, Kulm, Wu, 2004), que 
estudiaran algún tópico específico a la luz de un componente o constructo del CDC y que incluyeran ejemplo(s) del instrumento de recogida de datos (preferentemente sobre situaciones-problema que el profesor debiera resolver), para obtener información sobre qué aspectos puntuales se están estudiando del constructo o del tópico específico;

b. se elaboraron tablas de comparación, que recogían cinco aspectos esenciales: referencia (autores, año y tópico específico), objetivos de investigación, breve descripción de las situaciones-problema, preguntas terminales y clasificación de dimensiones e indicadores; $y$

c. el énfasis del análisis fueron las preguntas que cada instrumento de recolección tenía y su correspondiente clasificación de las dimensiones e indicadores

Un ejemplo de las tablas de comparación construidas, puede observarse en la Tabla 1.10, que recupera una parte del cuestionario de enseñanza de las matemáticas de An, Kulm y Wu (2004). Cada pregunta se clasificó en tres partes separadas por un guión. De izquierda a derecha, primero se clasificó el componente al cual pertenece (A, B o C); segundo, la dimensión de ese componente (desde I a VI según se trate) y tercero, el número y letra del indicador correspondiente. De este modo, A - IV - 1 significa que la pregunta se clasificó en el componente A (conocimiento del contenido a enseñar), en la dimensión IV (conocimiento del currículo) y en el indicador 1 (contenido escolar).

Se revisaron 14 estudios, con un total de 24 problemas (casos o situacionesproblema) que generaron una exploración de 79 preguntas en total. Del análisis preliminar de estas preguntas, se obtuvo la Tabla 1.11.

Una exploración descriptiva de las frecuencias permite concluir que: (a) un 45\% son preguntas enfocadas a los conocimientos esenciales del contenido; (b) cerca de un 30\% fueron preguntas referentes al proceso cognitivo que tiene el estudiante ante la situación, problema o concepto; y (c) por número total de preguntas por componentes del CDC: el $67 \%$ de las preguntas fueron sobre el contenido; el $20 \%$ sobre las estrategias y representaciones instruccionales y un 63\% sobre el conocimiento de los procesos de aprendizaje del estudiante.

Este ejercicio y análisis de clasificar las preguntas de los instrumentos de recogida de datos de los estudios sobre el CDC, no pretende ser un estado de la cuestión extenso de las investigaciones hechas a la fecha y qué énfasis tienen sus estudios. La exploración está limitada a los autores revisados y en algunos casos, a encontrar ejemplos de instrumentos o preguntas sobre cómo investigar el constructo, particularmente sobre las situacionesproblemas. Será necesario incorporar más estudios al respecto, con formas adicionales o complementarias de valorar el CDC y sobre diferentes tópicos matemáticos, para reunir un amplio y extenso número de investigaciones que permitan tener un acercamiento más preciso y exacto sobre todo lo estudiado del CDC en el campo de la educación matemática. Aspectos que rebasan la finalidad de este estudio y análisis. 
Tabla 1.10. Ejemplo de preguntas y clasificación según el SDI del CDC del Problema 1 sobre el Cuestionario sobre Enseñanza de las Fracciones, por An, Kulm, Wu (2004, p.152).

Objetivos Breve descripción de la Preguntas terminales Clasificación, según específicos situación-problema dimensiones e indicadores del CDC (Tabla 1.9)

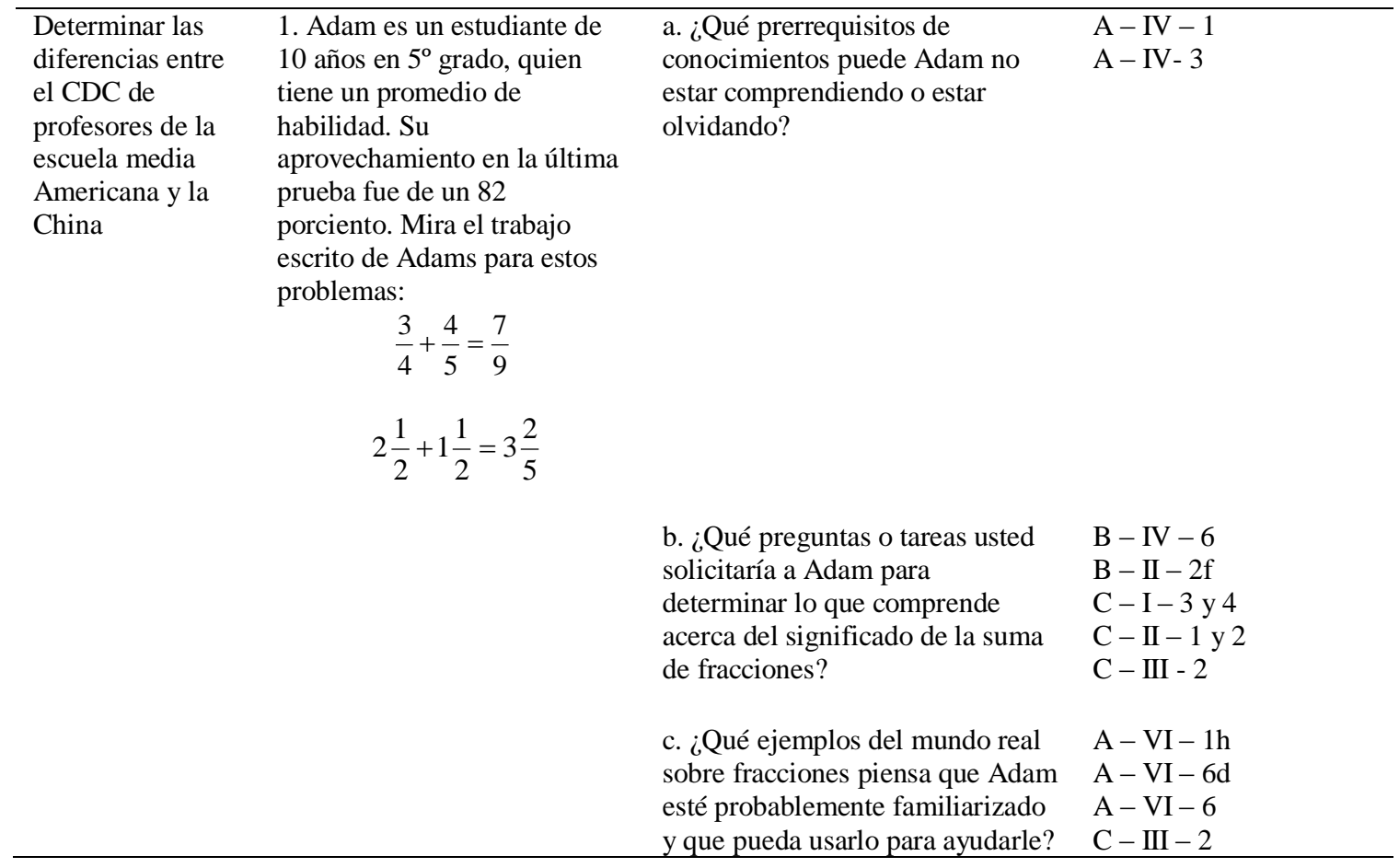

Respecto a los autores analizados se pudo apreciar diferencias en el énfasis de los componentes del CDC. Algunos más sobre el contenido (ej. Even, 1993 y Even y Tirosh, 1995) y otros enfocados sobre el conocimiento del estudiante (ej. An, Kulm y Wu, 2004).

Tabla 1.11. Clasificación de 79 preguntas (en 24 problemas) según el SDI del CDC

\begin{tabular}{|c|c|c|c|c|c|c|}
\hline \multirow[b]{2}{*}{$\begin{array}{l}\text { Componentes } \\
\text { CDC }\end{array}$} & \multicolumn{6}{|c|}{ Dimensiones } \\
\hline & $\mathrm{I}$ & II & III & IV & $\mathrm{V}$ & VI \\
\hline $\mathrm{A}-$ & Concepciones & Fuentes & Disposición & Currículo & Creencias & Conocimientos \\
\hline Contenido & 9 & 2 & 0 & 6 & 0 & $\begin{array}{c}\text { esenciales } \\
36\end{array}$ \\
\hline $\begin{array}{l}\text { B - Representa- } \\
\text { ciones instruc- } \\
\text { cionales }\end{array}$ & $\begin{array}{c}\text { Concepciones } \\
5\end{array}$ & $\begin{array}{c}\text { Fuentes } \\
1\end{array}$ & $\begin{array}{c}\text { Currículo } \\
2\end{array}$ & $\begin{array}{c}\text { Vinculación } \\
0\end{array}$ & $\begin{array}{c}\text { Estrategias } \\
\text { Específicas } \\
7\end{array}$ & $\begin{array}{c}\text { Dificultades } \\
1\end{array}$ \\
\hline $\begin{array}{l}\mathrm{C}- \\
\text { Estudiante }\end{array}$ & $\begin{array}{c}\text { Conocimiento } \\
\text {. Proceso } \\
\text { Cognitivo } \\
23\end{array}$ & Diagnóstico & Estrategias & Materiales & & \\
\hline
\end{tabular}

Nota: una misma pregunta puede explorar diferentes indicadores y componentes 
No obstante, el análisis y clasificación de las preguntas de diferentes investigaciones sí nos dan pautas sobre cierto énfasis de los estudios realizados sobre el CDC. Por ejemplo, es posible notar que existe una marcada inclinación hacia estudios sobre el conocimiento del contenido a enseñar y sobre los procesos de aprendizaje del estudiante (con marcada tendencia a los procesos cognitivos). Esto no sólo a la luz de los instrumentos y preguntas, sino también a partir de los propósitos u objetivos de investigación de los diferentes estudios revisados. Particular atención tienen las pocas preguntas e incluso, los pocos estudios sobre las estrategias y representaciones instruccionales del contenido matemático y las formas para corregir errores o dificultades conceptuales de los estudiantes. Así lo indican Hill, Schilling y Ball (2004), quienes al estudiar las diferentes teorías sobre investigación del conocimiento del profesor y sus implicaciones, encontraron que en relación a la investigación sobre las representaciones instruccionales referido en el CDC de Shulman, en educación matemática resultan ser pocas por lo que este aspecto tendrá particular interés para esta investigación.

Por otra parte, la exploración permitió justificar y validar las dimensiones e indicadores del CDC, con lo cual resultó ser un instrumento útil para el análisis de los estudios hechos sobre CDC y su énfasis e interés sobre ciertos componentes o constructos.

Este ejercicio analítico a partir de las dimensiones e indicadores del CDC, permitió que la investigación se centrara en el estudio del CDC con especial énfasis en dos categorías: el conocimiento de las estrategias y representaciones instruccionales (componente B) y el conocimiento de los procesos de aprendizaje del estudiante (componente C). Asimismo, el estudio versará sobre el tema de la representación gráfica en Estadística, el cual será abordado en el siguiente capítulo.

\subsection{EN SÍNTESIS}

El CDC es una perspectiva teórica que surge a partir del conocimiento base para la enseñanza de Lee Shulman. A diferencia de otras perspectivas de investigación didáctica, favorece el estudio del profesor a la luz del conocimiento del contenido específico que enseña. El estudio del CDC, como modelo de formación de profesores y de objeto de investigación, ha tenido un interés particular en los últimos años; tal es el caso de la educación matemática.

Desde su aparición en las ciencias de la educación, el CDC ha sido objeto de análisis y de estudio, llevando a varios expertos a formular críticas sobre la teoría, pero al mismo tiempo, a un reconocimiento general sobre sus bondades, alcances y fortalezas, como dominios de conocimientos que todo profesional de la educación en cualquier campo disciplinario debe poseer. Aun cuando el análisis del constructo ha llevado a diferentes autores a modificar, ajustar, e incluso, proponer elementos nuevos a las características y componentes del CDC, tres de éstos se han mantenido en común: el conocimiento del contenido a enseñar, el conocimiento de las estrategias y representaciones instruccionales y el conocimiento de los procesos de aprendizaje del estudiante sobre el contenido a enseñar.

En este capítulo, además de conocer el origen y evolución del CDC como parte de una perspectiva más general para la enseñanza, propuesta por Shulman y colaboradores; de 
explorar y estudiar sus características; se identificaron, integraron y describieron un conjunto de categorías y elementos por cada componente del CDC. A partir de ahí y de un análisis de contenido de las diferentes aportaciones de expertos e investigadores (tanto de educación matemática como de otras disciplinas), ayudó a construir el sistema de dimensiones e indicadores del CDC. Estas sirvieron, no sólo para generar una amplia gama de posibles agendas de investigación sobre el CDC, sino también como un instrumento útil para explorar lo que se ha investigado en educación matemática respecto de los constructos o tópicos del CDC y del énfasis que los diferentes investigadores le han dado a sus investigaciones.

Del análisis de las dimensiones e indicadores del CDC y de las investigaciones realizadas en el campo de la educación matemática, se obtuvo una perspectiva general muy útil sobre el estado de la cuestión de la investigación didáctica del profesor de matemática a la luz del CDC. Se consiguió obtener un conjunto de características (conceptuales y metodológicas), las cuales serán tomadas en cuenta para la presente investigación y que a continuación se describen a manera de principios rectores de esta tesis:

a. existe un marcado énfasis del estudio del conocimiento del contenido a enseñar, en comparación con el conocimiento de las estrategias y representaciones instruccionales y del conocimiento del proceso de aprendizaje del estudiante;

b. es necesario continuar y desarrollar más estudios sobre el CDC, sobre diferentes contenidos y tópicos matemáticos, que permitan ayudar a clarificar más su significado y características, tanto como modelo de formación de profesores como objeto de investigación;

c. aunque los estudios sobre el CDC en educación matemática acentúan sus resultados y conclusiones sobre el tópico matemático que investigan, éstas sirven como referente teórico y metodológico en el momento de generar una nueva investigación sobre el profesor en tópicos diferentes;

d. las tendencias actuales de investigar sobre el CDC indican la necesidad de estudios bajo una perspectiva cualitativa principalmente, a través de estudio de casos;

e. los criterios de selección de los profesores son de carácter intencional, según el objetivo y naturaleza del estudio, del escenario y contexto de la investigación; y

f. se acentúan como instrumentos de investigación para estudiar la didáctica del profesor desde la perspectiva del conocimiento, los cuestionarios sobre situaciones-problema y las entrevistas clínicas; y como recurso de registro las observaciones y audio grabaciones.

Los diferentes estudios presentados evidencian una vez más la necesidad de continuar haciendo esfuerzos para mejorar la formación de los profesores de matemáticas, de investigar de formas diferentes el conocimiento del profesor; de explorar y profundizar sobre su forma de pensar y conocer, sus dificultades y su manera de aprender a enseñar; y de traducir los resultados de investigación a propuestas o programas de formación de profesores, con enfoques diferentes y con impacto en el cambio y mejora del desarrollo profesional del profesor. 
80 Conocimiento didáctico del contenido sobre la representación de datos: estudios de casos

Jesús Enrique Pinto Sosa 


\section{CAPÍTULO 2: Marco teórico del estudio de la representación gráfica en Estadística}

Este capítulo tiene un doble propósito: primero, contextualizar y ubicar la investigación dentro del marco de referencia de la educación estadística y segundo, presentar el marco teórico de la representación gráfica que sustenta la investigación. Para ello, se ha organizado el documento en cinco partes.

En la primera y segunda parte se presenta una introducción al campo de la investigación en educación estadística en general y en la formación de los profesores de Estadística como línea concreta de investigación, respectivamente. Para ello se presentan algunas investigaciones sobre el conocimiento del profesor, específicamente sobre sus concepciones para, posteriormente, resaltar el estudio e interés del CDC en la educación estadística.

La tercera parte, desarrolla el marco teórico de la representación gráfica. Se inicia con una descripción sobre su importancia como objeto de estudio, seguido de una revisión de los principales autores que han investigado sobre el tema, sus contribuciones y su relación con el problema de investigación. Le sigue la cuarta parte, que resume algunos hallazgos importantes sobre los niveles de comprensión gráfica y los tópicos de estudio de la representación gráfica; seguido de un análisis y caracterización de los diseños e instrumentos utilizados. Se presenta un análisis de ítems de diferentes instrumentos revisados, con el propósito de vislumbrar los marcos teóricos que subyacen en su diseño y fijar las primeras posiciones conceptuales y metodológicas para el trabajo de investigación.

Por último, en la quinta parte, se presentan los aspectos teóricos relevantes para esta investigación. Con base en el marco teórico, los análisis hechos en la tercera parte del capítulo y la naturaleza de la investigación, se presentan los objetivos de aprendizaje (genéricos y específicos) de la representación gráfica en el nivel de pensamiento estadístico. Estos objetivos enmarcarán y justificarán la construcción de los instrumentos de investigación y definirán qué aspectos del CDC sobre este tema van a ser explorados.

\subsection{LA INVESTIGACIÓN EN EDUCACIÓN ESTADÍSTICA Y EL CONOCIMIENTO DIDÁCTICO DEL CONTENIDO DEL PROFESOR}

La investigación en educación estadística es un campo de innovación y desarrollo constituido por todas aquellas personas (educadores estadísticos) que se interesan o trabajan por mejorar la enseñanza, el aprendizaje, la comprensión, la valoración, el uso o las actitudes hacia la Estadística, de modo que, la investigación en educación estadística es 
investigación sobre la enseñanza y aprendizaje de la Estadística (Batanero, 2001a; Bacelar, et al. 2001). El área de trabajo, desarrollo, práctica y estudio no es exclusiva de los profesores e investigadores matemáticos y educadores matemáticos ya que, desde sus orígenes, adquiere un papel de interdisciplinariedad (Batanero, 2001a), por lo que es común encontrar profesionales de otras áreas como son psicólogos, educadores, economistas, matemáticos, estadistas, por mencionar a algunos, involucrados en esta línea de investigación.

Aún cuando el marco teórico y metodológico de la investigación en educación matemática puede servir como referente para la investigación en educación estadística, ésta se conceptúa desde un punto de vista interdisciplinar, aplicada a los contextos en los cuales se utiliza. Denominada también estudio de la estocástica (particularmente en Europa, al referirse al estudio de la Probabilidad y Estadística), según Shaughnessy (1992), la investigación en educación estadística es un campo de investigación relativamente joven (Batanero, et al, 2000) que cada día cobra mayor relevancia a nivel internacional. Así lo demuestran el surgimiento de congresos como las Conferencias Internacionales sobre la Enseñanza de la Estadística (ICOTS, International Conference on the Teaching of Statistics, por sus siglas en inglés), las reuniones de trabajo, presencial o satelital de la Asociación Internacional sobre Educación Estadística (IASE, International Association for Statistical Education), las reuniones de los Institutos Internacionales de Estadística (ISI, International Statistical Institute) y los Foros Internacionales de Investigación sobre Razonamiento, Pensamiento y Cultura Estadística (SRTL, Statistical Reasoning, Thinking and Literacy); y grupos de investigación, como por ejemplo, el Statistical Education Research Group de la Universidad de Granada; y el International Study Group for Research on Learning Probability and Statistics.

Desde sus orígenes a la fecha han emergido diferentes líneas de investigación en el campo de la educación estadística. Éstas se han generado con el propósito de delimitar su campo de acción y presentar las prioridades de investigación en el área. Por ejemplo, Shaughnessy (1992) y Shaughnessy y Bergman (1993) a partir del estado de la cuestión de diferentes estudios sobre educación estadística, coinciden la necesidad de desarrollar futuras investigaciones sobre:

a. desarrollo de instrumentos de medición, en la variedad de contextos y niveles escolares,

b. concepciones e ideas equivocadas de los estudiantes de secundaria,

c. estudios transculturales,

d. concepciones de los profesores sobre la Probabilidad y Estadística,

e. efecto de la instrucción en la enseñanza,

f. efectos de los programas por computadoras, $y$

g. el rol de la metacognición en la toma de decisiones según diferentes variables.

Por su parte, Batanero, et al. (2000) sugirieron como áreas específicas que requieren de resultados de investigación las siguientes:

a. razonamiento estadístico (que incluye el análisis y la discusión sobre razonamiento, pensamiento y capacidad estadística), 
b. tecnología (y su papel en la enseñanza),

c. razonamiento inferencial (que incluye el estudio de ayudas para diferentes niveles de conocimientos matemáticos para comprender la Estadística inferencial), $\mathrm{y}$

d. formación de profesores (que incluye el conocimiento del profesor sobre el contenido y el conocimiento pedagógico sobre la Estadística).

Una tercera clasificación de las prioridades a investigar la presentó Ito (en Bacelar, et al., 2001), profesor emérito de la Universidad de Nagoya, Japón, quien las agrupó en cinco categorías:

a. capacidad estadística del futuro ciudadano,

b. formación de profesores de Estadística,

c. enseñanza de la Estadística y métodos estadísticos para futuros usuarios,

d. enseñanza de la Estadística y métodos estadísticos para futuros "productores" y "analistas" de datos oficiales y no oficiales, y

e. enseñanza de la Estadística teórica y aplicada para futuros "productores" de métodos estadísticos.

En el año 2002 Batanero añade un área de investigación que se ha consolidado en los últimos años: alfabetización estadística (Statistic Literacy), según la cual se concibe que un ciudadano culto debe ser capaz de controlar sus intuiciones sobre el azar, diferenciar las que son correctas e incorrectas y aplicar el razonamiento para controlar sus intuiciones. Esta área de investigación también ha sido reconocida recientemente en el documento denominado "Estudio conjunto ICMI/IASE. Educación Estadística en la Matemática escolar: retos para la enseñanza y la formación del profesor" (2006) elaborado por la International Commission on Mathematical Instruction (ICMI) y la IASE.

Más recientemente, Shaughnessy (2007) clasifica la necesidad de hacer investigación en tres grandes grupos: a) investigación sobre cuestiones conceptuales en Estadística, b) investigación sobre cuestiones de enseñanza en Estadística, y c) algunas cuestiones metodológicas para la investigación en Estadística.

Sobre las cuestiones conceptuales, Shaughnessy afirma que se necesita más investigación sobre las concepciones que sobre Estadística tiene los estudiantes de educación superior. De igual modo, expresa que el uso de gráficos generados por los estudiantes es un área muy interesante para estudiar su pensamiento estadístico, a través de lo que se llama inscripciones (inscriptions, por Roth y Bowen, 2001), una muy poderosa herramienta para investigar el pensamiento del estudiante. Menciona que los estudiantes no sólo proporcionan información acerca de las técnicas que usan para la graficación sino también del nivel de pensamiento que tienen respecto del manejo de los datos y es a través de las inscripciones cómo se puede conocer cómo el estudiante piensa acerca de las tendencias sobre el tiempo, la variación, las medidas de tendencia central y la distribución. Shaughnessy también recomienda que se necesita más investigación sobre desarrollo conceptual de los estudiantes en Estadística cuando trabajan en ambientes tecnológicos y sobre las concepciones de los profesores acerca de la Estadística. 
Sobre las cuestiones de enseñanza, Shaughnessy expresa que es necesario contestar a la siguiente pregunta ¿cuál es el conocimiento estadístico necesario para la enseñanza? Piensa que es necesario explorar cuál es el conocimiento esencial que los profesores deben tener para enseñar Estadística, lo que Shulman (1987) denomina conocimiento didáctico del contenido. Recomendó también que es necesario investigar sobre el discurso en el salón de clases en Estadística y que existe muy poca investigación con estudiantes y profesores sobre sus creencias y actitudes hacia la Estadística.

Sobre las cuestiones metodológicas, Shaughnessy sugiere el uso de múltiples metodologías de investigación al estudiar sobre las concepciones de los estudiantes.

Como puede apreciarse, al igual que en educación matemática, la formación de profesores de y sobre Estadística es un área con amplio reconocimiento como objeto de estudio. Dentro de este campo, se han detectado una variedad de problemas objeto de preocupación de los investigadores, los cuales se pueden agrupar de la siguiente forma:

a. conocimientos del profesor sobre las dificultades de aprendizaje y conocimientos, concepciones y creencias y actitudes de sus alumnos (Shaughnessy, 2007, 1992; Batanero, 2001a y 2000);

b. la preparación y formación específica de los profesores en Estadística (Shaughnessy, 1992; Batanero, et al. 2000; Batanero, 2001a y 2000);

c. enseñar Estadística en contextos diferentes a la matemática (Batanero, 2000),

d. los conocimientos, concepciones, creencias y actitudes del profesor (Shaughnessy, 1992; Batanero, et al., 2000);

e. el uso de las nuevas tecnologías por parte del profesor (Shaughnessy, 1992; Batanero, 2001a);

f. el estudio del desarrollo de conceptos de los estudiantes en ambientes tecnológicos (Shaughnessy, 2007);

g. conocimientos didácticos del profesor sobre los tópicos a enseñar (Shaughnessy, 2007; Batanero, 2001a; Bacelar, et al., 2001);

h. desarrollo de instrumentos de evaluación (Shaughnessy, 1992; Batanero, 2001a);

i. alfabetización estadística (Batanero, 2002); y

j. el estudio de los gráficos generados por los estudiantes como herramienta para explorar su pensamiento estadístico (Shaughnessy, 2007).

De interés particular para el presente trabajo son los conocimientos y concepciones del profesor de Estadística, así como el conocimiento didáctico del contenido que, según Shaughnessy (1992 y 2007) y Batanero, et al. (2000) han sido poco estudiados. Este interés ha sido reconocido recientemente por el estudio ICMI/IASE (2006) en el que se justifica y plantea la necesidad de hacer más investigación en este sentido:

Se debería prestar más atención a las concepciones y creencias estadísticas de los profesores... El conocimiento didáctico del contenido requerido para la enseñanza y el modo en que los profesores usan su conocimiento estadístico al enseñar Estadística también debe tenerse en cuenta (Mickelson y Heaton, 2004). 
El esfuerzo de investigación que se ha concentrado sobre la educación del profesor de matemáticas y su desarrollo profesional en la década pasada no se ha reflejado en la educación estadística... Este olvido debe ser subsanado, promoviendo la investigación específicamente orientada sobre la educación y desarrollo profesional de profesor para enseñar Estadística (Shaughnessy, en prensa) (ICMI/IASE, 2006, p.3).

A continuación se presentan los antecedentes sobre los estudios del conocimiento didáctico del contenido y la Estadística.

\subsubsection{Antecedentes del estudio del conocimiento didáctico del contenido en educación estadística}

Una de las primeras investigadoras en educación estadística que hace referencia de manera explícita al estudio del CDC es Batanero, et al (2000). Estos investigadores al delimitar los dominios de conocimiento que debe tener el profesor de Estadística, se refieren al "conocimiento pedagógico en estadística", el cual está integrado por conceptos de pedagogía, conceptos de psicología, conceptos específicos sobre concepciones erróneas, conceptos sobre intuiciones, epistemología, currículo y materiales en Estadística. Batanero (2002) reconoce que el cambio del currículo debe incluir no sólo el conocimiento estadístico, sino también del conocimiento didáctico del contenido y describe como componentes básicos:

a. la reflexión epistemológica sobre el significado de conceptos y procedimientos particulares que se pretenden enseñar (sobre la naturaleza del conocimiento estocástico, su desarrollo y evolución),

b. análisis de las transformaciones del conocimiento para adaptarlos a los diferentes niveles de enseñanza,

c. estudio de las dificultades, errores y obstáculos de los alumnos en el aprendizaje y sus estrategias en la resolución de problemas que permitirá orientar mejor la tarea de enseñanza y evaluación del aprendizaje, y

d. análisis del currículo, situaciones didácticas, metodología, metodología de enseñanza para temas específicos y recursos didácticos específicos.

Dentro de su análisis, Batanero y colaboradores identifican elementos teóricos desde la perspectiva del CDC de Shulman (1986b). Primero reconocen elementos del conocimiento de la pedagogía general y fines de la educación, aspectos que están dentro del conocimiento base para la enseñanza de Shulman y colaboradores. Segundo, se identifican los componentes del CDC: el conocimiento del contenido estadístico a enseñar, la didáctica específica de la Estadística (denominada por Batanero y colaboradores como "transformaciones") y el conocimiento de los proceso de aprendizaje del estudiante (creencias, concepciones, errores y dificultades) del contenido estadístico a enseñar.

Otro antecedente que se tiene del CDC en estadística es el trabajo de Watson (2001). Sobre los tipos de conocimiento de Shulman (1986b y 1987) diseñó un instrumento para medir los perfiles de competencia de los profesores en dos tópicos: azar y datos. El cuestionario consistió en 10 secciones con ítems que permitían explorar tanto como sea 
posible los siete tipos de conocimiento de Shulman. Las secciones fueron: 1) factores significativos en la enseñanza del azar y los datos, 2) amplia escala de planeación de las unidades, incluyendo recursos y fuentes consultadas, 3) plan para la enseñanza de un tópico específico de selección del profesor, 4) prácticas actuales de enseñanza del azar y los datos, incluyendo retroalimentación de los estudiantes sobre su satisfacción y dificultades percibidas, 5) apreciación y potencial de los planes de enseñanza para dos tópicos específicos (muestreo y media), 6) una escala Likert de confianza en la enseñanza de tópicos particulares (ej. azar, lenguaje, probabilidad, mediana), 7) una escala Likert de las creencias acerca de la Estadística en la vida diaria, 8) respuestas a los ítems de la encuesta previamente administrada a los estudiantes, incluyendo respuestas esperadas apropiadas e inapropiadas de ellos y cómo el profesor podría usar estas respuestas en su salón de clases, 9) experiencia del profesor en términos de años de experiencia docente y estudios previos y 10) aprendizajes profesionales previos y de interés y oportunidades de desarrollo.

Watson (2001) administró este cuestionario a 43 profesores de primaria y secundaria y estableció los resultados en relación a los tipos de conocimiento de Shulman y la habilidad del profesor para reflexionar sobre su práctica. Entre los principales resultados encontró que algunos profesores tenían una apreciación muy limitada de cómo sus alumnos podrían contestar preguntas tales como encontrar un error en un gráfico circular o identificar un reporte erróneo de la media sobre el muestreo de una población. Asimismo, los profesores, a menudo se limitaban a sugerir cómo ellos podrían utilizar las respuestas de sus alumnos en su salón de clases.

Posteriormente, Watson (2005), utilizó el cuestionario anterior como base para un nuevo cuestionario que permitiera evaluar el conocimiento que tienen los profesores para conseguir una alfabetización cuantitativa (quantitative literacy), es decir, la habilidad que tienen para usar las matemáticas en la vida cotidiana, en el trabajo, la comunidad y la vida civil. Afirma que a los profesores se les puede administrar este tipo de instrumentos para monitorear su progreso favorable en relación a los tipos de conocimiento de Shulman.

En su tesis doctoral, Sorto (2004) hace referencia a la teoría del CDC de Shulman y lo presenta como un modelo teórico que ayuda a comprender el conocimiento del profesor. En este documento Sorto contrasta el CDC con otros modelos (Peterson, 1988 y Lloyd y Wilson, 1998) y al realizar el análisis de contenido de diferentes documentos que en Estados Unidos se utilizan para la formación de profesores (estándares nacionales y estatales para la acreditación de profesores), menciona al CDC como una manera de sintetizar los tres tipos de conocimiento que todo profesor deber tener: de la matemática, de los estudiantes y de las prácticas de instrucción.

También en 2004, Sorto y White presentan en el ICME (en Dinamarca) una ponencia titulada Statistical knowledge for teaching (Conocimiento estadístico para la enseñanza) cuyo propósito fue contribuir a la discusión actual y análisis del content knowledge for teaching (conocimiento del contenido para la enseñanza). Se plantearon dos preguntas centrales: ¿cuáles son los aspectos centrales del conocimiento estadístico necesario para la enseñanza del nivel secundaria? y ¿qué aspectos del contenido y del CDC necesitan los profesores de secundaria para enseñar análisis de datos y estadística? Para ello se exploraron el CDC de los profesores sobre análisis de datos y estadística. Analizaron 10 
documentos diferentes de Estados Unidos vinculados con los principios y estándares para la certificación de profesores y administraron un cuestionario a 42 futuros profesores de secundaria. El cuestionario midió dos dominios de conocimiento: conocimiento puro de estadística (pure statistical knowledge) y conocimiento estadístico aplicado a la enseñanza (statistical knowledge applied to teaching).

Sobre el "conocimiento estadístico aplicado a la enseñanza" el cuestionario se centró sobre el conocimiento que tiene el profesor del aprendizaje de los estudiantes. Los aspectos que consideraron en el cuestionario dentro de este dominio fueron: interpretación de las respuestas verbales (orales) y escritas en relación al contenido y el examen de las estrategias de los estudiantes y solución de los ejercicios para hacer inferencias acerca de sus conocimientos. En cada ítem del cuestionario a los futuros profesores se les confrontó con cada respuesta del estudiante. Entre los principales resultados encontraron que las dificultades de los futuros profesores sobre el conocimiento estadístico aplicado a la enseñanza son más notorias y acentuadas. Los profesores no reconocen los errores acerca de la media y el rango para datos categóricos y no piensan qué significa o dice la medida de tendencia central y de dispersión acerca de los datos.

Las contribuciones de Watson (2001 y 2005), Sorto (2004) y Sorto y White (2004) son consideradas como los primeros trabajos que hacen referencia el estudio del CDC en Estadística y que ponen sobre la mesa la discusión sobre la relevancia, significado y valor del CDC en el campo de la educación estadística, a veces considerado como tal, "conocimiento didáctico del contenido", o bien, "conocimiento estadístico para la enseñanza" o "conocimiento estadístico aplicado a la enseñanza".

Posteriormente, Burgess en 2006 sugiere un marco teórico para el conocimiento del profesor de Estadística. Analiza los modelos teóricos de Shulman (1986b) y Sherin, Sherin y Madanes (2000) sobre el conocimiento del profesor. Compara los referentes teóricos de las investigaciones en educación matemática y estadística y propone un marco teórico que puede ser usado para estudiar el conocimiento del profesor y el conocimiento estadístico para la enseñanza (Statistical knowledge for teaching). Su propuesta toma las aportaciones de Hill, Schilling y Ball (2004) quienes diferencian conocimiento común del contenido (common knowledge of content) del conocimiento especializado del contenido (specialised knowledge of content); de Ball, Thames y Phelps (2005) quienes refinaron y describieron en dos subcategorías el CDC de Shulman: conocimiento del contenido y del estudiante, y conocimiento del contenido y de la enseñanza.

Ball (2005, en Noll, 2007) define conocimiento común de contenido como "el conocimiento matemático esperado de algún adulto bien educado", que incluye la habilidad para "reconocer respuestas erróneas, descubrir definiciones imprecisas en los libros de textos, usar la notación correctamente y la habilidad para hacer el trabajo asignado a los estudiantes" (p.13). Ball define conocimiento especializado del contenido a "el conocimiento matemático y las técnicas necesarias de los maestros en su trabajo, más allá de que lo se espera que tenga un adulto bien educado", que incluye la habilidad para "analizar errores y evaluar ideas alternativas, dar explicaciones matemáticas y usar representaciones matemáticas, y ser explícito acerca del lenguaje y práctica matemática" (p.14). Ball define conocimiento de contenido y estudiantes y conocimiento de contenido y 
enseñanza, como el conocimiento que combina conocimiento de contenido y de los estudiantes o del contenido y enseñanza, respectivamente. Esta combinación de conocimiento incluye la habilidad para "interpretar el pensamiento incompleto de los estudiantes" (p.16).

El modelo que propone Burgess (2006) toma en cuenta los componentes de razonamiento y pensamiento estadístico de Wild y Pfannkuch (1999): reconocimiento de los datos (más que contar o depender de evidencia anecdótica), transnumeración (ser capaz de capturar apropiadamente los datos referidos a situaciones reales y el uso de representaciones de esos datos para conseguir extraer información de ellos), consideración de la variación (que supone establecer juicios a partir de los datos, describir patrones acerca de la variación y tratar de comprender los datos en relación al contexto), razonamiento con modelos estadísticos (desde los simples, como tablas y gráficos, a los complejos, así como ser capaz de encontrar patrones y resumir datos en múltiples formas) e integración de lo estadístico y contextual (tomando la relación entre los dos como un componente esencial del pensamiento estadístico). El análisis de Burgess representó un primer acercamiento desde la perspectiva de la educación estadística por identificar el marco teórico propio sobre el conocimiento del profesor de Estadística. Su modelo lo representa como se muestra en la Figura 2.1.

\begin{tabular}{|c|c|c|c|c|c|c|}
\hline & & & \multicolumn{4}{|c|}{ Conocimiento estadístico para la enseñanza } \\
\hline & & & \multicolumn{2}{|c|}{ Conocimiento del contenido } & \multicolumn{2}{|c|}{$\begin{array}{c}\text { Conocimiento didáctico del } \\
\text { contenido }\end{array}$} \\
\hline & & & $\begin{array}{l}\text { Conocimiento } \\
\text { común del } \\
\text { contenido }\end{array}$ & $\begin{array}{l}\text { Conocimiento } \\
\text { especializado } \\
\text { del contenido }\end{array}$ & $\begin{array}{l}\text { Conocimiento } \\
\text { del contenido y } \\
\text { estudiantes }\end{array}$ & $\begin{array}{c}\text { Conocimiento } \\
\text { del contenido y } \\
\text { enseñanza }\end{array}$ \\
\hline \multirow{8}{*}{ 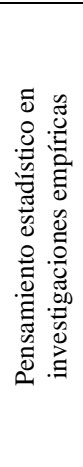 } & \multirow{5}{*}{$\begin{array}{c}\mathrm{P} \\
\mathrm{e} \\
\mathrm{n} \\
\mathrm{s} \\
\mathrm{a} \\
\mathrm{m} \\
\mathrm{i} \\
\mathrm{e} \\
\mathrm{n} \\
\mathrm{t} \\
\mathrm{O}\end{array}$} & $\begin{array}{l}\text { Necesidad de los } \\
\text { datos }\end{array}$ & & & & \\
\hline & & Transnumeración & & & & \\
\hline & & Variación & & & & \\
\hline & & $\begin{array}{l}\text { Razonamiento con } \\
\text { modelos }\end{array}$ & & & & \\
\hline & & $\begin{array}{lll}\text { Integración } & \text { de } & \text { la } \\
\text { estadística } & \text { y } & \text { el } \\
\text { contexto } & & \\
\end{array}$ & & & & \\
\hline & \multicolumn{2}{|c|}{ Ciclo investigativo } & & & & \\
\hline & \multicolumn{2}{|c|}{ Ciclo interrogativo } & & & & \\
\hline & \multicolumn{2}{|c|}{ Disposiciones } & & & & \\
\hline
\end{tabular}

Figura 2.1. Componentes del conocimiento del profesor en relación al pensamiento estadístico y de investigación (Burgess, 2006).

En el modelo, Burgess añade que es importante conocer cuánto utiliza el profesor los diferentes elementos que forman parte de la resolución de un problema en Estadística: el ciclo investigativo (problema, plan, datos, análisis y conclusión), el ciclo interrogativo (generar, buscar, interpretar, criticar y juzgar) y las disposiciones, tales como escepticismo e imaginación.

Según Burgess, el marco teórico que propone puede ser usado para investigar el conocimiento del profesor, así como el conocimiento de la enseñanza de la estadística. Burgess afirma que los componentes "conocimiento del contenido y estudiantes" y 
"conocimiento del contenido y enseñanza" quedan agrupados en el CDC de Shulman y señala que dada la diferencia entre el aprendizaje de las matemáticas y la estadística, algunos de los componentes de Ball y colaboradores pueden no ser apropiados para la enseñanza y aprendizaje de la Estadística.

En 2006 la International Commission on Mathematical Instruction (ICMI) y la International Association for Statistical Education (IASE) (ICMI/IASE, 2006) convocaron a investigadores, profesores e instituciones formadoras de profesores a participar en el Estudio Conjunto "Educación Estadística en la Matemática Escolar: Retos para la Enseñanza y la Formación del Profesor" para analizar la enseñanza de la estadística en los niveles escolares y hacer recomendaciones sobre cómo mejorar la formación de los profesores de Estadística para tener mayor éxito al formar estudiantes estadísticamente cultos. En su documento de discusión reconocen la necesidad de estudiar sobre el CDC e incluye, como parte de los tópicos del foco de atención del Tema 2, Actitudes, conocimientos concepciones y creencias de los profesores, con relación a la educación estadística. Las preguntas orientadoras fueron: ¿qué instrumentos de investigación y estrategias son útiles para determinar qué conocimiento de estadística y de enseñanza de la estadística tienen los profesores?, ¿qué conocimiento didáctico del contenido básico y qué competencias requieren los profesores para enseñar satisfactoriamente estadística en diferentes niveles escolares? y ¿cómo se relacionan estas competencias?

En 2007, Sorto presentó un trabajo cuyo propósito fue evaluar el conocimiento de futuros profesores de estadística a nivel secundaria a través del diseño de lecciones (lesson design). Para ella, dos aspectos importantes que se entrecruzan en el currículum para el aprendizaje y enseñanza de la Estadística son el conocimiento conceptual del contenido y el CDC. Señala que la pregunta que los formadores de profesores se hacen es ¿cómo medir estos aspectos del conocimiento que son diferentes pero están relacionados? Sorto afirma que la evaluación del conocimiento conceptual ha sido estudiado y que existe muchas sugerencias al respecto; sin embargo, la evaluación del CDC todavía está en una etapa de desarrollo, especialmente en el área de la Estadística.

Igual en 2007, Noll presentó su tesis doctoral en educación matemática, la cual tuvo como objetivo explorar el conocimiento estadístico para la enseñanza (statistical knowledge for teaching) de maestros auxiliares (teaching assistant) de la universidad. Sustentó su trabajo en la investigación sobre el conocimiento del profesor y se basó en el constructo de conocimiento matemático para la enseñanza (Mathematical Knowledge for Teaching, MKT) de Ball, Lubienski y Mewborne (2001). Noll menciona que el concepto del CDC impactó significativamente el trabajo desarrollado por Ball y colaboradores y representó el punto de partida para la introducción del constructo del MKT, dado que Shulman (1986b, p.9) hace referencia del CDC como una dimensión del conocimiento de la materia para la enseñanza. En su tesis, Noll también hace referencia al "conocimiento estadístico para la enseñanza" como lo hicieron Sorto y White (2004) y Burgess (2006), y aunque no utiliza el CDC como teoría para estudiar el conocimiento del profesor, lo incluye como referente.

Finalmente, Shaughnessy (2007) en su capítulo sobre la "Investigación sobre el Razonamiento y Aprendizaje de la Estadística" en el Second Handbook of Research on Mathematics Teaching and Learning, sobre las recomendaciones de futuras 
investigaciones, afirma que es necesario estudiar ¿cuál es el conocimiento estadístico necesario para la enseñanza? Sugiere que es importante averiguar que así como existe un conocimiento especial en ciertas áreas de las matemáticas (ej. álgebra y geometría), constituido por conocimiento sobre los errores y dificultades de los estudiantes, ejemplos y contraejemplos y tipo de conocimientos que hacen más efectivo y eficaz la enseñanza, es importante explorar ¿qué es necesario para enseñar satisfactoriamente Estadística? En este sentido hace referencia a los trabajos de Deborah Ball y colaboradores (Mathematical Knowledge for Teaching, MKT) y de Lee Shulman (Pedagogical Content Knowledge, PCK).

Como se puede apreciar, a través de estos trabajos y con el transcurrir de los años, cada día ha tomado mayor relevancia el estudio del CDC en Estadística. Primero, fue reconocido por diferentes autores, como una teoría para investigar sobre el conocimiento del profesor. Posteriormente, se hicieron algunos estudios (Watson, 2001 y 2005; Sorto y White, 2004) utilizando principalmente el cuestionario como instrumento de recogida de información. Después Burgess (2006) hace un análisis de las diferentes teorías que existen para analizar el conocimiento del profesor y presenta una propuesta para estudiar el conocimiento estadístico para la enseñanza. En los últimos años, el CDC ha cobrado mayor relevancia de tal modo que existe un interés ampliamente reconocido por el ICMI/IASE (2006) y Shaughnessy (2007) por estudiar su naturaleza conceptual, metodológica y explorar el CDC específico para la enseñanza de la Estadística.

\subsubsection{El estudio del conocimiento didáctico del contenido en Estadística}

Recientemente, en el 2008 en Monterrey (México) se celebraron tres congresos internacionales de amplio reconocimiento:

a. el Estudio Conjunto "Educación Estadística en la Matemática Escolar: Retos para la Enseñanza y la Formación del Profesor" convocado por el ICMI/IASE (ICMI Study and IASE Round Table Conference) del 30 de junio al 4 de julio,

b. el 11th International Congress on Mathematical Education (ICME) del 6 al 13 de Julio, y

c. el Encuentro Latinoamericano de Educación Estadística (ELEE), los días 4 y 5 de julio.

Con base en las contribuciones de las diferentes investigaciones presentadas en estos congresos, se encontraron siete trabajos relacionados con el CDC y Estadística: Godino, Batanero, Roa y Wilhelmi (2008), Watson y Callingham (2008), Burgess (2008), Chick y Pierce (2008) y González y Pinto (2008).

Godino, Batanero, Roa y Wilhelmi (2008) presentan un modelo de CDC con un ciclo formativo para incrementar simultáneamente el conocimiento estadístico y el conocimiento pedagógico. En este ciclo, según Godino, et al (2008) a los profesores primero se les dio un proyecto estadístico para trabajar del cual llevaron a cabo un análisis didáctico. Una guía de análisis, basada en la noción de una didáctica apropiada (didactical suitability), ayudó a incrementar las competencias relacionadas con los diferentes componentes del CDC y su habilidad para llevar a cabo el análisis didáctico. Al mismo 
tiempo proporcionó al formador de profesores información respecto al conocimiento previo de los futuros profesores y su aprendizaje.

Godino, et al (2008) identifican como componentes del CDC:

a) Epistemología: reflexión epistemológica sobre el significado de los conceptos enseñados (ej. reflexión sobre diferentes significados de aleatorización).

b) Cognición: predicción del aprendizaje de los estudiantes, errores, obstáculos y estrategias.

c) Recursos de enseñanza y técnicas: experiencia con buenos ejemplos de situaciones de enseñanza, herramientas didácticas; capacidad crítica para analizar libros de textos, documentos curriculares y adaptar el conocimiento estadístico a diferentes niveles de enseñanza.

d) Motivar: habilidad para estimular el interés de los estudiantes y tomar en cuenta sus actitudes y creencias.

e) Interacción: habilidad para crear buenas comunicación en el salón de clases y usar la evaluación como una forma para guiar la instrucción.

Al comparar estos componentes con los de Shulman se puede apreciar que la propuesta de Godino, et al (2008), va más encaminada a la formación de profesores que al conocimiento didáctico del contenido en sí mismo, es decir, más como modelo para la formación de profesores que como objeto de estudio. Proponen un conjunto de componentes que en su denominación son diferentes a las de Shulman. No obstante, se puede observar que la Epistemología incluye elementos del conocimiento del contenido a enseñar; los Recursos de enseñanza y técnicas, elementos del conocimiento de las estrategias y representaciones instruccionales; y la Cognición, elementos del conocimiento del estudiante. Al parecer, los componentes Motivar e Interacción son dos nuevos elementos del CDC que aporta la propuesta de Godino, et al (2008).

Para introducir este conocimiento pedagógico, Godino, et al (2008) desarrollaron una "Guía para Analizar y Evaluar la Didáctica Apropiada" (Guide to Analyse and Evaluate the Didactial Suitability", GAEDS por sus siglas en inglés), donde sugieren seis dimensiones para el análisis didáctico: la epistemológica, lo cognitivo, los recursos, lo emocional, la interacción y lo ecológico. Esta guía sirvió como instrumento para desarrollar y evaluar el CDC de los futuros profesores.

Analizaron el conocimiento estadístico y el CDC de 55 futuros profesores de primaria, previo a tomar 45 horas del curso "Curriculum en Matemáticas en Educación Primaria" impartido en segundo año en la Facultad de Educación a nivel universitario. El curso es principalmente práctico, donde a los futuros profesores se les da una breve introducción a algunos materiales didácticos que resumen el CDC en las diferentes áreas matemáticas. Posteriormente se les presentó el análisis didáctico y la GAEDS para evaluar la idoneidad de un proceso de enseñanza cuyo tema fue "Revisa tus intuiciones acerca del azar". Después de recoger los datos y trabajar en pequeños grupos se les solicitó completar el análisis en casa y escribir un informe con una discusión completa del proyecto, incluyendo todos los gráficos estadísticos y procedimientos que usaron y sus conclusiones respecto a las intuiciones de las personas acerca del azar y la habilidad para estimular una 
secuencia aleatoria. Finalmente, los informes se presentaron en clase con el objetivo de debatir acerca del CDC necesario para la enseñanza de la Estadística en la escuela primaria, la estadística y las características didácticas de cada proyecto.

Para el análisis de los informes, los autores agruparon en cuatro categorías los conocimientos estadísticos y competencias de los profesores, del 1 al 4, siendo cuatro el nivel óptimo esperado. En el nivel 1 se clasificó la mayoría de los futuros profesores (60\%) y en el nivel 4 únicamente el 5.5\%. También presentaron un análisis a partir de las seis dimensiones de la GAEDS, calificando cada una en una escala de 0 a 5. Los promedios obtenidos de cinco de estas dimensiones fueron: Ecológico (1.29), Interaccional (1.95), Emocional (1.95), Epistémico (2.03) y Cognitivo (2.16). Se pudo apreciar que para los futuros profesores el análisis didáctico resultó difícil.

Los resultados señalan que los futuros profesores tienen dificultad en aplicar la GAEDS y en valorar la idoneidad de un proceso didáctico, lo cual es razonable dada la escasez de tiempo dedicado a su formación y la complejidad del CDC. Sin embargo, Godino, et al (2008) afirman que la GAEDS es una herramienta útil para introducir reflexiones sistemáticas sobre diferentes facetas que afectan a la enseñanza y aprendizaje de la Estadística. Su propuesta representa una estrategia para la formación del CDC de futuros profesores.

Watson y Callingham (2008), exploraron el CDC de 42 profesores (20 del nivel Secundaria y 22 de Primaria) de tres diferentes Estados de Australia, con el objetivo de investigar el conocimiento que tienen del contenido, y su reflexión sobre el conocimiento que tienen los estudiantes acerca de la Estadística y el CDC que utilizan a partir de las respuestas de éstos. Se les administró el Instrumento de Perfiles del Profesor (Teacher Profile Instrument) basado en el cuestionario de Watson (2001). Previamente, a los profesores se le solicitó información sobre sus antecedentes en matemáticas, su experiencia en enseñanza de la Estadística y los niveles escolares de experiencia docente.

Para su investigación, únicamente consideraron los 12 ítems que estaban principalmente dirigidos a explorar el CDC del profesor. Para diseñar los primeros ocho ítems, utilizaron tres artículos actuales publicados en medios de comunicación (revista o periódico) en el contexto de Australia. Se les solicitó a los profesores: predecir el rango de respuestas de sus estudiantes a partir de ciertas preguntas específicas y explicar cómo pueden utilizarlas en el, incluyendo cómo pueden intervenir para dirigir o corregir las respuestas inapropiadas de sus estudiantes. Los tópicos fueron: a) la probabilidad de ganar a partir de títulos de las noticias sobre eventos deportivos en artículos publicados en revistas o periódicos, b) un gráfico circular que sumaba el $128.5 \%$ en un artículo sobre comerciantes minoristas, c) un gráfico sobre asociación, d) unas preguntas sobre indemnización extraído de un artículo sobre la relación entre muerte por accidentes de auto y muerte por infarto.

La segunda parte del instrumento estaba formada por ítems en los que los profesores debían reaccionar sobre las respuestas que los estudiantes dieron a preguntas reales. Las opciones de respuesta mostradas a los profesores fueron de diferentes niveles de comprensión del tópico. En la primera, se trataba de predecir el color de la pelota extraída 
de una caja entre dos con distinta cantidad de pelotas pero la misma proporción entre dos diferentes colores. En el resto de las preguntas se usó una tabla de doble entrada acerca de diferentes situaciones como la relación entre el cáncer pulmonar y el hecho de ser fumador donde no se mostraba ninguna asociación.

Las respuestas a cada ítem fueron codificadas del 0 al 4, siendo el significado de cada código el siguiente: $0=\sin$ respuesta, $1=$ no usó el contenido matemático del problema, $2=$ usa una simple idea general o ideas del problema, $3=$ usa dos o más ideas sin relacionarlas y $4=$ la discusión incluye referencias sobre probabilidad y realiza una interpretación correcta usando ejemplos específicos. A partir del Modelo de Crédito Parcial Lineal (Partial Credit Model, PCM) y del programa Quest, los profesores fueron clasificados en tres diferentes grupos: bajo, medio y alto nivel de CDC.

Los resultados de Watson y Callingham (2008), señalan que en el nivel "bajo", los profesores sólo sugerían respuestas parcialmente correctas de los alumnos a cada pregunta. En el nivel "medio" los profesores fueron capaces de sugerir tanto respuestas correctas como incorrectas para los gráficos, que relacionaron la indemnización de muerte por accidente automovilístico y por infarto. Asimismo, lograron identificar errores y dieron algunas sugerencias para mejorar el gráfico circular. Sin embargo, sólo aportan ideas generales simples para utilizarlas en el aula con los estudiantes. En el nivel "alto" los profesores siguen teniendo dificultad para lograr puntajes altos, especialmente de las preguntas relacionadas con las respuestas de los estudiantes y para planear actividades de intervención en el aula. Sin embargo, mostraron una clara tendencia en centrarse sobre conceptos matemáticos en el razonamiento de los problemas y sugirieron tantas respuestas correctas como incorrectas de los estudiantes sobre los tópicos. Watson y Callingham (2008) concluyen que su estudio es un intento inicial por caracterizar el CDC de los profesores con respecto a los conocimientos requeridos para enseñar Estadística.

Burgess (2008) se interesó en explorar ¿qué conocimiento del profesor es necesario para enseñar Estadística usando investigaciones estadísticas en Primaria? Para ello, a través del estudio de casos de corte cualitativo, comparó el conocimiento de dos profesores noveles de escuelas Primaria (Linda y Rob), ambos en su segundo año de docencia y titulado a través de un programa de formación para profesor. El autor se basó el modelo de Burgess (2006) para examinar el conocimiento del profesor en Estadística sobre tres pilares: el CDC de Shulman (1986b), el conocimiento del profesor de matemáticas de Hill, Schilling y Ball (2004) y el modelo de pensamiento estadístico de Wild y Pfannkuch (1999).

A ambos profesores se les proporcionó una unidad de enseñanza con varios conjuntos de datos multivariados. El primer conjunto de datos tenía cuatro variables categóricas, mientras que el resto de los conjuntos de datos aunque incluían también cuatro variables, dos al menos debían ser numéricas. Los datos estaban recogidos en un conjunto de 24 cartas de datos que podían manipularse y ordenarse para descubrir información sobre esos datos. En una reunión inicial con el investigador, las unidades fueron discutidas con los profesores, y se señalaron las principales ideas estadísticas a considerar como el uso del ciclo investigativo. Después, los profesores desarrollaron su propia secuencia de la lección. El desarrollo de cada una de ellas fue videograbadas editándose un video de cada una 
centrado en determinados episodios ocurridos. Cada video fue mostrado al profesor y la discusión y análisis generados fue audiograbada. Las grabaciones de video y audio fueron analizadas en relación a las celdas del marco teórico de Burgess (2006) recogido en la Figura 2.2.

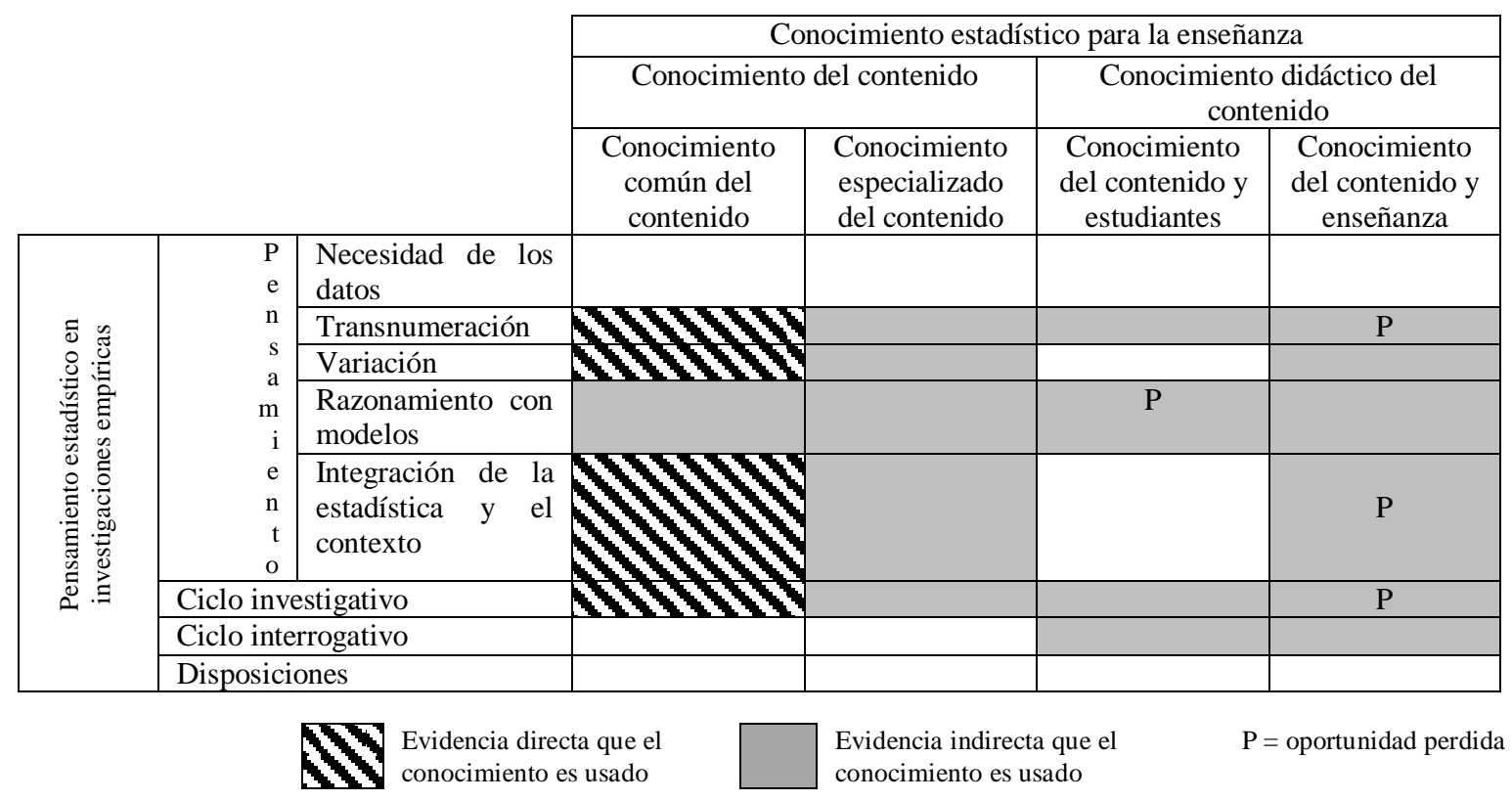

Figura 2.2. Perfil del conocimiento estadístico para la enseñanza de Linda, según Burgess (2008)

Según Burgess, por cada profesor es posible identificar uno o más "incidentes" (hechos) que surgen de dentro de las lecciones del profesor o de las entrevistas realizadas. En algunos casos, los incidentes revelaron una situación en la cual un aspecto del conocimiento debería ser usado pero no fue así; en cuyo caso, el incidente fue codificado sobre la celda como una oportunidad perdida, mostrado por una "P" (ver Figura 2.2.). Por otro lado, las celdas en blanco en los perfiles indican que no hubo evidencia sobre el uso de conocimiento en relación a esas celdas durante algunas de las lecciones.

Entre sus principales hallazgos, Burgess indica que el conocimiento que usa Linda en la enseñanza es relativo al pensamiento estadístico. Únicamente perdió cuatro oportunidades cuando podía haber usado el conocimiento no fue así. Estas oportunidades perdidas fueron la ausencia de verificación de la validez de los enunciados obtenidos de una tabla de doble vía por parte de los estudiantes, y que no estimuló explícitamente a los estudiantes a pensar acerca de problemas reales. Por su parte, Rob presentó un perfil muy diferente con 14 oportunidades perdidas para usar el conocimiento. Por ejemplo, perdió oportunidades en todas las categorías de conocimiento relacionadas con la transnumeración; con la mayoría de las categorías relacionadas al ciclo interrogativo y de los componentes relacionados con el CDC: conocimiento del contenido y estudiantes y conocimiento del contenido y enseñanza. Muchos de los errores de Rob son atribuidos a su falta de conocimiento del estudiante. Por ejemplo, no es capaz de ayudar a un estudiante a responder una pregunta, no motiva al estudiante a analizar datos que podrían promediarse o para qué podrían usarse los datos. 
Burgess (2008) concluye que el marco teórico usado fue útil para determinar qué conocimiento necesitaba el profesor durante la enseñanza de las investigaciones estadísticas. Asimismo, señala que es útil para conocer el perfil de conocimiento del profesor, pudiendo hacer un análisis vertical por cada componente del conocimiento estadístico necesario para la enseñanza (incluyendo el CDC); o bien horizontal, por cada componente del pensamiento estadístico. Burgess sugiere que la formación de profesores no puede centrarse solamente sobre un tipo de conocimiento sino debe integrar todos los aspectos simultáneamente. El modelo que propone es útil para lograr esta visión integradora dado que la mayoría de los profesores no han experimentado el aprendizaje de la estadística a través de investigaciones. Sugiere la necesidad de que los profesores aprendan a enseñar a partir de la práctica con alumnos y mediante observaciones sobre cómo éstos aprenden de las investigaciones estadísticas.

Por otra parte, Chick y Pierce (2008) reportan los resultados de un breve estudio con 27 estudiantes para profesor sobre sus actitudes, conocimientos, concepciones y creencias en relación a la educación estadística, así como su capacidad para reconocer e implementar affordances a través de ejemplos estadísticos del mundo real. El marco de referencia que presentan se sustenta en la necesidad de que los profesores de Estadística deben tener tanto conocimiento estadístico como conocimiento pedagógico relacionado con la educación estadística, de tal modo que incorporen el análisis conceptual entre las rutinas de cálculo de valores o fórmulas estadísticas. Afirman que la enseñanza de la Estadística requiere de un apropiado CDC en el área. Plantean dos preguntas en relación al CDC de los profesores: ¿qué CDC básico y qué competencias necesitan los profesores para enseñar Estadística a niños de Primaria? y ¿qué instrumentos de investigación son útiles para determinar el CDC de estadística de los estudiantes para profesor de escuelas Primarias?

Los 27 estudiantes para profesor estaban matriculados en un curso de educación matemática, habían realizado más de tres semestres de cursos en educación matemática sobre pedagogía. También habían estudiado el concepto de azar y el análisis de datos en su primer año y diez meses antes de la investigación habían visto el tema de comprensión gráfica basado en los niveles cognitivos de Curcio (2001). Se les pidió que imaginaran que tenían que trabajar sobre "el medio ambiente" con niños de $6^{\circ}$ grado (11 años de edad) y debían planificar en parejas una lección para enseñar a los niños algunos aspectos de los datos estadísticos usando información local sobre el almacenamiento del agua.

Previamente a la planificación de las lecciones identificaron individualmente qué datos estadísticos sobre el tema deberían ser considerados y anotaron algunas preguntas que podrían hacer a los niños. Esta actividad formó parte de un taller de 110 minutos en el que los estudiantes para profesor escribieron sus respuestas y se recogieron las planificaciones de la lección para su análisis. Además se utilizó el instrumento de Garfield (1996) con diez ítems de STARC-CHANCE Abbreviated Scale (SCAS), con una escala Likert de cinco puntos para explorar las actitudes y creencias de los estudiantes para profesor acerca de la Estadística. Se añadieron siete preguntas adicionales relacionadas con la enseñanza de la Estadística en Primaria y la experiencia de los estudiantes en matemáticas.

Sobre los resultados relativos al CDC de los estudiantes para profesor, Chick y Pierce (2008) reconocieron que las planificaciones de lección escritos no proporcionan un 
completo retrato del $\mathrm{CDC}$, que son los aspectos más fácilmente revelados en la enseñanza práctica real. No obstante, Chick y Pierce señalan que los conceptos que debían ser enseñados se incluyeron en las planificaciones. Tanto los tipos de actividades planificadas y el conocimiento que demostraron tener sobre los estudiantes reveló mucho acerca de su CDC. Cerca de la mitad de las parejas reconocieron la importancia de ayudar a los estudiantes en el desarrollo de los niveles de comprensión de Curcio. Asimismo, por lo menos 10 de las planificaciones mencionaron conceptos o ideas que no fueron claramente articuladas en las lecciones.

Chick y Pierce (2008) piensan que la tarea de planificar lecciones pueden ser útiles como herramienta de investigación para identificar el CDC, aunque no sea la única. Afirman que las lecciones en sí mismas pueden ser usadas para examinar fortalezas y debilidades del CDC del profesor, así como demostrar si los profesores son capaces de resaltar las ideas estadísticas usando recursos de forma efectiva y válida. Finalmente, concluyen que su estudio muestra que se necesitan trabajar más con los profesores de Primaria para ayudarles a desarrollar el conocimiento estadístico y su CDC.

Otra investigación que hace referencia al CDC en Estadística es el de González y Pinto (2008). El objetivo del estudio fue conocer las formas de conocimiento y las concepciones de cuatro estudiantes para profesor de matemáticas de Secundaria respecto a la enseñanza de la representación gráfica en Estadística y la relación que guardan su concepción de la matemática con la de Estadística. El trabajo de González y Pinto (2008) se basa en el estudio de dos dimensiones del conocimiento del contenido a enseñar y del conocimiento de las estrategias y representaciones instruccionales del CDC, respectivamente: las concepciones del tópico y las concepciones de la enseñanza y aprendizaje del tópico (ver dimensiones e indicadores del CDC en Pinto y González, 2006).

A través del estudio de cuatro casos, de corte cualitativo, y usando la metodología de Llinares (2000) y Sánchez y Llinares (2003) en el estudio del CDC, así como los niveles cognitivos de representación gráfica de Curcio (1987) y Friel, Curcio y Bright (2001), les pidieron a los estudiantes: 1) clasificar 20 problemas de representación gráfica, que fueron seleccionados de diferentes libros de textos utilizados por estudiante de Secundaria y que incluían diferentes gráficos (ej. histogramas, circular, barras, tallo y hoja) según los diferentes niveles cognitivos de Curcio (1987): leer datos, leer entre datos y leer más allá de los datos; 2) análisis específico de cinco problemas de representación gráfica, seleccionados entre los 20 anteriores con el propósito de explorar las razones por las que los futuros profesores incluyen un problema para enseñar la representación gráfica, qué entienden por cada uno, cómo enseñarían la representación gráfica a partir de ese problema y cómo ayudarían a sus estudiantes a que aprendan; finalmente, 3) una entrevista individual semiestructurada, con el propósito de ampliar las respuestas de los futuros profesores, así como obtener información sobre su formación matemática y su concepción de la matemática y su enseñanza.

González y Pinto (2008) encontraron que estos alumnos perciben la enseñanza de manera similar a la expresada por Sánchez y Llinares (2003) como transmisión de contenidos, manejo de instrumentos útiles y como comunicación, de forma que el aprendizaje, aunque requiera esfuerzo personal, también está ligado a una buena 
transmisión por parte del profesor o la satisfacción personal del estudiante. Valoran la utilidad de la estadística en contextos naturales y la necesidad de que la formación en Estadística esté centrada en la resolución de problemas en la vida diaria.

No obstante, aunque los futuros profesores consideran que la Estadística forma parte de las matemáticas, es fácil de aprender y no perciben alguna dificultad asociada con su aprendizaje, mostraron un conocimiento precario de estadística y un escaso o nulo conocimiento sobre el tratamiento de representación gráfica. Desconocen los diferentes niveles cognitivos asociados a la representación gráfica de Curcio (1987), así como los componentes y procesos para su interpretación. La enseñanza, de acuerdo a su concepción, está centrada en la construcción de gráficos, el análisis de conceptos y en la aplicación de algoritmos y fórmulas. González y Pinto (2008) concluyen que los futuros profesores necesitan una formación específica sobre diferentes representaciones gráficas, sus características, dificultades y su valor en el proceso de enseñanza y aprendizaje. Su trabajo constituye un primer referente para comprender el CDC de los futuros profesores a partir del estudio de las concepciones.

Como se puede apreciar, actualmente hay un claro y decidido interés en estudiar el CDC en Estadística. Los trabajos que se expusieron en 2008 reflejan un esfuerzo importante por conocer el CDC, principalmente de los estudiantes para profesor (de Primaria y Secundaria). En ellos se utilizaron como instrumentos de recogida de información los cuestionarios, la GAEDS a partir de diseño de proyecto, la planificación de una lección y la clasificación y análisis de problemas específicos. Se trata de explorar fundamentalmente el conocimiento que tienen los profesores de la Estadística de los estudiantes, así como sus concepciones sobre la Estadística y su enseñanza y aprendizaje mediante el análisis cuantitativo de datos a excepción de los trabajos de Pinto y González (2008b) y Pinto (2008), que presentan los resultados preliminares de su tesis doctoral, se encontraron sólo dos trabajos de corte cualitativo a través del estudio de casos: González y Pinto (2008) y Burgess (2008), el primero sobre el tema de la representación gráfica.

Por otro lado, las conclusiones del grupo de trabajo del Tema 2 (actitudes, conocimientos concepciones y creencias de los profesores, con relación a la educación estadística) del ICMI/IASE celebrado en 2008, ponen de manifiesto la complejidad del estudio y comprensión del CDC. Concluyen que es necesario e importante utilizar múltiples metodologías para comprender más sobre su naturaleza conceptual, metodológica y las implicaciones que tiene el CDC para la enseñanza de la Estadística.

\subsection{LA REPRESENTACIÓN GRÁFICA COMO LÍNEA DE INVESTIGACIÓN}

Durante los últimos 15 años, hemos sido testigos de un movimiento pedagógico en educación estadística encaminado a cambiar el enfoque de enseñanza, de la separación de la teoría con la práctica y de uso recetas, hacia el pensamiento estadístico, el uso de datos genuinos, la comprensión conceptual y el aprendizaje activo (Chance y Garfield, 2002). Su origen fue la reforma de la educación estadística (Moore, 1997) que afectó a la enseñanza y aprendizaje en todos los niveles de educación (Garfield, 2003 y Petocz y Reid, 2003), particularmente en Estados Unidos. Una reforma que, según Moore (1997), se centró sobre los contenidos y la pedagogía, pasando de estar el énfasis en el cálculo y procedimientos a 
centrarse en el razonamiento y el pensamiento estadístico. Uno de los documentos que recogió y explicitó esta nueva forma de conceptuar la enseñanza de la Estadística fue publicado por la NCTM (1991) que estableció estándares, pautas y recomendaciones, dirigidas a los profesores, sobre la manera de afrontar la enseñanza y aprendizaje de la Estadística en la escuela tanto en términos genéricos, como en cada tópico específico, como es el caso de la representación de datos.

La NCTM (1991) resaltó, entre otros aspectos, que las investigaciones deberían centrarse en las presentaciones de datos y promover una visión más aplicada del análisis de datos (Shaughnessy, Garfield y Greer, 1996). En este sentido, se preconizaba que los alumnos se involucraran en la recogida, organización y descripción de los datos y fueran capaces de construir, leer e interpretar gráficas, así como analizar tendencias y proponer conjeturas y predicciones a partir de los datos (NCTM, 1991). Así, la Estadística y el análisis de datos se incorporaron como un componente principal de la matemática escolar durante los 90s (NCTM, 1991 y 2000). Este cambio creó una enorme necesidad de programas para el desarrollo profesional de profesores en torno al análisis de datos tanto para aquellos profesores que no tuvieran experiencia con los problemas y situaciones de análisis de datos que tenían que enseñar, hasta los profesores con una amplia experiencia docente.

El incremento de los contenidos de Estadística en las escuelas y los colegios de educación superior ha conducido a varios intentos de estandarizar el currículo en Estadística. Más recientemente, en 2007 la American Statistical Association (ASA) publicó el reporte denominado Pautas para la Evaluación e Instrucción en Educación Estadística (Guidelines for Assessment and Instruction in Statistics Education, GAISE por sus siglas en inglés) desde preescolar hasta universidad. El reporte GAISE tiene su fundamento en los principios y estándares de la NCTM (2000) y es un intento por complementar las recomendaciones expresadas en este documento (Dosey, Halvorson, McCrone, 2008). El reporte GAISE permite desarrollar los conocimientos estadísticos en tres niveles de desarrollo (A, B, C) dependiendo del nivel escolar. Cada nivel debe desarrollarse a través de cuatro procesos basados en la realización de breves investigaciones estadísticas en el contexto escolar que incluyen; formular preguntas, colectar datos, analizar datos e interpretar resultados. El reporte GAISE expone seis recomendaciones (tomadas de Cobb, 1992) para enseñar un curso introductorio de Estadística, pero que pueden aplicarse a cualquier curso independientemente del nivel escolar:

1. Enfatizar la alfabetización estadística y el desarrollo del pensamiento estadístico.

2. Usar datos reales.

3. Hacer hincapié en la comprensión conceptual más que mero conocimiento y procedimientos.

4. Sostener un aprendizaje activo en el aula.

5. Usar la tecnología para desarrollar conceptos y analizar datos.

6. Usar evaluaciones que mejoren y evaluar el aprendizaje de los estudiantes.

Este desarrollo del currículo de Estadística a nivel internacional, la investigación sobre el aprendizaje y razonamiento estadístico ha cobrado más fuerza e interés entre los investigadores, profesores de Estadística y responsables de la formación de profesores. 
Según Shaughnessy (2007), la mayoría de las investigaciones recientes en educación estadística tratan el conocimiento del estudiante y su razonamiento estadístico. Según este autor, los trabajos se han centrado en el análisis de varios conceptos tales como medidas de tendencia central (media, mediana), variación, muestreo, encuestas, comprensión gráfica y tecnología y aprendizaje.

La representación de datos supone la selección apropiada de gráficos, la construcción e interpretación de tablas y gráficas, el resumen gráfico para variables simples, tanto cuantitativas como categóricas, el papel de los valores atípicos, el reconocimiento de formas/tendencias de datos (Garfield, delMas y Chance, 2003). Todo esto demanda un conjunto de tareas a nivel de alfabetización estadística, que como señalan Friel, Curcio y Bright (2001) implica tener la habilidad para leer y comprender gráficos y tablas estadísticas y que tiene mucha utilidad, tanto como forma de desarrollo del pensamiento crítico del estudiante, como objeto de alfabetización de los ciudadanos y como aprendizaje necesario a desarrollar en la escuela. Esta habilidad resulta más necesaria en la sociedad actual dado que el procesamiento de la información presentada en periódicos, revistas, reportes comerciales y en TV es dependiente de la habilidad lectora para la comprensión de gráficos (Monteiro y Ainley, 2006; Curcio, 1989).

Por consiguiente, el significado del análisis de datos adquiere una gran relevancia en la matemática escolar. Su actual significado incluye una dependencia de las representaciones gráficas (Shaughnessy, Garfield y Greer, 1996) reflejada en la percepción y uso de presentación de datos cuantitativos en nuestra sociedad altamente tecnológica (Friel, Curcio y Bright, 2001). Como señalan Friel y Bright (1996), el uso de gráficos está relacionado con el análisis de datos del proceso de investigación estadística.

La representación gráfica $(\mathrm{RG})$ es un concepto de interés en todos los niveles escolares de la educación estadística. Un gráfico estadístico es un "constructo desarrollado en un contexto cultural específico que interviene como mediador en la interpretación de los datos... una actividad relacionada con un complejo rango de elementos y procesos" (Monteiro y Ainley, 2006) y es considerado como una herramienta de razonamiento para aprender algo nuevo acerca del contexto que representa, obteniendo nueva información o aprendizaje de los datos (Pfannkuch, 2006). Los gráficos son esenciales para la representación, reducción y análisis de datos en el razonamiento y pensamiento estadístico (Shaughnessy, 2007).

Los gráficos (graphs) o representaciones gráficas (graphical displays) o diagramas (charts), utilizados como sinónimos por Henry (1995), se basan en datos cuantitativos y tienen un doble propósito: visualizar la presentación de datos y estudiar y analizar la naturaleza de los datos. Todas las fases del tratamiento estadístico (examinar y describir los datos, analizar e interpretar, y resumir los datos) o del razonamiento y pensamiento estadístico, requieren del apoyo gráfico, el cual resulta en la mayoría de los casos esencial, tal y como ha sido suficientemente reconocido por diversos autores (ej. Curcio, 1989; Henry, 1995; Pittenger, 1995; Friel, Curcio y Bright, 2001; Pfannkuch y Rubick, 2002; Garfield, 2003 y Shaughnessy, 2007). 
Para los matemáticos, el gráfico es "una valiosa ayuda en la solución de problemas aritméticos y algebraicos, la solución de fórmulas matemáticas y la representación de relaciones" (Arkin y Colton, 1940, p.4 en Curcio, 1989). Para los educadores estadísticos, según Curcio (1989), el gráfico es una ayuda para clarificar, organizar y resumir información cuantitativa encontrada en periódicos, revistas y anuncios.

La investigación sobre la RG en educación estadística en los últimos años ha tomado un mayor impulso. Esto se refleja es estudios actuales como los de Chick, 2004; Pfannkuch, Budgett, Parsonage y Horring, 2004; Sorto y White, 2004; Wu, 2004; delMas, Garfield, Ooms, 2005; Carrión y Espinel, 2006; Monteiro y Ainley, 2006 y 2007; Aoyama, 2006 y 2007; Espinel y Bruno, 2008; y Batanero, Arteaga y Ruiz, 2009; que expresan insistentemente su importancia, sus ventajas, su relación con subsiguientes fases del pensamiento estadístico y en las investigaciones que buscan comprender la naturaleza del proceso de su enseñanza y aprendizaje, tanto desde la perspectiva del profesor como del alumno. A continuación, se resumen algunos de los argumentos que justifican el interés que se tiene por el estudio de la RG en Estadística:

a. los gráficos proporcionan un significado para la comunicación y clasificación de datos; permiten la comparación de datos y presentan relaciones matemáticas que no se reconocerían fácilmente a partir, exclusivamente, de su forma numérica (Curcio, 1989);

b. los gráficos tiene un rol esencial en el análisis de datos y su presentación (Tukey, 1977; Wainer y Thissen, 1993; Cleveland, 1994); evitan "meter la pata" en la selección, análisis e interpretación de estadísticos (Peden, 2001); son herramientas para detectar las características en los datos (Friel, Curcio, Bright, 2001);

c. ayudan a descubrir resultados inesperados, confirmar los resultados esperados, desarrollar el plan necesario para el análisis de datos, resumir los resultados de una investigación y examinar los datos para estudiar las tendencias y otros efectos que el uso exclusivo de la Estadística descriptiva e inferencial puede olvidar (Pittenger, 1995);

d. están pensados para promover la comunicación de conceptos e ideas complejas (McKenzie y Padilla, 1986); se definen como cuadros o esquemas que intentan transmitir información acerca de los números y sus relaciones (Friel, Curcio, Bright, 2001);

e. los estudiantes necesitan aprender los fundamentos de la construcción de los gráficos usados en la ciencia (Pittenger, 1995), con el objeto de evitar los chartjunk (Tufte, 1983), definidos como elementos de un gráfico que no son esenciales para la representación de datos, criterios engañosos o modelos ineficientes de técnicas gráficas como, por ejemplo, software (ej. hojas de cálculo y programas gráficos) que proporciona misteriosos embellecimientos pero superfluos para la presentación de información inequívoca (ej. ofrecen muchas opciones, incluyendo ejes en tercera dimensión, color, pictogramas, y 
otras decoraciones no esenciales; formatos gráficos que son difíciles para interpretar);

f. los gráficos presentan conceptos de una manera concisa, que de forma escrita requería una excesiva descripción. Ofrecen a menudo una riqueza de información dentro de una pequeña cantidad de espacio (Weintraub, 1967; en McKenzie y Padilla, 1986). Bien diseñados, además, ayudan al investigador a presentar datos complejos de una manera coherente y memorable (Pittenger, 1995);

g. los gráficos son una importante herramienta para los investigadores y para la práctica de la ciencia, tanto porque resumen grandes cantidades de datos de forma económica como porque constituyen la mejor herramienta para presentar la covariación entre medidas continuas (Bowen y Roth, 1998);

h. la habilidad para interpretar los datos y realizar inferencias cuando aparecen presentados en forma gráfica es una habilidad de orden superior esencial en nuestra sociedad tecnológica (Curcio y Artzt, 1997 en Sharma, 2006);

i. los gráficos estadísticos se presentan con mucha frecuencia en artículos científicos y son una forma común de comunicación social, por lo que su inclusión adquiere un valor importante en el currículo escolar (Carrión y Espinel, 2006) y en la actualidad, los medios impresos de comunicación usan comúnmente gráficos para ilustrar argumentos periodísticos (ej. periódicos, revistas, boletines, reportes) que proporcionan nueva información al público en general (Monteiro y Ainley, 2006);

j. la representación de datos y su interpretación es la primera categoría de la alfabetización cuantitativa (quantitative literacy) a desarrollar en los estudiantes, $\mathrm{y}$ ha sido reconocido como uno de los aspectos fundamentales de la alfabetización científica que todo ciudadano debe tener en el Siglo XXI (Aoyama, 2006; con base en la NCTM y el informe PISA en OCDE, 1999); y

k. las gráficas son justamente representaciones visuales de la relación entre dos o más variables, y por tanto contienen un gran potencial para desarrollar la visualización matemática y el pensamiento visual (Dolores, 2008).

Por estas razones, los profesores deben desarrollar un CDC que les ayude a diseñar actividades para incrementar la comprensión conceptual del gráfico estadístico en sus estudiantes, basado en las relaciones entre los principales componentes del gráfico y los procesos necesarios para su interpretación (Friel, Curcio y Bright, 2001). Es trascendental, por lo tanto, realizar estudios que ayuden a comprender más la forma de aprender a enseñar la RG en la escuela (Shaughnessy, Garfield y Creer, 1996; Lee y Nelson, 2004). Hay que explorar los elementos teóricos que subyacen a la habilidad de comprensión lectora de las gráficas, las concepciones y dificultades que tienen los estudiantes en su adquisición, las concepciones y dificultades que tienen los profesores al enseñar la RG y las estrategias instruccionales que utilizan para diagnosticar y corregir los errores conceptuales de los estudiantes. Investigaciones que coadyuven en programas para formación de profesores 
(expertos o novatos) y que permitan conocer, cada vez más, la naturaleza epistemológica, conceptual y práctica del pensamiento y conocimiento del profesor.

Como objeto de investigación, algunos autores han identificado diferentes situaciones problemáticas en torno a la $\mathrm{RG}$, como por ejemplo:

a. La mayor parte de las investigaciones realizadas sobre la interpretación de gráficos estadísticos parece haber funcionado a un nivel de análisis estadístico, es decir, con un mayor énfasis en cuantificar y describir aciertos, desaciertos, errores y dificultades, o bien, se han realizado algunos estudios comparativos, por lo que hay todavía poca investigación respecto al razonamiento acerca de los datos (Pfannkuch y Rubick, 2002).

b. Los cursos introductorios de Estadística y los libros sobre métodos de investigación proporcionan una revisión limitada de buenas técnicas de graficación así como nociones relativas a su selección, diseño, edición, interpretación y evaluación (Pittenger, 1995).

c. En la escuela se enfatiza más en el uso de gráficos tradicionales (ej. pictogramas, barras, lineal y circular) y menos en los gráficos (ej. de puntos, tallo y hoja, y caja) que ayudan a conocer la naturaleza de los datos a partir de un análisis exploración de los mismos (Exploratory Data Analysis, EDA por sus siglas en inglés según Tukey, 1977) (Shaughnessy, Garfield, Greer, 1996; Peden y Hausmann, 2000).

d. La investigación sobre el análisis de datos todavía no ha tenido un desarrollo tan rico como la investigación tradicional de aprendizaje de probabilidad (en la cual hay un número de marcos teóricos que han surgido de la confluencia entre la psicología cognitiva y evolutiva, las matemáticas y la educación estadística) (Shaughnessy, Garfield y Greer, 1996).

e. La reforma de la educación estadística (Moore, 1997) impulsó investigaciones desde la perspectiva de la psicología educativa, la psicología cognitiva, la educación matemática y las ciencias de la educación (Garfield, 1995, en Chance y Garfield, 2002), pero todavía hay poca investigación sobre razonamiento estadístico.

En resumen, la $\mathrm{RG}$ tiene un papel esencial en la didáctica de la educación estadística y una función trascendental en el ámbito escolar por ser una habilidad básica tanto para las matemáticas, como para la Estadística y para la vida diaria de un ciudadano. Desde mediados de los 80s, los diferentes organismos internacionales dedicados al estudio de la educación estadística (ej. IASE) y de la matemática (ej. NCTM), e investigadores como Curcio, Friel, Cleveland, Tufte, Henry, Wainer, Pfannkuch, Watson; y más recientemente Monteiro, Ainley, Aoyama, Espinel y Batanero, han invertido esfuerzos significativos en la construcción y difusión del marco teórico que subyace a su enseñanza y aprendizaje y han promovido la puesta en marcha de propuestas y programas de formación de profesores. 
La investigación sobre RG continúa en desarrollo y poco a poco va ocupando un importante lugar en el mundo de la educación estadística siendo reconocida por los organismos internacionales (Shaughnessy, Garfield y Greer, 1996). No obstante, faltan estudios que ayuden a comprender más la forma de aprender a enseñar la RG en la escuela (Lee y Nelson, 2004), los profesores todavía tienen mucho que aprender acerca de los procesos de lectura, análisis e interpretación de información presentada en datos y gráficos (Friel, Curcio y Bright, 2001), y el uso de las gráficas (particularmente en México) se la relegado a simples auxiliares didácticos y se ha omitido o ignorado su uso para desarrollar la actividad cognoscitiva del pensamiento del estudiante (Dolores, 2008). Los problemas actuales, como los errores conceptuales que todavía tienen muchos profesores, las dificultades para explicar una idea abstracta en términos sencillos y el no ser capaz de corregir o anticiparse a los errores o dificultades del pensamiento de los estudiantes, ejemplifican claramente la pobre preparación de los profesores de Estadística (Burgess, 2002; Sorto, 2004, Monteiro y Ainley, 2006, Espinel, 2007). Investigaciones sobre ¿qué necesita conocer el profesor para enseñar la RG?, ¿cómo desarrollan y construyen el conocimiento estadístico sobre la RG?, ¿con qué dificultades se enfrentan en su enseñanza?, o ¿cómo aprenden a enseñar la RG?, permitirán caracterizar al profesor de Estadística a la luz de la investigación didáctica del CDC en Estadística y aportar mayor claridad sobre la enseñanza y aprendizaje de la RG.

\subsection{EL ESTUDIO DE LA REPRESENTACIÓN GRÁFICA EN ESTADÍSTICA}

La investigación sobre la enseñanza y aprendizaje de la RG ha sido analizada y sintetizada por varios investigadores, entre los cuales están Tufte (1983), McKenzie y Padilla (1986), Curcio (1989), Pittenger (1995), Friel, Bright y Curcio (1997), Peden y Hausmann (2000), Friel, Curcio y Bright (2001), Cebulla (2002), Lane (2002), Chick (2004), Pfannkuch, Budgett, Parsonage y Horring (2004), Wu (2004), delMas, Garfield y Ooms (2005), Monteiro y Ainley (2006 y 2007), Aoyama (2006 y 2007), González y Pinto (2008), Espinel, Bruno y Plasencia (2008), entre otros.

Los estudios sobre la RG permiten dar una idea de los diferentes aspectos en que se han centrado las investigaciones, las cuales para fines de este estudio se han agrupado en siete apartados: 1) investigaciones sobre el estudio de las concepciones, errores y dificultades de los estudiantes, 2) materiales y estudios para aprender y desarrollar la comprensión gráfica, 3) desarrollo de instrumentos para medir la comprensión gráfica, 4) estudios teóricos sobre la representación gráfica en Estadística, 5) investigaciones sobre las concepciones y comprensión conceptual de los estudiantes para profesor y los profesores sobre la representación gráfica, y 6) estudios sobre la formación de profesores en la enseñanza de la representación gráfica. A continuación se resumen algunos de los principales trabajos en cada apartado, intentando describir sus aportaciones al campo de investigación. 


\subsubsection{Investigaciones sobre el estudio de las concepciones, errores $y$ dificultades de los estudiantes}

Los primeros referentes en este grupo son los trabajos de Friel y Bright (1995 y 1996), Bright y Friel (1998a). En los dos primeros, Friel y Bright exploran el aprendizaje de los niños de primaria en la interpretación de gráficos (ej. lineal, barras, tallo y hoja e histograma). Bright y Friel (1998a) investigaron las formas en que los estudiantes de primaria interpretan un gráfico de barras. En estas investigaciones se encontraron evidencias que sustentan la existencia de una secuencia de estrategias de razonamiento por parte de los estudiantes y a partir de estos resultados se comienza a construir el marco de referencia sobre la graficación en Estadística.

Posteriormente encontramos trabajos que se han interesado en estudiar las concepciones de los estudiantes sobre conceptos específicos, como son la varianza, los errores y obstáculos en la comprensión del histograma y otros gráficos (ej. Menelaou, 2000), la correlación y la forma como interviene la RG en su comprensión e interpretación (Cebulla, 2002), así como investigaciones que han explorado el pensamiento del estudiantes acerca del gráfico de barras (Pereira-Mendoza y Mellor, 1991), tallo y hoja (Dunkels, 1994), gráfico de correlación (Estepa y Batanero, 1994), pictogramas (Watson, y Moritz, 2001) y del histograma (Meletiou y Lee, 2002) en Shaghnessy 2007.

Batanero (2001b), en su libro Didáctica de la Estadística, hace un análisis de las aportaciones sobre los conocimientos, errores y dificultades de los alumnos (ej. Curcio, 1989; Wainer, 1992; Friel, Curcio y Bright, 2001). De esta revisión se identificaron nueve dificultades que los alumnos presentan sobre el tema de la representación gráfica:

1. interpretar el contenido de los gráficos, además de la incapacidad de procesar la información contenida en ellos de forma coherente,

2. interpretar gráficos en los niveles superiores (ej. leer entre datos, leer más allá de los datos),

3. elegir incorrectamente el tipo de gráfico adecuado, utilizando un polígono de frecuencias cuando las variables son cualitativas, o un diagrama de barras horizontal para representar la evolución de producción industrial a lo largo de serie de años,

4. elegir escalas de representación poco adecuadas para el objetivo predeterminado,

5. omitir las escalas en alguno de los ejes horizontal o vertical, o ambos,

6. no especificar el origen de coordenadas,

7. no proporcionar suficientes divisiones (números de clases) en las escalas de los ejes,

8. desconocer el modo correcto en que debe ser empleado un software para construir gráficas, y

9. obtener un diagrama de sectores en los que éstos no son proporcionales a las frecuencias de las categorías o comparar cantidades heterogéneas en un mismo gráfico. 
Estudios más recientes, como los de Wu (2004), delMas, Garfield y Ooms (2005), Sharma (2006), Carrión y Espinel (2006) y Dolores y Cuevas (2007) son ejemplos de los últimos trabajos hechos en este campo.

Wu (2004) investigó la comprensión de gráficos estadísticos (Understanding of Statistical Graph, USG por sus siglas en inglés) en estudiantes de una escuela secundaria de Singapur. Desde una perspectiva cuantitativa, estudió la habilidad para leer, interpretar, construir y evaluar gráficos estadísticos. Desarrolló un modelo teórico para explorar la USG definido por cuatro niveles cognitivos: lectura, interpretación, construcción y evaluación de gráficos. Cada nivel contó con los objetivos específicos a desarrollar por los estudiantes. Entre sus principales resultados afirma que los estudiantes, generalmente, tienen una habilidad básica para resolver problemas de gráficos estadísticos y que obtuvieron un mejor desempeño en lectura y construcción de gráficos que en interpretación y evaluación de los mismos. Identificó 12 tipos de errores que cometen los estudiantes: 1) de comprensión, 2) explicaciones inciertas (no claras), 3) de cálculo, 4) de escalas, 5) relacionados con el título, etiquetas, especificadores y tipo de gráfico, 6) de gráfico circular, 7) del tamaño del pictograma, 8) de apariencia similar pero naturaleza diferente, 9) confusión entre frecuencia y valor de los datos, 10) relacionados con el uso de la información dada en el gráfico, 11) relacionados al uso del contexto, y 12) otros (miscelánea).

delMas, Garfield y Ooms (2005) evalúan las dificultades en la lectura e interpretación de representaciones gráficas de distribuciones de 542 estudiantes (197 de tres escuelas de bachillerato y 345 de 15 institutos de educación superior o universidades), quienes contestaron la Escala ARTIST (Assessment Resource Tools for Improving Statistical Thinking) y la Prueba CAOS (Comprehensive Assessment of Outcomes in Statistics). Los autores señalan que los alumnos tienen las siguientes dificultades al aprender a razonar acerca de las representaciones gráficas de distribuciones:

1. los estudiantes tienden a ver un conjunto de datos como puntos individuales más que un gráfico o conjunto de datos como una entidad;

2. no entienden que el área (de una barra) representa la frecuencia a diferencia de la longitud (representado en un gráfico de barras);

3. están más familiarizados con gráficos de barras o valores específicos de un gráfico, donde cada caso o datos es representado por una barra o una línea, y el orden de éstos es arbitrario; y

4. cuando hacen comparaciones de distribuciones los nóveles tienden a comparar trozos o parte de los datos, más que comparar entidades completas, considerando en su conjunto las medidas de tendencia central y de dispersión.

delMas, Garfield y Ooms (2005) señalan que a los estudiantes interpretan fácilmente histogramas simples (donde cada barra representa un valor), sin embargo, cuando necesitan utilizar más información, entonces se les hace más difícil. Los estudiantes tienen dificultad en muchos aspectos del razonamiento acerca de la representación gráfica de distribuciones, como leer los datos cuando las barras se refieren a intervalos de valores en lugar de los valores de una variable. Al parecer no están seguros de lo que representan los ejes y la mayoría prefiere gráficas donde una barra representa un valor o caso, más que una 
frecuencia. Según delMas, Garfield y Ooms (2005) esto puede atribuirse a tres razones: a) los estudiantes están muy familiarizados con el gráficos de barras desde la escuela Primaria y ver muchos en periódicos y revistas; b) el histograma da una total atención a los datos individuales, y c) es más difícil asociar un gráfico de barras con magnitudes (tamaño), como es requerido en un histograma, y los estudiantes tiene dificultad para razonar acerca de proporciones.

Por su parte, Sharma (2006), profesora investigadora de la Universidad de Waikato (Nueva Zelanda) llevó a cabo un estudio acerca de las dificultades de 29 estudiantes de Secundaria en el razonamiento estadístico de la interpretación de tablas y gráficas. Cada estudiante tenía que realizar dos tareas. La primera tarea incluía una tabla comparando temperaturas de dos ciudades y en ella se le hacían dos preguntas, una para explorar si el estudiante leía la tabla (ej. ¿qué es lo que conoce sobre la temperatura de la ciudad de Sigatoka y de Ba?) y otra para explorar si realizaba una interpretación (ej. ¿qué otra cosa revela esta tabla acerca de las temperaturas de Sigatoka y de Ba?). La segunda tarea contenía un gráfico de barras de las alturas de cuatro estudiantes de edad 4, 8, 13 у 19, respectivamente. Las primeras preguntas estaban relacionadas con su habilidad para leer literalmente el gráfico (ej. ¿cómo de altos son los niños de 4 años?) y las siguientes preguntas trataban de explorar la habilidad del estudiante en el uso de técnicas estadísticas de orden superior (ej. Un quinto niño en la familia tiene 10 años. Puedes decir cómo de alto es el niños de 10 años? Explica tu respuesta). Sharma realizó entrevistas individuales para profundizar en las respuestas de los estudiantes. Las respuestas a cada tarea se calificaron según cuatro grupos: sin respuesta, respuesta no estadística, respuesta parcialmente estadística y respuesta estadística.

Los resultados revelaron que para resolver las tareas muchos estudiantes se basan en experiencias previas (en la vida diaria y de la escuela) y en estrategias intuitivas. Los estudiantes pudieron leer y comparar datos presentados en un gráfico de barras pero fueron menos competentes en la lectura de tablas. Esto, según Sharma, puede ser debido al olvido de estos conceptos o a problemas lingüísticos y contextuales. Aunque los estudiantes, a menudo dan respuestas correctas, sus argumentos son incorrectos. Asimismo, los resultados muestran que, aunque los contextos que se usan en las tareas pueden ser un apoyo para que los alumnos usen sus conocimientos previos, ese conocimiento situacional es diverso y puede causar interpretaciones equivocadas de la información del gráfico. Sharma concluye que los estudiantes frecuentemente fracasan al conectar las matemáticas que aprenden en la escuela con situaciones reales en las cuales se necesitan esas matemáticas.

Carrión y Espinel (2006) desarrollaron una investigación comparativa entre estudiantes de España (Las Palmas) y Nueva Zelanda (Auckland) de 10 a 12 años de edad. $\mathrm{Su}$ objetivo era identificar y analizar qué dificultades y limitaciones tienen los estudiantes de primaria cuando usan representaciones (ej. gráficos de histograma, dispersión, caja, tallo y hoja) en el análisis de datos, específicamente se centraron en la traducción e interpretación de gráficos. Administraron un cuestionario que contenía cuatro tareas (una por cada gráfico) con un total de 14 ítems. Se les pidió a los alumnos que seleccionaran entre tres opciones la que ellos pensaran que era la más apropiada a la situación. El estudiante debería elegir la mejor opción para traducir el gráfico en una tabla o viceversa, según fuera la situación presentada. Carrión y Espinel (2006) detectaron que eran pocos los 
estudiantes capaces de comprender las relaciones entre los diferentes tipos de gráficos a partir de un único tipo de información dado. Concluyen que el proceso de traducción o conversión de gráficas a tablas necesita de más investigación

Desde la perspectiva de los gráficos que se comparten socialmente, es decir, aquellos usados por los medios de información, Dolores y Cuevas (2007) estudian las diferentes interpretaciones que dan los estudiantes de primaria y secundaria de una comunidad al sur de México a esos gráficos. Los instrumentos utilizados fueron de dos tipos: gráficas que se comparten socialmente en ambientes extraescolares, y una que se comparte en los grupos escolares de los niveles medio y superior. Detectan interpretaciones en las que la mayoría de los alumnos identifican lo que cambia (las variables), hacen lecturas de dato a dato privilegiando los máximos y mínimos y realizan descripciones cualitativas de cómo cambia algo aduciendo que sube o baja, no establecen relaciones covaracionales, no calculan cuánto cambian las variables ni usan las razones de cambio. Finalmente, Dolores y Cuevas (2007) concluyen que las evidencias obtenidas indican un escaso conocimiento sobre los significados de los conceptos sociales representados en las gráficas.

\subsubsection{Materiales y estudios para aprender y desarrollar la comprensión gráfica}

Tukey (1977), Chambers, Cleveland, Kleiner, Tukey (1983), Tufte (1983), Nortes (1987), Alaminos (1993) y Henry (1995) son varios de los autores que han sido considerados como referentes para aprender las técnicas de graficación. En sus textos, generalmente analizan y presentan procedimientos de RG, así como pautas sobre los elementos a incluir y analizar en los diferentes tipos de gráficos. Por ejemplo, Tufte (1983) sugirió que la excelencia en gráficos estadísticos consiste en un complejo de ideas comunicadas con claridad, precisión y eficiencia. Para él, la presentación de gráficos, debería incluir:

- mostrar los datos,

- inducir al revisor a pensar acerca de la sustancia más que la metodología,

- presentar muchos números en un espacio pequeño,

- hacer un conjunto de datos amplio y coherente,

- estimular a que los ojos comparen diferentes valores de los datos,

- revelar o mostrar los datos con diferente nivel de detalle,

- servir con un propósito razonablemente claro, como puede ser una descripción, exploración, tabulación o decoración, y

- estar estrechamente integrado con los estadísticos y descripciones verbales de los datos.

Aún cuando la mayoría de las investigaciones en educación estadística contienen implicaciones para la enseñanza, algunos trabajos ofrecen y alternativas para mejorar la comprensión y conocimiento de la RG en los estudiantes. Por ejemplo, Thompson (1994) propone una estrategia que consiste en incorporar datos significativos del estudiante en el aprendizaje de la Estadística, usando un Cuestionario de Información del Estudiante. A través del cuestionario, los estudiantes recogen datos de sí mismos y de sus compañeros y a partir de ahí realizan sus propias representaciones. Conners, Mccown y Roskos-Ewoldsen 
(1998) presentan un conjunto de cuatro estrategias como soluciones para minimizar el problema de la enseñanza de la Estadística a nivel superior: motivar a los estudiantes, disminuir la ansiedad matemática, trabajar con alumnos con diferentes niveles de rendimiento académico y promover el aprendizaje de conceptos. Por cada estrategia, los autores presentan ejemplos y procedimientos. Meletiou y Stylianou (2003) examinan el efecto de un curso diseñado para mejorar la comprensión de los gráficos y dirigido a estudiantes (con apoyo del programa Fathom®).

También se incluyen en este grupo aquellos trabajos de carácter didáctico que describen experiencias en el aula y permiten conocer cómo los estudiantes interpretan y analizan gráficos, así como proponer un conjunto de estrategias didácticas para desarrollan la comprensión gráfica en los estudiantes. Por ejemplo, el libro de Curcio (1989) está dirigido a profesores de nivel básico titulado Developing Graph Comprehension. Elementary and Middle School Activities, donde propuso un conjunto de actividades secuenciadas para desarrollar la comprensión gráfica desde preescolar a primaria. Curcio publicó una segunda edición de este libro en 2001. Pittenger (1995) presenta una breve descripción sobre técnicas gráficas generales y una lista bibliográfica sobre gráficos, principalmente de cajas y paralelos, circular, de barras y de dispersión. Mosenthal y Kirsch (1990a y 1990b) también proporcionan información sobre técnicas, características y procedimientos de representación de los gráficos circular, barras y lineal. Por su parte, Peden (2001), presenta una actividad en la que a partir de cuatro conjuntos de dados solicita a los estudiantes capturarlos, calcular la $r$ de Pearson, realizar gráficos de dispersión, y analizar, seleccionar e interpretar la forma mejor del gráfico. Peden y Hausmann (2000) analizaron los tipos de gráficos que hay en los libros de texto en los niveles introductorios y superiores de Psicología. Encontraron que sólo aparecen cinco tipos de gráficos en dichos libros: lineal, barras, circular, pictogramas y otros. A partir de su investigación describen algunas recomendaciones para construir estos gráficos.

Cada día tiene mayor interés el diseño de textos centrados en la enseñanza dela representación gráfica a partir de proyectos de desarrollo, de investigaciones o situaciones didácticas. Por ejemplo, Cazorla y Santana (2006) publican su libro Tratamento da informação para o ensino fundamental e médio (Tratamiento de la información para la enseñanza fundamental y media), dirigido a estudiantes y profesores, en el que proporcionan ejemplos concretos de situaciones problemáticas familiares e interesantes del tratamiento de datos cualitativos (tablas simples y dobles, gráficos circular y de barras) y de tratamiento de datos cuantitativos (media, moda, mediana, diagrama de árbol y relación entre dos variables). El documento está basado en los conceptos sugeridos por los Parámetros Curriculares Nacionales. El libro presenta tres secuencias didácticas, cada una con su objetivo general y objetivos específicos, una breve descripción de la actividad, los datos, y las actividades sugeridas para aprender los temas. Sobre el tema de la RG, hay algunos ejemplos contextualizados pensados para comprender las características de los gráficos y su construcción $\mathrm{y}$, al final, se incluye un conjunto de actividades complementarias para utilizar en el aula con los estudiantes. 


\subsubsection{Desarrollo de instrumentos para medir la comprensión gráfica}

Es cada vez más recomendable el uso de múltiples metodologías para estudiar el conocimiento del estudiante o del profesor sobre algún tópico estadístico (Shaughnessy, 2007). Esto implica investigaciones que aborden el objeto de estudio desde una perspectiva no sólo positivista sino también naturalista y con una diversidad de técnicas e instrumentos de recogida de datos. De este modo, podemos apreciar una gama de estudios con una amplia diversidad metodológica e instrumental en la forma de estudiar el conocimiento del estudiante o del profesor.

No obstante, en esta categorías de investigaciones incluimos ejemplos de trabajos que se han ocupado de diseñar un instrumento (o cuestionario), generalmente de corte cuantitativo, para evaluar o medir la representación gráfica. Muchos de ellos utilizaron otras técnicas de recogida de datos (ej. entrevista, observación de la clase) para complementar o profundizar sobre el conocimiento a explorar.

Unas de las primeras investigaciones que desarrolló instrumento para valorar o medir la comprensión de la RG de los estudiantes como el de Wainer (1980) quien desarrolló una prueba de graficación para niños de primaria (Test of graphicacy in Children). Las preguntas que utilizó en la prueba fueron clasificadas según Bertin (1973) en elementales, intermedias y de comprensión. Se trató de una prueba de ocho preguntas de respuesta de opción múltiple por cada forma de representación (gráfico circular, tabla, gráfico de barras y gráfico lineal).

McKenzie y Padilla (1986) diseñaron una Prueba de Graficación para Ciencias (Test of Graphing in Science, TOGS). A lo largo de su trabajo escriben brevemente la prueba presentando ejemplos de los ítems así como su nivel de validez y confiabilidad. Su énfasis fue evaluar la habilidad de graficación del gráfico lineal en estudiantes de séptimo, noveno y décimo grado escolar de Estados Unidos.

Curcio (1987 y 1989) desarrolló también una prueba de comprensión gráfica, pero dirigida a estudiantes primaria. Los gráficos con los que realizó el estudio fueron: barras, circular, lineal y pictogramas. En total utilizó doce ítems; para cada tipo de gráfico diseñó tres ítems con seis preguntas de opción múltiple. Clasifica los gráficos en función de tres categorías: leer los datos (literal), leer entre los datos (comparación) y leer más allá de los datos (abstracción, predicción e inferencia). Para cada gráfico había dos preguntas de cada aspecto de clasificación.

Por su parte, Wu (2004) en el estudio que hizo con los estudiantes de una escuela secundaria en Singapur, desarrolló una Prueba de Comprensión de Gráficos Estadísticos en Estudiantes (Test of students' understanding os Statistical Graph, TUSG por sus siglas en inglés). La prueba consistió en 10 preguntas con 53 ítems, cubriendo seis diferentes tipos de gráficos estadísticos: barras, sectores, lineal, pictograma, de puntos e histograma. Los gráficos estadísticos fueron seleccionados a partir de los programas oficiales de matemáticas de nivel Secundaria de Singapur. Cada pregunta en el TUSG tenía varias partes. Si una parte de una pregunta en particular requería una respuesta final y el razonamiento de la respuesta, esta fue tratada como dos ítems: tipo $f$ (de "final") y tipo $r$ (de 
"razonamiento"). Los ítems tipo $f$ solicitaban una respuesta final, como dar un valor o seleccionar una respuesta única. Los ítems tipo $r$ requerían descripciones, justificaciones y razonamientos que soportaran la respuesta final.

Otra prueba es la Evaluación Exhaustiva de los Resultados en Estadística (Comprehensive Assessment of Outcomes in Statistics, CAOS, por sus siglas en inglés) y la Escala ARTIST (disponibles en https://app.gen.umn.edu/artist/tests/index.html ) desarrollada por el equipo delMas, Garfield, Ooms (2005), las cuales se utilizaron para diseñar una prueba específica que midiera la representación gráfica de distribuciones dentro de las categorías de alfabetización estadística y razonamiento estadístico. Los ítems que evaluaron alfabetización estadística medían la habilidad para: comprender información presentada en un gráfico estadístico típico de distribuciones (ej. puntos, histograma, caja), identificar correctamente y conocer las escalas de medición, identificar algunas formas de distribución (ej. normal, sesgada, bimodal, uniforme), distinguir entre un gráfico de barra o serie temporal y un higrograma del de puntos y conocer los términos relacionados con la distribución. Los ítems que evaluaron razonamiento estadístico medían la habilidad del estudiante para: identificar un gráfico dada la descripción de una variable, combinar o comparar dos versiones de gráficos de un mismo conjunto de datos, conocer el impacto de sumar o modificar valores y conocer las razones de las formas de distribución. La prueba tenía 14 ítems, en donde se presentaba una situación con un gráfico y el estudiante seleccionaba la respuesta correcta a la pregunta del ítem. La prueba puede verse en delMas, Garfield y Ooms (2005).

\subsubsection{Estudios teóricos sobre la representación gráfica en Estadística}

En esta sección se incluyen trabajos principalmente de divulgación o de carácter teórico, que aportan elementos teóricos relativos a la representación gráfica en Estadística. Se intentará hacer un recorrido con el paso de los años para dar al lector una idea de la evolución que han tenido las aportaciones en esta línea de investigación. No obstante, como se podrá apreciar en este capítulo, también existen autores que han incorporado nuevos elementos al estudio de la RG a partir de los resultados de las investigaciones, como son la "comprensión gráfica" (graph comprehension) de Curcio 1987), el "sentido de los datos" (data sense) por Burgess (2002), el "sentido crítico" (critical sense) definido por Gal (2002), de los gráficos de algún medio de comunicación impresa (media graph o print graph) de Monteiro y Ainley (2006 y 2007) y Watson y Callingham (2003); entre otros.

Curcio (1989), Kosslyn (1989), Friel, Bright, Frierson y Kader (1997), Friel, Bright y Curcio (1997), Bright y Friel (1998b) y Friel, Curcio y Bright (2001) son los investigadores que iniciaron el estudio de los factores que inciden en la RG. Estos autores se interesaron en estudiar primero el significado de la RG, sus características y componentes. Por ejemplo, Kosslyn (1989) desarrolló una forma de analizar la información de un gráfico. Su esquema incluye el análisis de cinco elementos: (a) tipos de presentación visual, (b) fundamentos del procedimiento de evaluación del gráficos (principios) desde la perspectiva del procesamiento visual de la información por el ser humano y la teoría de símbolos desarrollada por Goodman (1968), (c) diagnóstico de las irregularidades de los principios (análisis sintáctico), (d) diagnóstico de las irregularidades de los principios 
(análisis semántico), y (e) diagnóstico de las irregularidades de los principios (análisis pragmático).

En un capítulo del libro de Gal y Garfield (1997), Friel, Bright, Frierson y Kader (1997) exponen lo que los profesores y estudiantes deberían conocer y ser capaces de hacer con respecto al aprendizaje de la Estadística en la escuela primaria. Presentan un número de conceptos a ser considerados (ej. aspectos relacionados con la comprensión gráfica), así como algunos aspectos sobre la complejidad de su aprendizaje. Se focalizan sobre la comprensión de la RG y muestran ejemplos de "buenas tareas" que pueden ser usadas para estudiar la comprensión gráfica. Posteriormente Bright y Friel (1998b) presentan un análisis más detallado de las fases del proceso de la comprensión gráfica para ayudar a los estudiantes a interpretar datos a partir de los gráficos de barras, lineal y de tallo y hoja.

Friel, Bright y Curcio (1997) conceptúan que la comprensión y uso de gráficas es una parte clave de lo que debe ser el conocimiento de la Estadística. Tradicionalmente, a los estudiantes se les solicita sólo leer información a partir del gráfico, sin embargo, es necesario también explorar la naturaleza de los datos de tal modo que les ayude a comprender mejor el uso y lectura del gráfico. En su artículo exponen el significado del "sentido gráfico" (graph sense) "como resultado de presentar gráficos diseñados a partir de los datos, explorando su uso en una variedad de contextos y relacionando éstos no sólo con la construcción del gráfico o con una simple extracción de datos para la lectura de gráficos" (p.224). Incluye un rango de conductas como: leer, describir, interpretar, analizar y extrapolar datos de un gráfico. Presentan algunos ejemplos que demuestran el valor de incluir este concepto en el contexto escolar.

En 2001, Friel, Curcio y Bright hablan de cuatro factores críticos que influyen en la comprensión gráfica: los propósitos para usar gráficos, las características de las tareas (descodificación visual del gráfico, taxonomía para analizar las capacidades a desarrollar en las tareas sobre graficación, el contexto), características de la disciplina (tipo y tamaño de datos y complejidad gráfica) y características del lector. Los autores establecen que un gráfico tienen cuatro componentes estructurales similares: armazón (ej. ejes, escalas, coordenadas, marcas de referencia), especificadores (dimensiones visuales utilizadas para representar los datos), etiquetas y fondo (algún color, coordenadas y cuadro sobre el cual el gráfico puede ser sobrepuesto). Sin embargo, como señala Monteiro y Ainley (2003) la familiaridad con estos componentes no es suficiente para asegurar la comprensión de un gráfico particular.

Gal (2002 en Monteiro y Ainley, 2003) incorpora los componentes de la alfabetización estadística en adultos. Expone que las actividades de análisis de datos, como lo es graficar, pueden darse en dos contextos principalmente: de investigación y de lectura. En "contextos de investigación" (enquiry contexts) el estudiante se involucra en una investigación empírica acerca de datos reales. Los sujetos se comportan como "productores de datos" o "analizadores de datos" y usualmente tienen que interpretar sus propios datos y resultados, así como reportar sus hallazgos y conclusiones. Los "contextos de lectura" (reading contexts) surgen de las situaciones de la vida diaria en la cual las personas ven e interpretan gráficas (viendo TV, leyendo el periódico, mirando anuncios mientras compran, visitando sitios en Internet, etc). 
delMas, Garfield y Ooms (2005) señalan que en los inicios de la investigación sobre representación gráfica los trabajos estaban más centrados en el sentido gráfico (graph sense), la graficación (graphicacy) y la comprensión gráfica (graphical representation) que sobre razonamiento distribucional (distributional reasoning) acerca de gráficas. Ellos definen sentido gráfico como la habilidad para conocer componentes de un gráfico, hablar el lenguaje de gráficos, comprender las relaciones entre tablas y gráficas y responder a preguntas acerca de gráficos. Por su parte, definen graficación como la habilidad para leer e interpretar gráficas. Afirman que la comprensión gráfica ha sido definida como la capacidad para traducir una gráfica a otra, o una tabla a una gráfica y ser capaz de interpretar relaciones o factores importantes en un gráfico. Según Friel, Bright y Curcio (2001) la comprensión gráfica es la "habilidad de los lectores de gráficar para derivar el significado de gráficos creados por otros o por ellos mismos” (p.32 en Shaughnessy, 2007).

En 2006 y 2007, Aoyama, investigadora de la Universidad de Tsukuba (Japón), presenta en el ICOTS-7 y en la International Electronic Journal of Mathematics Education, respectivamente; una propuesta sobre la jerarquía de la interpretación gráfica en estudiantes. Su propuesta se basa en uno de los componentes claves en la alfabetización estadística: la habilidad para extraer información cualitativa de la información cuantitativa y/o crear información desde ambos tipos de información. El fundamento teórico de esta idea está publicado en Aoyama y Stephens (2003).

Para el desarrollo de su propuesta, Aoyama realiza una investigación partiendo de las aportaciones y argumentos de Watson y Callingham (2003), quienes investigaron sobre la naturaleza jerárquica de la alfabetización estadística. Aoyama solicitó a 175 estudiantes de diferentes niveles escolares (39 de secundaria, 80 de bachillerato, 23 de universidad y 33 graduados) contestar un cuestionario donde debían responder a diferentes preguntas acerca de la interpretación de tres o cuatro gráficos en su contexto. La mayoría de los ítems eran de selección múltiple. Después de sus respuestas, entrevistó a una muestra de estudiantes para profundizar en sus argumentos y su pensamiento. Las respuestas fueron codificadas utilizando la Taxonomía SOLO (the Structure of Observed Learning Outcomes) de Biggs y Collis, 1991) y las puntuaciones fueron analizadas con el modelo Rash.

Aoyama (2006 y 2007) identificó cinco niveles diferentes que representan la jerarquía de la interpretación gráfica en los estudiantes. Estos fueron:

Nivel 1. Idiosincrático. Los estudiantes de este nivel no pueden leer valores o tendencias en gráficos. Se equivocan al relacionar algunas características extraídas del gráfico con contextos. Usualmente, sus respuestas en las entrevistas se basan sobre su limitada experiencia individual.

Nivel 2. Lectura básica del gráfico. Los estudiantes en este nivel pueden leer valores y tendencias en gráficos, pero no pueden explicar significados contextuales de tendencias o sus características, y no pueden contextualizar los eventos presentados.

Nivel 3. Literal / Racional. Los estudiantes en este nivel pueden leer valores y tendencias, explican significados contextuales literalmente en términos de características mostradas en el gráfico. No pueden sugerir una interpretación alternativa sino que usan 
únicamente los significados presentados. Generalmente son capaces de hacer preguntas sobre la confiabilidad de la información.

Nivel 4. Crítico. Los estudiantes en este nivel pueden leer gráficos y comprender los significados contextuales que se le presentan. Aún más, pueden evaluar la confiabilidad de los significados contextuales presentados en el gráfico.

Nivel 5. Hipotetizando y modelando. Los estudiantes en este nivel pueden leer gráficas y aceptar y evaluar la información presentada. Pueden formar su propia hipótesis exploratoria o sus modelos. En este nivel, los estudiantes actúan como "investigadores" estadísticos activos y no sólo como receptores de información.

Aoyama (2006 y 2007) afirma que el nivel 4 es una de las prioridades de la educación estadística en el contexto de la alfabetización estadística. Señala que el nivel 4 es importante para consumidores o receptores de información y el nivel 5 para productores de información. Según Aoyama (2007), las respuestas de los estudiantes de las tareas estaban influidas por su familiaridad con el contexto y su conocimiento acerca del fenómeno relacionado.

Recientemente también Espinel (2007) propone algunas reflexiones sobre cómo conducir la visualización de los datos para la formación del profesorado. Expone un análisis fenomenológico y epistemológico desde un punto de vista social y el problema de la percepción de las gráficas desde el punto de vista de la psicología cognitiva, con base en el análisis de la presencia de las gráficas en el Diseño Curricular Base de Primaria y Secundaria (de España). Espinel afirma que en la formación del profesor hace falta incluir temas claves relativos a las pautas para la construcción de gráficas, las dificultades y errores más frecuentes en los alumnos, algunas propuestas didácticas o materiales didácticos y nuevas modalidades de evaluación.

Shaughnessy (2007) hace un recorrido sobre el avance de las investigaciones sobre comprensión de los estudiantes acerca de las gráficas. Del análisis que hace de los diferentes estudios destacan dos aspectos importantes que se suman al conocimiento de la teoría sobre la RG: sobre los niveles cognitivos de desarrollo de la comprensión gráfica de Curcio (1987) y un conjunto de sugerencias sobre las implicaciones que tienen las investigaciones para la enseñanza.

Sobre los niveles cognitivos de Curcio (1987), Shaughnessy (2007), con base en los argumentos presentados en Shaughnessy, Garfield y Greer (1996), afirma que se requiere un cuarto nivel cognitivo para estudiar la comprensión gráfica y que va más allá de los datos, esto es, "leer detrás de los datos" (reading behind the data). Shaughnessy afirma que este nivel trata de establecer las conexiones que existen entre el contexto y el gráfico, además de buscar las causas especiales de variación en los datos a partir del gráfico (con base en Wild y Pfannkuch, 1999). Añade dos conductas que podrían caracterizar este nivel que son: mirar las causas posibles de variación y mirar las relaciones entre las variables de los datos. Concluye que las diferentes investigaciones sobre sentido gráfico indican: 
que los estudiantes tienen técnicas pobres de interpretación gráfica y son a menudo incapaces de razonar más allá de los datos. Además, a no ser que el gráfico sea sencillo, los estudiantes pueden tener problemas para leer un gráfico como un todo. En el caso especial de los gráficos estadísticos, leer detrás de los datos es fundamental para hacer conexiones entre el contexto y los datos. El sentido gráfico como es leer datos, leer entre datos y leer más allá de los datos es fundamental para el pensamiento, razonamiento y alfabetización estadística (p.991).

Shaughnessy (2007) hace algunas sugerencias sobre las implicaciones en la enseñanza del estudio de las dificultades y concepciones de los estudiantes. Estas van dirigidas principalmente a los profesores. Por ejemplo, sugiere que los profesores deberían: a) incluir una variedad de representaciones gráficas y b) ayudar a sus alumnos a ir más allá de tabular datos y construir gráficos y deben incluir el estudio de más elementos fundamentales utilizando el concepto del sentido gráfico de Curcio (1987 y 1989) y discutir los significados e interpretaciones de los gráficos, sobre todo de gráficos representados por ellos mismos.

Por último, Dolores (2008), profesor investigador del Departamento de Matemática Educativa del CINVESTAV-IPN (Centro de Investigación y de Estudios Tecnológicos del Instituto Politécnico Nacional, en México) aborda el tema de las gráficas que se comparten socialmente a través de los medios de comunicación o las que utilizan los científicos o especialistas. Deja entrever que las gráficas utilizadas en los textos de matemáticas y que por tanto permean el ambiente escolar difieren de las que se encuentran circulando fuera de la escuela, por lo que las gráficas viven fuera de la escuela penetrando los escenarios sociales más allá del escenario escolar. Dolores afirma que "los textos de matemáticas del bachillerato y en la educación superior suelen privilegiar el uso de gráficas en contextos solamente intramatemáticos" (p.54).

La propuesta de Dolores (2008) consiste en estudiar las gráficas socialmente compartidas. Por consiguiente, afirma que es necesario desarrollar habilidades y capacidades que preparen al estudiante para leer e interpretar gráficas extraescolarmente compartidas. Esto implicará necesariamente un cambio en la manera de enseñar la representación gráfica en el aula, dado que un ciudadano común lee e interpreta una gráfica de forma diferente a cómo habitualmente lo hace un estudiante en el aula, es decir, con motivaciones diferentes a las escolares. De esta manera, "no sólo es importante que un estudiante construya los conceptos matemáticos, sino también saber cómo los moviliza en sus interacciones sociales, la forma en cómo viven los conocimientos construidos, cómo son movilizados como argumento o se emplean, como herramienta para intervenir en su entorno" (Dolores, 2008, p.57).

\subsubsection{Investigaciones sobre las concepciones y la comprensión conceptual de los estudiantes para profesor y los profesores sobre la representación gráfica}

En esta categoría se encuentran los trabajos de investigación sobre las concepciones y conocimientos que tienen los futuros profesores o profesores de matemáticas o de estadística sobre la RG. Se podrá apreciar que en los últimos tres años la investigación en 
este sentido se ha incrementado, debido principalmente al interés de las convocatoria de los congresos del ICOTS-7 (en 2006) y del ICMI/IASE (en 2008). A continuación se presentan brevemente algunas de estas investigaciones que nos permitirá tener una idea sobre qué aspectos del profesor se está estudiando la RG.

El sentido de datos, que incluye la capacidad de generar la información sobre cuales gráficos y la estadística son construidos, como se considera, es una parte importante de acción de hacerse estadísticamente alfabetizado. Por ejemplo, Burgess (2002), investiga aun grupo de 30 estudiantes para profesor en el nivel elemental (de Nueva Zelanda). A los estudiantes se les entregó un conjunto de 16 tareas con una pregunta abierta con el apoyo de un "protocolo de carta de datos" para cada una. Cada carta contenía datos acerca de un niño (ej. nombre, edad, actividad favorita, color de ojos, peso y la pregunta). Cada estudiante debía escribir un reporte con los resultados interesantes acerca de los datos. El objetivo era explorar el conocimiento matemático y estadístico que tienen, cómo desarrollan y conceptúan el "sentido de los datos" (data sense) y el pensamiento estadístico mientras llevan a cabo una investigación estadística. Para Burgess (2002), el sentido de los datos incluye la capacidad de generar información sobre los cuales los gráficos y los valores estadísticos son construidos, y representa una parte importante de lo que es la alfabetización estadística. Burgess encontró que los estudiantes para profesor proponen la inclusión de muchos gráficos que sirven para presentar un informe de investigación, pero que tienen problemas severos para interpretarlos. Sugiere que la oportunidad de desarrollar el sentido de los datos debe ser una parte del proceso de resolución de problemas, como lo es a través de investigaciones.

En 2003, Monteiro y Ainley, presentan los resultados de un estudio piloto que puso de manifiesto la necesidad de fomentaren los futuros profesores el"sentido crítico" (critical sense) definido por Gal (2002) como una parte fundamental de la alfabetización estadística. Monteiro y Ainley (2003) definen sentido crítico como "la habilidad para mirar detrás de los datos y analizar profundamente la información y sus relaciones más que una aceptación simple de la impresión inicial dada por un gráfico" (p.2). La habilidad que tiene la persona de ver lo que hay detrás del gráfico a partir de un contexto real es lo que Monteiro y Ainley denominan sentido crítico. Ellos sugieren un cambio en el currículo de tal modo que se incorporen los contextos de investigación o de lectura (según Gal, 2002) para aprender la representación gráfica.

El estudio piloto de Monteiro y Ainley (2003) consistió precisamente en explorar el concepto de sentido crítico en 10 estudiantes para profesor del nivel Primaria. Se basaron en un par de entrevistas por participante donde se les solicitó trabajar con dos gráficos tomados de medios de comunicación impresos (media graphs): un gráfico acerca de la anticoncepción y la fertilidad y otro relativo a accidentes de carreteras. Se les hizo una pregunta básica: Si usted tuviera la oportunidad de hablar con la persona que elaboró este gráfico ¿existe alguna pregunta que le gustaría hacerle? ¿cuál? Los resultados sustentan su conjetura de que los contextos de investigación son más útiles para desarrollar el uso del sentido crítico de un gráfico. Sugieren que los profesores necesitan guiar el entorno pedagógico a situaciones en las cuales aspectos relevantes sean relativos al análisis crítico de los datos. 
Posteriormente Monteiro y Ainley (2006 y 2007) ampliaron estos resultados. Siempre interesados en el uso de gráficos presentes en los medios de comunicación impresa y generados en situaciones reales en un contexto escolar, analizaron las respuestas de 218 estudiantes para profesor de Brasil e Inglaterra centrándose en su habilidad para interpretar gráficos. Diseñaron un cuestionario para explorar cómo los estudiantes para profesor actúan de forma diferente cuando leen gráficos en diferentes contextos. El cuestionario constaba de dos partes. En la primera parte se les solicitó a los futuros profesores información demográfica y hablar sobre las situaciones de lectura de gráficos en diferentes contextos que podrían acceder a través de medios de comunicación impresa. En la segunda parte se presentó un gráfico tomado de un medio de comunicación impresa (acerca de accidentes en carretera), y debían responder a tres preguntas: a) Si usted tuviera la oportunidad de hablar con la persona que elaboró este gráfico ¿existe alguna pregunta que le gustaría hacerle? ¿cuál(es)?, b) si la información de estos dos gráficos se combinara ¿qué podría decir del gráfico?, y c) ¿piensa que esta información es real? Posteriormente, 13 estudiantes de Inglaterra participaron en una entrevista individual en profundidad con el propósito de explorar su proceso de interpretación de cada uno. Para ello, se apoyaron de un breve guión de entrevista que contenía algunas preguntas clasificadas según los niveles de Curcio (1987).

Los resultados de Monteiro y Ainley (2006 y 2007) sugieren que al hacer sus interpretaciones los estudiantes amalgamaron $\mathrm{su}$ conocimiento estadístico con otros elementos relacionados con su conocimiento y experiencia personal acerca del contexto del que procedían datos lo cual sustenta que se debe desarrollar el sentido crítico en las personas, es decir, realizar una lectura sofisticada de los gráficos supone reunir y activar un rango de diferentes tipos de conocimiento y experiencias. La entrevista confirmó que la forma de solicitar o hacer preguntas acerca de las predicciones de los datos ayudó a los estudiantes para profesor a construir sus interpretaciones de los datos que incluía aspectos que estaban ausentes en éstos y que los participantes manifestaron ser conscientes de que el conocimiento técnico acerca de la interpretación no era suficiente para responder a las preguntas (Monteiro y Ainley, 2007).

Monteiro y Ainley (2006 y 2007) refuerzan la hipótesis de la distancia que existe entre la escuela y los contextos extraescolares para la interpretación de gráficos. Sugieren nuevamente ponderar la inclusión en la enseñanza del análisis de los gráficos a partir de contextos de investigación y contextos de lectura, además de los contextos escolares. Concluyen que la enseñanza de las gráficas debería estar basada en la oportunidad para aprender y balancear la diversidad de elementos y conocimientos que intervienen en la interpretación de las gráficas.

Espinel (2007) por su parte, investigó los errores más frecuentes que se cometen en la construcción de gráficos identificando las dificultades de estudiantes para profesor de la Universidad de La Laguna (Tenerife, España). Estos alumnos tenían que construir un histograma y un polígono de frecuencias a partir de datos dados por intervalos. Después les presentó cinco gráficas construidas por alumnos para que evaluaran su construcción y clasificaran los errores cometidos. Entre sus hallazgos encontró que no todos los estudiantes para profesor leen e interpretan los histogramas correctamente y que hay un amplio fracaso en reconocer patrones de comportamiento de las variables que se acentúa si 
no se disponen de valores en los ejes o alguna otra referencia, como pudiera ser una escala de medición. También encontró que los futuros profesores no consideran el "cero" en la frecuencia de intervalos, etiquetan o nombran los números reales sobre los ejes de forma inadecuada, separan las barras del histograma o completan el polígono de frecuencias.

Arteaga, Batanero y Ruiz (2008) analizaron las gráficas producidas en una tarea abierta en la que 70 futuros profesores debían comparar dos distribuciones de una misma variable aleatoria con datos recogidos en la misma clase. Los resultados indican que algunos profesores no han adquirido la idea de distribución, produciendo gráficas con valores aislados de los datos. En muchos casos las gráficas no son pertinentes para resolver el problema planteado e incluso son incorrectas. Según Arteaga, Batanero y Ruiz (2008) una parte importante de los futuros profesores que producen la gráfica de cada distribución (por ejemplo en un diagrama de barras) construye gráficas separadas para cada distribución lo que dificulta su comparación. Concluyen que son pocos los que usan tanto la idea de promedio como la de dispersión y que llegan a una conclusión sobre el problema planteado.

Por su parte, Espinel y Bruno (2008) estudiaron las dificultades que presentan los estudiantes para profesores de Primaria, después de acabar su formación matemática en la universidad, en relación con algunos gráficos más habituales, específicamente en la construcción de histogramas; lectura, interpretación y razonamiento sobre distribuciones de datos y representaciones que aparecen en la prensa. Las dificultades que identificaron fueron:

1. En relación a los errores frecuentes: construir el histograma con barras separadas, colocan etiquetas en las barras u omiten el intervalo de frecuencia nula.

2. En relación a la construcción del polígono de frecuencias: no unen los segmentos por las marcas de clase, omiten el intervalo de frecuencia nula y confunden la frecuencia con los intervalos.

3. En relación a la lectura y razonamiento sobre distribuciones: distinguir gráficos de barras e histogramas, asignar la escala de una variable, razonar de forma global, identificar un gráfico a partir de la descripción de una variable y reconocer patrones de comportamiento de las variables.

4. En relación a los gráficos temporales: no disponen de un método para leer o interpretar cambios en el tiempo y muchos justifican sus respuestas con la observación visual.

Gitirana, Guimarães, Magina y Cazorla (2008) estudiaron las concepciones de 244 estudiantes para profesores y 43 profesores en enseñanza fundamental de São Paulo, Brasil. Se les administró un cuestionario sobre lectura, interpretación y construcción de tablas y gráficos. Gitirana, et al (2008) encontraron que a medida que el estudiante para profesor avanza en sus estudios incrementa el puntaje de respuestas correctas al cuestionario. No obstante, se encontraron resultados contradictorios, por ejemplo, los alumnos de los primeros años obtuvieron puntajes mayores en la construcción de un gráfico de barras que los estudiantes que acababan sus estudios de Pedagogía y los profesores. Asimismo, estos últimos presentaron una tendencia a construir gráficos utilizando el plano cartesiano con pares ordenados, no así los alumnos de los primeros años. 
Espinel, Bruno y Plasencia (2008) presentan los resultados de 190 estudiantes para profesores de la Universidad de Laguna (España), quienes habían recibido 12 horas de formación en Estadística, que incluyó conocimientos básicos sobre representación gráfica. El objetivo fue evaluar la comprensión de gráficas estadísticas de los futuros profesores como una primera fase en el diseño de materiales para mejorar su formación como profesores. Utilizaron 6 de los 12 ítems de delMas, Garfield y Ooms (2005). Los resultados señalan que la formación recibida por los futuros profesores les ayudó únicamente a explicitar información de los gráficos pero no a razonar más allá de la información proporcionada en el gráfico cartesiano. Según Espinel, Bruno y Plasencia (2008) los futuros profesores comprenden lo esencial de la estadística descriptiva pero carecen de experiencia para interpretar gráficos y cometen errores relacionados con la simetría, valores extremos y frecuencias acumuladas, identifican incorrectamente las variables relevantes y fracasan al interpretar la distribución de datos en un histograma. Los estudiantes no tienen en cuenta la distribución como un todo, sino que se centran en aspectos específicos, tales como el promedio o el valor extremo.

Dentro de este grupo de investigaciones también se encuentran los trabajos publicados por González y Pinto (2008) (mencionados en la sección 2.1). González y Pinto se interesaron en estudiar el CDC de los futuros profesores sobre el tema de la representación gráfica.

Más recientemente, Batanero, Arteaga y Ruiz (2009) presentaron los resultados de una investigación cuyo propósito fue evaluar la competencia gráfica de 88 futuros profesores de Primaria (en Granada, España) cuando mediante la elaboración de un proyecto estadístico cuyo objetivo fue proporcionarles información útil a los formadores de profesores (ver Godino, et al, 2008) sobre "Revisa tus intuiciones acerca del azar". En el desarrollo del proyecto, los participantes tuvieron la libertad de elaborar y usar cualquier gráfico estadístico y sintetizar y trabajar con algún ordenador si así lo deseaban. Utilizando el análisis semiótico de Font, Godino y D’Amore (2007), analizaron la producción e interpretación de gráficas de los estudiantes.

A partir de las respuestas de los futuro profesores, Batanero, Arteaga y Ruiz identificaron y caracterizaron cuatro niveles de complejidad semiótica en la construcción e interpretación de los gráficos: (1) representa las respuestas de aquellos alumnos que representan gráficamente únicamente sus resultados individuales, (2) cuando se representan los valores propios para el número de caras, (3) producción separada de gráficas por cada distribución, y (4) producción de gráfica conjunta de dos distribuciones. En general, los autores encontraron que los futuros profesores interpretan correctamente o parcialmente los gráficos, en todos los niveles, y la dificultad de interpretación de los gráficos incrementó con su complejidad semiótica. Una importante parte de los estudiantes que daban respuestas correspondientes a 2 y 4 , aun cuando construyeron correctamente los gráficos no los interpretaron o sólo lo hicieron parcialmente. Quedó demostrado que los futuros profesores no están familiarizados con el desarrollo de proyectos estadísticos o actividades modeladas. Batanero, Arteaga y Ruiz (2009) concluyen que la construcción e interpretación de gráficas confirma algunas de las dificultades descritas en Espinel, Bruno y Plasencia (2008). 


\subsubsection{Estudios sobre la formación de profesores en la enseñanza de la representación gráfica}

En esta categoría se agrupan aquellos estudios que tienen como propósito implementar una estrategia para formar a los profesores de Estadística en un tópico de estudio, como es la RG. Entre los estudios que abordan este tema está el de Chadjipadelis (1999) que desarrolla un programa para mejorar la formación de profesores de educación primaria en seis fases entre las que incluye el diseño, implementación, recogida de datos y evaluación por parte del profesor de un proyecto para la enseñanza de un tópico estadístico. Nicholson y Darnton (2003) sugieren usar en el aula actividades que impliquen contextos reales que motiven la discusión para lograr la comprensión del concepto y para que los profesores conozcan las concepciones, errores y dificultades de sus estudiantes. Lopes (2006) implementó un proyecto de comunidad de práctica como estrategia para la formación y desarrollo del conocimiento profesional de los profesores de Estadística de primaria. Pfannkuch (2006) realizó un estudio para mejorar la enseñanza y aprendizaje del gráfico de caja basado en el modelo de Wild y Pfannkuch (1999) sobre el razonamiento inferencial informal. Finalmente, Gould y Peck (2004) proponen un programa de formación de profesores Estadística de nivel secundaria denominado INSPIRE (Insight into Statistical Practice, Instruction and Reasoning).

Como puede apreciarse, la investigación generada sobre la RG en Estadística es muy diversa en cuanto a propósitos, marcos de referencia y técnicas e instrumentos de recogida de datos. Sin embargo, se aprecia una inclinación de investigaciones dirigidas a estudiar y comprender el pensamiento y conocimiento del estudiante y más recientemente sobre el conocimiento del profesor.

De la investigación generada acerca del conocimiento del profesor sobre la RG se puede apreciar un crecimiento en el número de investigaciones en los últimos tres años. Los trabajos presentados en esta sección permiten concluir que cerca del $80 \%$ se realizaron con estudiantes para profesor, principalmente del nivel Primaria y cerca del 60\% de éstos con la ayuda de un instrumento cuyo análisis y resultados fue de corte cuantitativo. Por otra parte, los marcos teóricos desde donde se estudia la RG son diversos, por un lado encontramos estudios cuyo interés fueron las concepciones, otros sobre el sentido de los datos, el sentido crítico, los gráficos en medios de comunicación impreso, las RG de las distribuciones o las dificultades de los profesores.

\subsection{PERSPECTIVAS COGNITIVAS DEL DESARROLLO DE LA REPRESENTACIÓN GRÁFICA EN ESTADÍSTICA}

A partir de esta revisión de la literatura, se procedió a realizar una exploración y análisis empírico de las investigaciones realizadas hasta el momento sobre tres elementos importantes: (1) el estudio de los niveles de comprensión gráfica, (2) los principales tópicos estudiados acerca de la representación de datos, y (3) los diseños metodológicos e instrumentos de investigación utilizados para valorar la comprensión de la RG. Estos aspectos jugaron un papel esencial para la delimitación y alcance de los objetivos de la tesis y para la definición de los aspectos metodológicos del estudio. 


\subsubsection{Niveles cognitivos de la comprensión gráfica}

En esta investigación se entiende por niveles cognitivos de la comprensión gráfica a las diferentes categorías o grados de desarrollo cognitivo que alcanza todo ciudadano en la comprensión de la RG, con base en un referente teórico determinado. Jollife (1991 en Friel, Curcio y Bright, 2001) los denomina tipos de comportamiento (kinds of behaviors), Curcio (1987) y Friel, Curcio y Bright (2001, p.129) los llama niveles de comprensión gráfica (levels of graph comprenhension); Sorto (2004) utiliza el término demandas cognitivas (cognitive demands) y las define como aquellos procesos mentales que las personas desarrollan cuando aprenden un tópico matemático; Garfield (2002) los llama categorías (categories) o tipos de resultados esperados de aprendizaje (type of learning outcome) y, a las habilidades específicas a desarrollar en los estudiantes, las llama tareas (tasks); Wu (2004) define la comprensión de gráficos estadísticos en términos de aspectos, elementos o fases (aspects).

Curcio (1987 y 1989) distingue tres niveles de comprensión gráfica:

a. Leer los datos, atendiendo únicamente los hechos explícitamente representados.

b. Leer entre los datos, lo cual requiere comparaciones, conceptos y técnicas matemáticas.

c. Leer más allá de los datos, que requiere la extensión, predicción o inferencia.

Como se mencionó con anterioridad, Shaughnessy (2007), con base en los argumentos presentados en Shaughnessy, Garfield y Greer (1996), afirma que se requiere un cuarto nivel cognitivo para estudiar la comprensión gráfica y que va más allá de los datos, esto es, "leer detrás de los datos" (reading behind the data).

En Friel, Curcio y Bright (2001) se amplía la información sobre la clasificación de Curcio (ver Tabla 2.1) a manera de taxonomía de los niveles de comprensión gráfica. En esta segunda versión, los autores incorporan una denominación diferente para cada nivel: elemental (extraer información de los datos), intermedio (encontrar relaciones en los datos) y en conjunto (ir más allá de los datos).

Una segunda clasificación de los niveles de aprendizaje proviene de Porter y Smithson (2001) y Porter (2002 en Sorto, 2004). Su propuesta se define en función de las actividades o demandas cognitivas vinculadas con diversas conductas de los estudiantes cuando aprenden los tópicos matemáticos específicos. Proponen cinco demandas cognitivas: memorizar hechos, definiciones y fórmulas; desarrollar procedimientos, resolver problemas rutinarios; comunicar en forma oral y escrita la comprensión de conceptos; resolver problemas no rutinarios, hace conexiones; y conjeturar, generalizar y probar (ver Tabla 2.2). 
Tabla 2.1. Taxonomía de habilidades requeridas para la comprensión gráfica según Curcio (1987) y Friel, Curcio y Brigth (2001)

\begin{tabular}{|c|c|c|}
\hline $\begin{array}{c}\text { ELEMENTAL } \\
\text { Leer datos } \\
\text { (extraer información de los } \\
\text { datos) }\end{array}$ & $\begin{array}{c}\text { INTERMEDIO } \\
\text { Leer entre los datos } \\
\text { (encontrar relaciones en los } \\
\text { datos) }\end{array}$ & $\begin{array}{c}\text { CONJUNTO } \\
\text { Leer más allá de los datos } \\
\text { (ir más allá de los datos) }\end{array}$ \\
\hline $\begin{array}{l}\text { - Lectura literal del gráfico } \\
\text { - Simplemente identificar los } \\
\text { hechos explícitamente en el } \\
\text { gráfico } \\
\text { - Extraer información elemental } \\
\text { - Identificar la información } \\
\text { encontrada en el título del } \\
\text { gráfico y las etiquetas de los } \\
\text { ejes } \\
\text { - No hay interpretación } \\
\text { - Es un nivel cognoscitivo muy } \\
\text { bajo de tarea } \\
\text { - Observar simples hechos y } \\
\text { relaciones en los datos } \\
\text { presentados gráficamente } \\
\text { - Interpretar relaciones cuando } \\
\text { las respuestas están } \\
\text { parafraseadas o expresadas en } \\
\text { los hechos } \\
\text { - Identificar o leer los } \\
\text { especificadores del gráfico }\end{array}$ & $\begin{array}{l}\text { - Interpretación de los datos en } \\
\text { el gráfico } \\
\text { - Habilidad para comparar } \\
\text { cantidades (ej. más grande, } \\
\text { más pequeño) } \\
\text { - Uso de otros conceptos } \\
\text { matemáticos o técnicos (ej. } \\
\text { suma, resta) } \\
\text { - Identificar las relaciones } \\
\text { matemáticas expresadas en el } \\
\text { gráfico } \\
\text { - Es lo que la mayoría de las } \\
\text { pruebas evalúa } \\
\text { - Requieren al menos de la } \\
\text { etapa de lógica e inferencia } \\
\text { pragmática necesaria } \\
\text { - Tanto las preguntas como las } \\
\text { respuestas se derivan del texto } \\
\text { - La respuesta está basada en los } \\
\text { datos presentados en el gráfico } \\
\text { - Reducir el número de } \\
\text { categorías de los datos a través } \\
\text { de una compilación y } \\
\text { combinación de operaciones } \\
\text { - Observar relaciones en un } \\
\text { gráfico e interpretarlas como } \\
\text { una presentación visual sin } \\
\text { referencia al significado de } \\
\text { elementos del gráfico en el } \\
\text { contexto } \\
\text { - Interpretar relaciones } \\
\text { las partes de los datos } \\
\text { las características del gráfico y } \\
\text { mayor atención a los } \\
\text { especificadores }\end{array}$ & $\begin{array}{l}\text { - Predecir o inferir de los datos } \\
\text { - Utiliza esquemas de } \\
\text { exploración previos (ej. } \\
\text { conocimiento previo, } \\
\text { conocimiento memorístico) } \\
\text { - La inferencia está hecha sobre } \\
\text { una "base de datos" en la } \\
\text { mente del lector, no el gráfico } \\
\text { - Reducción de todos los datos a } \\
\text { simples enunciados o } \\
\text { relaciones } \\
\text { - Interpretar relaciones cuando } \\
\text { las respuestas requieran } \\
\text { enunciados que vayan más allá } \\
\text { de la relación o de los } \\
\text { términos técnicos } \\
\text { - Determinar los valores de los } \\
\text { datos que se expresan en el } \\
\text { gráfico como evidencia para } \\
\text { soportar o rechazar una } \\
\text { proposición } \\
\text { - Autoevaluar la propia } \\
\text { evidencia generada por los } \\
\text { datos cuantitativos } \\
\text { - Comprender la estructura } \\
\text { profunda de los datos en su } \\
\text { totalidad, comparando } \\
\text { tendencias y observando } \\
\text { grupos } \\
\text { - Síntesis o integración de las } \\
\text { mayoría o de todos los valores } \\
\text { graficados }\end{array}$ \\
\hline
\end{tabular}


Tabla 2.2. Taxonomía de las demandas cognitivas de aprendizaje matemático, según Porter y Smithson (2001) y Porter (2002 en Sorto, 2004)

\begin{tabular}{|c|c|c|c|c|}
\hline $\begin{array}{c}A \\
\text { Memorizar } \\
\text { hechos, } \\
\text { definiciones y } \\
\text { fórmulas }\end{array}$ & $\begin{array}{c}B \\
\text { Realizar } \\
\text { procedimientos, } \\
\text { resolver problemas } \\
\text { rutinarios }\end{array}$ & $\begin{array}{c}C \\
\text { Comunicar la } \\
\text { comprensión de } \\
\text { conceptos }\end{array}$ & $\begin{array}{c}D \\
\text { Resolver } \\
\text { problemas no } \\
\text { rutinarios, hacer } \\
\text { conexiones }\end{array}$ & $\begin{array}{c}E \\
\text { Conjeturar, } \\
\text { generalizar, } \\
\text { probar }\end{array}$ \\
\hline $\begin{array}{l}\text { - Reconocer } \\
\text { - Identificar } \\
\text { - Recordar } \\
\text { - Recitar } \\
\text { - Nombrar } \\
\text { - Llamar }\end{array}$ & $\begin{array}{l}\text { - Hacer cálculos } \\
\text { - Hacer } \\
\text { observaciones } \\
\text { - Tomar } \\
\text { mediciones } \\
\text { - Comparar } \\
\text { - Desarrollar } \\
\text { fluidez }\end{array}$ & $\begin{array}{l}\text { - Comunicar ideas } \\
\text { matemáticas } \\
\text { - Uso de } \\
\text { representaciones } \\
\text { para modelos de } \\
\text { ideas } \\
\text { matemáticas } \\
\text { - Explicar } \\
\text { hallazgos y } \\
\text { resultados de } \\
\text { análisis } \\
\text { estadísticos } \\
\text { - Explicar el } \\
\text { razonamiento } \\
\text { - Describir } \\
\text { - Seleccionar }\end{array}$ & $\begin{array}{l}\text { - Aplicar y adaptar } \\
\text { una variedad de } \\
\text { estrategias } \\
\text { apropiadas para } \\
\text { resolver } \\
\text { problemas no } \\
\text { rutinarios } \\
\text { - Aplicar las } \\
\text { matemáticas } \\
\text { fuera del } \\
\text { contexto } \\
\text { matemático } \\
\text { - Analizar datos, } \\
\text { reconocer } \\
\text { patrones } \\
\text { - Explorar } \\
\text { - Juzgar }\end{array}$ & $\begin{array}{l}\text { - Completar } \\
\text { demostraciones } \\
\text { - Formular e } \\
\text { investigar } \\
\text { conjeturas } \\
\text { matemáticas } \\
\text { - Inferir } \\
\text { información de } \\
\text { los datos y hacer } \\
\text { predicciones } \\
\text { - Determinar la } \\
\text { verdad de un } \\
\text { modelo o } \\
\text { proposición } \\
\text { matemática }\end{array}$ \\
\hline
\end{tabular}

Garfield (2002), delMas (2002) y Garfield, delMas y Chance (2003) organizan los resultados esperados del aprendizaje en Estadística en tres categorías: alfabetización estadística, razonamiento estadístico y pensamiento estadístico (ver Tabla 2.3).

En su investigación sobre la comprensión gráfica en Estadística con estudiantes de una escuela secundaria de Singapur, Wu (2004) define ésta en función de cuatro elementos: lectura, interpretación, construcción y evaluación de gráficos. Cada elemento cuenta con varios componentes. Las habilidades que debe tener un estudiante de secundaria en cada elemento son:

a. Lectura del gráfico: extraer los datos directamente de uno o más gráficos y generar información calculando o mostrando datos de forma explícita en uno o más gráficos.

b. Interpretación de gráficos: formular opiniones de uno o más gráficos.

c. Construcción de gráficos: presentar o editar datos en forma gráfica.

d. Evaluación de gráficos: evaluar un gráfico respecto su exactitud y efectividad

Más recientemente, Aoyama (2006 y 2007) identificó cinco diferentes niveles que representan la ella llama la "jerarquía de la interpretación gráfica" en los estudiantes. Aoyama las clasifica por niveles:

Nivel 1. Idiosincrático.

Nivel 2. Lectura básica del gráfico.

Nivel 3. Literal / Racional.

Nivel 4. Crítico. 
Nivel 5. Hipotetizando y modelando.

Tabla 2.3. Taxonomía sobre los resultados esperados de aprendizaje en Estadística según Garfield (2002) y Garfield, delMas y Chance (2003)

\begin{tabular}{|c|c|c|}
\hline Alfabetización estadística & Razonamiento estadístico & Pensamiento estadístico \\
\hline $\begin{array}{l}\text { - Supone } \\
\text { conocimiento/comprensión y } \\
\text { uso del lenguaje básico y de } \\
\text { las herramientas de la } \\
\text { Estadística } \\
\text { - Conocimiento del significado } \\
\text { de los términos estadísticos } \\
\text { - Conocimiento del uso de los } \\
\text { símbolos estadísticos } \\
\text { - Reconocimiento y capacidad } \\
\text { de interpretar representaciones } \\
\text { de datos } \\
\text { - Incluye técnicas básicas e } \\
\text { importantes que pueden ser } \\
\text { usadas para comprender } \\
\text { información estadística o } \\
\text { resultados de investigación } \\
\text { - Organizar datos, construir y } \\
\text { presentar tablas y trabajar con } \\
\text { diferentes representaciones de } \\
\text { datos } \\
\text { - Incluye la comprensión de } \\
\text { conceptos, vocabulario y } \\
\text { símbolos } \\
\text { proluye una comprensión de la } \\
\text { de incertidumbre }\end{array}$ & $\begin{array}{l}\text { - Es la forma en que la gente } \\
\text { razona con ideas estadísticas y } \\
\text { adquiere sentido la } \\
\text { información estadística } \\
\text { - Supone conexiones de un } \\
\text { concepto con otro (ej. media y } \\
\text { desviación estándar) } \\
\text { Combinar ideas acerca de los } \\
\text { datos y del azar } \\
\text { - Significa comprender y ser } \\
\text { capaz de explicar procesos } \\
\text { estadísticos } \\
\text { - Interpretar completamente los } \\
\text { resultados estadísticos } \\
\text { - Hacer interpretaciones basadas } \\
\text { sobre un conjunto de datos o } \\
\text { resumen estadísticos de datos }\end{array}$ & $\begin{array}{l}\text { - Supone un conocimiento del } \\
\text { por qué y cómo se realizan las } \\
\text { investigaciones estadísticas } \\
\text { - Reconocimiento y } \\
\text { comprensión de los procesos } \\
\text { de investigación completos (ej. } \\
\text { preguntas de recogida de } \\
\text { datos, supuestos de diseño de } \\
\text { pruebas, etc.) } \\
\text { - Comprensión de cómo se usan } \\
\text { los modelos para simular } \\
\text { fenómenos aleatorios, cómo se } \\
\text { producen los datos para } \\
\text { estimar probabilidades } \\
\text { - Reconocimiento de cómo, } \\
\text { cuándo y por qué existen } \\
\text { herramientas inferenciales } \\
\text { - Comprender y utilizar el } \\
\text { contexto de un problema de } \\
\text { investigación } \\
\text { - Comprender el por qué y el } \\
\text { cómo las “grandes ideas" } \\
\text { subyacen en la investigación } \\
\text { estadística } \\
\text { - Comprensión de la naturaleza } \\
\text { de la variación y cuándo usar } \\
\text { apropiadamente métodos de } \\
\text { análisis de datos (ej. } \\
\text { resúmenes estadísticos y } \\
\text { presentaciones visuales) } \\
\text { - Supone la comprensión de la } \\
\text { naturaleza del muestreo, cómo } \\
\text { hacer inferencias a partir de la } \\
\text { muestra y por qué los diseños } \\
\text { experimentales son necesarios } \\
\text { para establecer causas }\end{array}$ \\
\hline
\end{tabular}

Si comparamos estos referentes teóricos de los niveles cognitivos de la RG observamos, por un lado, que la clasificación de Friel, Curcio y Bright (2001) está exclusivamente enfocada a la comprensión gráfica y ha sido utilizada predominantemente en los niveles escolares elementales. Su uso permite ubicar el proceso de adquisición, extensión y profundización de la comprensión gráfica de manera gradual. La clasificación de Porter y Smithson (2001) es una taxonomía para el aprendizaje en matemáticas independiente del tópico (ej. Álgebra, Geometría, Cálculo, Estadística). Sus niveles ejemplifican de manera más fraccionada las diferentes fases de aprendizaje matemático. Por otra parte, Garfield (2002), presenta una clasificación originada a partir de estudios en 
educación estadística y enfocada al aprendizaje de la Estadística a nivel de licenciatura y sobre diferentes tópicos de la disciplina (como puede ser la representación de datos). Wu (2004), con base en Curcio (1987) y Friel, Curcio y Bright (2001) hace unas adaptaciones a los niveles cognitivos y los adecua a nivel secundaria. Finalmente Aoyama (2006 y 2007) estudió las gráficas a partir de su interpretación y su propuesta de origina del trabajo con estudiantes de diferentes niveles educativos.

Por otro lado, Sorto (2004, p.84) realizó un cuadro-resumen de las tareas que demanda el tema de Análisis de Datos en Estadística. En este cuadro, incorpora las tareas específicas que demanda la RG en los estudiantes y profesores de nivel superior. La autora agrupa estas tareas utilizando como referente las categorías de delMas (2002) y Garfield (2002). La Tabla 2.4 presenta esta información.

Tabla 2.4. Tareas específicas que demanda la representación gráfica según Sorto (2004) con base en la clasificación de delMas (2002) y Garfield (2002)

\begin{tabular}{|c|c|c|}
\hline Alfabetización estadística & Razonamiento estadístico & Pensamiento estadístico \\
\hline $\begin{array}{l}\text { - Identificar datos categóricos y } \\
\text { numéricos } \\
\text { - Crear y leer información } \\
\text { presentada en representaciones de } \\
\text { datos }\end{array}$ & $\begin{array}{l}\text { - Formular preguntas que puede ser } \\
\text { dirigidas a partir de una colección } \\
\text { de datos } \\
\text { - Interpretar e integrar información } \\
\text { presentada en las representaciones } \\
\text { de los datos } \\
\text { - Identificar los malos usos de } \\
\text { causa-efecto en las } \\
\text { interpretaciones de correlación }\end{array}$ & $\begin{array}{l}\text { - Tomar decisiones sobre qué y } \\
\text { cómo medir } \\
\text { - Ampliar, predecir o inferir a partir } \\
\text { de la información presentada en } \\
\text { representaciones de datos para } \\
\text { responder a preguntas implícitas }\end{array}$ \\
\hline
\end{tabular}

La clasificación de Garfield y colaboradores es una taxonomía diseñada para organizar el contenido o un tópico específico en relación con los diferentes niveles cognitivos previstos en el aprendizaje de la Estadística. De este modo, sobre un mismo tópico (situación o caso), es posible incorporar elementos importantes sobre su alfabetización, su razonamiento y sobre su pensamiento estadístico. Para ello, delMas (2002) y Garfield, delMas y Chance (2003) presentan (ver Tabla 2.5) el tipo de tareas que permiten distinguir los tipos de ítems según los niveles cognitivos de aprendizaje. Estas preguntas permitirán construir los objetivos (conocimientos y habilidades) a desarrollar en los estudiantes por cada tópico estadístico.

delMas, Garfield y Ooms (2005) ampliaron los objetivos a desarrollar en los estudiantes de licenciatura sobre la lectura e interpretación de distribuciones gráficas. A nivel de la alfabetización estadística sobre la RG afirman que los estudiantes deben por lo menos:

- comprender información presentada en un típico gráfico estadístico de distribución (ej. de puntos, histograma y de caja),

- identificar correctamente y comprender las escalas de medición,

- identificar algunas formas comunes de distribución (ej. normal, sesgadas, bimodal, uniforme),

- distinguir entre un gráfico de barras y serie de tiempo de los histogramas, y

- comprender los términos relacionados con la distribución. 
Asimismo, a nivel de razonamiento estadístico sobre RG, según delMas, Garfield y Ooms (2005) los estudiantes deben:

- identificar un gráfico a partir de la descripción de una variable,

- elaborar dos versiones de gráficos de los mismos datos,

- comprender el impacto de incluir o remover valores, y

- comprender el razonamiento de las formas de distribución.

Tabla 2.5. Tareas que pueden distinguir el tipo de preguntas para los niveles de comprensión del aprendizaje estadístico, en delMas (2002) y Garfield, delMas y Chance (2003)

\begin{tabular}{ccc}
\hline Alfabetización estadística & Razonamiento estadístico & Pensamiento estadístico \\
\hline ¿Qué? & ¿Por qué? & Aplica \\
Define & ¿Cómo? & Critica \\
Identifica & Explica (el proceso) & Evalúa \\
Describe & & \\
Parafrasea & & \\
Traslada & \\
Interpreta & & \\
Lee & & \\
Construye & & \\
\hline
\end{tabular}

La clasificación de Garfield y colaboradores permitirá comprender el proceso de adquisición, extensión y profundización de la comprensión gráfica y, al mismo tiempo, identificar y clasificar los contenidos y objetivos de aprendizaje por tópico específico, construir la secuencia de aprendizaje y ayudar en la construcción de diferentes instrumentos de valoración. Esta clasificación ha sido asumida en otros estudios hechos con profesores de nivel educación superior como el de Sorto (2004).

\subsubsection{Tópicos de estudio de la representación de datos}

Sobre los diferentes tópicos de la representación de datos, además de los referentes teóricos revisados, se analizaron con particular atención tres documentos más: los documentos de la NCTM (1991 y 2003), los trabajos de Garfield, delMas y Chance (2003) y Sorto (2004).

Con base en los estándares de Estadística de la NCTM (1991 y 2003), se identificaron y agruparon los objetivos de la RG y el tipo de gráfico por nivel educativo (ver Tabla 2.6). Esta organización permite dar cuenta de la secuencia de aprendizaje, de las tareas y alcances del estudio de la representación de datos en alumnos americanos.

Por su parte, Garfield, delMas y Chance (2003) desarrollaron una agrupación de todos los tópicos de un curso de Estadística (a nivel superior), a partir de tres fuentes: investigadores, comisión de consejeros y voluntarios. Después de varias discusiones desarrollaron una lista de tópicos que se sugiere que formen parte de un programa de Estadística a nivel superior. A continuación se mencionan la agrupación de los tópicos sobre el tema de la representación de datos: 
- Representación de datos. Selección apropiada de gráficos, construcción e interpretación de tablas y gráficas, resumir gráficos para variables simples tanto cuantitativos como categóricos, valores atípicos, reconocimiento de formas/tendencias de datos.

- Medidas de centralización. Estimación de medidas de centralización a partir de gráficos.

- Medidas de dispersión. Estimación de medias de dispersión a partir de gráficos.

- Comparación de grupos. Comparar dos o más grupos usando gráficos y/o resúmenes numéricos.

- Datos bivariados cuantitativos. Diagrama de dispersión.

- Datos bivariados categóricos. Tablas de doble vía.

Tabla 2.6. Objetivos de aprendizaje del Estándar de Estadística, según NCTM (1991 y 2003) en EEUU

\begin{tabular}{|c|c|c|}
\hline Nivel & Objetivos & Gráficos \\
\hline $\mathrm{K}-4$ & $\begin{array}{l}\text { - } \quad \text { Recoger, organizar y describir datos } \\
\text { - } \quad \text { Construir, leer e interpretar datos presentados de } \\
\text { manera organizada } \\
\text { - } \quad \text { Formular y resolver problemas que impliquen } \\
\text { recogida y análisis de datos } \\
\text { - Explorar el concepto de causalidad }\end{array}$ & $\begin{array}{l}\text { Pictogramas } \\
\text { Inicios del gráfico de } \\
\text { puntos y de barras } \\
\operatorname{NCTM}(2003 \text {, nivel } 3-5) \text {, } \\
\text { adicional: } \\
\text { Lineales }\end{array}$ \\
\hline $5-8$ & $\begin{array}{l}\text { - } \begin{array}{l}\text { Recoger, organizar y analizar datos de forma } \\
\text { sistemática }\end{array} \\
\text { Elaborar, leer e interpretar tablas y diversas } \\
\text { representaciones gráficas, } \\
\text { - } \quad \text { Formular inferencias y argumentos convincentes que } \\
\text { se basen en el análisis de datos } \\
\text { Evaluar argumentos que estén basados en el análisis } \\
\text { de datos } \\
\text { Llegar a apreciar los métodos estadísticos como } \\
\text { medios potentes de toma de decisiones }\end{array}$ & $\begin{array}{l}\text { NCTM, 2003, nivel 6-8), } \\
\text { adicional: } \\
\text { Histograma } \\
\text { Cajas }\end{array}$ \\
\hline $9-12$ & $\begin{array}{l}\text { Asimilar y extraer inferencias a partir de diagramas, } \\
\text { tablas y gráficas que recojan datos de situaciones del } \\
\text { mundo real } \\
\text { - } \quad \text { Utilizar curvas de ajuste para efectuar predicciones a } \\
\text { partir de los datos } \\
\text { Entender y aplicar medidas de centralización, } \\
\text { dispersión y correlación } \\
\text { - Comprender el proceso de muestreo y reconocer el } \\
\text { papel que cumple en las afirmaciones estadísticas } \\
\text { Diseñar un experimento estadístico para estudiar un } \\
\text { problema, ejecutar el experimento y comunicar los } \\
\text { resultados } \\
\text { Analizar el efecto que producen las transformaciones } \\
\text { en la variable estadística sobre las medidas de } \\
\text { centralización y dispersión }\end{array}$ & $\begin{array}{l}\text { Distribuciones } \\
\text { Regresión }\end{array}$ \\
\hline $\begin{array}{l}\text { Pre- } \\
\text { universitario }\end{array}$ & $\begin{array}{l}\text { - Transformar datos como ayuda para la interpretación } \\
\text { de datos y la predicción } \\
\text { - Comprobar hipótesis utilizando la Estadística de } \\
\text { forma adecuada }\end{array}$ & \\
\hline
\end{tabular}


Por último, Sorto (2004) realizó un análisis de los contenidos y las demandas cognitivas para el aprendizaje de los contenidos estadísticos dentro del tema de Análisis de Datos. Construyó una matriz de los diversos contenidos vistos en diferentes programas oficiales de EEUU desde preescolar hasta el nivel de secundaria y con base en Porter y Smithson (2001), organizó todos los contenidos en siete "grandes ideas" con sus correspondientes tópicos:

1. Formulación de preguntas, diseño de estudios y colección de datos.

2. Representación categórica de datos: gráficos de barras, circular, pictogramas y tablas.

3. Representación numérica de datos: gráficos de tallo y hoja, histograma y de cajas.

4. Representación bivariada de datos: gráficos de dispersión, lineal y regresión.

5. Formas de distribución: formas de distribución de datos, simetría, curtosis, valores atípicos, conglomerados.

6. Medidas de centralización: media, mediana y moda.

7. Medidas de dispersión (recorrido): rango, RIQ, desviación estándar.

Sorto (2004) utilizó esta agrupación para diseñar el instrumento de recogida de información de su tesis doctoral que denominó Evaluación del Conocimiento Estadístico para la Enseñanza (Statistical Knowledge for Teaching Assessment) y que estaba dirigido a profesores de nivel superior. Su objetivo era doble: uno, valorar el conocimiento estadístico de los profesores sobre el tema de la representación de datos y otro, explorar este conocimiento estadístico aplicado a la enseñanza de la representación de datos. El instrumento consistió en ocho gráficos: barras, histograma, circular, pictograma, lineal, tallo y hoja, de dispersión, y de caja; clasificados entre las categorías 2,3 y 4 de su organización. Enfatizó sobre la representación de datos numéricos y las medidas de centralización y de dispersión. Suprimió representación de datos categóricos por ser fáciles (según una prueba piloto) y representación de datos bivariados por limitaciones de espacio y tiempo. Su trabajo se centró, en primer lugar, sobre aspectos de contenido estadístico (cinco de ocho ítems, con 11 de 17 preguntas), seguido del estudio del conocimiento sobre el aprendizaje del alumno (errores y dificultades) (tres de ocho ítems, seis de 17 preguntas).

Los estudios anteriores permiten visualizar tanto el desarrollo cognitivo de un estudiante que aprenda Estadística y $\mathrm{RG}$, como la relación que guardan diferentes contenidos estadísticos con la RG. De igual modo, se puede establecer la relación objetivo - contenido - gráfico, lo que permite obtener una imagen bastante completa de los gráficos que se estudian en los sistemas educativos (particularmente en Estados Unidos).

A partir de este análisis y de la revisión de algunos libros de texto de Estadística (aplicados en el área de Psicología y Educación, como Solanas, Salafranca, Fauquet y Núñez, 2005; APA, 2002) y los contenidos determinados en los programas de Estadística (ver Apéndice B) de nivel licenciatura, se delimitaron y definieron los tópicos a trabajar de la RG y sus correspondientes gráficos:

Representación categórica de datos: gráficos de barras, circular y puntos Representación numérica de datos: gráficos de tallo y hoja, histograma y de cajas 


\subsubsection{Diseño, instrumentos e ítems que estudian la representación gráfica}

Para identificar las características de los diseños de investigación, instrumentos de recogida de datos y características de los ítems que se han utilizado en los diversos estudios realizados sobre la RG se hizo un análisis en dos fases: primero, localización y análisis de los diseños e instrumentos de investigación; y segundo, análisis de los ítems que exploran la comprensión gráfica.

\subsubsection{Localización y análisis de los diseños e instrumentos de investigación}

El procedimiento fue localizar y analizar todos aquellos estudios que informaran sobre los instrumentos, técnicas de recogida de datos y procedimientos de análisis que utilizaron al investigar sobre la RG. Se examinaron trabajos como el de Mckenzie y Padilla (1986), Curcio (1987), Batanero, Godino y Navas (1997), Gordon (1998), Kurtz (1999), Menelaou (2000), Miller (2000), Peden (2001), Estrada (2002), Garfield (2003), Garfield, delMas y Chance (2003), Makar (2004), Canada (2004), Sorto (2004), entre otros. Interesó averiguar cómo estudiaron y analizaron la comprensión de la RG así como las características de sus diseños y procedimientos de investigación. La Tabla 2.7 presenta la matriz de una muestra de estos trabajos con la información de los objetivos de la investigación, las características del diseño y procedimiento metodológico, las principales fuentes bibliográficas utilizadas y/o la estructura del instrumento.

Como se puede apreciar, existe diversidad en los enfoques metodológicos y de investigación, así como de los instrumentos utilizados. Una explicación a esta diversidad son los diferentes marcos teóricos que sustentan cada estudio y esto tiene estrecha relación con la manera de estudiar la RG y por consiguiente los instrumentos de recogida de datos. Se encontraron diversas formas de aproximarse a la valoración del conocimiento de la RG (ej. cuestionario sobre situaciones-problema, estudios de casos y cuestionarios de opinión o tipo Likert). Sobresale el instrumento de Konold y Garfield (1993) el cual ha sido utilizado con mayor frecuencia, ya sea como referente para construir otros, o bien, usado parcial o totalmente. Igual se observa que prevalecen los estudios de corte cualitativo, los estudios de casos y el uso de la entrevista como recurso complementario para profundizar sobre los conocimientos del profesor.

Desde otro tipo de análisis, se hallaron estudios sobre las concepciones de la Estadística, de su enseñanza y aprendizaje y de algún tópico en concreto (ej. varianza, distribución, gráficas lineales, RG). 
Tabla 2.7. Matriz de los diseños e instrumentos de investigación sobre representación gráfica

\begin{tabular}{|c|c|c|c|}
\hline Autor (es) & Objetivo & Diseño y/ procedimiento & Basado en .../Rubros \\
\hline $\begin{array}{l}\text { Batanero, Godino } \\
\text { y Navas (1997) }\end{array}$ & $\begin{array}{l}\text { Conocer las } \\
\text { concepciones que los } \\
\text { profesores de primaria } \\
\text { tienen sobre los } \\
\text { promedios }\end{array}$ & $\begin{array}{l}\text { Encuesta a } 273 \text { profesores } \\
\text { Seis estudios de casos sobre las respuestas } \\
\text { incoherentes y falta de comprensión de } \\
\text { conceptos }\end{array}$ & $\begin{array}{l}\text { Konold y Garfield (1993) que miden } \\
\text { razonamiento estadístico }\end{array}$ \\
\hline Peden (2001) & $\begin{array}{l}\text { Explorar la } \\
\text { interpretación de } \\
\text { gráficos de dispersión } \\
\text { (estudiantes de psic.) }\end{array}$ & Ejercicio con cinco preguntas & Anscombe (1973) \\
\hline $\begin{array}{l}\text { Mckenzie y } \\
\text { Padilla (1986) }\end{array}$ & $\begin{array}{l}\text { Explorar la } \\
\text { construcción e } \\
\text { interpretación del } \\
\text { gráfico lineal } \\
\text { (estudiante de escuela } \\
\text { media y secundaria) }\end{array}$ & Encuesta & $\begin{array}{l}\text { Diseñado por los autores: } 26 \text { ítems } \\
\text { de opción múltiple }\end{array}$ \\
\hline Curcio (1987) & $\begin{array}{l}\text { Ampliar la perspectiva } \\
\text { del marco teórico de la } \\
\text { comprensión general } \\
\text { del discurso para } \\
\text { comprender un gráfico }\end{array}$ & $\begin{array}{l}\text { Estudio encuesta, correlacional y } \\
\text { comparación de variables }\end{array}$ & $\begin{array}{l}\text { Diseñado por los autores. } 12 \text { ítems } \\
\text { de opción múltiple. }\end{array}$ \\
\hline Garfield (2003) & $\begin{array}{l}\text { Evaluación del } \\
\text { razonamiento } \\
\text { estadístico }\end{array}$ & Encuesta & $\begin{array}{l}\text { Autores originales Konold y } \\
\text { Garfield (1993). Presentan } \\
\text { información de su validez, } \\
\text { construcción y confiabilidad. }\end{array}$ \\
\hline Kurtz (1999) & $\begin{array}{l}\text { Presenta ejercicios } \\
\text { para conectar al } \\
\text { alumno con el } \\
\text { aprendizaje de la } \\
\text { representación de } \\
\text { datos }\end{array}$ & $\begin{array}{l}\text { Es un libro de ejercicios con respuestas (pp. } \\
4-9 \text { ) }\end{array}$ & $\begin{array}{l}\text { Diseñado por el autor. } \\
\text { Rubros: } \\
\text { - Verdadero-Falso } \\
\text { (antecedentes de la } \\
\text { representación) } \\
\text { - Distribución de frecuencias } \\
\text { - Valores acumulados } \\
\text { - } \text { Gráficos: por intervalos, } \\
\text { - ordinales, nominal } \\
\text { - Preguntas breves }\end{array}$ \\
\hline $\begin{array}{l}\text { Garfield, J, } \\
\text { delMas, B. y } \\
\text { Chance, B. (2003) }\end{array}$ & $\begin{array}{l}\text { Es un programa de } \\
\text { EEUU, ARTIST } \\
\text { (Assessment Resouce } \\
\text { Tools for Improving } \\
\text { Statistical Thinking) } \\
\text { disponible en internet }\end{array}$ & $\begin{array}{l}\text { En una sección denominada Constructor de } \\
\text { evaluación, se puede obtener los ítems que } \\
\text { necesites sobre el tópico de interés. } \\
\text { Ver: } \\
\text { https://app.gen.umn.edu/artist/index.html }\end{array}$ & $\begin{array}{l}\text { Son } 146 \text { ítems sobre representación } \\
\text { de datos, subclasificados por tópico } \\
\text { y con base en los resultados de } \\
\text { aprendizaje clasificados en: } \\
\text { alfabetización, razonamiento y } \\
\text { pensamiento estadístico. }\end{array}$ \\
\hline Menelaou (2000) & $\begin{array}{l}\text { Estudia el desarrollo } \\
\text { de las concepciones } \\
\text { sobre variación de } \\
\text { estudiantes }\end{array}$ & Cuestionario abierto de 10 preguntas. & $\begin{array}{l}\text { Problemas } 7 \text { y } 10 \text {. Puede ser útil el } \\
\text { tipo de preguntas que se utiliza para } \\
\text { obtener diferentes niveles de } \\
\text { razonamiento. }\end{array}$ \\
\hline Makar (2004) & $\begin{array}{l}\text { Estudiar las formas de } \\
\text { comprensión de los } \\
\text { conceptos estadísticos } \\
\text { de variación y } \\
\text { distribución, } \\
\text { desarrollados en los } \\
\text { contextos de } \\
\text { aprendizaje acerca de } \\
\text { igualdad y evaluación } \\
\text { en futuros profesores. }\end{array}$ & $\begin{array}{l}\text { Cuestionario en dos partes. En la primera } \\
\text { (Impacto del curso) tiene cinco secciones y } \\
\text { la segunda (Preguntas sobre Estadística y } \\
\text { datos) consta de preguntas de selección y } \\
\text { abierta sobre conceptos estadísticos. }\end{array}$ & $\begin{array}{l}\text { La sección uno contiene: } \\
\text { antecedentes estadísticos, } \\
\text { expectativas, impacto de los temas } \\
\text { dados, impacto del tema de igualdad } \\
\text { para uso de datos y conformidad } \\
\text { (tipo Likert) con el curso. } \\
\text { La sección dos consistió en } 27 \text { ítems. } \\
\text { Sobre representación ver ítems: } 1-7 \text {, } \\
8-10,12,13-19,21,26,27\end{array}$ \\
\hline Estrada (2002) & $\begin{array}{l}\text { Estudiar los } \\
\text { conocimientos y } \\
\text { actitudes de los } \\
\text { profesores en } \\
\text { formación }\end{array}$ & $\begin{array}{l}\text { Cuestionario sobre conocimientos } \\
\text { estadísticos elementales, basado en Konold y } \\
\text { Garfield (1993). Ejemplos: } \\
\text { - concepto de media (2) } \\
\text { - interpretación de probabilidades } \\
\text { - representación gráfica y media } \\
\text { - interpretar datos de una encuesta } \\
\text { - relación media, mediana y moda y } \\
\text { distribuciones normales o no } \\
\text { - estimación, muestreo, representatividad }\end{array}$ & $\begin{array}{l}\text { Ver ítem. } 5 \text { sobre representación } \\
\text { gráfica y media }\end{array}$ \\
\hline
\end{tabular}


Continúa Tabla $2.8 \ldots$

\begin{tabular}{|c|c|c|c|}
\hline Autor (es) & Objetivo & Diseño y/ procedimiento & Basado en .../Rubros \\
\hline Gordon (1998) & $\begin{array}{l}\text { Estudiar las } \\
\text { concepciones del } \\
\text { estudiante sobre la } \\
\text { Estadística y del } \\
\text { proceso de aprendizaje } \\
\text { (estudiantes de } \\
\text { segundo año de } \\
\text { psicología) }\end{array}$ & 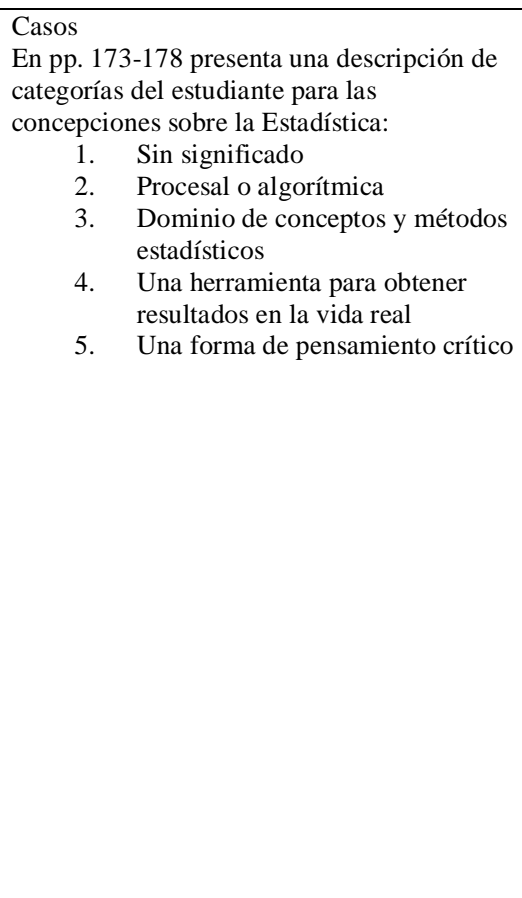 & $\begin{array}{l}\text { Incluye diferentes instrumentos: por } \\
\text { ejemplo: } \\
\text { A. Guía de preguntas de entrevista } \\
\text { para el estudio uno (preguntas } \\
\text { abiertas para conocer su } \\
\text { concepción) } \\
\text { B. Preparación para la encuesta } \\
\text { estadística (tipo autoreporte) } \\
\text { C. Forma de inscripción al Centro } \\
\text { de Aprendizaje de las } \\
\text { Matemáticas (información } \\
\text { demográfica, antecedentes } \\
\text { escolares y expectativas) } \\
\text { D. Encuesta sobre el curso de } \\
\text { Estadística en estudio uno } \\
\text { (sobre dificultades, errores, } \\
\text { preocupaciones, formas de } \\
\text { aprender Estadística - } \\
\text { autoevaluación a través de } \\
\text { preguntas abiertas) } \\
\text { E. Aprendizaje de la Estadística } \\
\text { (datos demográficos, preguntas } \\
\text { abiertas sobre cómo se aprende } \\
\text { Estadística, una escala tipo } \\
\text { Likert para autovalorar su } \\
\text { aprendizaje) } \\
\text { F. Guía de preguntas de entrevista } \\
\text { para estudiantes en estudio dos }\end{array}$ \\
\hline Miller (2000) & $\begin{array}{l}\text { Estudiar la concepción } \\
\text { y visión de los } \\
\text { profesores de la } \\
\text { Estadística desde el } \\
\text { enfoque teórico del } \\
\text { constructivismo }\end{array}$ & $\begin{array}{l}\text { Casos. Utiliza entrevistas con preguntas } \\
\text { abiertas, una pre y post observación. } \\
\text { Incluye: } \\
\text { - carta de solicitud de participación } \\
\text { - carta de consentimiento por parte del } \\
\text { participante }\end{array}$ & $\begin{array}{l}\text { Cuestionario por mail: información } \\
\text { general, percepción hacia la } \\
\text { Estadística, antecedentes y } \\
\text { enseñanza de la Estadística, } \\
\text { memorias personales en enseñanza } \\
\text { de la Estadística, el salón de clases } \\
\text { ideal, otros). } \\
\text { Entrevistas: enseñanza, aprendizaje } \\
\text { y estudiantes. Preguntas abiertas } \\
\text { para (a) autodescribir su forma de } \\
\text { enseñanza, cómo planea, } \\
\text { selecciona estrategias y recursos en } \\
\text { la enseñanza de la Estadística, (b) } \\
\text { su concepción de aprendizaje, del } \\
\text { aprendizaje del estudiante, forma } \\
\text { de evaluarlo) y (c) cómo enseña a } \\
\text { los estudiantes y cómo los evalúa, } \\
\text { expectativas del estudiante. } \\
\text { Contrastar con lo observado en } \\
\text { clases. }\end{array}$ \\
\hline Canada (2004) & $\begin{array}{l}\text { Concepciones de } \\
\text { profesores de primaria } \\
\text { sobre la variación }\end{array}$ & ND por ahora & $\begin{array}{l}\text { Post encuesta (datos y gráficos). Ver } \\
\text { items } 1 \mathrm{~b}, 1 \mathrm{c}, 2 \mathrm{a}, 2 \mathrm{~b}\end{array}$ \\
\hline Sorto (2004) & $\begin{array}{l}\text { Identificar los aspectos } \\
\text { importantes de } \\
\text { conocimiento } \\
\text { estadístico necesario } \\
\text { para la enseñanza en la } \\
\text { escuela media y } \\
\text { evaluar prospectiva de } \\
\text { las concepciones, } \\
\text { errores y obstáculos de } \\
\text { la Estadística para la } \\
\text { enseñanza del análisis } \\
\text { de datos }\end{array}$ & $\begin{array}{l}\text { Encuesta ( } 42 \text { profesores) y entrevista a } 7 \text {. La } \\
\text { encuesta tuvo como propósito conocer las } \\
\text { concepciones de los profesores para la } \\
\text { enseñanza del análisis de datos y de la } \\
\text { Estadística. La entrevista pretendió } \\
\text { profundizar en sus concepciones y evaluar la } \\
\text { confiabilidad del instrumento. }\end{array}$ & $\begin{array}{l}\text { Evaluación del conocimiento } \\
\text { estadístico para la enseñanza. Consta } \\
\text { de dos partes, en la primera es una } \\
\text { hoja de información demográfica y } \\
\text { antecedentes académicos; en la } \\
\text { segunda, ocho ítems de la prueba. } \\
\text { Presenta situaciones del área social. } \\
\text { Trae al final un ejemplo de la } \\
\text { entrevista para cada caso, en función } \\
\text { de las respuestas del cuestionario. }\end{array}$ \\
\hline
\end{tabular}




\subsubsection{Análisis de los ítems que exploran la representación gráfica.}

La siguiente fase de análisis fue revisar ítem por ítem cada instrumento utilizado en las investigaciones anteriores, con la finalidad de: a) identificar el marco teórico de la RG en que se sustenta, b) recoger las fuentes de validez en su construcción, c) identificar el tipo de gráficos utilizados y d) caracterizar el tipo de preguntas utilizadas.

Para cada ítem se analizaron los siguientes aspectos:

- autor / año,

- tipo de gráfico,

- dirigido a,

- contexto (área disciplinar que se hace referencia en el problema)

- objetivos de aprendizaje,

- clasificación según Curcio (1987): LD (leer datos), LED (leer entre datos) y LMAD (leer más allá de los datos),

- clasificación según Garfield (2002): alfabetización, razonamiento y pensamiento estadístico, $\mathrm{y}$

- clasificación según CDC: en conocimiento del contenido estadístico a enseñar, conocimiento de la estrategia y representación instrucctional y conocimiento del proceso de aprendizaje del estudiante.

La Figura 2.3 presenta un ejemplo del formulario utilizado para vaciar la información anterior.

Se registraron y analizaron cerca de 66 ítems, derivados principalmente de investigaciones (ej. Mckenzie y Padilla, 1986; Curcio, 1987; Batanero, Godino y Navas, 1997; Peden, 2001; Sorto, 2004) y de una base de ítems de Garfield (en el Constructor de Evaluaciones, ARTIST, The Assessment Builder, en http://data.gen.umn.edu/artist/assessment builder intro.html, recuperado en febrero de 2005). 


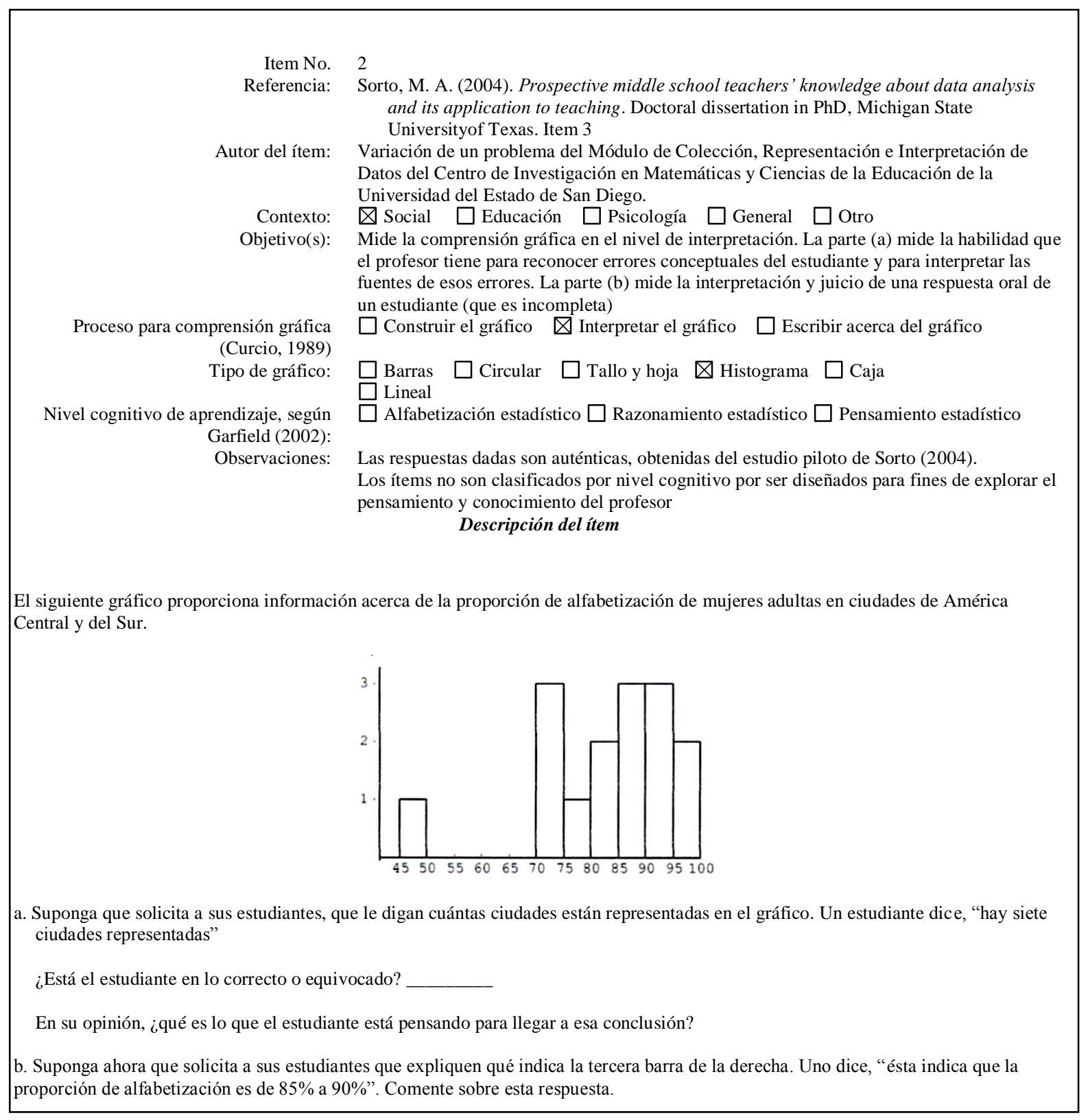

Figura 2.3. Ejemplo del tipo de análisis hecho por cada ítem que estudia la representación gráfica

Los resultados del análisis indicaron que la gran mayoría de los ítems miden el conocimiento del contenido estadístico; el 68\% de los ítems están vinculados con preguntas exclusivamente sobre la RG, mientras que el $22 \%$ incluye preguntas sobre el gráfico pero en relación a otros temas (medidas de centralización, de dispersión, muestreo, entre otros). Por último, del proceso de clasificación de las preguntas respecto del marco de referencia resultó más sencillo hacerlo con el modelo de Garfield (2002), esto es atribuible principalmente al nivel de complejidad de las preguntas de los ítems revisados y a que, en 
su mayoría, se trataron de ítems dirigidos a estudiantes de licenciatura, estudiantes para profesor o profesores en ejercicio.

\subsection{LA REPRESENTACIÓN GRÁFICA EN EDUCACIÓN SUPERIOR: EL PENSAMIENTO ESTADÍSTICO}

El análisis de los niveles cognitivos, de los tópicos de estudio y de los diseños, instrumentos y la revisión de ítems ayudó a construir un listado de objetivos de aprendizaje que se espera desarrollen los estudiantes sobre el tema de la RG en un curso de Estadística a nivel superior, los cuales a continuación se presentan por nivel de cognitivo. Estos objetivos representan el marco conceptual y metodológico en que se sustentó la tesis.

\subsubsection{Objetivos sobre representación gráfica, por nivel cognitivo}

Los objetivos se presentan según los niveles cognitivos de Garfield (2002), que están enfocados hacia el aprendizaje de la Estadística en el nivel de licenciatura. Las preguntas y palabras clave (que se encuentran entre paréntesis) ayudaron a diseñar y distinguir las tareas (conocimiento y habilidades), a desarrollar en los estudiantes por cada nivel cognitivo.

\subsubsection{Alfabetización estadística}

Responde al ¿qué?, define, identifica, describe, parafrasea, traslada, interpreta, lee, construye.

- Recoger, capturar, organizar datos de forma sistemática en un contexto apropiado y real.

- Conocer/comprender y usar el lenguaje básico y las herramientas de la Estadística (ej. conocimiento del significado de los términos o conceptos estadísticos, conocimiento del uso de los símbolos estadísticos, vocabulario y comprensión de la probabilidad como una medida de incertidumbre).

- Conocer la naturaleza Estadística de los datos (ej. identificar datos categóricos y numéricos, tipo de variables, escalas de medición).

- Determinar la importancia, utilidad y beneficios de las representaciones gráficas en Estadística y en el mundo real.

- Conocer, identificar y comparar los componentes, características y propiedades conceptuales y procedimentales, usos y abusos de las diferentes representaciones gráficas (ej. identificar los malos usos de causa-efecto en las interpretaciones de correlación).

- Elaborar, crear y/o construir diferentes representaciones gráficas, a partir del uso de diferentes técnicas básicas para comprender información estadística y resultados de investigación.

- Utilizar, seleccionar, reportar e interpretar las representaciones gráficas con la ayuda de un paquete estadístico por computadora.

- Extraer e interpretar información elemental de la RG (ej. identificar la información encontrada en el título del gráfico y las etiquetas de los ejes, observar simples hechos y relaciones en los datos presentados gráficamente, interpretar relaciones 
cuando las respuestas están parafraseadas o expresadas en los hechos, identificar o leer los especificadores del gráfico).

\subsubsection{Razonamiento estadístico}

Responde al ¿por qué?, ¿cómo?, explica el proceso.

- Analizar, describir, leer e interpretar diversas representaciones gráficas (ej. observar relaciones entre un gráfico e interpretarlas como una presentación visual con referencia al significado de elementos del gráfico y del contexto, interpretar relaciones, identificación de tendencias vistas en las partes de los datos, comparación local o global de las características del gráfico).

- Reconocimiento y comprensión de los procesos de investigación completos (ej. desde preguntas de colección de datos para seleccionar el análisis, supuestos de diseño de pruebas, instrumentos de investigación, etc.).

- Seleccionar e interpretar el tipo de gráfico apropiado a la situación o investigación científica que se trate.

- Establecer la relación entre las diferentes representaciones gráficas y los diferentes tópicos estadísticos (medidas de tendencia central, medidas de dispersión, distribuciones, Correlación, Pruebas Paramétricas y No paramétricas, etc.).

- Formular inferencias y argumentos convincentes que se basen en el análisis exploratorio de datos (ej. ampliar, predecir o inferir soluciones? a partir de la información presentada en representaciones de datos para responder a preguntas implícitas o de investigación, o bien, como ayuda para la toma de decisiones sobre estadísticos de prueba o falsas inferencias).

- Identificar las relaciones matemáticas expresadas en el gráfico.

\subsubsection{Pensamiento estadístico}

Aplica, critica, evalúa, generaliza.

- Formular y resolver problemas que impliquen recogida y análisis de datos en un contexto apropiado y real.

- Evaluar argumentos que estén basados en el análisis de las representaciones gráficas (ej. el por qué y las posibles atribuciones a los resultados, y valorar la propia evidencia, el contexto y el problema y sus relaciones).

- Identificar errores conceptuales y procedimentales en la selección, construcción, interpretación y escritura de representaciones gráficas.

- Asimilar y extraer inferencias a partir de diagramas o gráficas que recojan datos de situaciones del mundo real o de la investigación científica (ej. tomar decisiones sobre lo qué y cómo medir, esbozar conclusiones, comprender la estructura profunda de los datos, comparando tendencias y observando grupos).

- Comunicar los resultados de una investigación a partir de la selección, diseño, interpretación y escritura apropiada de y sobre los gráficos. 
Estos objetivos ejemplifican la diversidad y complejidad del desarrollo cognitivo, de la enseñanza y el aprendizaje de la RG vista de manera gradual, a partir de los niveles cognitivos de Garfield (2002). Recoge la información que se tiene hasta ahora y la traduce a los conocimientos y habilidades que se espera desarrollen los estudiantes durante su formación inicial profesional.

\subsubsection{Objetivos de aprendizaje específicos sobre representación gráfica en el nivel de pensamiento estadístico}

De los objetivos anteriores, se delimitaron los objetivos de aprendizaje específicos en el nivel cognitivo de pensamiento estadístico, por ser éste, el último nivel que se espera que desarrolle un estudiante que está finalizando sus estudios superiores. Se puede observar que, en varias ocasiones, se añade el contexto específico donde se deben aplicar los conocimientos sobre la RG, que son Psicología y Educación, por ser éste el objeto de estudio de la tesis y por ser consistente con la conceptuación de la educación estadística que señala que los conceptos deben ser estudiados y aplicados en contextos de la vida real o profesional de las personas. Estos fueron:

1. Formular y resolver problemas que impliquen recogida y análisis de datos en un contexto apropiado y real.

Objetivos/tópicos específicos:

a. Selección de gráficos dentro del contexto de un problema de investigación en educación y psicología.

b. Interpretación de gráficos dentro del contexto de educación y psicología (ej. casos, bases de datos, problemas, artículos de investigación, tesis, reportes de investigación, gráficos en medios de comunicación).

c. Escritura de gráficos dentro del contexto de educación y psicología (ej. casos, bases de datos, problemas, artículos de investigación, tesis, reportes de investigación, gráficos en medios de comunicación).

2. Evaluar argumentos que estén basados en el análisis de las representaciones gráficas (como, por ejemplo, interpretar el por qué y las posibles atribuciones a los resultados, así como aprender a valorar la propia evidencia, el contexto y el problema y sus relaciones).

Objetivos/tópicos específicos:

a. Criticar y evaluar gráficos (de casos, bases de datos, problemas, artículos de investigación, tesis, reportes de investigación, gráficos en medios de comunicación).

b. Evaluar la selección de un gráfico (analizando todo el contexto del problema o situación de investigación).

c. Atribuciones o causas de los resultados del gráfico.

d. Evaluar las interpretaciones y discusiones hechas del gráfico.

e. Establecer relaciones entre la interpretación del gráfico con el contexto y el problema. 
f. Evaluar las inferencias, toma de decisiones y recomendaciones establecidas a partir del gráfico.

3. Identificar errores conceptuales y procedimentales en la selección, construcción, interpretación y escritura de representaciones gráficas.

Objetivos/tópicos específicos:

a. Análisis de errores conceptuales (al seleccionar, construir, interpretar y escribir gráficos).

b. Identificar datos accidentales y engañosos.

4. Asimilar y extraer inferencias a partir de diagramas o gráficas que recojan datos de situaciones del mundo real o de la investigación científica (ej. tomar decisiones sobre lo qué y cómo hay que medir, esbozar conclusiones, comprender la estructura profunda de los datos, comparando tendencias y observando grupos).

Objetivos/tópicos específicos:

a. Tendencias.

b. Toma de decisiones a partir de la interpretación de gráficos.

c. Implicaciones y/o recomendaciones originadas del gráfico dirigidas a otros análisis estadísticos.

d. Implicaciones y/o recomendaciones originadas del gráfico dirigidas al problema de investigación o fines académicos.

5. Comunicar los resultados de una investigación a partir de la selección, diseño, interpretación y escritura apropiada de y sobre los gráficos.

Objetivos/tópicos específicos:

a. Elaboración del reporte apropiado (ej. estilo de edición, diseño y formato).

b. Redacción de interpretaciones, discusión con base en el contexto y el problema de investigación.

c. Establecer alcances y limitaciones en la interpretación de gráficos.

Estos objetivos evidencian el potencial que tiene la RG como tópico para desarrollar el razonamiento y pensamiento estadístico en los estudiantes, pero también la amplitud de lo que se puede enseñar o aprender sobre el tema; así como servir como referente tanto a investigadores para la realización de un estudio como a profesores y formadores de profesores para el desarrollo de materiales para la enseñanza.

\subsection{EN SÍNTESIS}

La educación matemática y la educación estadística tienen una estrecha relación como disciplinas científicas consideradas ambas enfocadas al estudio e investigación de la matemática y de la Estadística, respectivamente. De manera particular, en este capítulo, se ha mostrado que la educación estadística es un campo relativamente nuevo, pero en crecimiento permanente. La formación de profesores de Estadística no representa la excepción. Del estudio sobre el profesor surgen diferentes objetos de investigación: 
conocimiento de los procesos de aprendizaje de los alumnos, conocimiento de y sobre la Estadística, conocimiento sobre sus concepciones, creencias y actitudes, conocimiento didáctico del contenido y estudios sobre su alfabetización estadística.

Este capítulo justifica la necesidad de estudiar el CDC del profesor sobre el tema de RG. Llama la atención además, que el estudio del CDC en Estadística es un campo fértil por desarrollar, para lo cual es necesario identificar, organizar, integrar y analizar los diferentes estudios que existen en torno a un contenido o tópico estadístico y construir el marco teórico del CDC en relación a éste. Tal es el caso de la RG cuyo objeto de estudio resulta de interés tanto para las matemáticas, como para la propia Estadística y la vida diaria de los individuos.

En este capítulo se establece el marco teórico sobre la RG a través de la revisión de los principales investigadores en este campo, así como de las áreas y tópicos específicos sobre los que se han realizado los diversos estudios. Esto permitió tener un acercamiento a los aspectos de interés para esta investigación, como el análisis de los niveles de comprensión gráfica, los principales contenidos y gráficos estudiados, así como la exploración de los diseños metodológicos e instrumentos de investigación existentes lo que condujo a asumir las posturas conceptuales y metodológicas que se van a considerar para la investigación que se propone. En este sentido, los niveles cognitivos de aprendizaje desarrollados por Garfield (2002) y colaboradores, representan el marco conceptual idóneo para esta investigación, puesto que son el modelo que explica el desarrollo del aprendizaje del estudiante de educación superior.

Del análisis de los contenidos y tópicos específicos de la RG, y a partir de la clasificación de Sorto (2004), se consideró que el estudio de la representación categórica de datos (gráficos de barras, circular y puntos) y la numérica (gráficos de tallo y hoja, histograma y de cajas), constituyen los tópicos específicos de interés para esta investigación. Esto está fundamentado no sólo en las categorías y dominios de conocimiento estudiados, sino también en el análisis curricular de los diferentes programas de Estadística de carreras de Psicología y Educación en Mérida, México.

Respecto del análisis de los instrumentos de investigación, se han asumido las tendencias y recomendaciones sobre el diseño de investigaciones de corte cualitativo, a través de estudios de casos, el uso de cuestionarios sobre situaciones-problema y el uso de la entrevista como recurso complementario para profundizar sobre el conocimiento del profesor.

El estudio de los programas de Estadística de carreras de Psicología y Educación permitió contextualizar el escenario de investigación y relacionarlo con los referentes teóricos expuestos en el capítulo. El análisis curricular indicó que el objetivo de la Estadística en el nivel superior y para estas disciplinas está centrando en el conocimiento, análisis, explicación, aplicación, elaboración e interpretación de los conceptos básicos de la Estadística descriptiva usada como método para la investigación en esos campos, así como la selección y uso de técnicas estadísticas apropiadas, según la naturaleza del problema de investigación y del conocimiento de los principios y conceptos adecuados. De manera particular, sobre los objetivos de aprendizaje de la RG, los programas enfatizan sobre: 
a. la descripción de la terminología estadística utilizada,

b. el cálculo de diferentes tipos de frecuencias (absolutas, relativas y acumuladas),

c. la identificación de diferentes formas de representación de datos,

d. la valoración de las fuentes gráficas para la presentación tabular,

e. el conocimiento de las técnicas de elaboración de gráficos, y

f. la elaboración de tablas y gráficas.

Estos objetivos específicos resaltan los aspectos genéricos de los fines de la RG y los componentes de su comprensión. Sin embargo, dejan a un lado aspectos propios de la comprensión gráfica como son los niveles cognitivos intermedios de aprendizaje propuestos por Friel, Curcio y Bright (2001) y, más aún, los procesos cognitivos y estrategias instruccionales para su desarrollo propuestos por Wu (2004) y Curcio (1989): leer, construir, interpretar, escribir y evaluar gráficos a partir de las fases de recogida, organización y análisis de datos reales y significativos para los estudiantes.

Algunos resultados adicionales del análisis curricular indicaron que los gráficos más comúnmente estudiados en las carreras de Psicología y Educación son el histograma, el diagrama de barras, el circular y el polígono de frecuencias; y los menos estudiados, el de tallo y hoja, el de caja y el lineal. Resultados que confirman lo encontrado en diferentes investigaciones sobre la omisión en los programas de Estadística de los gráficos más enfocados a la exploración de análisis de datos. No más alentador resultó el análisis de las estrategias que se recomiendan para enseñar los tópicos estadísticos, las cuales son genéricas, de carácter fundamentalmente pedagógico, con bibliografía no actualizada en la mayoría de los casos y sin textos propios sobre RG.

La exploración y análisis hecho, tanto de los estudios encontrados sobre RG, así como de los instrumentos de investigación y de los programas de Estadística de carreras de Psicología y Educación en Mérida, México; llevó a establecer una propuesta de objetivos genéricos y específicos de aprendizaje, en el nivel cognitivo del pensamiento estadístico, sobre el tema de la RG. Esto ayudó a delimitar el campo de acción de la investigación, así como ser el referente teórico para la construcción de los instrumentos de recogida de información de la tesis. 


\section{CAPÍTULO 3: El problema}

Para la descripción del problema de investigación, dentro del marco de la didáctica de las matemáticas se ha organizado este capítulo en siete subencabezados: la necesidad de estudiar el CDC en educación estadística, el contexto del estudio, situaciones problemáticas, las cuestiones críticas, el problema, los objetivos y las hipótesis.

En el primer capítulo se presentó el marco teórico de la investigación sobre el CDC del profesor, donde se describió y analizó lo relativo al constructo, su definición, características, componentes, dimensiones e indicadores y principales investigaciones realizadas en el campo de la educación matemática. Dado que el contenido y el tópico específico de estudio era la educación estadística y, más concretamente, la representación gráfica, en el capítulo dos se analizó ésta a partir de su significado e importancia, el estudio del conocimiento del profesor de Estadística sobre este tópico, las investigaciones realizadas, así como un análisis de sus diseños e instrumentos de recogida de datos.

Por ello, en este capítulo se suman aspectos contextuales que motivan, enmarcan y justifican el problema a investigar. Se rescatan algunos aspectos ya asumidos en los capítulos anteriores, sobre todo lo referente a las posiciones conceptuales y metodológicas que formaron parte de las características de esta investigación.

\subsection{LA NECESIDAD DEL ESTUDIO DEL CDC EN ESTADÍSTICA}

Si bien es cierto que existe un progreso considerable en los últimos años de la investigación sobre la enseñanza en el salón de clases, las cuestiones vinculadas al aprendizaje del profesor y a su práctica son relativamente recientes como ámbito de investigación (Llinares, 1998). Además, los niveles donde se requiere más énfasis y desarrollo de investigaciones sobre el conocimiento del profesor son en el medio-superior y el superior (Koelher y Grouws, 1992;) y específicamente en educación estadística sobre las concepciones de los estudiantes y profesores (Shaughnessy, 2007). La investigación sobre la formación de profesores de Estadística, de su CDC y concepciones, cuando el escenario de enseñanza se centra en las áreas Humanidades y Ciencias de la Conducta de la educación superior, como es el caso de la Psicología y la Educación, aún es más incipiente. La necesidad de investigación en esta línea, tema y nivel educativo no es exclusiva del Estado de Yucatán (México) sino que representa un área de estudio poco explorada tanto en el ámbito nacional como internacional. 
Tanto en el campo de la educación matemática como de la Estadística, se ha demostrado que el CDC de los profesores juega un papel importante tanto como modelo teórico para la formación de profesores como objeto de estudio. Por ejemplo, gracias a los estudios sobre pensamiento y conocimiento del profesor y sobre la forma como éste toma decisiones, los educadores han podido reconceptualizar el currículo, su interpretación e implementación y todo ello determina los conocimientos y creencias del profesor (Thompson, 1992; Flores, 1998).

La investigación sobre el CDC debe tener una repercusión en la formación de profesores y en los procesos de enseñanza en las clases de matemáticas (Llinares, 1998 y García y Llinares, 1999), dado que "las acciones de los profesores influyen en los problemas que los estudiantes intentan resolver y en la forma en que ellos construyen el conocimiento" (Cobb, 1992, p.92; en Koelher y Grouws, 1992) y que la mayor parte de estos, desarrollan sus conocimientos y creencias durante sus años escolares y a partir de su propia experiencia como estudiantes de matemáticas (Owens, 1987; Ball, 1988; citados por Thompson, 1992).

Por lo tanto, el estudio del CDC cada día cobra mayor interés entre los investigadores en educación matemática y en las instituciones de formación de profesores. Esta situación adquiere mayor interés y relevancia en educación estadística por ser todavía un constructo teórico poco explorado y pendiente de estudiar (Batanero, 2002; ICMI/IASE, 2006; Sorto, 2007). Recientemente en 2008, el CDC fue objeto de estudio y análisis en una de las mesas de trabajo del ICMI/IASE.

La profesionalización de la enseñanza de la Estadística es un aspecto ineludible que es necesario ratificar en el contexto de los profesores que la imparten en carreras de las áreas de Humanidades y Ciencias de la Conducta. A partir de los resultados obtenidos en diversas investigaciones en educación estadística se hace necesario integrar un conjunto de conocimientos que confirmen la existencia de marcos teóricos propios para su enseñanza en carreras diferentes a las matemáticas. Es un hecho que, actualmente, hay grupos de profesores de Estadística cuya formación no es matemática, o bien, no tienen una formación especial de y sobre Estadística. El estudio conjunto de ICMI/IASE (2006) sintetiza perfectamente esta problemática:

se requiere una mejor preparación de estos profesores, que, con frecuencia, no han tenido suficiente formación en educación estadística (Russell, 1990; Gattuso y Pannone, 2002; Mendonça, Coutinho, y Almouloud, 2006). A pesar de que muchos futuros profesores de secundaria han cursado una licenciatura de matemáticas, generalmente sólo estudiaron estadística teórica (matemática) en su formación inicial. Pocos matemáticos reciben una formación específica en estadística aplicada, diseño de muestreo o de experimentos, análisis de datos de aplicaciones reales o uso del software estadístico. Estos profesores también necesitan formación en el conocimiento pedagógico relacionado con la educación estadística, a la que no pueden transferirse algunos principios generales válidos para la geometría, aritmética u otras ramas de las matemáticas (Russell, 1990; Batanero, Godino y Roa, 2004) (pp.2-3). 
La investigación del CDC del profesor de Estadística, permitirá acercarnos a comprender sus concepciones, las fuentes de obtención de sus conocimientos, sus conocimientos del contenido estadístico a enseñar, las estrategias y representaciones instruccionales y acerca del conocimiento sobre los procesos de aprendizaje de sus estudiantes, así como generar una nueva conceptualización de la enseñanza de la Estadística como profesión (Flores, 1998; Gil, 2000; y Llinares, 2003 y 1996).

\subsection{EL CONTEXTO DE LA INVESTIGACIÓN}

En el Estado de Yucatán (México), existen dos carreras que forman a profesores de matemáticas y que, de algún modo, les permite impartir la asignatura de Estadística en el nivel de educación básica (secundaria), media y superior: la Escuela Normal Superior de Yucatán (ENSY), que forma a Licenciados en Educación Secundaria (en Matemáticas) y la Facultad de Matemáticas de la Universidad Autónoma de Yucatán (FMUADY), que forma a Licenciados en Matemáticas y Licenciados en la Enseñanza de las Matemáticas. Si bien la ENSY prepara a profesores en el ámbito de la secundaria, no hay restricciones particulares para no poder impartir clases en niveles superiores. La FMUADY prepara a profesores para trabajar en el ámbito de bachillerato y nivel superior.

Adicionalmente, se encuentran aquellos profesores que imparten Estadística y que no han realizado su formación inicial en ninguna de estas dos carreras ni en Estadística. Por ejemplo, en el trabajo de Barrabí y Martín (2007) se señala que de 46 profesores (de un total de 62) que imparten Estadística en alguna de las 23 carreras del área social (Humanidades y Ciencias de la Conducta) de la Ciudad de Mérida, Yucatán; sólo el 25\% tiene formación en matemática o enseñanza de las matemáticas. En un estudio de corte cuantitativo, exploratorio y de tipo encuesta, Pinto, Martín y Barrabí (2007) identificaron las características y necesidades de la formación profesional (inicial y permanente) y de la práctica docente (estrategias de enseñanza, recursos materiales y estrategias de evaluación) de estos profesores. Con base en las respuestas al "Cuestionario para identificar y detectar las características y necesidades de los profesores de Estadística”, encontraron que:

- el $78 \%$ son hombres; mayoritariamente entre 26 a 41 años de edad (61\%);

- el $74 \%$ trabaja en instituciones de régimen privado y el $26 \%$ en instituciones públicas;

- el $41 \%$ de los profesores se encuentra trabajando a tiempo completo y el $59 \%$ por horas (tiempo parcial);

- el 65\% (30) tienen entre uno y seis años de experiencia en el área de Estadística y únicamente el 9\% (4) de éstos han impartido clase de Estadística durante más de 25 años;

- el 41\% (18) de los profesores de Estadística se han formado en el área de ingeniería; el 25\% (11) en matemáticas; y el 25\% (11) de los profesores estudió una licenciatura vinculada con el área social (ej. Educación, Psicología, Economía y Antropología);

- el 67\% (31) de los profesores tienen como nivel máximo de formación la maestría, de los cuales el $29 \%$ se especializó en el área económicoadministrativa, el $23 \%$ en la de matemáticas y el $15 \%$ en la de educación; y 
- del total de profesores que han cursado un posgrado (36), el 26\% lo realizó en el área de educación, el $26 \%$ en el área económico-administrativa, un $18 \%$ en matemáticas, el $8 \%$ en ingeniería y el $21 \%$ en otras.

Estos resultados confirman la diversidad de la formación inicial del profesor de Estadística en el área social, y dan cuenta de sus características demográficas y de formación profesional.

Por otro lado, desde 1989, la FMUADY ofrece la Especialización en Estadística (http://www.matematicas.uady.mx/programas/ee/index.html) con el propósito de fortalecer la formación de profesionales dedicados a asesorar proyectos estadísticos, tanto en lo referente a los contenidos, como a métodos y técnicas estadísticas y apoyar a las instituciones educativas para lograr una enseñanza de la Estadística de calidad en los niveles medio-superior y superior desde la perspectiva del contenido. Sin embargo, el programa no contempla entre sus características asignaturas, módulos o estrategias para que el profesorado mejore su conocimiento sobre la didáctica de dicho contenido.

Además de lo anterior, en entrevistas con autoridades de ambas instituciones (realizadas en noviembre de 2004) si bien reconocen e identifican programas y cursos de formación continua para profesores (centrados más en el aprendizaje de los contenidos), no hay ninguna iniciativa relacionada con la investigación en torno a la formación y caracterización de los profesores de Estadística (Pinto, Martín y Barrabí, 2007). En este sentido, el inicio de investigaciones vinculadas con las agendas de investigación sobre el conocimiento y la práctica del profesor de Estadística representa un vacío importante por cubrir en el Estado de Yucatán. El problema es más apremiante si centramos la atención en aquellos profesores que imparten Estadística a nivel superior en carreras del área social.

En un contexto más amplio, en México, en noviembre de 2004 se realizaron ocho entrevistas a profesores/investigadores del Departamento de Matemática Educativa del Centro de Investigación y de Estudio Tecnológicos del Instituto Politécnico Nacional (CINVESTAV-IPN, en el Distrito Federal, México) y del Instituto Tecnológico de Estudios Superiores de Monterrey (ITESM, en Monterrey, México). De estos investigadores, seis tenían el grado de Doctor en Matemática Educativa; seis tenían algún cargo directivo, coordinación de docencia o de investigación en Estadística y dos eran profesores de planta. Tres de ellos eran miembros de algún organismo académico y de investigación (ej. representante nacional en México ante el ICOTS, representante nacional en México y miembro del Comité Internacional del ICMI/IASE, 2006; vocal y miembro del Comité Latinoamericano de Matemática Educativa, CLAME) y todos tenían una amplia experiencia y reconocimiento nacional como expertos en educación matemática o estadística. La entrevista se centró en recoger su opinión sobre los problemas que tenía la educación estadística en México y que dieran su apreciación sobre las características generales de la presente investigación.

Las entrevistas corroboraron la necesidad de estudios sobre el profesor de Estadística y permitieron constatar que la situación de la educación estadística en México no es diferente a lo que ocurre en el ámbito internacional. De hecho, después de más de 15 años de la investigación de Sánchez (1989) quien escribió sobre la situación de la 
enseñanza de la Estadística en México, en pleno inicio del siglo XXI no sólo prevalecen los problemas sobre la formación de profesores, sino los relacionados con el desarrollo de investigación sobre la didáctica del profesor de Estadística. De hecho, según los investigadores que participaron en la entrevista, no existen hasta ahora instancias que regulen el currículo de la didáctica de las disciplinas escolares a nivel medio-superior y superior, ni existen procesos de selección o acreditación de profesores de matemáticas y estadística. Según Pinto, Martín y Barrabí (2007) esta situación no es difícil de explicar ya que no se ha diseñado ningún programa para la formación de profesores de Estadística desde la perspectiva del conocimiento didáctico del contenido.

Los entrevistados opinaron que el estudio del CDC del profesor de Estadística, representa una buena oportunidad para impulsar la educación estadística, no sólo porque es un constructo todavía no estudiado en México (en el campo de la educación matemática y de la estadística), sino porque retoma la necesidad de hacer investigación sobre la didáctica del profesor de Estadística.

Por otro lado, es preciso resaltar que en el contexto de México, a finales de 2004 se hizo una revisión de artículos de investigación y divulgación, de tesis de maestría y doctorado en matemática educativa del Departamento de Matemática Educativa del CINVESTAV-IPN y ITESM (Campus Monterrey) y no se encontró ningún estudio acerca del CDC en el campo de la educación matemática y estadística. Si había un limitado número de investigaciones sobre concepciones acerca de la matemática y sobre la E-A de ésta (ej. García, 1994) y un número importante de estudios sobre concepciones de un tópico específico (ej. el concepto de límite, variación, azar, derivadas, función, entre otros). De la participación y revisión de las investigaciones de autores mexicanos en congresos como el ICME 11, del ICMI/IASE 2008 y del ELEE en 2008, al parecer en México los trabajos se centran más sobre el estudio de las gráficas de distribuciones (Arteaga, Batanero y Ruiz, 2008), competencia gráfica (Batanero, Arteaga y Ruiz, 2009) y el estudio de las gráficas socialmente compartidas (Dolores y Cuevas, 2007 y Dolores, 2008). Si bien esto ejemplifica un avance en el desarrollo de la investigación en educación estadística en México, demuestra que todavía ésta es un campo fértil por explorar, más todavía si hablamos del CDC de los profesores de Estadística.

La necesidad de realizar investigación sobre el CDC de los profesores de Estadística en México quedó más respaldada por Pinto y González (2008a), quienes al realizar un análisis sobre los marcos teóricos de las investigaciones en educación matemática en México no encontraron el referente ni el uso del CDC de Shulman ni como objeto de investigación ni como marco teórico para la formación de profesores de matemáticas. Pinto y González (2008a) concluyen que si bien, el CDC en educación matemática ha tenido bastante interés en los últimos años y cada día tiene mayor atención y reconocimiento en el ámbito internacional (tanto en las instituciones educativas y centros de investigación, como parte de programas de formación inicial y permanente y de los procesos de evaluación, acreditación y selección de profesores), parece ser que en México no es así. Afirman que en México "todavía tiene un nulo o bajo nivel de construcción para la formación inicial y permanente de profesores y una relativa ausencia de investigación del CDC centrada en el profesor" (p.95). 


\subsection{SITUACIONES PROBLEMÁTICAS}

Con base en los marcos teóricos estudiados y en la revisión de la literatura se han detectado seis focos-problemas que se suman a la situación problemática de este estudio y cuyos síntomas actuales preocupan significativamente.

Sin lugar a dudas, es innegable el interés que tiene actualmente la enseñanza de la Estadística, dentro de la educación matemática, el cual viene ligado al rápido desarrollo de ésta como ciencia y como útil en la investigación, la técnica y la vida profesional (Batanero, 2000). Sin embargo, un primer foco de preocupación, es que todavía prevalece el uso la estadística, de forma procesal, cuyos conocimientos y competencias son pasivas e independientes del contexto en que se usa. Todavía se estudia una estadística cuyo énfasis es el cálculo y la elaboración de ejercicios o actividades encaminadas a los procesos exclusivamente, desligado del análisis conceptual y de la toma de decisiones en su uso (ICMI/IASE, 2006). Esto se demuestra, incluso, en que en el momento en que los estudiantes desarrollan una investigación aplicada y concreta, dependen de la asistencia de otra persona que les orienta y finalmente, decide sobre la selección e interpretación correcta de los datos estadísticos. En otros casos, "la información a veces sensacionalista de los resultados de pequeños estudios frecuentemente mal diseñados, es especialmente preocupante" (Cox, 1997, p. 273, en Batanero, 2002).

El segundo foco-problema que llama la atención, son los libros de texto utilizados para la enseñanza y aprendizaje de la Estadística. Como señala Holmes (2002 en Batanero, 2002) las lecciones de Estadística de los libros de matemáticas han sido hechas por matemáticos y carecen de aplicaciones realmente propias de la actividad estadística y los alumnos finalizan los cursos sin adquirir una competencia real para llevar a cabo una investigación estadística. Particularmente llaman la atención aquellos textos utilizados en carreras como Educación, Psicología, Antropología, Sociología, por mencionar algunos. Hay que destacar diversos elementos que repercuten en la enseñanza, como la selección del libro de texto, la selección, uso e implementación de ejercicios del libro, o en su caso, la modificación de éstos para fines de aprendizaje. Esto tiene gran interés dependiendo del contexto en que se utiliza la Estadística o la carrera del área social donde se esté impartiendo.

Un tercer foco-problema es que se sigue utilizando de forma incorrecta la Estadística. Por ejemplo, en un trabajo cuyo propósito fue analizar la formación estadística de investigadores, Batanero (2001a) pone de manifiesto que la Estadística se usa incorrectamente, no se comprenden conceptos aparentemente elementales y no hay valoración suficiente del trabajo del estadístico dentro de los equipos de investigación. En este sentido se coincide con Shaughnessy (1992), cuando afirma que si los investigadores y profesores tienen problemas con conceptos estadísticos, no nos debe sorprender que los estudiantes tengan concepciones inadecuadas de algunos conceptos matemáticos elementales. Aún cuando se han hecho diferentes recomendaciones para mejorar la enseñanza y aprendizaje de la Estadística, según el documento del estudio conjunto ICMI/IASE (2006): 
estas recomendaciones curriculares apenas se siguen, ya que la enseñanza de la Estadística se reduce u olvida con frecuencia y, en el mejor de los casos, se enseña demasiado formalmente, con pocos ejemplos de aplicaciones reales (Meletiou, 2003). Muchas veces, la enseñanza de la Estadística sólo consiste en realizar cálculos o demostrar teoremas matemáticos con poca oportunidad de diseñar experimentos, analizar datos o conectar la Estadística con el proceso general de indagación. Como consecuencia, los estudiantes finalizan la escuela secundaria con escasa comprensión de los principios básicos que subyacen en el análisis de datos, lo que explica muchos de los problemas que encuentran en el uso posterior de la estadística en su vida cotidiana o profesional o en los cursos de Estadística en la universidad (p.2).

De manera específica, sobre la enseñanza de la Estadística en áreas de estudio diferente a la matemática, Cortadi (en Bacelar, et al., 2001), profesor investigador del Instituto Mauá de Tecnología (San Paulo, Brasil), problematiza acerca del aprendizaje de estos estudiantes y afirma que, en la mayoría de las ocasiones, los estudiantes no comprenden por qué la Estadística se incluye en sus programas de estudio, puesto que no se hace referencia a la Estadística en su propio contexto. Añade que los profesores de Estadística deben facilitar la transferencia del conocimiento abstracto de un escenario (matemáticas) a otro. El mismo autor afirma que los estudiantes, que son principiantes en la universidad, no conocen los procesos científicos, las hipótesis, estudios observacionales, etc., lo que entre otras cosas, puede ocasionar en éstos una actitud negativa hacia la Estadística y utilizarla de forma instrumental, sin consideraciones conceptuales y epistemológicas. Para este autor, la falta de tradición en el desarrollo de actividades interdisciplinarias contribuye a esta situación. Éste es el cuarto foco-problema, la falta de contextualización de una Estadística dirigida a profesionales de otras áreas. Contextualización que depende por un lado del profesor (ej. creencia concepción, conocimiento de la materia, de las estrategias y representaciones instruccionales y del conocimiento de los procesos de aprendizaje de los estudiantes) y por otro del currículo escolar (ej. programa de curso, propósitos de la asignatura, materiales y estrategias de enseñanza recomendadas).

El quinto foco-problema, está relacionado con la reducida cantidad de contenido sobre Estadística en los planes de estudios, tanto en la formación de los alumnos, como de los profesores de Estadística. Uno de los problemas que están documentados en la literatura (ej. Batanero, 2000) es que, aunque los currículos de primaria y secundaria incluyen de forma generalizada recomendaciones sobre la enseñanza de la Estadística, en la práctica son todavía pocos los profesores que enseñan este tema o bien se trata muy brevemente y de forma excesivamente mecanizada. Por otra parte, los alumnos llegan a la universidad sin los conocimientos básicos y es preciso comenzar el programa repitiendo los contenidos de Estadística descriptiva y cálculo de probabilidades (Shaughnessy, 1992; Batanero, 2001a y Carrera, 2002 en Batanero 2002). Pero se insiste todavía en enseñar de forma tradicional y típica la Estadística enfatizando el cálculo y los algoritmos, incluso en la universidad. Por otro lado, también se reconoce que la formación de los profesores de matemática, sobre Estadística se ve relegada a ser uno de los últimos temas de estudio y que, normalmente, por falta de tiempo se trabaja de manera superficial. 
Por último, un sexto foco-problema es la falta de estudios en México sobre el CDC de Estadística, y más aún sobre la representación de datos. La situación es más delicada cuando, hasta la fecha, son escasos los trabajos encontrados en México sobre la educación estadística y la representación de datos, tanto en relación con el profesor como con los alumnos. Esta situación se agrava por la poca e insuficiente literatura en castellano disponible para los profesores como recurso para su actualización en la didáctica de la Estadística y el vacío que se tiene sobre el estudio de la didáctica de aquellos que trabajan en carreras del área social.

El esfuerzo de investigación que se ha concentrado sobre la educación del profesor de matemáticas y su desarrollo profesional en la década pasada no se ha reflejado en la educación estadística. Esto es evidente en conferencias (e.j., el ICMI Study 15), revistas (e.j., Journal of Mathematics Teacher Education), estados de la cuestión y libros, que apenas tratan el caso particular de la Estadística. Este olvido debe ser subsanado, promoviendo la investigación específicamente orientada sobre la educación y desarrollo profesional de profesor para enseñar Estadística (Shaughnessy, en prensa) (en ICMI/IASE, 2006, p. 3).

Si bien es cierto, que existen otros focos-problemas en la investigación sobre educación estadística y sobre el profesor, este trabajo se centra fundamentalmente en los anteriores: la enseñanza de la Estadística con énfasis en el cálculo y el algoritmo; la selección del libro de texto y el uso y modificación de ejercicios y actividades acorde a las necesidades de los programas de estudio de los estudiantes; la prevalencia de estudios que demuestran el uso incorrecto de la Estadística en la investigación (incluso la social) por parte de los profesores; la falta de contextualización de la formación de alumnos con estudios diferentes a la matemática; la falta de incorporación y estudio en profundidad de la Estadística, tanto por parte de los alumnos como de los profesores (específicamente en la universidad) y la falta de estudios en México sobre el CDC en matemáticas y estadística.

Estos focos-problemas, sumado a la falta de estudios sobre el profesor de Estadística en el Estado de Yucatán, plantean la necesidad de investigar sobre éste, es decir, sobre el conocimiento que tiene de las estrategias específicas de enseñanza y su aplicación cuando imparte clases, sobre el uso y selección de libros y ejercicios, sobre el origen y formas de usar el contenido estadístico en sus clases, la forma como contextualiza la enseñanza a alumnos con características e intereses diferentes a los matemáticos y la amplitud (en tiempo y profundidad) de la Estadística como programa de estudios, su concepción sobre el contenido estadístico y sobre su enseñanza-aprendizaje, así como su conocimiento de las estrategias y representaciones instruccionales y del estudiante. Es decir, el conocimiento didáctico del contenido que tiene sobre el contenido estadístico, particularmente de la RG.

\subsection{CUESTIONES CRÍTICAS}

Bajo esta perspectiva, las cuestiones críticas que principalmente nos interesaron fueron: ¿cuál es la concepción de la Estadística y de la enseñanza y aprendizaje del profesor?, ¿cómo planea su clase?, ¿qué concepciones subyacen en la selección y uso de los materiales para la enseñanza?, ¿cuáles son los conocimientos que tiene sobre las representaciones instruccionales del contenido que enseña?, ¿cómo surge el conocimiento 
del contenido y cómo evoluciona en la mente del profesor hasta ser un contenido para enseñar en la escuela?, ¿qué tipo de actividades (ejercicios o problemas) utiliza dentro de su enseñanza?, ¿cómo las utiliza?, ¿cuáles son sus conocimiento sobre los procesos de aprendizaje de alumnos cuyos intereses son diferentes a los matemáticos?, ¿qué estrategias específicas utiliza para corregir las ideas equivocadas o dificultades que tiene el estudiante sobre el contenido a aprender?, ¿de qué manera, sus conocimientos y concepciones, reflejan, el tipo de formación recibida como profesor de matemáticas?

No se trata de caracterizar o tipificar el conocimiento del profesor, sino comprender y profundizar en su pensamiento y conocimiento, saber cómo razona y cómo utiliza el conocimiento (¿cómo lo transforma?) para enseñar el contenido estadístico en sus clases.

\subsection{PROBLEMA}

Por lo tanto, el problema que originó esta investigación, se puede resumir con la siguiente pregunta de investigación:

¿Cuál es el conocimiento didáctico del contenido de la Estadística, con especial atención en la representación gráfica, en profesores de las carreras de Psicología y Educación?

El estudio del CDC de Estadística en esta área, trata de acercarnos a comprender un poco más la cognición del profesor, constituida por lo que conoce y hace y las razones por las que actúa (Pinto y González, 2006). De este modo, se trata de contribuir con información teórica útil, que posteriormente genere otras investigaciones, o bien, obtener recomendaciones dirigidas a las instituciones formadoras de profesores.

El trabajo se ha centrado en el CDC de la representación de datos estadísticos, uno de los primeros tópicos de un curso introductorio de Estadística en cualquier nivel escolar, sobre todo a nivel superior, así como el punto de partida del proceso estadístico del análisis de un conjunto de datos y el primer elemento fundamental del pensamiento estadístico (Pfannkuch y Rubick, 2002).

Se eligió el tópico de la representación gráfica porque los conceptos y las capacidades que genera, son imprescindibles para la alfabetización del ciudadano (statistic literacy) como ha sido ampliamente reconocido en muchas investigaciones de educación estadística (ej. Curcio, 1987; NCTM, 1991; Graesser, Swamer, Baggett y Sell, 1996; Shaughnessy, Garfield y Greer, 1996; Friel, Curcio, Bright, 2001; Sorto y White, 2004; delMas, Garfield, Ooms, 2005; Monteiro y Ainley, 2006 y 2007; Aoyama, 2006 y 2007). En la última década se ha generado un cuerpo de conocimiento sobre aspectos muy puntuales relativos al desarrollo del aprendizaje y a la planificación, construcción, interpretación, comunicación y análisis de representaciones gráficas en diferentes niveles escolares.

Por otro lado, la investigación sobre el conocimiento que poseen los profesores de Estadística que imparten clases en carreras de Psicología y Educación, áreas poco estudiadas en el campo de la educación estadística, responde a que éstas son las dos áreas que mayor uso hacen de la Estadística en la investigación en áreas sociales y así lo 
muestran los libros de texto. Asimismo, son ramas presentes en todo el ámbito internacional, y áreas relevantes en la formación de habilidades para la investigación social y consecuentemente, para la formación de futuros investigadores.

\subsection{OBJETIVOS}

Por tal motivo, los objetivos de investigación fueron:

a. Describir las concepciones que tienen los profesores sobre la Estadística, su enseñanza y aprendizaje y, más concretamente, sobre la representación gráfica.

b. Determinar el conocimiento acerca de la representación gráfica de los profesores de las carreras de Psicología y Educación.

c. Determinar el conocimiento de las estrategias y representaciones instruccionales del profesor sobre la representación gráfica en la Estadística.

d. Identificar los conocimientos del profesor sobre los procesos de aprendizaje, errores y dificultades de sus alumnos en la representación gráfica en Estadística.

El análisis se centró en dos componentes del CDC: conocimiento de las estrategias y representaciones instruccionales y conocimiento del proceso de aprendizaje del alumno ya que, en los estudios revisados, se ha encontrado poca información y resultados sobre estos dos componentes, tanto en relación con el CDC como en lo que se refiere a la educación estadística. Se estudió el CDC a partir de la construcción del SDI explicados en el capítulo uno y utilizando los objetivos genéricos y específicos de la RG (capítulo dos) correspondientes al nivel cognitivo del pensamiento estadístico.

\subsection{HIPÓTESIS DE TRABAJO}

A continuación se describen las hipótesis de trabajo que se plantearon a modo de supuestos sobre posibles respuestas o soluciones al problema de investigación.

La primera hipótesis de trabajo ha sido considerar que los profesores cuya formación inicial es matemática tienen una concepción formalista hacia la enseñanza de la Estadística, es decir, conciben la Estadística como ciencia de la demostración rigurosa, basada en un lenguaje y reglas formales, con fundamentos absolutos, cuyas verdades son verificables y normalmente son presentadas por el profesor, quien además enfatiza en el significado de los conceptos y la lógica de los procedimientos estadísticos.

La segunda hipótesis fue considerar que los profesores cuya formación inicial es diferente a la matemática tiene una concepción instrumentalista hacia la enseñanza de la Estadística, es decir, se concibe como un conjunto de procesos, algoritmos, reglas y prácticas, en la cual el profesor de manera preestablecida enfatiza en la enseñanza de demostraciones, reglas y procedimientos estadísticos.

La tercera hipótesis es que los profesores tienen un bajo nivel de construcción del conocimiento didáctico del contenido sobre la $\mathrm{RG}$, el cual se explica en función de su 
concepción de la enseñanza y aprendizaje de la Estadística y de las fuentes de obtención de su conocimiento.

La cuarta hipótesis de trabajo es que el conocimiento didáctico del contenido de cada profesor es único, construido a partir de su concepción hacia la Estadística y su enseñanza, su formación inicial, su práctica y experiencia docente, lo que le convierte en un modelo con características particulares y distintivas por profesor.

En resumen, la presente investigación pretende comprender el proceso de pensamiento y conocimiento del profesor y cómo éste ha aprendido a enseñar la RG, así como comprender cómo el conocimiento que tienen sobre el tópico se transforma para ser contenido enseñable. En el siguiente capítulo se describen los procedimientos metodológicos que ayudaron a explorar y analizar el CDC del profesor. 
Jesús Enrique Pinto Sosa 


\section{CAPÍTULO 4: Método}

Después de establecer las bases teóricas y de identificar el problema de investigación, surge la pregunta ¿cómo explorar el CDC de los profesores en relación con la representación gráfica en estadística? A partir de las conclusiones conceptuales y metodológicas que se revisaron en el primer capítulo sobre el CDC y de las dimensiones e indicadores establecidos (ver Tabla 1.9) se procedió a identificar cuáles iban a ser los aspectos en los que se centraría esta investigación.

Se ha realizado una investigación de corte cualitativo, centrada en un estudio de dos casos y cuya principal fuente de recogida de datos fue un cuestionario de situacionesproblema. La construcción del mismo se hizo teniendo en cuenta los niveles cognitivos de Garfield (2002), del cual se obtuvieron un conjunto de objetivos de aprendizaje sobre el tema de representación gráfica tal como se expuso en el capítulo segundo.

De este modo, en este capítulo, se presentan las bases teóricas, diseño y método de análisis del CDC sobre la representación gráfica. En él se abarcan las siguientes secciones: caracterización de la investigación, selección de los participantes, el escenario y contexto del estudio, los instrumentos y materiales, así como las técnicas e instrumentos de recogida de información. Finalmente se describen las técnicas de análisis de la información y la técnica de validez y fiabilidad del estudio.

\subsection{CARACTERIZACIÓN DE LA INVESTIGACIÓN}

Esta sección está dedicada a describir la metodología empleada en la investigación. En primer lugar, el trabajo se encuentra en la línea del conocimiento del profesor ya que pretendemos realizar un estudio del CDC del profesor tomando como base el conocimiento del contenido. En segundo lugar, se trata de una investigación cualitativa centrada en un estudio de casos.

\subsubsection{Línea de investigación: conocimiento profesional del profesor}

Como señalan Gil y Rico (2003) y Moreno y Azcárate (2003) los estudios e investigaciones sobre el pensamiento del profesor de matemáticas y su conocimiento profesional han experimentado en los últimos años un desarrollo considerable. 
Este trabajo se encuadra dentro de la perspectiva didáctica del conocimiento profesional del profesor, cuyo principal promotor fue Lee Shulman, que incorpora el conocimiento didáctico del contenido como una de las categorías del conocimiento base para la enseñanza (Shulman, 1986b y 1987). Esta investigación se centra en el estudio del CDC del profesor de Estadística en torno a la RG, específicamente se trata de analizar las concepciones que tiene el profesor en relación con la RG en Estadística, su enseñanza y aprendizaje, el conocimiento de las estrategias y representaciones instruccionales y el conocimiento de los procesos de aprendizaje de los estudiantes.

El conocimiento profesional del profesor representa un tema de interés por sus conexiones con las corrientes actuales de investigación en educación matemática (Contreras, 1998 en Gil y Rico, 2003). Se focaliza en la descripción del conjunto de saberes que los docentes ponen en juego en la enseñanza de un tópico escolar concreto y subraya el valor que tiene la comprensión de los contenidos curriculares por parte del profesor y los alumnos (López, 1999).

\subsubsection{Paradigma de investigación: cualitativo}

El propósito de esta investigación es comprender qué y cómo conoce el profesor de Estadística y qué hace con lo que conoce; se busca comprender y explicar la naturaleza del conocimiento del profesor, concebida de manera integral y compleja, en donde interactúan y se relacionan una variedad de elementos, pensamientos, conocimientos, concepciones y creencias. La intención del estudio es, precisamente, tratar de comprender esta complejidad, aunque no en su totalidad, sí se intentará un primer acercamiento.

Teniendo en cuenta lo anterior se ha realizado una investigación de corte cualitativo caracterizada (Taylor y Bogdan, 1987) por:

- explorar en un más amplio sentido las propias palabras de las personas, habladas o escritas,

- desarrollar e identificar conceptos, intelecciones y comprensiones partiendo de los datos,

- ver el escenario y a las personas en una perspectiva holística, en el contexto de su pasado y de las situaciones en las que halla,

- comprender detalladamente a las personas dentro del marco de referencia de ellas mismas,

- involucrarse en la manera de pensar, conocer, sentir y valorar de las personas, y

- aprender de y con las personas participantes de la investigación.

Según las perspectivas interpretativas y constructivistas (Guba y Lincoln, 1994; Angulo, 1995 citados en Rodríguez, Gil y García, 1999) la investigación cualitativa se caracteriza por:

- considerar la realidad como dinámica, global y construida en un proceso de interacción con la misma (nivel ontológico),

- asumir una vía inductiva, partiendo de la realidad concreta y los datos que ésta le aporta para llegar a una teorización posterior (nivel epistemológico), 
- tener un carácter emergente, construyéndose a medida que se avanza en el proceso de investigación (nivel metodológico), y

- la utilización de diversas técnicas que permiten recabar datos que informan de la particularidad de la situación (nivel técnico).

Para Stake (1998) y Rodríguez, Gil y García (1999) las características distintivas de una investigación cualitativa se resumen en tres aspectos fundamentales:

1) el objetivo de la investigación es la comprensión, centrada en la indagación de los hechos,

2) el papel que adopta el investigador, desde el inicio de la investigación es de interpretar los hechos desde dentro, asumiendo una profunda atención y comprensión empática sobre las creencias, concepciones y conocimiento del profesor,

3) el investigador, durante el proceso mismo del estudio, construye el conocimiento a partir del contexto natural del profesor, de acuerdo a los significados que le otorga al objeto de estudio y a través de la utilización de una variedad de formas de recogida de información.

Como se podrá apreciar en las siguientes secciones de este capítulo, todas estas características fueron asumidas para desarrollar la investigación.

Por consiguiente, se estudiará al profesor desde una perspectiva naturalista e interpretativa, dado que las acciones de éste están parcialmente determinadas por el contexto y ambiente en el que suceden (Sandín, 2003). El supuesto que subyace es que el CDC del profesor sólo pueden estudiarse en el contexto real donde trabaja.

\subsubsection{Diseño: estudio de casos}

Se estudió el CDC del profesor a partir del estudio de casos, dado que como señala Thompson (1992), éstos pueden ser utilizados intencionalmente y de manera puntual, para reflexionar acerca de sus conocimientos, concepciones, creencias y de su práctica. Se entiende como estudio de caso, "el estudio de la particularidad y la complejidad de un caso singular, para llegar a comprender su actividad en circunstancias importantes" (Stake, 1998, p.11), es decir, "el examen detallado, comprehensivo, sistemático y en profundidad del objeto de interés" (Rodríguez, Gil y García, 1999, p.92).

Además, esta investigación, se puede encuadrar dentro de los estudios colectivos, ya que, una vez que se identificó el problema de estudio nos vimos en la necesidad de comprender el problema a partir de por lo menos dos casos. Según Stake (1994 y 1998) los estudios colectivos buscan profundizar dentro de un aspecto o clarificar una teoría y los casos en sí mismos tienen un interés secundario dado que juegan un rol en favor de la comprensión de algo más. Cada estudio de caso es un instrumento para aprender sobre el objeto de estudio (Stake, 1998).

Los estudios de casos estaban encaminados a conocer cómo piensan, cómo conocen y qué han aprendido dos profesores de Estadística sobre la RG, cómo interactúan con sus 
estudiantes y la materia en cuestión, cómo resuelven las dificultades en clases, cómo plantean las actividades. Además permiten la oportunidad de acercarse al pensamiento y el conocimiento del profesor e indagar acerca de los procesos cognitivos que subyacen a su práctica y ejercicio docente.

Por último, cabe destacar que la decisión de estudiar al profesor desde un enfoque cualitativo en la modalidad de estudio de casos, coincide con la naturaleza metodológica del estudio del CDC y de la RG expuesta en capítulos anteriores.

\subsection{SELECCIÓN DE LOS PROFESORES PARA LOS ESTUDIOS DE CASOS}

Cuando se diseñó la investigación se trabajó con once profesores de carreras de Psicología o Educación y que estaban o habían impartido la asignatura de Estadística en el curso escolar 2005-2006. La Tabla 4.1 resume estos datos. Como puede apreciarse, existe mucha heterogeneidad en los antecedentes biográficos, de formación inicial y de experiencia de los profesores. Esto llevó a la decisión de incluir a todos en una primera fase, con el objeto de partir de su historial académico y conocer sus concepciones, su forma de planificar la enseñanza así como los aspectos propios del diseño e implementación del currículo de Estadística, para comprender su CDC acerca de la RG.

Fueron cinco las universidades que participaron en la primera fase del estudio, una de régimen público y el resto de carácter privado, todas ubicadas en la ciudad de Mérida del Estado de Yucatán, en México.

Tabla 4.1. Resumen de los datos demográficos y de formación inicial de profesores de Estadística en carreras de Psicología y Educación, curso 2005-2006

\begin{tabular}{ll}
\hline Criterios & Resultado \\
\hline Total & 11 profesores (seis de educación y cinco de psicología)
\end{tabular}

Formación inicial Seis matemáticos, tres ingenieros, un educador y un psicólogo

Otras asignaturas que Siete profesores con materias relacionadas con Estadística o Matemática; imparten tres no relacionado con Estadística o Matemáticas, uno no imparte otra

Otra formación

Dos con Mtría. en Matemáticas (educación), dos con especialización en docencia y/o maestría en educación (de educación y psicología), dos con Mtría. en Educ.(de educación y psicología), uno con maestría y doctorado en estadística (psicología), uno con maestría y doctorado en educación (psicología), uno con maestría en psicología (de psicología), uno es estudiante de maestría en enseñanza de la matemática (psicología) y dos sin estudios de posgrado.

Experiencia docente Varía de 4 a 34 años

Experiencia en docencia Varía de 1 a 14 años Estadística

Edad Varía entre 30 a 55 años (aprox.) 
En la segunda fase del estudio, se seleccionaron dos casos siendo los principales criterios: la oportunidad de aprender de cada profesor y que nos permita obtener una mejor comprensión del CDC sobre la RG. Esto coincide con la recomendación de Stake (1994) quien afirma:

El investigador examina varios intereses del fenómeno de estudio, seleccionando un caso de algo típico, pero aprendiendo de aquellos casos que parecen ofrecer la oportunidad de aprender. Mi opción debería ser tomar aquel caso del cual sentimos que podemos aprender más. Esto puede significar tomar aquel del cual podemos pasar la mayor parte de tiempo. El potencial del aprendizaje es un criterio diferente y a veces superior a la representatividad. A menudo es mejor aprender mucho de un caso atípico que un poco de un caso espléndidamente típico (p.243).

Por lo tanto el criterio fundamental no fue elegir un caso típico o no, sino en función de contribuir a una mejor comprensión del objeto de estudio.

Adicionalmente, ¿qué otros criterios se utilizaron?, ¿cómo se seleccionaron a los dos profesores para los estudios de casos? Los criterios específicos tuvieron en cuenta también la información obtenida en la primera fase y fueron:

$1^{\circ}$. El conocimiento sobre el tópico de la RG.

$2^{\circ}$. Una formación inicial distinta (ej. Matemático y Psicólogo).

$3^{\circ}$. Un caso de un profesor que impartía la asignatura de Estadística en la carrera de Psicología y otro en la carrera de Educación.

$4^{\circ}$. La experiencia docente en Estadística.

$5^{\circ}$. Que estuvieran en ese momento impartiendo la asignatura.

$6^{\circ}$. Buena voluntad, disponibilidad y motivación por colaborar y compartir su pensamiento y conocimiento.

$7^{\circ}$. Actitud positiva hacia el aprendizaje.

A partir de estos criterios, quedaron 3 de los 11 profesores. A dos de ellos (Alicia y Luis, pseudónimos), se les invitó a participar en la investigación con la posibilidad de dar voz a sus opiniones, pensamientos y conocimientos que nos permitiera aprender sobre cómo enseñan la asignatura de Estadística. Ambos aceptaron participar en el estudio. Se trata de dos profesores a tiempo completo de una universidad pública que ofrece entre sus carreras de Psicología y Educación. El tercer profesor, con Licenciatura en Administración de Empresas, no fue considerado dado que las respuestas al cuestionario fueron muy sucintas y además de impartir una clase de Estadística en la carrera de Psicopedagogía, también impartía clases en Relaciones Públicas, Periodismo y Artes Visuales en otra institución de educación superior.

Alicia tiene una formación inicial en Matemáticas, enseña Estadística a estudiantes de Educación posee una experiencia docente en esta materia de tres años, tiene una Maestría en Ciencias Matemáticas y su principal interés es la Matemática abstracta. Imparte, además asignaturas de contenido matemático en la carrera de Informática. Es una profesora comprometida con la enseñanza y con sus alumnos. Representó de interés porque se trataba de una profesora con amplio conocimiento de la matemática, pero al enfrentarse a 
impartir clases de Estadística en un contexto diferente, afrontó el reto de aprender a enseñar sobre la marcha, a partir de la experiencia y sus propios recursos.

Por su parte, Luis es Psicólogo, enseña Estadística a estudiantes de Psicología y tiene cuatros años de experiencia docente en Estadística. Cuenta con una Maestría en Psicología concretamente centrada en investigación social y su centro de interés es la investigación en psicología aplicada. Imparte además las asignaturas de Medición y Evaluación Psicosocial, Construcción de Instrumentos y Análisis de Datos con el SPSS. Luis ha participado en algunos cursos especializados de matemáticas y procede de una familia con formación matemática cuya actividad principal ha sido la docencia. Es un profesor preocupado porque los estudiantes aprendan el sentido de la Estadística en su profesión. Su interés reside en que no es matemático sino psicólogo; con experiencia en investigación social y práctica de la Estadística aplicada. Interesó como ha logrado aprender a enseñar la asignatura a partir de su contexto y biografía académica.

Es necesario precisar el significado que tiene para el Sistema Educativo Mexicano obtener una Maestría. La Maestría es considerada como requisito previo para ingresar a un doctorado, por lo que se expide (al igual que en el nivel de licenciatura) un título y cédula profesional al obtener el grado de Maestría. En México, generalmente se necesitan dos años más uno para la presentación y defensa de la tesis. El Consejo Nacional de Ciencia y Tecnología (CONACYT) es el principal organismo federal que evalúa y otorga el reconocimiento como Programa Nacional de Posgrado de Calidad a las maestrías y doctorados en México. El CONACYT marca la diferencia de programas de maestría con orientación profesionalizante y con orientación a la investigación. Los primeros tienen como objetivos ampliar y mejorar las competencias profesionales en un campo de especialidad (ej. la Maestría en Ciencias Matemáticas). Los segundos están encaminados a la formación encaminada a la investigación científica (ej. la Maestría en Psicología). La maestría que estudió Alicia corresponde a la primera de las opciones, mientras que la que estudió Luis corresponde a la segunda.

\subsection{DESCRIPCIÓN DEL ESCENARIO Y EL CONTEXTO}

Tanto Alicia como Luis son profesores que trabajan en una universidad pública (en adelante Universidad del Sureste, pseudónimo) que cuenta con un enfoque pedagógico que se sustenta en el enfoque constructivista. Los planes de estudio de las carreras de Psicología y Educación han sido modificados para adaptarse a este enfoque.

\subsubsection{Contexto de la carrera de Psicología}

La Licenciatura en Psicología tiene como objetivo:

Formar integralmente a los mejores profesionales en el área de la Psicología, para que mediante el pleno y cabal cumplimiento de la vocación Profesional, científica y tecnológica, puedan actuar responsablemente en sus deberes personales y/o comunitarios, ser generadores de cambio y mejoramiento continuo, para analizar los problemas de su entorno y proponer, implementar y evaluar soluciones a los 
mismos, tomando en cuenta los valores éticos, sociales y culturales, de acuerdo con las necesidades de desarrollo que demande la sociedad.

En cuanto al perfil de los egresados se señala que los estudiantes, en relación con la Estadística deben haber adquirido:

- conocimientos sobre principios de la ciencia y de la investigación y métodos psicológicos para detectar, planear, intervenir y evaluar en todas las áreas de la psicología, así como

- habilidades para detectar, investigar, evaluar, diagnosticar, planear e intervenir en las modalidades de prevención y rehabilitación (básica) en las diferentes áreas de la Psicología: educativa, clínica, social comunitaria y laboral para la solución de problemas.

Para ello los estudiantes deberán cursar asignaturas como: Medición y Evaluación de la Personalidad, Medición y Evaluación en el Proceso de Selección de Personal, Medición Psicosocial, Psicología Experimental, Psicometría I y II, Metodología y Estadística para la Investigación I y II; estas dos últimas directamente relacionadas con la Estadística.

El curso de Metodología y Estadística para la Investigación I, se imparte durante el primer semestre, tiene una duración de 90 horas y su objetivo es "aplicar los conceptos básicos de la metodología y estadística para la investigación, así como las técnicas que permitan desarrollar trabajos científicos (documentales y descriptivos) abarcando las áreas y la problemática actual de la psicología". Dentro de los contenidos de este curso se encuentra el tema de la RG.

El curso de Metodología y Estadística para la Investigación II, se imparte en el segundo semestre, tiene una duración de 90 horas y su objetivo es "aplicar en práctica las técnicas e instrumentos que permiten llevar a cabo investigaciones de tipo científico en las diversas áreas de conocimiento de la psicología".

Estos cursos de metodología y estadística integran contenidos de metodología científica con Estadística, de tal modo que paralelamente al estudio de los conceptos o fases de investigación se estudian, analizan y aplican los conceptos estadísticos. El número máximo de estudiantes es de 20 y las clases se imparten en un aula con sillas de paleta, proyector multimedia, recursos audiovisuales y pizarra. Además, se cuenta con una sala de cómputo que dispone de ordenadores suficientes para las clases prácticas en las que se usa el software SPSS.

\subsubsection{Contexto de la carrera de Educación}

Por su parte, la Licenciatura en Educación tiene como objetivo principal es:

Formar integralmente y con base en un enfoque humanista, profesionales de la educación que diseñen, instrumenten, ejecuten, evalúen e investiguen procesos 
educativos orientados al logro de una educación de calidad, que contribuya a la resolución de problemas en el área de currículum e instrucción, administración y orientación educativa en el entorno educativo local, regional, nacional e internacional.

Como parte del perfil de egreso al término de la carrera el estudiante debe tener las siguientes competencias en relación con las Estadística:

- analizar y comprender fenómenos sociales y educativos para proponer soluciones a los problemas identificados;

- utilizar y realizar investigaciones factibles y válidas, en el campo educativo, con base en el uso de métodos de investigación en las ciencias sociales, para resolver situaciones problemáticas y/o desarrollar proyectos;

- evaluar la pertinencia, relevancia y efecto de los programas educativos, cursos y de los aprendizajes de los estudiantes;

- diseñar, implementar y evaluar programas de orientación educativa para promover el desarrollo humano y comunitario; así como

- realizar investigaciones factibles y válidas en administración educativa, orientación educativa, currículo y/o la instrucción, con base en el uso de métodos de investigación.

Para dar cumplimiento a esas competencias los estudiantes deberán cursar asignaturas como: Teoría y Metodología de la Ciencia, Taller de Investigación Documental, Estadística, Investigación Educativa I (introducción a la investigación cuantitativa), Investigación Educativa II (introducción a la investigación cualitativa) e Instrumentos de Evaluación en Orientación.

Los estudiantes de Educación deben realizar, por lo tanto, un curso de Estadística, el cual se imparte en segundo semestre con una duración de 60 horas e incluye desde conceptos básicos de estadística descriptiva hasta estadística inferencial (ej. pruebas de hipótesis). Tiene como objetivo que "al finalizar el curso el alumno será capaz de utilizar la estadística descriptiva e inferencial en la interpretación de información obtenida de una investigación educativa".

El curso de Estadística se imparte en un aula con sillas de paleta, proyector multimedia, recursos audiovisuales y pizarra. El número máximo de estudiantes en este curso es de 25.

\subsection{INSTRUMENTOS Y MATERIALES}

El análisis de los marcos teóricos expuestos en los capítulos 1 y 2 permitió identificar los diferentes instrumentos y técnicas de recogida de información. Para la realización de la investigación se han utilizado los siguiente instrumentos: 1) los programas de cada curso de Estadística, 2) un guión para una entrevista acerca del contexto, la biografía y la planificación de las clases en torno al tema de la RG, 3) un cuestionario con 
situaciones-problema sobre la RG, 4) un guión para una entrevista en profundidad y 5) los materiales usados para la enseñanza de la RG de los profesores participantes.

\subsubsection{Programas de los cursos de Estadística}

Estos programas constituyen una descripción donde se refleja la primera intención del profesor sobre lo que quiere que los alumnos aprendan así como los contenidos, la metodología de enseñanza, los criterios de evaluación y la bibliografía a utilizar.

Se contó con los dos programas específicos que impartieron Alicia y Luis (ver Apéndice C), del cual se originó la Tabla 4.2 donde se presenta una comparación del tema de $\mathrm{RG}$ por diferentes componentes.

Tabla 4.2. Análisis del tema de la representación gráfica según los programas de Estadística de Psicología y Educación que imparten Alicia y Luis

\section{Programa de Estadística}

\begin{tabular}{|c|c|c|}
\hline Componente & Psicología & Educación \\
\hline Enfoque pedagógico & $\begin{array}{l}\text { Aplicación de la Estadística a la } \\
\text { investigación social }\end{array}$ & Centrado en los contenidos \\
\hline \multirow[t]{2}{*}{ Objetivo } & $\begin{array}{l}\text { Calcular los diferentes tipos de } \\
\text { frecuencias: absolutas, relativas y } \\
\text { acumuladas de un conjunto de datos }\end{array}$ & $\begin{array}{l}\text { Elaborar e interpretar gráficas con las } \\
\text { características de los datos }\end{array}$ \\
\hline & $\begin{array}{l}\text { Elaborar la representación gráfica de } \\
\text { un conjunto de datos }\end{array}$ & \\
\hline $\begin{array}{l}\text { Número de sesiones de } \\
\text { clase }\end{array}$ & 2 sesiones de 1.5 hrs. c/u por semana & 2 sesiones de $1.5 \mathrm{hrs}$. c/u por semana \\
\hline Contenidos & $\begin{array}{l}\text { Distribuciones de frecuencias } \\
\text { (absolutas, frecuencias relativas, } \\
\text { frecuencias acumuladas) } \\
\text { Representación gráfica del diagrama } \\
\text { de barras, histograma, polígono de } \\
\text { frecuencias y ojiva }\end{array}$ & $\begin{array}{l}\text { Gráfica de barras, polígono de } \\
\text { frecuencias, ojiva, histograma, de } \\
\text { pareto, circular, etc. } \\
\text { Interpretación de los datos de las } \\
\text { gráficas }\end{array}$ \\
\hline $\begin{array}{l}\text { Estrategias de } \\
\text { enseñanza }\end{array}$ & $\begin{array}{l}\text { Revisión bibliográfica, exposición y } \\
\text { ejercicios }\end{array}$ & $\begin{array}{l}\text { Exposición con demostración, trabajo } \\
\text { en pequeños grupos, ejercicios y SPSS }\end{array}$ \\
\hline Evaluación & Prueba escrita, trabajo y ejercicios & Prueba escrita y ejercicios \\
\hline Bibliografía & $\begin{array}{l}\text { Levin, J. y Lenin, W. (1999). } \\
\text { Fundamentos de Estadística en la } \\
\text { investigación social. México: Oxford } \\
\text { University Press }\end{array}$ & $\begin{array}{l}\text { APA (2001). Publication Manual of } \\
\text { the American Psychological } \\
\text { Association. Fifth Edition. } \\
\text { Washington, DC: APA }\end{array}$ \\
\hline
\end{tabular}


Con el fin de conocer el contexto, constitución y planificación de la Estadística en las carreras de Psicología y Educación, se procedió al análisis de su diseño curricular con base en Díaz-Barriga (2004), quien elaboró un "Instrumento para el análisis de programas de materia", haciendo énfasis en el análisis de evaluación curricular interna del programa (estructura, organización, consistencia e implementación). Este estudio se hizo a partir de las tres secciones que lo componen: la primera, sobre los fines, temas y objetivos de la Estadística; la segunda, sobre los temas y objetivos de aprendizaje de la representación de datos y la tercera sobre el análisis de las estrategias de enseñanza, las formas de evaluar y la bibliografía utilizada. Se revisaron siete programas de Estadística, de los cuales cinco son de carreras del área de Psicología y dos de Educación. En el Apéndice B se resume los principales hallazgos encontrados.

Aunque no se intenta hacer un análisis de la información en esta sección, sino sólo presentar los instrumentos utilizados, es preciso destacar que mientras el programa de Estadística en la carrera de Psicología integra el estudio de la metodología científica con la Estadística, en el caso de Educación se centra casi exclusivamente en el estudio de los contenidos estadísticos. Otra característica diferente es que en Psicología se hace explícita la necesidad de realizar una investigación empírica descriptiva, donde el estudiante debe recoger datos y hacer un análisis estadístico de los mismos. En el programa de Educación se menciona que se deberá utilizar la Estadística en la interpretación de información de una investigación educativa.

\subsubsection{Guión de entrevista contextual, biográfica y sobre la planificación de las clases del tema de RG}

Se realizó una primera entrevista a los 11 profesores que participaron en la primera fase del estudio. La entrevista definida como "una técnica en la que una persona (entrevistador) solicita información de otra o de un grupo (entrevistados, informantes), para obtener datos sobre un problema determinado" (Rodríguez, Gil y García, 1999) se apoya en la idea de que:

las personas son capaces de ofrecer una explicación de su conducta, sus prácticas y sus acciones a quien les pregunta sobre ellas... [se asume] que las personas pueden reflexionar, hasta cierto punto, sobre sus propias acciones, o, al menos, se les puede inducir a hacerlo. La noción de entrevista lleva implícito el supuesto de que el informante es un investigador, en la medida en que puede ofrecer explicaciones reflexivas y contrastarlas con la experiencia (Walker, 1989, p.113-114, en Angulo y Vázquez, 2003)

Basándonos en el trabajo de Sánchez y Llinares (2002) y Llinares (2000), se realizó una entrevista contextual, biográfica y sobre la planificación de la enseñanza de los profesores. Fue una entrevista semiestructurada, dado que se planificaron y organizaron previamente diversos aspectos de las preguntas aunque éstas se presentaron ocasionalmente en diferente orden y al mismo tiempo surgieron preguntas adicionales que permitieron explorar con mayor profundidad el objeto de estudio (Angulo y Vázquez, 2003). 
Un elemento esencial en la preparación (diseño) de las entrevistas es el guión de entrevista (Valles, 2003) que se realizó utilizando las etapas señaladas en Angulo y Vázquez (2003) que se describen brevemente a continuación:

\subsubsection{Definición de los objetivos}

La entrevista estuvo centrada sobre los aspectos del programa de curso, la planificación de la clase, las concepciones sobre la Estadística, su enseñanza y aprendizaje; así como del conocimiento del currículo sobre al RG. Específicamente la entrevista pretendió:

a. Describir la formación inicial y permanente y el contexto en el que trabajan los profesores de Estadística.

b. Indagar sobre el porqué de la decisión de ser profesor de Estadística y lo que pensaban que era necesario para poder empezar a enseñar.

c. Comprender las percepciones del profesor acerca del currículo en matemáticas y estadística y su propio rol como profesor de Estadística, su experiencia pasada como estudiante y aprendiz de Estadística y como profesor de Estadística.

d. Explorar las concepciones que tiene de la Estadística y su enseñanza y aprendizaje.

e. Indagar sobre las ideas y opiniones que tienen los profesores sobre la forma de planificar y organizar una clase de Estadística, los objetivos de la Estadística en carreras como Psicología o Educación, los principales contenidos incluidos en la enseñanza, las aproximaciones que usan en el salón de clases.

f. Aprender cómo los profesores se preparan para la instrucción, los materiales y actividades utilizados y cómo determinan lo que el alumno aprenderá.

Durante la entrevista el profesor expresó su concepción de la Estadística en función de los objetivos que se propone, su forma habitual de dar clases, el tipo de tareas que plantea a los alumnos o los conceptos que relaciona con la noción de RG, entre otros aspectos.

\subsubsection{Marco de referencia}

Para el diseño de la entrevista se revisaron aportaciones de autores que han diseñado y utilizado la entrevista como recurso de obtención de información en una investigación en educación matemática.

A partir de lecturas como García (1994), Vallecillos (1996), Carrillo (1998), Azcárate (1998), Ortiz (1998), Huerta (1998), Gordon (1998), Gil (2000), Miller (2000), Moreno (2000), Sánchez y Llinares (2002), se pudo definir y organizar la estructura del guión de entrevista, así como el diseño de cada una de las preguntas. Por ejemplo, se analizaron las dimensiones de que constó cada entrevista; el tipo, propósito y naturaleza de cada pregunta; el procedimiento y la técnica de realización de la entrevista; así como la forma de analizarla y presentar sus resultados. 


\subsubsection{Definición de los apartados}

El guión de entrevista estuvo organizado en ocho dimensiones. A continuación se mencionan y se describen brevemente.

a. Información general. Crear un ambiente de confianza.

b. Descripción del contexto. Ubicar y caracterizar el contexto laboral del profesor.

c. Antecedentes sobre la formación y enseñanza de la Estadística. Información sobre su experiencia y formación en Estadística, así como su motivación para ser profesor.

d. Salón de clases ideal. Primeras preguntas, de carácter inductivas, sobre los escenarios de enseñanza y aprendizaje de la Estadística. Permite corroborar tanto aspectos pedagógicos genéricos como específicos de la enseñanza y aprendizaje de la Estadística.

e. Concepciones. Primer eje central de la entrevista. Explora las concepciones que tiene el profesor de la matemática, de la Estadística, así como de la enseñanza y aprendizaje de la Estadística.

f. Programa de curso y enseñanza. Segundo eje central de la entrevista. Recoge información sobre los conocimientos que tiene el profesor sobre el currículo de Estadística, es decir cómo planifica, cómo selecciona los contenidos, cómo selecciona, modifica y usa los materiales, y cómo evalúa. Analiza también los conocimientos del profesor sobre las dificultades de la enseñanza de la Estadística y sobre el papel de la tecnología en clases.

g. Aprendizaje de los alumnos. Tercer eje central de la entrevista. Indaga sobre la concepción que tiene el profesor sobre el aprendizaje de la Estadística y sus conocimientos sobre los procesos de aprendizaje de los alumnos.

h. Formación inicial y permanente. Pretende obtener información sobre las estrategias y recursos de formación y actualización del profesor y las tendencias en la educación y enseñanza de la Estadística.

Estas dimensiones ayudaron a establecer el tipo de preguntas necesarias para lograr los objetivos de la entrevista.

\subsubsection{Revisión de los lineamientos metodológicos}

Para asegurar que el diseño, estructura y redacción de las preguntas esté con base en la metodología de investigación científica se recurrió a revisar autores como Miles y Huberman (1994), Sierra (1995), Cohen y Manion (2002), Angulo y Vázquez (2003), Rubio y Varas (2004) y Flick (2004). Se analizaron los lineamientos y características para la redacción de las preguntas, los elementos que debe tener un guión de entrevista, así como el proceso para validar su estructura y contenido. 


\subsubsection{Elaboración de las preguntas}

En esta etapa se reunió e integró la información recogida de las investigaciones que se consultaron, seguidos de la valoración sobre la pertinencia de las preguntas que se encontraron en cada investigación para incluirlas o no en el guión de entrevista. Después de seleccionar aquellas preguntas que estaban relacionadas con los objetivos y apartados se procedió a la revisión, traducción, modificación o redacción de las preguntas, según el caso.

\subsubsection{Clasificación y propósito de cada pregunta}

Esta etapa consistió en organizar cada pregunta en los apartados predefinidos, así como describir el propósito de cada una para asegurar su contribución a los objetivos establecidos.

\subsubsection{Análisis de jueces expertos y prueba piloto}

El guión de entrevista fue sometido a un proceso de validación por jueces expertos. Su selección se realizó teniendo en cuenta su experiencia investigadora (ej. en educación matemática o estadística), su línea de investigación (ej. conocimiento profesional del profesor, concepciones de estudiantes y profesores) y su experiencia en metodología de investigación en educación matemática (ej. construcción de entrevistas).

Se seleccionaron tres jueces expertos, quienes contestaron un Protocolo para la Validez de Contenido del Guión de Entrevista (ver Apéndice D) elaborado a partir de las recomendaciones de Rubio y Varas (2004). Los tres jueces eran profesores doctores en educación matemática, investigadores, miembros de la Sociedad Española de Investigación en Educación Matemática y reconocidos a nivel nacional e internacional por su contribución en la investigación en educación matemática. Tenían amplia experiencia en su línea de investigación: uno en formación de profesores de matemáticas y conocimiento profesional del profesor, otra en investigación en educación estadística y en el estudio de las concepciones de los estudiantes para profesor y la tercera en metodología de la investigación y estudio de las concepciones de los estudiantes. Además cuentan con experiencia en el diseño, realización y análisis de la entrevista como técnica de investigación cualitativa.

Junto con el guión de entrevista se les envió un documento técnico que describía brevemente los objetivos de la tesis y de la entrevista, el procedimiento de diseño, así como las características generales de la investigación. Se les solicitó valorar el guión en términos de: 1) la adecuación de las preguntas, 2) la estructura de las partes, 3) una valoración general, 4) la extensión y preguntas reiterativas, 5) la valoración específica de la redacción de las preguntas y 6) observaciones generales.

El guión de entrevista también fue sometido a una prueba piloto para comprobar si las preguntas encajaban con los objetivos propuestos, contrastar hasta qué punto funcionaba como se pretendía y si las respuestas provocaban el tipo de respuesta deseado; asimismo se utilizó para revisar la formulación de las preguntas, su secuencia, comprensión y relevancia 
(García, 2005). También sirvió para poner a prueba recomendaciones y orientaciones básicas sobre el proceso de la entrevista en educación matemática (Azcárate, 1998; Ortiz, 1998; Huerta, 1998).

En la prueba piloto participaron tres profesores de Estadística que impartían clase en alguna carrera del área social (Antropología, Comunicación y Contaduría Pública). Previo a la realización de las entrevistas, a cada profesor se le explicó el objetivo de ésta, la dinámica y se les solicitó su autorización para audiograbarla. Una vez finalizada se les pidió su opinión sobre las preguntas, el lenguaje utilizado y su relevancia.

Se analizaron las observaciones de los jueces y las audiograbaciones de las entrevistas realizadas a los profesores que participaron en la prueba piloto, según los criterios de Borg y Gall (1979): leer los comentarios de los sujetos, analizar pregunta por pregunta, analizar las respuestas emitidas y mejorar el instrumento lo que permitió hacer las correcciones y adecuaciones pertinentes al guión.

\subsubsection{Versión definitiva del guión de entrevista}

El guión de entrevista contextual, biográfica y sobre la planificación de las clases de la RG (ver Apéndice E) consistió en 35 preguntas clasificadas en ocho apartados: información general (1), descripción del contexto (3), antecedentes sobre la formación y enseñanza de la Estadística (4), salón de clases ideal (2), concepciones (5), programa de curso y enseñanza (13), aprendizaje de los alumnos (3) y formación inicial y permanente (4).

\subsubsection{Cuestionario didáctico sobre representación gráfica}

Para estudiar el conocimiento que tiene el profesor sobre las estrategias y representaciones instruccionales y sobre los procesos de aprendizaje del estudiante de la RG, se construyó un Cuestionario Didáctico sobre Representación Gráfica. Este consistió en cuatro situaciones hipotéticas de enseñanza-aprendizaje (casos) de la RG.

Una situación hipotética de enseñanza - aprendizaje es una herramienta que nos permite mostrar de forma narrativa y metafórica lo que el profesor normalmente dice y hace para que los estudiantes aprendan un concepto matemático (Llinares, 2000). Tomando como referencia el trabajo de Llinares (2000), la estructura de cada caso fue: (i) la descripción de una situación (ej. actividad, tarea, diálogo, exposición) de enseñanza y aprendizaje sobre un aspecto específico de la RG, (ii) la respuesta hipotética de un estudiante a algunos problemas o preguntas relativas al contenido de la $R G$ y (iii) algunas preguntas para el profesor (de carácter diagnóstico y acción).

Al igual que Moreno (2000), la intención no fue que los profesores se pusieran en situación de resolución de los problemas, sino que dichos casos sirvieran como contexto a partir del que reflexionar acerca de la Estadística, los conceptos que subyacen en un análisis, los criterios de interpretación y representación de gráficos. Se buscó que el profesor comentara aspectos relacionados con la didáctica del contenido, las dificultades específicas de cada problema, la forma de responder y situarse frente a las preguntas de los 
estudiantes y la forma como se enfrenta y resuelve los problemas que surgen en la enseñanza de la Estadística y la RG.

Los casos fueron construidos a partir del SDI del CDC (definido en el capítulo 1), los resultados obtenidos de la revisión de la literatura sobre investigación del aprendizaje de la RG (capítulo 2) y de los objetivos del pensamiento estadístico. El procedimiento de construcción del cuestionario se realizó en cuatro etapas:

1. Preguntas orientadoras para explorar el CDC.

2. Cuestionario diagnóstico sobre representación gráfica.

3. Análisis del cuestionario diagnóstico.

4. Versión definitiva del cuestionario didáctico sobre representación gráfica.

A continuación se describe detalladamente cada una estas etapas.

\subsubsection{Preguntas orientadoras para explorar el CDC.}

La revisión de la literatura sobre el CDC de educación matemática permitió identificar un conjunto preguntas que diversos investigadores han utilizado para estudiar al profesor en relación con alguna de las categorías, dimensiones e indicadores del CDC. Las Tablas F1 y F2 (Apéndice F) presentan estas preguntas organizadas por categorías del CDC y clasificadas según las SDI señalando si la pregunta se encontró en un cuestionario $(\mathrm{Cu})$ o en un guión de entrevista (E). A continuación se presentan dos ejemplos del tipo de preguntas identificadas:

\begin{tabular}{|c|c|c|c|}
\hline$\frac{\text { Instru- }}{\underline{\text { mento }}}$ & Dimensión [indicador] & Preguntas / procedimiento & $\frac{\text { Clasificación }}{\frac{\text { según SDI }}{\underline{\text { del CDC }}}}$ \\
\hline $\mathrm{Cu}$ & Currículo [materiales] & $\begin{array}{l}\text { ¿Qué preguntas o tareas usted solicitaría a Adam } \\
\text { para determinar lo que comprende? }\end{array}$ & B-III-2f \\
\hline $\mathrm{Cu}$ & $\begin{array}{l}\text { Cono Proc Cog [pre y } \\
\text { concep] } \\
\text { Estrategias [específicas] }\end{array}$ & $\begin{array}{l}\text { Uno de los estudiantes dijo, "la moda es perro, la } \\
\text { media pato y el rango es } 1 \text { a } 7 \text { " Si piensa que el } \\
\text { estudiante está en lo correcto, explique por qué. Si } \\
\text { está equivocado, identifique los errores }\end{array}$ & $\begin{array}{l}\text { C-I-3,4 } \\
\text { C-III-2 }\end{array}$ \\
\hline
\end{tabular}

Ambas preguntas fueron tomadas de un cuestionario $(\mathrm{Cu})$ utilizado en alguna investigación. La primera se incluyó en el componente del conocimiento de las estrategias y representaciones instruccionales (B), en la dimensión de Currículo (III), y el indicador referido a los materiales (2f), según el SDI del CDC (ver Tabla 1.9). Es una pregunta que trata de explorar qué conocimiento tiene el profesor sobre los materiales curriculares. La segunda pregunta se agrupó en el componente del conocimiento del estudiante (C), en dos dimensiones, tanto en la de conocimiento del proceso cognitivo del estudiante (I), en los indicadores referidos al conocimiento de las creencias y concepciones que tiene del estudiante (3 y 4); como de las estrategias específicas (III) para corregir alguna concepción inadecuada del concepto (2). 
La clasificación permitió tener una mayor claridad sobre el tipo y características de las preguntas por componente, dimensión e indicador estudiado del CDC. No es una clasificación única y acabada dado que una misma pregunta puede ubicarse o estar relacionada con alguno otro componente, dimensión e indicador del CDC.

\subsubsection{Cuestionario diagnóstico sobre representación gráfica.}

Merseth (1994) sugiere que el diseño de un caso (o situación de enseñanzaaprendizaje) debe estar basado en situaciones de la vida real, dado que permite que los profesores exploren, analicen y examinen representaciones lo más cercanas al salón de clases real. Ese fue el propósito al diseñar el cuestionario de diagnóstico sobre RG, obtener información sobre las concepciones, dificultades y errores de los estudiantes sobre el tema de la RG.

El cuestionario fue diseñado a partir de la revisión de las investigaciones centrada en la RG, de la valoración de cerca de 66 ítems catalogados y clasificados en función del autor, finalidad, contexto y nivel cognitivo (ver Capítulo 2) y con base en el análisis de los programas de las asignaturas de Estadística en carreras de Psicología y Educación (ver Apéndice B y C).

Para la elaboración del cuestionario se tuvieron en cuenta los objetivos que se plantean en torno a la $\mathrm{RG}$ en el nivel de pensamiento estadístico (ver sección 2.5.2. del Capítulo 2). Autores como Garfield (2002 y 2003), Sorto (2004) y Makar (2004) fueron referentes útiles para selección de los gráficos y el diseño de las preguntas del cuestionario. En todos los ejercicios se utilizaron situaciones que hicieran referencia a un contexto familiar para el estudiante de Psicología y de Educación (ej. número de minutos que tarda llegar a la escuela, porcentajes de alfabetización, puntuaciones en un examen, número de familias que residen en un pueblo). En general, el cuestionario pretendía explorar principalmente la habilidad del estudiante en:

- Seleccionar el gráfico representativo de los datos, dentro del contexto de un problema de investigación en Psicología y Educación.

- Interpretar los gráficos dentro de un contexto.

- Criticar y evaluar gráficos en diferentes contextos.

- Identificar y analizar errores conceptuales al seleccionar, construir, interpretar y escribir gráficos.

- Tomar decisiones a partir de la interpretación de gráficos.

- Redactar interpretaciones y discusiones sobre un problema de investigación que incluía un gráfico.

El cuestionario, incluía ocho ejercicios con diversos gráficos estadísticos (dos gráficos de tallo y hoja, uno de caja, un histograma, uno de barras, dos gráficos de puntos y un gráfico lineal) en donde a través de diversas preguntas el estudiante tenía que poner en juego sus habilidades en diferentes niveles cognitivos de la RG (ver Figura 4.1 un ejemplo de los ejercicios utilizados). En total fueron 27 preguntas, clasificados por niveles cognitivos, de los cuales el 18\% exploró la alfabetización estadística, el 25\% exploró el 
razonamiento estadístico y un $57 \%$ de las preguntas exploró el pensamiento estadístico acerca de la RG en estadística.

1. El profesor Diego del curso introductorio de estadística les solicitó a sus alumnos, representar a través de un gráfico el número de minutos que les lleva viajar de su casa a la escuela. Los datos del tiempo (en minutos) que tardan en llegar a la escuela fueron:

$\begin{array}{lllllllll}3 & 25 & 16 & 18 & 45 & 13 & 7 & 35 & 23 \\ 23 & 30 & 28 & 15 & 20 & 12 & 3 & 5 & 23 \\ 21 & 16 & 25 & 28 & 8 & 9 & 19 & 10 & \end{array}$

El gráfico que proporcionó uno de los estudiantes fue el siguiente:

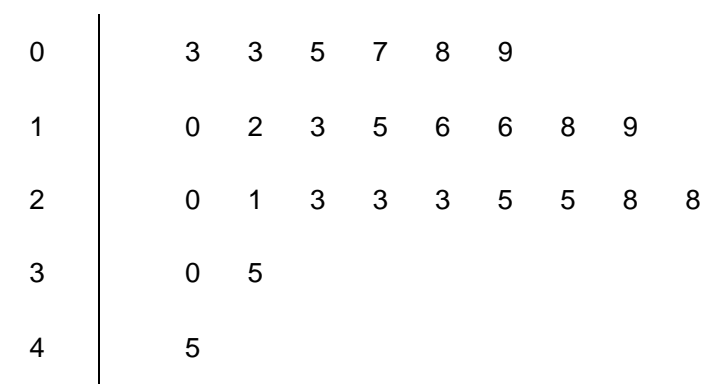

a. ¿Piensas que el estudiante seleccionó apropiadamente el gráfico? Explica tu respuesta

b. ¿Crees que es posible representar los datos de otra forma? Si es así, ¿cuál gráfico piensas? Argumenta tu respuesta

c. Elabora por lo menos tres conclusiones que se originan del gráfico de Tallo y Hoja

Figura 4.1. Ejemplo del ejercicio 1, utilizado en el cuestionario diagnóstico sobre representación gráfica dirigido a estudiante de Psicología y Educación

El cuestionario se administró a dos muestras de estudiantes. Primero, en mayo de 2005 a 57 estudiantes de la Facultad de Educación de la Universidad de Salamanca (España) que estaban cursando la diplomatura de educación social; y luego, en septiembre de 2005 a 49 estudiantes de Psicología y Educación de la Universidad del Sureste (México).

\subsubsection{Análisis del cuestionario diagnóstico.}

Para el análisis de las respuestas de los estudiantes al cuestionario se utilizó la escala de Sorto (2004, pp.117-118) que permite valorar cada respuesta de la siguiente forma:

4= La solución es completa y correcta.

$3=$ La solución es casi completa y correcta.

2= La respuesta está en la dirección correcta y contiene algunos elementos esenciales, tales como una cadena de razonamiento. 

1= Algo del trabajo es correcto, pero el estudiante eligió una opción prematura e incorrecta.
$0=$ La respuesta es totalmente errónea o sin sentido.

Si bien el análisis de las respuestas de los estudiantes confirmó el poco nivel que tienen de pensamiento estadístico sobre el tema de la RG, en realidad, el propósito central era identificar, recoger y analizar frases $\mathrm{u}$ oraciones textuales de los estudiantes que reflejaran errores conceptuales, concepciones equivocadas o dificultades en torno a la RG. Además, permitió valorar qué tipos de gráficos conocen, el grado de familiarización con el contexto de cada ejercicio y en qué preguntas hubo un mayor número de respuestas.

\subsubsection{Versión definitiva del cuestionario didáctico sobre representación gráfica.}

El cuestionario fue diseñado siguiendo el procedimiento de construcción de Llinares (2000) y Moreno (2000). Dado que el objetivo de la investigación era explorar las concepciones del profesor sobre la Estadística, su enseñanza y aprendizaje y el conocimiento de las estrategias y representaciones instruccionales y de los procesos de aprendizaje del estudiante sobre el tema de la RG, utilizando algunas sugerencias de Moreno (2000), se decidió que la mejor forma de acceder a este tipo de información era centrarse en aspectos relacionados con los estudiantes, las dificultades específicas de cada problema, la forma de responder y situarse frente a preguntas de los estudiantes.

Para la definición de cada uno de los casos, hubo que contemplar tanto el tipo de preguntas a partir del SDI del CDC como aquellos aspectos que interesaron de la RG a nivel de pensamiento estadístico.

Tabla 4.3. Clasificación de las preguntas del Cuestionario Didáctico sobre Representación Gráfica según el SDI del CDC

\begin{tabular}{|c|c|c|c|}
\hline Dimensión [indicador] & Clasificación $^{4}$ & Preguntas & Total (\%) \\
\hline \multicolumn{4}{|l|}{$\begin{array}{l}\text { Conocimiento de las estrategias y } \\
\text { representaciones instruccionales }\end{array}$} \\
\hline Estrategias & $\mathrm{B}-\mathrm{V}$ & $1 \mathrm{a}, 2 \mathrm{a}, 3 \mathrm{a}, 4 \mathrm{a}$ & $4(29 \%)$ \\
\hline Currículo [materiales] & B-III-2 & $1 \mathrm{a}, 3 \mathrm{a}$ & $2(14 \%)$ \\
\hline Currículo [programa] & B-III-1 & $4 \mathrm{~b}$ & $1(7 \%)$ \\
\hline \multicolumn{4}{|l|}{$\begin{array}{l}\text { Conocimiento del proceso de } \\
\text { aprendizaje del alumno }\end{array}$} \\
\hline $\begin{array}{l}\text { Cono Proc Cog [pre y } \\
\text { concepciones] }\end{array}$ & C-I-3,4 & $1 a, 1 b, 1 c-i, 2 b, 3 b-i, 3 c-i, 4 b$ & $7(50 \%)$ \\
\hline Estrategias [específicas] & C-III-2 & 1a, 1c-ii, 2a, 2c, 3b-ii, 3c-ii, & $6(43 \%)$ \\
\hline Cono Proc Cog [errores] & C-I-5 & 1a, 1b, 1c-ii, 2b, 3b-i, 3c-i, & $6(43 \%)$ \\
\hline $\begin{array}{l}\text { Diagnóstico [creencias y } \\
\text { concepciones] }\end{array}$ & C-II-1,2 & $1 \mathrm{~b}, 2 \mathrm{~b}, 3 \mathrm{~b}-\mathrm{ii}$ & $3(21 \%)$ \\
\hline Cono Proc Cog [dificultades] & C-I-10, 11 & 3bi, 3c-i, & $2(14 \%)$ \\
\hline Diagnóstico [estrategias] & C-II-4 & $2 \mathrm{a}$ & $1(7 \%)$ \\
\hline Materiales & C-IV & $2 \mathrm{c}$ & $1(7 \%)$ \\
\hline
\end{tabular}

${ }^{4}$ Con base en las Dimensiones e Indicadores de CDC (ver Tabla 1.9) 
Sobre las preguntas relacionados con alguna o varias dimensiones del CDC sobre RG (ver Tabla 4.3), éstas se agrupan básicamente en dos de sus componentes. Ejemplo de algunas preguntas relacionadas con el componente del conocimiento de las estrategias y representaciones instruccionales fueron ${ }^{5}$ :

1a. ¿Cómo ayudaría usted al estudiante a comprender el procedimiento para discriminar entre los gráficos anteriores?

2a. ¿Qué preguntas haría a Diego para comprender por qué ha dado esas respuestas? Por favor, argumente su respuesta.

3a. ¿Cuál cree Ud. que es el objetivo del que ha surgido este ejercicio?

4a. Describa la estrategia que utilizaría con sus alumnos, paso a paso, para ayudarles a criticar y evaluar el gráfico anterior.

4b-i. Si esta actividad se la planteara a sus alumnos, ¿qué interpretaciones le darían al criticar y evaluar el gráfico? Argumente su respuesta.

Algunas de las preguntas referentes al componente del conocimiento de los procesos de aprendizaje del estudiante fueron:

1b. Exprese las concepciones previas (ej. conceptos, creencias, reglas, significados) y las dificultades de aprendizaje que espera encontrar en sus estudiantes en discriminar entre un gráfico y otro.

2b. ¿Cuál cree que puede ser la causa del posible razonamiento de Diego a esta actividad? Explique su respuesta.

2c. ¿Cómo haría para corregir el error de Diego? Ejemplifique por favor.

$3 c-i$. La respuesta de Omar al inciso "b" fue "Hay siete ciudades representadas". En su opinión ¿por qué da esta respuesta?

Por otro lado, se diseñaron las preguntas para que durante la entrevista en profundidad se pudiera ahondar en el conocimiento del profesor sobre los distintos elementos seleccionados.

Se trataba primero de analizar qué aspectos de la RG y del conocimiento del profesor se querían explorar, y segundo, qué tipos de gráficos nos permitirían estudiar ese conocimiento. En cuanto a lo primero, se utilizaron tanto los resultados obtenidos por los estudiantes en el diagnóstico previo sobre la RG como la revisión del programa de los cursos de Estadística de Psicología y Educación. De este modo, nos centramos en el estudio de la RG en el nivel de pensamiento estadístico específicamente cuando el estudiante pone en juego habilidades para:

- identificar errores conceptuales $\left(93 \% \%^{6}\right)$,

- formular y resolver problemas en la selección del gráfico (71\%),

- criticar y evaluar gráficos $(57 \%)$,

- evaluar la selección del gráfico (43\%),

- formular y resolver problemas en la escritura del gráfico (36\%),

- formular y resolver problemas en la interpretación del gráfico $(21 \%)$,

- comunicar los resultados $(21 \%)$, y

\footnotetext{
${ }^{5}$ Los números 1a, 4b-i, etc. que aparecen al principio de cada pregunta indica a qué caso pertenece, sea al Caso 1, 2, 3 o 4; y el inciso representa el orden que ocupa dentro de las secuencia de preguntas asociadas a cada caso (a, b, c-i, c-ii, etc.).

${ }^{6}$ Es el porcentaje de preguntas que explora el cuestionario sobre dicha habilidad.
} 
- asimilar y extraer inferencias a partir de diagramas o gráficos (14\%).

Puede apreciarse, por lo tanto, que fueron varias las situaciones en donde el alumno proporcionaba alguna o varias respuestas para identificar algún error conceptual en un gráfico, o que tenían que seleccionar el gráfico más representativo, criticar su construcción, etc. Por medio de los Casos se intentó estudiar el CDC del profesor sobre estos dominios cognitivos del aprendizaje de los estudiantes. En la mayoría, si no en todas, las situaciones eran diferentes de las utilizadas por el profesor en sus clases, no eran las actividades habituales que proponían a los estudiantes, ni tampoco aparecían en los libros de textos de Estadística. Por tanto, el profesor tenía que enfrentarse a situaciones que se correspondían con algunos dominios cognitivos del nivel de pensamiento estadístico, y no sólo a aspectos relativos a la construcción e interpretación de gráficos tradicionales, al nivel de alfabetización o de leer datos y leer entre datos.

Un segundo aspecto a decidir fueron los tipos de gráficos a utilizar, los cuales fueron el gráfico de tallo y hoja, el de barras, un histograma y un pictograma.

Otro de los puntos críticos al que nos enfrentamos fue el relativo a la elección y/o redacción de la situación-problema de cada caso. Aunque principalmente utilizamos algunas de las respuestas literales dadas por los estudiantes en el cuestionario diagnóstico queríamos además plantear situaciones reales y familiares para los estudiantes de Psicología y Educación que impliquen: (i) estudiar el gráfico para conocer la naturaleza de los datos a partir de un análisis exploratorio de los mismos (Exploratory Data Analysis, $E D A)$; y (ii) relacionar el contexto con los elementos del gráfico y los procesos de pensamiento del estudiante (Monteiro y Ainley, 2006), así como aprender algo nuevo acerca del contexto que representa el gráfico, obtener nueva información o aprender a partir de los datos (Pfannkuch, 2006). Podemos resumir el uso de estos dos criterios para cada uno de los casos de la siguiente forma:

Caso 1: Se trata de una situación de clase, en donde una profesora solicita elaborar y elegir la mejor forma de representación. Los alumnos eligen el gráfico de tallo y hoja y a partir de ahí se generan preguntas relacionadas con la elección, crítica y evaluación del gráfico.

Caso 2: Se presenta la respuesta de un estudiante a una actividad relativa a la definición de una variable y su relación con un tipo de gráfico.

Caso 3: A partir de un histograma se presenta un segmento de una investigación social, donde el alumno tenía que interpretar, describir y evaluar el gráfico.

Caso 4: Se presenta un media graph que pone en juego la habilidad del estudiante para criticarlo y evaluarlo.

Finalmente el cuestionario consistió en cuatro casos con un total de 14 preguntas de respuesta abierta. La versión definitiva puede verse en el Apéndice G. Con ellos se abarcan 
todos los indicadores seleccionados para el estudio; en la Tabla 4.3 muestra la distribución de las preguntas por el SDI del CDC teniendo en cuenta que cada una se agrupa en una o más dimensiones o indicadores.

Puede apreciarse en la Tabla 4.3 que la mitad de las preguntas estuvieron orientadas hacia el conocimiento que tiene el profesor de las creencias y concepciones del estudiante sobre la RG, y un gran porcentaje sobre el conocimiento que tiene de los errores y las estrategias específicas para corregirlas (43\%). En menor porcentaje están las preguntas que exploran el conocimiento del profesor sobre las estrategias y las representaciones instruccionales de la RG (29\%).

A continuación se describe cada uno de los casos.

En el Caso 1 se usa una situación adaptada a partir de un ejercicio de Sorto (2004) que, utiliza un gráfico de tallo y hojas de Friel, Curcio, Frierson y Kader (1997) y diseña una situación idéntica a la nuestra salvo que sus preguntas están dirigidas al contenido (ej. ¿Cuántos estudiantes están en la clase?, ¿cuántos estudiantes tardan menos de 15 minutos para llegar a la escuela?, ¿cuál es el tiempo típico que tardan los estudiantes en llegar a la escuela?). En nuestro caso, además, se incluyó un histograma que representa los mismos datos para preguntar a los profesores sobre la forma de ayudar al estudiante a discriminar entre ambos gráficos, las concepciones y errores que tendrían, así como una valoración de algunas respuestas del estudiante y cómo corregiría esos errores.

Las dificultades presentadas en la interpretación del gráfico de Tallo y Hoja (TyH) por parte de los alumnos en el cuestionario diagnóstico, en discernir entre un gráfico y otro, así como los argumentos que usaron para decidir que el histograma era una mejor representación que el gráfico de TyH son tres aspectos que motivaron el uso este caso. A través de las preguntas se explora el CDC del profesor sobre la selección y evaluación de gráficos y aspectos tanto de las estrategias y representaciones instruccionales específicas como aquellas de diagnóstico de las concepciones de los alumnos y apoyo para superar sus errores.

La Tabla 4.4 agrupa cada pregunta según el SDI del CDC y los niveles cognitivos del pensamiento estadístico de la RG. Como se aprecia en dicha tabla todas las preguntas están encaminadas a explorar el conocimiento que tiene el profesor del proceso de aprendizaje del alumno. Sólo el ítem la trata acerca del conocimiento del profesor sobre el currículo de la RG y las estrategias que utiliza en el proceso de enseñanza con los estudiantes. Por otro lado, se explora el conocimiento que tiene sobre los criterios de selección de gráficos que manejan los estudiantes para un problema específico, los argumentos que utilizan para criticar y evaluar los gráficos, así como la forma en que evalúa y analiza los errores conceptuales del estudiante al seleccionar un gráfico. 
Tabla 4.4. Distribución de las preguntas del Caso 1 por SDI del CDC y los niveles cognitivos de pensamiento estadístico de la representación gráfica

\begin{tabular}{cccc}
\hline $\begin{array}{c}\text { Gráfico / } \\
\text { Pregunta }\end{array}$ & \multicolumn{1}{c}{ Pregunta tomada de ... } & $\begin{array}{c}\text { Clasificación } \\
\text { según el SDI del } \\
\text { CDC }\end{array}$ & $\begin{array}{c}\text { Clasificación de } \\
\text { niveles cognitivos } \\
\text { de Pensamiento } \\
\text { Estadístico }\end{array}$ \\
\hline $\begin{array}{c}\text { Tallo y Hoja e } \\
\text { Histograma } \\
\text { 1a }\end{array}$ & --- & $\begin{array}{c}\text { B-III-2 } \\
\text { B-V } \\
\text { C-I-3,4,5 } \\
\text { C-III-2 }\end{array}$ & 1a, 2a, 2b, 3a \\
1b & Van, De Jong y Verloop (2002) & $\begin{array}{c}\text { C-I-3,4,5 } \\
\text { C-II-1,2 }\end{array}$ & 1a, 2a, 2b, 3a \\
& & C-I-3,4 & 1a, 2a, 2b, 3a \\
1c-i & $\begin{array}{l}\text { An, Kulm y Wu (2004), Llinares } \\
\text { (1996), Moreno y Azcárate (2003) }\end{array}$ & C-I-5 & 1a, 2a, 2b, 3a \\
& $\begin{array}{l}\text { Even (1993), Llinares (1996), } \\
\text { Even y Tirosh (1999), Sánchez y } \\
\text { Llinares (2002), Moreno y } \\
\text { Azcárate (2003) }\end{array}$ & C-III-2 & \\
& & &
\end{tabular}

El Caso 2 fue construido con la respuesta que dio un estudiante (Diego) a un ejercicio del cuestionario diagnóstico, en el cual se pedían dos ejemplos de variables o situaciones que pudieran representarse gráficamente, especificando el tipo de gráfico que recomendaba y añadiendo una breve justificación. Al profesor se le preguntó acerca del conocimiento y razonamiento que manifestó Diego así cómo acerca de la manera de las concepciones inadecuadas o errores conceptuales que identificaba. La Tabla 4.5 agrupa cada pregunta del Caso 2 según el SDI del CDC y los niveles cognitivos del pensamiento estadístico de la RG.

El Caso 2 se construyó teniendo en cuenta la dificultad que tienen los estudiantes para establecer la relación entre una situación y su representación y la justificación (equivocada y limitada) de su selección. Se utiliza un gráfico barras (muy usado en los cursos de Estadística de Psicología y Educación) y se centra en el conocimiento del profesor sobre los procesos de aprendizaje de los alumnos, en los criterios que usan para la selección de gráficos respecto a una situación concreta y el análisis de errores relativos a la selección e interpretación de gráficos.

\footnotetext{
${ }^{7}$ Ver sección 2.5.2 (Capítulo 2)

Jesús Enrique Pinto Sosa
} 
Tabla 4.5. Distribución de las preguntas del Caso 2 por el SDI del CDC y los niveles cognitivos de pensamiento estadístico de la representación gráfica

\begin{tabular}{clcc}
$\begin{array}{c}\text { Gráfico / } \\
\text { Pregunta }\end{array}$ & \multicolumn{1}{c}{ Pregunta tomada de ... } & $\begin{array}{c}\text { Clasificación } \\
\text { según el SDI del } \\
\text { CDC }\end{array}$ & $\begin{array}{c}\text { Clasificación de } \\
\text { niveles cognitivos } \\
\text { de Pensamiento } \\
\text { Estadístico }\end{array}$ \\
\hline $\begin{array}{c}\text { Barras } \\
\text { a }\end{array}$ & An, Kulm y Wu (2004), & $\begin{array}{c}\text { B-V } \\
\text { C-II-4 } \\
\text { C-III-2 }\end{array}$ & \\
2b & An, Kulm y Wu (2004), Llinares & C-I-3,4,5 & 1a, 3a \\
& $\begin{array}{l}\text { (1996), Moreno y Azcárate (2003), } \\
\text { Even (1993), Even y Tirosh } \\
\text { (1999), Sánchez y Llinares (2002) }\end{array}$ & & \\
& & & \\
2c & Sánchez y Llinares (2002), An, & C-III-2 & 1a, 3a \\
& Kulm y Wu (2004), & & \\
\hline
\end{tabular}

En el Caso 3 se usa un histograma tomado de Sorto (2004) relativo a la alfabetización de la mujer adulta para el que los profesores tenían por un lado que juzgar si las respuestas dadas por algunos estudiantes a algunas cuestiones habían sido correctas o no, así como dar una explicación del proceso de pensamiento que éstos siguieron para llegar a esas respuestas. En nuestro caso, se añadieron dos elementos al contexto: (i) se circunscribió el gráfico al contexto de una investigación social y (ii) se presentó como si fuese un ejercicio que un profesor les entregó a sus estudiantes donde a partir del análisis del histograma tenían que indicar el propósito del gráfico, escribir alguna conclusión y recomendación que se pudiera deducir de él y valorar la posibilidad de que los datos pudieran representarse de alguna otra forma.

En este caso se exploraba la comprensión gráfica a nivel de interpretación y escritura del gráfico por parte del alumno. El gráfico, aunque es uno de los habitualmente utilizados en el contexto escolar, suele estar relacionado con diversas dificultades y errores conceptuales de los alumnos. También se diseñó a partir de las respuestas de los estudiantes al cuestionario diagnóstico y trata de indagar la forma en que el profesor enseña diversos aspectos relativos a la interpretación de gráficos, la toma de decisiones y discusión de gráficos y la redacción de un texto científico. También se explora el conocimiento del profesor del proceso de aprendizaje del estudiante (ver Tabla 4.6).

Como se observa en la Tabla 4.6 las preguntas estaban dirigidas a explorar el conocimiento que tiene el profesor sobre las creencias, errores y dificultades que subyacen en el estudiante. En las dos primeras preguntas se trataba de averiguar qué objetivos relaciona el profesor con la RG en un ejercicio de este tipo, así como indagar sobre qué conoce del currículo, cómo utiliza ese conocimiento, y qué estrategias específicas utiliza para retroalimentar al alumno. Por ello permite adentrarse en el conocimiento que tiene el profesor acerca de cómo interpretan gráficos los estudiantes, los textos que escriben acerca de esa interpretación o cómo analizan los errores conceptuales (al seleccionar, construir, interpretar y escribir sobre el gráfico). 
Tabla 4.6. Distribución de las preguntas del Caso 3 por el SDI del CDC y los niveles cognitivos de pensamiento estadístico de la representación gráfica

\begin{tabular}{|c|c|c|c|}
\hline $\begin{array}{l}\text { Gráfico / } \\
\text { Pregunta }\end{array}$ & Pregunta tomada de ... & $\begin{array}{c}\text { Clasificación } \\
\text { según el SDI del } \\
\text { CDC }\end{array}$ & $\begin{array}{c}\text { Clasificación de } \\
\text { niveles cognitivos } \\
\text { de Pensamiento } \\
\text { Estadístico }\end{array}$ \\
\hline $\begin{array}{c}\text { Histograma } \\
3 a\end{array}$ & --- & $\begin{array}{c}\text { B-V } \\
\text { B-III-2 }\end{array}$ & $\begin{array}{c}1 \mathrm{a}, 1 \mathrm{~b}, 1 \mathrm{c}, 2 \mathrm{~d}, 4 \mathrm{~b} \\
4 \mathrm{~d}, 5 \mathrm{~b}\end{array}$ \\
\hline $3 b$ & --- & $\begin{array}{l}\text { B-I-2 } \\
\text { B-III-1,2 } \\
\text { B-V }\end{array}$ & $1 b, 1 c, 2 e, 4 b$ y $4 c$ \\
\hline $3 c-i$ & $\begin{array}{l}\text { Llinares (1996), Even (1993), Even } \\
\text { y Tirosh (1999), Sánchez y } \\
\text { Llinares (2002), Sorto (2004) }\end{array}$ & C-I-3,4,5,11 & $1 b, 1 c, 3 a, 5 b$ \\
\hline $3 c-i i$ & $\begin{array}{l}\text { An, Kulm y Wu (2004), Llinares } \\
\text { (1996), Even (1993), Sánchez y } \\
\text { Llinares (2002) }\end{array}$ & $\begin{array}{l}\text { C-II-1,2 } \\
\text { C-III-2 }\end{array}$ & $1 b, 1 c, 3 a, 5 b$ \\
\hline $3 d-i$ & $\begin{array}{l}\text { Llinares (1996), Even (1993), Even } \\
\text { y Tirosh (1999), Sánchez y } \\
\text { Llinares (2002) }\end{array}$ & C-I-3,4,5,11 & $1 \mathrm{a}, 2 \mathrm{a}, 2 \mathrm{~b}, 3 \mathrm{a}$ \\
\hline $3 d-i i$ & $\begin{array}{l}\text { An, Kulm y Wu (2004), Llinares } \\
\text { (1996), Even (1993), Sánchez y } \\
\text { Llinares (2002) }\end{array}$ & C-III-2 & $1 \mathrm{a}, 2 \mathrm{a}, 2 \mathrm{~b}, 3 \mathrm{a}$ \\
\hline
\end{tabular}

Finalmente, en el Caso 4 se incluye un media graph tomado de Garfield (2002) diseñado originalmente para medir, en el nivel de alfabetización estadística, qué errores identifica un estudiante en la construcción y presentación de un gráfico y cómo los corregiría. A partir del gráfico", se plantean preguntas como “¿Qué está erróneo en este gráfico? Liste dos cosas y argumenta tu respuesta” y “QQué podrías hacer para corregir estos errores? Justifica tu razonamiento” y de esta misma forma se incluyó en el cuestionario diagnóstico del estudiante. Para el cuestionario del profesor, se añadió un contexto escolar en el que una profesora pide a sus estudiantes criticar y evaluar el gráfico. A diferencia de Garfield se solicitó al profesor que describiera qué estrategia utilizaría con sus alumnos, paso a paso, para ayudarles a criticar y evaluar el gráfico, y suponiendo que utilizara esta actividad con sus alumnos, qué interpretaciones piensa que le darían y cuáles serían correctas. La Tabla 4.7 agrupa cada pregunta del Caso 4 según el SDI del CDC y los niveles cognitivos del pensamiento estadístico de la RG.

\footnotetext{
${ }^{8}$ Identificado con el código $I D=Q 0710$ en el Constructor de Pruebas - Base de datos de ítems (Items Database - Assessment Builder, en https://app.gen.umn.edu/artist/user/continue_search.asp )
} 
Como se aprecia en la Tabla 4.7, el Caso 4 analiza qué estrategias usa el profesor, tanto las específicas como aquellas que tienen que ver con su conocimiento del estudiante, su concepción de la E-A de la RG, algunos aspectos de la planificación curricular y las estrategias instruccionales que usa para ayudar al estudiante a criticar y evaluar gráficos.

Tabla 4.7. Distribución de las preguntas del Caso 4 por el SDI del CDC y los niveles cognitivos de pensamiento estadístico de la representación gráfica

\begin{tabular}{cccc}
$\begin{array}{c}\text { Gráfico / } \\
\text { Pregunta }\end{array}$ & Pregunta tomada de ... & $\begin{array}{c}\text { Clasificación } \\
\text { según el SDI del } \\
\text { CDC }\end{array}$ & $\begin{array}{c}\text { Clasificación de } \\
\text { niveles cognitivos } \\
\text { de Pensamiento } \\
\text { Estadístico }\end{array}$ \\
\hline $\begin{array}{c}\text { Media graph } \\
4 \mathrm{a}\end{array}$ & Moreno y Azcárate (2003) & $\begin{array}{c}\text { B-I-2 } \\
\text { B-V }\end{array}$ & $1 \mathrm{c}, 2 \mathrm{a}, 3 \mathrm{a}$, \\
$4 \mathrm{~b}-\mathrm{i}$ & Moreno y Azcárate (2003) & $\begin{array}{c}\text { B-III-1 } \\
\text { C-I-3,4 }\end{array}$ & 1c, 2a, 3a, \\
& & B-III-1 & 1c, 2a, 3a, \\
$4 \mathrm{C}-\mathrm{ii}$ & Moreno y Azcárate (2003) & & \\
\hline
\end{tabular}

El cuestionario didáctico sobre representación gráfica en su versión definitiva, explora diferentes aspectos del pensamiento estadístico, como se aprecia en la Tabla 4.8. 


\section{Tabla 4.8. Clasificación de los items del cuestionario didáctico sobre representación} gráfica según los niveles de pensamiento estadístico

1. Formular y resolver problemas que impliquen recogida y análisis de datos en un contexto apropiado y real

Objetivos/tópicos específicos

a. Selección de gráficos dentro del contexto de un problema de investigación en educación y psicología

b. Interpretación de gráficos dentro del contexto de educación y psicología (ej. casos, bases de datos, problemas, artículos de investigación, tesis, reportes, gráficos en medios de comunicación)

c. Escritura de gráficos dentro del contexto de educación y psicología (ej. casos, bases de datos, problemas, artículos de investigación, tesis, reportes de investigación, gráficos en medios de comunicación)

\author{
Preguntas CDC Profesores \\ 1a, 1b, 1c-i, 1c-ii, 2a, 2b, 2c, 3a, 3d- \\ i, 3d-ii, \\ 3a, 3b, 3c-i, 3c-ii,
}

3a, 3b, 3c-i, 3c-ii, 4a, 4b,

2. Evaluar argumentos que estén basados en el análisis de las representaciones gráficas (ej. el por qué y las posibles atribuciones a los resultados, y valorar la propia evidencia, el contexto y el problema y sus relaciones)

Objetivos/tópicos específicos

a. Criticar y evaluar gráficos (de . casos, bases de datos, problemas, artículos de investigación, tesis, reportes de investigación, gráficos en medios de comunicación)

b. Evaluar la selección de un gráfico (analizando todo el contexto del problema o situación de investigación)

c. Atribuciones o causas de los resultados del gráfico

d. Evaluar las interpretaciones y discusiones hechas del gráfico

e. Establecer relaciones de la interpretación del gráfico con el contexto y el problema

f. Evaluar las inferencias, toma de decisiones y recomendaciones originadas del gráfico

\section{Preguntas CDC Profesores}

1a, 1b, 1c-i, 1c-ii, 3d-i, 3d-ii, 4a, $4 \mathrm{~b}$,

1a, 1b, 1c-i, 1c-ii, 3d-i, 3d-ii

3. Identificar errores conceptuales y procedimentales en la selección, construcción, interpretación y escritura de representaciones gráficas

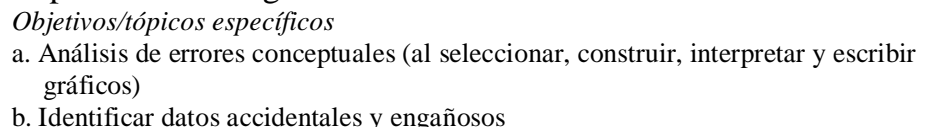

b. Identificar datos accidentales y engañosos

4. Asimilar y extraer inferencias a partir de diagramas o gráficas que recojan datos de situaciones del mundo real o de la investigación científica (ej. tomar decisiones sobre lo qué y cómo medir, esbozar conclusiones, comprender la estructura profunda de los datos, comparando tendencias y observando grupos)

Objetivos/tópicos específicos

a. Tendencias

b. Toma de decisiones a partir de la interpretación de gráficos

c. Implicaciones y/o recomendaciones originadas del gráfico dirigidas a otros análisis estadísticos

d. Implicaciones y/o recomendaciones originadas del gráfico dirigidas al problema de investigación o fines académicos
Preguntas CDC Profesores

$$
\begin{gathered}
3 \mathrm{a}, 3 \mathrm{~b} \\
3 \mathrm{~b} \\
3 \mathrm{a}
\end{gathered}
$$

5. Comunicar los resultados de una investigación a partir de la selección, diseño, interpretación y escritura apropiada de y sobre los gráficos

Objetivos/tópicos específicos

a. Elaboración del reporte apropiado (ej. edición, diseño y formato)

b. Redacción de interpretaciones, discusión con base en el contexto y el problema de investigación

c. Establecer alcances y limitaciones en la interpretación de gráficos
Preguntas CDC Profesores

3a, 3c-i, 3c-ii,

Los aspectos del CDC que se estudiaron estaban relacionados con los objetivos que deberían alcanzarse en torno al pensamiento estadístico de los estudiantes de Psicología y Educación, como: 1) identificar errores conceptuales, 2) formular y resolver problemas en la selección de los gráficos, 3) criticar y evaluar gráficos, 4) evaluar la selección del gráfico 
y 5) formular y resolver problemas en la escritura del gráfico (ej. escribir interpretaciones, conclusiones y relaciones a partir del gráfico).

\subsubsection{Entrevista en profundidad respecto de las respuestas al cuestionario}

La siguiente etapa de la recogida de datos consistió en una entrevista en profundidad con Alicia y Luis. La entrevista tuvo dos propósitos específicos: 1) clarificar las respuestas individuales de los profesores al cuestionario didáctico sobre RG y explorar más detalladamente su CDC, y 2) asegurar la fiabilidad del cuestionario.

Para este estudio asumimos la noción de entrevista en profundidad de Taylor y Bogdan (1987, p.101) que consiste en encuentros cara a cara entre el investigador y los informantes dirigidos hacia la comprensión de las perspectivas que tienen los informantes respecto de sus vidas, experiencias o situaciones específicas, tal como las expresan con sus propias palabras. Como señala Sorto (2004): "la información obtenida del cuestionario escrito es suficiente para una descripción general de algunos de los aspectos del conocimiento para la enseñanza, pero este es limitado y algunas veces difícil de interpretar" (p.119). Por ello se les pidió a los profesores explicar su pensamiento, reflexionar sobre sus respuestas o dar explicaciones a respuestas incompletas para desarrollar un detallado y fiel esquema del conocimiento de la materia. Por consiguiente, las respuestas a la entrevista complementaron la información dada en el cuestionario escrito

Se diseñó un protocolo de entrevista diferente para cada caso (ver Apéndice H) con base en las respuestas escritas al cuestionario. Además se siguieron las indicaciones de Rodríguez, Gil y García (1999). Cada entrevista contenía un conjunto de preguntas específicas organizadas por cada Caso del cuestionario y estuvieron centradas en explorar los argumentos que tenía el profesor de sus respuestas. Ejemplo de preguntas fueron:

- ¿Por qué el estudiante da esa respuesta?

- Podrías ampliar tu respuesta por favor.

- ¿Qué respuestas darían los estudiantes ante estas preguntas?

- Describe un ejemplo por favor.

- ¿Por qué crees esto?

Al final de las preguntas de cada Caso se le preguntó a cada profesor su opinión sobre la situación-problema. Por ejemplo:

- ¿Qué opinión te merece esta actividad?

- ¿Qué resaltarías? ¿qué te llama más la atención?

- ¿Qué conocimientos puede adquirir el alumno con este ejercicio? ¿qué objetivo de aprendizaje se pretende?

- Específica pros y contras de utilizarla en tu aula (alcances y limitaciones).

- ¿Qué modificarías?

- Describe una actividad que pueda ayudar al estudiante a discriminar entre un gráfico y otro. Ejemplifica por favor (y muestra evidencias).

- Describe una actividad para el estudiante identifique errores conceptuales y procedimentales en la selección, construcción, interpretación y escritura de representaciones. Ejemplifica por favor cada una (y presenta evidencias). 


\subsubsection{Materiales de los profesores}

Según Moreno (2000), el análisis de los materiales del profesor disponibles nos permite extraer unas primeras conclusiones que volverán a ser utilizadas una vez que se disponga de los correspondientes análisis particular y general de los profesores investigados. Valles (2003), bajo la denominación de materiales documentales, los define como una estrategia metodológica de obtención de información en la que investigador se instruye convenientemente sobre algo antes de tratarlo o escribir sobre ello.

El análisis de los materiales disponibles, como señala Moreno (2000), tiene un doble propósito: a) corroborar lo procedente del cuestionario y las entrevistas y b) proporcionar matices que diferencien actuaciones específicas de cada uno de los profesores.

$\mathrm{Si}$ bien son varias las clasificaciones que existen en torno a los materiales documentales, para fines de esta investigación, los que se le solicitaron a cada profesor y que estuvieron disponibles para el análisis fueron:

1. Notas de curso

Son los apuntes del profesor escritos en una libreta específica o en hojas sueltas o sobre fotocopias del material bibliográfico que utilizaba. Son explicaciones o esquemas de organización de algún tópico, o bien, interpretaciones o respuestas a los ejercicios, anotaciones sobre la secuencia de sus clases, observaciones o recordatorios sobre un tema o los siguientes.

\section{Ejercicios}

Bajo esta denominación se agruparon los materiales que el profesor utilizó como tareas, problemas, ejemplos, casos, prácticas, situaciones y/o actividades de aprendizaje, sea tomado de alguna fuente bibliográfica o de su creación. Los ejercicios implicaban que los estudiantes tenían que poner en juego su razonamiento para la resolución de problemas (sea de carácter rutinario o novedoso) en torno al tópico de estudio.

Se presentaron en forma de hojas sueltas, en apuntes, o en la identificación en libros de texto o en las libretas de los estudiantes.

\section{Exámenes}

Los exámenes fueron las pruebas que cada profesor utilizó al término de una unidad o período determinado para valorar si el estudiante había logrado o no los objetivos de aprendizaje, pudiendo ser en lápiz y papel u on-line.

4. Programa de la asignatura

Es el documento en extenso donde se expresa la intencionalidad, los objetivos, contenidos, estrategias de enseñanza, criterios de evaluación y bibliografía recomendada 
para la impartición del curso de Estadística. Están basados en los programas sintéticos que se encuentran en los planes de estudio de cada carrera. El análisis de cada programa se presentó en este mismo capítulo y en el Apéndice $\mathrm{C}$ se pueden encontrar los programas de Estadística de la carrera de Psicología y de Educación.

\section{Bibliografía}

Se contó con la lista bibliográfica recomendada y utilizada por cada profesor, que ayudó a comprender tanto la concepción de cada profesor, qué características de los textos considera relevantes cada uno y su relación con la enseñanza y aprendizaje de la RG.

\section{Libreta del estudiante}

Se solicitó contar con una o dos libretas de los estudiantes del curso de cada profesor. Esto permitió corroborar la correspondencia entre la información obtenida a partir de las entrevistas, el cuestionario y los diferentes materiales proporcionados por el profesor.

\section{Presentaciones de exposición}

Se trata de las presentaciones disponibles en archivo electrónico (generalmente en power point) y que cada profesor utilizó para la enseñanza de los tópicos del programa.

8. Materiales de lectura o de apoyo

Estos son textos de lectura sobre el tema a estudiar, donde se exponen las explicaciones y ejemplos. Generalmente el profesor las da antes de la enseñanza de un tópico o como apoyo para comprender más un tema. Pueden ser algún libro de texto, direcciones electrónicas que el profesor utiliza como recursos para actualización y formación, tanto en relación con el contenido como de su didáctica. En ocasiones se utilizan como fuente para seleccionar ejercicios o tareas para el estudiante.

\subsection{TÉCNICAS DE RECOGIDA DE INFORMACIÓN}

Una vez que se seleccionaron los dos profesores que iban a ser los casos a estudiar en la investigación, el procedimiento fue contactar con cada uno de ellos, con el conocimiento y aprobación de la autoridad correspondiente.

A cada profesor se le explicaron las características del estudio, se señaló que el objetivo de investigación no era evaluar su enseñanza sino conocer cómo enseña Estadística y, más específicamente la RG,

En caso de aceptar participar en la investigación se les solicitó firmar una carta de consentimiento (Apéndice I) donde manifestaban tener conocimiento del propósito de la investigación y de las fases de la misma, así como que estaban de acuerdo con que las entrevistas fueran audiograbadas y que podrían libremente dejar de participar en la misma en cualquier momento y sin dar alguna razón. Ambos profesores aceptaron y firmaron la carta. 
La entrevista contextual y biográfica se realizó durante el mes de marzo de 2006 y se dividió en dos partes debido a la extensión de las respuestas de los profesores; así, cuando ellos mismos indicaron se suspendió la entrevista y se continuó en una segunda sesión. En cualquier caso, la hora y los días elegidos fueron por decisión de cada profesor y se realizó en su centro de trabajo. En el caso de Alicia la duración de cada una de las dos partes de esta entrevista fue de 51' y 52' respectivamente. Para el caso de Luis la duración fue de 57' y 86', respectivamente.

El Cuestionario Didáctico sobre Representación Gráfica se entregó a principios de marzo de 2006 en el caso de Alicia, y a finales de abril a Luis y fue recogido en la tercera semana de mayo en ambos casos.

Después de analizar el cuestionario y la entrevista contextual y biográfica se procedió a definir el protocolo de la entrevista en profundidad. Esta se realizó en una sola sesión para ambos profesores en el mes de julio. Para el caso de Alicia la duración de la entrevista en profundidad fue de $1 \mathrm{~h} 41$ ' y en el caso de Luis fue de $1 \mathrm{~h} \mathrm{37}$ '. La hora, día y lugar para la entrevista en profundidad fue acordada previamente con cada profesor.

La solicitud de materiales se hizo a partir del primer contacto que hubo con cada profesor y se recibieron paulatinamente a lo largo del estudio. En el caso de Luis no se recibió la libreta de ningún estudiante inscrito en su curso.

El investigador realizó anotaciones en dos momentos de la recogida de datos: la entrevista contextual y biográfica y la entrevista en profundidad en las que se incluyó la descripción de algunos hechos observables sobre la actitud, las expresiones y reacciones del profesor, que no podían ser recogidas a través de la grabación de audio.

\subsection{ANÁLISIS DE DATOS}

A continuación se describe el procedimiento de análisis de los datos agrupado por los instrumentos y materiales utilizados: a) transcripción y análisis de las entrevistas, b) método de análisis del cuestionario didáctico sobre $R G, c)$ análisis de los materiales disponibles y d) análisis de las concepciones, creencias, errores y dificultades.

\subsubsection{Transcripción y análisis de las entrevistas}

Todas las entrevistas fueron audiograbadas, posteriormente se escuchó la grabación de cada una y se transcribieron (ver Apéndices J y K). Para la transcripción se optó por respetar las convenciones ortográficas según Farías y Montero (2005), sin embargo, dada la naturaleza del contexto donde se desarrolló el estudio y con el fin de comprender mejor el discurso del profesor, aunque manteniendo que el registro de los datos fuera lo más exacto posible, se optó añadir y/o modificar algunas convenciones:

- Los puntos suspensivos indica una suspensión en el discurso seguido de un cambio brusco de énfasis. Ejemplo: 
Mira, hay algo que para mí es así, como que... siempre les digo a los muchachos que es parte de mi primera clase, creo que es un poco de mi formación más que nada familiar.

- Entre corchetes se indican la reacción del entrevistado ante un tema o ante lo que se dice y cualquier comentario que aclare alguna palabra, expresión o incidencia. Ejemplo:

Me dicen "bueno ¿por qué no eres su asistente?” y era algo así como necesito correr [realizar y ejecutar] un ANOVA y yo "con quince datos la hago pero con 500 ¿cómo le hago?".

- Se utilizaron comillas para señalar los diálogos (monólogos) del profesor cuando daba algún ejemplo o explicación. Ejemplo:

Por ejemplo, me dijo, en un curso que apareció [se ofreció] le dije "yo ya tomé el anterior y la verdad me pareció bastante malo pero porque era muy matemático pero me gustaría tomar este". Por ejemplo, cursos sobre regresiones, no sé nada de regresiones, y me dijo "oye, pues hace mucho que no tomo [participo] uno. ¡Vamos!”.

- Los gestos o expresiones clarificadoras se colocaron entre paréntesis. Ejemplo:

Por ejemplo, recuerdo la primera vez que obtuvimos un alfa negativa porque (jaja)... le digo "todos los libros dicen que esto no es posible ipor qué?".

Dada la infinidad de pausas, titubeos, falsos arranques y repeticiones que caracterizan al discurso oral y con el objeto de evitar una difícil lectura de la transcripción se procedió a realizar una edición baja de cada transcripción:

A este respecto, entendemos por grado "bajo" de edición aquella en la que apenas se elimina la mayoría de las muletillas, repeticiones y pausas puramente accidentales. De modo que se respeta el orden del discurso y no se hace ninguna clase de adiciones. Como así resalta mucho el tono propio de una conversación, lo más lógico es conservar también en tales textos las preguntas o intervenciones de quien haya conducido la entrevista. Este grado es el más respetuoso y recomendable en caso de que haya necesidad de intervenir el texto a fin de aligerarlo (Farías y Montero, 2005, p.12).

Como puede apreciarse en las transcripciones, se han numerado las intervenciones del investigador y del profesor entrevistado anteponiendo la inicial E (de Entrevistador) y A (de Alicia) o L (de Luis) según se trate de uno u otro.

Una vez realizada la transcripción, se procedió a revisarla y validarla. Para ello se contó con la ayuda de dos personas (ayudantes de investigación) que escucharon por lo menos dos veces cada entrevista y revisaron dicha transcripción. Con ello se detectaron y corrigieron algunos errores. Además el investigador utilizó sus notas de campo para recordar y en su caso aclarar algunos fragmentos de la entrevista.

Posteriormente, se construyeron una tablas discursivas que nos ayudaron a organizar la información para poder trabajar con los discursos de cada profesor en dos 
niveles simultáneos, uno más esquemático, y otro más minucioso y detallado (Farías y Montero, 2005). A continuación se explica brevemente cómo se diseñaron dichas tablas

En un documento o archivo de Word, se insertó una tabla con seis columnas. La primera, y más angosta, se utilizó para identificar la secuencia temporal de cada fragmento. La segunda columna, para resumir las preguntas o intervenciones del investigador. La tercera, para señalar el código de la unidad de análisis de cada entrevista. La cuarta, y más ancha, para insertar las respuestas del entrevistado. Se añadió una quinta columna que se denominó categoría, donde se incluyó el código del SDI del CDC a que se relacionaba el fragmento del discurso. En la última columna, bajo la denominación preguntas por añadir, se incluyeron comentarios, preguntas o dudas en torno a la respuesta del profesor. Estos comentarios se utilizaron para construir el protocolo de entrevista en profundidad y para seleccionar los materiales que avalaban lo que cada entrevistador dijo. La Figura 4.2 ejemplifica la tabla discursiva.

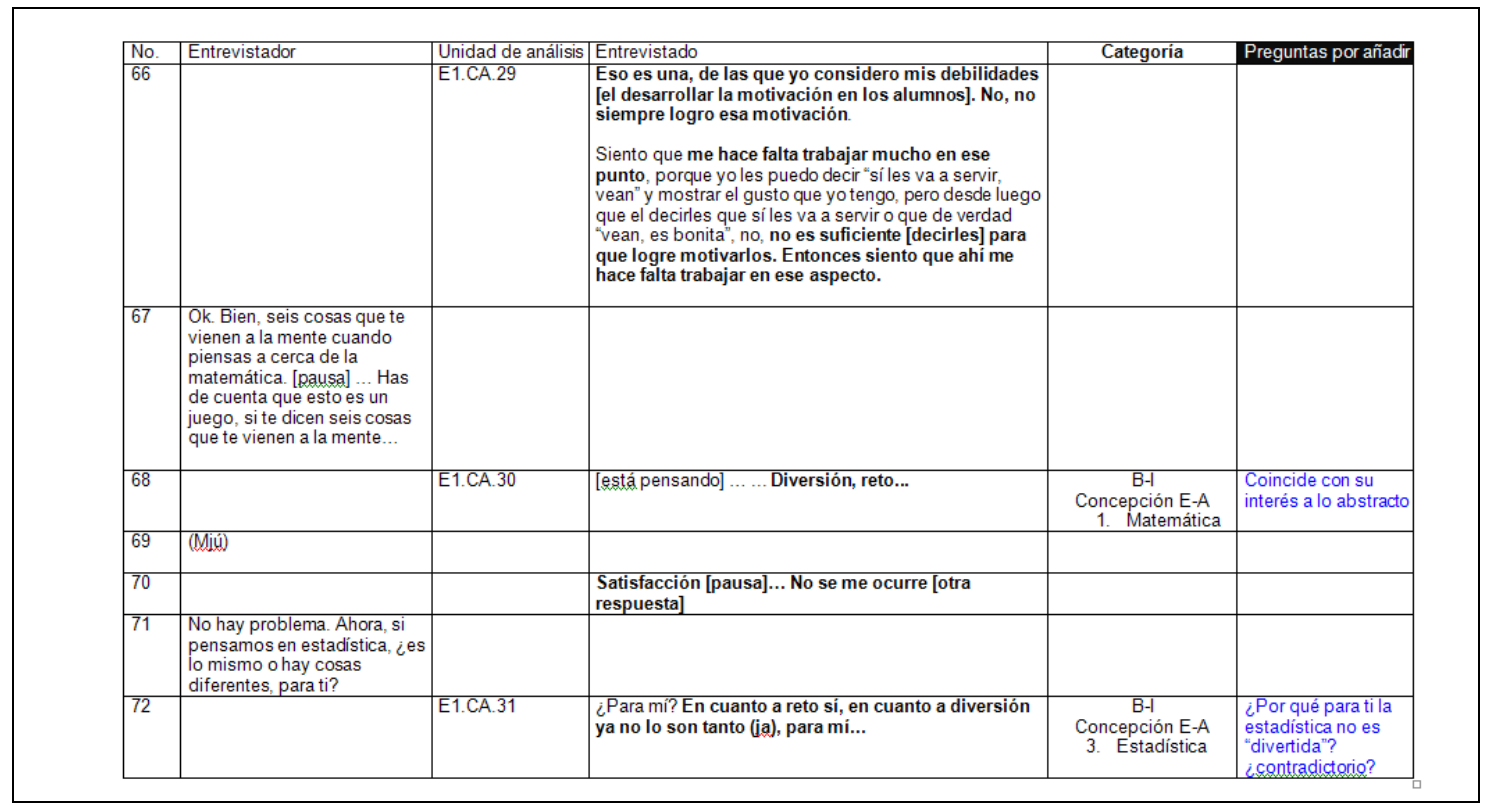

Figura 4.2. Ejemplo de tabla discursiva en la entrevista contextual y biográfica de Alicia

La construcción de estas tablas discursivas se comenzó por la segunda (preguntas del entrevistador) y la cuarta columna (respuestas del profesor). Para la identificación de las unidades de análisis se realizó un análisis de contenido de las respuestas del profesor caracterizado por cuatro ideas centrales (Guba y Lincoln, 1981, en Llinares, 1992): 1) fue un proceso guiado por unas normas (ej. identificar las divisiones perceptivas que ayudan a convertir los datos brutos en subconjuntos manejables, desarrollar un proceso de codificación) que permiten clarificar y definir el procedimiento y criterios para la selección de "trozos" de información, 2) también fue sistemático una vez definidas esas reglas y procedimientos, 3) se intentó, además de obtener información descriptiva, hacer inferencias a través de la comparación, contrastación y determinación de diversos vínculos y relaciones, y 4) en la fase interpretativa se realizaron inferencias sobre el contenido latente 
y se obtuvieron las conclusiones sobre el significado del contenido. Consecuentemente, el procedimiento de análisis de contenido de las entrevistas (Llinares, 1992 y 2000) fue el siguiente:

a. Lectura de cada transcripción.

b. Identificación de las ideas centrales mediante un sombreado negro en las que se refleja la idea básica en que se apoya y se articula el sistema conceptual del profesor en relación al tema estudiado (Llinares, 1992). Pueden representar una acción docente que sería deseable para la enseñanza del tópico o bien, las razones o fundamentos en que se apoya la idea central.

c. Identificación de las unidades de análisis.

d. Asignación del proceso de codificación de las unidades de análisis, el cual consistió: la primera inicial indica la fuente de información, a continuación aparece la inicial de la palabra Caso (C) seguida de la inicial del nombre del profesor $(\mathrm{A}$ o L $)$ y finalmente el número correspondiente a cada unidad de análisis. Ejemplo:

"considerando bastantes ejemplos... en qué les pueda servir o dónde van aplicar lo que es la estadística" (E1.CA.26).

Este es un segmento de la respuesta a la entrevista contextual y biográfica (E1) del Caso Alicia (CA), cuya unidad de análisis es la \#26. Para el caso de la entrevista en profundidad el código será E2 y para hacer referencia al Caso Luis se identificará el código CL.

e. Identificación de la categoría, dimensión e indicador del CDC con base en el SDI (quinta columna). Así, en la Figura 4.2, la unidad de análisis E1.CA.31 se identificó con el código de B-I-3, que corresponde a la categoría de estrategias y representaciones instruccionales (B), la dimensión de concepciones sobre la E-A (I) y el indicador son las matemáticas (3).

f. La asignación del código del SDI del CDC ayudó a reagrupar las respuestas de los profesores en otras formas o categorías de análisis, que permitieron identificar las categorías preliminares y la forma de presentar el análisis de los resultados de cada caso. Por ejemplo, se agruparon todas las unidades de análisis a las que se asignó la clave B-I-1 del SDI, y así sucesivamente. A esta reagrupación Farías y Montero (2005) la denomina la sustitución del discurso del orden cronológico por uno temático.

Este análisis se hizo tanto en la entrevista contextual y biográfica como para la entrevista en profundidad. La diferencia sustancial fue la dependencia de esta última con las respuestas dadas al cuestionario. 


\subsubsection{Método de análisis cuestionario didáctico sobre representación gráfica}

Para el análisis del cuestionario didáctico sobre RG se procedió según Llinares (2000), es decir, se revisaron las respuestas a cada pregunta del cuestionario y la transcripción de la entrevista en profundidad. Posteriormente el procedimiento analítico fue similar al expuesto en el análisis de las entrevistas.

Las respuestas del cuestionario se clasificaron en unidades de análisis y se les asignó el código $\mathrm{Cu}$ (de Cuestionario), seguido de la inicial de la palabra Caso y la inicial del nombre del profesor (CA o CL), el número de la situación-problema (sea 1, 2, 3 ó 4) y el inciso que representa la pregunta. Finalmente, un número que representa la respuesta del profesor. Ejemplo:

"Quizá sea producto de la creencia de que una buena representación gráfica es aquella que sin recurrir a número brinda información" (Cu.CL.1ci.1)

Se trata de un fragmento del cuestionario $(\mathrm{Cu})$, del Caso Luis $(\mathrm{CL})$, del Caso 1 pregunta $c$, inciso $i$ (1ci), respuesta 1 del profesor.

Las respuestas a cada situación-problema fueron analizadas y se consideró toda la información obtenida en su conjunto (entrevista contextual y biográfica, entrevista en profundidad y materiales disponibles). Se hizo el análisis de las relaciones, atribuciones y explicaciones de las concepciones y dominios del CDC a partir de todas las fuentes de información. Posteriormente, se agruparon las respuestas en función del SDI del CDC.

\subsubsection{Análisis de los materiales disponibles}

Los materiales disponibles se analizaron a la luz de la teoría del análisis de contenido según Bardín (1986).

En la presentación de resultados, cada material se identificó por un código: notas de curso (Ncu), ejercicios (Eje), exámenes (Exa), programa de la asignatura (Pro), bibliografía (Bib), libreta del estudiante (Lib), presentaciones de exposición (Pre) y materiales de lectura o de apoyo (Mat); seguido de la inicial la palabra Caso y la inicial del nombre del profesor (CA o CL) y el número consecutivo del material. Ejemplo:

El programa de Estadística (Pro.CA.04) especifica por cada unidad las estrategias de enseñanza sugeridas.

Se trata del programa de Estadística (Pro) que imparte Alicia (CA) en el análisis de las estrategias declaradas (04).

Este análisis permitió: 1) corroborar lo dicho en las entrevistas y 2) comprender la concepción y el CDC del profesor a partir de los materiales con que dispone o utiliza para la enseñanza de la RG. 


\subsubsection{Análisis de las concepciones, creencias, errores y dificultades}

Mención particular merece el análisis de las concepciones, las creencias, errores y dificultades. A continuación expondremos qué definición asumimos en cada una, así como el procedimiento para el análisis de la información.

Concepciones. En esta investigación asumiremos la definición de concepciones en consonancia con la de Moreno y Azcárate (2003):

Las concepciones son organizadores implícitos de los conceptos, de naturaleza esencialmente cognitiva y que incluyen creencias, significados, conceptos, proposiciones, reglas, imágenes mentales, preferencias, etc., que influyen en lo que se percibe y en los procesos de razonamiento que se realizan. El carácter subjetivo es menor en cuanto se apoyan sobre un sustrato filosófico que describe la naturaleza de los objetos matemáticos (p. 267)

Tal como señala Gil y Rico (2003), las concepciones son mantenidas con plena convicción, son consensuadas y tienen procedimientos para valorar su validez. De esta manera, también asumimos la caracterización que Pehkonen (2001) y Saari (1983, en Attorps, 2006) hacen de las concepciones para distinguirlas de las creencias. Ellos definen concepciones como una creencia consciente, referido como una creencia de orden superior y basada sobre procesos de razonamiento semejante los cuales están por lo menos justificados y aceptados por el propio individuo. Más aún, las concepciones son como un lado subjetivo del "concepto" (Sfard (1991, p.3)

Por consiguiente, cuando estudiamos las concepciones del profesor, estamos haciendo referencia a una acepción de naturaleza esencialmente cognitiva y que se apoya sobre una base pedagógica y conceptual del contenido o de la materia en cuestión, donde predomina la argumentación racional por encima de los sentimientos y experiencia.

En la investigación nos centramos en estudiar dos grupos de concepciones que tiene el profesor: a) sobre la Estadística, su aprendizaje y enseñanza, y 2) sobre la representación gráfica, su aprendizaje y enseñanza.

Para explorar las concepciones sobre la Estadística, su aprendizaje y enseñanza nos basamos en el trabajo de Reid y Petocz (2002) y Petocz y Reid (2002), quienes clasificaron las concepciones de la Estadística, con base en un estudio fenomenográfico realizado a 20 estudiantes universitarios de la carrera de matemáticas, a quienes se les hizo preguntas como: ¿qué entiendes/sabes acerca del quehacer de la Estadística?, ¿qué es lo que entiendes por el término Estadística?, dime lo que piensas que la Estadística es, ¿qué es Estadística? Como parte de los resultados identificaron seis tipos de concepciones sobre la Estadística. Cada concepción se agrupa en focos de atención en función de cuál es el énfasis que se le concede a la Estadística (como técnica, uso de datos, significado). Las concepciones fueron: 
Foco: Técnica

1. Estadística como una actividad numérica individual. La concepción sobre la Estadística es limitada y fragmentada. Ven a la Estadística como un tipo de matemáticas el cual supone el uso "operaciones/cálculos aburrido", "números", o "probabilidad".

2. Estadística como el uso específico de técnicas estadísticas. Los estudiantes ven a la Estadística como técnicas individuales que pueden ser usadas para mirar los datos, graficar, colectar datos, realizar una regresión, un estadístico.

3. Estadística como una colección de técnicas estadísticas. Los estudiantes describen la Estadística como una colección o conjunto o "cúmulo" de diferentes técnicas que pueden ser usadas al tiempo que se trata con los datos. Son conscientes de un rango de técnicas, más que sólo una. A menudo describen la Estadística haciendo una lista de estas técnicas

Foco: Uso de datos

4. Estadística como análisis e interpretación de datos. El estudiante describe la Estadística como la comprensión, interpretación y darle sentido a los datos. Los estudiantes exploran las diferencias entre relaciones encontradas en los datos y usan esas relaciones para esbozar conclusiones acerca de los datos. Aquí, los estudiantes describen la estadística usando las otras tres concepciones.

5. Estadística como una forma de comprender la vida real usando diferentes modelos estadísticos. Los estudiantes expresan que la Estadística es una forma de comprender las situaciones de la vida real usando una variedad de modelos estadísticos. Incluye la interpretación de un conjunto de datos y obtener información de éstos, además son capaces de utilizar una variedad de modelos para comparar sus datos con la realidad y probar la pertinencia de sus conclusiones.

Foco: Significado

6. Estadística como una herramienta global usada para dar sentido al mundo y desarrollar significados personales. Los estudiantes se centran sobre la comprensión y darle sentido a la realidad usando métodos. Más allá, los estudiantes usan métodos estadísticos para desarrollar su propio pensamiento, para crear nuevas interpretaciones de datos y de la vida. Los estudiantes activamente relacionan su conocimiento estadístico a los datos, los modelos interpretativos, amplían aspectos de la realidad y para su propio pensamiento creativo y crítico. Esta concepción es bastante similar a otras concepciones que se focalizan sobre la importancia del significado.

La característica de estas concepciones es que son inclusivas, de este modo, los estudiantes o profesores que reportan un nivel superior será quien tenga un mayor rango de características que se aproximen a la concepción sobre la Estadística. Otras características se muestran en la Tabla 4.9 donde se representan tres significados cualitativamente diferentes entre las concepciones definidas: aproximación, focos, entidad profesional. El primero tiene que ver con la aproximación a la Estadística, desde el punto de vista de la 
tarea o habilidad mental que implica, como recopilar métodos estadísticos, aplicar técnica estadísticas a los datos y crear modelos y explicaciones que ayuden a comprender la realidad. El segundo nivel de significados está en el énfasis que se le concede a la definición (técnica, datos, significado). Finalmente, la entidad profesional se refiere a una forma de pensamiento acerca de cómo los estudiantes (o profesores) comprenden el trabajo profesional a partir de su concepción, Reid y Petocz (2002) distinguen tres niveles diferentes:

- Técnica extrínseca, que describe una percepción de que el trabajo profesional está constituido por un grupo de técnicas que pueden ser usadas cuando las situaciones del trabajo lo demanden).

- Significado extrínseco, que describe una percepción del trabajo profesional como el desarrollo de significados inherentes a la disciplina, donde hay un reconocimiento a la Estadística, vista hacia afuera (externa al individuo) centrada en explorar y examinar los significados encontrados en un conjunto de datos.

- Significado intrínseco, la gente percibe que el trabajo profesional está relacionado con su propio desarrollo personal y profesional, se ve la Estadística como una herramienta para crear y desarrollar su visión del mundo en los contextos de su vida y de la profesión.

Reid y Petocz (2002) analizaron además las concepciones a partir del análisis de esos tres niveles.

Tabla 4.9. Resultados de las concepciones sobre la Estadística, según Reid y Petocz (2002).

\begin{tabular}{lllll}
\hline \multirow{2}{*}{ Aproximación } & \multicolumn{2}{c}{ Focos } & \\
\cline { 2 - 4 } & Técnica & Datos & Significado & Entidad profesional \\
\hline Recopilar & $\begin{array}{l}\text { Concepción 1 } \\
\text { Concepción 2 } \\
\text { Concepción 3 }\end{array}$ & & Técnica extrínseca \\
Aplicar & & Concepción 4 & \\
& & Concepción 5 & $\begin{array}{c}\text { Significado } \\
\text { extrínseco }\end{array}$ \\
Crear & & & Concepción 6 & $\begin{array}{c}\text { Significado } \\
\text { intrínseco }\end{array}$ \\
\hline
\end{tabular}

Como puede apreciarse en la Tabla 4.9, se pueden establecer diferentes relaciones en torno a estos tres niveles de análisis de las concepciones sobre la Estadística, lo cual nos permite comprender mejor naturaleza de cada concepción y las implicaciones que puede tener en el aprendizaje, la enseñanza y en la formación profesional del individuo. 
Para el análisis de las concepciones sobre el aprendizaje y enseñanza de la Estadística también nos basamos en el trabajo de Petocz y Reid (2002). Como complemento a su investigación publicada en Reid y Petocz (2002) generaron también un conjunto de concepciones sobre el aprendizaje y enseñanza de la Estadística.

Las concepciones sobre el aprendizaje de la Estadística, según Petocz y Reid (2002) fueron definidas como sigue:

Concepción A. Hacer: el aprendizaje de la Estadística es hacer actividades requeridas para aprobar o hacer bien las evaluaciones o exámenes.

Concepción B. Colectar: el aprendizaje de la Estadística es colectar información y métodos para después usarlos. Conjunto de técnicas que necesitan ser adquiridas para luego ser usadas "después".

Concepción C. Aplicar: el aprendizaje de la Estadística es la aplicación de métodos para comprender estadísticas. Hacer actividades prácticas (ejemplos, revisar resultados y obtener respuestas correctas) que provean la capacidad de comprender la asignatura de la Estadística.

Concepción D. Relacionar: el aprendizaje de la estadística es relacionar la teoría y la práctica para comprender la Estadística. Los estudiantes intentan encontrar cómo la práctica de los ejercicios puede informar sobre la forma de comprensión de la teoría estadística y viceversa. Los estudiantes describen una intención para usar la estadística en las situaciones de la vida real y disfrutan tratando con datos reales.

Concepción E. Expandir: el aprendizaje de la Estadística es utilizar los conceptos estadísticos para comprender áreas más allá de la Estadística. El propósito es comprender lo que ellos (los estudiantes) hacen, el significado de los datos resumidos y el significado de lo que hacen con los números en el mundo real. Ven cómo la Estadística puede ser utilizada fuera de la asignatura o en un contexto fuera la de universidad.

Concepción F. Cambiar: el aprendizaje de la Estadística es acerca del uso de conceptos estadísticas para cambiar su visión. Los estudiantes se centran en la calidad del cambio de sus propias comprensiones de la idea más amplia de la Estadística y del mundo. Ven a la Estadística como una herramienta intelectual que puede ser usada para informar sus conocimientos en muchas otras áreas, o resolver problemas en otras áreas. Creen que el estudio de la Estadística les lleva (empuja) a cambiar la forma como ellos ven el mundo.

Mientras que las concepciones sobre la enseñanza de la estadística, son las siguientes (Petocz y Reid, 2002):

1. Concepción: Proporcionar materiales, motivación, estructura. Clases para proporcionar buenos materiales (como guías o notas), interacción, motivación (ser 
entusiasta, no aburrido), o estructura (ej. clases para la teoría y laboratorio de práctica).

2. Concepción: Explicar materiales y ayudar con el trabajo de los estudiantes. Los estudiantes esperan que en sus clases se expliquen los materiales (tópicos) coherentemente, proporcionando guías claras para el trabajo, cómo evaluar las tareas y las formas de trabajo. Las exposiciones del profesor deben ayudar a resolver los problemas y dudas que enfrentan los estudiantes, revisando y proporcionando los materiales adecuados a ellos en función de sus características, antecedentes académicos y etapas de desarrollo.

3. Concepción: Relacionar conceptos estadísticos y guiar el aprendizaje. Los estudiantes esperan que en las clases se relacione los conceptos estadísticos, clarificando, explicando, elaborando ideas, especialmente en situaciones inusuales o diferentes, y haciendo conexiones entre las áreas del curso.

4. Concepción: anticipar las necesidades de aprendizaje del estudiante. Los estudiantes esperan que las clases se centren sobre las características de cada estudiante para proporcionar materiales y métodos que mejoren su aprendizaje. Los estudiantes esperan ser enseñados por profesionales de la enseñanza, que conozcan los mejores métodos para enseñar ciertos conceptos y conocer qué hacer cuando los estudiantes no comprenden ciertas ideas.

5. Concepción. Ser un catalizador de "mentalidad abierta". Los estudiantes tienen una visión integradora de la responsabilidad de las clases. Esperan que el profesor muestre la importancia de la Estadística para la vida en general, ayudando a los estudiantes a cambiar su visión del mundo y abriendo sus mentes a nuevas posibilidades. Se trata de ayudar al estudiante a desarrollar altos niveles de comprensión de la estadística.

Al igual que las concepciones sobre la Estadística, las del aprendizaje y su enseñanza tienen como características que son jerárquicas e incluyentes.

El trabajo de Reid y Petocz (2002) y Petocz y Reid (2002) nos ayudó a explorar las concepciones que los profesores tienen de la Estadística, su aprendizaje y enseñanza. A partir de las respuestas obtenidas de los diferentes instrumentos de recogida de datos, se identificaron las expresiones que nos dieron cuenta del tipo de concepción que el profesor tiene.

En el análisis también nos ayudó el trabajo de Gordon (1998) quien identificó cinco categorías sobre las concepciones de la Estadística: 1) sin significado, 2) proceso o algoritmo, 3) dominio de conceptos estadísticos y métodos, 4) una herramienta para obtener resultados en la vida real y 5) una forma de pensamiento crítico. Su trabajo nos permitió comprender mejor las características del trabajo de Reid y Petocz (2002) y así favorecer a la identificación de las expresiones de los profesores. 
Para el análisis de las concepciones sobre la representación gráfica, su aprendizaje y enseñanza, lo primero que hicimos fue caracterizar la concepción sobre el tópico. Analizamos las diferentes aportaciones en relación a la definición del concepto de representación gráfica, descritas en el Capítulo 2 e identificamos y diferenciamos cinco grandes concepciones como: 1) técnica de graficación, 2) comunicar resultados, 3) interpretar relaciones en contextos reales, 4) análisis exploratorio de datos y 5) herramienta para desarrollo el pensamiento estadístico. A continuación se explican brevemente las concepciones sobre la representación gráfica:

Concepción 1. Técnica de graficación. La representación gráfica se concibe como un conjunto de técnicas de graficación así como nociones relativas a su selección, diseño, edición; centrado en la construcción de gráficos con propósitos meramente descriptivos, principalmente tradicionales o populares (ej. barras, circular, pictograma), que usualmente presentan limitadas cantidades de datos. Esta concepción relega a la $\mathrm{RG}$ a un simple auxiliar didáctico y se ha omitido o ignorado su uso para desarrollar la actividad cognoscitiva del pensamiento del estudiante. Su uso está orientado a que el alumno identifique los componentes estructurales del gráfico o bien, la combinación de un conjunto de elementos, dispuestos de acuerdo a unos criterios técnicamente definidos.

Concepción 2. Comunicar resultados. En esta concepción se refiere a la representación gráfica como una serie de métodos y técnicas cuantitativas que tiene el propósito de mostrar la presentación y visualización de resultados de un conjunto de datos. Comprende examinar, describir e interpretar los de manera literal, así como resumir y presentar resultados a través de gráficas. Generalmente se abocan a la edición y presentación de resultados de datos provenientes de investigaciones (estadísticas o científicas) y ayudan a presentar conceptos y datos concretos de manera coherente. Son una forma común de comunicación social, cuidando que el tipo de RG sea adecuado al tipo de público que está dirigido. Comúnmente son gráficos convencionales (ej. circular, barras, pictogramas), categóricos y descriptivos, que también se encuentran en periódicos, revistas y anuncios. Usualmente el gráfico contiene un limitado conjunto de datos, el cual permite recuperar el mensaje en un rastreo rápido, centrado en la lectura y localización de valores o tendencias como recurso para la interpretación.

Concepción 3. Interpretar relaciones en contextos reales. La representación gráfica es entendida como la capacidad para traducir una gráfica a otra, o una tabla a una gráfica y ser capaz de interpretar relaciones o factores importantes en un gráfico (Friel, Bright y Curcio, 2001). Es la habilidad de los lectores para derivar el significado de gráficos creados por otros o por ellos mismos. Incluye la habilidad para leer e interpretar gráficas, así como la habilidad para conocer componentes de un gráfico, hablar del lenguaje de gráficos, comprender las relaciones entre tablas y gráficas, comprender sobre razonamiento distribucional y responder preguntas acerca de gráficos, es decir, adquirir el sentido gráfico (graph sense, según Friel, Bright y Curcio (1997). Se identifican también nuevos elementos de la 
representación gráfica como es el "sentido de los datos" (data sense) por Burgess (2002), y el "sentido crítico" (critical sense) definido por Gal (2002).

Como resultado de esta concepción se diseñan y analizan gráficos a partir de datos reales, explorando su uso en contextos de la vida real y profesional. Incluye no sólo leer, escribir e interpretar el gráfico, sino escribir y establecer relaciones o factores importantes a partir del contexto. Los tipos de gráficos incluyen los descriptivos o categóricos y algunos de corte analítico, aunque generalmente dependerán del nivel escolar, del contexto y las razones por las que se estudian los gráficos. Se estudian y analizan los fundamentos de la construcción del gráfico en ciencias, la interpretación y escritura de conclusiones a partir del gráfico, incluyendo criterios engañosos o modelos ineficientes de técnicas gráficas (los chartjunk, según Tufte, 1983).

Concepción 4. Análisis exploratorio de datos. En esta concepción los gráficos son justamente representaciones visuales de la relación entre dos o más variables, y por tanto contienen un gran potencial para desarrollar la visualización matemática y el pensamiento visual. Los gráficos son una valiosa ayuda en la solución de problemas aritméticos y algebraicos, la solución de fórmulas matemáticas y estadísticas y la representación de relaciones. Se definen como cuadros o esquemas que intentan transmitir información acerca de los números y sus relaciones. Tiene estrecha relación con el análisis exploratorio de datos (Exploratory Data Analysis, EDA por sus siglas en inglés según Tukey, 1977) que ayudan a conocer la naturaleza de los datos. Permiten la exploración, análisis y presentación de hechos numéricos por medio de puntos, líneas, áreas y otros símbolos o formas geométricas; incluyendo gráficos de corte analítico que presentan más datos, como son el de puntos, tallo y hoja, de caja, histograma, gráfico de dispersión, lineal, regresión y las distribuciones; que nos conducen a ver lo que puede suceder y "estimular el ojo para comparar diferentes piezas de datos y revelan los datos en varios niveles de detalle, dando una amplia visión en conjunto de la estructura fina" (Tufte, 1983, p.13 en Henry, 1995). Comprende el análisis variacional y de tendencias lineales multivariadas que permiten visualizar más información de los datos. Estos van más allá de la descripción concreta de los datos, para estimular al lector a analizar los datos contenidos en éste. Ayudan al investigador a tomar decisiones sobre futuros análisis estadísticos y pruebas de hipótesis, a sustentar los resultados e inferencias estadísticas, así como a presentar datos complejos de una manera coherente y memorable.

Concepción 5. Herramienta para desarrollar el pensamiento estadístico. En esta concepción, la representación gráfica se entiende como una herramienta de razonamiento para aprender algo nuevo acerca del contexto que representa, obteniendo nueva información o aprendizaje de los datos (Pfannkuch, 2006). Aquí, un gráfico estadístico es un "constructo desarrollado en un contexto cultural específico que interviene como mediador en la interpretación de los datos... una actividad relacionada con un complejo rango de elementos y procesos" (Monteiro y Ainley, 2006). Además de las características de las concepciones anteriores, los gráficos son esenciales para la representación, reducción y análisis de datos en el 
razonamiento y pensamiento estadístico (Shaughnessy (2007), así como ayudar a descubrir resultados inesperados, confirmar los resultados esperados, desarrollar el plan necesario para el análisis de datos, resumir los resultados de una investigación y examinar los datos para estudiar las tendencias y otros efectos que el uso exclusivo de la Estadística descriptiva e inferencial puede olvidar (Pittenger, 1995).

Los gráficos tienen un rol esencial en el análisis de datos y su presentación (Tukey, 1977; Wainer y Thissen, 1993; Cleveland, 1994); evitan "meter la pata" en la selección, análisis e interpretación de estadísticos (Peden, 2001); son herramientas para detectar las características en los datos (Friel, Curcio, Bright, 2001); los gráficos son una importante herramienta para los investigadores y para la práctica de la ciencia, tanto porque resumen grandes cantidades de datos de forma económica como porque constituyen la mejor herramienta para presentar la covariación entre medidas continuas (Bowen y Roth, 1998).

El análisis, interpretación y presentación de resultados está estrechamente relacionado con el conocimiento del contexto, de tal modo que su estudio comprende además el análisis de los gráficos de algún medio de comunicación impresa (media graph o print graph) que se encuentran para ilustrar argumentos periodísticos (Monteiro y Ainley, 2006); dirigidos para proporcionar información al público en general y muy comúnmente usados y vistos en la vida diaria.

Se trata de una concepción integral que reconoce la representación gráfica y su interpretación como categoría de la alfabetización cuantitativa (quantitative literacy) a desarrollar en los estudiantes, y ha sido reconocido como uno de los aspectos fundamentales de la alfabetización científica que todo ciudadano debe tener en el Siglo XXI (Aoyama, 2006; con base en la NCTM y el informe PISA en OCDE, 1999).

Vista de este modo, la representación gráfica es entendida como una herramienta para desarrollar el pensamiento crítico y estadístico del estudiante, centrándose en el estudio de una diversidad de gráficos en diferentes contextos (ej. de investigación y de la vida real).

Una característica de esta clasificación es que es de naturaleza jerárquica e incluyente, es decir, la concepción 1 es el primer nivel y la concepción 5 es la más extendida e incluyente.

Sobre la concepción del aprendizaje, el análisis estuvo centrado en explorar cómo entiende el aprendizaje de la RG el profesor. Nos basamos en examinar qué niveles cognitivos de RG desarrolla en los estudiantes, a partir de tres autores: Curcio (1989), Garfield (2002) y Aoyama (2006). Curcio (1989) conceptúa el estudio de la RG a través del desarrollo gradual utilizando los niveles de leer datos, leer entre datos, leer más allá de los datos y leer detrás de los datos (esta última reconocida por Shaughnessy, 2007). Garfield (2002) asume el desarrollo cognitivo del estudiante a partir de tres grandes categorías: alfabetización, razonamiento y pensamiento estadístico; cada uno presenta los resultados esperados por cada tópico estadístico que se estudie (ej. la RG). Por último, Aoyama (2006) 
presenta una "jerarquía de la interpretación gráfica", la cual clasifica en cinco niveles: 1) idiosincrático, 2) lectura básica del gráfico, 3) literal / racional, 4) crítico y 5) hipotetizando y modelando. El análisis de la concepción a partir de estas tres clasificaciones nos permitió establecer una perspectiva diferente sobre el aprendizaje vista a partir de cada autor, así como identificar diferencias y asociaciones en su concepción.

Sobre las concepciones de la enseñanza de la RG, identificamos aquellos enunciados que nos dieron indicios del énfasis que hace cuando enseña el tópico, o bien, aquellas expresiones que denotaban las actividades instruccionales en clases. Posteriormente, tratamos de identificar alguna oración o frase que caracterizara su enseñanza sobre la RG.

A partir de la información recogida de los diferentes instrumentos, se procedió a identificar todas las afirmaciones y argumentos que cada profesor externó en relación a la RG. Estas fueron clasificadas en función del énfasis, sentido u orientación que le dieron en relación al tópico de estudio. De esta manera, algunas afirmaciones trataban sobre el significado y concepción de la RG, otras sobre el aprendizaje de éste y finalmente, el resto se ubicaron sobre su enseñanza.

En todo momento el propósito del análisis de las concepciones no buscó la ubicación del profesor en alguna categoría, sino sirvió para comprender más sobre su conocimiento. Por consiguiente, es posible que el profesor presente alguna característica identificada en una o más concepciones. No obstante, nos abocamos a seleccionar aquellas que sea más representativa de sus expresiones, afirmaciones y argumentos, y que sea consistencia en el discurso que dio en las diferentes fases de la investigación.

Creencias. La definición de creencia que más se ajusta al tratamiento y utilización de nuestro trabajo está en consonancia con la de Moreno y Azcárate (2003):

Las creencias son conocimientos subjetivos, poco elaborados, generados a nivel particular por cada individuo para explicarse y justificar muchas de las decisiones y actuaciones personales y profesionales vividas. Las creencias no se fundamentan sobre la racionalidad, sino más bien sobre los sentimientos, las experiencias y la ausencia de conocimientos específicos del tema con el que se relacionan para cada individuo (p.267)

Como señala Pajares (1992, en Gil y Rico, 2003), las creencias son verdades personales indiscutibles sustentadas por el individuo, con un fuerte componente evaluativo y afectivo. De acuerdo a Pehkonen (2001, en Attorps, 2006) las creencias pueden referirse como un conocimiento subjetivo individual el cual además incluye sus sentimientos (opiniones o impresiones) con respecto a fenómenos sin incluir siempre fundamentos defendibles en un sentido objetivo. Añade que las creencias son escépticas y abstractas desde las experiencias personales del individuo, y usualmente se adquieren de forma incosciente. Contrariamente al conocimiento objetivo una creencia siempre contiene una dimensión afectiva (Pehkonen, 2001, p.13). 
El trabajo se centró sobre el conocimiento que tiene cada profesor de las creencias de los alumnos, de tal modo que lo que hicimos fue identificar todas aquellas expresiones dichas por el profesor, basadas hipotéticamente sobre los sentimientos, experiencias, emociones, opiniones e impresiones de los estudiantes tienen sobre la Estadística o de la RG; con poco nivel de elaboración, de carácter subjetivo, ausencia de conocimientos específicos del tema y sin una sólida base pedagógica que las sustenten.

El análisis consistió en identificar aquellas expresiones que el profesor externó en torno a lo que los alumnos dicen, piensan o sienten sobre la Estadística o la RG. Identificamos estas expresiones y las presentamos con la correspondiente argumentación del profesor. De esta manera, el conocimiento de las creencias identificadas en cada profesor dependió de la información que nos proporcionó en los diferentes instrumentos de recogida de información.

Errores y dificultades. Para nuestra investigación asumiremos que cuando un alumno proporciona una respuesta incorrecta a una cuestión matemática que se le plantea se puede decir que su respuesta es errónea, y la solución proporcionada es un error en relación a la cuestión propuesta (Rico, 1995).

La dificultad está más relacionada con aquello que impide conseguir, ejecutar o comprender correctamente el concepto o tópico matemático.

Dado que ambos conceptos están íntimamente relacionados, decidimos utilizar los dos términos juntos, como errores y dificultades.

A través del cuestionario didáctico sobre RG logramos explorar el conocimiento de cada profesor sobre los errores y dificultades del estudiante. Por tal motivo, nos abocamos a analizar de cada situación-problema (C-1, C-2, C-3, C-4) los errores y dificultades que el profesor piensa que tienen los alumnos, así como las atribuciones que le da a éste. Posteriormente, con ayuda del trabajo de Rico (1995), las agrupamos en categorías, de tal modo que nos ayudara a analizar los resultados de una manera diferente y así comprender mejor el conocimiento del profesor.

\subsubsection{Análisis intercaso}

Para el análisis intercaso, se elaboraron unas figuras que representan con descriptores o palabras clave los resultados obtenidos en los diferentes componentes del CDC estudiados a través de esta investigación.

A partir de las respuestas obtenidas en cada una de las dimensiones e indicadores, definimos un conjunto de rasgos característicos que se lograron estudiar del CDC del profesor, cuyos resultados pormenorizados se presentan a través de descriptores o palabras claves. 
Estas figuras (ver sección 5.3 en el Capítulo 5) nos sirvieron para contrastar el CDC de cada profesor en cada componente y dimensión. Se podrá observar que se identifican algunas líneas rectas que representan las interrelaciones entre las categorías.

El modelo del diseño de estas figuras fue tomado de Marks (1989, 1990a y 1990b).

Para el análisis intercaso de las concepciones sobre la Estadística y la representación gráfica, además de los elementos teóricos descritos en la literatura, se analizaron las concepciones que sobre la Estadística tienen los profesores a partir de algunas subcategorías de análisis de Carrillo y Contreras (1993, en Carrillo, 1998) quienes para estudiar las concepciones de la matemática, su aprendizaje y enseñanza utilizan descriptores de tendencias didácticas agrupadas en tradicional, tecnológica, espontaneista e investigativa, cada una de ellas, con un conjunto de indicadores. En nuestra investigación, y específicamente para el análisis de las concepciones, tomamos en consideración algunos indicadores que nos permitieron caracterizar las concepciones de los profesores. Estos se presentan agrupados en los siguientes descriptores clave que incluimos en el análisis del intercaso:

Sentido de la asignatura

Orientación

Objetivo

Finalidad

Aprendizaje

Aprendizaje

Tipo

Proceso

Tipo de agrupación

Dificultades del alumno

Participación del alumno

Enseñanza

Papel del alumno

Metodología

Programación

Papel del profesor

Evaluación

Carácter

Criterios

Instrumento principal

Diagnóstico

Valoración del proceso

Con base en la descripción de cada uno de los indicadores expuestos por Carrillo (1998), identificamos las afirmaciones y argumentos que proporcionó el profesor durante las entrevistas y con ello, caracterizamos sus respuestas. Esto nos permitió tener un conocimiento más completo de las concepciones de cada profesor. 


\subsubsection{El informe de los resultados}

Dado que el interés de la investigación era captar la riqueza y detalles de los significados en cada profesor (caso) de su CDC, incluyendo sus motivaciones, sentimientos, deseos y propósitos, así como comprender la experiencia vivida y narrada por él mismo, se utilizó como técnica de presentación de resultados el modo narrativo, el cual es caracterizado por presentar la experiencia concreta humana como una descripción de las intenciones, mediante una secuencia de eventos en tiempos y lugares, en donde los relatos biográficos son los medios privilegiados de conocimiento e investigación (Huberman, Thompson y Weinland, 2000, en Bolivar, 2002).

A través del informe narrativo se presentaron descripciones de incidentes particulares de cada profesor, en forma de relatos que permitieron comprender cómo su concepción y conocimiento le da sentido a su enseñanza de la Estadística y particularmente de la RG. Las descripciones se basan en la experiencia, sentimientos, vivencias, intenciones, deseos y acciones dependientes del contexto específico del profesor (Bolivar, 2002). Lo importante fue comprender los significados que subyacen en la mente del profesor, la experiencia a través de su práctica docente, los sentidos singulares que expresa y las lógicas particulares de argumentación que despliega.

Se trata de un análisis paradigmático de datos narrativos de ordenación sincrónica (Bruner, 1988 en Bolivar, 2002), es decir, el análisis procede de determinadas categorías para llegar a determinadas interpretaciones del grupo de estudio. La ordenación de los resultados está enmarcada como respuestas categóricas a las cuestiones del investigador. En primer lugar, los conceptos estudiados se derivaron de la teoría del CDC (a través del SDI) y se aplicaron para determinar cómo las respuestas de cada profesor (caso) se agruparon en la matriz de categorías. Posteriormente, mediante un proceso reflexivo de los significados, las categorías se derivaron inductivamente de los datos, lo que permitió la adecuación progresiva de éstas.

Para realizar este análisis y finalmente obtener el informe final de cada caso se procedió como sigue:

1. Tomando como referencia el SDI del CDC, se reunieron fragmentos de información (unidades de análisis) por cada dimensión e indicador. Estos fragmentos fueron tomados de las diferentes fuentes de información, E1, E2, Cu y los materiales, así como las notas del investigador.

2. Con base en la Tabla 1.9 del SDI del CDC, las unidades de análisis fueron agrupadas en las categorías que se muestran en la Tabla 4.10. 
Tabla 4.10. Relación entre las categorías utilizadas para presentar los resultados de la investigación y el SDI del CDC

\begin{tabular}{|c|c|c|}
\hline \multirow[b]{2}{*}{$\begin{array}{l}\text { Categorías presentadas en } \\
\text { el capítulo de resultados }\end{array}$} & \multicolumn{2}{|c|}{ Dimensiones del CDC } \\
\hline & $\begin{array}{c}\text { B } \\
\text { Conocimiento de las estrategias } \\
\text { y representaciones } \\
\text { instruccionales }\end{array}$ & $\begin{array}{c}\text { C } \\
\text { Conocimiento del proceso de } \\
\text { aprendizaje del estudiante del } \\
\text { tópico específico }\end{array}$ \\
\hline $\begin{array}{l}\text { a. Formación, interés y } \\
\text { motivación }\end{array}$ & $\begin{array}{l}\text { II. Fuentes de obtención de su } \\
\text { conocimiento }\end{array}$ & \\
\hline $\begin{array}{l}\text { b. Concepciones sobre la } \\
\text { enseñanza y aprendizaje } \\
\text { de la Estadística y de la } \\
\text { representación gráfica }\end{array}$ & I. Concepciones de E-A & \\
\hline $\begin{array}{l}\text { c. Conocimiento del } \\
\text { currículo }\end{array}$ & III. Currículo & \\
\hline $\begin{array}{l}\text { d. Conocimiento de las } \\
\text { estrategias y } \\
\text { representaciones } \\
\text { instruccionales }\end{array}$ & $\begin{array}{l}\text { V. Estrategias de enseñanza } \\
\text { específicas }\end{array}$ & \\
\hline $\begin{array}{l}\text { e. Conocimiento del } \\
\text { estudiante }\end{array}$ & & $\begin{array}{l}\text { I. Conocimiento del proceso } \\
\text { cognitivo }\end{array}$ \\
\hline $\begin{array}{l}\text { f. Identificación y } \\
\text { diagnóstico del } \\
\text { conocimiento del } \\
\text { estudiante }\end{array}$ & & II. Diagnóstico \\
\hline $\begin{array}{l}\text { g. Estrategias específicas } \\
\text { para corregir } \\
\text { concepciones } \\
\text { inadecuadas }\end{array}$ & & III. Estrategias \\
\hline $\begin{array}{l}\text { h. Dificultades para } \\
\text { enseñar }\end{array}$ & VI. Dificultades & \\
\hline
\end{tabular}

Esta forma de organización respondía no sólo al análisis de las dos categorías del estudio del CDC (las estrategias y representaciones instruccionales y conocimiento del estudiante) sino también a los objetivos de la investigación y a la información generada por cada profesor.

3. Una misma unidad de análisis podría ser igualmente útil para más de una categoría. Por consiguiente se obtuvo una cantidad amplia de fragmentos por cada categoría. Para fines de organización, se crearon tantos archivos electrónicos en Word como categorías creadas.

4. El siguiente paso fue la reducción del material bruto y sucesivas recursiones para que las categorías preestablecidas puedieran irse reformulando hasta lograr un mejor ajuste e interpretación de los datos. Se marcaron o señalaron los episodios principales recogidos de cada profesor. De esta manera seleccionamos las 
unidades de análisis que más interesaron incluir en nuestro informe para cubrir los objetivos del estudio y por consiguiente se prescindió de las demás.

5. Después se examinaron las unidades de análisis de cada categoría con el propósito de identificar los principales temas que merecían prestar más atención. En esta etapa fue común repasar las transcripciones completas para comprender el sentido de los diálogos, así como reflexionar sobre lo que quería decir el profesor o la profesora.

6. Una vez identificados los temas de interés que merecían mayor atención por cada categoría se procedió a ponderar qué párrafos podrían ilustrar las conclusiones que le daban significado.

7. Con base en Stake (1998) el análisis e interpretación se realizó, en algunas ocasiones a partir de la suma categórica de las respuestas (reiteración o repetición una y otra vez) y en otras de interpretación directa (significado del ejemplo, fragmento o párrafo).

8. Se escribió la interpretación de los fragmentos, buscando que el significado apareciera mediante un ejemplo particular y se intentó aportar detalles que permitieran que el lector hiciera también su propia interpretación. En ocasiones fue útil representar los resultados a través de una figura o una tabla que resumiera la descripción de las categorías encontradas.

9. El informe final de cada caso procuró, en la medida de lo posible, atender a cuatro niveles diferentes de análisis e interpretación, como círculos concéntricos:

a. El primer nivel será literal. Le damos todo el valor a las palabras tal como fueron, a la descripción de los fragmentos o diálogos del profesor(a), respetando las palabras propias de éste. Esto evitará falsas interpretaciones o interpretaciones meramente alegóricas.

b. El segundo nivel es el conceptual. Las palabras poseen determinados significados vinculados a los conceptos vertidos por el profesor(a), según la categoría que se trate. A partir del sentido literal, se trata de darle sentido y significado a las palabras, las estructuras cognitivas que hay en la mente, así como las emociones, sentimientos y experiencia del profesor.

c. El tercer nivel es el analítico del CDC. Se analiza el conocimiento del profesor(a) a la luz del marco teórico del CDC y del SDI, ¿qué conocimiento se tiene de las estrategias y representaciones instruccionales? y ¿qué conocimiento se tiene de las creencias, errores y dificultades de los alumnos?

d. Por último, el nivel analítico de la $R G$. Se trata de analizar el conocimiento del profesor(a) a la luz del marco teórico de la RG, ¿qué se conoce sobre la RG? y ¿qué se conoce sobre la enseñanza y aprendizaje de la RG? 
10. Después de cada encabezado del capítulo procuramos analizar los resultados a la luz de la investigación en educación matemática y específicamente sobre el tema de la RG. Esto nos permitió desarrollar el nivel analítico del CDC y de la RG. Como complemento de este análisis, al final de cada caso, se presenta una sección denominada "En síntesis", dentro de la cual resumimos las características del CDC de la RG de cada profesor a partir de las categorías encontradas.

11. La integración final del informe permitió renombrar algunas categorías y mover el orden de las mismas.

12. Después de la presentación del informe de cada caso, pensamos oportuno incluir un breve análisis intercaso, no con el objeto de establecer semejanzas y diferencias, sino como otro criterio o nivel de análisis e interpretación y comprensión de las diferencias en sus concepciones, conocimientos y contextos donde enseñan.

Los informes de cada profesor se presentan en el capítulo correspondiente a los resultados. En el último capítulo, se encuentra la discusión de los mismos y las conclusiones, describiendo la consecución de los objetivos, las hipótesis de trabajo, las limitaciones, la contribución de la tesis y las implicaciones para futuras investigaciones y para la enseñanza.

\subsection{FIABILIDAD Y VALIDEZ}

Al igual que en el enfoque cuantitativo, la investigación de carácter cualitativo exige también sistematización y rigor metodológico (Pérez, 1994), sólo que desde una perspectiva diferente. En este sentido, es básico primero establecer las bases conceptuales de lo que entendemos por fiabilidad y validez desde la perspectiva cualitativa.

Por fiabilidad se entiende "el grado en que las respuestas son independientes de las circunstancias de la investigación y por validez, la medida en que se interpreta de forma correcta" (Pérez, 1994, pp. 77-78). Para Pérez (1994) lo central en la fiabilidad de una investigación cualitativa está en la concepción que se tenga de la naturaleza de los datos, del proceso de investigación seguido y de la presentación de los resultados, es decir, depende de la estandarización de los registros en los que se debe partir de una categorización elaborada. Dicho de otra forma, hay que lograr que el registro de datos esté sistematizado, organizado, sea objetivo, haya recursos para el registro de la información, diversos momentos de recogida de la información, y esté definido el procedimiento científico para generación de categorías con el fin de lograr la mayor precisión y sistematización en todo el proceso (Pérez, 1994).

Por otro lado, la validez se relaciona más con la exactitud, es decir, según Pérez (1994) las conclusiones deben representar efectivamente la realidad empírica y el constructo elaborado por el investigador represente o mida categorías reales. En pocas palabras, se trata de un problema de consistencia. 


\subsubsection{Fiabilidad: externa e interna}

Muchas son las técnicas que se pueden utilizar para obtener la fiabilidad y validez de un estudio cualitativo; en la literatura sobre metodología de la investigación, se pueden encontrar los distintos tipos y características de las técnicas posibles a utilizar, dependiente del tipo de estudio y de la naturaleza ontológica, epistemológica y metodológica del mismo. Para esta investigación se asumió la clasificación de fiabilidad externa e interna de Pérez (1994):

Fiabilidad externa: Se relaciona con la cuestión de si un investigador independiente descubrirá los mismos fenómenos o elaborará idénticos contrastes en un mismo escenario u otro similar.

Técnicas: Se recomienda solucionar cuatro problemas: a) los referidos al status del investigador, b) selección de los informantes; situaciones y condiciones sociales, c) constructos y premisas analíticos y a d) métodos de recogida y análisis de datos.

Fiabilidad interna: se refiere al grado en que un segundo investigador, a partir de un conjunto de contrastes elaborados previamente, ajustaría a ellos sus datos como se hizo en la investigación original.

Técnicas: descripciones de bajo nivel interferencial, varios investigadores, participantes-ayudantes, revisión por otros investigadores y datos registrados automáticamente (pp.78-79).

En cuanto al cuidado de la fiabilidad externa, el rol del investigador fue de respeto y de empatía con los profesores, ser un oyente consciente de las diferencias individuales y evitar ser prejuicioso e intervenir y hacer comentarios para no influir o provocar distorsión de la información. En todo momento se intentó crear y tener un ambiente relajado y de confianza, siendo flexible en los días, tiempos y lugar de las entrevistas y durante éstas, a pesar de la insistencia para que respondiera a las preguntas difíciles o complejas, se intentó que en ningún momento el profesor se sintiese ni evaluado, ni observado ni enjuiciado. Cada vez que fuese necesario se motivó con palabras de aliento y recordando la importancia que tiene su aportación en la investigación.

Otro de los elementos claves que inciden en la fiabilidad externa es la selección de los informantes. En esta investigación se siguió un procedimiento organizado, sistemático y bajo criterios preestablecidos que ayudaron a que la selección de los dos casos esté fundamentada y fuera de prejuicios e intereses personales.

Adicionalmente, se cuidó el proceso de recogida y análisis de información. Desde el contacto con los autoridades e informantes (con apoyo de cartas de invitación y entrevistas cara a cara), contar con una bitácora de citas y fases a desarrollar, así como definir previamente (con apoyo de la literatura) el proceso de instrumentación y recogida de los datos (paso a paso), de los procedimientos analíticos (inductivo-deductivo) que se hicieron por cada constructo (ej. creación del SDI del CDC y de los objetivos a nivel de pensamiento estadístico de la RG) y del uso frecuente de esquemas, tablas y figuras que ayudaron a la obtención de categorías para el análisis de los datos. Todo esto se hizo 
cuidando que el método de recogida y análisis de los datos estuviera suficiente claro y fundamentado.

En cuanto a la fiabilidad interna, se contó con el apoyo de un segundo investigador que validó el SDI del CDC. Se utilizó un cuestionario con dos muestras (Salamanca, España y Mérida, México) de estudiantes que ayudó a definir el cuestionario didáctico sobre RG y se obtuvo el apoyo de dos ayudantes de investigación que ayudaron en la transcripción y validación del discurso oral de los profesores.

\subsubsection{Validez: triangulación}

Al igual que con el concepto de fiabilidad, la literatura en métodos de investigación presenta diversos autores y tipos de técnicas de validación cualitativa. Para esta investigación, la técnica de validación fue la triangulación, la cual implicó:

a. recoger una variedad de datos y realizar comparaciones múltiples de un fenómeno único (Pérez, 1994),

b. que los datos se recojan desde puntos de vista distintos y realizar comparaciones múltiples de un fenómeno único, de un grupo utilizando perspectivas diversas y múltiples procedimientos (Pérez, 1994),

c. la combinación de metodologías en el estudio de un mismo fenómeno (Denzin, 1979 p.281 en Pérez, 1994, p.81),

d. un control cruzado entre diferentes fuentes de datos: personas, instrumentos, documentos o la combinación de éstos (Kemmis, 1992 en Pérez, 1994, p.81), y

e. recoger observaciones / apreciaciones de una situación o algún aspecto de ella desde una variedad de ángulos o perspectivas, después de compararlas y contrastarlas (Elliot, 1980 en Pérez, 1994, p.81).

Para nuestro estudio, se recurrió a la triangulación metodológica. Según Pérez (1994) consiste en utilizar diferentes métodos o colección de instrumentos sobre un mismo objeto de estudio. Más específicamente lo que se logra es:

Si los resultados obtenidos a través de métodos diferentes son parecidos, podemos hablar de convergencia entre medidas independientes. El contraste de los datos nos permitirá determinar a través de un análisis riguroso si los resultados obtenidos presentan o no una perspectiva integradora (Pérez, 1994, p.84).

La forma como se cuidó la triangulación fue a través del uso de las siguientes técnicas de recogida de datos: entrevista contextual y biográfica, cuestionario didáctico sobre RG, entrevista en profundidad y documentos del profesor (notas de curso, ejercicios, exámenes, programa de la asignatura, bibliografía, libreta del estudiante, presentaciones de exposición y páginas Web utilizadas). 
Jesús Enrique Pinto Sosa 


\section{CAPÍTULO 5: Resultados}

Este capítulo da respuestas a los objetivos de investigación y a la pregunta ¿cuál es el conocimiento didáctico del contenido de la Estadística, con especial atención a la representación gráfica, en profesores de Psicología y Educación? detallándose los resultados obtenidos de los dos profesores estudiados. Está dividido en tres secciones principales: la primera y segunda muestran los resultados encontrados por cada caso; y una tercera sección donde se hace un breve análisis y discusión de los dos casos conjuntamente.

Para cada uno de los casos (Alicia y Luis) se presentan los resultados obtenidos agrupados en los siguientes apartados: formación, interés, motivación como profesor(a), origen y desarrollo del conocimiento del profesor(a), concepciones sobre la enseñanza y aprendizaje de la Estadística y de la representación gráfica, conocimiento del currículo, conocimiento de las estrategias de enseñanza específicas, conocimiento del estudiante, identificación y diagnóstico del conocimiento del estudiante, estrategias específicas para corregir errores y dificultades de los estudiantes. La última parte sintetiza el CDC del profesor, a partir de los hallazgos obtenidos.

Finalmente, en el análisis intercaso se discuten y analizan ambos casos, buscando comprender el CDC de la representación gráfica a partir de la biografía académica y contextual y el planeamiento didáctico de cada profesor, su experiencia en la docencia de la Estadística, sus concepciones y conocimientos sobre el tópico en cuestión identificando tanto los aspectos comunes como diferentes en cada caso.

\subsection{EL CASO DE ALICIA: APRENDER A ENSEÑAR ESTADÍSTICA A FUTUROS EDUCADORES}

A lo largo de este apartado se presentan los resultados relativos al caso de Alicia. En primer lugar se muestra información sobre su formación inicial y experiencia docente, su motivación como profesora de Estadística, así como el contexto laboral donde trabaja. En segundo lugar, se caracteriza el conocimiento que Alicia tiene sobre la representación gráfica, considerando tanto su origen como su desarrollo a partir de la práctica docente. En tercer lugar, se presentan sus concepciones sobre la Estadística, su enseñanza y aprendizaje, así como de la representación gráfica. En cuarto y quinto lugar, se exponen y analizan los conocimientos que tiene del currículo (programa y materiales), de las estrategias de enseñanza y representaciones instruccionales específicas, respectivamente. Como sexto 
encabezado, se explora el conocimiento que mostró Alicia de los estudiantes (creencias, errores y dificultades). En séptimo y octavo lugar se analiza cómo Alicia identifica y diagnóstica el conocimiento del estudiante así como cuáles son las estrategias específicas que utiliza para corregir las concepciones erróneas de los estudiantes, respectivamente. En noveno lugar, se muestran las dificultades a las que se enfrenta cuando trata de enseñar la representación gráfica. La última parte sintetiza el CDC de Alicia, a partir de los hallazgos obtenidos.

\subsubsection{Formación profesional, interés y motivación como profesora}

Para exponer cuál fue la formación inicial de Alicia, vamos a considerar diferentes aspectos relativos a su interés hacia la matemática en general y hacia la Estadística en particular, el modo en que llegó a ser profesora, el contexto donde actualmente trabaja y su motivación como profesora.

Alicia es una profesora con formación inicial en matemática con un máster también en matemáticas. Su interés principal es la matemática abstracta porque le gusta más las cuestiones analíticas y algebraicas en contraposición con la matemática aplicada. Como profesora de la Universidad del Sureste, realiza actividades de docencia, investigación, tutoría y gestión académica. Su docencia está repartida entre dos carreras, Informática y Educación.

Desde que era estudiante, Alicia pretendía ser docente e investigar acerca de un tema de su agrado como las ecuaciones diferenciales. Sus inicios como docente se produjeron al terminar el máster de matemáticas, cuando le ofrecieron ser profesora de la universidad. Al principio fue docente de alumnos inscritos en alguna carrera relacionada con las ciencias exactas (ej. matemáticas, informática o enseñanza de las matemáticas), pero posteriormente la invitaron a trabajar en un Campus donde se ofrecen carreras de diferentes áreas, incluyendo Educación.

Alicia se autodefine como una profesora novel, poco experimentada en la enseñanza de la Estadística y sin ninguna formación como docente. Es la segunda ocasión que imparte la asignatura de Estadística, así lo manifestó en varias ocasiones:

es una flaqueza [al referirse al conocimiento o experiencia que tiene en la enseñanza de la Estadística] porque desde que yo terminé lo que es la carrera, en ningún momento he estudiado algo a cerca de docencia o de cómo dar clase (E1.CA.15)

Incluso afirma "no me siento tan fuerte en ese sentido porque sólo la he dado muy pocas veces" (E1.CA.21) al referirse a la experiencia que piensa que tiene para enseñar Estadística. No obstante, Alicia cree que la experiencia que ha tenido al trabajar con distintos tipos de alumnos (ej. personas de administración de recursos humanos) que no son del área de matemáticas le ayuda a la hora de dar la asignatura a los alumnos de Educación aunque esta situación le genera un desafío como profesora y un interés por aprender cómo enseñar Estadística: 
Desconozco muchas cosas, pero si tengo muchas ganas de aprender Estadística, pero siento que eso es diferente, una cosa es lo que yo siento y lo que me emociona de ir descubriendo cosas nuevas respecto de la Estadística (E1.CA.35).

Alicia siente una gran satisfacción y gusto por enseñar, particularmente cuando los alumnos contestan a sus preguntas porque así se asegura de que están yendo bien. Esta satisfacción se ve fortalecida cuando los estudiantes tienen buenos antecedentes académicos y no tienen miedo a las matemáticas.

Durante el trabajo de campo, Alicia siempre manifestó disposición y colaboración para compartir su manera de pensar y de enseñar la asignatura de Estadística.

Al principio, denotó nervios o estaba apenada por no poder responder a ciertas preguntas, las cuales varias de ellas reconoció no las había reflexionado o pensado. Por ese motivo en ocasiones tardaba mucho en dar la respuesta. (Nca.CA.07)

Su principal preocupación se centra en cómo enseñar a los estudiantes que no tienen una formación matemática (como los de Educación) y así manifiesta del siguiente modo las diferencias entre dar clase a estudiantes de Informática frente a los de Educación:

... al menos con el área de Informática siento que de cierta forma hablamos un mismo lenguaje, y de cierta forma cuando empiezo a dar una clase ... como que hay una base matemática que me permite hacer referencia a algunas otras cosas. Y en el caso de Educación, justamente lo que te decía que pasaba, de que escribo la sumatoria pensando de que todo el mundo va a entender lo que es una sumatoria, un símbolo y resulta que no. Entonces es un poco lo que me ocurre (E1.CA.19 y 20)

Una característica a destacar de su persona es su sensibilidad y preocupación por sus alumnos que se manifiesta en la angustia que tiene de no encontrar la forma de motivarlos o quitarles el miedo que tienen hacia la Estadística. No obstante, está tratando de que por medio de ejercicios los alumnos entiendan de qué trata la Estadística. Esta preocupación, que se manifiesta repetidas veces a lo largo de la investigación, le lleva a considerar que una de las mayores responsabilidades que todo profesor debe tener es: "saber de lo que está hablando, de tener conocimiento de lo que va a enseñar, de hallar la mejor forma para que el alumno pueda entender los temas y demás" (E1.CA.109).

En relación con su interés a lo abstracto e intangible de las matemáticas, Alicia manifiesta en varias ocasiones que es emocionante lograr descubrir o demostrar algo nuevo acerca de la Estadística y que le gustaría que sus estudiantes se emocionaran igualmente. No obstante, reconoce que no sabe cómo contagiar este gusto y emoción cuando se trata de Estadística.

Podemos apreciar que para Alicia tiene un gran valor el dominio de los contenidos y que eso representa un elemento esencial de ser profesora. Ella empieza como docente con la expectativa de impartir clases al nivel escolar con estudiantes similares a cuando ella estudió matemáticas. Sin embargo, se encontró desde el inicio con el desafío de enseñar Estadística a estudiantes de Educación, que enfrentó con mucho ánimo, pero al mismo tiempo confrontando sus concepciones sobre la asignatura, aprendiendo de los alumnos y resolviendo sus propios dilemas. Su primer aprendizaje fue darse cuenta que todos los alumnos no aprenden del mismo modo. Conforme adquiere experiencia docente, Alicia 
reconoce un vacío en su formación para enseñar Estadística, sobre todo para contagiar y motivar a sus alumnos.

Desde un inicio Alicia manifestó "no saber enseñar" porque no tiene una formación como docente. Aunque esto representa un reconocimiento de sus debilidades, puede tener algunas implicaciones para en la enseñanza. Por ejemplo, Mellado, Blanco y Ruiz (1999) afirman que algunos profesores que se sienten poco cualificados para enseñar (en ciencias), inseguros y con poca confianza, pueden transmitir ese sentimiento a sus alumnos y fomentar actitudes negativas hacia la asignatura.

\subsubsection{Origen y desarrollo del conocimiento de Alicia}

En cuanto al pensamiento y conocimiento de Alicia, ¿cuáles son las fuentes de su conocimiento como profesora?, ¿cómo y cuándo conoció y accedió a éste?, ¿cómo es el nuevo conocimiento que tiene?, ¿cómo se relaciona con su formación inicial? y ¿cómo y dónde surgen las explicaciones del profesor? Las respuestas a estos interrogantes están relacionadas con la dimensión B-II (Fuentes de obtención de su conocimiento, según el SDI) del conocimiento de las estrategias y representaciones instruccionales.

Su concepción sobre la evolución de la enseñanza de la Estadística se reduce a afirmar que "No creo que haya cambiado mucho de cómo nos daban clase a nosotros a cómo... [enseñamos]. Creo que no" (E1.CA.110), al menos entre todas las personas que ella sabe que enseñan Estadística piensa que siguen enseñando igual (a como les enseñaron). Ante la insistencia de la pregunta, responde que "ahora hay más oportunidad de tener [ej. software estadístico y calculadoras] que puedan hacer algunos cálculos porque antes se hacían completamente a mano" (E1. CA.111).

Alicia afirma que su formación inicial ha influido mucho en su concepción de la docencia: enseña como le enseñaron durante la carrera. De esta forma le da seguridad y desenvolvimiento como profesora; aunque en ocasiones se enfrenta a situaciones en las que manifiesta no saber qué hacer con exactitud, y entonces actúa más en función de como siente o cree que se debe de hacer. Alicia afirma que así fue como aprendió Estadística:

Así como me enseñaron Estadística... hace rato me preguntabas por qué ejercicios. Así aprendí Estadística (C1.CA.93).

Y afirma que, al referirse al programa de Estadística para Educación, "definitivamente fue muy diferente a ésta" (E1.CA.116). Ella describe del siguiente modo cómo aprendió Estadística:

Trabajamos muy poco con lo que es Estadística descriptiva. Así muy como "esto es Estadística descriptiva, muy bien vamos a estimadores” y "¿qué es un estimador de máxima verosimilitud, demuéstralo, por qué y demostrarlo, qué es una distribución de probabilidad, qué significado [tiene], integrales y demuestra qué es una distribución de probabilidad, integra, ve que el área bajo la curva te da uno y los teoremas demuéstralos". Es muy diferente a lo que estoy viendo. (E1.CA.116)

La forma en que trata de actualizarse es leyendo y consultando a otras personas que considera que sí están especializados en Estadística. En relación a la ayuda que solicita de 
otros colegas Alicia afirma que "en cuanto a contenido, porque en cuanto a cómo enseñarla considero que están igual que yo" (E1.CA.115).

El tipo de lecturas que hace versa principalmente sobre cómo impartir la materia y los tipos de ejercicios que pueden hacer los estudiantes de Educación:

Trato de leer, de documentarme, eso sí he tratado de hacer y de... cómo otras personas que sí están especializadas en esto, cómo dan Estadística, trato de hacer esto [está pensando]. Tratando de leer y ver de cómo...[Por ejemplo] (Mjú)... Hace poco me topé con algunos libros de la Universidad Pedagógica Nacional en cuanto a cómo dar la materia de Estadística y los tipos de ejercicios que ellos realizan. Como ese tipo de cosas trato de encontrar, algo que me pueda ayudar. (E1.CA.113)

A Alicia le fue difícil contestar acerca del tipo de lecturas o recursos didácticos específicos para la enseñanza de la Estadística porque siente que no tiene formación como profesora de Estadística y no sabe o no tiene conocimiento de qué fuentes le pueden informar acerca de la enseñanza de la Estadística. Alicia lo que intenta con la búsqueda de información es:

tratar de ver qué es lo que se está haciendo en otras universidades, qué es lo nuevo que hay, dónde me quedé de cuando la última vez que di Estadística, si hay algo nuevo, qué hay de diferente, pero te digo no te puedo hablar mucho de eso porque a penas estoy en ese proceso, apenas estoy retomando Estadística (E1.CA.115).

En las lecturas que utiliza (ej. Mat.CA.02 y 03), generalmente se presenta el concepto (definición acompañado con la fórmula Estadística) y características (ej. secuencia de pasos del procedimiento, modalidades o variantes en las que se utiliza el concepto sobre el tema), seguido de ejemplos que expliquen el concepto y posteriormente ejercicios para practicar. Son similares a los temas que presentan los libros de texto.

El tipo y características de los ejercicios de estas lecturas son muy parecidos a los que ella entregó como parte de los documentos que se revisaron. El análisis de estos se presentará en otra sección de este capítulo.

Al parecer, el origen del conocimiento que Alicia tiene de la Estadística parte de los estudios que realizó en la licenciatura y en el máster. Su forma de enseñar se ve influida por la forma como a ella le enseñaron, así como por las características y naturaleza de los textos que usualmente utilizó y estudió durante la carrera. Alicia no conoce otro enfoque pedagógico para enseñar o aprender Estadística. Aún cuando intenta localizar información que le ayude, desconoce dónde, cómo y qué buscar. Habitualmente recurre a colegas para aclarar dudas sobre aspectos exclusivamente del contenido estadístico y las primeras lecturas en que se apoya son genéricas, abordan sólo aspectos de contenido, sin profundizar en éste y sin información sobre estrategias y representaciones instruccionales para su enseñanza.

Podemos observar que la percepción que tiene Alicia es muy coincidente con la manera con que un profesor principiante se inicia como docente, donde los antecedentes escolares y sus experiencias como alumnos durante la carrera al aprender Estadística influyen en su forma de enseñar los contenidos (Mellado, Blanco y Ruiz, 1999). Estos 
autores afirman que muchos profesores utilizan métodos didácticos muy similares a sus profesores cuando fueron alumnos, es decir, enseñan como les enseñaron y se mueven bajo un esquema tradicional de enseñanza (Blanco, 1997).

Alicia mantiene un conocimiento sobre la Estadística y su enseñanza de los años 80, donde se concebía una estadística centrada en la organización y análisis de la información a partir del uso de fórmulas matemáticas y la aplicación de conceptos estadísticos. Dado que enseña como le enseñaron, cree que la forma para actualizarse es a través del uso de textos como aquellos con los que aprendió, olvidándose del tipo de estudiantes a quienes les enseña Estadística. No considera la Estadística como un campo propio de estudio y además desconoce la evolución que ha tenido en los últimos veinte años.

\subsubsection{Concepciones sobre Estadística, su aprendizaje y enseñanza}

Uno de los aspectos claves del CDC se encuentra en la primera dimensión del conocimiento de las estrategias y representaciones instruccionales: las concepciones que el profesor tiene sobre la Estadística, su aprendizaje y enseñanza (B-I según el SDI) y de manera particular, las concepciones que tiene sobre el tópico (la representación gráfica), su aprendizaje y enseñanza. En este sentido, se recogió información que nos proporcionó evidencia de cuáles son las concepciones de Alicia sobre la estadística, sobre su enseñanza y aprendizaje, y más específicamente sobre la representación gráfica.

Presentaremos primero lo relativo a las concepciones sobre la Estadística, su aprendizaje y enseñanza y más adelante abordaremos las específicas a la representación gráfica. Los apartados que hemos tenido en cuenta para analizar las concepciones de Alicia han sido agrupados en relación con:

- El significado de Estadística

- El aprendizaje

- La enseñanza

- La manera habitual de enseñar

A continuación se describe y analiza brevemente cada una.

El significado de Estadística. Alicia manifiesta la diferencia que hay entre la matemática de la Estadística señalando que mientras la primera le induce a usar las palabras "diversión, reto, satisfacción..." (E1.CA.30), al tratarse de Estadística suprime la diversión: "En cuanto a reto sí, en cuanto a diversión ya no lo son tanto (ja), para mí..." (E1.CA.31). En este sentido, su concepción alude una palabra que denota un desafío para ella como profesora, más que una palabra que englobe el significado de la Estadística. A pesar de ello en otro momento manifestó que le gusta enseñar la asignatura aunque tiene una gran preocupación porque los alumnos sienten temor o rechazo hacia las matemáticas.

... pero siento que independientemente de que sea estadística, al menos en el caso de los alumnos de Educación, sienten temor, rechazo hacia lo que es matemáticas. (E1.CA.10) 
Como que se bloquean un poco cuando escuchan que se trata de estadística. Y me pasa algo que... por ejemplo, escribo una fórmula que según yo, con formación matemática se me hace sencilla, y descubro que el sólo el hecho de escribir la anotación de sumatoria les causa pavor (E1.CA.11)

De hecho, para ella la Estadística es una parte de las matemáticas, aunque no argumentó su respuesta. Esto idea contrasta con la concepción de que la educación estadística se diferencia de la educación matemática, dado que la primera principalmente se conceptúa desde un punto de vista interdisciplinar, aplicada a los contextos en los cuales se utiliza; mientras que la segunda, no tiene necesariamente esa condición (Batanero, 2001a). Por consiguiente, no reconoce el campo de la educación estadística, como un campo propio, de innovación y desarrollo constituido por todas aquellas personas (educadores estadísticos) que se interesan o trabajan por mejorar la enseñanza, el aprendizaje, la comprensión, la valoración, el uso o las actitudes hacia la Estadística (Batanero, 2001a; Bacelar, et al. 2001), cuya área de trabajo, desarrollo, práctica y estudio no es exclusiva de los profesores e investigadores matemáticos y educadores matemáticos ya que, desde sus orígenes, adquiere un papel de interdisciplinariedad (Batanero, 2001a).

El aprendizaje. Para que aprendan Estadística, Alicia afirma que es importante que los estudiantes "vayan descubriendo, vayan despertándose algunas dudas, algunas interrogantes” (E1.CA.27) de esta forma el aprendizaje será más significativo y se lograría "más motivación porque sí tendría una razón de ser" (la Estadística) (E1.CA.28). Para ella, que los alumnos aprendan Estadística significa:

que sepan desde el significado de la palabra Estadística, qué es, para qué sirve, y que más que nada, entiendan los conceptos y los puedan aplicar. Eso es lo que más me preocupa, que los apliquen en su vida diaria y en su práctica profesional (E1.CA.101).

Esta concepción de Alicia mantiene cierta relación con el objetivo del curso de Estadística que imparte: "Utilizar la Estadística descriptiva e inferencial en la interpretación de información obtenida de una investigación educativa" (Pro.CA.01). Las palabras "utilizar" y "obtenida de una investigación educativa" hacen alusión al carácter aplicado de la Estadística en el contexto de estudiante de Educación. Si bien Alicia enfatizó mucho el significado y utilidad de la Estadística, no lo hizo de igual modo sobre la aplicación de ésta en la práctica profesional del estudiante de Educación (ej. en proyectos de investigación educativa).

Los siguientes aspectos caracterizan la concepción que tiene sobre el aprendizaje de la Estadística:

- Los alumnos deben aprender contenidos o temas estadísticos

Según Alicia, el estudiante de Educación debe aprender Estadística porque "tienen que trabajar información... tener un buen uso y no sólo manejarla bien, sino también cómo obtener esa información" (E1.CA.51). Más adelante, por "información" ella se refiere a los contenidos o temas definidos en el programa de Estadística (ej. muestreo, media, mediana, moda, intervalos de confianza). 
- Desarrollar el razonamiento estadístico relacionando aquello que se va a aprender con lo ya conocido

Por ejemplo, si se trata comprender el concepto de promedio habrá que ayudar al alumno por medio de preguntas que partan de lo que ya conoce y que le permitan comprender la utilidad de la medida, cómo se obtuvo y el significado real que tiene:

En este sentido pues están súper familiarizados con el promedio de sus calificaciones. Entonces preguntarles "bueno, cuando tú obtienes el promedio de tu calificación ¿qué significado tiene?, ¿por qué nada más manejas una sola calificación?, digamos en el transcurso de alguna materia, de ¿cómo obtuviste esa calificación?", y entonces ellos ya van diciendo "pues de [que] hubieron tantos parciales, se calificó de esta forma y luego obtenemos esa calificación eh... final", y "y por qué sólo esa calificación están considerando" (E1.CA.38).

- Es esencial que el alumno esté motivado y dispuesto

Para Alicia es fundamental que el profesor maneje diversos contextos de aplicación de los conceptos para que puedan aplicarlo en esos nuevos escenarios. Lo esencial en un salón de clases es que los alumnos estén motivados y con la disposición por aprender:

... que sea un salón en el que se puedan concentrar, de hecho acá me gustan bastante los salones porque no tienen ventanas en la que pasa alguien y se pueden distraer viendo a alguna persona. Entonces me gusta que estén, no sé, todos concentrados en lo que estamos haciendo, que haya disposición por parte de los alumnos, porque considero que es importante... Entonces disposición y motivación, ambas cosas... (E1.CA.23 y 24)

Alicia opina que si de entrada piensan [los alumnos] que no les va a servir de nada la Estadística o que es un relleno en su carrera de Educación, entonces va a ser difícil que aprendan y ahí es en donde trata de motivarlos:

De participar en clase, de estar presente en la clase, de hacer los ejercicios, de preguntar, de no conformarse con lo que uno le está diciendo sino que quiera ir un poco más allá, de que realmente quiera aprender, no conformarse con lo que el maestro dijo y se acabó, y si "sólo me puso un ejercicio, se acabó", sino que se preocupe por estar buscando, preguntando, pidiendo más ejercicios (E1.CA.107).

- La dificultad principal es la interpretación

Respecto a las dificultades que tienen los estudiantes en relación con el aprendizaje de la Estadística indica que la mayor dificultad es "la interpretación en general" porque aunque los alumnos sí logran mecanizar los cálculos y construir gráficos:

si les cambias el problema se los preguntas de otra forma o les dices que te interpreten eso que acaban de hacer... no te lo logran explicar, bueno algunos sí, o sea no todos, pero sí siento que esa es una de las [dificultades]... la interpretación (E1.CA.95)

Considera que esta dificultad se debe al miedo que tienen los estudiantes hacia las matemáticas, por lo que evita en ocasiones el uso de simbología Estadística para que no predisponga ante el contenido a estudiar. 
La enseñanza. Los recursos que conceptúan, caracterizan y definen su manera de enseñar son los ejercicios y las preguntas que usa para que los alumnos comprendan los conceptos.

Lo que normalmente hago es que además de los ejercicios y de que esté pendiente que todos estén haciendo y preguntándoles (E1.CA.86)

O sea haciéndoles preguntas de tal forma que vayan llegando a entender la utilidad de una medida y cómo se obtuvo esa medida y qué significado tiene realmente, digamos en este caso (E1.CA.39)

Estos recursos los utiliza tanto para hacer razonar al estudiante como para detectar dificultades. Esta concepción se ha mantenido desde su ingreso como profesora en la universidad, aunque intenta cambiarla.

... sentía que enseñar estadística o cualquier otra materia consistía en venir dar la explicación, poner algunos ejemplos, preguntarle a los alumnos ¿se entendió? ¿no se entendió? (E1.CA.06)

[ahora] estoy tratando de, al menos tratando porque se me hace bastante difícil, de que sí por medio de los ejercicios vayan tratando de verdad de entender de qué es lo que se trata, digamos la materia en este caso de estadística (E1.CA.07)

En reiteradas ocasiones, Alicia afirma que le gusta que los alumnos trabajen en clase, porque piensa que con ello puede supervisar lo que hacen y los estudiantes tienen la oportunidad de presentar sus dudas y preguntas. De este modo, puede identificar las dificultades que tienen cuando hacen los ejercicios, y les hace preguntas para explorar si tienen o no una determinada dificultad.

Trato de que pasen a hacer el ejercicio frente al grupo y en ese momento tan solo el hecho de cómo van planteando el problema, cómo lo van resolviendo, yo me voy dando cuenta cuando alguien ya lo entendió o nada más lo está haciendo mecánicamente (E1.CA.87).

La manera habitual de enseñar. Alicia usualmente para enseñar expone y utiliza ejemplos. Al completar la frase, "mi método o estrategia de enseñar Estadística es ...", respondió "En explicar y dar ejemplos" (E1.CA.50). Su descripción de la manera habitual de impartir Estadística se puede apreciar en la Figura 5.1.

Una de las estrategias que para Alicia se debe utilizar al enseñar Estadística son los ejemplos, más incluso que la explicación:

[está pensando] Yo creo que [se debería enseñar Estadística] considerando bastantes ejemplos, en los que se puedan entender o darse cuenta de... en qué les puede servir o dónde van a aplicar lo que es la Estadística. Siento que sí se requieren bastantes ejemplos más que la explicación (E1.CA.26). 


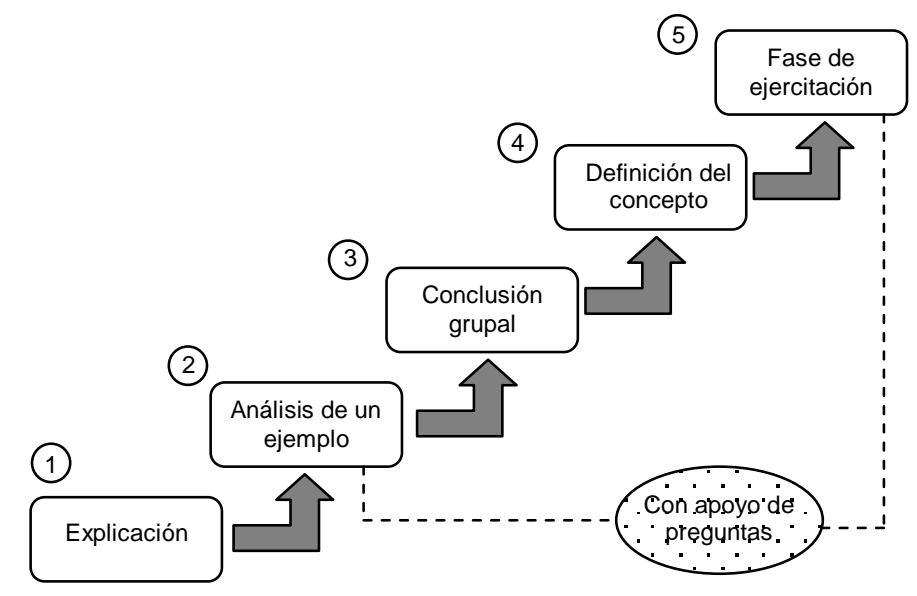

Figura 5.1. Forma habitual de la clase de Alicia

Esto ayudaría a que el alumno vaya descubriendo por sí mismo el significado de los conceptos estadísticos. De hecho, afirma que la responsabilidad del profesor "no sólo es dejar unos cuantos sino tratar de encontrar los mejores ejercicios y ponérselos [a los alumnos]" (E1.CA.108)

Esta explicación de su forma habitual de clase, mantiene correspondencia con la forma en que planea su clase (E1.CA.71):

Primero, consulta en el programa los temas a tratar.

Segundo, revisa la bibliografía.

Tercero, analiza cómo abordan los tópicos los diferentes textos.

Cuarto, trata de encontrar ejemplos aplicados al campo de la educación.

Quinto, selecciona los ejemplos que utilizará con los estudiantes.

¿Cómo elige los ejercicios que utilizará con sus alumnos? Alicia con regularidad sigue la siguiente secuencia:

Primero, busca ejercicios que aborden la definición matemática.

Segundo, realiza ejemplos concretos de su uso (aplicación) que les sea fácil de comprender a los estudiantes.

Tercero, usa ejemplos para aplicar lo visto (ejercitación).

Cuarto, localiza y presenta ejercicios sobre las distintas modalidades con la que el estudiante se puede enfrentar en su resolución.

El siguiente texto ejemplifica esta secuencia:

Estoy trabajando con la distribución normal: primeramente vimos lo que es la distribución estandarizada y entonces así ejemplos específicamente de encontrar área bajo la curva para $z$ que está entre tal y tal valor, para que al menos manejen bien lo que es la tabla y reconozcan áreas, cómo encontrar - que si la $z$ o la probabilidad, primero. Después ya cuando vemos para qué nos va a servir esa distribución, entonces empiezo a ver ejemplos en donde, ya sea aplicar lo que es la distribución 
normal en este caso y también, por ejemplo si siento que hay algún problema a la hora de... o con qué problema se podrían enfrentar a la hora de utilizar su tabla: de que si necesitas sacar el área bajo la curva de... si estamos hablando de una probabilidad inferior (digamos), y de repente tienen que calcular una que esté por arriba de cierto límite o entre dos que sean diferentes. Localizo ejemplos en donde tengan que pensar esto que no se dé directamente... luego las distintas modalidades con las que se podrían enfrentar (E1.CA.77)

Su concepción también se refleja en los recursos informáticos que utiliza. Para ella la tecnología la utiliza básicamente para búsquedas de Internet.

A la hora de mi clase es un poco a la antigua de que escribir y notas y demás. Muy pocas veces, casi nunca utilizo digamos proyector o presentaciones, no soy muy dada las presentaciones. En el caso del SPSS [Statistical Package for Social Science] pues si vamos al centro de cómputo trabajamos en eso. Pero soy más bien, así como que a la antigüita (E1.CA.99).

De hecho afirma que no utiliza con frecuencia el SPSS (que aparece en el programa de la asignatura de Estadística), aunque esto lo atribuye al poco tiempo que el programa destina para aprender este software.

La forma de evaluar los contenidos y objetivos de aprendizaje de la asignatura de Estadística “... básicamente son ejercicios escritos y exámenes escritos” (E1.CA.81) es coherente con su manera de concebir la enseñanza de la Estadística.

Mira, por lo general les pido trabajos, ejercicios. Básicamente son una serie de problemas en los que tienen que ir resolviéndolos con distintos grados de dificultad. Básicamente es eso y luego evaluaciones, bueno exámenes escritos. En ese caso dividimos en dos partes, por ejemplo el examen, porque también manejamos el SPSS, entonces una parte fue en el salón de clases, ellos hicieron unos cálculos digamos a mano y dieron su descripciones en el caso de Estadística descriptiva, y luego también en el centro de cómputo se hizo una evaluación en cuanto al manejo del SPSS (E1.CA.79 y 80)

Todos estos rasgos caracterizan la concepción que Alicia tiene de la Estadística, su aprendizaje y enseñanza de forma coherente con su formación inicial. Alicia concibe la Estadística como una parte de las matemáticas centrada en el análisis e interpretación de datos (Concepción 4 de Reid y Petocz, 2002) puesto que hace alusión a la comprensión, interpretación y dotar de sentido a los datos, la exploración de las diferencias entre los datos y el uso de esas relaciones para esbozar conclusiones acerca de los mismos. Mantiene una aproximación en la aplicación de la Estadística pero en situaciones concretas de clase o dentro del contexto exclusivamente académico, basado en ejercicios tomados del libro de texto.

Las respuestas de Alicia indican una clara consciencia del material conceptual y la interpretación. Se refiere a la Estadística en términos de habilidades técnicas, conocimiento de hechos y comprensión de los conceptos estadísticos presentados en clase (Gordon, 1998). Según Gordon, en esta concepción se percibe la estadística como la interpretación y comprensión de un conjunto de problemas y es vista en términos de obtención de información para reunir la exigencia de evaluación como asignatura. 
Esta concepción (Reid y Petocz, 2002) le lleva a mostrar a los estudiantes un significado extrínseco de la Estadística, es decir, una percepción de que el trabajo profesional es relativo a los objetos de la disciplina. En este sentido, los estudiantes perciben cómo a través de la Estadística se explora y evalúa el significado de un conjunto de datos. Se muestra una visión limitada de que el trabajo profesional simplemente existe y que la Estadística es ajena a la experiencia del estudiante, se visualiza como una asignatura que "se ve por fuera" de la profesión y no como una habilidad o competencia que le servirá en el ejercicio profesional. Esto conlleva a que los estudiantes creen que sólo los especialistas en Estadística pueden saber de ella, y necesitan suayuda en las situaciones que la profesión lo requiera. Comúnmente se identifica cuando escuchamos expresiones como "no te preocupes, no serás experto" o bien, "no tienes que saber Estadística, recurre a un especialista y listo".

Por otro lado, la concepción de Alicia sobre el aprendizaje de la Estadística transita entre aplicar (los métodos estadísticos) y relacionar (la teoría con la práctica) (Concepción C y D de Petocz y Reid, 2002). Considera que para que el alumno aprenda es necesario que sea capaz de relacionar la teoría y la práctica. Utiliza los ejercicios para ayudar a comprender la teoría de la Estadística y viceversa. No obstante, aún cuando habla de "aplicaciones" estas se reducen a actividades prácticas (ejemplos, revisar resultados y obtener respuestas correctas) que desarrollan la comprensión de la asignatura, y no situaciones de la vida real con bases de datos reales.

Por consiguiente, Alicia demuestra una concepción sobre la enseñanza de la Estadística centrada en relacionar conceptos estadísticos y guiar el aprendizaje (Petocz y Reid, 2002) caracterizado por relacionar los conceptos estadísticos, clarificando, explicando, aclarando dudas, especialmente en situaciones inusuales o diferentes, e intentando hacer conexiones con las áreas del curso. Esta concepción incluye: a) proporcionar materiales a los estudiantes, motivar y presentar una clase lógicamente bien estructurada, así como b) proporcionar actividades, como ejercicios y lecturas, y ayudar con el trabajo de los estudiantes.

La Figura 5.2 resume la relación entre estas concepciones. Observamos que existe relación entre la manera como concibe la Estadística (con énfasis en el análisis de datos), intentando establecer la relación teoría y práctica, explicando los conceptos estadísticos, clarificando y aclarando dudas, proporcionando materiales a los estudiantes en una clase lógicamente bien estructurada.

Alicia sostiene una concepción hacia la Estadística centrado en la definición de conceptos, el cálculo y la elaboración de ejercicios o actividades encaminadas a los procesos exclusivamente, desligado del análisis conceptual y de la toma de decisiones en su uso (ICMI/IASE, 2006). 


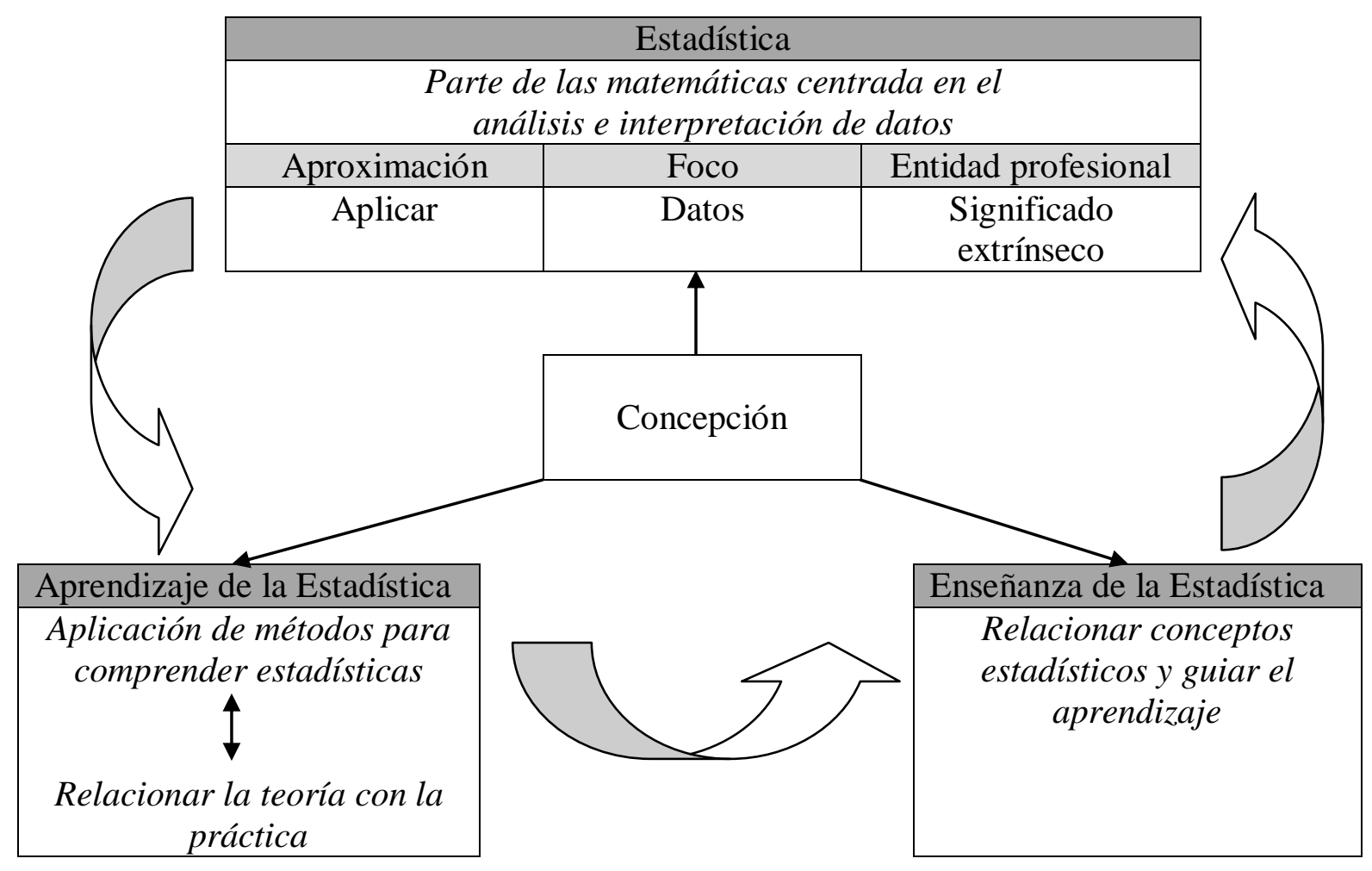

Figura 5.2. Concepciones de Alicia sobre la Estadística, su aprendizaje y su enseñanza, con base en Reid y Petocz. (2002) y Petocz y Reid (2002)

En otras palabras, la Estadística se enseña formalmente, con pocas aplicaciones reales (Meletiou, 2003, en ICMI/IASE, 2006, p.2), consistiendo muchas veces, en realizar cálculos o demostrar teoremas matemáticos con poca oportunidad de diseñar experimentos, analizar datos o conectar la Estadística con el proceso general de indagación. Como consecuencia, los estudiantes finalizan la universidad con escasa comprensión de los principios básicos que subyacen en el análisis de datos, lo que explica muchos de los problemas que encuentran en el uso posterior de la estadística en su vida cotidiana o profesional (ICMI/IASE, 2006).

\subsubsection{Concepciones sobre la representación gráfica, su aprendizaje y enseñanza}

Para la identificación de la concepción tanto de la representación gráfica, de su aprendizaje, como de la enseñanza, se seleccionaron aquellos episodios en que fueron mencionadas durante la investigación.

Sobre el significado de la representación gráfica. Las respuestas incluidas en este apartado son las siguientes: 
E1.CA.88: un gráfico a simple vista es para que te des una idea global de lo que está pasando

E1.CA.88: tenía que ver el hecho de que estuviera bien tu escala de medición

E2.CA.07: debe dejar clara para la persona que esté viendo el gráfico la información

Cu.CL.3a.1: entiendan que en una representación sus gráficos deben ser claros y entendibles para el lector

E2.CA.72: ellos se van a ver como lectores en un momento dado con esta información. Ver si para ellos con este diagrama está clara la información que les están dando.

Podemos apreciar que Alicia tiene una concepción de la representación gráfica como técnica de graficación (Concepción 1, ver sección 4.6.4), centrada en la construcción de gráficos y orientada a que los alumnos tengan particular cuidado en incluir y analizar los componentes estructurales del mismo, o bien, los criterios técnicamente definidos para su construcción. Sólo utiliza gráficos descriptivos, como los de barras, circular, pictogramas y uno analítico como el histograma.

Sobre el aprendizaje de la representación gráfica. Se puede apreciar que el desarrollo cognitivo que espera conseguir en sus alumnos está en un nivel de comprensión gráfica de leer datos y leer entre datos (Curcio, 1989), centrado en la lectura literal del gráfico, extraer información elemental y en la interpretación de los datos en el gráfico. de la RG:

Ejemplos de las respuestas listadas por Alicia sobre su concepción del aprendizaje

E1.CA.105: [se aprende mejor la RG] dando cuenta para qué les va a servir el hecho de tener ordenados sus datos, de tener una presentación digamos gráfica o de ordenar sus datos

E1.CA.105: [se aprende mejor la RG] tomando en cuenta de que no es precisamente para ellos sino que a lo mejor van a dar a conocer un resultado

E1.CA.66: [propósito] puedan saber cuál es el tipo de representación que más se apega al problema específico

E1.CA.66: [propósito] si ya se tiene la representación, que ellos puedan deducir y saber de qué se trata esta representación

E1.CA.107: [responsabilidad el alumno] De participar en clase, de estar presente en la clase, de hacer los ejercicios, de preguntar, de no conformarse con lo que uno le está diciendo

E1.CA.107: [responsabilidades del alumno] que se preocupe por estar buscando, preguntando, pidiendo más ejercicios.

E1.CA.24: [responsabilidades del alumno] que haya disposición por parte de los alumnos 
Según la clasificación de Garfield (2002), sostiene una concepción del aprendizaje de la RG vinculada con el desarrollo de la alfabetización estadística en su fase inicial, lo cual supone conocimiento/comprensión y uso del lenguaje básico y de las herramientas de la Estadística y de símbolos estadísticos; conocimiento y uso de técnicas básicas de graficación para comprender la información estadística; organizar datos, construir y presentar tablas y trabajar con diferentes representaciones de datos; identificar datos categóricos y numéricos, así como identificar y comprender las escalas de medición. No obstante, le concede poco o nulo valor a comprender información presentada en un típico gráfico estadístico de distribución (ej. de puntos, histograma y de caja), identificar algunas formas comunes de distribución (ej. normal, sesgadas, bimodal, uniforme), distinguir entre un gráfico de barras y serie de tiempo de los histogramas, y comprender los términos relacionados con la distribución.

Para Alicia aprender RG está íntimamente relacionado con construcción de gráficos, de tener "excelentes" gráficos cumpliendo todos los criterios técnicos, y que puedan interpretar (a partir de los propios datos). Le concede mucho peso a que el alumno participe en clases, se preocupe por su propio aprendizaje y esté dispuesto a aprender. No obstante, piensa y sabe poco sobre las dificultades que éste tiene sobre la RG.

Según la clasificación de Aoyama (2006 y 2007) busca desarrollar la lectura básica del gráfico, en la cual los estudiantes puedan leer valores y tendencias en gráficos, pero no pueden explicar significados contextuales de tendencias o sus características, y no pueden contextualizar los eventos presentados.

Sobre la enseñanza de la representación gráfica. Sobre la enseñanza de la RG, Alicia manifestó una concepción centrada en definir, explicar y dar algunos ejemplos de gráficos, sin profundizar en la interpretación de los mismos. Se caracteriza por proporcionar y solicitar ejercicios específicos, principalmente de construcción de gráficos, utilizando un muy reducido número de recursos para su enseñanza (ej. revisión de tareas en clases y pizarra). Enfatiza en la identificación del tipo de variables y escalas de medición.

Un extracto de las afirmaciones fueron:

E1.CA.82: [de la evaluación] algunos ejercicios en clase en donde tenían que hacer, desde sus distribuciones de frecuencias, luego algunas gráficas, manejamos histogramas, mmm... algunos pictogramas

E1.CA.82: [de la evaluación] les pedí ejercicios en donde les daba algunos datos y tuvieran que hacer sus distribuciones y sus gráficas

E1.CA.103: al revisar sus tareas, sus ejercicios es donde me doy cuenta si ya entendieron, por lo que responden o cómo responden

E1.CA.104: pasarlos a la pizarra con un ejemplo específico: de que hagan algún diagrama

E2.CA.03: damos la definición del gráfico y decimos "un gráfico consta de este..."

E1.CA.50: explicar y dar ejemplos 
E1.CA.67: básicamente tratamos de trabajar con algunos ejemplos específicos

E1.CA.38: hago énfasis en el caso de los histogramas en cuanto a la escala que están manejando

E2.CA.61: soy impositiva en ese aspecto de que les digo "esto es para tal y esto es para tal"

E2.CA.62: estaba viendo qué gráfico iban a utilizar y si se dieron cuenta por qué, pero... yo ya les había dicho de qué forma y como que ellos iban a responder

E2.CA.62: les di información con distintas variables y les pedía que hicieran los gráficos

E2.CA.38: hago énfasis en el caso de los histogramas en cuanto a la escala [de los ejes y la interrupción de los mismos] que están manejando

E2.CA.39 de los ejercicios en donde están sacando su distribución de frecuencias, les pido que hagan algún gráfico

E2.CA.39: hagan todos los gráficos sin ver cuál es mejor o cuál se prestaría más para ese tipo de información

E2.CA.40: Sólo trabajé con el histograma ... a partir de ahí tienen que dar una distribución por ejemplo, de frecuencias y obtener sus medidas centrales o de dispersión a partir de ese gráfico

E2.CA.61: por lo general trabajo con las definiciones y digo "bueno con estas variables utilizamos esto y con tales variables este tipo de gráficas"

E2.CA.70: Darle tres tipos de variables, por ejemplo, de las numéricas que sean algunas discretas y unas continuas, y que me hagan un gráfico sin decirles específicamente cuál

E2.CA.97: básicamente (vuelvo a lo mismo) el tipo de problema [que vemos] es, de cierta información, que hagan el histograma pero no analizamos profundamente

E2.CA.120: [en una ocasión] trajeron sus revistas o sus periódicos en donde les pedía que determinaran qué variables se estaba dando y que me explicaran que es lo que se estaba representando y que se estaba midiendo

Alicia señala que nunca ha tomado un curso sobre enseñanza de la Estadística y que enseña como "siente" o cree que debe ser, sin saber si lo está haciendo bien (E1.CA.16).

En resumen, como se aprecia en la Figura 5.3, la concepción que tiene Alicia sobre la RG se ubica en la primera de cinco tipos. Está centrada a la identificación de los elementos del gráfico yla forma como aborda la enseñanza es bajo una modelo centrado en un estilo tradicional (Moreno y Azcárate, 1997) de definir, explicar y dar ejemplos.

La concepción sobre la RG de Alicia es consistente con su concepción hacia la Estadística. Mantiene el mismo estilo tradicional, cuyo énfasis es el aprendizaje de conceptos, el análisis de ejemplos y la práctica de ejercicios; con una enseñanza basada en explicaciones y ejercicios. 


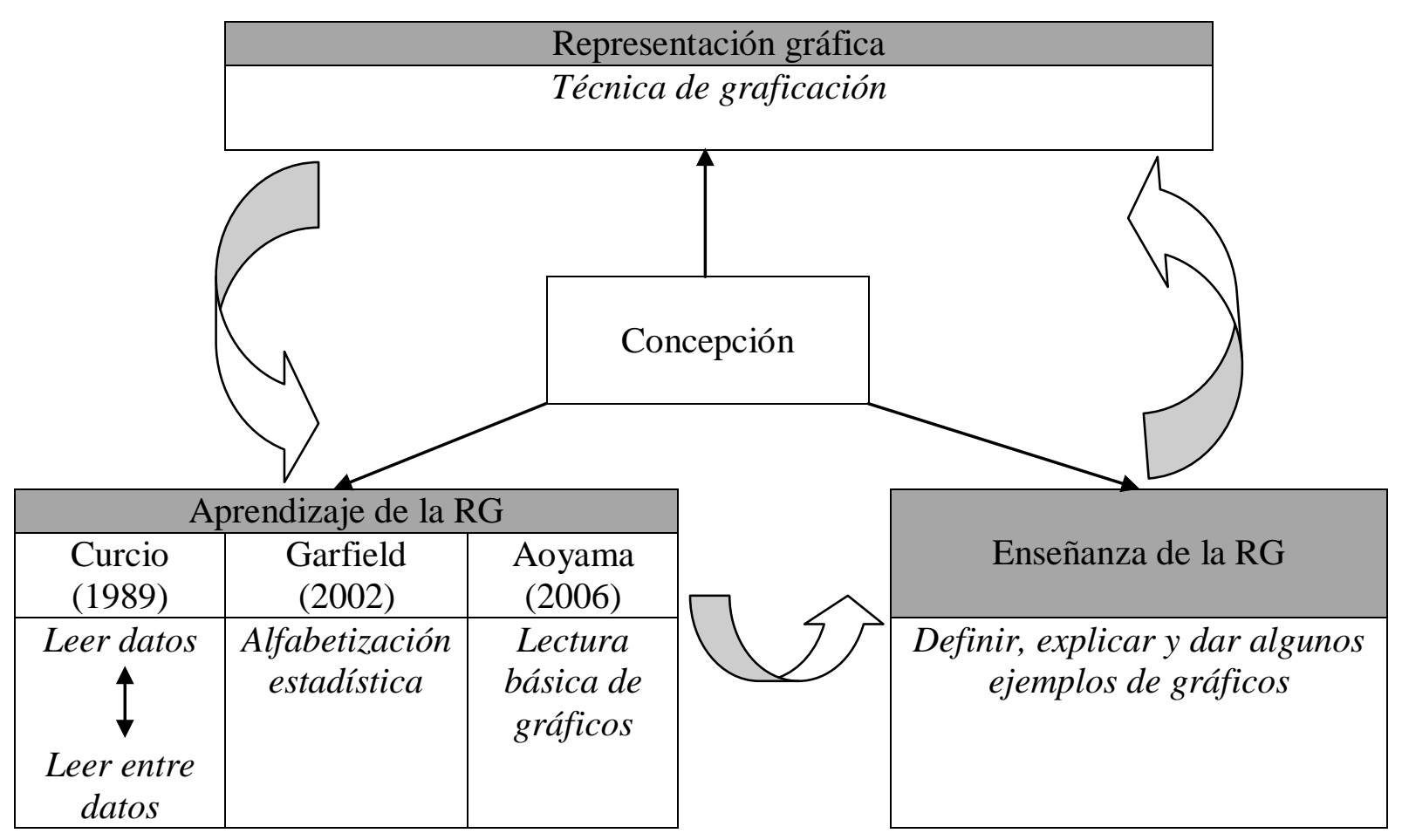

Figura 5.3. Concepciones de Alicia sobre la representación gráfica, su aprendizaje y su enseñanza

A partir de estos análisis consideramos que Alicia asume que lo esencial del aprendizaje de la RG es sólo leer información a partir del gráfico, construirlos identificando los componentes estructurales del mismo. Esta concepción contradice lo que autores como Friel, Bright y Curcio (1997) recomiendan sobre el aprendizaje de la RG, que es explorar la naturaleza de los datos de tal modo que ayude a comprender mejor el uso y lectura del gráfico, presentando gráficos diseñados a partir de los datos, explorando su uso en una variedad de contextos y relacionando éstos no sólo con la construcción del gráfico o con una simple extracción de datos para la lectura de gráficos (sentido gráfico).

Por otra parte, observamos que Alicia centra su atención en el análisis de los componentes estructurales del gráfico (armazón, especificadores, etiquetas y fondo), haciendo escasas alusiones al propósito del gráfico. No obstante, deja a un lado otros tres factores críticos que influyen en la comprensión gráfica: las características de las tareas (descodificación visual del gráfico, taxonomía para analizar las capacidades a desarrollar en las tareas sobre graficación, el contexto), las características de la disciplina (tipo y tamaño de datos y complejidad gráfica) y las características de las personas a quienes está dirigido el gráfico (Friel, Curcio y Bright, 2001).

Por último, desconoce los avances en torno a su aprendizaje y su enseñanza como los trabajos de Monteiro y Ainley (2003) y Aoyama (2006) sobre la incorporación y 
análisis de media graph; el análisis de datos a través de los contexto de investigación y de lectura de Gal (2002), entre otros.

\subsubsection{Conocimiento del currículo}

Otra dimensión que se exploró fue el conocimiento del currículo de la asignatura de Estadística y específicamente de la representación gráfica (B-III según el SDI). Primero nos centramos en analizar lo que conoce y utiliza del currículo de Estadística, es decir, acerca del propósito y los objetivos de aprendizaje, de los contenidos, de las estrategias específicas de enseñanza, de la forma de evaluar, de la bibliografía y los materiales (ej. textos, audiovisual, calculadora, internet, software). Posteriormente, el eje central del análisis fue el conocimiento que tiene Alicia del currículo específico del tema de la representación gráfica.

Esta sección se organizó en dos apartados: primero se presenta el análisis de los conocimientos que Alicia manifestó sobre el programa de Estadística, y segundo, el análisis puntal sobre el conocimiento del currículo de la representación gráfica.

\subsubsection{Del programa de la asignatura de Estadística}

En cada uno de los subapartados siguientes se describe el conocimiento de Alicia acerca del programa de Estadística comparándolo con el programa correspondiente (ver Apéndice C). La información se ha organizado en cuatro subapartados:

- Objetivos y propósitos

- Contenidos

- Actividades instruccionales

- Criterios de evaluación

Objetivos y propósito. Alicia considera que la Estadística es importante para los estudiantes de Educación dado que necesitan manejar, obtener datos y sacar conclusiones de la información que se trate:

...el manejo de esta información desde luego que tiene que hacerlo de la mejor manera, tiene que tener un buen uso de esta información y no sólo manejarla bien, sino también cómo obtener esa información. Entonces en ese sentido creo que es bastante útil. Además de que... cómo obtener la información, cómo manejarla y las conclusiones que puedan obtener con esta información" (E1.CA.51 y 52)

Para ella el propósito de la asignatura de Estadística es lograr que los estudiantes de Educación entiendan los conceptos, comprendan para qué les servirán y cómo les van a servir (E1.CA.53):

...primero que tengan conocimiento acerca de lo que es la Estadística y los conceptos que se manejan en Estadística. Primero que los conozcan [los conceptos], en algunos casos que los puedan reconocer, y en otros casos que puedan aplicar estos conocimientos (E1.CA.54 y 55)

... un mejor entendimiento de lo que es la Estadística y la buena aplicación al menos de las partes que considero más importantes (E1.CA.63). 
Estas "partes" que hace mención, se refieren a los temas de muestreo, estimación y prueba de hipótesis:

Siento que es fundamental que hagan bien su muestra y que no se vayan con la finta [idea equivocada] de no hacerlo bien, porque ya de ahí no van a tener resultados satisfactorios... que con su muestra sepan resumir su información, que sería lo que es Estadística descriptiva y que puedan hacer buenas estimaciones, y desde luego que puedan hacer una... tomar alguna buena decisión a la hora de hacer sus pruebas de hipótesis (E1.CA.64 y 65).

Al contrastar sus respuestas con el objetivo de la asignatura de Estadística observamos que existen algunas diferencias conceptuales importantes:

Objetivo de aprendizaje de Estadística: Utilizar la Estadística descriptiva e inferencial en la interpretación de información obtenida de una investigación educativa (Pro.CA.01).

Al parecer, Alicia le da un mayor valor al conocimiento y significado de los conceptos estadísticos con algunas aplicaciones; sin embargo, no hace alusión al tipo y características de éstas ni tampoco hizo alusión al uso de la Estadística aplicada a la Investigación Educativa. Del análisis de los materiales que entregó (ej. Mat.CA.04, Eje.CA.08, 11 y 15 y Ncu.CA.04) se desprende que por "aplicaciones" entiende el uso de los conceptos a través de la práctica de ejercicios con las siguientes instrucciones: elaborar una tabla y distribución de frecuencias, construir el gráfico (de barras o histograma) y excepcionalmente algunas preguntas de leer datos (ej. ¿cuántos alumnos respondieron D (casi siempre)?, ¿qué proporción de alumnos optó por $B$ (raras veces)? o ¿entre cuántos valores se encuentran todos los datos?). Se encontraron algunas variaciones de estas "aplicaciones", por ejemplo: calcular y construir el intervalo de confianza, probar o aceptar una hipótesis o bien, calcular el tamaño de la muestra que debe usarse en un problema. No se encontró evidencia de otro tipo de aplicaciones.

Contenidos. Sobre el valor que Alicia concede a los contenidos estadísticos, en repetidas ocasiones expresó que centra su atención en los temas de medidas de tendencia central y de dispersión, el muestreo y la inferencia Estadística y no tanto en gráficos o tablas. Inicialmente no fue capaz de justificar su respuesta, aunque después dijo que por orden de importancia. La importancia está relacionada con la idea de que los estudiantes se tienen que enfrentar a situaciones reales donde tengan que poner en juego sus conocimientos y sepan qué hacer y esos temas son fundamentales. Por ejemplo, sobre el tema de muestreo:

que sepan exactamente ¿cómo obtener su muestra? Siento que es fundamental que hagan bien su muestra y que no se vayan con la finta [idea equivocada] de no hacerlo bien, porque ya de ahí no van a tener resultados satisfactorios. Entonces, que sepan muestrear bien, que con su muestra sepan resumir su información, que sería lo que es Estadística descriptiva y que puedan hacer buenas estimaciones, y desde luego que puedan hacer una... tomar alguna buena decisión a la hora de hacer sus pruebas de hipótesis (E1.CA.64- 65)

Justifica además su relevancia por las preguntas que hacen los alumnos al enfrentarse a una investigación o proyecto. 
Se considera experta en el dominio de contenidos referentes a "la parte de Estadística descriptiva, y en lo que se refiere digamos a estimación de parámetros, intervalos de confianza" (E1.CA.14).

Actividades instruccionales. El programa de Estadística (Pro.CA.04) sugiere para cada unidad diversas estrategias de enseñanza. En total son nueve las unidades que deben cubrirse en 40 sesiones de hora y media cada una (60 horas). A casi todas las unidades se le asigna un promedio de 4 sesiones, excepto a la unidad de Pruebas Paramétricas que requiere 8 sesiones. Entre las estrategias de enseñanza que se sugiere que use el profesor, en esas nueve unidades están la exposición y la solución de ejercicios indicándose que la exposición debe estar acompañada de un interrogatorio por parte del profesor (MTC). En las cuatro primeras unidades se sugiere que se realice trabajo en pequeños grupos (Introducción, Tablas y Gráficos, MTC y MD); en cinco unidades se incluye el análisis de casos estadísticos en investigación social (Introducción, Inferencia Estadística, Prueba de Hipótesis, Pruebas Paramétricas y Reporte de Resultados) y sólo en dos unidades aparece la elaboración de una práctica (Introducción y Prueba de Hipótesis).

Alicia conoce y utiliza únicamente tres estrategias: definir, presentar ejemplos y dar explicaciones (utilizando el interrogatorio). Estas dos últimas sugeridas en el programa de la asignatura. Esto es coherente con la manera habitual de impartir sus clases, así como con los ejemplos que proporcionó en diversas ocasiones. Aún cuando el programa de la asignatura sugiere el uso de análisis de casos estadísticos en investigación social y la elaboración de una práctica, Alicia no utiliza estas estrategias.

Criterios de evaluación. Sobre las formas de evaluar el aprendizaje, Alicia utiliza dos, una de ellas consiste en la realización de ejercicios:

Mira, por lo general les pido trabajos, ejercicios. Básicamente son una serie de problemas en los que tienen que ir resolviéndolos con distintos grados de dificultad (E1.CA.79)

Así, está al tanto de lo que hacen en clase los estudiantes, hace pensar a los estudiantes, e incita a que pregunten.

...cuando los dejo en el salón de clase... me interesa estar al pendiente de lo que están haciendo. Que cuando lo estén haciendo, no sé en algunos casos, siento que planteo problemas de tal forma que les haga pensar, de que les mueva un poco el...de lo que ya sabían y pregunten. Bueno qué preguntan y tratar de que entiendan ese pues ciertos problemas específicos (E1.CA.84 y 85)

Otro instrumento de evaluación son los exámenes escritos. Se trata de pruebas escritas que contienen de 4 a 6 ejercicios en uno o dos folios y el estudiante debe responder cada uno de ellos en folios aparte. Los ejercicios de los exámenes (Exa.CA.01 y 02) están centrados en el cálculo (ej. medidas de tendencia central, curtosis y sesgo, porcentajes, tamaño de muestra, probabilidad) y la construcción de algunos gráficos (ej. distribución de frecuencias, histograma y barras), así como intervalos de confianza. Ver ejemplo Figura 5.4 . 


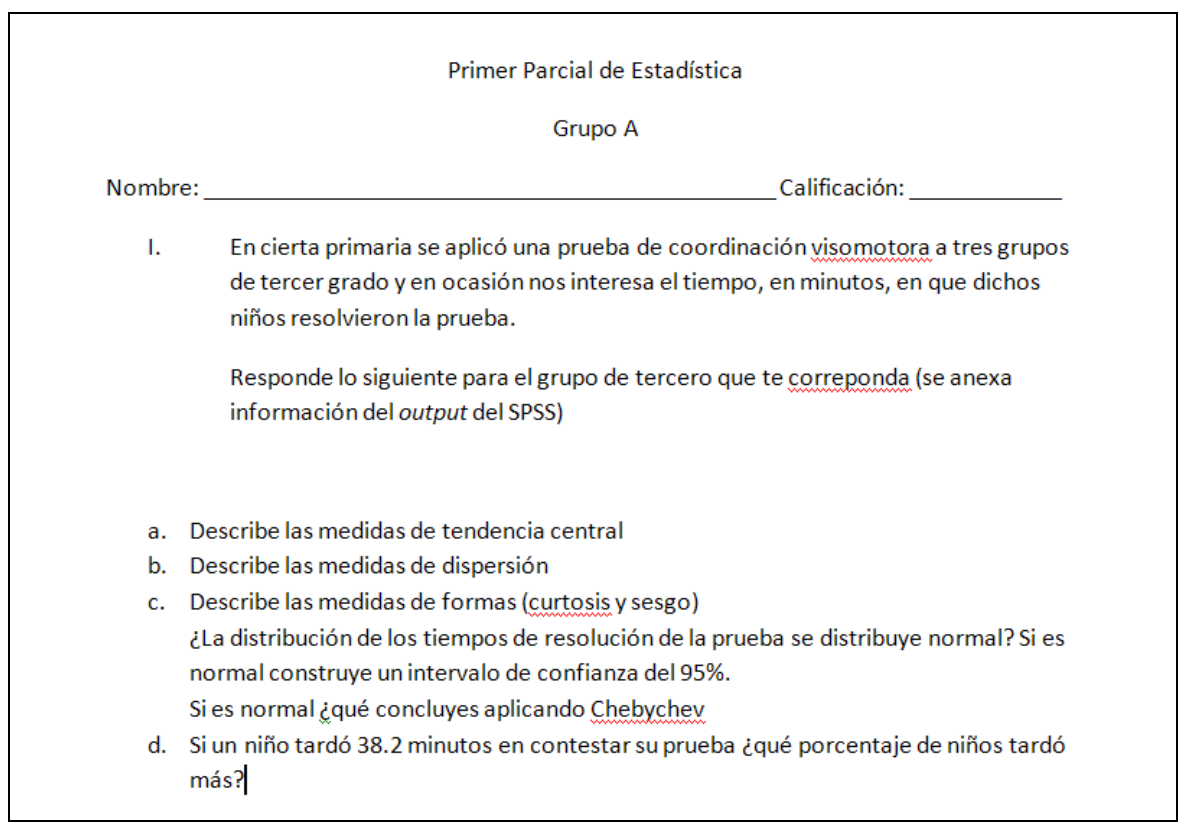

Figura 5.4. Ejemplo del tipo de ejercicios en los exámenes de Alicia (Eje.CA.01)

De los instrumentos de evaluación que sugiere el programa de Estadística (Pro.CA.03), se la asigna un 50\% de la calificación total a las pruebas escritas, un $20 \%$ a las tareas, ejercicios y participación y un $30 \%$ a un trabajo integrador. Alicia no hace alusión ni utiliza como instrumento de evaluación el trabajo integrador, aunque en otro momento de la entrevista Alicia reconoce que sí se debería utilizar:

[Está pensando] Bueno ahí creo que no sería sólo haciendo ejercicios ya planteados sino que si ellos pudieran hacer un trabajo en el que tuvieran que hacer ya Estadística, es decir, si se tuvieran que enfrentar al problema de hacer, digamos una pequeña investigación en la que tengan que recabar la información, los datos. Desde ahí, y que se vayan dando cuenta para qué les va a servir el hecho de tener ordenados sus datos, de tener una presentación digamos gráfica o de ordenar sus datos, tomando en cuenta de que no es precisamente para ellos sino que a lo mejor van a dar a conocer un resultado. Entonces siento que sí sería mucho mejor que pudieran estar trabajando en esto (E1.CA.105)

Sin embargo esto resulta complicado por el tiempo reducido que tiene para cubrir el programas y termina "poniendo ejercicios y ejercicios", pero reconoce que sería mucho mejor que los estudiantes se enfrenten "a tener que hacer Estadística" (E1.CA.105).

Como podemos darnos cuenta, el conocimiento que tiene Alicia del currículo de Estadística tiene estrecha relación con sus concepciones. Del objetivo del programa hace énfasis en la comprensión de conceptos estadísticos y someramente alude al para qué y cómo le servirán al estudiante. Deja a un lado las aplicaciones de la Estadística en el contexto de la Educación aunque reconoce que debería solicitar un proyecto de investigación ("pequeña investigación") donde el alumno le encuentre sentido a la asignatura. Nuevamente subraya el valor de los ejercicios prácticos para mostrar o enseñar las diferentes modalidades de la resolución de problemas de carácter más bien rutinario. 
Habla de una estadística aplicada a la profesión en el futuro, dejando la responsabilidad al estudiante para que sea él mismo quien le encuentre uso y sentido en su trabajo o profesión. Minimiza el valor de temas de carácter descriptivo (ej. tablas y gráficos) y le otorga más peso a temas como muestreo, estimación y pruebas de hipótesis. Evalúa principalmente a través de exámenes escritos y usa el dictado de definiciones, explicaciones y ejemplos como estrategias más frecuentes.

Alicia tiene un limitado conocimiento del currículo de Estadística por varias razones: a) el programa que utiliza resulta obsoleto puesto que tiene más de diez años , b) su concepción de la Estadística, su aprendizaje y enseñanza, c) el desconocimiento del campo de la educación estadística (ej. objetivos, propósitos, recomendaciones didácticas, formas de evaluar, materiales o recursos). Por ejemplo, no menciona los fines principales de la enseñanza de la Estadística: a) comprender y a apreciar el papel de la estadística en la sociedad conociendo sus diferentes campos de aplicación y el modo en que la estadística ha contribuido a su desarrollo, y b) comprender y valorar el método estadístico, es decir, lo que la estadística puede responder y la forma básica de razonamiento, su potencia y limitaciones (Batanero, 2000 y 2001a). Tampoco incorpora en su enseñanza algunas de las recomendaciones como las que emitió reporte GAISE$^{9}$ sobre cómo debe organizarse un curso introductorio de Estadística, pero que pueden aplicarse a cualquier curso independientemente del nivel escolar:

1. Enfatizar la alfabetización estadística y el desarrollo del pensamiento estadístico.

2. Usar datos reales.

3. Hacer hincapié en la comprensión conceptual más que mero conocimiento y procedimientos.

4. Sostener un aprendizaje activo en el aula.

5. Usar la tecnología para desarrollar conceptos y analizar datos.

6. Usar evaluaciones que mejoren y evaluar el aprendizaje de los estudiantes.

Estos y otros avances en materia de currículo no fueron considerados en los argumentos de Alicia.

\subsubsection{De los objetivos y contenido de aprendizaje de la representación gráfica}

El conocimiento del currículo sobre la representación gráfica (RG) se presenta organizado de la siguiente manera:

- Significado, objetivos, propósitos y expectativas

- Contenidos

- Actividades instruccionales

- Materiales para la enseñanza

- Evaluación del aprendizaje

\footnotetext{
${ }^{9}$ GAISE (Guidelines for Assessment and Instruction in Statistics Education, GAISE por sus siglas en inglés) publicado por la American Statistical Association (ASA, 2007)
} 
Significado, objetivos, propósitos y expectativas. El significado que le otorga Alicia a la representación gráfica está relacionado con la construcción del gráfico, su claridad y comprensión para el lector (Cu.CL.3a.1)

Al hablar con Alicia sobre el objetivo de aprendizaje que espera lograr con sus estudiantes sobre el tema de la RG expresó:

... Bueno que si ellos tienen a la mano los datos puedan saber cuál es el tipo de representación que más se apega al problema específico, por un lado; y por otro, que si ya se tiene la representación, que ellos puedan deducir y saber de qué se trata esta representación (E1.CA.66)

\section{Esto coincide con lo establecido en el programa de Estadística (Pro.CA.02):}

Unidad 2. Tablas y gráficas Estadísticas

Sesiones: 4 (de 1.5 hrs., c/u)

Objetivo: Elaborará e interpretará tablas y gráficas de acuerdo a las características de los datos Categoría de aprendizaje: Clasificación ${ }^{10}$

Tablas

- Diferentes tipos de tablas (simple y cruzadas) con las que se pueden organizar frecuencias, porcentajes y otros parámetros

- Formas de redacción de conclusiones a partir de la interpretación de la tabla

Gráficas

- Diferentes gráficas de barras, polígono de frecuencias, ojiva, histograma, de pareto, circular, etc.

- Interpretación de los datos de las gráficas

Se constató que el programa le dedica poco tiempo al tema de la RG (cuatro sesiones de hora y media cada una). Además, Alicia no le dedica mucho tiempo a objetivos que van más allá de definir o identificar las características y de elaborar (construir) gráficos:

Creo que no hicimos algún ejercicio de ese estilo [C-1] de que ellos eligieran cuál es el que se... Tan sólo las ventajas o desventajas de cada uno dependiendo de hacia qué estuviera dirigido. Básicamente se vio las definiciones, se hicieron ejemplos, pero no puntualizamos este hecho de cuál sería mejor en cada caso. Al menos yo no trabajé ese punto (E2.CA.27)

Alicia manifestó en varias ocasiones que su principal interés era cubrir el programa de la asignatura, por lo que ella se centraba principalmente en presentar a los alumnos tres tipos de gráficos: barras, histograma y circular, dando la definición y las características de cada gráfico, exponiendo algunos ejemplos y finalmente, construyéndolos según los componentes estructurales del mismo. De este modo, Alicia cumple lo que dice el programa en cuanto a mostrar los diferentes gráficos y luego dibujarlos o elaborarlos:

(mmm) No. Lo que pasa es lo que te comentaba, como que de cierta forma creo que ya entendieron bien el gráfico de barras y sólo les digo "a ver dibujen o hagan un gráfico de barras" (E2.CA.71)

\footnotetext{
${ }^{10}$ En el modelo de Marzano, et al (1992) el nivel de clasificación se refiere a agrupar cosas en categorías definidas con base en sus atributos, y se encuentra en la Dimensión 3 denominada Extensión y Profundización del Conocimiento.
} 
Un dato importante que refleja el significado que tiene Alicia de la RG, se obtuvo al contestar el C-3 del cuestionario, una situación hipotética en la que el profesor utiliza un ejercicio para que el estudiante escriba el objetivo del uso de un histograma en un contexto, así como que establezca alguna conclusión y recomendación a partir del gráfico y que sugiera una forma mejor para representar los datos. El inciso $3 a$ le preguntó a Alicia: ¿Cuál cree Ud. que es el objetivo del que ha surgido este gráfico? Su respuesta fue la siguiente:

El objetivo es que los alumnos entiendan que en una representación sus gráficos deben ser claros y entendibles para el lector (Cu.CA.3a.1)

Según los objetivos de pensamiento estadístico de la representación gráfica (apartado 2.5.2), un ejercicio como el C-3 implica desarrollar en el estudiante la selección e interpretación del gráfico en un contexto educativo, escribir conclusiones y recomendaciones a partir del gráfico, criticar y evaluar la selección del gráfico, identificar posibles errores conceptuales en su construcción y tomar decisiones a partir del contexto y del gráfico, sin embargo, Alicia simplemente se centró en que el estudiante debía valorar si el gráfico era o no claro y el significado de los componentes estructurales del gráfico (ej. ejes y frecuencia). Este énfasis guarda estrecha relación con lo que establece el programa y los objetivos de Alicia por lo que no desarrolló niveles cognitivos de RG más allá de la alfabetización Estadística.

Durante el análisis de las situaciones-problema (C-1, C-2, C-3, C-4), en varias ocasiones se le preguntó a Alicia sobre el objetivo de cada caso o bien, su utilidad. Para Alicia los casos presentados permitían desarrollar principalmente en sus alumnos la habilidad para seleccionar, evaluar y criticar un gráfico, y analizar los errores conceptuales. Sin embargo, en la planificación e impartición de sus clases se centra en que el alumno "se dé cuenta" de la información del gráfico, identifique los componentes estructurales del gráfico, y analice los elementos para que lo reconstruyan de forma que quede claro lo que se desea plasmar en él para los lectores. Su énfasis está, por lo tanto, en los elementos que debe tener un gráfico, su construcción y la claridad.

Contenidos. En cuanto a los contenidos relacionados con la RG, analizamos las respuestas a los casos del cuestionario didáctico.

- Del histograma y el tallo y hoja

En el C-1 se trataba de explorar el conocimiento que Alicia tiene del histograma y del diagrama de tallo y hoja $(\mathrm{TyH})$. Concretamente, en la pregunta la se le preguntó ¿Cómo ayudaría usted al estudiante a comprender el procedimiento para discriminar entre los gráficos anteriores? [histograma y $\mathrm{TyH}$ ], a lo que ella contestó que a través de algunas preguntas. A continuación se muestra un segmento de la entrevista donde se le preguntó sobre el significado que le da a una de las preguntas del ítem la:

E: Comentas que ellos [los estudiantes] te digan " ¿cuáles son los beneficios y las dificultades que presentan cada gráfico", ¿qué crees que te contestarían? y ¿qué te deberían contestar? 
A: Cuando me haces esa pregunta se me hace difícil porque te digo que me contestarían lo que yo quisiera que me contesten o lo que yo creo que me van a contestar. Lo que creo que debe ser correcto y no siempre es así, se me hace difícil pensar qué es lo que me van a contestar.

E: ¿Qué te deberían contestar correctamente? ¿Qué respuesta correcta esperas de ellos?

A: Pues... lo que comentábamos de que por ejemplo aquí hay un poco de pérdida de información [al referirse al histograma], de que en este caso [al referirse al TyH] si está claro cuáles son digamos las unidades o cuáles son los elementos o los datos que se están manejando...

E: ¿En cuanto a las dificultades?

A: En cuanto a las dificultades (mmm)... que por ejemplo este [el TyH] sí es un poco más explícito, pero que si tuviéramos muchos más datos, pues a lo mejor sería más difícil describirlos todos, o sea ya sería un... bastante información prácticamente serían eso, sólo que ordenada. Y que a lo mejor el histograma, esa sería una de sus ventajas de que si tenemos mayor cantidad de información si se puede resumir.

Para Alicia el histograma tiene dos características: 1) la pérdida de información, es decir, que al agruparse los datos en intervalos de clase, se "pierde" el dato ya que éste se suma a una categoría que agrupa en conjunto todos los datos que caen en esa clase, y 2) que el histograma debe usarse cuando "tenemos mayor cantidad de información", es decir, una muestra amplia de datos; sin embargo, Alicia no es más explícita en este sentido. Además, ella piensa que las barras de un histograma representan la cantidad de datos que hay en ese grupo.

Respecto al diagrama de TyH, respondió que es útil cuando se quiere mostrar, ver o "conocer los datos que se están manejando y que éstos pueden representarse en unidades y decenas que aparecen en este" (E2.CA.4). El diagrama de TyH es útil ya que los datos "...están ordenados y puedes visualizar las cantidades en las unidades en que las que estamos trabajando" (E2.CA.18).

Alicia piensa que “...a lo mejor y es suficiente un histograma para resumir la información, o si quieren ser un poco más detallados a lo mejor se quedan con el de tallo y hoja" (E2.CA.26).

- Del gráfico de barras

En el C-2 Alicia generó un conjunto de preguntas vinculadas a explorar por qué el alumno ha dado esa respuesta. Básicamente son preguntas centradas en los especificadores o los elementos que tiene el gráfico (ej. altura, variable, población y media) y cómo se identifica en el gráfico. Afirma que la clave está en la definición de la variable, que para el caso del gráfico debe ser discreta.

Lo que yo entiendo es que por ejemplo cuando trabajas con un gráfico de barras se está refiriendo a una variable que sea discreta, y en este caso no es una variable discreta ¿si? (E2.CA.58)

- Del histograma

En el histograma (C-3), Alicia vuelve a resaltar lo esencial que el alumno debe tener presenta ante una representación: los componentes y la claridad. 
... de cierta forma ellos se van a ver como lectores en un momento dado con esta información. Ver si para ellos con este diagrama está clara la información que les están dando (E2.CA.72)

Creo que deben de tener ellos bien claro lo que está representando este histograma para que puedan contestar (E2.CA.73)

[el objetivo es que] se den cuenta de que cuando se presenta la información no es precisamente para ti, si no a lo mejor es para que otras personas les quede claro lo que tú estás dando en ese diagrama (E2.CA.92)

Afirma que los estudiantes en general creen que es muy fácil comprender el histograma, pero en realidad no es así y que la clave (del C-3) es identificar y definir el tipo de variable y distinguir el tipo de porcentajes que se encuentran representados en el gráfico (E2.CA.90).

- Del gráfico de medios de comunicación impresa (media graph o print graph)

En el C-4, Alicia se centró en dos cuestiones relativas al gráfico: qué es lo que representa y la identificación de un error. Logró identificar que se representa el tiempo (en minutos) para llegar al lugar de trabajo (E2.CA.100) y el error fue que "estaba viendo los porcentajes y este... y no completan el $100 \%$ entonces creo que esa parte fue la que... dije iqué está pasando, qué falta!” (E2.CA.103).

Nuevamente resalta la necesidad primera que el estudiante tiene de saber "a qué variable se está manejando y qué estamos midiendo de la variable” (E2.CA.104).

Actividades instruccionales. Respecto de las actividades instruccionales (estrategias de enseñanza) que especifica el programa (Pro.CA.04) se sugiere que: "se mostrará cada uno de los diferentes tipos de gráficas", exposición, y en cuanto a las Tablas se sugiere la exposición, el trabajo en pequeños grupos y ejercicios.

En los siguientes diálogos se muestran las actividades que Alicia afirma utilizar cuando imparte sus clases:

E: ¿logras trabajar así en el salón de clase? (C-1)

A: Tan sólo las ventajas o desventajas de cada uno dependiendo de hacia qué estuviera dirigido, Básicamente se vio las definiciones, se hicieron ejemplos, pero no puntualizamos este hecho de cuál sería mejor en cada caso. Al menos yo no trabajé ese punto (E2.CA.27)

E: ¿trabajas alguna actividad en tus clases para hacer que el estudiante comprenda este aspecto de la interpretación, de la toma de decisiones a partir de un gráfico, de la escritura de esa interpretación? (C-3)

A: Básicamente es la definición, algunos ejemplos y algunas características por ejemplo, que el tipo de variable, de información, pero no profundizo tanto. (E2.CA.96)

Se identifican tres estrategias que utiliza para enseñar la RG: 1) exponer definiciones, 2) presentar ejemplos (en ocasiones a manera de demostración) y 3) exponer explicaciones y características del concepto. Estas estrategias coinciden con las descritas 
en el apartado anterior relativo a la enseñanza de la Estadística y coincide con la forma habitual de enseñar que ella afirmó utilizar en sus clases.

Materiales para la enseñanza. En cuanto a los recursos o materiales que conoce y utiliza Alicia, comentó cuatro: libros, revistas (o periódicos), Internet y el SPSS.

- Libros de texto

Al mencionar el uso de los libros de texto, Alicia acude a éstos para localizar ejemplos útiles para su clase:

... empiezo a ver cómo manejan o cómo abordan estos temas en los distintos libros... Trato de encontrar ejemplos o de ver que manejen Estadística, en ese caso pues con un enfoque a la Educación (E1.CA.71)

Sólo uno ${ }^{11}$ de los seis libros que utiliza (Bib.CA.01) presenta aplicaciones (ejemplos y ejercicios) a las Ciencias Sociales y a la Educación. Cuatro son de estadística matemática y uno para administradores. Por otro lado, todos los textos abordan la RG de manera muy superficial, donde se privilegia que a partir de algunos datos el estudiante organice, elabore y construya la distribución de frecuencias, o bien, el gráfico que se le indique. El programa en extenso (Apéndice C) en el tema de gráficas hace referencia al manual de estilo de publicación de la American Psychological Association (APA) $)^{12}$.

El texto de Wayne (1988) presenta la RG como técnica de graficación. Inicia el tema con definiciones, características de gráficos descriptivos y categóricos y uno analítico (el histograma), luego incluye ejemplos y posteriormente ejercicios cuyo objetivo es organizar los datos y representarlos a partir de gráficos específicos. El Manual de la APA, por su parte, menciona las características de forma que debe tener la presentación de figuras (ej. los gráficos), dando mayor valor a los elementos de edición del formato.

\section{- Revistas o periódicos}

\section{Del uso de revistas o periódicos:}

Lo que sí hice es que ellos trajeron sus revistas o sus periódicos en donde les pedía que determinaran qué variables se estaba dando y que me explicaran qué es lo que se estaba representando y qué se estaba midiendo. Esa actividad fue la que hicieron, trajeron sus revistas y dijeron 'esto se está midiendo, esto se está haciendo'. Y bueno y discutieron entre 'a ver tú dices que es esto y tú crees que eso se esté midiendo o es otra cosa la que se está midiendo’ (E2.CA.120)

\footnotetext{
${ }^{11}$ Wayne, D. (1988). Estadística con aplicaciones a las Ciencias Sociales y a la Educación. Buenos Aires: GrawHill.

12 APA. (2001). Publication Manual of the American Psychological Association. Fifth edition. Washington. D.C.: APA.
} 
Esta actividad está estrechamente vinculada con la habilidad de analizar las características conceptuales de cada gráfico, sus componentes estructurales y las variables y escalas de medición, así como identificar ventajas y desventajas de cada gráfico. Alicia mencionó el uso de las revistas sólo en esta ocasión.

- Internet

En relación con el Internet, Alicia dijo que lo utiliza exclusivamente para fines de actualización del contenido y la enseñanza de la Estadística:

... el uso de Internet. Precisamente ando buscando escuelas o instituciones en donde se maneje o que trabajen con Educación y que si tienen temas de Estadística, si se da Estadística, cómo lo manejan para tener un poquito más de referencia (E1.CA.74)

Las direcciones electrónicas son principalmente de instituciones iberoamericanas que ofrecen información tanto para profesores como estudiantes en el estudio de diversos tópicos matemáticos, ya sea a nivel bachillerato o licenciatura. En las direcciones electrónicas se constató que, al igual que en los libros de textos, la RG se utiliza para la organización y presentación de un conjunto de datos (no agrupados, agrupados en tablas de frecuencia, agrupados en intervalos de frecuencia y promedios ponderados). Los ejemplos y ejercicios que se presentan no están relacionados en su mayoría con contextos de ciencias sociales o de Educación, aunque sí con contextos de la vida diaria (ej. cine, fumadores, revistas, edades teléfono, familias).

De los 42 ejercicios que se incluían en las páginas electrónicas, cinco tratan la RG, de ellos tres estaban en el nivel de leer entre datos y dos en leer más allá de los datos. Al parecer, ninguno de estos los utilizó Alicia con sus estudiantes de Educación.

\section{- Uso del SPSS}

Sobre el recurso del software SPSS ella comentó que no lo utiliza con frecuencia, más que lo que establece el programa.

No es tan frecuente [el uso de SPSS al salón de clases]. Primero estuvimos trabajando con la parte teórica. Cuando concluimos con eso entonces fuimos al Centro de Cómputo. Te estoy hablando digamos de dos semanas, pero en la parte de Estadística descriptiva. Ahora todavía no hemos visto toda la parte de prueba de hipótesis o intervalos y demás. Toda esa parte no la hemos manejado y desde luego que sí, pienso llevarlos... (E1.CA.100)

De hecho, según el programa de Estadística (Pro.CA.02), sólo se debe dedicar una sesión al final del programa al uso de SPSS y durante la entrevista Alicia manifestó que ya los había cubierto y utilizó más sesiones.

Evaluación del aprendizaje. Sobre la forma de evaluar la RG, Alicia afirma que utiliza principalmente los ejercicios: 
Hicieron algunos ejercicios en clase en donde tenían que hacer, desde sus distribuciones de frecuencias, luego algunas gráficas, manejamos histogramas, mmm... algunos pictogramas. Entonces les pedí ejercicios en donde les daba algunos datos y tuvieran que hacer sus distribuciones y sus gráficas (E1.CA.82)

Sobre el análisis de estos ejercicios se hablará en una sección posterior.

Del conocimiento que tiene Alicia del currículo sobre la RG, podemos afirmar que es igualmente limitado. La mayoría de las respuestas que da son congruentes con lo establecido en el programa de la asignatura, promueve el aprendizaje de la RG al nivel de leer datos y específicamente definir qué es cada gráfico, sus características y los elementos para su construcción. Estudia gráficos descriptivos y categóricos y sólo uno de carácter analítico (el histograma) preocupándose de cumplir con lo establecido en el programa. Se apoya en libros de texto que orientan la $\mathrm{RG}$ hacia la construcción de gráficos y hacia algunos elementos de forma para la presentación de resultados de alguna investigación. Tiene una cantidad reducida de ejercicios sobre RG, y los pocos que utiliza están a un nivel de lectura literal de datos, y en su mayoría no presentan un contexto aplicado a la profesión de Educación.

De igual forma, este conocimiento se puede explicar a partir de: a) el enfoque y características curriculares del programa de la asignatura, b) las concepciones que sobre la RG tiene Alicia, y c) el desconocimiento del contenido y estudio de la representación gráfica, más allá de los establecido en los libros de los años 80s y 90s y de considerarla simplemente como técnica de graficación.

El conocimiento que Alicia manifiesta nuevamente contrasta con las tendencias actuales sobre la RG, su aprendizaje y enseñanza. Por ejemplo, gran parte del material en que se apoya son libros de textos que hacen un gran énfasis en la matemática y que presentan una concepción obsoleta de la RG. Esto coincide con Pittenger (1995) quien afirma que todavía existen libros en los cursos introductorios de Estadística que proporcionan una revisión limitada de buenas técnicas de graficación así como nociones relativas a su selección, diseño, edición, interpretación y evaluación de gráficos. Es fundamental también tener presente que generalmente, como señala Holmes (2002 en Batanero, 2002) las lecciones de Estadística de los libros de matemáticas han sido hechas por matemáticos y carecen de aplicaciones realmente propias de la actividad estadística y los alumnos finalizan los cursos sin adquirir una competencia real para llevar a cabo una investigación estadística. Particularmente llaman la atención aquellos textos utilizados en carreras como Educación, Psicología, Antropología, Sociología, por mencionar algunos, con pocas aplicaciones originadas en datos reales inherentes a la profesión y centrados más en técnicas de graficación.

Las últimas ediciones de libros proporcionan una concepción de la RG más orientada hacia la comprensión gráfica, el sentido de los datos o el sentido crítico. Por mencionar sólo algunos, puede verse el trabajo de Moore (2000) y el de Salkind (2000), quienes incluyen preguntas que ayudan al estudiante a ir más allá de los datos y detrás de los datos. 
Otro aspecto que llama la atención es la revisión frecuente que hace Alicia de páginas electrónicas para ver direcciones particulares que muestran la RG de forma similar a cuando recibió su formación inicial y a los libros de textos que utiliza. Desconoce la diversidad de recursos y materiales on-line que le permitirían no sólo actualizarse en la Estadística y en el tema de la RG, sino tener acceso a materiales con los que se muestre una perspectiva diferente sobre la Estadística.

Como ocurrió en el análisis del programa general de Estadística, Alicia deja a un lado el desarrollo que existe actualmente en relación al aprendizaje y enseñanza de la RG empezando con la modificación del currículo escolar.

\subsubsection{Conocimiento de las estrategias y representaciones instruccionales}

Otra dimensión esencial es la relativa al conocimiento de las estrategias de enseñanza específicas usadas en las clases. A través de los diferentes instrumentos y materiales recogidos para esta investigación se identificaron, exploraran y analizaron las estrategias que Alicia conoce y utiliza en sus clases. El Cuestionario Didáctico sobre Representación Gráfica fue un instrumento que nos permitió estudiar en profundidad esta dimensión del CDC, sobre todo a partir de las situaciones-problema.

Las estrategias específicas se agruparon en cuatro tipos: 1) definiciones y explicaciones, 2) preguntas, 3) ejemplos y ejercicios e 4) instrucciones.

\subsubsection{Definiciones y explicaciones}

Alicia reconoció que, como parte de su forma habitual de dar clase, es importante presentar la definición matemática. Esto quedó confirmado en varias ocasiones en las respuestas que proporcionó en la entrevista en profundidad:

... Básicamente se vio las definiciones, se hicieron ejemplos, pero no puntualizamos este hecho de cuál sería mejor en cada caso (E2.CA.27)

... por lo general trabajo con las definiciones y digo "bueno con estas variables utilizamos esto y con tales variables este tipo de gráficas" (E2.CA.61)

Siento que la mayoría de las veces como que damos la definición del gráfico y decimos "un gráfico consta de este..." y en el caso por ejemplo del histograma, pero creo que es lo que nos falta a lo mejor profundizar o hacer más ejercicios. Creo que eso es lo que ocurre, como que damos la definición y damos por hecho que con la sola definición los alumnos ya van a entender qué es lo que está ocurriendo (E2.CA.03)

Básicamente es la definición, algunos ejemplos y algunas características por ejemplo, que el tipo de variable, de información, pero no profundizo tanto (E2.CA.96)

Como que de cierta forma doy por sentado ";ah ya lo entendieron! quedó claro con mi definición que es un histograma, ya todo el mundo sabe para qué sirve y cuando lo va a utilizar" (E2.CA.122) 
Esta afirmación se evidencia en la libreta del estudiante (Lib.CA.01) donde se muestra que se daba la definición del gráfico y seguidamente un ejemplo (ver Figura 5.5), acompañado de algunas explicaciones.

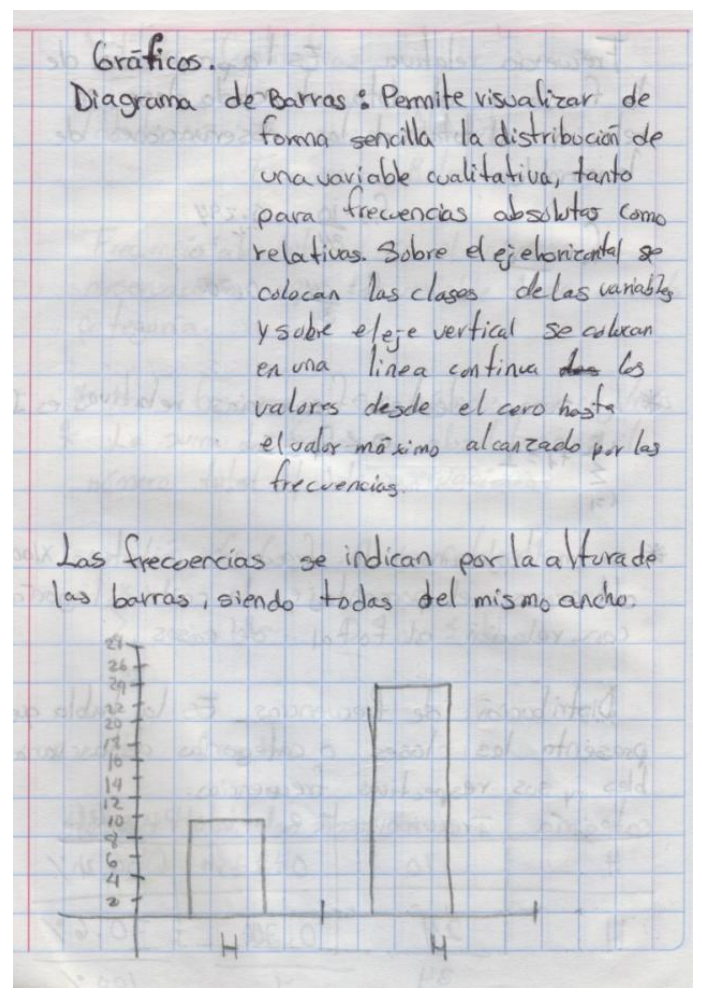

Figura 5.5. Ejemplo de definición utilizado por Alicia del tema de gráfico circular

Generalmente Alicia utiliza las definiciones en dos momentos:

1) Como cierre de un proceso inductivo. Alicia utiliza ejemplos de la vida real que conecten el tema nuevo con algo ya visto o familiar, o bien, enfatizar la importancia y utilidad del tema. Después de una explicación, la cual generalmente va acompañado de preguntas, presenta la definición matemática del concepto, a manera de síntesis o conclusión. Aquí la definición viene a finalizar un proceso inductivo en la presentación de un nuevo tema.

2) Al iniciar tema nuevo. Por ejemplo, inicia con la definición del histograma, presenta algunas de sus características, y a continuación expone los criterios para su construcción (Lib.CA.01). Del mismo modo lo hace con el gráfico circular y el de barras.

Las definiciones provienen, generalmente, de los libros textos o de las notas de curso que Alicia utiliza en sus clases y, al parecer, se las dicta a los estudiantes o las escribe en la pizarra para que las copien. 
Sus características son similares a las de la definición de la Figura 5.2: primero se indica con qué tipo de variable (ej. cualitativa o cuantitativa) está asociada esa gráfica para después describir cómo se construye (ej. ejes horizontal y vertical, valores, frecuencias absoluta y relativa) especificando la secuencia de pasos que deben seguir los alumnos.

Estas definiciones vienen acompañadas de explicaciones, donde Alicia comenta, complementa, aclara, describe y fundamenta cada característica del gráfico (C-1), por ejemplo, para qué tipo de variables (cualitativa o cualitativa, o bien, discreta o continua) es útil cada gráfico (C-2).

\subsubsection{Preguntas}

Otra de las estrategias y representaciones instruccionales que utiliza habitualmente Alicia son las preguntas. Desde las primeras exploraciones sobre sus concepciones, cuando hablaba de su forma habitual de dar clase, señaló el uso frecuente que hace de las preguntas. Durante esta investigación se descubrió que Alicia utiliza esta estrategia en dos contextos diferentes: 1) a partir de su conocimiento de la enseñanza de la $\mathrm{RG} \mathrm{y}$, específicamente de los materiales (ej. ejemplos y ejercicios) que utiliza, y 2) a partir de las situaciones-hipotéticas que se le plantearon en el cuestionario.

En el primer contexto, utiliza las preguntas como recurso para hacer pensar al estudiante y así desarrollar su razonamiento estadístico, explorar los significados que subyacen en su pensamiento e inducir a que se dé cuenta de sus concepciones erróneas sobre algunos conceptos. En este contexto, las preguntas que realiza se pueden agrupar en función de la finalidad que persigue:

\section{- Para desarrollar el razonamiento estadístico y saber si se comprendió el concepto}

[Por ejemplo] En este sentido pues están súper familiarizados con el promedio de sus calificaciones. Entonces preguntarles "bueno, cuando tú obtienes el promedio de tu calificación ¿qué significado tiene?, ¿por qué nada más manejas una sola calificación?, digamos en el transcurso de alguna materia, de ¿cómo obtuviste esa calificación?", y entonces ellos ya van diciendo "pues de [que] hubieron tantos parciales, se calificó de esta forma y luego obtenemos esa calificación eh... final", y "y por qué sólo esa calificación están considerando" (E1.CA.38)

... haciéndoles preguntas de tal forma que vayan llegando a entender la utilidad de una medida y cómo se obtuvo esa medida y qué significado tiene realmente, digamos en este caso (E1.CA.39)

- Para reforzar el conocimiento adquirido

... y hacerles preguntas que yo considero que les pueden hacer entender más el concepto o que les pueden generar alguna duda para reforzar el conocimiento (E1.CA.45)

Eso ya aparentemente ya lo saben, pero si les cambias el problema se los preguntas de otra forma o les dices que te interpreten eso que acaban de hacer, ya te dijeron que si rechazaron la hipótesis pero "¿qué significa eso?" y no te lo logran explicar, bueno algunos sí, o sea no... (E1.CA.95) 
- Cuando algo no está claro, no se ha entendido y necesita identificar un error o dificultad

Entonces cuando veo que algo está... como que nada más lo está escribiendo o lo está copiando de algún lado, entonces les voy preguntando, les voy diciendo "bueno este... por qué escribiste esto, qué es lo que vas a contestar", les voy haciendo preguntas y es como voy viendo más o menos quiénes son los que tienen alguna dificultad y que es lo que está pasando. (E1.CA.87)

En el segundo contexto, es decir a partir de las situaciones-problema, la Tabla 5.1 resumen las preguntas que se recogieron del cuestionario y de la entrevista en profundidad.

Las preguntas representan un instrumento valioso para desarrollar el razonamiento pedagógico del estudiante sobre el tópico de estudio, es decir, la aplicación y análisis del conocimiento. Con ellas Alicia busca que el estudiante desarrolle su capacidad analítica, más allá de la adquisición de definiciones (de carácter memorístico) y de los procedimientos a realizar. En las preguntas que sugiere Alicia se observa una clara intención de que los estudiantes se vayan dando cuenta, de forma inductiva, de las características de cada gráfico, de la naturaleza de los datos representados para lograr que aprendan.

RG:

Estas preguntas se agruparon en función del nivel de pensamiento estadístico de la

- explorar la interpretación de los componentes estructurales del gráfico,

- explorar las características y condiciones en la construcción de un gráfico,

- desarrollar el sentido crítico en un gráfico, y

- conocimiento propositivo para mejorar un gráfico

A continuación se describirá brevemente cada una de estos tipos de preguntas.

Más de la mitad de las preguntas (52.6\%) están orientadas a explorar la interpretación de los componentes estructurales de un gráfico que el estudiante tiene o a partir de la información de la situación-problema. Estas interpretaciones se agrupan en dos apartados: aquellas centradas en el conocimiento de los componentes estructurales del gráfico (ej. eje, intervalos, frecuencia, porcentaje) y aquellas relacionadas con el conocimiento de los datos a partir del contexto del problema. Ejemplo de estas preguntas:

¿qué significado tiene en el grafo cada uno de los ejes? (Cu.CA.3b.1)

¿qué representan los autos y sus posiciones en el gráfico? (Cu.CA.4a.4)

Poco más de un tercio de las preguntas (31.57\%) están orientadas a explorar las características y condiciones en la construcción de un gráfico. De este modo encontramos que Alicia se preocupa por saber si el alumno identifica la variable que se está estudiando, a quién estará dirigido el gráfico, las ventajas y desventajas de cada gráfico y el grado de precisión que se quiere de éste: 
Primero les preguntaría ¿cuál es la variable a estudiar? (Cu.CA.4a.1)

¿qué tan precisos quieren ser con sus gráficos? (Cu.CA.1a.3)

Tabla 5.1. Preguntas elaboradas por Alicia como estrategia para responder a casos del cuestionario didáctico sobre representación gráfica

\begin{tabular}{|c|c|c|}
\hline $\begin{array}{c}\text { C-1, ítem 1a } \\
\text { ¿Cómo ayudaría usted al } \\
\text { estudiante a comprender el } \\
\text { procedimiento para discriminar } \\
\text { entre los gráficos anteriores? }\end{array}$ & $\begin{array}{c}\text { C-3,ítem 3b } \\
\text { Usted le entregó a sus alumnos } \\
\text { este ejercicio y les solicitó que lo } \\
\text { resolvieran ¿cómo les ayudaría } \\
\text { a resolverlo correctamente? }\end{array}$ & $\begin{array}{c}\text { C-4, ítem 4a } \\
\text { Describa la estrategia que } \\
\text { utilizaría con sus alumnos, paso } \\
\text { a paso, para ayudarles a criticar } \\
\text { y evaluar el gráfico anterior }\end{array}$ \\
\hline $\begin{array}{l}\text { Para este ejemplo en particular } \\
\text { les preguntaría ¿cómo es que } \\
\text { obtuvieron sus gráficos? } \\
\text { (Cu.CA.1a.1) } \\
\text { ¿qué representan esos números } \\
\text { que aparecen en el gráfico de } \\
\text { tallo y hoja? (Cu.CA.1a.1) } \\
\text { También les pediría que } \\
\text { basándose únicamente en sus } \\
\text { diagramas (sin ver sus datos) me } \\
\text { dijeran a cuántas personas les } \\
\text { llevó exactamente } 23 \text { minutos } \\
\text { llegar a la escuela ¿este dato [23] } \\
\text { lo podrían obtener con el } \\
\text { histograma y por qué? } \\
\text { (Cu.CA.1a.2) } \\
\text { Después de estas preguntas } \\
\text { tendríamos ejemplos en los } \\
\text { cuales los alumnos establecieran } \\
\text { ¿a qué personas van dirigidas los } \\
\text { datos? (Cu.CA.1a.3) }\end{array}$ & $\begin{array}{l}\text { ¿qué significado tiene en el grafo } \\
\text { cada uno de los ejes? (Cu.CA.3b.1) } \\
\text { ¿qué significa el intervalo } 45 \text { - } \\
50 ? \text { (Cu.CA.3b.1) } \\
\text { ¿qué significa que su frecuencia } \\
\text { sea } 1 \text { según el contexto del } \\
\text { problema? (Cu.CA.3b.1) } \\
\text { ¿qué podrían incluir en el grafo } \\
\text { para que fuera más entendible } \\
\text { para cualquier lector? (Cu.CA.3b.2) }\end{array}$ & $\begin{array}{l}\text { Primero les preguntaría } \\
\text { ¿cuál es la variable a estudiar? } \\
\text { (Cu.CA.4a.1) } \\
\text { ¿qué significa viajar al lugar de } \\
\text { trabajo? (Cu.CA.4a.2) } \\
\text { ¿qué representan el 50\%, el 32\% } \\
\text { y el 11\%? (Cu.CA.4a.3) } \\
\text { ¿qué representan los autos y sus } \\
\text { posiciones en el gráfico? } \\
\text { (Cu.CA.4a.4) } \\
\text { ¿está claro para el lector lo que } \\
\text { representan las posiciones de los } \\
\text { autos? (Cu.CA.4a.5) } \\
\text { ¿qué es lo que está midiendo la } \\
\text { variable? (E2.CA.98) }\end{array}$ \\
\hline $\begin{array}{l}\text { ¿qué tan precisos quieren ser con } \\
\text { sus gráficos? (Cu.CA.1a.3) } \\
\text { ¿cuáles son los beneficios y las } \\
\text { dificultades que presentan cada } \\
\text { uno de estos gráficos en [el] } \\
\text { problema? (Cu.CA.1a.3) }\end{array}$ & & \\
\hline
\end{tabular}

Un tercer grupo eran preguntas orientadas a desarrollar el sentido crítico en un gráfico, es decir, confrontar la validez de la información y su pertinencia con el tipo de gráfico. Aquí se ubican las preguntas cuyo propósito fue cuestionar al estudiante si un dato se podría obtener a través de otro gráfico (C-1), o bien, si está claro para el lector lo que representan las posiciones de los autos (C-4). Por ejemplo:

...¿este dato [23] lo podrían obtener con el histograma y por qué? (Cu.CA.1a.2) 
¿está claro para el lector lo que representan las posiciones de los autos? (Cu.CA.4a.5)

Finalmente, en una pregunta explora el conocimiento propositivo del estudiante para mejorar un gráfico, y por ejemplo le pregunta qué incluiría para que el gráfico fuese más entendible para el lector (C-3):

¿qué podrían incluir en el grafo para que fuera más entendible para cualquier lector? (Cu.CA.3b.2)

Las preguntas que utiliza Alicia de manera habitual (primer contexto), difieren de las que utilizaría a partir de las situaciones del cuestionario (segundo contexto). En el primero encontramos preguntas más relacionadas con reforzar el conocimiento y aclarar dudas del estudiante, mientras que en el segundo, se obtuvieron cuatro tipos de preguntas centradas principalmente en la exploración de los componentes estructurales del gráfico y sus características.

\subsubsection{Ejemplos y ejercicios}

Otra de las estrategias que Alicia utiliza son los ejemplos y ejercicios. Para ella los ejemplos son actividades de aprendizaje que se presentan y utilizan en el salón de clases y que tienen una relación directa con el conocimiento y la comprensión de los conceptos o temas del programa y generalmente se presentan inmediatamente después de una definición o explicación del tema. Los ejercicios, en cambio, son actividades de aprendizaje cuyos principales objetivos son, por un lado, desarrollar la práctica y, por otro, confirmar que se han comprendido los conceptos. A pesar de esta diferencia, en repetidas ocasiones Alicia utiliza indistintamente uno y otro término:

En cuanto a los ejercicios, trato de dar ejemplos que estén relacionados con su área o al menos con el área social (E1.CA.76)

Por tal motivo, para esta investigación, englobaremos dentro de esta estrategia los ejemplos que ella utiliza en las clases, así como los ejercicios que usa tanto para adquirir el conocimiento, como para profundizar en él o reforzarlo.

A continuación vamos a analizar los tipos y características de los ejercicios que utiliza Alicia en función del uso que hace de ellos y el objetivo para el cual los usa.

[hago] un recuento de ejercicios tratando de, primero saber de qué tema estamos hablando, que estén relacionados y enfocándome en alguna cuestión que yo quiera reforzar o recalcar, localizo los ejercicios correspondientes, hago como que una reunión de varios ejercicios y ya se los entrego para que ellos realicen (E1.CA.76)

Alicia utiliza los ejercicios fundamentalmente con tres propósitos: elaborar gráficos, calcular valores estadísticos e interpretar gráficos. A continuación se describen las características y usos que le da a éstos. 


\section{- Elaborar gráficos}

Esta estrategia representacional la usa para evaluar el conocimiento de los estudiantes sobre la construcción de gráficos:

[está pensando] Hicieron algunos ejercicios en clase en donde tenían que hacer, desde sus distribuciones de frecuencias, luego algunas gráficas, manejamos histogramas, mmm... algunos pictogramas. Entonces les pedí ejercicios en donde les daba algunos datos y tuvieran que hacer sus distribuciones y sus gráficas (E1.CA.82).

O bien, para lograr que el estudiante discrimine entre un gráfico y otro:

...dibujan tres histogramas, diagramas de barra diferentes con respecto a las unidades que manejan... (E2.CA.37)

...Dentro de los ejercicios en donde están sacando su distribución de frecuencias, les pido que hagan algún gráfico... les digo que hagan todos los gráficos sin ver cuál es mejor o cuál se prestaría más para ese tipo de información (E2.CA.39)

Se trata de actividades en las que a partir de un conjunto de datos el estudiante debe organizarlos, elaborar una tabla de frecuencias (absolutas y relativas) y, finalmente, construir uno o más gráficos determinados (ej. barras, histograma, circular o pictograma). La Figura 5.6 muestra un ejemplo representativo de este tipo de ejercicios.

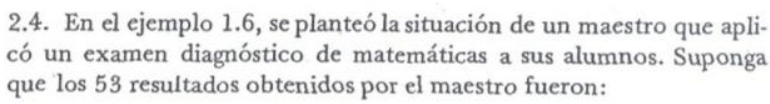

2.4. En el ejemplo 1.6, se planteó la situación de un maestro que aplicó un examen diagnóstico de matemáticas a sus alumnos. Suponga que los 53 resultados obtenidos por el maestro fueron:

$\begin{array}{rrr}4 & 1 & 5 \\ 8 & 6 & 6 \\ 6 & 9 & 6 \\ 4 & 9 & 11 \\ 7 & 5 & 3\end{array}$

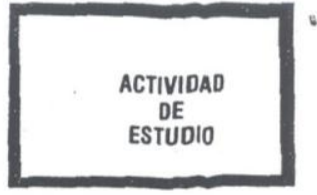

Organice estos datos en una tabla de distribución de frecuencias y construya las correspondientes gráficas de barras de frecuencias y de frecuencias relativas.

Figura 5.6. Ejemplo representativo del tipo de ejercicios que utiliza Alicia en el tema de la $R G$ 
La intención de Alicia es que el estudiante aprenda cómo elaborar el gráfico a partir de los componentes estructurales del mismo:

... por ejemplo, en el caso de graficar un histograma por ejemplo, el hecho de manejar bien su escala de mediciones, y que en algunos casos sí puedes no empezar desde digamos desde cero, y empezar desde cierto valor, pero que en algunos otros casos eso puede distorsionar visualmente la información que estamos manejando. Entonces específicamente les puse unas... se refería al mismo problema y se refería a la preferencia acerca de algo, y tenían, las escalas estaban variadas, se refería a los mismos... los histogramas en este caso a un mismo problema y así visualmente que me dijeran en cuál notan mayor preferencia o si había mucha diferencia. Ese tipo de ejemplos (E1.CA.70)

... les di información con distintas variables y les pedía que hicieran los gráficos. Entonces como de cierta forma estaba viendo qué gráfico iban a utilizar y si se dieron cuenta por qué (E2.CA.62)

Darle tres tipos de variables ¿no? por ejemplo, de las numéricas que sean algunas discretas y unas continuas, y que me hagan un gráfico sin decirles específicamente cuál, sino que se apegue al tipo de variable. Igual este... variable cualitativa, cómo podrían representar gráficamente ese tipo de variable (E2.CA.70)

que hagan un diagrama y que puedan escribir qué ventajas le encuentran y qué desventajas, por separado para cada uno... (E2.CA.36).

Alicia se centra en la identificación de cuáles son las variables y de qué tipo son (cualitativas o cuantitativas, o bien, discretas o continuas), las escalas o niveles de medición (nominal, ordinal, intervalos, razón), los ejes (horizontal o vertical) y los valores (frecuencia absoluta o relativa, o porcentajes). No obstante, las instrucciones o indicaciones para que los alumnos identifiquen el tipo y las características de las variables, los niveles de medición, los ejes o el tipo de valores no se incluyen explícitamente en los ejercicios. Posiblemente sean instrucciones que solicita verbalmente a través de preguntas.

Así describió un ejemplo que utiliza cuando enseña los histogramas para que los estudiantes se den cuenta de la escala [sic] que están manejando. Se trata de un ejemplo (Mat.CA.04) con una muestra de 74 empleados a quienes se les preguntó su opinión sobre un candidato a delegado sindical y cuyas respuestas posibles eran Totalmente en contra, En contra, Indiferente, A favor y Muy a favor. Se muestran tres gráficas de barras donde se representan los datos obtenidos. La diferencia que existe entre cada uno radica en la forma de presentación de la información, así, el primero es un gráfico en el que el eje de ordenadas se inicia cero, en otro gráfico el eje se inicia en 13 y se inserta un símbolo para representar la discontinuidad y en el tercero la frecuencia se inicia en 13 , se inserta un símbolo de discontinuidad y se modifica el tamaño del gráfico. Ver Figura 5.7. 

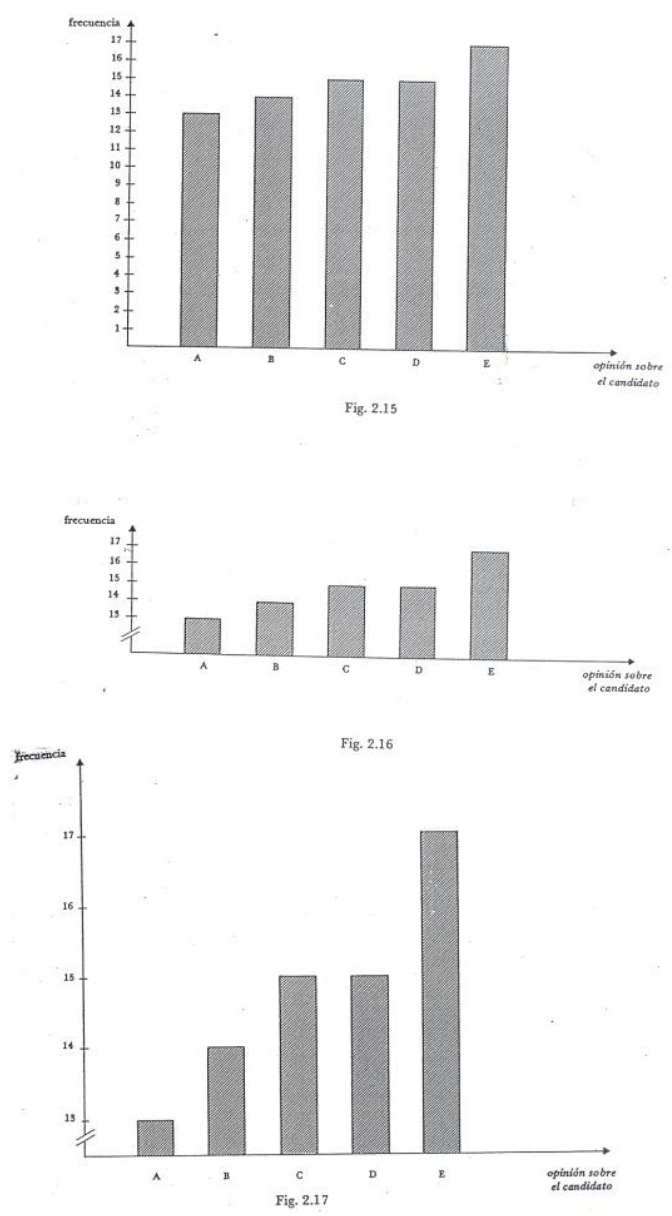

Figura 5.7. Ejemplo utilizado por Alicia para que los alumnos comprendan la importancia del uso de la escala en los ejes

Al analizar este ejercicio, se identificó que Alicia tiene un error conceptual entre los histogramas y los gráficos de barras. Alicia, al exponer este ejemplo, de manera reiterativamente hace referencia a él como un histograma cuando por la naturaleza de los datos (variable cualitativa y escala ordinal) se trata de un gráfico de barras. Con ejercicios de este tipo, ella intenta que el estudiante evite construir gráficas que conduzcan a interpretaciones erróneas teniendo sumo cuidado en la definición de la escala de los ejes y la interrupción de los mismos.

Es que es algo en lo que hago énfasis en el caso de los histogramas en cuanto a la escala que están manejando, porque normalmente ellos sí escriben sus barras, pero por ejemplo, si estamos hablando de números a veces no tienen cuidado en cuanto a la escala de... (más bien... aquí no tanto), pero en la frecuencia, por ejemplo se les ocurre empezar digamos si estamos manejando muchos datos a lo mejor se les ocurre empezar desde... desde cien y de allí ya empiezan... y eso es lo que les puntualizo y por eso utilicé ese ejemplo (E2.CA.38).

Analizando los materiales que entregó Alicia, todos los ejercicios de este tipo proceden de algún texto y en el $68 \%$ de ellos de lo que se trata exclusivamente es que el estudiante elabore uno o más gráficos con unas características determinadas: 
Elabora con estos datos una tabla de distribución de frecuencias y las correspondientes gráficas de barras de frecuencias y de frecuencias relativas

Elabora, también, el diagrama de pareto, el diagrama de pastel y un pictograma. (Eje.CA.14)

a. Constrúyase una distribución de frecuencias relativas y una distribución de frecuencias relativas acumuladas con límite de clase de 2.25 a $2.75,2.75$ a 3.75 , etc.

b. Trácense un histograma de frecuencias relativas y una gráfica de frecuencias relativas acumuladas (Eje.CA.19)

Aunque Alicia manifestó que utilizaba también en sus clases ejercicios para determinar el gráfico que mejor represente ciertos datos, en el material revisado no se encontró ninguno de este tipo. Posiblemente, Alicia haya realizado este tipo de actividad mediante preguntas o instrucciones verbales

En relación con el contexto de los ejercicios, el 59\% describe un conjunto de datos de un contexto educativo: puntajes de pruebas psicológicas o de inteligencia, estaturas de alumnos, exámenes (diagnósticos o resultados de alguna disciplina), forma de trasladarse a la escuela (caminando o en un vehículo), preferencia por alguna asignatura y valores en una encuesta de opinión a los estudiantes. No obstante, se encontraron ejercicios (algunos utilizados como ejemplo con los alumnos) alejados del contexto educativo: bombillas, sueldos, acciones vendidas, empresas, monedas, consumo diario de agua, mediciones de terremotos. Sobre esto, Alicia manifestó que "es difícil encontrar ejemplos que estén relacionados con el área de educación" (E1.CA.68) pero reconoció que es necesario encontrar ejemplos apropiados para estos estudiantes.

En resumen, Alicia utiliza un amplio número de ejercicios cuyo objetivo central es elaborar o construir un gráfico, y cuyo propósito es que los estudiantes identifiquen y comprendan los compontes estructurales del gráfico.

\section{- Calcular valores estadísticos}

Otro grupo de ejercicios que encontramos fueron los que además de solicitar que el estudiante elabore una tabla de frecuencias y el o los gráficos específicos, también debe calcular y/o interpretar algún valor estadístico (ej. media, mediana, moda, asimetría, curtosis).

Sólo trabajé con el histograma como el ejercicio que te mostré, en donde doy el histograma y a partir de ahí tienen que dar una distribución por ejemplo, de frecuencias y obtener sus medidas centrales o de dispersión a partir de ese gráfico. (E2.CA.40)

La Figura 5.8 presenta un ejercicio con estas características. 


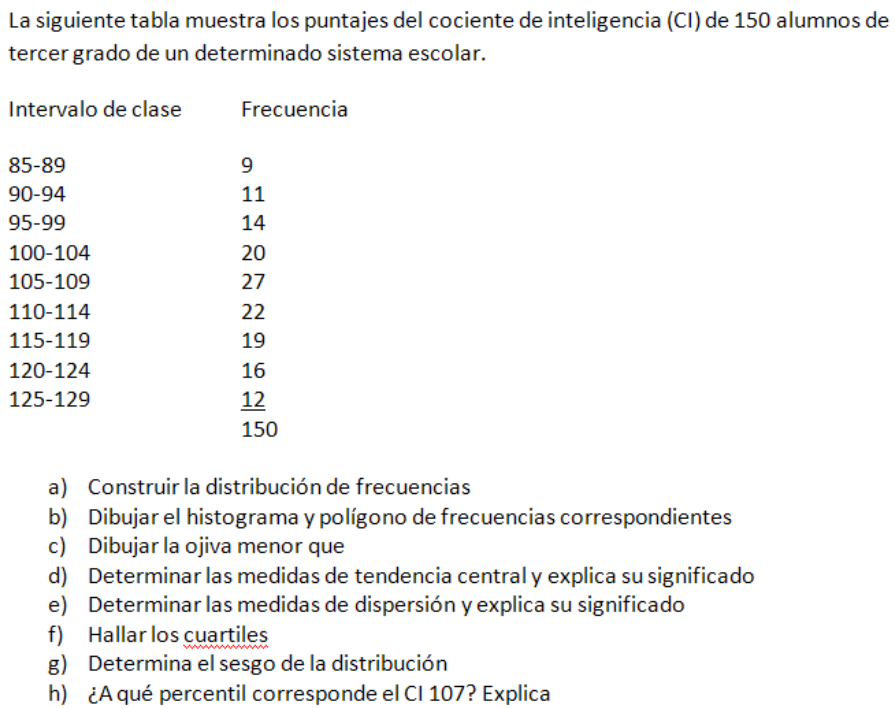

Figura 5.8. Ejemplo de ejercicio que utiliza Alicia donde solicita el cálculo de valores estadísticos

Entre los materiales que entregó Alicia (ej. Lib.CA.01) se observó que algunos ejercicios el estudiante además de elaborar tablas de frecuencias y gráficas debe realizar cálculos estadísticos con lápiz y papel. En ellos, es fundamental que el estudiante utilice una fórmula y siga los pasos que Alicia les ha enseñado previamente.

De los 22 ejercicios que se analizaron sólo en 3 de ellos además de solicitar la elaboración del gráfico se pedía el cálculo de ciertos valores estadísticos, y los tres eran anotaciones de puño y letra de Alicia, es decir, que ella añadió esos incisos a los ejercicios. De hecho, la Figura 5.5 es un ejercicio elaborado por Alicia, no tomado de algún texto.

- Interpretar gráficos

Un reducido número de ejercicios ( 3 en total) estaban centrados en explorar el o los gráficos y, a partir de ahí, contestar algunas ciertas preguntas relativas a su interpretación. La Figura 5.9 (Eje.CA.12) muestra uno de estos. 
2.8. En una escuela se aplicó el mismo examen diagnóstico a todos los alumnos de los cuatro grupos que ingresaban a quinto grado. Los resultados se muestran en los siguientes histogramas de frecuencias relativas. Analícelos con cuidado y conteste la siguiente pregunta: ¿con qué ventajas y desventajas se encontrará el maestro que trabaje con cada uno de estos grupos?
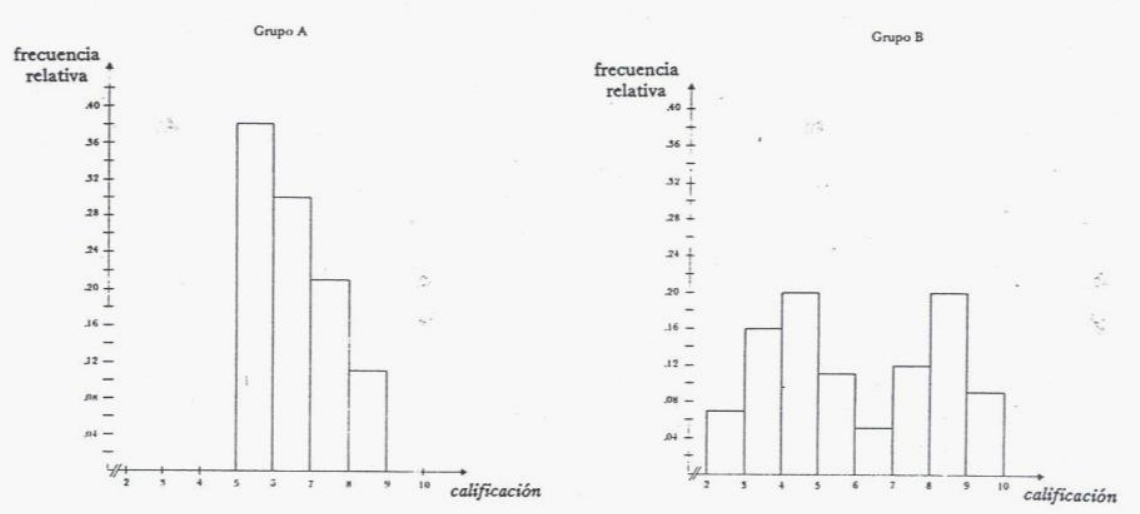

Fig. 2.11

Fig. 2.12
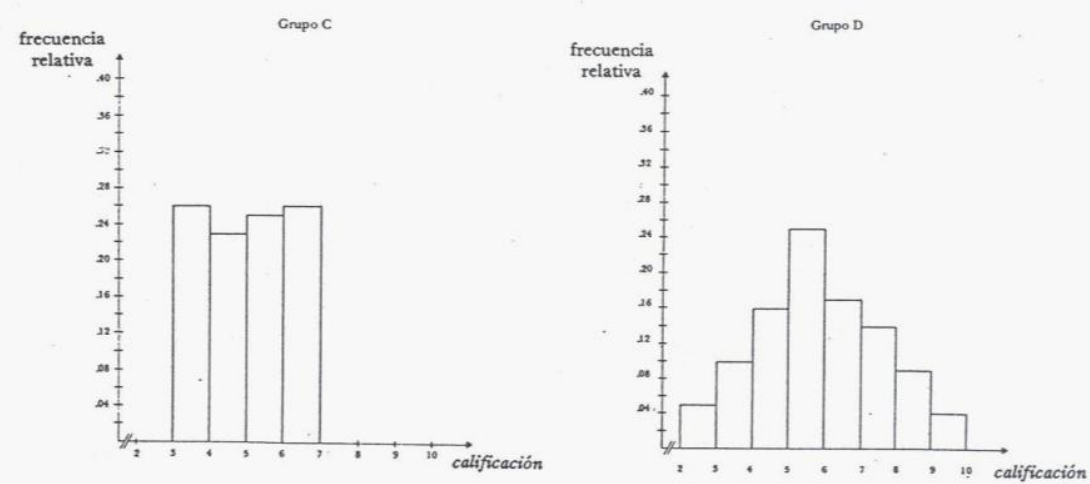

Fig. 2.13

Fig. 2.14

Figura 5.9. Ejemplo del tipo de ejercicio centrado en la interpretación de la $R G$

A diferencia de los otros ejercicios, en este (Figura 5.9) el alumno encuentra un gráfico ya construido y la actividad que deber realizar es responder a preguntas sobre los componentes estructurales del gráfico, siendo este tipo de preguntas muy escasas entre todos los ejercicios analizados. De hecho, sólo se encontraron nueve de estas preguntas, las cuales se clasificaron siguiendo a Curcio (1987) en leer datos (LD), leer entre datos (LED) y leer más allá de los datos (LMD):

Determinar el número de tubos que tienen una duración inferior de 900 horas (Eje.CA.04) LED

¿Existe algún valor o intervalo de valores que sea interpretativo del tiempo empleado por los niños? Si existe, ¿cuál? (Eje.CA.11) LMD

¿Entre cuáles valores se encuentran todos los datos? (Eje.CA.11) LED

¿De qué tamaño fue la muestra considerada? (Eje.CA.15) $L D$

¿Cuántos alumnos respondieron D (Casi siempre)? (Eje.CA.15) LED

¿Qué proporción de alumnos optó por C (Algunas veces)? (Eje.CA.15) LED

Universidad de Salamanca 
¿Qué proporción de alumnos optó por B (Raras veces)? (Eje.CA.15) LED

¿Qué porcentaje de alumnos tuvieron un puntaje mayor que 7 en este examen? (Eje.CA.22) LED

Dado el número limitado de ejercicios y preguntas con estas características no podemos establecer ninguna conclusión sobre la interpretación y niveles cognitivos de desarrollo de los gráficos. No obstante, pudimos apreciar que los ejercicios que nos entregó se orientan más en la lectura literal de datos y leer entre datos.

\subsubsection{Instrucciones}

Las instrucciones son indicaciones, actividades, señalamientos u órdenes que Alicia solicitaba a sus estudiantes con el propósito de ayudarles a comprender diversas cuestiones sobre la RG. A diferencia de los ejercicios que se presentan en papel, las instrucciones por lo general son verbales, apoyadas en ocasiones de algún objeto concreto.

También les pediría que basándose únicamente en sus diagramas (sin ver sus datos) me dijeran a cuántas personas les llevó exactamente 23 minutos llegar a la escuela... (Cu.CA.1a.2)

y que si estos no estaba tan claro para ellos, qué podrían incluir en el grafo para que fuera más entendible para cualquier lector (Cu.CA.3b.2)

En el C-1 Alicia indicó que pediría a los alumnos que observaran los gráficos de TyH y el histograma para que se dieran cuenta de los valores representados en ellos, mientras que en el C-3 (donde se le presentó un histograma) Alicia señaló que pediría a los estudiantes que corrijan o complementen la información que aparece en el gráfico. En ambos casos, Alicia también se apoya en las preguntas.

Un resultado que nos parece importante reseñar, es que Alicia reconoce que no realiza actividades (ej. ejercicios o casos) similares a las del cuestionario que le propusimos. La Tabla 5.2 recoge y sintetiza los momentos y la forma como Alicia nos expresó este hecho. Esto se refleja perfectamente en la siguiente afirmación:

¡No! De hecho no trabajo mucho con gráficos. Básicamente es la definición, algunos ejemplos y algunas características por ejemplo, que el tipo de variable, de información, pero no profundizo tanto. (E2.CA.96) 
Tabla 5.2. Afirmaciones que confirman que Alicia no hace actividades similares a los casos del cuestionario Pregunta / Caso Ejemplo(s)

¿logras trabajar así en el salón de clase? (C-1)

¿Alguna actividad que tú trabajes con ellos, donde el alumno escriba la interpretación de lo que identifica en el gráfico? (C-1)

¿Trabajas alguna actividad, que puede ayudar al estudiante a establecer la relación que guarda la variable de una investigación, la escala de medición, el tipo de gráfico y su justificación? (C2)

¿Qué te pareció la actividad? (C-2)

¿Qué te llama más la atención? (C-2)

Alguna actividad que ayude al estudiante a comprender el gráfico de barras (C-2)

¿Alguna otra cosa harías con ellos para que resolvieran correctamente el ejercicio, además de lo que tú estás planteando? (C-3)

¿Trabajas alguna actividad en tus clases para hacer que el estudiante comprenda este aspecto de la interpretación, de la toma de decisiones a partir de un gráfico, de la escritura de esa interpretación y poder discutir algo y recomendar algo a partir del gráfico? (C-3)

¿Alguna actividad que utilices para ayudar al estudiante a que comprenda el histograma? (C-3)

¿Alguna otra estrategia que utilizarías con ellos para ayudarles a que ellos critiquen y evalúen el gráfico? (C-4)
"Creo que no hicimos algún ejercicio de ese estilo de que ellos eligieran cuál es el que se... Tan sólo las ventajas o desventajas de cada uno dependiendo de hacia qué estuviera dirigido. Básicamente se vio las definiciones, se hicieron ejemplos, pero no puntualizamos este hecho de cuál sería mejor en cada caso. Al menos yo no trabajé ese punto" (E2.CA.27)

“(mmm) No así tan puntual no. O sea te digo les pedí que saquen su distribución, pero no mayor información" (E2.CA.41)

“(mmm) No" (E2.CA.69)

"[está pensando] Estoy tratando de pensar si hubiera hecho alguna actividad así, y... no, no sé" (E2.CA.60)

"Como que de cierta forma no hago tantas actividades para que ellos vayan descubriendo las cosas" (E2.CA.61)

"(mmm) No. Lo que pasa es lo que te comentaba, como que de cierta forma creo que ya entendieron bien el gráfico de barras y sólo les digo "a ver dibujen o hagan un gráfico de barras" (E2.CA.71)

“(mmm) [está pensando] No, creo que no”(E2.CA.74)

"No" (E2.CA.95)

“[está pensando] ¡No! Es que básicamente (vuelvo a lo mismo) el tipo de problema [que vemos] es, de cierta información, que hagan el histograma pero no analizamos profundamente" (E2.CA.97)

“[está pensando] No" (E2.CA.110bis) 
Es decir, Alicia no desarrolla el nivel cognitivo de pensamiento estadístico en sus estudiantes, sino que las actividades que utiliza pertenecen parcialmente al nivel de alfabetización estadística. Busca que los estudiantes conozcan y usen algunas técnicas básicas de graficación; organizar datos, construir y presentar gráficos (principalmente descriptivos y categóricos). No obstante, no atiende suficientemente lo relativo a la comprensión de la información estadística (comprensión gráfica) y no le concede valor a comprender información presentada en un típico gráfico estadístico de distribución (ej. de puntos, histograma y de caja), identificar algunas formas comunes de distribución (ej. normal, sesgadas, bimodal, uniforme), distinguir entre un gráfico de barras y serie de tiempo de los histogramas, y comprender los términos relacionados con la distribución. Los elementos de la RG a nivel de pensamiento estadístico descritos en la sección 2.5.2 no los contempla.

Alicia enseña la RG a partir de un limitado repertorio de estrategias específicas que son coherentes con su concepción de la enseñanza y aprendizaje de la Estadística, y que está centrada en las explicaciones, el uso de ejemplos y la ejercitación a través de prototipos similares a los utilizados en el aula centrados en la construcción de gráficos y en la identificación de algunas de sus características.

De las cuatro estrategias y representaciones instruccionales generadas a partir del cuestionario, tres de ellas son representaciones verbales (definiciones y explicaciones, las preguntas y las instrucciones) y una concreta (ejemplos y ejercicios) (McDiarmid, Ball y Anderson, 1989). La fuente de donde surgen las representaciones verbales denominadas explicaciones, preguntas e instrucciones es la propia Alicia, es decir, las crea o construye ella misma; mientras que las definiciones, los ejemplos y ejercicios se obtienen de los libros de texto.

Por otra parte, en cuanto a la forma de las representaciones instruccionales que utiliza, las definiciones y explicaciones, los ejemplos y ejercicios, y las instrucciones están centradas en el profesor, es decir, es Alicia la principal protagonista, la que planea la estrategia y ejecuta. Las preguntas están centradas en la interacción entre el profesor y los estudiantes. No se contemplan estrategias centradas en el estudiante, donde sea el protagonista o quien se involucre activamente en actividades de construcción de conceptos, procesos o relaciones.

Sobre los propósitos de cada una de las representaciones instruccionales, Alicia utiliza:

- Las definiciones y explicaciones para presentar la definición y/o características del gráfico

- Las preguntas para explorar los componentes estructurales del gráfico y analizar sus características

- Los ejemplos y ejercicios para evaluar el conocimiento de los estudiantes sobre la construcción de gráficos y para lograr que discrimine entre un gráfico y otro 
- Las instrucciones para explorar las características del gráfico

Sobre los contextos y momentos de las representaciones instruccionales utiliza:

- Una definición o explicación cuando cierra un proceso inductivo de aprendizaje y al inicio de cada tema

- Una pregunta cuando quería reforzar el conocimiento y aclarar las dudas del estudiante

- Un ejemplo o ejercicio cuando solicita que se elaboren gráficos

- Una instrucción cuando desea que se corrija un error en el gráfico.

La mayoría de las representaciones instruccionales que Alicia utiliza son del tipo verbal, son de su propia autoría y están centradas en la actuación de las clases; lo que nos lleva a pensar en las limitaciones que éstas tienen para promover el aprendizaje de sus estudiantes (ej. alumnos pasivos, dependientes del profesor). Se utilizan dependiendo del momento de la clase en función de lo que se necesita o pregunta el alumno.

Las representaciones asociadas al uso de los textos (las definiciones y ejercicios) presentan el problema de que son materiales obsoletos, con una concepción sobre la RG de los años 80s. Las definiciones que dicta a sus estudiantes se centran casi exclusivamente en las características geométricas del gráfico y en sus componentes estructurales y los ejercicios, en su mayoría, tienen como objetivo la elaboración de gráficos.

Alicia utiliza las preguntas en sus clases habitualmente para reforzar el conocimiento y aclarar dudas, mientras que a partir del cuestionario didáctico generó una diversidad de formas de preguntas, que fueron agrupadas en cuatro categorías: explorar la interpretación de los componentes estructurales del gráfico, explorar las características y condiciones en la construcción de un gráfico, desarrollar el sentido crítico en un gráfico y conocimiento propositivo para mejorar un gráfico. Aun cuando entre las dos primeras categorías se agrupan el 83\% de las preguntas, a través de la diversificación de los tipos de actividades, y si usara ejercicios como los del cuestionario, podría desarrollar, ampliar y darle más sentido a las preguntas como representación instruccional.

Estos resultados confirman nuevamente la concepción que tiene Alicia de la RG, su aprendizaje y enseñanza. Utiliza un reducido número de representaciones instruccionales orientadas a la construcción de gráficos y sus características, limitando así el conocimiento que se debe promover sobre el aprendizaje de la RG en los estudiantes. Si bien, las representaciones que utiliza dan mayor certidumbre a Alicia en cuanto a que se generan por ella misma y de acuerdo a las circunstancias de la clase, promueven una participación pasiva en el estudiante y refleja una desatención al papel que le otorga en el aprendizaje, no utiliza textos actualizados ni mucho menos otro tipo de recursos o materiales para la enseñanza de la RG. La forma en que utiliza las representaciones es lineal, en el sentido que 
cada una tiene un propósito y un momento específico para ser utilizada y no se contempla la interacción de varios tipos de representaciones para desarrollar un objetivo específico y promover el aprendizaje.

Por último, estas representaciones instruccionales distan mucho de los avances en materia de enseñanza de la RG. Por ejemplo, las recomendaciones de Meletiou y Stylianou (2003) para mejorar la comprensión de los gráficos; el proceso de desarrollo de los niveles cognitivos de la comprensión gráfica a través de actividades interactivas y en contextos reales de Curcio (1989, 2001), la información sobre técnicas gráficas generales y una lista bibliográfica sobre gráficos, principalmente de cajas y paralelos, circular, de barras y de dispersión en Pittenger (1995), la inclusión de textos actualizados con novedades recientes en cuanto a la forma de abordar el estudio de la RG, incluyendo niveles cognitivos de leer más allá de los datos y detrás de los datos de Moore (2000) y Salkind (2000), y las aplicaciones prácticas que presentan la revista Teaching Statistics dirigidas a los profesores de Estadística, por citar algunos ejemplos.

\subsubsection{Conocimiento del estudiante}

El tercer componente del CDC, conocimiento de los procesos de aprendizaje del alumno, o de manera breve, conocimiento del estudiante, nos permitió explorar el conocimiento de Alicia sobre el conocimiento del proceso cognitivo que tiene de los estudiantes, la forma de diagnosticar e identificar dificultades y las estrategias específicas que utiliza para corregir las concepciones erróneas.

En esta sección presentamos el conocimiento de Alicia del proceso cognitivo del estudiante en dos de sus dimensiones: a) las creencias y b) errores y dificultades. La fuente principal de obtención de esta información fue el cuestionario didáctico sobre representación gráfica.

\subsubsection{Creencias}

Las creencias que Alicia piensa que tienen los alumnos en relación con el aprendizaje de la RG son:

- Los gráficos que se ven en la escuela son los más adecuados para representar datos

- El gráfico de barras y el histograma sirven para representar siempre algo

- Lo que el profesor hace o dice está bien

- Es difícil de entender gráficos no convencionales

A continuación explicaremos cada una.

Los gráficos que se ven en la escuela son los más adecuados para representar datos. Alicia piensa que los estudiantes no discriminan entre el histograma y el TyH porque tienen la creencia de que los histogramas son los más utilizados dado que están más familiarizados con éste. 
Por ejemplo en la televisión o cuando leen el periódico se presentan más ese tipo de gráfico (E2.CA.14)

Es más por ejemplo nosotros no lo vimos [el TyH] en la materia porque este... bueno no aparece en el temario y en la bibliografía que utilizamos no en todos los casos aparece ese diagrama (E2.CA.15)

Revisando los textos de primaria a bachillerato se puede apreciar que los gráficos que más aparecen son: el circular, el de barras y el histograma. Estos mismos gráficos son también los más usados en los principales medios de difusión escrita. Cuando hay que seleccionar entre un gráfico y otro, el estudiante escogerá aquél del que tiene un mayor conocimiento. Eso es lo que ocurrió al tener que decidir entre el histograma y el TyH.

Según Alicia, existe una predisposición del estudiante por seleccionar gráficos en función de la frecuencia con que aparece en los medios de comunicación, o bien, en función de lo que ha aprendido el alumno (C-2).

Durante la entrevista se le preguntó a Alicia a qué le atribuye que Diego haya elegido el gráfico de barras (C-2). Alicia argumentó que, en muchas ocasiones, los estudiantes eligen el gráfico entre los que mejor conocen. Ante la posibilidad de errar, el estudiante tiende a escoger una respuesta rápida y fácil, posiblemente esta respuesta no esté razonada ni fundamentada.

El gráfico de barras y el histograma sirven para representar siempre algo. También Alicia aseveró que "habrá alumnos que a lo mejor no se pongan a razonar del todo y crean que con un diagrama de barras o con un histograma siempre van a poder representar algo" (E2.CA.56).

En este sentido, Alicia piensa que los estudiantes creen que mediante el histograma o el gráfico de barras se puede representar cualquier tipo de datos. Esta creencia, como se mencionó antes, puede estar siendo inducida por solicitar al estudiante que construya exclusivamente ciertos gráficos (ej. histograma y barras) para un único conjunto de datos descontextualizados. Esto no sólo es conceptualmente inadecuado, sino que, además, se limita a ciertos tipos de gráficos que utiliza el estudiante cuyo propósito principal es la organización de un conjunto de datos.

Lo que el profesor hace o dice está bien. Alicia también piensa que los estudiantes, generalmente, hacen lo que el profesor les pide y buscan con ello cumplir con las expectativas de éste. Según ella, ésto es, en ocasiones, más importante para ellos que el hecho de comprender el significado de los conceptos y procedimientos. Alicia lo expresa de la siguiente forma:

... creo que soy impositiva en ese aspecto de que les digo "esto es para tal y esto es para tal" y ellos de cierta forma no cuestionan, porque la maestra dijo que... "la maestra dijo que para este tipo de variables es barras y para este tipo de variables es histograma" ¿si? (E2.CA.61)

... es un poco como que yo ya les había dicho de qué forma y como que ellos iban a responder así pero no porque lo pensaran, o sea no que ellos pensaran bien las cosas (E2.CA.62) 
... es [que] se van por lo que creen que debe ser pero más bien lo que creen que para mi va estar bien, y no porque ellos realmente piensen. Contestan pensando en que porque esto es lo que dice la maestra que está bien y entonces si contesto esto va estar bien mi tarea digamos, no porque puedan discernir (E2.CA.65)

Es difícil de entender gráficos no convencionales. Alicia también afirma que en ocasiones el estudiante cree que es difícil comprender determinados gráficos analíticos (con variables cuantitativas y continuas), como lo es el de $\mathrm{TyH}$, debido principalmente al miedo a las matemáticas y a cierto bloqueo mental al ver números o símbolos matemáticos o estadísticos.

....siento que en el caso de el de tallo y hoja, sólo de ver los números como que inconscientemente piensan "esto es difícil de entender" por el sólo hecho de que aparezcan los números, siento que eso es lo que ocurre... creo que sigue el miedo a la matemática, entonces como que en este caso a pesar de que aparecen números en el histograma, sienten que es más una figura, un diagrama, algo que pueden entender (E2.CA.21)

Siento que sí [existe un bloqueo]. Por ejemplo aquí como está [el T y H], no lo pensarían como que se podría ver de cierta forma como digamos una barra que te indique cuántos elementos hay, sino que ven los números así y ya no.... no sé por qué le tienen miedo (jaja) (E2.CA.22)

En síntesis, la Tabla 5.3 presenta las diferentes creencias que Alicia piensa que tienen los estudiantes respecto a la RG, con su correspondiente atribución. Podemos darnos cuenta que las causas de las creencias de los estudiantes tiene un origen más didáctico, es decir, depende del profesor, por lo que la solución está en la planificación y acción de alguna estrategia que ayude a eliminar o modificar la creencia. Por ejemplo, la primera creencia se debe a que en la escuela se enseña la RG descontextualizada, de lo que ocurre con los gráficos de los medios de comunicación escrita (los media graph o print graph) y además sólo se estudian gráficos descriptivos y categóricos, los cuales son muchas veces diferentes a los que encontramos en los media graph. Esta atribución coincide con delMas, Garfield y Ooms (2005) quienes afirman que los estudiantes están muy familiarizados con gráficos (como el de barras) desde la escuela Primaria y ver muchos en periódicos y revistas.

La tercera y cuarta creencia tiene relación igual con lo que el profesor hace o deja de hacer en el aula.

La segunda creencia está relacionada tanto con el docente como con el alumno. Respecto del docente, porque de él depende de si incluye o no el análisis de otros tipos de gráficos en el currículo escolar, así como de las estrategias que utiliza para motivar a sus estudiantes y quietarles miedo o el bloqueo mental que tienen. Respecto del estudiante, porque dependerá de las experiencias previas de aprendizaje que tuvo y de la actitud y disposición que tenga hacia la asignatura. 
Tabla 5.3. Relación del tipo de creencias y las atribuciones que Alicia conoce de los estudiantes

\begin{tabular}{|c|c|c|c|c|}
\hline Caso & Gráfico & Objetivo & Creencia & Atribución \\
\hline C-1 & $\begin{array}{c}\text { TyH } \\
\text { e } \\
\text { Histograma }\end{array}$ & $\begin{array}{l}\text { Seleccionar, criticar y } \\
\text { evaluar el gráfico }\end{array}$ & $\begin{array}{l}\text { Los gráficos que se ven en } \\
\text { la escuela son los más } \\
\text { adecuados para representar } \\
\text { datos }\end{array}$ & $\begin{array}{l}\text { Seleccionar gráficos en } \\
\text { función de la frecuencia con } \\
\text { que aparece en los medios } \\
\text { de comunicación }\end{array}$ \\
\hline $\mathrm{C}-1$ & $\begin{array}{c}\text { TyH } \\
\text { e } \\
\text { Histograma }\end{array}$ & $\begin{array}{l}\text { Seleccionar, criticar y } \\
\text { evaluar el gráfico }\end{array}$ & $\begin{array}{l}\text { Es difícil de entender } \\
\text { gráficos no convencionales }\end{array}$ & $\begin{array}{l}\text { Miedo a las matemáticas y a } \\
\text { cierto bloqueo mental al ver } \\
\text { números o símbolos } \\
\text { matemáticos o estadísticos }\end{array}$ \\
\hline $\mathrm{C}-2$ & Barras & $\begin{array}{l}\text { Definir una variable y } \\
\text { relacionar con el tipo } \\
\text { de gráfico }\end{array}$ & $\begin{array}{l}\text { El gráfico de barras y el } \\
\text { histograma sirven para } \\
\text { representar siempre algo }\end{array}$ & $\begin{array}{l}\text { Solicitar al estudiante que } \\
\text { construya exclusivamente } \\
\text { ciertos gráficos (ej. } \\
\text { histograma y barras) para } \\
\text { un único conjunto de datos } \\
\text { descontextualizados }\end{array}$ \\
\hline $\mathrm{C}-2$ & Barras & $\begin{array}{l}\text { Definir una variable y } \\
\text { relacionar con el tipo } \\
\text { de gráfico }\end{array}$ & $\begin{array}{l}\text { Lo que el profesor hace o } \\
\text { dice está bien }\end{array}$ & Figura de autoridad \\
\hline
\end{tabular}

Alicia también reconoce que el alumno no está acostumbrado a pensar sino a contestar de manera impulsiva sin querer revisar, observar, pensar. Esto mismo se aplica en el aprendizaje de la RG.

Finalmente, nos dimos cuenta que estas creencias se sustentan en impresiones, opiniones y sentimientos equivocados en relación a la RG. Por lo tanto, las creencias que menciona Alicia repercuten de manera desfavorable en el aprendizaje de la RG y pueden ser causa de errores y dificultades vinculadas con la adquisición del contenido correspondiente.

\subsubsection{Errores y dificultades}

El conocimiento que tiene Alicia de los errores y dificultades de los alumnos se ha identificado a partir de los casos (C-1, C-2, C-3, C-4) del cuestionario didáctico sobre la representación gráfica. La descripción de cada caso puede consultarse el Capítulo 4 (sección 4.4.3). Para cada uno se presentan las respuestas de Alicia, seguido de su análisis, para finalmente resumir errores y dificultades expresadas por ella en cada caso.

Caso 1. Gráficos: tallo y hoja e histograma. El C-1 trata de una situación de clase, en donde una profesora solicita elaborar y elegir la mejor forma de representación. Se presentan dos gráficos: el tallo y hoja y el histograma. Los alumnos eligen el TyH y a partir de ahí se generan preguntas relacionadas con la elección, crítica y evaluación del gráfico. La situación gira en torno a lo que el profesor les preguntó a los estudiantes ¿qué gráfico es el que representa mejor los datos? La mayoría de ellos contestó "Me cuesta trabajo 
discernir entre un gráfico de y otro, diferenciar qué grafico es el más adecuado para cada situación”. Alicia explicó las razones por la que los estudiantes le contestaron así al profesor:

( $\mathrm{mmm}$ ) Porque creo que no ha entendido del todo en qué consiste digamos cada uno de los gráficos. A lo mejor sí sabe la forma que tiene, puede decir este es un histograma y este es de tallo y hoja, pero no sabe exactamente en qué consiste o qué significan por ejemplo estos números que aparecen ¿si? O sea si lo ve tal vez si pueda decir el nombre del gráfico, pero exactamente ¿en qué le está ayudando?, ¿qué información puede obtener del gráfico? es la que no tiene muy clara. Eso es lo que yo creo (E2.CA.01)

Para ella los estudiantes no han profundizado sobre las características de los gráficos y lo atribuye principalmente al profesor:

Siento que la mayoría de las veces como que damos la definición del gráfico y decimos "un gráfico consta de este..." y en el caso por ejemplo del histograma, pero creo que es lo que nos falta a lo mejor profundizar o hacer más ejercicios. Creo que eso es lo que ocurre, como que damos la definición y damos por hecho que con la sola definición los alumnos ya van a entender qué es lo que está ocurriendo (E2.CA.03)

En estos segmentos se puede apreciar que Alicia identifica un error por desconocimiento del significado de los valores representados en los gráficos, el cual está relacionado con el conocimiento de los componentes estructurales, la finalidad del gráfico e información del contexto. La causa de este error es de origen didáctico dado que Alicia manifiesta que el profesor no profundiza ni aborda la representación gráfica para este objetivo, sino que sólo se limita a dar la definición del gráfico.

Para indicar cómo ayudaría al estudiante a comprender el procedimiento para discriminar entre el TyH y el histograma, explicó:

los alumnos tenían la idea de que sólo ellos iban a ver el gráfico, o sea no lo estaban tomando como que es una representación que debe dejar clara para la persona que esté viendo el gráfico la información. (E2.CA.07)

Entonces, lo que ocurría al menos en los ejemplos que yo les dejaba es que no escribían por ejemplo de qué datos se trataba, escribían los números y sí dibujaban el gráfico, pero como que daban por sentado que ya se entendía de lo que se trataba porque ellos ya habían leído el problema, porque ellos estaban respondiendo (E2.CA.08)

De esto modo otro error que identifica es que los estudiantes dan por hecho que con información mínima y la construcción misma del gráfico otras personas lo comprenderán, es decir, ignoran la naturaleza y finalidad del gráfico dejando a un lado los elementos del contexto, la situación de donde de origina el gráfico y el lector (usuario) a quién está dirigido el gráfico.

Alicia atribuye este error tanto al profesor como a la dificultad del estudiante de ver de manera global e integral la representación gráfica. También puede ser producido por causa de una omisión, olvido o desconocimiento de los criterios para elaborar un gráfico por parte del estudiante, o bien, de experiencias previas de aprendizaje donde el énfasis de la enseñanza estuvo centrado en la construcción del gráfico sin tener en cuenta a quién va 
dirigido. Esto último puede haber sido reforzado durante los años escolares del estudiante durante los cuales, lo central era la elaboración de los gráficos con lápiz y papel o usando Excel y la función del profesor era verificar si los estudiantes cumplían los condiciones mínimas (ej. ejes, estructuras, etiquetas) para su elaboración. En algunos casos, incluso, se les permite a los estudiantes "jugar" con la apariencia del gráfico sin pensar más que en los colores, formas y tamaños del mismo.

En esta situación-problema también expresó que las principales dificultades que tiene el estudiante es que confunde algunos conceptos. Por ejemplo, Alicia afirma que los alumnos sí entienden el histograma, es decir, "si están sus datos agrupados sí entienden que el intervalo que aparece son... o más bien, la barra habla de la cantidad de datos que caen en ese grupo" (E2.CA.02). Sin embargo, Alicia explicó que cuando se habla de "continuidad de la variable" entonces se confunden, es decir, no distinguen que el "intervalo" de la barra de un histograma es diferente al de un gráfico de barras.

En el caso de las variables discretas el hecho de entender que si van a trabajar con un histograma tendrían que ver de cierta forma como que [se necesita que sea] continua la variable o si no, trabajar más que con el histograma con un diagrama de barras si sólo se trata de puntos específicos. Creo que esa la diferencia que hay entre un diagrama de barras y el histograma es lo que les causa confusión (E2.CA.20)

... creen entender el histograma aunque no siempre es así, ya que se confunden un poco con los intervalos, con la continuidad de la variable (Cu.CA.1b.2)

En este sentido, Alicia asegura que los estudiantes todavía no tienen claro el concepto y distinción entre variable discreta y variable continua. Esta confusión les lleva a cometer errores en cuanto a construir un gráfico de barras cuando la naturaleza de los datos que se tienen reflejan una continuidad de la variable, o lo contrario, pretender construir un histograma cuando se trata de una variable cualitativa o bien, cuantitativa sin agrupar en intervalos.

Caso 2. Gráfico: barras. El C-2 presenta la respuesta de un estudiante a una actividad relativa a la definición de una variable y su relación con un tipo de gráfico (de barras). Ante la pregunta ¿qué preguntas haría a Diego para comprender por qué ha dado esas respuestas? Por favor, argumente su respuesta, Alicia le pediría a Diego contestar las siguientes preguntas:

¿A qué altura se refiere en la variable? (Cu.CA.2a.1)

¿Cuál es su población de donde va a tomar la variable? (Cu.CA.2a.2)

¿A qué media se refiere? (Cu.CA.2a.3)

Las principal razón es "para determinar si tiene claro de qué altura está hablando, y si se dio cuenta de que si obtiene la media de la población no sería una variable" (Cu.CA.2a.4). Para Alicia es importante averiguar si para Diego las dos alturas que menciona (de la variable y la justificación) se refieren a lo mismo:

porque aquí está hablando de la altura de el... (bueno eso es lo que creo), se está refiriendo a la altura, más bien a la frecuencia que van a tener sus barras y aquí no está claro a la altura de... ¿de qué? ¿a la altura de alguna persona? ¿a la altura de qué? (E2.CA.42) 
si se trata de distintas poblaciones o si se trata de una misma población pero distintas muestras, por el tipo de variable que está dando, o sea, que quede claro ¿dónde va a tomar las alturas?, ¿a qué altura se está refiriendo? (E2.CA.44)

Por lo que creo que está pensando, que a lo mejor va a decir "la población de estudiantes" y a lo mejor es cuando se daría cuenta que la media no le... no sería... (E2.CA.45)

Según Alicia, un error es que Diego confunde lo que es una variable con media poblacional. Para ella:

no tiene claro realmente su variable porque habla de la 'media de altura'. A menos que esté hablando de distintas poblaciones, porque una sola media pues no sería una variable, bueno sí podría ser pero a menos que sean varias muestras isi? (E2.CA.43)

... si se trata de distintas poblaciones o si se trata de una misma población pero distintas muestras, por el tipo de variable que está dando, o sea, que quede claro ¿dónde va a tomar las alturas?, ¿a qué altura se está refiriendo? (E2.CA.44)

Por lo que creo que está pensando, que a lo mejor va a decir "la población de estudiantes" y a lo mejor es cuando se daría cuenta que la media no le... no sería... (E2.CA.45)

Si sólo está hablando de una población, la media realmente no sería una variable sino sería un solo dato, ¿si? y que si es una población ya específica pues ya tenemos ese valor. No va a variar, o sea ya lo tendrían (E2.CA.46)

De igual manera, piensa que Diego confunde la variable con la longitud de las barras (Cu.CA.2b.1) debido a:

creo que cuando dice altura se refiere a la frecuencia que tiene la barra o sea el dato. Creo que a eso refiere con que se ven bien las alturas (E2.CA.51)

En resumen, Alicia piensa que Diego está confundiendo los dos tipos de alturas. Por un lado está la "altura" que hace referencia a la variable y por otro están las "alturas" que menciona en la justificación. No le queda claro al estudiante "que la media sería un solo valor, si se está refiriendo a una sola población o a un solo grupo" (E2.CA.47). Pensar en "media de altura" como variable es confundir el constructo con un parámetro, es decir, con un valor numérico que se refiere a datos poblaciones; mientras que una variable es un atributo o característica susceptible de adoptar diferentes valores. Por eso Alicia argumenta que Diego no tiene claro el concepto de variable, porque el ejemplo que escribe como tal no es una variable sino un parámetro. No obstante, abre una posibilidad de que la respuesta de Diego tenga sentido, siempre y cuando:

esté pensando en distintas muestras a lo mejor de una misma población y si podría hacer su gráfica, entonces a lo mejor...(E2.CA.52)

Un segundo error que encuentra es que Diego no logra establecer la asociación que debe existir entre el tipo de variable y el tipo de gráfico, es decir, su razonamiento es limitado porque no logra comprender el significado de variable, su clasificación y su relación con la naturaleza de los datos (ej. escala de medición) y la forma y propósito de la representación gráfica. Al igual que en el C-1 reconoció que los estudiantes no diferencian 
entre variable discreta y continua. Comentó que "cuando trabajas con un gráfico de barras se está refiriendo a una variable que sea discreta, y en este caso no es una variable discreta" (E2.CA.58), es decir, Diego "no se ha dado cuenta [del tipo de variable]..." (E2.CA.59). Sobre la causas del razonamiento de Diego o por qué escogió la variable "media de altura", Alicia simplemente contestó "no sé... no sé por qué se le ocurrió" (E2.CA.. En otro momento de la entrevista comentó "creo que es el [gráfico] que más conoce, es el que más utiliza" (E2.CA.55).

Caso 3. Gráfico: histograma y circular. En el C-3 se presenta un segmento de una investigación social, donde el alumno tenía que interpretar, describir y evaluar el gráfico de histograma. En la situación se presentan las respuestas de dos estudiantes (Omar y María), así como la respuesta de un alumno que afirmó que sí es posible representar los datos de una mejor forma que el histograma, alegando que el gráfico circular sería el mejor, "mejor interpretado, más comprensible y reflejaría mejor los datos".

En este caso, se presentan dos errores en la interpretación del histograma. Por un lado está el de Omar quien afirma que "hay siete ciudades representadas" y por otro el de María que afirma que "Del 45-50\% de las mujeres alcanzan un nivel de 1. Entre 70-79\% nivel 3. Entre $75-80 \%$ nivel 1.5, etc". En el primer caso el error es no tomar en cuenta que las alturas de las barras muestran la frecuencia (o el número) de ciudades dentro de la cual un rango de porcentaje de alfabetización de mujeres adultas en cada barra; mientras que el error de María es que piensa que las frecuencias son categorías (niveles). Veamos a continuación que respuestas dio Alicia sobre estos errores y las atribuciones que le dio.

En la afirmación de Omar, logra identificar que la respuesta que da es incorrecta e identifica como fuente de error el contar las barras.

Porque cree que cada una de las barras corresponde a una ciudad (Cu.CA.3ciO.1)

Bueno cuando él habla de siete ciudades representadas veo que en el histograma que les están dando hay precisamente siete barras y me da la idea de lo que él está pensando es que cada una de las barras representa una ciudad y lo que está diciendo es el número de mujeres. Todavía no quedaría claro qué es lo que está contando ahí, pero está hablando del número de mujeres en una ciudad, es lo que creo que percibe en este diagrama (E2.CA.75)

Ella acierta al afirmar que Omar pensó en que "cada una de las barras representa una ciudad". No obstante, se aprecia un error en su interpretación porque afirma que lo que el gráfico "está diciendo es el número de mujeres". Más aún, añade que ese número de mujeres es "en una ciudad". Ella misma duda de su respuesta al expresar "todavía no quedaría claro qué es lo que está contando". Así lo confirma cuando se le preguntó sobre qué está entendiendo Omar por frecuencia.

no está muy claro lo que él está entendiendo, porque él dice que son ciudades, entonces no está claro si está pensando que hay tres ciudades o no.... sería tres... ¿tres qué?... ¿tres mujeres en esa ciudad? $\mathrm{O}$ ¿tres qué? (E2.CA.82)

Las interpretaciones o razones que Alicia pudo proporcionar en este $\mathrm{C}$ - 3 son: a) las barras representan el porcentaje de alfabetización de la mujer adulta en América Central y del Sur, b) el estudiante piensa que el porcentaje de alfabetización de la mujer adulta 
representa diferentes ciudades, c) contó las barras del gráfico, no se dio cuenta que es el porcentaje de alfabetización, o que d) el estudiante piensa que cada barra en el histograma representa una ciudad, no la frecuencia del porcentaje de alfabetización.

Podemos apreciar en este primer error del C-3, que Alicia identifica correctamente que Omar está en un error y logra expresar cuál es ese este. No obstante, no acierta con las razones por las que el alumno comete error, lo que nos lleva a pensar que Alicia no comprendió cómo interpretar el significado de frecuencia en el contenido de la representación del histograma. Dicho por ella misma, el C-3 fue un ejercicio que resultó un poco difícil.

Sobre la conclusión de María, Alicia respondió que la alumna "no ha entendido cómo es que se está midiendo el nivel de alfabetización y piensa que 1, 2 y 3 son dichos niveles y no las frecuencias con la que ocurren los niveles (Cu.CA.3ciM.1). Alicia reconoce adecuadamente que la alumna está equivocada, y afirma que María está pensando en los niveles de alfabetización, haciendo alusión también a la "frecuencia con la que ocurren los niveles". De hecho, en la situación-problema no se habla de "niveles" de alfabetización. Al ampliar su respuesta, comentó:

...Bueno lo que debió de responder, es que por ejemplo entre que hay eh... cuando habla de porcentaje entre 70 y 75 digamos que hay tres eh... qué sería, tres ciudades en donde hay un eh... un porcentaje de alfabetización entre 70 y $75 \%$ (E2.CA.77).

De esta manera, Alicia logró identificar el razonamiento adecuado de lo que representan las frecuencias (eje $y$ ) y los porcentajes (eje $x$ ) en el histograma.

En este caso, en el inciso $d$-i, un alumno afirmó que sí es posible representar los datos de una forma mejor que el histograma, alegando que el gráfico circular sería el mejor, "mejor interpretado, más comprensible y reflejaría mejor los datos". Ante la pregunta ¿por qué da esta explicación el alumno?, Alicia responde:

Yo creo que el alumno asocia porcentajes o proporciones con los gráficos circulares y como aquí se habla de porcentajes, cree que el gráfico más apropiado es el circular (Cu.CA. 3di.1).

En este caso, Alicia logra identificar que la fuente de error del estudiante es la concepción inadecuada de que cuando se tienen valores en porcentajes es posible utilizar el el gráfico circular.

(mmm) [está pensando] Bueno creo que cuando intentara hacerlo se daría cuenta de que no estamos hablando del porcentaje de una sola ciudad por ejemplo en la que se distribuye varias categorías y de esos porcentajes, sino que los porcentajes se refieren más bien a las distintas variables. Creo que cuando ya tratara de hacer el gráfico, allí se daría cuenta o al menos encontraría esa complicación (E2.CA.87)

Opina que las dificultades que tienen los estudiantes en el momento de describir una conclusión y de redactar una recomendación a partir de un gráfico se debe a que no tiene claro el significado de variable o bien, de una deformación del concepto de variable. Por ejemplo, para la situación en la que el estudiante pretende utilizar el gráfico circular en vez 
del histograma, confunde la variable "porcentaje de alfabetización" con el que habitualmente se representa en el eje $y$ (frecuencia o porcentaje). Lo explica del siguiente modo:

Como se trata de un porcentaje por ejemplo, están acostumbrados que los porcentajes los manejan en la frecuencia y no como un dato en sí, creo que eso les causaría un poco de confusión (E2.CA.78).

Alicia hace referencia a que el C-3 se trata del porcentaje de alfabetización de la mujer adulta que se representa sobre el eje $x$, cuando según ella, regularmente se encuentra sobre el eje $y$, es decir, donde comúnmente están la frecuencia de los datos. Esto no le ocurriría al estudiante, según argumenta Alicia, si tuviera claro el concepto de variable. De ser así, podría identificar el tipo de variable que corresponde al gráfico.

Además menciona otro error que está íntimamente relacionado con el contexto de donde emergen los datos, que el estudiante no comprende lo que se mide a través del gráfico.

(mmm) Porque creo que deben de tener ellos bien claro lo que está representando este histograma para que puedan contestar. Y si para empezar ellos no tienen claro lo que está midiendo o cuál es la variable con la que se está trabajando creo que no van a poder resolver bien este problema (E2.CA.73).

Finalmente, está el error de carácter técnico, que el estudiante comete por falta de cuidado, es decir, por no leer ni observar los datos del gráfico.

Si él hubiera leído este eje, se daría cuenta de a qué se refieren los datos, que no se refieren a las ciudades como él está planteando, sino que se refiere al porcentaje de alfabetización (E2.CA.80).

Caso 4. Gráfico: comunicación impresa (media graph o print graph). En el C-4 se presenta un media graph que pone en juego la habilidad del estudiante para criticarlo y evaluarlo. Aquí se le preguntó al profesor sobre las interpretaciones que el estudiante daría al interpretar el gráfico.

Las interpretaciones que el estudiante daría al media graph, según Alicia fueron:

...creo que los alumnos primero entenderían que el $50 \%$ de las personas recorren un camino más largo para llegar al trabajo, por la distancia a la que aparece el autito, y justamente esto es lo que se deben dar cuenta, que el lector pensaría en distancias al ver este gráfico y no en tiempo y esto ocasionaría confusión... (Cu.CA.4bii.1)

[está pensando] Es un poco lo que digo acá, que creo que pensarían como es eh... aquí aparece más alejado el auto de... a lo mejor pensarían que es una distancia más larga la que se recorre, o sea pensando que es distancia la variable que se está midiendo. Creo que es lo que me responderían (E2.CA.107)

Este es un error de interpretación no válida lógicamente, el cual es atribuible no al contenido específico, sino a un error que se produce por falacias en el razonamiento (Rico, 1995). Alicia argumenta que el alumno puede confundir la variable tiempo con la velocidad o la distancia, principalmente por la proporción en que los autos están representados: "Está 
más lejos uno de otro, en el sentido de que es un auto, entonces creo que lo asociarían con distancia" (E2.CA.108). La falacia está en que el gráfico no representa velocidad o distancia, sino el tiempo (en minutos) que se viaja diariamente al lugar de trabajo. No obstante, Alicia pensó que sí existe un problema en el diseño del gráfico y que eso contribuye a que el estudiante genere interpretaciones inadecuadas. Ella insistió que el gráfico puede llevar a que el estudiante piense en distancias.

Finalmente, hace nueva alusión al error de carácter técnico, al afirmar que el estudiante no se daría cuenta que no se completa el $100 \%$ de la gente que viaja diariamente al lugar de trabajo.

De entrada creo que no se van a dar cuenta porque creo que no es una costumbre a ver si da el $100 \%$ o qué es lo que está pasando, creo que no; y sería algo que les tendría que hacer notar, es lo que creo (E2.CA.112).

Menciona que "no es costumbre" que el estudiante se fije en este criterio cuando tiene que analizar un gráfico como el media graph. No obstante, más allá de un "simple" error técnico por parte del estudiante, esto puede ser debido tanto a la dificultad por parte del estudiante a comprender y analizar este tipo de gráficos, al programa de la asignatura que en la mayoría de las ocasiones no contempla el análisis de este tipo de gráficos, o bien de origen didáctico, atribuible al profesor por la manera como presenta y enseña este gráfico.

Con el ánimo de ayudar a caracterizar y analizar el tipo de errores y dificultades que Alicia identificó a través de las situaciones problemas, los agrupamos en cuatro categorías: a) errores por ignorancia o desconocimiento de conceptos previos, b) errores de reconocimiento y comprensión de la información del gráfico, c) errores en la comprensión de conceptos y d) errores relacionados con el contexto. Como se podrá observar, una misma categoría puede ubicarse en otra, o bien, estar íntimamente relacionada con otros errores. Esto es de esperar, dado que los errores y dificultades tienen como característica común el estudio de la representación gráfica a través de diferentes situaciones-problemas interconectados por preguntas y que presentan diferentes contextos y tipos de gráficos. A continuación se describen brevemente estas categorías:

a. Errores por ignorancia o desconocimiento de conceptos previos. Este tipo de errores tienen relación con la falta de conocimiento del estudiante sobre conceptos específicos previos necesarios para resolver un problema relacionado con la RG. Aquí se agruparon los siguientes:

- error por desconocimiento del significado de los valores representados en los gráficos,

- no tienen claro el concepto y distinción entre variable discreta y variable continua, y

- no logra establecer la asociación que debe existir entre el tipo de variable y el tipo de gráfico. 
Específicamente, desconoce conceptos como componentes estructurales del gráfico, características de cada gráfico, variable discreta, variable continua, relación variable y tipo de gráfico.

b. Errores de reconocimiento y comprensión de la información del gráfico. Se trata de errores relacionados con la falta de apreciación, observación y comprensión de los elementos o componentes estructurales del gráfico:

- no distinguen que el "intervalo" de la barra de un histograma es diferente al de un gráfico de barras,

- no tomar en cuenta que las alturas de las barras muestran la frecuencia,

- interpretación no válida lógicamente, y

- errores de carácter técnico.

Específicamente, se trata de errores relacionados con identificar, observar y comprender el intervalo de la barra de un histograma, las categorías de un gráfico de barras, la altura de las barras, la frecuencia, errores de omisión y falta de observación global de los elementos del gráfico.

c. Errores en la comprensión de conceptos. Aquí se ubican algunos errores que tienen que ver con errores de carácter conceptual, es decir, el estudiante tiene un concepto equivocado o inadecuado:

- deformación del concepto de variable,

- confunde lo que es una variable con media poblacional,

- confunde la variable con la longitud de las barras, y

- confunde las frecuencias con categorías.

Específicamente, Alicia identifica los siguientes conceptos que el alumno no comprende o tiene una idea equivocada de cada uno: variable, media poblacional, longitud de barras, frecuencia, porcentaje, categoría.

d. Errores relacionados con el contexto. Agrupan los errores relacionados con la identificación, comprensión y uso de la información del contexto de la situación de donde se originan los datos, como es el problema de investigación:

- no comprende lo que se mide a través del gráfico, y

- los estudiantes dan por hecho que con información mínima y la construcción misma del gráfico otras personas lo comprenderán.

Específicamente, se identifica una falta de conocimiento de la información, como es el objetivo, la población, a quién está dirigido, entre otros. 
Esta clasificación nos permite identificar claramente:

a) Lo que no conoce el estudiante: concepto de variable, variable discreta y variable continua, características y componentes (elementos) del gráfico, relación variable-tipo de gráfico.

b) Lo que no observa de los elementos del gráfico: los ejes, los intervalos (los de los rectángulos) del gráfico de barras y del histograma, la frecuencia, los porcentajes, los elementos del media graph, las categorías de un gráfico de barras.

c) Lo que confunde: qué y que no es una variable, diferencia entre variable y media poblacional, diferencia entre variable y longitud de los rectángulos (en el gráfico de barras), diferencia entre frecuencia, categorías y porcentajes.

d) Lo que no considera del contexto: propósito del gráfico, lo que se mide a través del gráfico, a quién está dirigido el gráfico.

Si contrastamos estos errores, en cuanto a los cuatro factores críticos que influyen en la comprensión gráfica según Friel, Curcio y Bright (2001), Alicia considera principalmente errores relacionados con el primero (los propósitos para usar gráficos) y el cuarto (las características del lector) a partir del inciso (d) que tratan de los errores relacionados con el contexto. No identifica errores, o bien no los considera como factores importantes aquellos que tienen que ver con las características de las tareas (descodificación visual del gráfico, taxonomía para analizar las capacidades a desarrollar en las tareas sobre graficación, niveles cognitivos, contexto del problema) y las características de la disciplina (tipo y tamaño de datos y complejidad gráfica).

De los elementos o componentes estructurales (Friel, Curcio y Bright, 2001), Alicia identifica errores relacionados principalmente con el armazón (ej. ejes, escalas, coordenadas, marcas de referencia) y etiquetas (ej. categorías de las barras, frecuencia, porcentajes). No menciona o no considera errores en cuanto a especificadores (dimensiones visuales utilizadas para representar los datos) y de fondo (algún color, coordenadas y cuadro sobre el cual el gráfico puede ser sobrepuesto).

Podemos observar también que los errores que más menciona son conceptos que están relacionados con los conocimientos previos que el alumno debe tener para estudiar la RG: variable, tipos de variables, definición de variable, características de los gráficos

La Tabla 5.4 nos presentan otra mirada a los errores y dificultad que Alicia identificóen los estudiantes y sus correspondientes atribuciones. Sólo en dos de ellos Alicia atribuye el error al profesor y la manera como aborda la enseñanza de la RG en el aula (ver error 1 y 2). Los demás errores son atribuidos al estudiante. 
Tabla 5.4. Relación del tipo de errores y dificultades y las atribuciones que conoce Alicia de los estudiantes a partir del cuestionario

\begin{tabular}{|c|c|c|c|}
\hline Caso & Gráfico / Objetivo & Error & Atribución(es) \\
\hline \multirow[t]{4}{*}{$\mathrm{C}-1$} & \multirow[t]{4}{*}{$\begin{array}{l}\text { TyH e Histograma } \\
\text { Seleccionar, criticar } \\
\text { y evaluar el gráfico }\end{array}$} & $\begin{array}{l}\text { 1. Error por desconocimiento del } \\
\text { significado de los valores en la RG }\end{array}$ & $\begin{array}{l}\text { El profesor sólo se limita a dar } \\
\text { la definición }\end{array}$ \\
\hline & & $\begin{array}{l}\text { 2. Los estudiantes dan por hecho que } \\
\text { otras personas lo comprenderán }\end{array}$ & $\begin{array}{l}\text { Énfasis en técnicas de } \\
\text { graficación y } \\
\text { descontextualización del } \\
\text { gráfico }\end{array}$ \\
\hline & & $\begin{array}{l}\text { 3. No distinguen que el "intervalo" de la } \\
\text { barra de un histograma es diferente al de } \\
\text { barras }\end{array}$ & $\begin{array}{l}\text { Ignorancia de los elementos de } \\
\text { un gráfico }\end{array}$ \\
\hline & & $\begin{array}{l}\text { 4. No tienen claro el concepto y } \\
\text { distinción entre variable discreta y } \\
\text { continua. }\end{array}$ & Ignorancia de conceptos \\
\hline \multirow[t]{4}{*}{$\mathrm{C}-2$} & \multirow{4}{*}{$\begin{array}{l}\text { Barras } \\
\text { Definir una variable } \\
\text { y relacionar con el } \\
\text { tipo de gráfico }\end{array}$} & $\begin{array}{l}\text { 5. Confunde lo que es una variable con } \\
\text { media poblacional }\end{array}$ & $\begin{array}{l}\text { Comprensión inadecuada del } \\
\text { concepto }\end{array}$ \\
\hline & & $\begin{array}{l}\text { 6. Confunde la variable con la longitud } \\
\text { de las barras }\end{array}$ & $\begin{array}{l}\text { Comprensión inadecuado del } \\
\text { concepto }\end{array}$ \\
\hline & & $\begin{array}{l}\text { 7. No logra establecer la asociación que } \\
\text { debe existir entre el tipo de variable y el } \\
\text { tipo de gráfico }\end{array}$ & $\begin{array}{l}\text { No comprende el significado } \\
\text { de variable y la naturaleza de } \\
\text { los datos }\end{array}$ \\
\hline & & $\begin{array}{l}\text { 8. No tienen claro el concepto y } \\
\text { distinción entre variable discreta y } \\
\text { variable continua }\end{array}$ & Ignorancia de conceptos \\
\hline \multirow[t]{5}{*}{$\mathrm{C}-3$} & \multirow{5}{*}{$\begin{array}{l}\text { Histograma y circular } \\
\text { Interpretar, describir } \\
\text { y evaluar el gráfico }\end{array}$} & $\begin{array}{l}\text { 9. No toma en cuenta que las alturas de } \\
\text { las barras muestran la frecuencia }\end{array}$ & $\begin{array}{l}\text { Ignorancia de los elementos } \\
\text { del gráfico }\end{array}$ \\
\hline & & $\begin{array}{l}\text { 10. Confunde las frecuencias con } \\
\text { categorías }\end{array}$ & $\begin{array}{l}\text { Comprensión inadecuado del } \\
\text { concepto }\end{array}$ \\
\hline & & $\begin{array}{l}\text { 11. Deformación del concepto de } \\
\text { variable }\end{array}$ & $\begin{array}{l}\text { Comprensión inadecuado del } \\
\text { concepto }\end{array}$ \\
\hline & & $\begin{array}{l}\text { 12. No comprende lo que se mide a } \\
\text { través del gráfico }\end{array}$ & Desconocimiento del contexto \\
\hline & & 13. Errores de carácter técnico & $\begin{array}{l}\text { No lee ni observa los } \\
\text { elementos del gráfico }\end{array}$ \\
\hline \multirow[t]{2}{*}{$\mathrm{C}-4$} & \multirow{2}{*}{$\begin{array}{l}\text { Media graph } \\
\text { Criticar y evaluar el } \\
\text { gráfico }\end{array}$} & 14. Interpretación no válida lógicamente & $\begin{array}{l}\text { Ignorancia de los elementos } \\
\text { del gráfico }\end{array}$ \\
\hline & & 15. Errores de carácter técnico & $\begin{array}{l}\text { No lee ni observa los } \\
\text { elementos del gráfico }\end{array}$ \\
\hline
\end{tabular}


Del tipo y atribuciones de los errores, estos son diversos y pueden encontrarse en diferentes gráficos y para diferentes objetivos de aprendizaje (ej. para seleccionar, evaluar y criticar un gráfico; definir una variable y relacionarlo con el gráfico; interpretar, describir y evaluar un gráfico). No obstante, encontramos algunos resultados intersantes:

- En todas las situaciones-problema (C-1, C-2, C-3, C-4) hace referencia al desconocimiento del estudiante de la variable y la diferencia que existe entre la discreta y la continua.

- En el C-1 y el C-4 se hizo referencia a errores atribuidos a la falta de conocimiento del contexto. Estos gráficos contiene más información que los otros sobre el contexto en que se construyeron y a quiénes está dirigido.

- En el C-1, C-3 y C-4 se hizo referencia al error por desconocimiento de los componentes o elementos del gráfico. Estos casos presentaron un diseño de gráfico. El C-2 trató de la definición de un gráfico.

- En el C-2 se resaltó la dificultad de establecer la relación entre la variable y el tipo de gráfico.

- Sobre el TyH se identificó el error por desconocimiento de los valores representados en el gráfico.

- Sobre el histograma y el gráfico de barras, se resaltó el error de no comprender el significado de continuidad de la variable y de la diferencias en el diseño de los rectángulos que se representan en el eje $x$.

- En el histograma y el media graph, destaca el error por falta de apreciación y observación de los elementos del gráfico.

- Del media graph, se resaltaron los errores que pueden haber en su construcción y diseño.

Los errores y dificultades encontrados por Alicia coinciden con algunos identificados en la literatura:

1. interpretar el contenido de los gráficos, además de la incapacidad de procesar la información contenida en ellos de forma coherente (Batanero, 2001b),

2. elegir incorrectamente el tipo de gráfico adecuado (Batanero, 2001b),

3. relacionados con el título, etiquetas, especificadores y tipo de gráfico (Wu, 2004),

4. confusión entre frecuencia y valor de los datos (Wu, 2004),

5. relacionados con el uso de la información dada en el gráfico (Wu, 2004),

6. relacionados al uso del contexto (Wu, 2004), y

7. no entienden que el área (de una barra) representa la frecuencia a diferencia de la longitud (representado en un gráfico de barras) delMas, Garfield y Ooms (2005)

Además, Alicia identificó los siguientes:

- no tienen claro el concepto y distinción entre variable discreta y variable continua,

- no logra establecer la asociación que debe existir entre el tipo de variable y el tipo de gráfico,

- no distinguen que el "intervalo" de la barra de un histograma es diferente al de un gráfico de barras, 
- no tiene en cuenta que las alturas de las barras muestran la frecuencia,

- errores de carácter técnico (por no observar detenidamente el gráfico),

- confunde lo que es una variable con media poblacional,

- los estudiantes dan por hecho que con información mínima y la propia construcción del gráfico otras personas lo comprenderán, y

- dar por sentado que los media graph son correctos.

Por último, llamó la atención que en varios momentos de la entrevista, cuando se le preguntó sobre el razonamiento del estudiantes, Alicia contestó evasivamente o reconoció no saber al respecto. Veamos algunos ejemplos:

- Desconocimiento a cómo los alumnos obtienen, llegan o construyen algunos gráficos y a las respuestas que darían sobre lo que representan los datos que aparece en éstos:

E: Cuando tú les preguntes “¿cómo es que obtuvieron sus gráficos?”, ¿qué crees que te contesten los alumnos? (C-1, inciso 1a)

A: (mmm) Creo que habrán unos que sí (jaja) me contesten... (mmm) No sé que me contestarían exactamente (E2.CA.05)

- Desconocimiento de lo que los alumnos conocen sobre los beneficios y las dificultades de los gráficos:

E: Al final comentas que ellos te digan "¿cuáles son los beneficios y las dificultades que presentan cada gráfico", ¿qué crees que te contestarían? Primero, ¿qué crees que te contestarían? y ¿qué te deberían contestar? (C-1, inciso 1a)

A: (Mjú)... Cuando me haces esa pregunta se me hace difícil porque te digo que me contestarían lo que yo quisiera que me contesten o lo que yo creo que me van a contestar. Lo que creo que debe ser correcto y no siempre es así, se me hace difícil pensar qué es lo que me van a contestar. (E2.CA.11)

No logro hacer la diferencia entre eso... (E2.CA.12)

- Dar por sentado que los alumnos ya entendieron la RG sin pensar o conocer sobre su proceso de desarrollo cognitivo:

E: ¿Qué te llamó más la atención del caso? Al momento de checar el caso ¿qué te llamó más la atención? (C-1, opinión general)

A: ... Lo que me llamó la atención es que por lo general no te pones a pensar si realmente ya entendieron el gráfico, como que, al menos, en mi caso doy por sentado de que sí lo entendieron, de que sí saben de que se trata un histograma (E2.CA.30)

E: Si pudieras identificar pros y contras del caso uno, ¿qué dirías? (C-1, opinión general)

A: [está pensando] No sé (mmm) Es que todavía me sorprende la respuesta que dan... Es lo que te decía, no me pongo a pensar en eso, si yo viera esto, a mí me daría trabajo pensar que me digan esto "que no logran discernir entre un gráfico y otro" (E2.CA.34) 
Estos ejemplos nos permiten afirmar que Alicia tiene un limitado conocimiento sobre el razonamiento del estudiante. Tal como comentó en otro momento, enseña como cree, pero sin tener pleno conocimiento de qué conoce el estudiante y por qué hace o presenta ciertos errores y dificultades al aprender la RG.

\subsubsection{Identificación y diagnóstico del conocimiento del estudiante}

Del análisis de información obtenida, no hay suficiente evidencia para afirmar que Alicia conoce y utiliza una diversidad de formas para diagnosticar el conocimiento del estudiante, es decir, no se identificaron respuestas que permitan caracterizar que de manera intencional y consciente busca identificar las creencias, los errores y dificultades del estudiante del tópico en cuestión. Más aún, ella no es consciente de la existencia y necesidad de este conocimiento. Esto también se sustenta por el reconocimiento de Alicia de no saber qué contestar a ciertas preguntas y la sorpresa que generaron muchas de estas.

No obstante, pudimos identificar algunos aspectos que nos permitieron conocer lo que hace al respecto. Por ejemplo, para saber si el alumno ha comprendido un tema, sigue los siguientes pasos:

Primero, solicita a los alumnos que realicen los ejercicios.

Segundo, revisa si están o no correctos para ver qué dificultades tiene el estudiante (de manera individual o grupal durante las clases).

Tercero, se acerca a aquellos estudiantes que tienen dificultades y les hace preguntas para intentar que sea él mismo quien identifique su propio error.

Del mismo modo procede en el tema de la RG:

a la hora de revisar sus tareas, sus ejercicios es donde me doy cuenta si ya entendieron, por lo que responden o cómo responden. Así me doy cuenta de qué es lo que está pasando (E1.CA.103).

Añade que un recurso útil es que salgan a la pizarra a realizar un ejemplo específico (ej. que dibujen una distribución de frecuencias) y les va haciendo preguntas para valorar si lo comprenden o no.

En reiteradas ocasiones, Alicia afirma que le gusta que los alumnos trabajen en clase, porque piensa que con ello puede supervisar lo que hacen y los estudiantes tienen la oportunidad de presentar sus dudas y preguntas. De este modo, identifica las dificultades que éstos tienen cuando hacen los ejercicios, y haciéndoles preguntas explora si tienen o no alguna dificultad en particular.

Trato de que pasen a hacer el ejercicio frente al grupo y en ese momento tan solo el hecho de cómo van planteando el problema, cómo lo van resolviendo, yo me voy dando cuenta cuando alguien ya lo entendió o nada más lo está haciendo mecánicamente. Entonces cuando veo que nada más lo está escribiendo o lo está copiando de algún lado, entonces les voy preguntando, les voy diciendo "¿por qué escribiste esto?, ¿qué es lo que vas a contestar?”, les voy haciendo preguntas y es cómo voy viendo más o menos quiénes son los que tienen alguna dificultad y qué es lo que está pasando (E1.CA.87) 
Con base en el cuestionario didáctico sobre RG, hallamos que dos de los recursos que utiliza para identificar y diagnosticar el conocimiento del estudiante son: las preguntas y los ejercicios. La siguiente respuesta lo confirma, cuando se le pregunta ¿cómo sabrías si un alumno ya logró discriminar bien entre uno y otro gráfico?:

[está pensando] Yo creo que le haría estas preguntas en esta parte y hacer más ejercicios para ver si ya se entendió (E2.CA.29)

A continuación presentamos cómo utiliza estos recursos para diagnosticar el conocimiento del estudiante.

Preguntas. Por ejemplo, en la situación-problema (C-2), Alicia utiliza como recurso para diagnosticar el pensamiento y razonamiento de Diego preguntas encaminadas a explorar el significado que tiene el estudiante de "variable", "población", "media" y "media poblacional". Diego planteó una situación inusual, abstracta y compleja, por lo que Alicia se ve en la necesidad de insistir con estas preguntas y explorar así lo que tiene en la mente el estudiante.

En el C-3, ante la pregunta ¿cómo le harías para que Omar se diera cuenta de su error? Ella afirmó:

Creo que es un poco a lo que se refiere mi respuesta de que preguntándoles ¿qué es lo que están entendiendo?, que vieran qué tipo de información les están dando y qué datos son los que están manejando (E2.CA.79).

Generalmente las preguntas que utiliza giran en relación a qué entiende el alumno por el concepto, o bien, qué información o datos muestra el gráfico y por qué piensa el alumno que es correcto lo que hizo.

Ejercicios. Por ejemplo, en el C-2, Alicia le solicita a Diego que construya el gráfico de barras con la variable "la media de altura":

... que hiciera un ejercicio en donde precisamente con su variable, que él estableció, hiciera su diagrama de barras o lo que el dice ¡que lo haga!, "a ver muy bien, entonces para la variable que tú estás diciendo escribe, haz el histograma [sic]" y para ver qué es lo que va hacer (E2.CA.49)

... lo que siento que haría con él, es que se ponga hacerlo. Que justamente ya que tenga bien su variable que haga, que trate de hacer el tipo de gráfico que él está proponiendo, para ver a qué dificultades se va a enfrentar cuando esté tratando de hacer el gráfico que él dice (E2.CA.53)

En otro momento, Alicia al darse cuenta de que los alumnos no tenían cuidado con sus escalas a la hora de identificar o escribir la frecuencia en el gráfico o sus intervalos, muestra un ejercicio (ver Figura 5.7) donde explora lo que el alumno estaba pensando:

Entonces en algunas había puesto una escala digamos de, si estamos hablando de veinte la máxima frecuencia, era del uno al veinte; en otra trabajamos de cinco en cinco por decir, entonces veías la diferencia, y en otra que tendían mucho hacer, que de repente les da flojera, que son muchos números y en la escala de la frecuencia de repente "te cortan" y te dicen "pues voy a empezar de diez" y pa delante. Entonces una de las gráficas estaba justamente cortada. Entonces para que se dieran cuenta de que: si un gráfico a simple vista es para que te des una idea global de lo que está pasando, pues si 
tenía que ver el hecho de que estuviera bien tu escala porque así de buenas a primeras te daba percepciones distintas las tres gráficas y se trataba del mismo problema. Cosas así. (E1.CA.88)

En ambos ejemplos observamos que el tipo de ejercicios tiene que ver con la construcción del gráfico y los elementos del mismo. Al parecer la intención es que el alumno se de cuenta de su propio error e identificar las dificultades que enfrenta en cada tipo de ejercicio.

A través de estos resultados, pudimos corroborar que la forma habitual que ella utiliza en la identificación y diagnóstico tiene relación con los errores y dificultades y no con las creencias y concepciones del estudiante. Asimismo, se centra en revisar las tareas y ejercicios de los alumnos, solicitarle pasar a la pizarra para que resuelvan algún ejercicios delante del grupo y hacerles algunas preguntas relacionadas con la información o datos que muestra el gráfico y por qué piensa el alumno que es correcto lo que hizo. Estos recursos los utiliza más para verificar el aprendizaje adquirido que para explorar los conocimientos previos de los estudiantes.

\subsubsection{Estrategias específicas para corregir errores y dificultades}

Cuando analizamos las estrategias específicas que Alicia utiliza para corregir los errores y dificultades de los estudiantes, volvimos a identificar las mismas estrategias y representaciones instruccionales de la sección 5.1.6: explicaciones, preguntas, ejercicios, instrucciones.

Recordemos que estas estrategias fueron exploradas a partir de algunos incisos del cuestionario, cuyo propósito era conocer cómo el profesor corrige los errores y dificultades que el alumno presenta en cada situación (ver Tabla 4.3 del Capítulo 4).

A continuación presentamos las respuestas de Alicia agrupadas según el tipo de estrategia que sugiere.

\subsubsection{Explicaciones}

En el C-1, ante la pregunta del inciso lc-ii ¿qué harías para ayudar al estudiante a ver sus errores e inducirlo a aprender a discernir entre un gráfico de $T y H$ y de histograma?, Alicia respondió:

Le haría notar que en el histograma se pierde información ya que por ejemplo se ve que hay 2 tiempos menores de 5 minutos pero no se sabe cuáles son esos 2 tiempos mientras que en el diagrama de tallo y hoja se puede saber exactamente cuántos tiempos son menores que 5 y también cuáles son esos tiempos. Esto lo haría pidiéndole al estudiante que sin ver sus datos y viendo sólo sus diagramas, contestara cuántos tiempos son menores que 5 minutos (Cu.CA.1c-ii).

Además de algunas preguntas que utiliza, en esta respuesta hace alusión a la explicación ("le haría notar") y a la instrucción ("sin ver sus datos y viendo sólo sus diagramas"). Ambas las utilizaría para que el alumno se dé cuenta de las ventajas y desventajas de cada gráfico a partir de la información de los datos. 


\subsubsection{Preguntas}

Alicia afirma que cuando se enseña Estadística el profesor debe buscar que los alumnos vayan descubriendo y se vayan despertando dudas a través de preguntas que ellos logren contestarlas. De ese modo, según Alicia, los alumnos no van a olvidar tan fácilmente y tendrán un aprendizaje más significativo.

Para corregir algunos errores Alicia recurre nuevamente a las preguntas. Por ejemplo, en el C-1, ella manifestó que les haría las siguientes preguntas con el propósito de darse cuenta si realmente los alumnos entendieron el ejercicio:

¿Cómo es que obtuvieron sus gráficos? (Cu.CA.1a.1)

¿Qué representan esos números que aparecen en el gráfico de tallo y hoja? (Cu.CA.1a.3)

¿Cómo es que justamente estos números son los que escribieron? (E2.CA.4)

¿Cuáles son los beneficios y las dificultades que presentan cada uno de estos gráficos? (Cu.CA.1a.3)

No obstante, reconoció no saber qué le contestarían los alumnos ante de estas preguntas.

En el C-2, ella mencionó las siguientes preguntas con el propósito de determinar si para el alumno (Diego) las dos alturas se refieren a lo mismo, así como entender a qué se refiere con esa variable:

¿A qué altura se refiere en la variable? (C-2.CA.2a.1)

¿Dónde va a tomar las alturas? (E2.CA.44)

¿A qué altura se está refiriendo? (E2.CA.44)

¿Cuál es la población de donde va a tomar la variable? (Cu.CA.2a.2)

¿A qué media se refiere? (Cu.CA.2a.3)

¿La barra más alta corresponde a las alturas mayores? (Cu.CA.2c.2)

Alicia amplía su razonamiento sobre estas preguntas:

Bueno mi respuesta es pensando que esté confundiendo los dos tipos de altura, entonces si está manejando las alturas como una misma situación, lo que pretendo con este ejercicio que le daría es que vea que no necesariamente la altura de los alumnos que tenga mayor frecuencia es la altura mayor ¿si? para que logre distinguir la diferencia entre los dos tipos de altura (E2.CA.54).

En el C-3, inciso 3ci, se le preguntó ¿cómo ayudaría a los estudiantes a comprender a qué tipo de variable se refiere el gráfico?, ella contestó:

Creo que es un poco a lo que se refiere mi respuesta de que preguntándoles ¿qué es lo que están entendiendo?, que vieran qué tipo de información les están dando y qué datos son los que están manejando (E2.CA.79)

... y que a la vez viera a qué se refieren cada una de las frecuencias, qué significados tienen estás frecuencias para esta información que le están dando ¿si ? Para que saliera del error de pensar que son las ciudades las que están representadas (E2.CA.81)

Básicamente la razón por la que Alicia utiliza estas preguntas es que son para hacer pensar a los estudiantes, hacerlos reflexionar, es decir, "que pensaran mejor las cosas 
cuando ven un gráfico, que lo puedan analizar" (E2.CA.115) y por consiguiente se den cuenta de sus propios errores y así puedan corregirlos.

$\mathrm{Si}$ analizamos las características de estas preguntas, observamos que la mitad aproximadamente están centradas en explorar lo que significan determinado elementos o componentes estructurales del gráfico. Por ejemplo: ¿a qué altura se está refiriendo?, ¿qué representan esos números que aparecen en el gráfico de tallo y hoja?, ¿qué datos son los que están manejando? y ¿a qué se refieren cada una de las frecuencias? Igual nos dimos cuenta que un mismo número de preguntas estaba centrado en el análisis del contexto. Por ejemplo, ¿cómo es que obtuvieron sus gráficos?, ¿cuál es la población de donde va a tomar la variable? y ¿qué tipo de información les están dando?

\subsubsection{Ejercicios}

Para Alicia, otra manera de corregir los errores y dificultades de los estudiantes fueron los ejercicios, así lo manifestó en el C-2 para corregir el error de Diego:

... que hiciera un ejercicio en donde precisamente con su variable, que él estableció, hiciera su diagrama de barras o lo que él dice ique lo haga!, "a ver muy bien, entonces para la variable que tú estás diciendo escribe, haz el histograma [sic]" y para ver qué es lo que va hacer (E2.CA.49).

Específicamente ante la pregunta del inciso $2 c$, ¿cómo haría para corregir el error de Diego? Ejemplifique por favor, Alicia respondió:

Pidiéndole que considerara las alturas de los alumnos del salón y que hiciera una gráfica de estos datos (Cu.CA.2c.1)

... luego le preguntaría si la barra más alta corresponde a las alturas mayores (Cu.CA.2c.2)

... es que se ponga hacerlo [el gráfico]. Que justamente ya que tenga bien su variable que haga, que trate de hacer el tipo de gráfico que él está proponiendo, para ver a qué dificultades se va a enfrentar cuando esté tratando de hacer el gráfico que él dice (E2.CA.53).

Lo que pretende Alicia es que Diego "vea que no necesariamente la altura de los alumnos que tenga mayor frecuencia es la altura mayor isi? para que logre distinguir la diferencia entre los dos tipos de altura" (E2.CA.54). Alicia recurre a un contexto con el que el estudiante está familiarizado (las alturas de sus compañeros de clase) y le pide que haga el gráfico, que represente los datos.

En este caso, pudimos observar que el tipo de ejercicios a que hace alusión tienen que ver con la construcción de la gráfica.

\subsubsection{Instrucciones}

El C-3 recoge los ejemplos que evidencian las instrucciones que Alicia pedíría a los estudiantes para corregir sus errores o concepciones inadecuadas. Recordemos que en dos momentos se le pregunta ¿qué estrategias utilizarías para que Omar y María analicen si su razonamiento es correcto? (C-3.cii) y ¿qué harías ante esta respuesta? (C-3.dii). 
Pedirle que analizara qué significados tiene la frecuencia en este gráfico de barras (C-3.CA.3ciiO.1) ... y que leyera a qué se refiere el eje horizontal del gráfico (Cu.CA.3ciiO.2)

Pedirle que lea bien el problema y que lea a qué se refiere el eje horizontal de la gráfica (Cu.CA.3ciiM.1)...

y que observara cómo se estaba midiendo el nivel de alfabetización (Cu.CA.3ciiM.2)

Pedirle al alumno que con la información que se tiene hiciera un diagrama circular (C-3.CA.3dii.1) ...pero que analizara muy bien antes cómo los investigadores habían medido el grado de alfabetización (C-3.CA.3dii.2)

y [analizara] de cuántas ciudades se está hablando (C-3.CA.3dii.3)

... y que pensara muy bien cómo debía presentar su diagrama para que éste fuera claro al lector (Cu.CA.3dii.4)

Observamos que Alicia utiliza diferentes instrucciones: analizar, leer, observar, hacer y pensar. Al parece utiliza los verbos "analizar", "leer" y "observar" como sinónimos, haciendo referencia a que el alumno se diera cuenta (antes de resolver la situación, el problema o ejercicio) de la información del gráfico. Llama la atención que después de cada verbo se encuentra una afirmación en forma de pregunta, las cuales están orientadas a conocer el qué de la representación gráfica (ej. ¿qué significados tiene la frecuencia? y ¿a qué se refiere el eje horizontal del gráfico?) y a conocer el cómo (ej. ¿cómo se estaba midiendo el nivel de alfabetización?, ¿cómo los investigadores habían medido el grado de alfabetización? y ¿cómo debía presentar su diagrama para que éste fuera claro al lector?).

También observamos que Alicia pide al estudiante hacer o realizar alguna acción, específicamente que hiciera el gráfico circular, con el propósito de que se diera cuenta de lo complicado que es representar este gráfico a partir de los datos:

Bueno creo que cuando intentara hacerlo se daría cuenta de que no estamos hablando del porcentaje de una sola ciudad por ejemplo en la que se distribuye varias categorías y de esos porcentajes, sino que los porcentajes se refieren más bien a las distintas variables (E2.CA.87).

Creo que justamente es pedirles el diagrama circular para que se dieran cuenta de la diferencia entre los tipos de porcentaje que se estarían manejando, y que se fijaran bien en la información antes, para que luego cuando intentaran hacer el diagrama a lo mejor tuvieran un poco más claro y no sólo así (E2.CA.88)

Esta acción tiene relación con la construcción del gráfico.

Es importante señalar que las estrategias identificadas para corregir los errores que cometen los estudiantes están relacionadas entre sí, es decir, puede utilizarse simultáneamente. Dependiendo de las respuestas y comportamiento del estudiante, Alicia está dispuesta a utilizar ya sea alguna explicación, pregunta, ejercicio o instrucción, o una combinación de éstas.

La Tabla 5.5 presenta un resumen de las estrategias sugeridas por Alicia a partir de las preguntas del cuestionario didáctico sobre la RG. Encontramos que: 
- Lo común a todas las situaciones es que realice preguntas para explorar si el alumno ya entendió el ejercicio, para ayudarlo a entender un concepto y para hacerlo pensar.

- Utiliza la explicación para presentar las ventajas y desventajas del gráfico.

- Utiliza los ejercicios para que el alumno distinga entre un concepto.

- Para corregir algún error de razonamiento del estudiante (ej. Diego, Omar o María) utiliza las instrucciones.

- Todas las estrategias tienen estrecha relación con lograr que el estudiante identifique las características y elementos del gráfico y cómo construirlo.

Tabla 5.5. Resumen de las estrategias y propósito de aprendizaje sugeridas por Alicia a partir de las preguntas del cuestionario

\begin{tabular}{|c|c|c|c|c|}
\hline Caso & Gráfico/Objetivo & Preguntas del cuestionario & $\begin{array}{l}\text { Estrategia } \\
\text { sugerida }\end{array}$ & $\begin{array}{l}\text { Propósito de } \\
\text { Alicia }\end{array}$ \\
\hline \multirow[t]{2}{*}{$\mathrm{C}-1$} & $\begin{array}{l}\text { TyH e Histograma } \\
\text { Seleccionar, criticar y } \\
\text { evaluar el gráfico }\end{array}$ & $\begin{array}{l}\text { ¿Qué harías para ayudar al } \\
\text { estudiante a ver sus errores e } \\
\text { inducirlo a aprender a discernir } \\
\text { entre un gráfico de TyH y de } \\
\text { histograma }\end{array}$ & . Explicación & $\begin{array}{l}\text { Darse cuenta de } \\
\text { las ventajas y } \\
\text { desventajas de } \\
\text { cada gráfico }\end{array}$ \\
\hline & & & Preguntas & $\begin{array}{l}\text { Darse cuenta si } \\
\text { entendió el } \\
\text { ejercicio }\end{array}$ \\
\hline \multirow[t]{2}{*}{$\mathrm{C}-2$} & $\begin{array}{l}\text { Barras } \\
\text { Definir una variable y } \\
\text { relacionar con el tipo }\end{array}$ & $\begin{array}{l}\text { ¿Cómo haría para corregir el } \\
\text { error de Diego }\end{array}$ & Preguntas & $\begin{array}{l}\text { Ayudar entender } \\
\text { a qué se refiere } \\
\text { con esa variable }\end{array}$ \\
\hline & & & Ejercicios & $\begin{array}{l}\text { Logre distinguir } \\
\text { la diferencia entre } \\
\text { los dos tipos de } \\
\text { altura }\end{array}$ \\
\hline \multirow[t]{3}{*}{$\mathrm{C}-3$} & $\begin{array}{l}\text { Histograma y circular } \\
\text { Interpretar, describir } \\
\text { y evaluar el gráfico }\end{array}$ & $\begin{array}{l}\text { ¿Qué estrategias utilizarías para } \\
\text { que Omar y María analicen si su } \\
\text { razonamiento es correcto? y ¿qué } \\
\text { harías ante esta respuesta? }\end{array}$ & Preguntas & $\begin{array}{l}\text { Hacer pensar a } \\
\text { los estudiantes }\end{array}$ \\
\hline & & & $\begin{array}{l}\text { Instrucciones } \\
\text { (ej. leer y observar) }\end{array}$ & $\begin{array}{l}\text { Darse cuenta de } \\
\text { la información } \\
\text { del gráfico }\end{array}$ \\
\hline & & & $\begin{array}{l}\text { Instrucciones } \\
\text { (ej. observar y hacer } \\
\text { el gráfico) }\end{array}$ & $\begin{array}{l}\text { Darse cuenta de } \\
\text { lo complicado } \\
\text { que es representar } \\
\text { el gráfico }\end{array}$ \\
\hline
\end{tabular}

Los resultados obtenidos nos permiten concluir que las estrategias que propone tienen estrecha relación con las estrategias y representaciones instruccionales descritas en la sección 5.1.6, es decir, son semejantes en cuanto al tipo de representaciones, forma, propósitos, contextos y momentos, así como recursos o materiales. No se encontró ninguna estrategia diferente a las antes descritas. 
Aún cuando estas estrategias tienen consistencia con las respuestas que reiteradamente Alicia nos dio sobre cómo trabaja con sus alumnos (explicar, preguntar y poner ejercicios), nos manifestó que no hace ninguna actividad similar a las propuestas en el cuestionario con sus estudiantes, o lo que es más preciso, no trabaja a ese nivel (interpretación y escritura) de análisis la representación gráfica:

Sólo trabajé con el histograma como el ejercicio que te mostré, en donde doy el histograma y a partir de ahí tienen que dar una distribución por ejemplo, de frecuencias y obtener sus medidas centrales o de dispersión a partir de ese gráfico (E2.CA.40).

(mmm) No así tan puntual no. O sea te digo les pedí que saquen su distribución, pero no mayor información (E2.CA.41) sus alumnos.

Reconoce que no elabora, realiza o implementa actividades de esa naturaleza con

\subsubsection{Dificultades para enseñar}

La interacción con Alicia nos permitió conocer sobre sus dificultades para enseñar. De manera reiterativa manifestó no tener preparación como docente y que lo que enseña es producto de la experiencia y de cómo ella piensa que debe ser. Con frecuencia expresó la dificultad de responder a determinadas preguntas durante las entrevistas. Por ejemplo, en la primera entrevista se identificaron 54 pausas prolongadas con la etiqueta "está pensando", mientras que en la entrevista a profundidad fueron 61 pausas prolongadas identificadas.

La Tabla 5.6 muestra algunos ejemplos de la dificultad que representó para Alicia contestar a diferentes preguntas.

Específicamente, ¿con qué aspectos tiene dificultades Alicia? A continuación enunciaremos los aspectos que identificamos a lo largo del estudio:

- Da por sentado que el alumno ya comprendió

Al preguntarle sobre lo que le llamó la atención de los casos que se le presentaron fue frecuente escuchar respuestas como:

.. Lo que me llamó la atención es que por lo general no te pones a pensar si realmente ya entendieron el gráfico, como que al menos en mi caso doy por sentado de que sí lo entendieron, de que sí saben de qué se trata un histograma (E2.CA.31) (C-1)

mmm) El tipo de ejercicio en sí, incluso para mi fue un poco difícil, o sea, como que lo volví a leer y vuelvo a ver qué me están midiendo aquí, otra vez... y todavía así como que lo tengo que releer, releer para entenderlo bien entonces...(E2.CA.91) (C-3) 
Tabla 5.6. Ejemplos de las dificultades expresadas por Alicia para enseñar

\begin{tabular}{|c|c|c|}
\hline Caso & Entrevistador & Respuesta de Alicia \\
\hline $\mathrm{C}-1$ & $\begin{array}{l}\text { E: ¿Qué crees que te contestarían? } \\
\text { ¿Cuáles son los beneficios y } \\
\text { las dificultades de cada } \\
\text { gráfico?" }\end{array}$ & $\begin{array}{l}\text { A: Cuando me haces esa pregunta se me hace } \\
\text { difícil porque te digo que me contestarían lo } \\
\text { que yo quisiera que me contesten o lo que yo } \\
\text { creo que me van a contestar. Lo que creo que } \\
\text { debe ser correcto y no siempre es así, se me } \\
\text { hace difícil pensar qué es lo que me van a } \\
\text { contestar. (E2.CA.11) } \\
\text { A: No logro hacer la diferencia entre eso... } \\
\text { (E2.CA.12) }\end{array}$ \\
\hline $\mathrm{C}-1$ & $\begin{array}{l}\text { E: Ante estas preguntas ¿qué crees } \\
\text { que te contesten ellos? }\end{array}$ & $\begin{array}{l}\text { A: }(\mathrm{mmm}) \text { No sé qué me contestarían } \\
\text { exactamente. (E2.CA.5) }\end{array}$ \\
\hline $\mathrm{C}-1$ & $\begin{array}{l}\text { E: Si pudieras identificar pros y } \\
\text { contras del caso uno, ¿qué } \\
\text { dirías? }\end{array}$ & $\begin{array}{l}\text { A: [está pensando] No sé }(\mathrm{mmm}) \text { Es que todavía } \\
\text { me sorprende la respuesta que dan... Es lo que } \\
\text { te decía, no me pongo a pensar en eso, si yo } \\
\text { viera esto, a mí me daría trabajo pensar que me } \\
\text { digan esto "que no logran discernir entre un } \\
\text { gráfico y otro". (E2.CA.34) }\end{array}$ \\
\hline $\mathrm{C}-4$ & $\begin{array}{l}\text { E: En tu conclusión. Si tú esto [el } \\
\text { caso 4] se lo das a uno de tus } \\
\text { alumnos [y le dices] "a ver } \\
\text { critícame este gráfico" ¿Qué } \\
\text { crees que te digan? }\end{array}$ & $\begin{array}{l}\text { A: [está pensando] No sé exactamente, a lo mejor } \\
\text { habría algunos que me digan "que está bien el } \\
\text { gráfico, que se entiende perfectamente" [está } \\
\text { pensando] ..." (E2.CA.113) }\end{array}$ \\
\hline
\end{tabular}

En diferentes momentos reconoce que le hace falta analizar más en profundidad su práctica:

creo que eso es lo que me falta un poquito en el sentido de que como que yo ya les digo "estas van a usar y eso van a usar" pero no dejo que ellos se den cuenta por sí solos ¿si?, creo que soy impositiva en ese aspecto de que les digo "esto es para tal y esto es para tal" y ellos de cierta forma no cuestionan, porque la maestra dijo que... (E2.CA.115)

... que a lo mejor a veces no lo analizamos, lo vemos "¡ah sí!", damos por sentado que se trata de algo que no es así (E2.CA.115)

- Desconoce las atribuciones y explicaciones de las respuestas que da el estudiante

En la entrevista en profundidad muestra un desconocimiento sobre la forma de pensamiento de los estudiantes; así en las respuestas al cuestionario contestó:

“[está pensando] No sé... no sé porque se le ocurrió poner la media” (E2.CA.50)

[está pensando] Creo que en todos los casos son preguntas que me parecen muy interesantes, importantes y que por el momento no hago, y que considero que son aspectos que son importantes a la hora de ver gráficos (E2.CA.116) 
- Encontrar y usar ejercicios con enfoque constructivista para mostrar el significado de la Estadística

Aún cuando utiliza los ejercicios como recurso para enseñar y como estrategia para corregir ciertos errores de los estudiantes, también reconoció la dificultad de utilizar ejercicios bajo el enfoque constructivista.

se me hace bastante difícil, de que sí por medio de los ejercicios vayan s tratando de verdad de entender de qué es lo que se trata, digamos la materia en este caso de Estadística (E1.CA.7)

Alicia reconoció que para ella enseñar Estadística o cualquier otra materia "consistía en venir a dar la explicación, poner algunos ejemplos, preguntarles a los alumno ¿se entendió? ¿no se entendió?” (E1.CA.6). No obstante, al implementar la Universidad en modelo pedagógico basado en el constructivismo, se le hace difícil comprender qué ejercicios ayudarían a cumplir con los principios del modelo.

- Motivar a los alumnos

Un gran desafío que ella a diario de plantea es cómo motivar a sus alumnos.

Entonces para mí es un poco difícil motivarlos y tratar de que no le tengan ese temor, de que es una materia que definitivamente les va a ayudar (E1.CA.11)

- Identificar por qué los alumnos le tienen miedo a la Estadística

Relacionado con la dificultad anterior, Alicia percibe que al inicio de sus clases lo alumnos manifiestan miedo hacia la asignatura, pero al preguntarle sobre los motivos fue común la siguiente respuesta:

"No lo sé” (E1.CA.89bis)

“¡No lo sé!. Siento... bueno, pienso que porque no sólo con los de Educación me pasa, si no en general siempre que se trata de matemáticas..." (E1.CA.90)

- Encontrar ejemplos y ejercicios contextuales para los estudiantes de Educación

Alicia reconoce que le es difícil localizar ejemplos para el contexto de Educación, así como darle el énfasis o el tipo de discurso adecuado o necesario al perfil de los estudiantes de la carrera (ej. que manejen bien las escalas, que expresen para qué servirá la información del gráfico y que no sea exclusivamente mecánico).

es un poco difícil, de encontrar ejemplos que estén relacionados con el área de Educación, porque siento que eso, al menos, les permite familiarizarse y no trabajar con otro tipo de datos, que ellos consideran que nada tiene que ver con su carrera (E1.CA.68).

Las limitaciones en cuanto a no conocer el tipo de trabajo o situaciones con el que el estudiante de Educación se va a enfrentar durante el ejercicio de su profesión, el desconocimiento del vocabulario propio de la carrera y de la poca o nula formación 
para la investigación social de Alicia, son aspectos que permiten comprender esta dificultad.

Las dificultades para enseñar de Alicia las podemos agrupar en dos categorías, aquellas que tienen que ver con el:

1) Conocimiento del estudiante, de las formas de aprender los conceptos, de las creencias, concepciones, errores y dificultades; así como estrategias específicas para motivar al estudiante y minimizar el miedo a la asignatura.

2) Conocimiento del currículo, de los ejemplos y ejercicios, recursos y materiales para enseñar Estadística y representación gráfica a estudiantes de Educación.

Todos estos aspectos, Alicia los atribuye a su falta de experiencia como profesora de Estadística.

Básicamente en Estadística pues no [creo tener experiencia en enseñar], no me siento tan fuerte en ese sentido porque sólo lo ha dado muy pocas veces (E1.CA.21)

En mi caso siento que realmente yo nunca he tomado un curso o algo para dar clase sino que lo hago así como crea que debe ser, entonces siento que a lo mejor ahí es una de mis dificultades (E1.CA.91)

... algo acerca de cómo enseñar, no. Sólo Estadística, cualquier cosa de matemáticas, entonces sí es un problema... ¿sí? (E1.CA.94)

Su formación es fundamentalmente matemática y ha aprendido a ser docente a partir de la experiencia adquirida al dar la asignatura. No obstante, ella tiene interésen aprender más sobre cómo enseñar, particularmente "un poco técnicas de enseñanza, un poco de manejo de qué tipo de actividades aparte de sólo ejercicios y tareas y escribir, ¿qué otras cosas podría yo utilizar? (E1.CA.118).

\subsubsection{En síntesis: el conocimiento didáctico del contenido de Alicia}

El conocimiento didáctico del contenido incluyó el análisis del conocimiento en dos de sus componentes: las estrategias y representaciones instruccionales y el conocimiento del estudiante, componentes B y C, según el SDI del CDC.

En las estrategias y representaciones instruccionales contemplamos el estudio de las concepciones del profesor sobre la asignatura y del tópico a tratar, en este caso la Estadística y la representación gráfica, respectivamente. También incluimos el estudio del origen y fuentes de conocimiento del profesor, el conocimiento del currículo, el conocimiento de estrategias específicas (representaciones instruccionales) y las dificultades para enseñar.

Sobre el componente del conocimiento del estudiante, nos centramos en el conocimiento que tiene el profesor de las creencias, errores y dificultades, así como de la forma como identifica, diagnostica y corrige determinados errores y dificultades. 
A partir de estas dimensiones, a continuación, se resume el CDC de Alicia.

Contexto, origen y desarrollo del conocimiento. Alicia es una profesora con formación matemática, con un master en matemáticas y cuyo interés siempre ha sido la matemática abstracta. Circunstancialmente se enfrenta a impartir la asignatura de Estadística en un contexto diferente al habitual: estudiantes de la carrera de Educación. Desde sus inicios como profesora se ha preocupado por motivar a sus estudiantes y contagiarles el gusto por la matemática; no obstante, no sabe cómo hacerlo. Esto le lleva a concebir la Estadística como un desafío. Con el paso de los años, ha intentado hacer lo que para ella es mejor, sobre la marcha, sin una formación especial para ser docente o para enseñar Estadística, lo que le ha llevado a buscar alternativas para formarse como profesora. No obstante, aún cuando intenta localizar información que le ayude, desconoce dónde, cómo y qué buscar.

Al parecer, el origen del conocimiento que Alicia tiene de la Estadística es su formación inicial. Su forma de enseñar se ve influida por la forma como a ella le enseñaron, así como a las características y naturaleza de los textos que usualmente utilizó durante la carrera. Habitualmente recurre a colegas para aclarar dudas sobre aspectos exclusivamente del contenido estadístico. Según testimonio de ella misma, enseña como le enseñaron y cree que la forma para actualizarse es a través de los textos con que aprendió, olvidándose del tipo de los estudiantes a quienes les enseña Estadística. No considera la Estadística como un campo propio de estudio y además desconoce la evolución que ha tenido en los últimos 20 años.

Concepción sobre la Estadística, su aprendizaje y su enseñanza. Congruente con su formación inicial y la manera como fue formada, Alicia conceptúa a la Estadística como parte de las matemáticas, sin hacer referencia al campo de la educación estadística. Para ella la Estadística no es tan divertida como otras asignaturas. Si bien Alicia hace alusión al carácter "práctico" o "aplicado" de la Estadística a la vida diaria o la práctica profesional del estudiante de Educación, se enfoca más a explicaciones y ejemplos que abordan los conceptos estadísticos sin mencionar los diversos contextos de aplicación de éstos. Al parecer su concepción de la enseñanza está centrada en el contenido con énfasis más en la comprensión conceptual, con un marcado énfasis en el trabajo en el aula, sin recursos audiovisuales, sin apoyo de un software, basado en evaluar el aprendizaje a través de ejercicios y pruebas escritas.

Por consiguiente, encontramos que Alicia concibe la Estadística como una parte de las matemáticas centrada en el análisis e interpretación de datos. Mantiene una aproximación en la aplicación de la Estadística pero en situaciones concretas de clase o dentro del contexto exclusivamente académico, basado en ejercicios (en ocasiones prácticos) tomados del libro de texto. Esta concepción le lleva a mostrar a los estudiantes un significado extrínseco de la Estadística, por lo que muestra a los estudiantes una visión limitada de que el trabajo profesional simplemente existe y que la Estadística es ajena a la experiencia del estudiante, se visualiza como una asignatura que "se ve por fuera" de la profesión y no como parte de una habilidad o competencia que le servirá en el ejercicio profesional. 
Por otro lado, la concepción de Alicia sobre el aprendizaje de la Estadística transita entre aplicar (los métodos estadísticos) y relacionar (la teoría con la práctica). Considera que para que el alumno aprenda es necesario relacionar la teoría y la práctica y para lograrlo, utiliza ejercicios para ayudar a comprender la teoría de la estadística. No obstante, aún cuando habla de "aplicaciones" estas se reducen a actividades prácticas (ejemplos, revisar resultados y obtener respuestas correctas) que desarrollan la comprensión de la asignatura, y no situaciones de la vida real con bases de datos reales. Esta concepción tiene relación con la de enseñanza de la Estadística centrada en relacionar conceptos estadísticos y guiar el aprendizaje caracterizado por relacionar los conceptos estadísticos, clarificando, explicando, aclarando dudas, especialmente en situaciones inusuales o diferentes, y haciendo conexiones entre las áreas del curso.

Concepciones sobre la representación gráfica, su aprendizaje y enseñanza. Alicia tiene una concepción de la representación gráfica como técnica de graficación, centrada en la construcción de gráficos y orientada a que los alumnos tengan particular cuidado en incluir y analizar los componentes estructurales del mismo, o bien, el cuidado de los criterios técnicamente definidos para su construcción. Piensa que la RG debe centrarse la lectura literal del gráfico, extraer información elemental y en la interpretación de los datos en el gráfico. Sostiene una concepción del aprendizaje de la RG vinculada con el desarrollo de la alfabetización estadística abocado casi exclusivamente hacia el conocimiento y uso del lenguaje básico y de las herramientas de la Estadística, del uso de símbolos estadísticos; conocimiento y uso de técnicas básicas de graficación importantes; organizar datos, construir y presentar tablas y trabajar con diferentes representaciones de datos; identificar datos categóricos y numéricos, así como identificar correctamente y comprender las escalas de medición.

Para Alicia aprender RG está íntimamente relacionado con construcción de gráficos, de tener "excelentes" gráficos cumpliendo todos los criterios técnicos, y que los alumnos puedan interpretar. Le concede mucho peso a que el alumno participe en clases, se preocupe por su propio aprendizaje y esté dispuesto a aprender. No obstante, refleja una concepción de la enseñanza de la RG centrada en definir, explicar y dar algunos ejemplos de gráficos, sin profundizar en la interpretación de los mismos. Se caracteriza por proporcionar y solicitar ejercicios específicos, principalmente de construcción de gráficos, utilizando un muy reducido número de recursos para su enseñanza (ej. revisión de tareas en clases y pizarra). Enfatiza en la identificación del tipo de variables y escalas de medición.

La concepción sobre la RG de Alicia es consistente con su concepción hacia la Estadística. Mantiene el mismo estilo tradicional, cuyo énfasis es el aprendizaje de conceptos, el análisis de ejemplo y la práctica de ejercicios; con una enseñanza basada en explicaciones y ejercicios. Asume que lo esencial del aprendizaje de la RG es sólo leer información a partir del gráfico, centrado en la construcción del mismo e identificando (cuando mucho) los componentes estructurales del mismo. Esta concepción contradice lo que autores como Friel, Bright y Curcio (1997) recomiendan sobre el aprendizaje de la RG, que es explorar la naturaleza de los datos de tal modo que ayude a comprender mejor el uso y lectura del gráfico, presentando gráficos diseñados a partir de los datos, explorando su uso en una variedad de contextos y relacionando éstos no sólo con la construcción del gráfico o con una simple extracción de datos para la lectura de gráficos (sentido gráfico). 
Conocimiento del currículo. Alicia expresó que el objetivo de la asignatura es la comprensión de conceptos estadísticos y someramente alude al para qué y cómo le servirán al estudiante. Deja a un lado el uso aplicativo de la Estadística en el contexto de la Educación y más cuando reconoce que debió solicitar un proyecto de investigación donde el alumno le encuentre sentido a la asignatura. Nuevamente subraya el valor de los ejercicios prácticos para mostrar o enseñar las diferentes modalidades que existen de la resolución de problemas, aunque siempre son de carácter más bien rutinario. Habla de una estadística aplicada a la profesión, pero en el futuro, dejando la responsabilidad al estudiante que sea él mismo quien le encuentre uso y sentido en su trabajo o profesión. Minimiza el valor de temas de carácter descriptivo (ej. tablas y gráficos) y le otorga más peso a temas como muestreo, estimación y pruebas de hipótesis. Evalúa principalmente a través de exámenes escritos y usa el dictado de definiciones, explicaciones y ejemplos como estrategias más frecuentes.

Por consiguiente, Alicia tiene un limitado conocimiento del currículo de Estadística. Esto puede ser atribuido a varias razones: a) al programa que utiliza, el cual mantiene un diseño, propósitos, contenidos, criterios de evaluación, sugerencias instruccionales y bibliografía que han sido superado hace más de10 años, b) a su concepción de la Estadística, su aprendizaje y enseñanza, c) al desconocimiento del campo de la educación estadística (ej. objetivos, propósitos, recomendaciones didácticas, formas de evaluar, materiales o recursos).

Del conocimiento que tiene Alicia del currículo sobre la RG, podemos afirmar que es igualmente limitado, aunque muchas de las respuestas que proporciona son congruentes con lo establecido en el programa de la asignatura que imparte. Por ejemplo, promueve el aprendizaje de la RG al nivel de leer datos y específicamente se centra en definir qué es cada gráfico, sus características y los elementos para su construcción. Estudia gráficos descriptivos y categóricos y sólo uno de carácter analítico (el histograma). Se preocupa más en cumplir con lo establecido en el programa, basando nuevamente su enseñanza en definir, explicar y dar ejemplos. Se apoya en libros de texto que orientan la RG hacia la construcción de gráficos y hacia algunos elementos de formato para la presentación de resultados de alguna investigación. Tiene una cantidad reducida de ejercicios sobre RG, y los pocos que utiliza están a un nivel de lectura literal de datos, y en su mayoría no son del contexto aplicado a la profesión de Educación.

Este conocimiento se puede explicar a partir de: a) el enfoque y características curriculares del programa de la asignatura que imparte, b) las concepciones que sobre la RG tiene Alicia, y c) el desconocimiento del contenido y estudio de la representación gráfica, más allá de los establecido en los libros de los años 80s y 90s y de conceptuarla simplemente como técnica de graficación.

Conocimiento de las estrategias y representaciones instruccionales. Alicia conoce un limitado repertorio de estrategias y representaciones instruccionales, cuya característica común son las explicaciones, el uso de ejemplos y la ejercitación a través de prototipos similares a los utilizados en el aula centrados en la construcción de gráficos y en la identificación de algunas de sus características. Cuatro fueron las representaciones 
instruccionales que utiliza: a) definiciones y explicaciones, b) preguntas, c) ejemplos y ejercicios, y las d) instrucciones.

Respecto del tipo de representaciones, tres de ellas son representaciones verbales (definiciones y explicaciones, las preguntas y las instrucciones) y una concreta (ejemplos y ejercicios).

Sobre la fuente de donde surgen las representaciones verbales denominadas explicaciones, preguntas e instrucciones es la propia Alicia, es decir, las crea o construye ella misma; mientras que las definiciones, los ejemplos y ejercicios surgen de los libros de texto.

En cuanto a la forma de las representaciones, se encontró que las definiciones y explicaciones, los ejemplos y ejercicios, y las instrucciones están centradas en el profesor, es decir, es Alicia la principal protagonista, la que planea la estrategia y ejecuta; mientras que las preguntas están centradas en la interacción entre el profesor y los estudiantes, es decir, dependiendo del tipo de preguntas, se logra una débil, moderada o fuerte interacción entre estos. No se identificaron representaciones centradas en el estudiante,

Sobre los propósitos de cada una de las representaciones instruccionales, hallamos que Alicia utiliza: las definiciones y explicaciones para presentar la definición y/o características del gráfico; las preguntas para explorar los componentes estructurales del gráfico y analizar sus características; los ejemplos y ejercicios para evaluar el conocimiento de los estudiantes sobre la construcción de gráficos y para lograr que discrimine entre un gráfico y las instrucciones para explorar las características del gráfico.

Sobre los contextos y momentos, encontramos que utiliza: una definición o explicación cuando cierra un proceso inductivo de aprendizaje y al inicio de cada tema; una pregunta cuando quería reforzar el conocimiento y aclarar las dudas del estudiante; un ejemplo o ejercicio cuando solicita que se elaboren gráficos; y una instrucción cuando desea que se corrija un error en el gráfico.

Estas representaciones instruccionales guardan relación con el conocimiento que tiene Alicia del currículo de Estadística y de la RG, así como con sus concepciones. Por ejemplo, la mayoría de las representaciones que utiliza son del tipo verbal, que se derivan principalmente de su propia autoría y están centradas en la actuación de las clases; lo que nos lleva a pensar en las limitaciones que éstas tienen para promover el aprendizaje de sus estudiantes (ej. alumnos pasivos, dependientes del profesor). Asimismo, las utiliza según el momento de la clase, en cuanto a lo que se necesita o pregunta el alumno. Además, las cuatro mantienen mucha relación con su forma habitual: explicar y dar ejemplos.

Por otra parte, las representaciones cuya fuente se derivan de los textos (las definiciones y ejercicios) presentan el problema de que son materiales obsoletos, con una concepción sobre la RG de los años 80. Las definiciones que dicta a sus estudiantes se centran casi exclusivamente en las características geométricas del gráfico y en sus 
componentes estructurales y los ejercicios (en su mayoría) tienen como objetivo la elaboración de gráficos.

Sobre las preguntas encontramos un hecho importante. Al parecer, en sus clases las utiliza para reforzar el conocimiento y aclarar dudas, mientras que a partir del cuestionario didáctico generó una diversidad de formas de preguntas, que fueron agrupadas en cuatro categorías: explorar la interpretación de los componentes estructurales del gráfico, explorar las características y condiciones en la construcción de un gráfico, desarrollar el sentido crítico en un gráfico y conocimiento propositivo para mejorar un gráfico.

Conocimiento del estudiante. Sobre esta dimensión del CDC nos centramos únicamente en el conocimiento que tiene Alicia de las creencias, errores y dificultades de los estudiantes, a partir del cuestionario didáctico de la RG.

Sobre el conocimiento de las creencias de los estudiantes, Alicia habló de cuatro: a) los gráficos que se ven en la escuela son los más adecuados para representar datos, b) el gráfico de barras y el histograma sirven para representar siempre algo, c) lo que el profesor hace o dice está bien y d) es difícil de entender gráficos no convencionales. Sobre las atribuciones de éstas, ella piensa que tiene un origen más didáctico, es decir, depende del profesor, por lo que la solución está en la planeación y acción de alguna estrategia que ayude a eliminar o modificar la creencia. Alicia afirma que el alumno no está acostumbrado a pensar sino a contestar de manera impulsiva sin querer revisar, observar, pensar. Esto mismo se aplica en el aprendizaje de la RG.

Sobre el conocimiento de los errores y dificultades de los estudiantes, encontramos un total de 15 , los cuales se agruparon en cuatro categorías:

a. Errores por ignorancia o desconocimiento de conceptos previos. Este tipo de errores tienen relación con la falta de conocimiento del estudiante sobre conceptos específicos que debió tener para resolver el problema relacionado con la RG. Aquí se agruparon los siguientes:

- error por desconocimiento del significado de los valores representados en los gráficos,

- no tienen claro el concepto y distinción entre variable discreta y variable continua, y

- no logra establecer la asociación que debe existir entre el tipo de variable y el tipo de gráfico.

b. Errores de reconocimiento y comprensión de la información del gráfico. Se trata de errores relacionados con la falta de apreciación, observación y comprensión de los elementos o componentes estructurales del gráfico:

- no distinguen que el "intervalo" de la barra de un histograma es diferente al de un gráfico de barras,

- no tomar en cuenta que las alturas de las barras muestran la frecuencia, 
- interpretación no válida lógicamente, y

- errores de carácter técnico.

c. Errores en la comprensión de conceptos. Aquí se ubican algunos errores que tienen que ver con errores de carácter conceptual, es decir, el estudiante tiene un concepto equivocado o inadecuado:

- deformación del concepto de variable,

- confunde lo que es una variable con media poblacional,

- confunde la variable con la longitud de las barras, y

- confunde las frecuencias con categorías.

d. Errores relacionados con el contexto. Se agrupan los errores relacionados con la identificación, comprensión y uso de la información del contexto de la situación de donde se originan los datos, como es el problema de investigación:

- $\quad$ no comprende lo que se mide a través del gráfico, y

- los estudiantes dan por hecho que con información mínima y la construcción misma del gráfico otras personas lo comprenderán.

Esta clasificación nos permitió identificar claramente:

a) Lo que no conoce el estudiante: concepto de variable, variable discreta y variable continua, características y componentes (elementos) del gráfico, relación variable-tipo de gráfico.

b) Lo que no observa de los elementos del gráfico: los ejes, los intervalos (los de los rectángulos) del gráfico de barras y del histograma, la frecuencia, los porcentajes, los elementos del media graph, las categorías de un gráfico de barras.

c) Lo que confunde: qué y que no es una variable, diferencia entre variable y media poblacional, diferencia entre variable y longitud de los rectángulos (en el gráfico de barras), diferencia entre frecuencia, categorías y porcentajes.

d) Lo que no considera del contexto: propósito del gráfico, lo que se mide a través del gráfico, a quién está dirigido el gráfico.

Estos resultados nos permiten afirmar que Alicia logró identificar un conjunto de creencias, errores y dificultades a partir del cuestionario didáctico. Cerca de la mitad de éstas coincidieron con los encontrados por otros investigadores. No obstante, en diferentes momentos Alicia manifestó el desconocimiento de cómo los alumnos construyen algunos gráficos y las respuestas que darían sobre ciertas representaciones, sobre las dificultades de los estudiantes de ciertos gráficos (ej. histograma, TyH) particularmente cuando se describe un contexto en el área de Educación. 
También exploramos el conocimiento que tiene Alicia en la identificación y diagnóstico de las creencias, errores y dificultades. La forma habitual con que identifica los errores y dificultades consiste en revisar las tareas y ejercicios de los alumnos, pasarlos a la pizarra para resuelvan algún ejercicios delante del grupo y hacerles algunas preguntas relacionadas a la información o datos que muestra el gráfico y por qué piensa el alumno que es correcto lo que hizo. Estos recursos los utiliza más para verificar el aprendizaje adquirido que para explorar los conocimientos previos de los estudiantes. Nunca había pensado la necesidad de diagnosticar creencias o concepciones de los estudiantes.

A partir del cuestionario didáctico también averiguamos el conocimiento que tiene Alicia de las estrategias para corregir determinados errores de los estudiantes. Encontramos que utiliza las mismas estrategias y representaciones instruccionales: preguntas, explicaciones, ejercicios e instrucciones. Lo común a todas las situaciones-problemas es que realice preguntas para explorar si el alumno ya entendió el ejercicio, para ayudarlo a entender un concepto y para hacerle pensar. Utiliza la explicación para presentar las ventajas y desventajas del gráfico. Utiliza los ejercicios para que el alumno elabore el gráfico y distinga los elementos del gráfico. Para corregir algún error de razonamiento del estudiante utiliza las instrucciones. Todas las estrategias tienen estrecha relación con lograr que el estudiante identifique las características y elementos del gráfico, así como construirlo.

Dificultades para enseñar. En los diferentes momentos de la investigación identificamos algunas dificultades que Alicia reconoció para enseñar Estadística. Las agrupamos en dos categorías. Aquellas que tienen que ver con el conocimiento del estudiante, de las formas de aprender los conceptos, de las creencias, concepciones, errores y dificultades, y del estudio de las atribuciones; así como estrategias específicas para motivar al estudiante y minimizar el miedo a la asignatura; y con el conocimiento del currículo, de los ejemplos y ejercicios, recursos y materiales para enseñar Estadística y representación gráfica a estudiantes de Educación.Todos estos aspectos, Alicia lo atribuye a su falta de experiencia como profesora de Estadística.

Un punto importante por remarcar, es que Alicia nos manifestó que no hace ninguna actividad similar a las propuestas en el cuestionario con sus estudiantes, o lo que es más preciso, no trabaja a ese nivel (interpretación y escritura) de análisis la representación gráfica. 


\subsection{EL CASO DE LUIS: DISFRUTAR ENSEÑANDO ESTADÍSTICA A PARTIR DE INVESTIGACIONES CONTEXTUALES}

A continuación se presentan los datos obtenidos a partir de los diferentes instrumentos utilizados en el caso de Luis. La forma de organizar la presentación es la misma que seguimos con Alicia. Al final, presentamos en síntesis el CDC que tiene, a partir del análisis de los hallazgos encontrados.

\subsubsection{Formación profesional, interés y motivación como profesor}

Primeramente vamos a describir cómo fue la formación inicial de Luis, y cómo se desarrolló su interés hacia la matemática y hacia la estadística. De igual modo indagaremos sobre cómo llegó a ser profesor y cuál es el contexto donde trabaja actualmente.

Luis es Psicólogo de formación aunque previamente había estudiado durante un año asignaturas de la carrera de Ingeniería Mecatrónica debido al interés que tenía hacia las matemáticas. Finalmente dejó esta carrera por la incompatibilidad de horarios.

Después de finalizar la carrera de Psicología, Luis trabajó durante cuatro años en bachillerato, primero ocupando un cargo de carácter administrativo y luego centrándose en la enseñanza de la Filosofía. Posteriormente, en 2002, se le ofreció un puesto para trabajar en la Universidad del Sureste, en la carrera de Psicología, impartiendo asignaturas como Metodología y Estadística. Al mismo tiempo, inició sus estudios de máster en Psicología. Estadística:

Luis relata de la siguiente manera sus primeras nociones sobre la enseñanza de la

Con cosas que van a usar y entender, o sea, lo que para mí es... [interrumpe y cambia de idea]. Antes de comenzar a dar clase aquí, o sea cuando me dijeron que diera clase de estadística, yo entré en mayo [2002] y comenzaba en septiembre, de mayo a julio, estuve como supervisor en otra asignatura. Esa época lo que hice fue acercarme a gente de otras licenciaturas a preguntarles "qué era metodología", la respuesta común era "una materia que no tiene relación con nada más y que te sirve para hacer tu tesis", "qué era estadística" lo mismo (E1.CL.79)

Luis es profesor a tiempo completo en la Universidad del Sureste y realiza actividades relacionadas con la docencia, la investigación, la extensión y la gestión.

Estoy dedicado casi por completo a la parte de la docencia. Como te decía tengo dos materias a mi cargo, las dos en primer año, la materia de Metodología y Estadística. Son cuatro horas semanales por grupo, son cuatro grupos, y Filosofía de las Ciencias son tres horas por grupo, entonces tengo 28 horas frente a grupo, lo cual realmente me lleva la mayor parte del tiempo estando allá (E1.CL.24)

Imparte además las asignaturas de Medición y Evaluación Psicosocial y Construcción de instrumentos (que son materias que disfruta porque se trata de la aplicación directa de la Estadística a una tarea específica). Para organizar estas asignaturas Luis afirma que su formación como psicólogo y conocedor del plan de estudios de la carrera le ayudó mucho a comprender la asignatura de Estadística y a vincularla con otras 
materias que imparte en Psicología. El siguiente texto ejemplifica de qué forma los contenidos de una asignatura los relacionaba con los de Estadística:

Mi primera relación con la Psicología viene por allá, pero se reúne con otra cosa que a mí me impactó mucho: mi segunda materia [que impartía] fue "Elaboración de métodos y técnicas para la evaluación del aprendizaje cognitivo". Era elaboración de exámenes, pero veíamos análisis de reactivos, discriminación de reactivos, determinar la dificultad de un reactivo a través de coeficiente biserial. Todo esto que para mí comenzaba a ser algo muy interesante (E1.CL.05)

Luis afirma que los dos temas que más disfruta, conoce y con los que aporta su experiencia a los estudiantes son la Estadística multivariada y el diseño de instrumentos. No obstante, en ambos no ha tenido oportunidad trabajar como a él le gustaría "podría aportar bastante y todavía no he tenido el espacio" (E1.CL.50).

La experiencia de Luis no sólo se refiere a la docencia en Estadística, sino también a su papel como asesor y colaborador de proyectos de investigación en el campo de la Psicología.

Y realmente un poco [también] mi función colaboro con la mayor parte de los proyectos de investigación de aquí como consultor, por decirlo de alguna manera. Por ejemplo ayer estuve trabajando con dos alumnos que están en Becas de PRIORI [Programa de Investigación y Orientación hacia la Investigación de la UADY], que entregan hoy sus proyectos, revisando un poco dudas que tengan y demás. Mañana tengo una cita con un profesor de aquí de la Facultad para revisar su proyecto que va a someter precisamente la siguiente convocatoria de PRIORI (E1.CL.25)

Según el relato de Luis, es frecuente que los estudiantes y los profesores le soliciten asesoría sobre pruebas de hipótesis, análisis de resultados, manejo de bases de datos, análisis multivariados, entre otros.

Este interés hacia la investigación nació durante sus estudios de Psicología:

Y comienzo en ese momento un proyecto de investigación como estudiante. Ahí fue donde mi tarea personal, la que me puse, es diseñar el proyecto más que nada para usar algunas técnicas, o sea un proyecto en el cual yo usara diferencias con medias, correlaciones y ya llegar a una predicción a través de regresión, o sea, el proyecto fue pensado para eso (E1.CL.18)

Una característica de Luis es que es un profesor dinámico y entusiasta con una forma de enseñar espontánea y que manifiesta de manera permanente su gusto por las matemáticas:

Te decía yo comienzo mi semestre contándoles y abiertamente, o sea, mi primera [intervención] es "el maestro que tienen aquí es a alguien a quien le gustan las matemáticas y las disfruta", ¿ah?, y obviamente se empiezan a reír, y les digo "en serio me gustan, o sea el hecho de que tienen sentido" (jaja) (E1.CL.176)

... es que si realmente yo disfruto de enseñar estadística voy a ir encontrando siempre más elementos para acercar más la estadística hacia ellos. Eso creo que he caído otra vez en la cuenta de eso y sobre todo de siempre darle un sentido hacia lo que ellos están viendo, que de pronto puedan encontrar eso... como te decía poco a poco irlos acercando a "tienes la capacidad". Eso es lo que creo que ha sido para mi interesante... (E1.CL.227) 
Según él, ante diversas situaciones de enseñanza no se queda con la duda, pregunta. Para él deben conjugarse cinco elementos que todo profesor debe presentar ante sus alumnos: acercarse [a los alumnos], leer, estudiar, gusto por la matemática y por la computadora (E1.CL.22).

Esta forma de conceptuar la enseñanza de la Estadística se origina a partir de la ineludible necesidad de cambiar la mentalidad de los estudiantes y va a determinar su manera de entender la enseñanza. A partir de los relatos de Luis, tres son las principales razones que sustentan esta concepción:

- Por experiencias desagradables durante sus estudios de Psicología, caracterizada por una enseñanza basada en la fórmula matemática, pero sin relación con el contexto

Tomé algunos cursos en la Facultad de Matemáticas, pero nunca me gustaron. Era una formación muy basada en la fórmula matemática, y yo no... precisamente lo que necesitaba era ver cómo esto lo entendía en Psicología, cómo lo entendía en Instrumentos de medición y todas las situaciones eran casi siempre despeje de una fórmula, de tratar de obtener otra forma de encontrar el resultado, pero no veía el uso inmediato a estas situaciones [dentro del contexto de la psicología] (E1.CL.14)

O sea una de las cosas que yo veía como una gran deficiencia que había tenido en mi formación, aunque me había gustado mucho estadística de primer año y lo había podido poco a poco integrar a la elaboración de exámenes; se desvinculó y después ya no volvió a aparecer (E1.CL.10)

- Por la necesidad de encontrar respuestas a sus interrogantes, específicamente sobre la vinculación de la Estadística con la Psicología

Aunque comencé a tomar esta, digamos educación formal, talleres y cursos en Estadística, en incluso en SPSS, alguno que apareció de MINITAB y cosas así, era formación que no me satisfacía, no tenía el sentido relacionado inmediato a un contenido de mi profesión [psicología]. Además porque era siempre o en matemáticas o uno que tomé por ejemplo en economía: muy desvinculados a lo que yo podía hacer. Eso me fue llevando a que me pusiera a estudiar y un poco a discutir con Celia, bueno "oye por qué esa prueba y no está otra" y ya comenzar... (E1.CL.15)

- Por encontrarle significado y sentido a los que hacía, lo que le llevó a la decisión de comenzar a tratar de estudiar por su cuenta (E1.CL.13)

Un poco al principio aprendiendo cosas como que en urgencia de que "hay que hacer esto", "hay que hacer aquello" sin entender todavía el por qué lo hacía (E1.CL.09)

No entendía mucho de cuáles eran los principios que estaban por debajo de eso [del SPSS] y pues aprendí digamos la mecánica de la Estadística durante ese año, pero me dio cierta ventaja, porque era uno de los pocos que sabían usar el SPSS en ese momento (E1.CL.10)

Tanto con la Dra. Irma Castellón como al principio con la Dra. Celia Novelo comienza con análisis factoriales, y yo ya no, o sea ya era un momento en el cual no tenía la menor idea de qué estaba haciendo. O sea sabía que había que oprimir y qué hacer y podía entregarte la salida [output] y "entiendo que esto va junto, que esto va junto". ¿Por qué? No lo sé (E1.CL.12)

Sobre si ha cambiado la forma de enseñar estadística, Luis afirmó "sí hay una diferencia enorme" (E1.CL.202). En este sentido, centra su explicación haciendo alusión a la existencia (en el mercado) de cada vez más revistas o journals especializados en el campo de la enseñanza de la Estadística. Asimismo, reconoce la necesidad de trabajar con 
datos reales, significativos y con sentido. Finalmente, habla de un aprendizaje situado y socializado, vinculado con los contextos de aplicación de donde emergen los datos.

Sobre las revistas señaló que son una herramienta útil para conocer los procesos cognitivos y reflexivos de los alumnos. Mencionó revistas como la American Journal of Statistics y Teaching Statistics. También hizo alusión a una página de Internet de la Universidad de Búfalo (http://ublib.buffalo.edu/libraries/projects/cases/case.html ).

Mira yo siento que aurita sí estamos en un proceso, porque incluso cuando leo acerca en Journals de cómo enseñar Estadística y demás, que hay un proceso cada vez más de acercarnos a qué está sucediendo en el propio alumno, cuáles son los procesos cognitivos, los procesos reflexivos que se están llevando a cabo, cuáles serían herramientas... (E1.CL.205)

Sobre el aprendizaje situado, como se puede apreciar a continuación, Luis afirma la necesidad de que el aprendizaje tenga un contexto:

Sería el mundo ideal y no puedo, pero creo que un aprendizaje situado en el que tú digas "estoy en este campo, tengo este problema, es mi problema de investigación y aquí el profesor me está mostrando que hay una herramienta que puede ayudarme a resolver este problema", creo que allí es cuando vas a caer en la cuenta: esta es una buena herramienta que me sirve en estas situaciones, o sea eso sería para mí un ideal (E1.CL.207)

Lo anterior, le ha llevado a Luis a ampliar y/o modificar su forma de enseñar Estadística. Se preocupa por utilizar ejemplos contextuales, intenta identificar y comprender los estilos de aprendizajes de los estudiantes lo que le lleva a modificar el programa del curso en función de las necesidades que surjan en clase:

Entonces fue cuando comencé a leer por ejemplo, de utilizar siempre ejemplos muy ligados a la vida diaria, de buscar mientras más se pueda, estar pendientes de cómo están respondiendo los alumnos en diferentes estilos de aprendizaje para ir vinculando hacia ellos lo que estoy mostrándoles, he tratado de utilizar más herramientas computacionales no solamente el SPSS para hacer representaciones (E1.CL.211)

Eso me ha llevado a qué situaciones puedo crear, que puedan servir y cumplir siempre con esos objetivos, pues al mismo tiempo a mi me van dando un poquito más de conocimiento de qué incluir (E1.CL.212)

En resumen, Luis se formó y estudió la carrera de Psicología que es donde trabaja actualmente. Esto sin lugar a duda ha favorecido el conocimiento que tiene del perfil de egreso del estudiante y específicamente del papel de la asignatura de Estadística. Desde un principio manifestó el gusto por aprender y estudiar Estadística. Su experiencia como estudiante y como ayudante de investigación le llevó a proponerse (ya como profesor) cambiar la mentalidad del estudiante sobre la Estadística, buscando vincular ésta con la Psicología para que el estudiante le encuentre sentido.

Dos cosas favorecen la actitud de Luis hacia la Estadística: por una parte, imparte también materias que están ligadas a ésta (Medición y Evaluación, y Construcción de Instrumentos) y por otra, es ayudante y asesor de proyectos de investigación tanto por la parte metodológica como la parte de análisis estadísticos. Se autodefine como un profesor dinámico y entusiasta, donde es fundamental acercarse a los estudiantes, leer, estudiar, 
tener gusto por lo que enseña e incorporar la computadora como instrumento clave en su enseñanza.

Luis se mantiene actualizado y conoce los cambios que se han dado en torno a la enseñanza de la Estadística. Ante la respuesta espontánea y rápida de que el cambio ha sido "enorme", menciona algunas de las características: materiales y recursos diversos (journals, Webs) y especializados en educación estadística, incorpora el estudio de la Estadística utilizando bases de datos reales para darle sentido, utiliza ejemplos contextuales, busca comprender los estilos de aprendizaje del alumno y cree en el aprendizaje situado del aprendizaje.

Varios de estos cambios que señala coinciden con algunas de las recomendaciones sugeridas por diferentes organismos internacionales que se dedican al investigar sobre el aprendizaje y la enseñanza la Estadística, como por ejemplo la American Statistical Association y el Mathematical Association of América (en Moore, 2000) que dio un conjunto de directrices que marcan hacia dónde debe dirigirse en la enseñanza de la Estadística, como: (1) énfasis en los diferentes elementos del pensamiento estadístico (ej. la necesidad de los datos, la importancia de producir los datos la omnipresencia de la variabilidad y la medición y modelación de la variabilidad); (2) incorporar más datos y conceptos, menos recetas y énfasis en el cálculo; tanto como sea posible, automatizar (a través del uso de la tecnología) el uso de cálculos y construcción de gráficos; darle valor verdadero a los datos reales (no meramente ficticios, hipotéticos) provenientes de contextos reales; (3) fomentar el aprendizaje activo a través de alternativas de clases (ej. resolución de problemas en grupo y discusión, ejercicios de laboratorio, demostraciones basadas sobre datos generados en clase, presentaciones escritas y orales y proyectos tanto grupales como individuales)

\subsubsection{Origen y desarrollo del conocimiento de Luis}

En cuanto al conocimiento de Luis, ¿cuáles son las fuentes de su conocimiento como profesor?, ¿cómo y cuándo conoció y accedió a éste?, ¿cómo se relaciona con su formación inicial? y ¿cómo y dónde surgen sus explicaciones? Intentaremos dar respuestas a estos interrogantes, en lo que representa la dimensión B-II (Fuentes de obtención de su conocimiento, según el SDI) del conocimiento de las estrategias y representaciones instruccionales.

Los rasgos que caracterizan el origen y desarrollo del conocimiento de Luis se agruparon de la siguiente manera:

- Familia de profesores y bastante matemática

- Aprender de los demás: lo fuerte de la formación inicial

- La actitud como estilo de vida para la formación

- Forma inicial de aprender Estadística: basado en la fórmula matemática y ejercicios

- Forma de actualizarse: aprender de los alumnos, cursos, colegas, leer reportes de investigación 
Familia de profesores y bastante matemática. Luis proviene de una familia "bastante matemática", donde los padres y todos sus hermanos han estado vinculados con carreras del área de ciencias exactas o de la ingeniería.

Yo vengo de una familia bastante matemática, o sea mi papá es Ingeniero, Profesor de Cálculo, con Maestría en Enseñanza de las Matemáticas. Casi todos sus hermanos se dedican al área de la física o de las matemáticas. Entonces para mí es muy normal entender algo de pronto por matemáticas o estar hablando algo y agarrar un papel y tratar de dibujarlo o de hacer algo con eso que estás diciendo. (E1.CL.01)

Luis piensa que crecer bajo este entorno familiar le permitió acercarse de manera natural al conocimiento matemático, así como familiarizarse con los problemas vinculados con la matemática y, al mismo tiempo, le permitió desarrollar cierta seguridad en su conocimiento.

Pero siento que al mismo tiempo todo este background familiar me hace sentir muy tranquilo y muy paciente cuando estoy en clase, o sea, de estar buscando siempre otras formas de explicar, otras formas de proponerle situaciones, porque encuentro que para mí es sencillo revisarlo así, y creo que otras personas pudieran acceder a pensarlo también así (E1.CL.03) profesores.

Otro aspecto importante por destacar es que Luis proviene de una familia de

Otra parte que no te había dicho, [es que] todas estas personas de mi familia que se dedican a matemáticas: todos son profesores. Entonces la docencia para mí también es un área muy marcada, entonces dices "tengo dos herramientas que para mí son naturales en mi vida que eran las dos primeras [asignaturas] que me ofrece la carrera..." Me resulta muy, muy agradable, muy tranquilo y bueno esa fue la primera parte ¿no? de lo que es antes de meterme a psicología como tal (E1.CL.06)

Además de la influencia familiar, otro aspecto que incidió en su interés hacia la investigación en el campo de la Estadística fue su actividad como ayudante de investigación durante la carrera. Luis señala que le motivó muchísimo que una profesora con gran prestigio le invitara a ser su asistente:

Ya estando digamos en el transcurso de la carrera tengo un poco la ventaja o la buena suerte de que viene la Dra. Irma Castellón hacer un año sabático acá, necesita un asistente. Me dicen "bueno ¿por qué no eres su asistente?" y era algo así como necesito correr [realizar y ejecutar] un ANOVA y yo “con quince datos la hago pero con 500 ¿cómo le hago?” (E1.CL.07)

Entonces ella comenzó a enseñarme en situaciones de urgencia cómo resolver esto, y pues en ese momento usar el SPSS con programación de cuando tenías que poner tus instrucciones y todo eso. Es durante un año que estoy ahí trabajando con ella (E1.CL.08)

Para Luis la actitud de los profesores investigadores le ayudó a interesarse más por la Estadística, a que le fuese encontrando sentido y se sintiera a gusto con sus conocimientos.

Estaba en cuarto año (más o menos) de la carrera. Una de las cosas que en ese momento me sirvió es precisamente la actitud de ella [de la Dra. Celia] hacia mi fue de casi igual a igual. Por ejemplo, me dijo, en un curso que apareció [se ofreció] le dije "yo ya tomé el anterior y la verdad me pareció 
bastante malo pero porque era muy matemático pero me gustaría tomar este". Por ejemplo, cursos sobre regresiones, no sé nada de regresiones, y me dijo "oye, pues hace mucho que no tomo [participo] uno. ¡vamos!". (E1.CL.16)

El mismo Luis reconoce que ambas influencias iniciales favorecieron el desarrollo de su conocimiento, interés y gusto hacia la Estadística y la investigación:

Como te digo, creo que sí hay mucho de esto de lo familiar... Pero si creo que es una combinación de toda esa experiencia familiar y al mismo tiempo estos eventos muy particulares como el ser asistente de estos dos personas dedicadas a la investigación, el ser invitado a poder participar en otros proyectos, que me fue llevando a interesarme y sobre todo a mi una de las cosas que, te digo como en mi ambiente familiar las matemáticas, o sea lo entendí siempre como un lenguaje claro (E1.CL.35)

Aprender de los demás: lo fuerte de la formación inicial. Una de las características de Luis en cuanto a su formación, es la importancia que le concede a aprender de los demás. Esta actitud se evidenció en tres momentos diferentes: de la discusión con sus compañeros de clase, con sus estudiantes y con expertos. Esto ya lo hacía desde su formación inicial cuando trabajaba con sus compañeros de curso compartiendo la información que obtenía, discutía y posteriormente preguntando a su profesor.

Pero tenía yo una segunda tarea que era: invité a dos compañeros que estaban en segundo año, que les veía que les interesaba algo de investigación, algo de Estadística. Entonces nos sentábamos los tres. Les mostraba lo que ya había avanzado y que ellos lo comentaran un poco más. Entonces entre los tres era un momento como de aprendizaje ahí entre nosotros tres y llegar después con Celia y decirle "oye mira hicimos tal cosa, nos salió esto, aquí sí ya no entendemos, o sea ¿qué paso aquí?" (E1.CL.19)

Cuando empieza a trabajar como profesor de Estadística continúa con su acercamiento a los demás y a su forma de percibir la Estadística, por ejemplo, preguntando acerca de este tema a los estudiantes.

Antes de comenzar a dar clase aquí, o sea cuando me dijeron que diera clase de estadística, yo entré en mayo [2002] y comenzaba en septiembre, de mayo a julio, estuve como supervisor en otra asignatura. Esa época lo que hice fue acercarme a gente de otras licenciaturas a preguntarles "qué era metodología", la respuesta común era "una materia que no tiene relación con nada más y que te sirve para hacer tu tesis", "qué era Estadística" lo mismo (E1.CL.79)

Esto le ha permitido conocer más sobre cómo aprende el estudiante Estadística.

Ha sido una experiencia sinceramente muy agradable en la cual yo mismo he aprendido mucho de los alumnos, porque precisamente el estar trabajando casi siempre a través de - no de resolución de problemas, o sea como ejercicios- o sea, a tratar de pensar siempre un poco más grande, eso me ha llevado a darme cuenta de cuáles son las temáticas difíciles, de cuáles son los puntos donde hay que ser un poco más mecánico, en dónde hay que ser un poco más reflexivo. Creo que ha sido una experiencia que a mí me ha dejado mucho, mucho como profesor, la he disfrutado bastante (E1.CL.52)

También se acerca a profesores expertos y les pregunta sobre aspectos relativos a las pruebas estadísticas, principalmente relacionado con el significado del valor obtenido y el por qué de cierto resultado. 
Además valora mucho las experiencias fuera del aula, ya que considera que la interacción con otras personas, particularmente profesores investigadores, le permitió comprender el significado y utilidad de la Estadística:

Cuando aprendí Estadística es cuando estuve con alguien que estaba trabajando con datos de investigaciones y era jugar con los datos, o sea era ver qué significaban, era darles un sentido y allí aprendí estadística, entonces por eso ahora para mi es necesario siempre estar en el salón de clase dando sentido a las cosas E1.CL.204

La actitud como estilo de vida para la formación. Otras características de la personalidad de Luis que influyen en su quehacer docente y que él mismo reiteró en diversas ocasiones a lo largo de las entrevistas que se le realizaron son las siguientes:

\section{- Gusto por la Estadística}

Siempre por ejemplo, como te decía que mi materia está mezclando Metodología con Estadística esto es algo que hago: digamos dejo muy claro desde el principio, que para mí me gusta y siento natural el área de las matemáticas por una razón muy particular, más que nada por la metodología, para hacer claro ante ellos que pudiera haber un sesgo mío hacia lo cuantitativo y que lo que quiero, precisamente de antemano, ponerlo a la vista para que ellos sean lo suficientemente críticos ante mí, de decirme "Luis estás numerizando demasiado las cosas o estás...". (E1.CL.02)

Entonces, realmente disfruto estas asignaturas. A veces extraño un poco asignaturas de contenido, pero he tratado siempre de que Estadística tenga contenido de Psicología, por ejemplo te voy a dar un caso. (E1.CL.40)

Siento que primero, que es disfrutable, o sea es ampliamente disfrutable, que es algo en lo cuál existe una gran posibilidad de una satisfacción y un desarrollo personal y que creo que puedo contribuir también al desarrollo académico de alguien (E1.CL.51)

- Estudioso, caracterizado por ser autodidacta, así como preguntar y discutir sobre los contenidos estadísticos

Y es cuando comienzo a tratar de estudiar por mi parte (E1.CL.13)

Eso me fue llevando a que me pusiera a estudiar y un poco a discutir con Celia, bueno "oye por qué esa prueba y no está otra" y ya comenzar...(E1.CL.15)

Entonces ese momento de que alguien que ya tiene el renombre de... y la formación se ponía [a averiguar y ver] cómo podía ir, podía aprender igual que yo, entonces me motivó muchísimo (E1.CL.17)

- Abierto al diálogo, con la finalidad de acercase a los alumnos para lograr la confianza de éstos para preguntar, así como explorar sus dificultades y necesidades

Entonces, creo que también es una parte muy importante como profesor de Estadística el ser una persona muy abierta a que los alumnos se acerquen y puedan preguntar, y de pronto tengo alumnos que les di clase hace tres años y se acerca "no me acuerdo, pero sé que me puedes ayudar", o sea, de que puedan venir y sentarse y trabajar aquí conmigo un rato, y esta apertura siento que es básica para... precisamente porque siempre es vista la asignatura como la parte árida de la carrera, la parte que "tienes que pasar", porque si no, no puedes o como lo simple que te va a servir para titularte (E1.CL.48) 
- Abierto a la crítica de otros colegas

... aurita tengo una retención muy interesante en clase, porque una compañera, maestra de la escuela, me pidió entrar a la clase. Ella lo que está haciendo es evaluando mis métodos. Le dije "Ok hacemos un cambio: con toda libertad entra a mi clase, pero la tomas como alumna" y está tomando la clase tal cual, pero "quiero que cada vez que puedas me digas qué ves de positivo, qué ves de negativo, cuáles son las cosas que crees que funcionan, cuáles son las que no funcionan", y creo que por ejemplo, este diálogo constante [hace referencia a la entrevista] es una de las herramientas que por lo menos ya desde el punto de vista de alguien más, parece que funcionan bastante (E1.CL.166)

- Curioso, inquieto e informal, caracterizado por su iniciativa en proponer formas diferentes de enseñar Estadística, así como su espontaneidad en romper los estereotipos que el alumno tiene del profesor

Soy muy curioso, estar buscando por todas partes. Soy muy informal en ese aspecto, en el sentido de que soy así de sentarme y estar "hoy tengo duda de cómo... o sea dentro de un mes me toca ver prueba ANOVA, entonces de qué otras formas puedo hacerle", entonces... mmm... (E1.CL.213) pero ya te dije, soy inquieto en el salón de clase no puedo hacer de otra manera (jajaja) o sea ya es personalidad mía, o sea de hecho es cuando les digo "el día de hoy vengo acelerado" o sea, es "mejor díganme cuando estoy yendo muy rápido porque estoy acelerado para la clase de hoy" (E1.CL.226)

Forma inicial de aprender Estadística: basado en la fórmula matemática y ejercicios. Sobre la formación que recibió durante la carrera de Psicología, a Luis le resulta difícil expresar lo que realmente aprendió.

O sea en el sentido de cómo recuerdo lo que fue para mí la estadística, cuando estudié en la carrera estadística fueron dos cursos. Sé que aprendí mucho, pero ¿aprendí realmente estadística? Sé que aprendí mucho de algo, ¿qué era? no te puedo definir exactamente qué era ese algo, ok. (E1.CL.203)

Por ejemplo, recuerdo la primera vez que obtuvimos un alfa negativa porque (jaja)... le digo "todos los libros dicen que esto no es posible ¿por qué?”. Entonces “¡ah! mira pues es que se te olvidó invertir los reactivos entonces hay un reactivo que está considerado negativamente y eso produce esto", “¡ah!”. O sea cosas que de pronto pues...la parte autodidáctica pues no encuentras dónde. Como esto fue más o menos lo fuerte de la formación inicial (E1.CL.20)

Por otro lado, manifestó que todavía prevalece enseñar Estadística a partir de la fórmula matemática y descontextualizada de situaciones reales ya que lo ha comprobado en algunos cursos de actualización que ha tomado:

Sinceramente tenían un nivel en algunos momentos un poquito elevado para mi, en cuanto que como era una maestría para matemáticos, en enseñanza de las matemáticas, de pronto era sentarme y "a ver explícame de aquí acá no entiendo nada, aquí ya entiendo de qué se trata. Toda la derivación de la fórmula no me la sé". Entonces era sentarme un poquito a leer, era un juego más, más familiar, pero nunca fue algo que yo dijera "lo voy a hacer", o sea digo, como te digo o sea allí si he sido muy informal (E1.CL.221)

Comentó que los profesores que le impartieron Estadística fundamentalmente se dedicaban a leer el texto y a solicitar ejercicios de carácter rutinario. Por ejemplo:

..., por decirte leer en un libro que el segundo momento de la media es la varianza, el tercer momento es la curtosis, el cuarto momento es la simetría, y tú dices “(ajá) ¿qué sentido tiene?”. Me sirvió más adelante en algún momento para contestar una prueba acerca de cálculo porque lo relacioné con velocidad y aceleración y demás pero ¿qué sentido tenía? Ninguno (E1.CL.223) 
Recuerdo que todo era una serie muy mecánica y eso es lo que te digo, para mí sí es base pero no le da ninguna relación con el contexto real (E1.CL.224).

Para Luis la Estadística es como una herramienta que ayuda a entender lo que está sucediendo en la vida real, particularmente en los contextos de la profesión, no obstante:

Precisamente eso es lo que siento que en muchos momentos cuando yo me iba a tomar cursos de estadística no había, o sea no había esa Estadística como una herramienta, se veía como un fin (E2.CL.43)

Luis expresó que si "no hubiera tenido después una experiencia que me acercara a la investigación y le diera sentido, para mi Estadística no significaría nada, porque el proceso que se llevó fue precisamente el que para mí no era...” (E1.CL.223).

Forma de actualizarse: aprender de los alumnos, cursos, colegas, leer reportes de investigación. Las estrategias o formas que utiliza Luis para mantenerse actualizado las podemos agrupar en tres: lectura y análisis de reportes de investigación, discusión con otros colegas y cursos de actualización.

- Lectura y análisis de reportes de investigación a través de artículos en revistas especializadas, que le ayudan a encontrar ejemplos y contextos de investigación en el ámbito de la Psicología

lo que sí trato es ir leyendo constantemente reportes de investigación. Creo que es uno de mis recursos más utilizados. Allí soy de no irme por una sola línea, o sea de pronto me voy a la biblioteca y es ver de las últimas revistas "bueno hoy voy a tomar una de clínica a ver qué se está haciendo en clínica" y de temas que me llamen la atención y leer me sirve en dos partes [sentidos]: siento que me sirve mucho en Estadística, también me sirve en las temáticas de metodología. Como mis alumnos escogen, entonces una de las cosas que me mantiene un poquito como que actualizado de qué está sucediendo y por dónde, es ir de pronto a revisar las revistas (E1.CL.217)

- Discusión con colegas de otras profesiones, con el propósito de aclarar dudas, ampliar sus conocimientos sobre el tema, o bien, obtener una visión diferente sobre los contenidos de Estadística y su enseñanza

Uno de mis recursos más frecuentes es irme a discutir con otro profesor, que estudió la Especialidad en Estadística, que tiene una visión muy distinta. El es mucho más matemático, hace años que no está en el área de Estadística, pero que hemos visto que disfrutamos los dos de la discusión (E1.CL.215)

Entonces llego así realmente de que "oye hoy quiero hablar contigo de tal cosa que me está pasando en el salón" y esa es una discusión de pronto de una semana, de encontrarnos en los pasillos "oye sí es cierto tal y tal cosa podríamos hacer y otra". Ahora le digo " voy a estudiar el Doctorado en Metodología" y me dice "¡Mejor! Ya hay más cosas que pelearnos", porque además son dos visiones distintas (él mucho más matemático), le digo "Sí que bueno que sepan ese teorema, pero no lo vamos a aplicar aquí, o sea no van a calcularme eso" y él "es que tienes que ponerle", y yo "sí sabrán todos los conceptos necesarios pero no los puedo volver matemáticos. Son psicólogos". Es uno de mis recursos (E1.CL.216) 
- Cursos de actualización sobre los contenidos pero no sobre la didáctica o enseñanza de la Estadística

En estos últimos tiempos han sido casi todos en estadística multivariada, uno en regresión lineal múltiple, otro que tenía que ver con ecuaciones estructurales y otro, uno base de métodos multivariados en general (E1.CL.219)

A través de estos diálogos, encontramos dos aspectos que pueden explicar la concepción y el conocimiento inicial que Luis tiene de la Estadística: que proviene de una familia de profesores y con formación matemática, y que fue invitado a participar como ayudante de investigación. De hecho, esto último lo señala por él mismo en el sentido de que si no hubiera tenido esa experiencia no hubiese comprendido el significado de la Estadística.

Otros aspectos no menos importante que favorecen el conocimiento que tiene de la asignatura es su actitud hacia el aprendizaje y que sea autodidacta. Siendo estudiante procuraba cultivar el hábito de estudio, preguntando, discutir (con compañeros), además ser ayudante de investigación, preguntar a sus estudiantes y a colegas, ser abierto al diálogo y a la crítica. Estas características favorecieron su formación en Estadística y su manera incluso de actualizarse.

Por otra parte, Luis logra identificar algunos aspectos de la enseñanza de la Estadística que adquirió durante el tiempo de estudiante: centrada en la fórmula matemática, en el cálculo, sin fundamento, descontextualizada de la profesión y de situaciones reales; cuya estrategia didáctica era la lectura de textos y hacer ejercicios de carácter rutinarios. En contraposición, y a partir de su experiencia como ayudante de investigación, concibe la Estadística como una herramienta que debe ayudar a entender lo que está sucediendo en la vida real, particularmente en el contexto de la Psicología.

Además se interesa sobre lo que piensan los alumnos de la asignatura y con frecuencia les hace preguntas que le ayudan a conocer sus motivaciones y preocupaciones. Le concede valor al estudio de los contenidos estadísticos, apoyándose en la consulta y discusión con colegas o expertos y en cursos específicos de actualización. Estos cursos están focalizados exclusivamente en el contenido, no en su enseñanza. Finalmente, recurre a la lectura y análisis de reportes de investigación, que se encuentran en artículos de investigación (en castellano e inglés) para plantear ejemplos del ámbito de la Psicología a sus alumnos.

\subsubsection{Concepciones sobre la Estadística, su aprendizaje y enseñanza}

El primer aspecto clave del CDC se encuentra en la primera dimensión del conocimiento de las estrategias y representaciones instruccionales: las concepciones que el profesor tiene sobre la enseñanza y aprendizaje del tópico estadístico (B-I según el SDI). En este sentido, se recogieron evidencias acerca de las concepciones de Luis sobre la estadística, su enseñanza y aprendizaje, y más específicamente sobre la representación gráfica. 
En primer lugar presentaremos los resultados sobre las concepciones de la Estadística, su aprendizaje y su enseñanza. Los apartados que hemos tenido en cuenta para analizarlas han sido agrupadas en relación con:

- El significado de Estadística

- El aprendizaje

- La enseñanza

- La manera habitual de enseñar

A continuación se describe y analiza brevemente cada una.

El significado de Estadística. De manera reiterativa (42 ocasiones) Luis define la Estadística como una "herramienta" que ayuda a entender lo que está sucediendo en el entorno y a resolver determinadas problemáticas.

...pero para mí es una herramienta que me ayuda a entender lo que está sucediendo (E1.CL.44)

Debe ser en un proceso de resolución de problemas, pero pensado cuál es el problema que se me presenta y cómo la Estadística es una herramienta en estos procesos (E1.CL.56)

Precisamente porque muchas veces encuentro discusiones de aquí con gente ¿no? que me dice, “¡ah mira! Pues es que este trabajo a leguas se ve que le pusieron Estadística para darle validez". Entonces en ese momento a mi me duele decirlo, es mi herramienta de trabajo, y ver como muchas personas no le dan el uso adecuado, cuando siento que pronto en una situación lo ves como la herramienta que te puede servir para resolver una problemática, entonces allí tiene sentido un curso de Estadística (E1.CL.57)

"esas son las bases para poder saber si puedes o no usar estadística", porque es más, son parte de lo que siempre les digo "la Estadística no es lo que le da validez a algo, es la herramienta que puede servirte en muchos momentos, y como toda herramienta la usas o no la usas dependiendo de qué problema tienes" (E1.CL.59)

se requiere esa tarea [de reflexión] para que cuando encuentran la herramienta digan "esta es la herramienta para responder a esto", no de antemano decirles como "tus variables son de este tipo, la única opción es esta" (E1.CL.68)

Para Luis la Estadística es una herramienta que puede servir en muchos momentos, y que como tal la usas o no dependiendo del problema que haya que resolver. Es una herramienta que ayuda, que da las bases para saber si puedes o no usar ciertos estadísticos.

El aprendizaje. Para caracterizar la concepción que tiene Luis sobre el aprendizaje de la Estadística se han considerado los siguientes aspectos:

- Cada alumno cuenta con ciertas habilidades o antecedentes y aprende de manera distinta

Concibo que cada alumno lleva al salón sus mejores habilidades y cada uno tiene habilidades distintas, y algo rico del salón de clase es que al ver tus habilidades puede servirme de modelo para probar esas habilidades en mi, o para descubrir en cuáles necesito cooperar o colaborar contigo porque son habilidades que no voy a desarrollar o no quiero desarrollar, o no tengo. Entonces 
precisamente como siempre les digo "hay muchas formas de hacer esto", y además siento que en esta diversidad puedo evaluar diferentes momentos de un aprendizaje (E1.CL.153)

- Desarrollar el pensamiento reflexivo es fundamental en Estadística

Para poder lograr que el alumno aprenda Luis resalta el valor que tiene el desarrollo del pensamiento reflexivo:

Precisamente lo que he estado tratando cada vez más es llevar hacia allá la clase [la resolución de problemas], porque creo que es en ese proceso en el cual hay una verdadera reflexión de por qué la Estadística sirve, ¿si? (E1.CL.57)

Para desarrollar este pensamiento reflexivo Luis considera que no se debe presentar la Estadística como si fuera una serie de pasos que el alumno debe aplicar de forma mecánica sino que se debe procurar que relacione los datos con el contexto, con la situación problemática planteada y con el marco conceptual de la investigación de donde se originaron los datos:

Primero que haya un pensamiento reflexivo sobre la problemática, porque una de las cosas que de pronto siento que se da en los cursos de Estadística es: "si tu variable es independiente tiene tantas categorías, tu variable dependiente tantas otras, la prueba a usar es esta", y no hay una reflexión de cuáles son las condiciones de investigación, cuál era la verdadera pregunta, o sea, esta clase de reflexión no se da. Entonces cuando... te digo cuando de pronto por ejemplo en esta situación de los estudios de caso. Nuestro primer estudio de caso era un reporte de un periódico, de una investigación, de pronto los alumnos comenzaron a decirme (E1.CL.58)

El problema es que quieras en todos los casos, precisamente por no hacer esta reflexión, meter Estadística porque hay que hacerlo. Y es lo que trato de decirles, "apréndelo, que sepas decidir cuándo usarlo, a lo mejor en tu carrera no vuelves a usarlo, pero que tengas las bases para decir aquí esto serviría" (E1.CL.60)

Para Luis "se requiere esa tarea [de reflexión] para que cuando encuentran la herramienta digan 'esta es la herramienta para responder a esto', no de antemano decirles como 'tus variables son de este tipo, la única opción es esta' " (E1.CL.68).

- Invitar al alumno a resolver situaciones y a aprender de sus errores

Me gusta plantear un reto interesante al cual puedo invitar al alumno a resolverlo y que se sienta seguro de que lo que va a suceder siempre va a ser un aprendizaje, o sea eso es lo que me gusta: el decirles "pase lo que pase incluso lo errores voy a estar yo acá" para ir haciendo como que el coaching, "qué pasó, dónde estuvo el error" [por ejemplo] (E1.CL.201)

- Desarrollar el razonamiento estadístico en el estudiante a partir de la formulación de un problema, y la fundamentación y validez en la toma de decisiones estadísticas

Al reflexionar sobre el pensamiento reflexivo Luis indica que los procesos esenciales del razonamiento estadístico que deben prevalecer en el estudiante son dos. Uno es formular la problemática de una situación, sea de investigación o de una necesidad de información cuantitativa, la cual se caracteriza por identificar el 
objetivo, la justificación (teórica) y la definición fundamentada de las variables del estudio:

Yo creo que de entrada saber formular bien una problemática, creo que eso es la situación básica en la estadística. Creo que muchas veces precisamente los alumnos, o las propias personas al no saber cómo presentar claramente un problema se traba [se atora] el proceso, entonces ya no puedes avanzar, porque no está bien identificada, clarificada la situación en la cual quieres trabajar. Entonces creo que allí es donde comenzamos (E1.CL.64)

El segundo es la fundamentación y validez en la toma de decisiones estadística, caracterizado por la claridad en las ideas, capacidad argumentativa y establecimiento de razones, supuestos y condiciones en que se utilizan los estadísticos de prueba:

Lo siguiente para mí es garantizar la claridad en las ideas y las razones por las cuales se debe usar la estadística, qué supuestos hay para usar en una prueba, en qué condiciones deja de ser válido (E1.CL.65)

\section{Luis ilustra esto con el siguiente ejemplo:}

Por ejemplo mira, voy a darte un caso ayer que estábamos trabajando aquí con los alumnos de PRIORI, y de pronto había una gran dificultad de saber si realmente su problema está planteado como grupos correlacionados, si eran realmente parejas o era en grupos totalmente independientes, y eso trababa todo el proceso, o sea, no poder clarificar qué es lo que te interesaba trabajar con parejas de novios o te interesaba trabajar con gente que está en un noviazgo. O sea es que hay una razón diferente (teórica) que te lleva a eso, o sea si no lo tienes claro [el problema a investigar] desde antes, ya no se puede avanzar y el resultado es tan grande, que la base de datos se tiene que estructurar de modo distinto si respondes a una cosa o si respondes a otra, $i$ ah? entonces era sentarse y decir "bueno ¿que querías hacer, bueno cuál era tu tema, cuál era... hacia dónde ibas", todo este proceso previo es lo que lleva allá ¿ah? (E1.CL.66)

Para que se pueda dar lo anterior, Luis afirma que es importante conseguir que los alumnos realicen un proceso de interpretación:

En la Estadística como tal, trato de tener los dos niveles: un nivel que sea el digamos el mecánico, en el sentido de que entiendas los pasos, entiendas las fórmulas; y otro más que es ¿por qué lo voy a usar?, o sea "encuentra la variable independiente, encuentro la variable dependiente, ¿es dicotómica? ... sí es ... ¿ ¿es intervalar? ... sí es", entonces sí puedo usarlo. En ese momento siento que comienza el proceso de comprensión (E1.CL.192).

Nuevamente aquí Luis resalta el valor que tiene que el estudiante logre fundamentar las decisiones que toma en torno al análisis estadístico.

- Las dificultades mayores en los estudiantes son la descontextualización y la notación.

[suspira] Lo que siento aquí, y que poco a poco estoy tratando de romper, es el sin sentido que tenía la Estadística. Para mi es lo que cada año es mi dificultad más fuerte. Me ha tocado y aquí en la escuela es muy común que tenga yo en los salones a gente que ya ha estudiado otra carrera, y que por lo tanto ya ha llevado los cursos y que me diga "sé usar una prueba $t$ ", o sea "sé qué es", pero al final me diga "¡ah!, no sabía, por qué se usaba", ¿si? He tenido gente, por ejemplo gente de contaduría, 
que en su plan de estudios utilizan el SPSS. Pueden llegar [a decir]: "aquí está la base de datos, córrelo [ejecútalo]", pero lo que no podían leer es un reporte de investigación. Entonces aurita siento que hacia allá están [las dificultades] (E1.CL.167)

La dificultad más fuerte que he tenido que salvar en general, es el sin sentido que tenía la Estadística, y es dotarla precisamente, de un sentido, y es lo que quiero (E1.CL.168)

Después de eso la notación, o sea, ya específicamente en necesidades, la notación. Cuando se les presenta de pronto una notación que implica un avance en álgebra cuesta mucho trabajo. Creo que cuesta mucho trabajo, precisamente por la lectura, o sea, la dificultad para leer una fórmula. Por ejemplo, recuerdo que al ver una sumatoria de " $i$ " hasta " $k$ ", me tardé en explicar, y cuando era la sumatoria de " $i$ " hasta " $k$ " por la sumatoria de " $j$ " hasta " $r$ " costaba trabajo. Incluso, por ejemplo, tengo a un alumno que estudió casi toda la carrera de Ingeniería, me decía "¿y nos vamos a meter a notación matricial?", le digo "no tanto, pero...", me dice "es que, lo puedo resolver" le digo, "ok, sí, vamos a resolverlo". Ya después me dice, "¡ah!, no es lo mismo, es diferente" (E1.CL.169)

Luis afirma que la notación es una dificultad muy fuerte, que es lo que más trabajo le da y junto con la descontextualización se propicia una desconexión entre la investigación y la Estadística.

Más concretamente al preguntarle ¿cuándo consideras que el alumno ya ha aprendido? Luis utiliza tres criterios para responder: 1) cuando el estudiante busca evidencia para sustentar sus decisiones, 2) cuando entiende lo que es la herramienta y su uso, y 3) cuando puede leer información e identificar información falsa o equivocada.

Cuando, para tomar una decisión o para evaluar si una decisión fue bien tomada él puede, él busca evidencia y grados de confianza en esa evidencia. Por ejemplo, de pronto cuando me decían hoy "oye sí es diferencia estadística pero es tan pequeñita que en lo práctico no sirve" o sea, en ese momento aprendió algo de Estadística, o sea cuando puede entender lo que es la herramienta como tal y el uso de la herramienta (E1.CL.188)

Ya en lo que es la práctica de la carrera por ejemplo, cuando puede leer información, cuando puede detectar qué información está fundamenta y qué información no está fundamentada con datos empíricos (E1.CL.189)

La enseñanza. Sobre la enseñanza de la Estadística, Luis considera que para él es fundamental:

- Trabajar en proyectos de investigación

Por ejemplo, el que haya la necesidad del tiempo presencial tan marcado y las faltas de asistencias, cuando para mí hay muchas cosas [más importantes]: que es que ellos estén trabajando en el proyecto de investigación, pero que vengan a mí a decirme "bueno estas son mis dudas y aurita nos vamos a meter a la biblioteca a seguir trabajando y te vemos dentro de cuatro días con todo el proceso" a que nos veamos en el salón de clase... (E1.CL.29)

Cerca de 40 ocasiones Luis mencionó la palabra "investigación", siempre haciendo referencia a la necesidad de que el alumno aprenda Estadística a partir de la definición y realización de una pequeña investigación en su área profesional. 
- Es esencial la interacción y atención personalizada del estudiante

Pues mira, sinceramente yo no cambiaría mi estructura de 20 alumnos por salón. De hecho aurita que tengo en un salón 22 [alumnos], lo comienzo a sentir un poco pesado, ¿por qué?, porque me permite una interacción frecuente con ellos, a resolver directamente las cosas, ¿si?; y creo que precisamente, la fórmula cual trabajamos aquí, que es tratar de eliminar toda distancia entre nosotros y los alumnos creo que es primordial en este momento en la materia (E1.CL.53)

Te voy a decir que en mi clase de estadística lo que vas a encontrar todos los días es una interacción de cómo están entendiendo por ejemplo todo el lenguaje que les estoy proponiendo. Por ejemplo hoy que incluimos el término de "estadísticamente significativa". Entonces bueno escribí la hipótesis “... y es estadísticamente significativa entre...". me preguntaron... bueno no sé ¡Juan!, "a qué te... qué entiendes por esto" (E1.CL.70)

\section{- La base debe ser una fuerte formación en metodología y Estadística}

Yo estoy convencido totalmente de que una fuerte formación en Metodología y en Estadística tiene que ser la base de una Licenciatura en Psicología, ¿por qué?, precisamente por la naturaleza de nuestra ciencia que es tan fácil que traspase y comience a ser una pseudo ciencia y se meta con todas estas otras cosas... (E1.CL.37)

O sea, una fuerte formación aquí [al referirse a los primeros semestres de la carrera de Psicología] siento que es muy importante (E1.CL.38)

- La utilidad es lo primero

Al preguntarle sobre las seis cosas que le vienen a la mente al pensar en la Estadística respondió:

La utilidad es lo primero que en estadística, o sea para mí eso es lo básico o sea pensar en la utilidad (E1.CL.62)

Los aspectos más importantes del programa de Estadística para él son:

Regresarlos a la utilidad, o sea, la utilidad y por qué es útil, creo que es uno de los aspectos más importantes (E1.CL.75)

En el C-4 a Luis se le preguntó sobre ¿Qué conocimientos se promueven a partir de una actividad como esta? El resumió su respuesta en cuatro aspectos que reflejan una vez más su concepción sobre la utilidad de la Estadística:

Primero, creo que es muy importante allí precisamente ese... la cotidianidad de la información (E2.CL.139)

el aprender a leer la información (E2.CL.140)

a valorar cada uno de los elementos (E2.CL.141)

a utilizar en la vida diaria todo aquello que ya se discutió en el salón de clase (E2.CL.142)

Por lo que considera que es importante que los datos provengan de una fuente informativa: 
Sobre todo en el hecho de que parte de la asignatura que yo doy es eso: de alguna manera mostrarles la utilidad diaria de tanto de la Metodología como de la Estadística y al ser un elemento informativo, una revista entonces pueden ver con claridad cómo se representa adecuada o inadecuadamente información (E2.CL.138)

\section{- Relacionar la Estadística con otras asignaturas}

Para Luis es indispensable que el alumno vea la conexión de la Estadística con otras asignaturas. El siguiente texto lo ejemplifica:

Por ejemplo, cuando estamos viendo áreas bajo la curva normal, y estandarización de puntuaciones, me decían "aquí si no nos has dicho para que nos va a servir", entonces cuando de pronto llego [al tema], les digo "ok mira resulta que tengo aquí las puntuaciones de un Kuder [una prueba psicológica que se utiliza para preferencias vocacionales]... mira pero tengo un problema, tenemos puntuaciones de una mujer, aquí tenemos puntuaciones de un varón, cómo le hago para saber qué debo como orientador vocacional recomendar". Entonces cuando comienzan a vincularlo, que es algo que en tercer semestre les va tocar hacer. Ya sé que ellos van a llegar en ese momento con un conocimiento de cuál es el proceso que se llevó para tomar esa tabla o baremo, donde simplemente dices puntuación 30 se transforma a 94, ya hay un razonamiento una comprensión (E1.CL.81)

Esta relación se favorece debido a que Luis imparte otras asignaturas de la carrera de Psicología.

Y otro momento que me jala mucho [que lo entusiasma], es las otras asignaturas que imparto que es Medición y Evaluación Psicosocial, Construcción de instrumentos, que digamos es la otra parte donde me siento muy a gusto, porque ya allí es la estadística aplicada a una tarea específica (E1.CL.39)

Como al mismo tiempo tienen la clase de comunicación, al mismo semestre y uno de los temas que hay allí es el de persuasión, trato de estar en relación con las otras materias (E1.CL.111)

\section{- Proporcionar ejemplos contextuales o situaciones reales aplicados a la Psicología}

Para Luis es también necesario el uso de ejemplos contextuales o de situaciones reales aplicados a la Psicología a partir de contextos y bases de datos reales y del análisis de artículos o tesis publicadas que utilicen datos del área.

Para presentarles un ejercicio [de Chi Cuadrado] no [nada] mas llego y digo "estos son los datos", sino por ejemplo, los datos del primer ejercicio es una simulación de la tesis de licenciatura precisamente de Celia Novelo. Después más adelante vamos a hacer un ejercicio que es de tomado a semejanza de una investigación de Lilia Cámara, y antes de presentarles los datos les doy el contexto, qué es lo que pretendía el investigador, qué quería averiguar, por qué hace así la situación. Que ellos antes de que yo les ponga los datos comiencen a hacer hipótesis de qué se esperaría en esa situación, qué situaciones creen ellos que debieran de probarse (E1.CL.41)

Esta clase de cosas que en algún momento cuando llegas con la técnica permiten ver por qué esa técnica se va a utilizar (E1.CL.42)

Por ejemplo, hacia el final del semestre comienzan ellos a trabajar con una base de datos, es una base de datos mía. Entonces las preguntas y los problemas de clase son los que tengo de esa base de datos, publicados artículos (E1.CL.46) 
Entonces de pronto cuando a ellos les digo "bueno el investigador se plantea tal y tal cosa", y resuelven el ejercicio y les paso el artículo. O sea, "lo que tú estas reportando, la decisión que tu tomaste y todo está publicada así como tú la hiciste en tal lugar". Esta situación de pronto he sentido en muchos momentos que es un aliciente un... o sea no estoy tan lejano de poder hacer esto y que se puedan ellos acercar, ¿sí? (E1.CL.47)

Para Luis el uso de ejemplos contextuales o situaciones reales permitirá "dar sentido" a los datos. Este dar sentido fue mencionado por Luis en 37 ocasiones, con lo que representa la importancia que para él tienen el tipo de ejemplos que se le muestren a los estudiantes.

El ideal para Luis, a partir del uso de ejemplos es lograr en el alumno un aprendizaje situado:

a mí me encantaría poder llegar a un aprendizaje situado, un aprendizaje en el cual de situaciones reales, donde ellos están tomando datos, ellos puedan estarse dando cuenta de lo que sucede (E1.CL.194)

- Un marcado énfasis en la resolución de problemas

Luis afirmó que la Estadística debería enseñarse a partir de la resolución de problemas específicos del área de Psicología.

Debe ser en un proceso de resolución de problemas, pero pensado cuál es el problema que se me presenta y cómo la Estadística es una herramienta en estos procesos, ¿si? (E1.CL.56)

Entonces cuál era mi tarea, hacer todo lo contrario, o sea buscar precisamente analizar todas esas problemáticas para que diga "bueno, esto que estoy usando en Estadística me va a servir para resolver problemas de Psicología, y para ser un psicólogo, o sea que como psicólogo puedo usar esta herramienta" (E1.CL.80)

Se pudo apreciar que Luis invierte tiempo para hacer pensar al alumno sobre el problema que se pretende resolver a partir de un contexto y del valor que para él tiene la argumentación que el alumno proporciona.

Entonces es ese proceso de "cuál es el problema que se me está presentando aurita resolverlo y verlo como algo que no es complejo, sino que es analizable y que se va a ir sintetizando después en algo más complejo, pero que puedo yo ir..." [a manera de autorreflexión de un alumno ante un problema]. (E1.CL.77)

La justificación siento que es un elemento importante porque allí al decir "porque se ven bien las alturas" es mucha de las razones que de pronto encuentro, o sea "por qué lo haces, por qué rotas, por qué pones en tercera dimensión, por qué..." (E2.CL.60)

\section{- Utilizar la metodología de proyectos}

Yo he tratado de incluir la mayor parte de ventajas del modelo, como por ejemplo, tratar de que la asignatura cambie. Como te decía la otra vez, de un modelo secuencial de enseñanza a una metodología de proyectos, ¿si? Estamos haciendo, por ejemplo actualmente tratando de desarrollar más habilidades con ellos. Por ejemplo tengo una serie de estudios de casos que se van trabajando por fuera de la clase (E1.CL.30) 
Afirma que la metodología de proyectos permite hacer razonar al estudiante y por consiguiente fundamentar lo que está haciendo.

En el momento actual, como estoy tratando de llevarlo más hacia una metodología de proyectos, una de las situaciones es pensar a la Estadística como aquella herramienta que me va a servir para fundamentar mis conclusiones y las posibles generalizaciones que haga de mis datos... (E1.CL.93)

Luis comenta el siguiente ejemplo para mostrar cómo utiliza la metodología de proyectos:

Por ejemplo aurita tienen un estudio de caso, que dura cuatro semanas. Les presento una situación, el efecto Mozart, de esta idea de que a través de la música clásica se mejora tu capacidad. Bueno, entonces ellos leen un caso hay información científica proveniente de journals. Tienen que leer en inglés y ellos tienen durante cuatro semanas que elaborar todo un análisis de esta información, y es una tarea que ellos saben que es durante el tiempo y no es parte específica del trabajo en clase sino que ellos puedan en clase decirme "oye tenemos una duda, de por qué dicen que es un diseño... ¡no sé! un diseño de grupo control con..." O sea, no lo vemos [en clase así] y podamos aclarar algunas cosas, pero son dudas que aparecen y que... Pero el trabajo es un trabajo de que ellos estén reuniéndose por fuera y con el primer... Por ejemplo esto de los estudios de caso es primera ocasión que lo utilizo. Con el primero [caso] fue fantástico o sea me dijeron que la experiencia les gustó (E1.CL31)

Para él, la metodología de proyectos debe estar caracterizada por los siguientes elementos: utilizar casos cuya base sea el método científico, preferentemente de investigación aplicada para que identifiquen el diseño de investigación y la información estadística utilizada. La actividad se realiza fuera de clase.

- Utilizar los recursos multimedia y las tecnologías de la información

Para Luis también la enseñanza de la Estadística debe ir acompañada del uso de las tecnologías de la información y comunicación, y particularmente del uso de recursos multimedia y del sistema de educación en línea.

Sobre los recursos multimedia hace referencia al uso de Applets, que le permiten la simulación de diferentes pruebas estadísticas.

Pues mira lo ideal sería tener mucho más acceso a recursos multimedia. Estoy tratando de incluirlos cada vez más, por ejemplo el trabajo en la simulación, por ejemplo cuando hacemos pruebas de hipótesis, de poder mostrarles las regiones de aceptación o de rechazo y que ellos puedan... Lo hemos estado incluyendo poco a poco y algunos Applets y todos esos, pero a veces me es más problemático, de pronto llegar a cómputo no se abre el Applet, la red se traba [atora], o sea allí sí, aunque creo que soy uno de los profesores que más recursos utiliza dentro de la clase (E1.CL.54)

Al referirse al sistema de educación en línea, Luis comentó que para los cursos de Estadística utiliza el Sistema de Gestión de Aprendizaje (Learning Management Systems) denominado Dokeos.

Te digo estamos implementando el sistema de educación en línea, utilizar con frecuencia cómputo (E1.CL.55) 
También Luis hace referencia al uso de paquetería de software específico de Estadística como el SPSS. Más adelante se comentará al respecto.

Ante la pregunta ¿qué papel tiene la tecnología en la enseñanza de la Estadística? Luis afirmó que le permite dar más significado:

Le permite dar más significado, le permite unir lo visual con el proceso reflexivo que hay que ver para entender la estadística. Esto es algo muy importante. Antes me la pasaba tratando de hacer gráficas. Por ejemplo, en que estamos viendo prueba $t$, o sea representación de las curvas que están en la parte de arriba de la fórmula y la aproximación a la población en la parte de abajo y todo esto..., bueno ahora es mucho más fácil ¿no? Dejarles esto para que ellos puedan revisar (E1.CL.187).

\section{- Ganar la confianza de los alumnos}

Lo que busca Luis es que los estudiantes se "acerquen" a la Estadística. Que no la vean lejos. Por eso, para él es importante ganar su confianza, que sepan que pueden leer una investigación, proporcionarles el contexto para motivarlos, relacionar lo que ellos encontraron con la conclusión a que llegaron los investigadores (de los artículos o reportes de investigación). Al hablar de "ganar la confianza" logramos identificar algunos elementos que lo caracterizan:

- Que los alumnos no tengan miedo a la Estadística y reconozcan sus propias capacidades y potencialidades:

Una de las cosas que varias veces he tenido el gusto de que me digan es que se pueden acercar precisamente a la Estadística y la investigación sin miedo. Que ya no lo ven como algo tan complicado. Varias veces me han tocado alumnos que han cursado uno o dos semestres en otras licenciaturas, y que dicen "recuerdo que esto me lo enseñaron pero no lo aprendí, y aquí estoy resolviendo los problemas, estoy resolviendo las situaciones, estoy usándola en mi proyecto y sé por qué”. Porque por ejemplo hay momentos que tengo como que muy pensados en las clases (E1.CL.45)

- Mostrar la asignatura de una manera sencilla y fácil, accesible para todos:

A veces he llegado... bueno aquí me lo han tomado a veces como que no tan bueno, les he dicho "yo prefiero de pronto quedarme dos o tres clases discutiendo una investigación que puse como ejemplo, aunque yo diga 'aquí debería yo estar en la siguiente prueba' ", porque lo que me impulsa es que se acerquen a la estadística sin miedo. Y una de esas cosas es... o sea siempre me... todos los meses tengo el mismo comentario ¿no? que yo les digo "bueno la siguiente prueba es un poquito más tardada pero es igual de fácil que la anterior", y me dicen "siempre dices lo mismo, pones la fórmula y a la primera vez que vemos la fórmula se nos hace tan difícil", pero después me dicen "no, sí es cierto es tan fácil como la anterior", en el sentido de que pues vamos [analizando] "cuál es el problema acá" "el problema es que no sé cómo entender estos símbolos" "bueno pues vamos a resolver los símbolos" (E1.CL.76). 
- Trabajar colaborativamente e interpelar constantemente al estudiante

Cuando se le preguntó sobre su método o estrategia para enseñar Estadística, afirma que lo que uno puede encontrarse como habitual en su clase es una interacción porque el trabajo en equipo es la base del aprendizaje:

Trabajar en grupo, donde cada quien aporta su parte de lo que está aprendiendo en ese proceso. Toda la asignatura siempre es trabajando en grupo (E1.CL.82)

Para Luis el trabajo en equipo le permite al alumno desarrollar las habilidades de forma más integrada.

pero creo que lo que está aquí reportado, que hizo un equipo, me está hablando de unas habilidades mucho más complejas, que tiene que ver con analizar, buscar información, analizarla, ver cómo presentarme la información, cumplir con requisitos ... Te voy a decir: sí creo que lo que ahora hago con ellos [sus actuales alumnos], algunos de mis alumnos de años previos no pueden hacerlo, porque no se les presentaba [enseñaba] la situación de este modo ¿si? (E1.CL.140).

La manera habitual de enseñar. Por último, se identificó y caracterizó la forma habitual que Luis sigue para enseñar Estadística. Luis no sigue una secuencia particular ni rígida para enseñar sino sus clases están caracterizadas por diferentes momentos que se producen de manera flexible y que dependen del contexto y del objetivo de la clase.

Como se puede apreciar en la Figura 5.10 se identificaron tres momentos de la clase. Un primer momento es la fase de inducción (o preparación y motivación hacia la clase) y cierre que Luis realiza. Con frecuencia, y particularmente cuando inicia un nuevo tema, motiva a sus estudiantes preguntándoles “¿cómo van?” Generalmente explora los conocimientos previos que tienen los alumnos (evaluación diagnóstica):

Continuamente durante las clases hay momentos en los cuales me siento con ellos a ver cómo va el semestre, o sea, qué ha pasado hasta ese momento. Lo que hago en ese momento es pedirles, que ya no sea un comentario, sino respondan un pequeño cuestionario. Entonces llevo estos datos recogidos de ellos y a partir de eso les presento información, o sea, les hago una presentación de lo que fue para mi la interpretación de esos datos y a partir de ello vamos viendo, por ejemplo, si fueron representaciones adecuadas o no, porque como te digo como he estado haciendo sondeos de qué es... cómo van. Por ejemplo este año no tuve que enseñar a calcular medidas de tendencia central y variabilidad porque al momento de hacer el sondeo me di cuenta que todos identificaban con claridad cada una [de las MTC], incluso habían temas que no estaban incluidos (como media geométrica, media armónica, y demás), que no eran necesariamente parte del programa, que los conocían (E1.CL.109) 


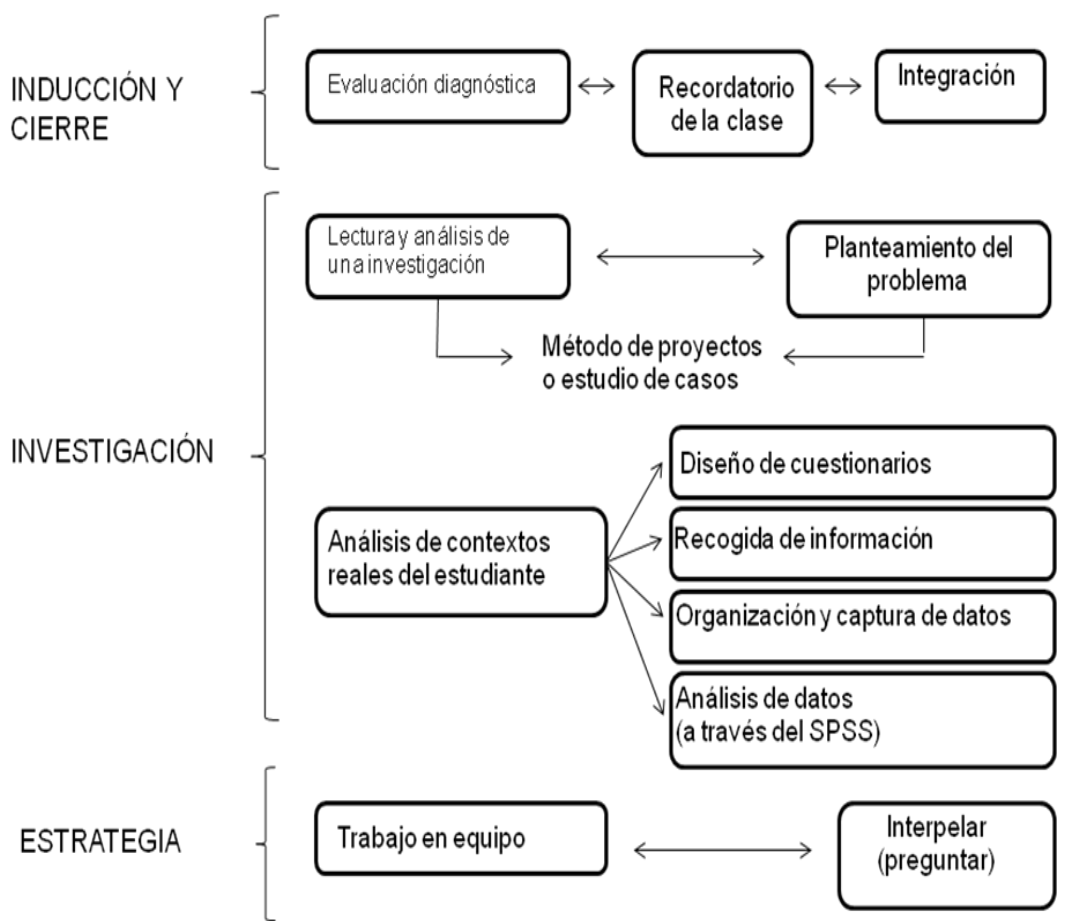

Figura 5.10. Forma habitual de la clase de Luis

Esta valoración también sirve para identificar las dificultades de los alumnos:

Lo que pasa es que realmente, como estamos en constante diálogo en el salón de clase, precisamente es el momento en el que estoy yo evaluando eso. ¿Por qué?, porque lo que hago es que mientras estás resolviendo algo (p.e. un ejercicio), estoy interactuando con ellos, o sea, no sé, Maru "oye y, entonces, ¿cuál sería la decisión?" "tal cosa", "pero Juan, y la hipótesis y la frase estadística, ¿cómo estaría establecida?" (E1.CL.164)

Este momento también se caracteriza porque sirve de recordatorio de lo visto en clase y para la integración con los temas vistos hasta ese entonces:

Para ellos es natural que estoy trabajando e incluso desde el momento del encuadre, del principio de la clase, en el momento en el que recuperábamos dónde estábamos antes, y hacia dónde vamos; desde ese momento yo estoy identificando cosas, porque en ese momento comienzo con "oye el último tema según yo, fue esto, hicimos esto y aquello", y saben que estoy en ese momento recuperando información. Para ellos ya es lo que hago todos los días (E1.CL.166)

Un segundo momento que Luis utiliza en sus clases, es el que hemos denominado de investigación, caracterizado por la lectura y análisis de investigaciones y el análisis de contextos reales del estudiante. En el primer caso, se trata de vincular la Estadística con la investigación del área y la metodología de estudio, donde el alumno debe aprender a identificar una problemática o errores metodológicos y conceptuales en el manejo de pruebas de hipótesis. Por ejemplo: 
Un caso, por ejemplo, cuando vimos Diseños de Investigación les puse tres investigaciones, que tenían violaciones a la validez interna. Les dije "Bueno éstos: los tres tienen violaciones a la validez interna. El trabajo de ustedes es identifícalas". Me decían "pero ¿cómo?, o sea ¿es un resumen, una tabla?". Entonces ellos tenían que entregarme un reporte en el cual me dijeran ¿qué fue lo que sucedió?, ¿por qué?, ¿qué harían para corregir la situación? (E1.CL.147)

La segunda manera de vincular la Estadística con la investigación es a partir del análisis de datos reales de la información generada por los mismos estudiantes. Este momento se caracteriza por diseñar un cuestionario, recoger información, organizar, capturar y analizar datos con el apoyo del SPSS. Luis lo ejemplificó de la siguiente forma:

Trato de hacerlo, dentro de las limitaciones que aurita me dan [enfrento], en el sentido de que por ejemplo, al principio de curso, como antes ya habíamos visto la idea de cómo es un cuestionario, les diseño uno chiquito [breve] acerca de un tema que ellos me dicen. Les indico de dónde provienen las cosas. Y de los datos que ellos me dan, los 80 datos por ejemplo, aurita estamos con esos datos jugando con las pruebas cuando vamos a cómputo. Generalmente en clase son ejercicios ya prehechos por mí. Cuando vamos a cómputo [les digo] "vamos a ver si los muchachos o muchachas les gusta tipos de películas diferentes" porque eso fue el tema, o sea que en ese momento se vean ubicados ellos como parte del propio proceso y permite entonces que haya una posibilidad de qué es lo que pudiera yo esperar. Pero aun así, todo lo que tengo en clase trato siempre de que esté relacionado con la propia carrera, que esté relacionado siempre con algo que hayan visto o que se espera que pronto toquen [vean] (E1.CL.195)

La metodología particular que utiliza Luis en este momento de su clase generalmente es la metodología de proyectos o el estudio de casos. El primero relacionado con el desarrollo de proyectos que implique trabajo de campo y el planteamiento de una situación real. El segundo, a partir de análisis de artículos o reportes de investigación, donde se plantea una situación que es necesario validar, replicar o bien fundamentar a partir de la Estadística.

El tercer momento que caracteriza la enseñanza de Luis son las dos estrategias que de manera permanente están incorporadas en sus clases: el trabajo en pequeños grupos de discusión y la interpelación o habilidad para preguntar.

Sobre el trabajo en grupo, además de lo ya comentado, Luis habla de la importancia de esta estrategia y lo resume del siguiente modo:

Siento que la socialización del conocimiento es uno de los elementos más importantes, pero sobretodo encuentro que en esa situación - en un equipo pequeño primero y después frente a los demás como grandes equipos - es más fácil romper algo que llega muchas veces a Estadística y a Metodología, [que] ahorita siento que incluso el propio programa de Prepa [Bachillerato] está propiciando que suceda, que llega ya, que es una idea de incapacidad ante el tema, o sea sentir que es un tema que no voy a entender... (E2.CL.93)

y al estar trabajando en un equipo con el cual te sientes a gusto, con el cual puedes hablar y sobretodo que se ha creado un ambiente de corresponsabilidad porque es algo que enfatizo mucho con ellos: que para ser un buen equipo tiene que ser responsable de su propio aprendizaje y de saber que los otros saben tanto como tú, conocen tanto como tú y que si no han llegado allá [al resultado] son tan responsable como ellos de "ayudarlos" a seguir (E2.CL.93) 
Sobre interpelar o preguntar a los alumnos, Luis sostiene que es una característica que todo profesor debe tener con sus alumnos. La utiliza en todos los momentos que sea necesario durante sus clases y en las asesorías.

Entonces en ese momento trato de que durante las clases, durante una semana, todos hayan sido interpelados por mi cuando menos una vez. No es un proceso de que yo agarró la libreta y estoy apuntando cuantas veces, sino que trato de hacerlo en una dinámica, de tal modo que realmente que ellos sientan que estamos trabajando en conjunto. Eso es lo que yo quiero (E1.CL.165) utiliza.

Más adelante comentaremos más sobre el tipo y características de preguntas que

Luis afirmó que en el proceso de enseñanza y aprendizaje la responsabilidad recae tanto en el profesor como en los alumnos. Por una parte el profesor debe seleccionar los medios adecuados para lograr el aprendizaje y debe potenciar la motivación en los alumnos y por otra los alumnos deben colaborar participando activamente en las actividades.

Luis utiliza los momentos descritos en diferentes circunstancias y dependiendo del objetivo de la clase y caracterizan su manera habitual de enseñar la Estadística.

Todos estos rasgos caracterizan la concepción que Luis tiene de la Estadística, su aprendizaje y enseñanza. Para él, la Estadística es una herramienta que ayuda a entender lo que está sucediendo en el entorno y en la solución de diversas problemáticas del contexto, donde lo importante es el significado y sentido de los datos. El eje central de la asignatura gira entorno a la concepción de la relación que debe existir entre la metodología de la investigación y la Estadística, lo queconlleva a desarrollar el razonamiento estadístico del estudiante a partir de la formulación de una problemática y orientar el análisis hacia los fundamentos y validez en la toma de decisiones.

Luis concibe la Estadística como una herramienta global usada para dar sentido al mundo y desarrollar significados personales (Concepción 6 de Reid y Petocz, 2002). Los estudiantes usan los métodos estadísticos para desarrollar su propio pensamiento, para crear nuevas interpretaciones de datos y de la vida, crean su conocimiento estadístico a partir del manejo de datos reales. Considera la Estadística como algo aplicado a la investigación en un área disciplinar o en la sociedad (Gordon, 1998), reconociendo tanto los alcances y limitaciones de su uso; conceptuándola como base para el método científico y como una forma de pensamiento crítico. Esta concepción, le permite a Luis mostrar a los estudiantes un significado interno (Reid y Petocz, 2002) de la Estadística, a percibir que su trabajo profesional está relacionado con el académico. En este sentido, los estudiantes visualizan la Estadística como parte integral de su futuro profesional, asumen el desarrollo de habilidades de análisis e interpretación de datos como inherente para el ejercicio de la profesión. 
Por otro lado, la concepción de Luis sobre el aprendizaje de la Estadística transita entre expandir: utilizar conceptos para comprender otras áreas, y cambiar: usar los conceptos para cambiar su visión del mundo (Concepción E y F de Petocz y Reid, 2002). Para Luis es esencial comprender lo que piensa y hace el estudiante, hacerles ver el significado que tienen los datos en el mundo real. Intenta que el alumno utilice la Estadística en diferentes contextos, así como que la vean como una herramienta intelectual que puede ser usada para resolver problemas en otras áreas y que su estudio les lleve a cambiar la forma de ver el mundo.

Particular atención tiene la concepción del aprendizaje de Luis al referirse a dos conceptos: el aprendizaje situado y a la socialización del conocimiento. El primero, destaca la importancia de la actividad y el contexto para el aprendizaje, en la cual aprender y hacer son acciones inseparables (Díaz-Barriga, 2003). Según esta autora, el principio nodal del aprendizaje situado es que los alumnos aprendan en contextos significativos y reales, involucrando a los estudiantes en el mismo tipo de actividades que enfrentan o enfrentarán en diferentes campos de conocimiento. En otras palabras, implica diseñar estudios, recoger datos, analizar sus resultados, preparar reportes y realizar presentaciones orales (Smith, 1998).

Por su parte, la socialización del conocimiento, descansa en la teoría de Vigotsky que se basa principalmente en el aprendizaje sociocultural y en el medio en la cual se desarrolla. Vigotsky considera que para que un alumno aprenda, el contexto ocupa un lugar central y la interacción social se convierte en un elemento esencial en el desarrollo cognitivo. Por consiguiente, el aprendizaje es producto de la socialización del sujeto en el medio, donde la interacción grupal o situaciones colectivas en clases favorecen y facilitan el aprendizaje. Otros autores, como Giraud (1997) relacionan la socialización con el aprendizaje cooperativo, que es una actividad basada en el trabajo en pequeños grupos en la solución de problemas y que es ampliamente reconocido por el efecto que tiene tanto en el aprovechamiento académico como en la motivación, la socialización, la confianza en el aprendizaje del estudiante y las actitudes hacia la asignatura.

Luis demuestra una concepción sobre la enseñanza de la Estadística centrada tanto en anticipar las necesidades de aprendizaje del estudiante como en ser catalizador de su "mentalidad abierta” (Petocz y Reid, 2002). En otras palabras, considera las características y necesidades de los estudiantes para proporcionar materiales y métodos que mejoren su aprendizaje. Le da mucha importancia a conocer mejores métodos para enseñar ciertos conceptos y saber qué hacer cuando los estudiantes no comprenden. Sostiene una concepción integral de la Estadística que transmite a suss estudiantes. 


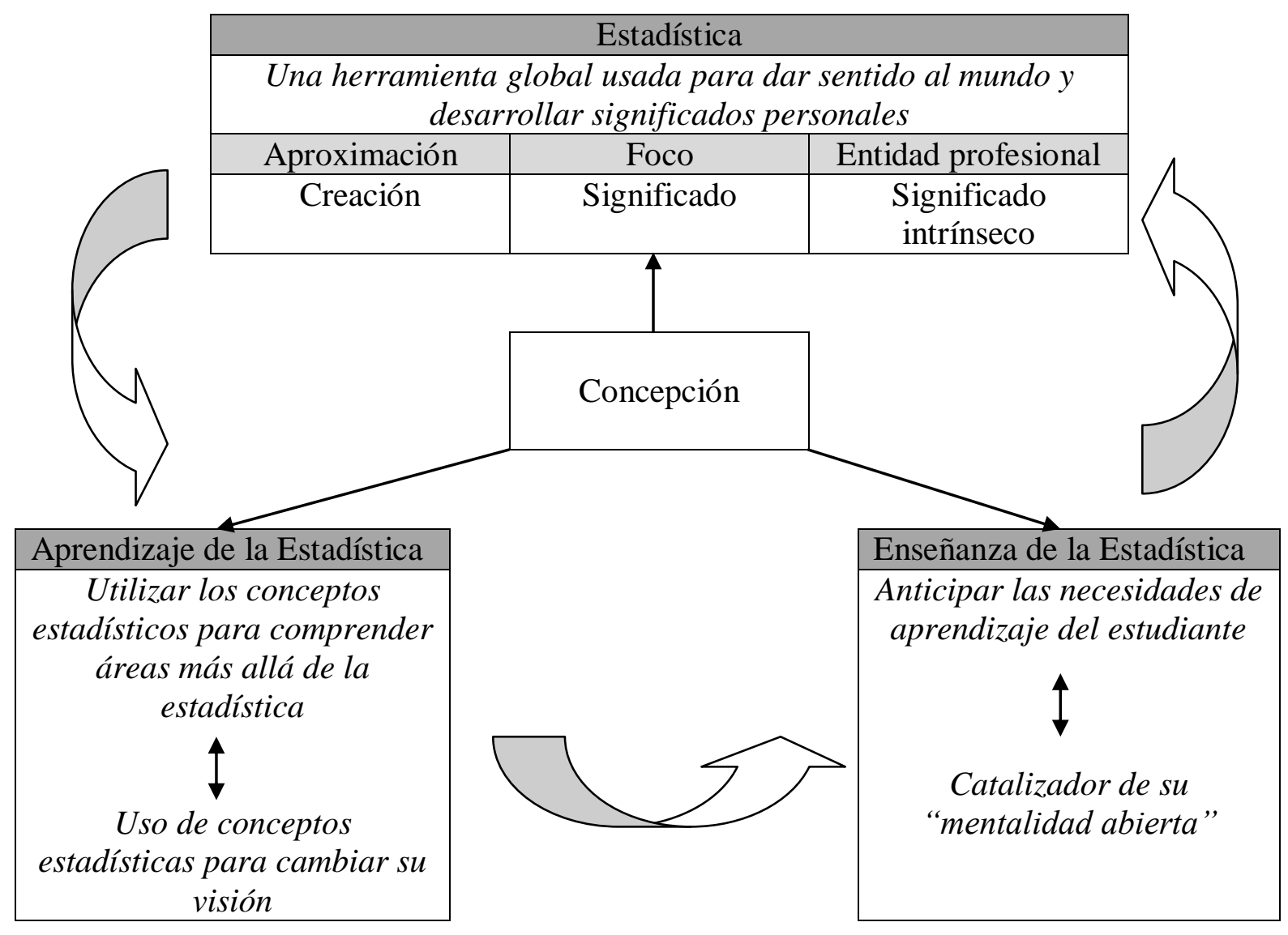

Figura 5.11. Concepciones de Luis sobre la Estadística, su aprendizaje y su enseñanza, con base en Reid y Petocz. (2002) y Petocz y Reid (2002)

La Figura 5.11 sintetiza y representa sus concepciones. Según la clasificación de Reid y Pecotz (2002) y Petocz y Reid (2002) Luis se encuentra en los niveles superiores de cada una de las concepciones. Se preocupa porque los estudiantes la vean como una herramienta con sentido y significado, tanto para su vida como en su profesión.

\subsubsection{Concepciones sobre la representación gráfica, su aprendizaje y enseñanza}

Para la identificación de la concepción tanto de la representación gráfica, de su aprendizaje, como de la enseñanza, se seleccionaron aquellas evidencias que se refieren a estos aspectos.

Sobre el significado de la representación gráfica. Las respuestas incluidas en este apartado fueron las siguientes:

E1.CL.172: comenzar a darles el sentido

E1.Cl.97: ese es el tema que yo siento que es base para todo lo que sigue

E1.CL.111: trato de estar en relación con las otras materias 
E1.CL.195: esté relacionado con la propia carrera

E2.CL.17: siempre les digo "a mi no me gustan las gráficas de tercera dimensión, rotadas y demás porque siento que allí te vas por esos elementos"

E2.CL.19: mientras más elementos de color y demás, se cambia la información [de la representación gráfica]

E2.CL.20: lo importante es qué quiere decir el que está dando esa información

E2.CL.20: comenzamos hablar también de un poco de la ética de la información

Cu.CL.3a.1: contextualizar la representación gráfica de datos

Cu.CL.3a.2: propiciar su uso para la formación de conclusiones

E2.CL.68: una gráfica que tenía un sentido, que lo que quería hacer era representar algo en particular

E2.CL.68: de esa gráfica se obtuvieran conclusiones, se obtuviera información a partir de ella

E2.CL.68: veía, como que la intencionalidad del uso

E2.CL.69: para algo se va a utilizar, tiene un sentido esa utilización

E2.CL.90: se puede obtener información a partir de la gráfica. Hay cosas que se pueden deducir de esa gráfica

E2.CL.104: el gráfico es un referente a algo que ya está dicho en el texto

E2.CL.34: es una representación resumen y que cada elemento resume algún dato

E2.CL.26: se pueden ver con mucha más claridad la naturaleza de cada una de las representaciones

E2.CL.13: de la naturaleza de ese número, de ese dato, cada escala de medición te aporta información acerca de la naturaleza de ese dato y lo que puedes hacer con él

E2.CL.13 al momento de no hacer referencia a la escala de medición, en ese momento ya no sabes hasta dónde puedes llegar con esa información

E2.CL.115: utilizar al gráfico como punto de partida para obtener más información

Podemos apreciar que Luis tiene una concepción de la representación gráfica como interpretar relaciones en contextos reales (Concepción 3, ver sección 4.6.4) centrado en la habilidad para dotar de significado los gráficos creados por otros o por ellos mismos, para conocer los componentes de un gráfico, responder preguntas acerca de gráficos, adquirir el sentido gráfico o el sentido de los datos. Busca que los estudiantes diseñen y analicen gráficos a partir de datos reales, explorando su uso en contextos de la vida real y de su profesión. Aquí se incluye no sólo leer, escribir e interpretar el gráfico, sino escribir y 
establecer relaciones o factores importantes a partir del contexto, estudiar y analizar los fundamentos de la construcción de gráficos, la interpretación y escritura de conclusiones a partir del gráfico, incluyendo criterios engañosos o modelos técnicas gráficas impropias.

En esta concepción podemos apreciar la inclusión de las anteriores (como técnica de graficación y como comunicar resultados).

Sobre el aprendizaje de la representación gráfica. En diferentes momentos Luis resaltó que lo primero que se debe buscar es que lo alumnos identifiquen con claridad las escalas de medición de una variable y que la puedan representar adecuadamente según su escala. También considera que los alumnos deben aprender a leer gráficas e identificar representaciones confusas o falsas. Piensa que la mejor forma de aprender es a través de la resolución de problemas y de procesos reflexivos.

Para él, un alumno ya aprendió cuando puede leer información, detectar qué información está o no fundamentada con datos empíricos (E1.CL.189). Para ello procura conocer a los alumnos, conocer cuáles son los procesos cognitivos, los procesos reflexivos que está desarrollando.

El desarrollo cognitivo que espera conseguir en sus alumnos está en un nivel de comprensión gráfica de leer entre datos y leer más allá de los datos (Curcio, 1989), es decir, centrado en la interpretación de los datos, comparar algunos gráficos, observar relaciones e interpretarlas, dárle significado a los elementos del gráfico dentro de un contexto, comparar local o globalmente sus características, prestar atención a los especificadores, interpretar algunas relaciones (ej. variable-escala de medición-tipo de gráfico) e identificar algunas tendencias.

Ejemplos de sus afirmaciones son las siguientes:

E1.CL.171: [dificultades] ... el sin sentido que era representar datos

E1.Cl.171: [dificultad] ... [los alumnos] no piensan en la posibilidad de representarlo de maneras diferentes

E1.CL.176: [dificultad] para interpretar las representaciones

E1.CL.193: [aprende cuando] se da cuenta que una representación es inadecuada o incompleta

E1.CL.193: [aprende cuando] se da cuenta que la información que visualmente tiene no corresponde a lo que esperaba con respecto a los datos

E1.CL.83: no se pueden aprender estadística sin saber los supuestos y los fundamentos

E2.CL.93: la socialización del conocimiento es uno de los elementos más importantes

E1.CL.135: trabajando en grupo aprendemos más

E1.CL.195: en clase trato siempre de que esté relacionado con la propia carrera

E1.CL.60: “apréndelo, que sepas decidir cuándo usarlo, a lo mejor en tu carrera no vuelves a 
usarlo, pero que tengas las bases para decir aquí esto serviría"

E1.CL.148: “corrige y dime ¿qué paso?,¿en qué te confundiste?”,

E1.CL.164: mientras estás resolviendo algo (p.e. un ejercicio), estoy interactuando con ellos

E1.CL.198: mi responsabilidad es poner los medios para llegar a un aprendizaje y estimularlos hacia ello

E1.CL.199: La responsabilidad del éxito del curso es de ambos y que mientras ellos me vayan diciendo que algo funciona yo seguiré trabajando

E2.CL.104: siento que pocas veces se interpreta una gráfica

Sostiene una concepción del aprendizaje de la RG vinculada con el desarrollo de la alfabetización estadística (Garfield, 2002) en su fase inicial, que supone un conocimiento/comprensión y uso del lenguaje básico y de las herramientas de la Estadística, del uso de símbolos estadísticos; conocimiento y uso de técnicas básicas de graficación para comprender información estadística; organizar datos, construir y presentar tablas y trabajar con diferentes representaciones de datos; identificar datos categóricos y numéricos, así como identificar correctamente y comprender las escalas de medición. No obstante, le concede poco o nulo valor a comprender la información presentada en un gráfico estadístico de distribución (ej. de puntos, histograma y de caja), identificar algunas formas comunes de distribución (ej. normal, sesgadas, bimodal, uniforme), distinguir entre un gráfico de barras y serie de tiempo de los histogramas, y comprender los términos relacionados con la distribución.

Para Luis aprender la RG está íntimamente relacionado con la interpretación de los gráficos bajo ciertos supuestos y fundamentos, sobre todo aquellos que provienen de bases de datos de contextos hipotéticos relativos a la profesión del estudiante. Como puede apreciarse en los comentarios le concede mucho valor a la interacción y el diálogo con los estudiantes, siendo ambos (profesor y alumno) corresponsables del aprendizaje y haciendo referencia a la socialización del conocimiento.

Busca desarrollar un nivel literal/racional (Aoyama, 2006 y 2007) de la representación gráfica, en la cual los estudiantes pueden leer valores y tendencias, explicar significados contextuales literalmente en términos de las características mostradas en el gráfico. No pueden sugerir una interpretación alternativa sino que usan únicamente los significados presentados y generalmente son capaces de hacer preguntas sobre la confiabilidad de la información.

Sobre la enseñanza de la representación gráfica. Luis manifestó una concepción centrada en cuestionar las características y fundamentos de las gráficas a partir de una diversidad de preguntas para explorar los elementos del gráfico, los fundamentos de sus decisiones y la relación con el contexto de donde surgen los datos. Solicita la construcción de gráficos a partir de cuestionarios que recojan información de los propios estudiantes y de proyectos de investigación sobre algún tema de la profesión. Para guiar el aprendizaje se basa siempre en la interacción con los estudiantes, en la exposición de representaciones 
gráficas por equipos con la ayuda del power point o de SPSS, así como en la revisión de gráficas presentes en los reportes de investigación que los estudiantes entregan como producto final de la asignatura.

\section{Un extracto de sus comentarios relativos a esta cuestión fueron:}

E1.CL.110: les presentaba representaciones totalmente erróneas, otras muy buenas y la idea era que ellos fueran marcando... después vimos

E1.CL.110: [les preguntaba] ¿qué sería?, ¿por qué representar a través de una gráfica circular?, ¿por qué representar...?

E1.CL.110: una clase muy interactiva... ellos trataban de interactuar para decirme "¿qué significa lo que te estoy diciendo?"

E1.CL.113: con estos datos [de] ustedes [los alumnos] ... vamos a entender lo que significa hacer un histograma

E1.CL.162: [evaluación] ... a través de un ejercicio en el salón de clase... con apoyo del SPSS

E1.CL.162: [evaluación] datos que procesaron en SPSS... tenían que hacer una presentación en power point de esos datos que se les había dado

E1.CL.162: Era un trabajo que era en equipo y ellos tenían que presentarme allí, esta información

E1.CL.109: responden un pequeño cuestionario.. datos recogidos de ellos

E1.CL.109: ... les presento información, o sea, les hago una presentación de lo que fue para mi la interpretación de esos datos

E1.CL.109: ... vamos viendo, por ejemplo, si fueron representaciones adecuadas o no

E1.CL.165: trato de que durante las clases, durante una semana, todos hayan sido interpelados por mi cuando menos una vez

E1.CL.217: ir leyendo constantemente reportes de investigación

E2.CL.21: les dejo esa libertad de hacerlas en el graficador de Office o hacerlas en el graficador de SPSS

E2.CL.22: generalmente lo que hago es más que nada corrección de errores

E2.CL.55: cada equipo elabora de ese cuestionario que tenemos de esa base de datos, se les pide que hagan un reporte descriptivo

E2.CL.48: en el reporte [de investigación que hacen] que escojan aquellas gráficas y tablas que se consideren adecuadas para resumir la información, pero hasta allá

E2.CL.67: $\mathrm{Si}$ estamos en el centro de cómputo se pide que se hagan algunas representaciones de tal variable

E2.CL.32: "hoy vamos a representar nivel nominal" es bueno... "ok, vamos a representar 
un gráfico de áreas ... si es un gráfico de áreas entonces ¿qué tendrías que poner?"

E2.CL.65: [pregunta] a partir del nivel de medición, ¿cuáles serían las características de ese nivel de medición?, ¿qué se está representando en la gráfica?, cada uno de los elementos de la gráfica ¿qué dicen de ese nivel de medición?, eso es algo que hacemos siempre. En esa sesión en eso nos centramos.

E2.CL.137: [pregunta] "bueno ¿qué tipo de gráfico es?" [ellos dicen] "bueno tal", [les digo] "este gráfico, ¿cuáles son sus características?"

E2.CL.137: Entonces hacemos una revisión de esas características, se mencionan las más importantes y cada una se revisa, o sea ¿está o no está esa característica allí?

E2.CL.01: [pregunta] de repente, “qqué pasaría si rotas el eje y cambias el gráfico?”, porque para el caso del gráfico de tallo y hoja... "o sea si lo giramos y lo dejamos en... o giramos el gráfico del histograma, ¿qué pasa? o sea ¿qué semejanzas encuentras entre los dos?"

Esporádicamente Luis utiliza la manipulación del gráfico con ayuda del SPSS para analizar y explorar las características y elementos del gráfico. Remarca que el análisis que hace con los estudiantes está centrado en la revisión del tipo de variables y las escalas de medición de gráficos descriptivos o categóricos, sin el propósito de compararlo que los estudiantes discriminen en uno y otro.

La Figura 5.12 nos muestra las concepciones que Luis tiene de la RG. Sus concepciones están relacionadas con las de la Estadística como el valor que concede al uso de contextos reales del sentido de los datos para que los estudiantes reflexionen sobre las interpretaciones de los gráficos, al menos de manera literal. Sin embargo, no contempla actividades específicas para desarrollor los diferentes niveles cognitivos de la RG y se limita a la revisión de gráficos descriptivos y categóricos y sólo uno de carácter analítico (histograma), lo cual también explica su concepción de la RG.

Luis suele mencionar el "sentido del gráfico" pero no en como los contemplan Friel, Bright y Curcio (1997) quienes lo definen "como resultado de presentar gráficos diseñados a partir de los datos, explorando su uso en una variedad de contextos y relacionando éstos no sólo con la construcción del gráfico o con una simple extracción de datos para la lectura de gráficos" (p.224). No se encontró evidencia de que Luis incluya el uso y análisis de gráficos en una "variedad de contextos" sino sólo en el contexto en el que los estudiantes deciden realizar su investigación. El análisis depende más de la decisión del estudiante de incluir o no determinado gráfico, mientras que el papel de Luis es revisar si éstos están o no bien diseñados y correctamente interpretados. Por otra parte, el sentido gráfico abarca un rango de conductas como leer, describir, interpretar, analizar y extrapolar datos de un gráfico, así como la capacidad para traducir una gráfica a otra, de una tabla a una gráfica y ser capaz de interpretar relaciones o factores importantes en un gráfico (delMas, Garfield y Ooms, 2005). No encontramos suficiente información para asegurar que estas cuatro últimas sean tenidas en cuenta por Luis, más bien entiende por "sentido" a considerar que los datos provenienen de contextos reales. 


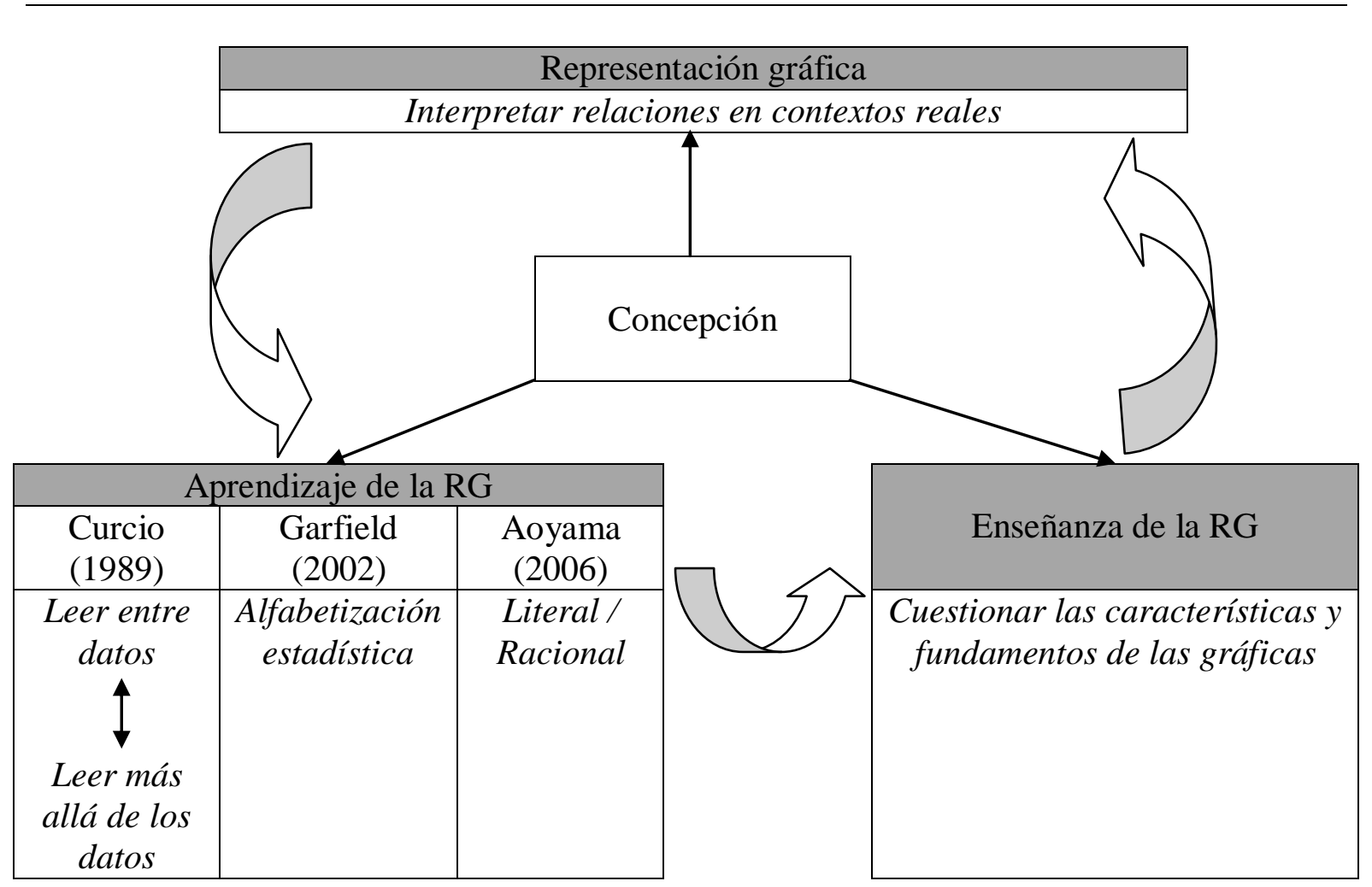

Figura 5.12. Concepciones de Luis sobre la representación gráfica, su aprendizaje y su enseñanza

Friel, Bright y Curcio (1997) conceptúan que la comprensión y uso de gráficas como una parte clave de lo que debe ser el conocimiento de la Estadística. Tradicionalmente, a los estudiantes se les solicita sólo leer información a partir del gráfico, sin embargo, es necesario también explorar la naturaleza de los datos para les ayude a comprender mejor el uso y lectura del gráfico. En el caso de Luis, aún cuando considera el análisis de gráficos en contextos reales, la RG no representa una parte clave en Estadística, es decir, no es un tema central (como lo es para él las pruebas de hipótesis), por lo que no contempla el análisis exploratorio de datos (EDA) (que se menciona en la Concepción 3 de la RG).

Luis centra el análisis, o al menos se aproxima, en los cuatro factores críticos que, según Friel, Curcio y Bright (2001), influyen en la comprensión gráfica: los propósitos para usar gráficos, las características de las tareas (descodificación visual del gráfico, taxonomía para analizar las capacidades a desarrollar en las tareas sobre graficación, el contexto), características de la disciplina (tipo y tamaño de datos y complejidad gráfica) y características del lector. Si bien el análisis incluye la revisión de algunos componentes estructurales como el armazón (ej. ejes, escalas, coordenadas, marcas de referencia), las etiquetas y el fondo (algún color, coordenadas y cuadro sobre el cual el gráfico puede ser sobrepuesto), considera más importante analizar cómo se llega al gráfico a partir de las variables, las escalas, la correspondencia escala de medición - gráfico y el contexto de donde se origina. 
Desconoce los avances en torno al aprendizaje y enseñanza de la RG, como son los trabajos de Monteiro y Ainley (2003) y Aoyama (2006) sobre la incorporación y análisis a través de media graph; el análisis de datos a través de los contexto de investigación y de lectura de Gal (2002), entre otros.

Por último, si bien existe cierta relación entre la concepción de la Estadística y la RG, percibimos que no se le concede la relevancia debida a esta última porque Luis no consideralos conocimientos necesarios para un aprendizaje y una enseñanza de acuerdo a las tendencias que establecen las investigaciones en educación estadística.

\subsubsection{Conocimiento del currículo}

A partir de los instrumentos utilizados en la investigación se exploró su conocimiento del currículo de Estadística y más específicamente de la representación gráfica (B-III según el SDI), es decir, los objetivos de aprendizaje, los contenidos, las estrategias específicas de enseñanza, la forma de evaluar, la bibliografía y los materiales (ej. textos, audiovisual, calculadora, internet, software) que utiliza. En primer lugar se presenta la parte correspondiente al conocimiento que tiene Luis acerca del programa de Estadística, y luego la parte correspondiente a la representación gráfica.

\subsubsection{Del programa de la asignatura de Estadística}

En cada uno de los apartados siguientes se describe el conocimiento de Luis acerca del programa de Estadística comparándolo con el programa correspondiente (ver Apéndice C). La información se ha organizado en cuatro apartados:

- Objetivos y propósitos

- Contenidos

- Actividades instruccionales

- Criterios de evaluación

Objetivos y propósitos. Luis considera que la asignatura que lleva por título Metodología y Estadística para la Investigación I descansa en el principio de que para aprender Estadística se requiere del estudio de la metodología científica para que los alumnos descubran su relevancia y utilidad, así como sus fundamentos para la toma de decisiones.

La materia está fusionada con metodología y considerando eso, al principio se le concebía como una herramienta dentro de la metodología para poder hacer investigación empírica dentro de un campo de la Psicología. De hecho en el programa de estudios, en las cartas descriptivas todavía dice eso, se dice que están conjuntas y que sirve como herramienta (E1.CL.86)

Para justificar esa fusión utiliza los siguientes argumentos:

Por otra parte, además dentro de la propia formación tanto lo que es el eje de investigación de la carrera requiere estadística como una herramienta, o sea por ejemplo, el siguiente semestre ellos se enfrentan a Psicometría y Psicología experimental que no les enseñan más Estadística, pero hablan 
de normalización de puntuaciones o hablan de control de variables extrañas en... O sea, cosas que suponen conocimientos estadísticos (E1.CL.91)

Este principio, según Luis debe reflejarse también en el salón de clases. De hecho, lo que se busca con las actualizaciones del programa es que el alumno entienda las bases conceptuales y metodológicas en que descansa la Estadística:

Lo que he estado tratando de hacer en estos tres últimos años es cambiar un poco esta visión a que más que sea sólo el accesorio para una metodología cuantitativa, que tenga una función fundamental, que es lo que te decíamos la otra vez: que hay una forma de pensar en estadística (E1.CL.87)

Se trata por lo tanto, de ir más allá de la sola definición e identificación de variables, del cálculo de valores estadísticos y de seguir una secuencia de pasos para ejecutar una prueba de hipótesis. Luis lo ejemplifica del siguiente modo:

Como por ejemplo, (te voy a dar un caso), hoy me entregaron un trabajo los muchachos en el cual la única prueba estadística que se ha visto en este momento en el curso, estamos en pruebas de (ji) cuadrada, pero en el reporte que ellos tenían que leer les hablaba de ANOVAS, de otras cosas; pero como ya saben leer una decisión estadística me decían "este símbolo no lo sé pero sé que aquí rechazaron la hipótesis nula", o sea, que llegaran a esa generalización de algunos principios estadísticos, que antes como se veía como una herramienta para analizar datos categóricos, se limitaba allá, y ahora que ellos comiencen a trabajar más precisamente en usar las herramientas (E1.CL.88)

\section{El objetivo de aprendizaje de la asignatura de Estadística para Luis es:}

Lo que dice tal cual [el programa], que es: conocer todo un conjunto de pruebas paramétricas y no paramétricas que sirvan como herramienta para realizar un reporte de una investigación empírica. $\mathrm{O}$ sea, es más o menos un curso en el cual se te presentan las herramientas y tú llegas y agarras la que necesitas y las usas (E1.CL.92)

Este objetivo tiene relación con el descrito en el programa de la asignatura Metodología y Estadística para la Investigación II que actualmente está impartiendo en el segundo semestre de la carrera. En ella se abordan el análisis y la toma de decisiones a partir de pruebas de hipótesis de una problemática actual de Psicología.

En el segundo semestre, la parte importante está en la lógica de la prueba de hipótesis. De hecho es el tema más complicado en clase, o sea lo que es identificar una un nivel de significancia, una zona de confianza, zona de rechazo, zona de aceptación (E1.CL.96)

Cuando se le pide que explique cuál es el objetivo del primer semestre, en el que se incluye el tema de la representación gráfica señala:

Durante el primer semestre realmente trabajan con estadística descriptiva, y lo que hago es un sondeo de cómo están viniendo los muchachos de preparatoria... (E1.CL.94)

Entonces durante el primer semestre lo que hacemos es un reconocimiento de uso, o sea, por ejemplo, darles situaciones y que ellos vayan de alguna manera interpretando si era correcto o incorrecto, si era más apropiado hacer tal o cual cálculo. Realmente durante el primer semestre está más cargado hacia metodología más que en Estadística (E1.CL.95) 
Esto coincide con el programa de la asignatura de Estadística. De hecho el $60 \%$ de los contenidos están enfocados hacia los aspectos de metodología como: conceptos generales de la investigación, investigación documental, lineamientos de la APA e investigación empírica.

Objetivo general: Aplicar los conceptos básicos de la metodología y estadística para la investigación, así como la técnicas que permitan desarrollar trabajos científicos (documentales y descriptivos) abarcando las áreas y la problemática actual de la psicología (Pro.CL.01)

Se puede apreciar el valor y el peso que tiene la metodología en el programa y su relación con la Estadística, de hecho, cuando se le pregunta sobre lo que espera del alumno en su asignatura, Luis nuevamente resalta el valor de la investigación:

Mira, como están unidas las materias, mi primera expectativa es que comprendan a la investigación como una parte fundamental de la construcción de la ciencia (E1.CL.104)

La segunda, que tengan un interés real por la investigación y precisamente en este interés real que vean a la estadística como una herramienta básica para fundamentar sus conclusiones. Cuando comienzo la parte de Estadística, por cómo está estructurada les digo "bueno, hoy terminamos por dos meses y medio Metodología, nos vamos a Estadística", siempre la respuesta es así de como que "¡ya llego matemáticas!", no sé qué..., les digo miren "a mí me van a ver disfrutarlo y espero que la disfruten tanto como yo". (E1.CL.105)

Podemos por lo tanto considerar que el primer propósito de Luis es que sus alumnos comprendan y se interesen por la investigación científica, para posteriormente lograr un segundo y tercer propósito: que vean a la Estadística como una herramienta y que no le tengan miedo. Lo ejemplifica de la siguiente manera:

Por ejemplo hoy presentaron examen y uno de ellos me estaba mostrando que ya había hecho varias partes en SPSS, y me dice "sabes que se siente rico cuando terminas de hacerlo tu solito, porque en clase (la verdad) llegaba momentos en los cuales me enredaba, con eso de que había que cruzar las tablas me enredaba, pero ya cuando me senté, hice todos los ejercicios. Es fácil”. O sea, que ellos se den cuenta no es tan complicado. Es una herramienta accesible. Creo que esa es otra de la cosas: se ha formado una fuerte aversión a las estadísticas y una de mis metas también es esa, hacerlo accesible a todos, pero por eso te digo que para mí, la parte importante está en la investigación (E1.CL.106)

Contenidos. En cuanto a los contenidos que enseña durante el curso ${ }^{13}$, manifestó que lo primero que considerason los supuestos y los requisitos de toda prueba estadística.

Trato de hacer mucho énfasis con ellos en los supuestos y los requisitos de toda prueba, que esa es una de las cosas que me he dado cuenta es una de las debilidades muy fuertes cuando estamos en estadística inferencial, o sea, la violación constante a supuestos y requisitos... (E1.CL.98)

\footnotetext{
${ }^{13} \mathrm{Al}$ momento de la entrevista Luis estaba impartiendo la asignatura de Estadística del segundo semestre que trata de pruebas de hipótesis. La del primer semestre es donde se ve estadística descriptiva y la representación gráfica
}

Jesús Enrique Pinto Sosa 
Un segundo elemento es la interpretación estadística:

Después de esto quizá a lo que me saltaría es a la interpretación. Un elemento que cada vez está más presente es la interpretación de resultados, el poder leer incluso un artículo y poder sacar de él información. (E1.CL.99)

Luis lo ejemplificó así:

Entonces aurita lo que he estado haciendo es precisamente el que ellos entiendan en realidad cuál es la estructura, qué significa cada elemento, qué función tiene, obviamente tenemos trabajo manual, pero después es trabajar en nuestra herramienta computacional y que ellos interpreten y que ellos sepan. Por ejemplo, hoy presentaron examen de prueba de (ji) cuadrada manual, pero entregan un ejercicio, precisamente el próximo viernes con todo... habiendo pasado todos los ejercicios de clase, haberlos hecho en SPSS, traerme las salidas [output de SPSS], las interpretaciones y demás. Entonces son los dos elementos (E1.CL.100)

Podemos identificar las fases que sigue Luis para abordar el estudio de las pruebas estadísticas: 1) estructura, 2) significado, 3) función y características de la prueba, 4) fase de cálculo, 5) análisis a partir del SPSS, 6) interpretación y 7) conclusión.

Actividades instruccionales. Entre las actividades instruccionales que Luis utiliza hizo alusión básicamente a tres: la interacción con los estudiantes, el aprendizaje a través de la metodología de proyectos y estudios de caso.

Luis indica que lo primero que realiza para lograr que sus estudiantes aprendan es interactuar con ellos, no sólo a través del diálogo sino también provocando en ellos dudas para motivarles.

Tengo diferentes medios. Por ejemplo, uno de ellos es, como te digo siempre, ando jugando en la clase. En una interacción con ellos (E1.CL.190)

Para ello plantea preguntas o situaciones que provoquen en los estudiantes un conflicto cognitivo:

... es precisamente antes de avanzar, el verificar, a veces yo intencionalmente, algunas pequeñas dudas, algunos errores, plantearles situaciones y que ellos inmediatamente caigan en la cuenta de si se puede o no se puede hacer (E1.CL.191)

Como se dijo antes, Luis se apoya mucho en la metodología por proyectos y los estudios de casos, no sólo como recursos para mantenerse actualizado sino también como estrategia de enseñanza de la asignatura de Estadística.

Como te decía la otra vez, de un modelo secuencial de enseñanza a una metodología de proyectos, ¿si? Estamos haciendo, por ejemplo actualmente tratando de desarrollar más habilidades con ellos. Por ejemplo tengo una serie de estudios de casos que se van trabajando por fuera de la clase. (E1.CL.30)

Ambas estrategias se describirán en la sección del conocimiento de las estrategias y representaciones instruccionales. 
El programa de Estadística (Pro.CL.04) especifica por cada unidad las estrategias de enseñanza sugeridas. En total son siete unidades que deben cubrirse en 45 sesiones de hora y media cada una (60 horas). A la parte de Estadística en las ciencias de la conducta se le dedica 4 sesiones, a Estadística descriptiva se le destina 6 sesiones y al Análisis estadístico computarizado, 8 sesiones.

En relación con las estrategias de enseñanza se sugiere que el profesor utilice las siguientes:

Metodología de la enseñanza: Análisis y discusión de los temas, elaboración de fichas bibliográficas y de trabajo, ejercicios de metodología y estadística (Pro.CL.05)

Específicamente para los temas de estadística (ej. la representación gráfica) el programa recomienda la revisión bibliográfica, exposición, discusión grupal y la elaboración de ejercicios.

Luis va más allá de lo dispuesto en el programa procurando interactuar con sus alumnos para que analicen y discutan los conceptos estadísticos, provocar el cuestionamiento a través de preguntas, usar la metodología por proyectos y el estudio de casos.

Criterios de evaluación. Considera cuatro formas de evaluar: exámenes, ejercicios y problemas, participación activa y elaboración del proyecto.

Allí sí hay criterios muy claros. Ellos identifican por ejemplo (de que todos estos tipos de evaluación), cuáles son parte del rubro exámenes, ejercicios y problemas; otro rubro que tienen que ver con participación activa; y el rubro de proyecto de investigación. O sea hoy saben que lo que hicieron tiene que ver con el rubro de pruebas, exámenes y problemas. Eso sí está claramente para ellos: que puede ser un problema llevado a casa, que puede ser un problema hecho aquí. Eso también ya lo saben. Saben que hay esa diversidad, pero que va a ese rubro. Y saben también cuáles son las cosas que van a las tareas, cuáles son las cosas que van a participación activa, y lo que están haciendo por ejemplo en su proyecto (E1.CL.152)

A continuación se describirá la manera cómo evalúa a partir de estos criterios:

- Exámenes

Se trata de pruebas escritas, de lápiz y papel o a través del sistema de gestión del aprendizaje Dokeos. Este tipo de evaluación es considerada por Luis como "tradicional".

- Tareas, problemas en el salón de clases y reportes

Luis engloba dentro del concepto de tarea, la actividad que el estudiante realiza para desarrollar el aprendizaje casi siempre para ejercitar lo visto en clase utiliza dos tipos de tareas: las que son de carácter rutinario o mecánico y que generalmente son individuales (ver Figura 5.13) y las que son para desarrollar habilidades y que generalmente son colaborativas (ver Figura 5.14) 
Tenemos esas tareas como las primeras que te mostré, que es mucho más mecánica, es una práctica (E1.CL.159)

Pero ésta [señala en el ordenador] implica sentarse con el grupo de trabajo y discutir si va a ser la hipótesis o no, cuál va a ser el trabajo y elementos en los cuales hay que leer otra vez todo lo que ya hemos presentado [durante las clases] (E1.CL.160)

En la Figura 5.13 se aprecia un ejercicio (Eje.CL.05) que utiliza con sus alumnos para comprender el uso de la prueba estadística $t$ de Student de diferencia para diseños de dos muestras, tanto independientes como relacionadas. El propósito es que los estudiantes resuelven el ejercicio, sin olvidar la interpretación de los resultados. En las instrucciones Luis les indica que deben utilizar un nivel de significancia de 0.05 , deben resolverlo "a mano" y debe incluirse la prueba a utilizar, la hipótesis nula y alterna, los cálculos y la interpretación. En todos los ejercicios se presentan una situación dentro de un contexto de Psicología.

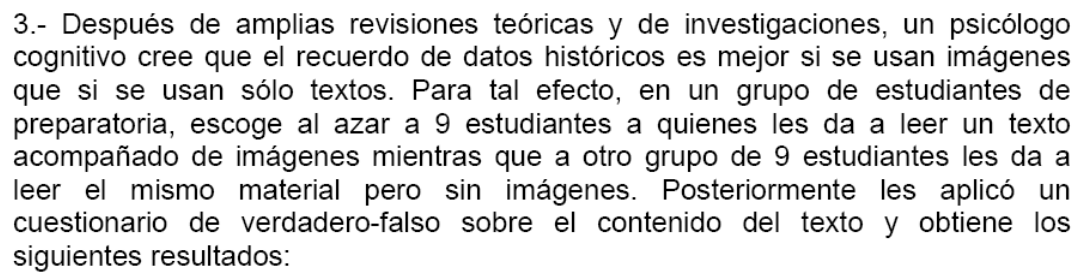
cognitivo cree que el recuerdo de datos históricos es mejor si se usan imágenes que si se usan sólo textos. Para tal efecto, en un grupo de estudiantes de preparatoria, escoge al azar a 9 estudiantes a quienes les da a leer un texto acompañado de imágenes mientras que a otro grupo de 9 estudiantes les da a leer el mismo material pero sin imágenes. Posteriormente les aplicó un cuestionario de verdadero-falso sobre el contenido del texto y obtiene los siguientes resultados:

\begin{tabular}{|c|c|}
\hline Texto con imágenes & Texto sin imágenes \\
\hline 13 & 11 \\
14 & 13 \\
15 & 16 \\
10 & 13 \\
13 & 14 \\
14 & 14 \\
17 & 12 \\
19 & 15 \\
17 & 12 \\
\hline
\end{tabular}

¿Es diferente el recuerdo de datos históricos dependiendo del tipo de texto usado?

Figura 5.13. Ejemplo de ejercicio de carácter rutinario o mecánico que utiliza Luis

En la Figura 5.14 observamos un ejemplo de ejercicio (Eje.CL.03) para desarrollar la habilidad deestablecer una hipótesis. Se observa que las primera cinco preguntas tienen que ver con la metodología de la investigación y la última sobre las hipótesis estadística. Generalmente este tipo de actividades son en equipos. 
Generando hipótesis

Instrucciones. Este ejercicio deberá realizarse por cada equipo de investigación.

Considerando el proyecto de investigación presentado en Metodología y Estadística para la Investigación I, contesten a lo siguiente:

1. ¿Cuál es la pregunta de investigación?

2. Identifiquen las variables implicadas en la pregunta de investigación

a.......

b........

n.......

3. Definan operacionalmente cada una de las variables identificadas

Una vez identificadas las variables, el siguiente paso es predecir la relación entre estas variables al escribir una hipótesis. Una hipótesis es una predicción de la relación entre dos (o más) variables. Esto es, establecer al cambiar la puntuación de una persona en una de las variables (VI), cuál será el cambio en la otra variable (VD).

En primer lugar, establecerán la hipótesis de trabajo, que es aquella hipótesis que el investigador tiene después de revisar la literatura pertinente. Es aquella que desea probar.

4. Establezcan la(s) hipótesis de trabajo

Las hipótesis no son adivinaciones. Deben existir razones lógicas y empíricas para ellas. Un investigador debe tener bases para establecer sus hipótesis.

5. Establezcan las razones lógicas, teóricas y/o empíricas para la(s) hipótesis de trabajo que propusieron

Ahora deberán establecer la(s) hipótesis nula(s) y alternas necesarias para la investigación. Algunos estudios sólo tendrán una Ho y una $\mathrm{H} 1$, otros tendrán una Ho y varias $\mathrm{H} 1, \mathrm{H} 2$, Hn y algunos más tendrán varias Ho y sus respectivas $\mathrm{H} 1$

6. Establezcan la(s) hipótesis nula(s) y alterna(s) necesarias

Documento a entregar: Resolución al ejercicio, estilo APA (2001), engrapado.

El documento debe tener:

1. Portada

2. Respuestas

3. Referencias

Figura 5.14. Ejemplo de ejercicio colaborativo para desarrollar la habilidad para elaborar hipótesis

Luis resalta el valor de las tareas colaborativas que son actividades que solicita no de un día a otro, sino con dos semanas para que los alumnos puedan desarrollarlas. Según Luis este tipo de tareas favorece el aprendizaje cooperativo y colaborativo:

Primero trato de que sean tareas que desarrollen siempre habilidades, eso es para mi lo básico. Creo que la habilidad muchas veces permite adquirir conocimientos más prácticos, o sea que ellos tengan habilidades... (E1.CL.138) 
y todas mis tareas siempre son colaborativas, o sea, siempre una de las cosas que trabajo con ellos es que si yo quisiera les puedo marcar 15 ejercicios a cada rato de esto y yo me encargo de que salgan siendo expertos de eso. El número de ejercicios puede ser infinito, pero haciendo cinco ejercicios con un grupo que está contigo trabajando puede ser mucho más rico, y va haber más aprendizaje de los que esperabas. Ellos están trabajando y me he dado cuenta que realmente sucede. O sea, aurita terminando el examen, grupos que se quedaron trabajando porque me entregan ejercicios el viernes, ¡y están allí!, el equipo de cuatro personas, juntos ¿si? Esto para mi le da un valor enorme a la asignatura, y lo trabajo siempre en todas mis asignaturas, tanto en la Filosofía como en ésta, o sea siento, que las habilidades que puedan ellos obtener son las que les va a permitir acceder a más conocimientos, porque podría enseñarles algo muy específico (E1.CL.139)

Luis realiza la evaluación de sus alumnos en diferentes momentos siendo de carácter formativa más que sumativa. Mostró como ejemplo tres situaciones diferentes para valorar el conocimiento y habilidades de los estudiantes: 1) problemas en el salón de clases (incluso en pequeños grupos), 2) elaboración de un trabajo (reporte) y c) encontrar su error (aprender de sus errores como fuente de aprendizaje).

Ejemplo 1. Por ejemplo, ha habido ocasiones en los cuales la evaluación es un problema en el salón de clases. Les digo: "Bueno, sí tienen que estudiar. Tienen examen" "pero y ahora ¿cómo va a ser?". Ese día van a ver. De pronto llego, "Bueno aquí tienen un problema. Cada equipo de trabajo reúnase. Nos vemos en hora y media", porque cada momento tiene cosas distintas. Por ejemplo, aurita en Estadística para la parte manual necesito de este tipo de pruebas (E1.CL.145)

Ejemplo 2. Por ejemplo, cuando vimos Diseños de Investigación les puse tres investigaciones, que tenían violaciones a la validez interna. Les dije "Bueno éstos: los tres tienen violaciones a la validez interna. El trabajo de ustedes es identifícarlas". Me decían "pero ¿cómo?, o sea ¿es un resumen, una tabla?". Entonces ellos tenían que entregarme un reporte en el cual me dijeran ¿qué fue lo que sucedió?, ¿por qué?, ¿qué harían para corregir la situación? (E1.CL.147)

Ejemplo 3. Esas fueron las instrucciones. Y una de las cosas que he tratado de formar mucho con ellos es que yo siempre he creído que no tengo que tenerle miedo a un error, y les he dicho "Bueno de pronto puede ser que en el primer examen, en este examen hayas tenido errores", pero les doy la oportunidad de "corrige y dime ¿qué pasó?, ¿en qué te confundiste?", y a veces llegan y dicen "Pues no me quedaba claro qué tenía que poner aquí (el valor crítico) y aquí (el valor obtenido por fórmula). Siempre los confundía". "Me lo tienes que decir. Tienes que decírmelo, o sea, lo que necesitas es encontrar el error, y pero no yo decírtelo, sino que vengas y me digas" [a manera de respuesta del profesor] y darle la oportunidad al alumno de hacerlo (E1.CL.148)

\section{Entre los reportes en ocasiones se trata de realizar una actividad en forma de investigación documental:}

Entonces y siguiendo una estructura de toda la materia, por ejemplo, cuando vimos en primer semestre Estadística descriptiva, les pedí un trabajo de investigación documental sobre las diferentes medidas y se les pedía cosas muy específicas, por lo menos, [por ejemplos] la definición de lo que son las medidas de tendencia central, utilizando cuando menos dos fuentes y al final requisitos. Del conjunto total de fuentes referenciales, el $70 \%$ tiene que ser de libros que estén físicamente en la biblioteca, y un $30 \%$ podrán ser de Internet. Hay requisitos muy específicos para que ellos estén buscando esta información, pero porque estamos buscando que no haya ese apego total a un texto. También tengo materiales que les doy, o sea diapositivas, material mío, con el que se trabaja, que ellos puedan en todo momento (E1.CL.116). 
- Participación activa e interacción en clase

Para realizar tanto una evaluación diagnóstica, como formativa o sumativa considera que es necesario acercarse a los alumnos y valorar las interacciones que se produce entre ellos.

La primera es en el propio salón de clase. Estamos en constante interacción. Al momento de estar dando la clase, siempre hay un momento con lo que tú sabes qué crees que va a pasar. Inicia todo un proceso de diálogo conmigo. Por ejemplo, resulta que hay un caso especial para esto y les pongo la situación “¿qué le ven de diferente?, o sea ¿por qué es un caso especial?". Entonces comienzan "pues resulta que es el número de sujetos" [a manera de respuesta de los estudiantes] "¿sólo el número de sujetos?" [pregunta el profesor], “¡no!” [contestan los alumnos], "pues bueno, aquí hay otro caso especial, coincide que es el número de sujetos pare la tabla es del mismo tipo. La condición para este caso especial son de tablas 2 x 2 entre 20 y 40 sujetos...”. (E1.CL.141)

O sea, en este momento estoy generando aprendizajes y más adelante comienzo la comprobación de que haya sucedido, siempre en diálogo. Esa es una de mis herramientas básicas (E1.CL.142)

Esta interacción se produce por la habilidad de Luis de interpelar o cuestionar a los estudiantes acerca de su razonamiento estadístico.

- Elaboración de proyectos y estudios de casos

Luis llama proyectos a aquellas actividades grupales que los estudiantes realizan y que les permite hacer una investigación en un contexto real donde recogerán, analizarán e interpretarán los datos entregando un reporte de investigación. Por otra parte, los estudios de casos son generalmente el análisis de investigaciones realizadas donde el estudiante analiza el contexto, valora los aspectos metodológicos y estadísticos del estudio, realiza un experimento, contrasta y discute los resultados y esboza una conclusión. Más adelante se describirá más ampliamente las características de cada una.

Al observar el programa de Estadística (Pro.CL.03), se aprecian algunas diferencias con lo expresado por Luis.

Criterios de evaluación: Las unidades se evaluarán de la siguiente manera: la unidad 2 será evaluada por medio de la elaboración de fichas (10\%), las unidades 3 será evaluada por exposición grupal (10\%), la unidad 4 será evaluada con la elaboración del diseño de un proyecto de investigación (investigación documental y empírica 40\%) y las unidades 1, 5, 6 y 7 serán evaluadas con exámenes parciales (30\%), finalmente en cada una de las diferentes unidades del programa se realizarán ejercicios (10\%) (Pro.CL.03)

En el programa extenso (ver Apéndice C) se señala que los instrumentos de evaluación de las unidades que tratan los contenidos estadísticos (la 5, 6 y 7) son los exámenes y los ejercicios. Luis trató brevemente acerca de los exámenes y los ejercicios. No obstante, incorpora tres instrumentos diferentes para evaluar a sus estudiantes: los proyectos, los estudios de casos y la participación activa. 
Como podemos darnos cuenta, el conocimiento de Luis del currículo de Estadística tiene estrecha relación con sus concepciones. Del objetivo del programa hace énfasis en la adquisición de las bases conceptuales y metodológicas de la investigación en Psicología en que se sustenta la Estadística. Esto tiene relación con la asignatura, la cual incluye un fuerte contenido sobre conceptos de ciencia, de metodología, investigación documental y estilos de redacción. Para él, lo central es que primero comprendan qué es investigar, lo segundo que vean a la Estadística como herramienta y lo tercero que no le tengan miedo. Como parte de las actividades instruccionales que utiliza están la interacción con los alumnos, la metodología de proyectos y los estudios de casos; actividades no mencionadas en el programa en extenso. Cuando evalúa también va más allá de lo que establece el programa, ya que incorpora la participación activa, la elaboración de un proyecto de investigación y de estudios de casos; con lo cual encontramos mucha relación con las actividades que hace en el aula.

Es preciso destacar lo que para nosotros representan los puntos clave del conocimiento de Luis sobre el currículo de Estadística que están relacionados entre sí y que pueden explicar parcialmente sus concepcionesy su forma de actuar como profesor. Lo primero es que el currículo de la carrera donde imparte clases ofrece un curso que integra la metodología y la Estadística, concediéndole a la asignatura en un $75 \%$ de las clases el estudio de los contenidos y habilidades propias del método científico. Lo segundo es que la carrera tiene como eje transversal el aprender a investigar, es decir, los estudiantes de Psicología desde el inicio hasta el final de la carrera se habitúan a hacer investigación, por lo que la adquisición de conocimiento y habilidades de la metodología adquiere una relevancia fundamental. Por último, la tercera clave está en el poco tiempo que se le otorga al estudio de la Estadística (25\% de las clases) ya que se destina sólo seis horas a la parte de Estadística descriptiva y nueve a sesiones de trabajo en la sala de informática para el uso del SPSS. Esto nos permite explicar el poco tiempo que se le da al estudio de la RG.

En conclusión, Luis tiene un conocimiento amplio sobre el currículo de la Estadística en el contexto de la carrera donde imparte clases. Coincide con los fines principales de la enseñanza de la estadística en la formación de los alumnos que Batanero (2000 y 2001a) expresa de la siguiente manera: a) que lleguen a comprender y a apreciar el papel de la estadística en la sociedad conociendo sus diferentes campos de aplicación y el modo en que la estadística ha contribuido a su desarrollo, y b) que lleguen a comprender y a valorar el método estadístico, es decir, lo que la estadística puede responder y la forma básica de razonamiento, su potencia y limitaciones. No obstante, no sabemos hasta qué punto, la unión entre metodología y Estadística incline más la balanza hacia la primera, o mejor dicho, desconocemos cómo logra integrarla en la práctica real. Quizá parte de la respuesta es que Estadística se imparte en dos semestres, y posiblemente en el segundo semestre Luis tiene oportunidad de ampliar más los contenidos estadísticos.

El conocimiento de Luis coincide con la mayoría de las seis recomendaciones que la American Statistical Association (ASA, 2007) publicó a través de la GAISE para enseñar un curso introductorio de Estadística:

1. Enfatizar la alfabetización estadística y el desarrollo del pensamiento estadístico.

2. Usar datos reales. 
3. Hacer hincapié en la comprensión conceptual más que mero conocimiento y procedimientos.

4. Sostener un aprendizaje activo en el aula.

5. Usar la tecnología para desarrollar conceptos y analizar datos.

6. Usar evaluaciones que mejoren y evaluar el aprendizaje de los estudiantes.

Quizá un elemento que haría falta es la primera recomendación sobre el énfasis de la alfabetización y el desarrollo del razonamiento y pensamiento estadístico; para lo cual habría que conocer su desarrollo y evolución, así como las últimas aportaciones y recomendaciones emitidas por los organismos internacionales dedicados a la investigación en educación estadística, como la IASE, o bien, de autores como Moore (2000), Wild y Pfannkuch (1999) y Pfannkuch y Wild (2003), Garfield (2002), Ben-Zvi y Garfield (2004) y Garfield y Ben-Zvi (2008), por citar sólo algunos.

\subsubsection{De los objetivos y contenidos de aprendizaje de la representación gráfica}

El conocimiento del currículo de Luis sobre la RG se presenta organizado de la siguiente manera:

- Significado, objetivos, propósitos y expectativas

- Contenidos

- Actividades instruccionales

- Materiales para la enseñanza

- Evaluación del aprendizaje

Significado, objetivos, propósitos y expectativas. Para Luis el objetivo de aprendizaje relacionado con la representación gráfica es que el estudiante interprete gráficos.

La cosa es que ellos pudieran interpretar. Lo que trataba de hacer es darles sentido porque precisamente una de las cosas que desde el principio había notado es que, por lo menos lo que traen ellos de Prepa [bachillerato], es Estadística sin contenido, o sea, Estadística en donde lo que se les enseña es calcular una media de un conjunto de datos que quién sabe qué son (E1.CL.112)

Luis hace alusión a la frase "darles sentido", entendiendo esto como encontrar significado a la RG a partir de datos reales y dentro de un contexto. Este "sentido" tiene que ver con la intencionalidad del uso, es decir, para qué servirá, a quiénes está dirigido y por qué. Así lo reconoce Luis al hablar sobre el objetivo del C-1:

Lo que veía es que primero una de las cosas que se presentaba aquí es que había una intencionalidad en el uso, o sea que era una gráfica que tenía un sentido, que lo que quería hacer era representar algo en particular y por eso se decía cómo se usan en situaciones ya prácticas las gráficas y una de las cosas que veía en las preguntas que se les presentaba a los estudiantes es que de esa gráfica se obtuvieran conclusiones, se obtuviera información a partir de ella. Entonces estas son las dos cosas que veía, como que la intencionalidad del uso (E2.CL.68)

Por otro lado, en el C-3 en cuanto al objetivo de la situación-problema, Luis señaló que ese ejercicio pretendía "contextualizar la representación gráfica de datos y propiciar su 
uso para la formación de conclusiones" (Cu.CL.3a.1 y 2). El significado que Luis le da a la "contextualización" está estrechamente relacionado con "O sea que es... para algo se va a utilizar, tiene un sentido esa utilización" (E2.CL.69) y "y otra es que además se puede obtener información a partir de la gráfica. Hay cosas que se pueden deducir de esa gráfica" (E2.CL.90).

Luis habla con sus estudiantes sobre el significado de la RG, haciendo alusión a la necesidad de saber y tener claro qué información queremos proporcionar a partir del gráfico:

Entonces les decía "es que en la representación gráfica, tú puedes dar mucha información, pero hay que saber qué tipo de información quieres dar". La representación gráfica desgraciadamente les decía, "desde mi punto de vista y por varias cosas que he leído, no somos tan buenos los seres humanos en evaluar al mismo tiempo diferentes elementos de un gráfico, o sea al evaluar el largo, no evaluamos el ancho, al evaluar la posición no evaluamos... o sea las diferentes elementos de un gráfico no son evaluados al mismo tiempo. Entonces mientras más elementos de color y demás, se cambia la información (E2.CL.19)

Según Luis, el alumno debe darse cuenta que una representación gráfica es inadecuada cuando la información visual no corresponde a lo que se espera de los datos o bien, cuando la representación es incompleta de algún modo. Hace referencia también a que el alumno debe lograr identificar los errores en las representaciones gráficas.

Al abordar con Luis los propósitos que pretende el programa de Estadística en el tema de la representación gráfica responde:

En ese primer semestre lo que hacemos primero es que ellos puedan identificar con claridad las escalas de medición de una variable, y que puedan ellos representar adecuadamente una variable con respecto a la escala de medición, que entiendan con claridad por qué un histograma es para una variable continua, o sea, esta clase de cosas para mí es muy, muy importante. Ese es un elemento (E1.CL.107)

Y el segundo, que puedan leer información y puedan también identificar representaciones confusas o falsas de datos (E1.CL.108)

Podemos apreciar que los propósitos de Luis respecto de la enseñanza de RG son en el primer semestre: 1) identificar las escalas de medición y las variables, 2) representar gráficamente una variable, y 3) comprender la relación variable-gráfico; y en el segundo semestre: 4) leer información, e 5) identificar representaciones confusas o falsas.

Si contrastamos la respuesta de Luis con lo que establece el programa de curso de Estadística encontramos (Pro.CL.02):

Unidad 6. Estadística descriptiva

Objetivo General: Obtener el análisis estadístico descriptivo por medio de frecuencias y medidas de tendencia central y de dispersión de un conjunto de datos de una investigación de un tema actual y de interés para la psicología

Tema 6.1. Distribución de frecuencias

Sesiones: 2 (3 horas)

Objetivos específicos: 
6.1.1 Calcular los diferentes tipos de frecuencias absolutas, relativas y acumuladas de un conjunto de datos

6.1.2 Elaborar la representación gráfica de en conjunto de datos

Contenidos:

Distribución de frecuencias absolutas

Distribución de frecuencias relativas

Distribución de frecuencias acumuladas

Representación gráfica de la distribución:

- Diagrama de barras

- Histograma

- Polígono de frecuencias

- Ojiva

Como se puede apreciar, el tema de la RG forma parte de la unidad de Estadística Descriptiva y solamente estipula dedicarle 2 sesiones de hora y media cada una. De igual manera, nos dimos cuenta que el programa sólo establece "calcular" los diferentes tipos de frecuencias y "elaborar la representación gráfica", sin considerar la parte de interpretación. Parece que Luis intenta ir más allá de este objetivo, no obstante, queda la interrogante, en realidad ¿logra sus objetivos teniendo en el programa previsto únicamente tres horas para este tema?

Durante el análisis de las situaciones-problema (C-1, C-2, C-3, C-4), en varias ocasiones se le preguntó a Luis cuál era el objetivo de cada caso o bien, su utilidad. Para Luis los casos presentados permiten desarrollar principalmente en los alumnos la habilidad para seleccionar, evaluar y criticar un gráfico, y analizar los errores conceptuales. Sin embargo, en la planificación y desarrollo de sus clases se centra en que el alumno conozca las características (ventajas y desventajas) de cada gráfico, así como la forma de representarlos a partir de las variables o escalas de medición que se traten. El énfasis está en la construcción del gráfico y en ayudar a los alumnos a corregir concepciones erróneas cuando exponen sus representaciones delante del grupo. Luis señala que esto último no lo planifica al principio sino que se produce según las circunstancias de la clase.

Contenidos. Sobre el conocimiento de Luis de los contenidos relacionados con la RG, analizamos sus respuestas a la luz de las situaciones-problemas del cuestionario didáctico. Se presenta a continuación su conocimiento en relación con cada gráfico.

- Del histograma y el tallo de hoja

Luis expresó de la siguiente manera las características (ventajas) del TyH y del histograma:

Por ejemplo el gráfico de tallo y hoja al indicar claramente el dato como tal y al mostrar abiertamente la frecuencia de repetición del dato específico, permite tener una mayor riqueza en la descripción, conoces más cuáles son los datos, lo que es una ventaja (E2.CL.03)

pero para un resumen el histograma es mucho más fácil de entender ¿si? (E2.CL.04)

Entonces son dos vías diferentes, una cosa es cuando necesitas dar un resumen inmediato o sea cuál es lo que más encuentras, y otra es la naturaleza de los datos que están allá, cuántas veces se repite uno, junto a quienes está, si hay algún intervalo donde hay más o menos datos ... (E2.CL.05) 
Luis mostró el siguiente ejemplo usando las variables "edad" y "promedio de calificación":

Entonces al estar trabajando con varias bases de datos entonces de pronto si graficas la edad "bueno como la edad está en años completos el histograma me da más información; pero en esta otra variable que era el promedio en la materia que hay 'pedacitos', que hay más posibilidad de que haya decimales, tallo y hoja me da más información, ¿por qué?, porque me lo describe mejor y me deja huecos cuando presento la edad, porque son... además primero porque era un intervalo muy pequeñito", o sea comienzan a hacer esa clase de análisis ¿no? (E2.CL.07)

- Del gráfico de barras

En el C-1 Luis generó un conjunto de preguntas con el objetivo de explorar por qué el alumno ha dado esa respuesta. Básicamente son preguntas centradas en los especificadores o los elementos que tiene el gráfico (ej. altura y ancho de las barras, espacio entre las barras). Luis afirma que "todos los elementos dentro del gráfico tienen un sentido, tienen un significado" (E2.CL.34) y que es fundamental explorar primero cuál es el que tienen los estudiantes.

Entonces al preguntarles "¿qué representa la altura?" es ver la naturaleza de ese elemento, ver que quede muy claro (precisamente lo que te decía): que no es una representación bonita, es una representación resumen y que cada elemento resume algún dato (E2.CL.34)

De hecho, Luis habla de cinco preguntas que les hace a sus alumnos para saber si logran entender las características del gráfico de barras:

... además de los ejes, son las que generalmente hago con el gráfico de barras, o sea ¿qué representa cada uno de esos elementos?, ¿qué representa la altura?, ¿qué representa el ancho?, ¿qué representan los espacios?, la escala que está en el eje $X$, en el eje $Y$, ¿qué hay representado en el eje $X$ ? Son cinco preguntas que les hago con frecuencia en este gráfico. Siento que son las que nos llevan a entender las características del gráfico de barras (E2.CL.50)

\section{- Del histograma}

En el C-3 se le preguntó ¿cuál cree Ud que es el objetivo del que ha surgido el ejercicio del $C$-3? A lo que respondió:

Contextualizar la representación gráfica de datos (Cu.CL.3a.1)

Y propiciar su uso para la formación de conclusiones (Cu.CL.3a.2)

Sobre los aspectos que modificaría del C-3 hizo referencia al contexto:

Añadiría alguna pregunta que vaya para aclarar específicamente cuál es el objetivo de los investigadores al presentar este gráfico (E2.CL.117)

Una pregunta que les aclarará cuál es la situación que se está representando, para evitar precisamente esta confusión de Omar que él está pensando que lo que se está representando son ciudades... que lo importante son las ciudades, ir hacia allá (E2.CL.118) 
- Del gráfico en medios de comunicación impresa (media graph o print graph)

Luis habló de los errores en el gráfico:

Y una de las cosas en este [gráfico] que se presenta, es la proporción entre las líneas porque realmente esto al observarlo parece no guardar una proporción. Y una de las cosas en este [gráfico] que se presenta, es la proporción entre las líneas porque realmente esto al observarlo parece no guardar una proporción (E2.CL.126)

\section{Al preguntar ¿qué deberían contestar los estudiantes al momento de criticar y evaluar el gráfico? respondió:}

Primero una de las cosas que en el momento de incluir otros elementos como distractores podrían llevar a no centrarse a la información principal (E2.CL.133)

Otro que en un buen gráfico cada uno de los elementos debe representar específicamente la frecuencia o el porcentaje o el intervalo al cual se refiere y aquí las diferentes barras, las diferentes líneas no están representando adecuadamente esas proporciones (E2.CL.134)

Actividades instruccionales. Una de las estrategias que utiliza para enseñar la RG es la exposición con interrogatorio apoyándose en el uso de presentaciones generalmente en Power Point, en Excel o de la visualización del gráfico en SPSS:

Entonces llevo estos datos recogidos de ellos y a partir de eso les presento información, o sea, les hago una presentación de lo que fue para mí la interpretación de esos datos y a partir de ello vamos viendo, por ejemplo, si fueron representaciones adecuadas o no, porque como te digo como he estado haciendo sondeos de qué es... cómo van (E1.CL.109)

En este sentido, repitió en diversas ocasiones que el interrogatorio consistía en identificar y analizar los errores en el gráfico:

Entonces toda la información que les presentaba tenía que ver con esto, y había representaciones totalmente erróneas, otras muy buenas y la idea era que ellos fueran marcando. Después de esto hubo una clase mucho más aclaratoria de cada una de las representaciones, o sea ya después vimos ¿qué sería?, ¿por qué representar a través de una gráfica circular?, ¿por qué representar...? ... Ellos en ese momento trataban de interactuar para decirme "¿qué significa lo que te estoy diciendo?”. Ya después en la representación les ponía gráficos y me decían "bueno sí..., pues allí por cómo están tus ejes parece que está maravilloso pero si lo pones diferente va a ser otra cosa" (E1.CL.110)

En este párrafo se muestra que Luis cambiaba los gráficos modificando su diseño o algunos elementos estructurales con el propósito de que el alumno vea otras perspectivas $u$ opciones de análisis del mismo.

Respecto de las estrategias que señala el programa (Pro.CL.04) sobre el tema de representación gráfica al que se le destina sólo dos sesiones de clase son: revisión bibliográfica, exposición y ejercicios. En este sentido se constató que Luis va un poco más allá de lo propuesto en el programa. Él aborda la enseñanza de la RG a partir de actividades donde el estudiante construye gráficos y éstos se analizan generalmente ante toda la clase para identificar las características y los errores mediante la estrategia de exposición con interrogatorio. 
Materiales para la enseñanza. Luis utiliza en sus clases, una diversidad de recursos. A continuación comentaremos brevemente cada uno.

- Textos

Un primer recurso son los textos relativos al programa y los más específicos sobre el tema que está estudiando con los alumnos. Evita recomendar algún libro de texto debido a la estructura, naturaleza y los objetivos de la asignatura que fusionan -Metodología y Estadística. Espera que los alumnos sean independientes y aprendan a buscar por su propia cuenta a partir de la bibliografía que les proporciona en el programa.

Hay unos [libros] recomendados en la carta descriptiva y como ellos tienen de principio las cartas descriptivas, y al iniciar el semestre se les vuelve a dar las cartas [descriptivas]. Entonces saben que hay una serie de libros que están allí, que pueden usar, pero que yo les diga búscalo en tal lugar, realmente... mmm [disiente con su cabeza] (E1.CL.117) (E1.CL.118).

De los ocho textos que Luis mencionó en la entrevista y que utiliza con más frecuencia, seis están centrados en metodología de la investigación en ciencias sociales, uno en el aprendizaje del SPSS y sólo uno ${ }^{14}$ trata específicamente de Estadística. Este último es el que recomienda el programa (Pro.CL.05) respecto del tema de gráficas. Contiene un capítulo sobre organización de datos, en el cual se describe paso a paso cómo se construye los gráficos de barras, circular y el histograma. Contiene ejercicios donde a partir de un conjunto de datos, el estudiante debe construir el gráfico.

Antes recomendaba una antología que preparó con una profesora y aunque se encuentra en la biblioteca ya no se sugiere y no se utiliza debido a la fusión de la asignatura de Metodología con la Estadística. No obstante, Luis comentó que los criterios que se tuvieron en cuenta en el momento de compilar la antología fueron: a) temas actualizados y conocidos, b) que sean del ámbito de la Psicología o Ciencias Sociales o Metodología, c) que se ajuste al programa, lo visto en clase y en las sesiones de cómputo.

Tomamos textos actualizados. Textos que todos estuvieran dentro del ámbito de la Psicología, que fueran siempre textos de Estadística en ciencias sociales, de metodología en ciencias sociales. Cuidamos mucho el campo de lo que es Estadística, el uso de fórmulas, porque nos interesaba sobre todo que no resultara incoherente lo que pasara en el salón de clase, lo que pasara después en la sala de cómputo, y además, con toda sinceridad, textos conocidos por nosotros y manejados por nosotros (E1.CL.125)

14 Levin, J. y Lenin, W. (1999). Fundamentos de estadística en la investigación social. México: Oxford University Press. 
- Sistemas de de búsquedas de información en revistas electrónicas

Otro recurso que utiliza Luis son las bases de datos electrónicas. Desde el año anterior a los estudiantes de nuevo ingreso se les imparte un curso de inducción donde se les muestran todas las bases de datos electrónicas disponibles.

Este curso de inducción a mi me garantiza que desde que entra a mi primera clase puedo decirles que vayan y que en la biblioteca tienen toda la información posible de todos los textos. Este curso de inducción lo damos [profesores] en conjunto con la biblioteca y nos ha sido de mucha, mucha utilidad, porque incluye no solamente la biblioteca física, sino lo que son servicios electrónicos. Para el primer día de clase pueden hacer búsquedas en EBSCO, en Difusión científica, en SISBI, en Janium (por mencionar algunas), en todos los servicios que tiene la Universidad del Sureste (E1.CL.115)

Este recurso lo utiliza sobre todo para la parte metodológica, particularmente para conocer el estado del arte de su proyecto (investigación documental) en contextos del área de la Psicología.

\section{- Material de lectura y ejercicios}

Trata de cuidar el equilibrio entre teoría y práctica. Para ello se apoya principalmente en la lectura de artículos de investigación que sirvan tanto para conocer el proceso científico de la investigación como para abordar el estudio de algún tópico estadístico.

Entonces lo que ha pasado es que generalmente la teoría viene después, por ejemplo todo el proceso de razonamiento viene durante la clase, y después la búsqueda específica en un texto qué significa un dato estadísticamente significativo, eso viene después. Generalmente viene como una tarea. No es un material que les pida que lean previamente, porque lo que me interesa en ese momento es la resolución del problema, o sea qué se entiende y sobre todo...(E1.CL.72)

- Medios audiovisuales de apoyo

Luis menciona varios recursos audiovisuales como retroproyectores, proyector multimedia y todos los que encuentra que le ayudan a lograr el objetivo de aprendizaje.

Sí me valgo bastante de elementos como son los retroproyectores, el proyector de acetatos, utilizo mucho lo que es cómputo (E1.CL.183)

Como ya habrás visto utilizo todos los medios disponibles, dependiendo del tema, buscando todas las herramientas que me sean posibles. Recuerdo cuando trabajamos descriptiva que era como con un grupo que estaba súper inquieto y yo también andaba acelerado, con las plumas [bolígrafo], jugando con cosas muy concretas (E1.CL.182)

Luis afirma que cuanto más recursos tenga mejor atenderá la diversidad de sus alumnos:

El hecho de que sé que algunos teniendo un acetato claro y unas notas están satisfechos, pero otros requieren de mayor movilidad y trato de tener la variedad suficiente para que todos tengan un 
enganche a su propio estilo de aprendizaje. Además soy bastante inquieto en el salón, o sea esta vez yo soy el que también necesito todo eso para hacerla interesante. Entonces sí es un elemento importante para mi (E1.CL.185)

- Bases de datos reales

De manera reiterativa mencionó el uso y manejo de bases de datos reales como recurso para la enseñanza de la Estadística.

Por ejemplo, hacia el final del semestre comienzan ellos a trabajar con una base de datos, es una base de datos mía. Entonces las preguntas y los problemas de clase son los que tengo de esa base de datos, publicados artículos (E1.CL.46)

A través de las bases de datos (en el SPSS) pide a los estudiantes que realicen diferentes análisis y representaciones gráficas acompañados de un conjunto de cuestionamientos para reflexionar y la manipulación de los datos para explorar cambios en las representaciones gráficas.

Generalmente cuando estamos trabajando con esto ya tenemos varias bases de datos, entonces... comenzamos a jugar con ellos, o sea por ejemplo... "bueno vamos a sacar tal base de datos y vamos a hacer de tal variable un histograma y al mismo tiempo hacer un gráfico de tallo y hoja", "de tal variable... no sé... pon tú, ¿qué gráfico quieres hacer" porque muchas veces lo que hago con ellos es "bueno cuál se te antoja, a ver cuál [gráfico] se te antoja", "a ver bueno pues voy hacer un gráfico de pastel [circular]" . Entonces ok, "y ahora qué ventajas tiene frente a este otro que habíamos dicho primero" entonces... y es un poco ir viendo dónde es más fácil encontrar la información (E2.CL.06)

Entonces aquí la situación era estos datos son ustedes [los alumnos], o sea entonces vamos a entender lo que significa una media, vamos a entender lo que significa hacer un histograma. De hecho sí te puedo decir, esa primera clase de pronto me decían "oye y por qué no calculaste la curva ojiva y por qué no calculaste...", les digo "¿por qué?, ¿la necesitaba?” "pues no [responden los alumnos], pero yo sé de que cuando se hace... comienzas acá, terminas acá, o sea el ejercicio completo es todo esto". Algo así como si hubiera una necesidad [por parte de los alumnos] de representarlo por todas las formas posibles, o sea casi, casi, haz un pictograma, un... de todo [las formas de representación posible] (E1.CL.113)

El valor de estas bases de datos para Luis radica en que provienen de contextos útiles para el estudiante.

Lo que haría es ubicarla dentro de los datos que ya están manejando, o sea por ejemplo se quiere representar la pregunta cinco, que tal cosa o sea porque allí sí trato de que sigamos en una línea de datos usables, o sea que ellos quieran informarle a alguien eso, porque siento que es lo importante (E2.CL.62)

- Applets

Otro recurso que menciona es el uso de Applets, pequeñas aplicaciones escritas el lenguaje Java que aparecen incrustadas en las páginas de hipertexto de Internet. Su principal característica es que a diferencia de un programa, un Applet no puede ejecutarse de manera independiente, ofrece información gráfica y a veces interactúa con el usuario, de tal modo que le permite manipular o modificar valores estadísticos y al mismo tiempo visualizar y explorar el comportamiento. 
Pues mira lo ideal sería tener mucho más acceso a recursos multimedia. Estoy tratando de incluirlos cada vez más, por ejemplo el trabajo en la simulación, por ejemplo cuando hacemos pruebas de hipótesis, de poder mostrarles las regiones de aceptación o de rechazo y que ellos puedan... Lo hemos estado incluyendo poco a poco y algunos Applets y todos esos, pero a veces me es más problemático, de pronto llegar a cómputo no se abre el Applet, la red se traba [atora], o sea allí sí, aunque creo que soy uno de los profesores que más recursos utiliza dentro de la clase (E1.CL.54)

En un momento tenía mi archivo con mis Applets de curva normal, con los de prueba $t$, con chi, con todo..., para calcular muestras, pero en ese momento como vi que estaba perdiendo mucho tiempo en cómputo, dejé de hacerlo, y no me era suficiente el proyectarlo, porque pues lo que necesitaba era la interacción del alumno directo con lo que estaba pasando (E1.CL.212)

\section{- Sistema de Gestión del Aprendizaje (SGA)}

\section{Como ya se mencionó Luis tiene sus cursos de Estadística en la plataforma Dokeos.}

... ya estoy introduciendo lo que es el uso de la plataforma Dokeos [que es un Sistema Informático de Gestión del Aprendizaje]. Creo que me va a ser mucho más fácil el darles muchos más de esos elementos, el pedirles por ejemplo que visiten sitios [de Internet] ya establecidos con recursos para enseñanza de las estadísticas (E1.CL.184)

Justifica y menciona las ventajas del SGA del siguiente modo:

me están diciendo refiriéndome a [sistema] Dokeos uno me decía "mira, aurita sé que puedo en cualquier momento ir a buscar allá los materiales de clase, esté donde yo esté, o sea puedo reunirme a estudiar, se me olvidan y los puedo bajar". Esta disponibilidad de recursos, el hecho de que puedan en cualquier momento ponerse en contacto, puedan dejarme preguntas, creo que les da una cercanía a sentir que hay un involucramiento mucho más fuerte de mi parte con su aprendizaje. Siento que están ellos persiguiendo eso (E1.CL.186)

Este recurso de aprendizaje lo empezó a utilizar la semana anterior al inicio de las entrevistas.

Por ejemplo estamos aurita dando de alta el sistema de educación en línea para acompañar a la asignatura. Le dimos de alta la semana pasada están comenzando a utilizarlo, o sea ya tiene ellos está información. (E1.CL.32)

Te digo estamos implementando el sistema de educación en línea, utilizar con frecuencia cómputo (E1.CL.55)

\section{- Cuestionario de contexto}

Para obtener bases de datos reales los alumnos deben elaborar un cuestionario para obtener información demográfica sobre ellos mismo con algunas variables de interés.

porque por ejemplo, generalmente son bases de datos que formamos de algún cuestionario que ellos contestan en algún momento y de cuestionarios que yo tengo de otros años. Entonces con esos pues podemos ir viendo (E2.CL.08)

En algún momento recuerdo que en el primer año (o sea porque realmente esto, te digo lo fui cambiando a partir del segundo año que di clase), en el primer año cada ejemplo venía de un lugar 
diferente, comenzábamos otra vez la situación o sea no había una idea de qué se quiere decir, entonces al estar trabajando con un cuestionario o con una pequeña encuesta que hagan entre ellos mismos hay información que de pronto quieren saber, porque incluso hasta los temas que escogemos siempre son temas de pareja, temas... cosas que quieren saber qué respondieron y qué se dijo de tal cosa (E2.CL.63)

Con los datos, los alumnos elaboran una base de datos (en SPSS) y luego deben representar determinadas variables identificadas en el cuestionario. Ejemplo de un cuestionario (Lib.CL.02) puede apreciarse en la Figura 5.15 sobre el tema de satisfacción marital.

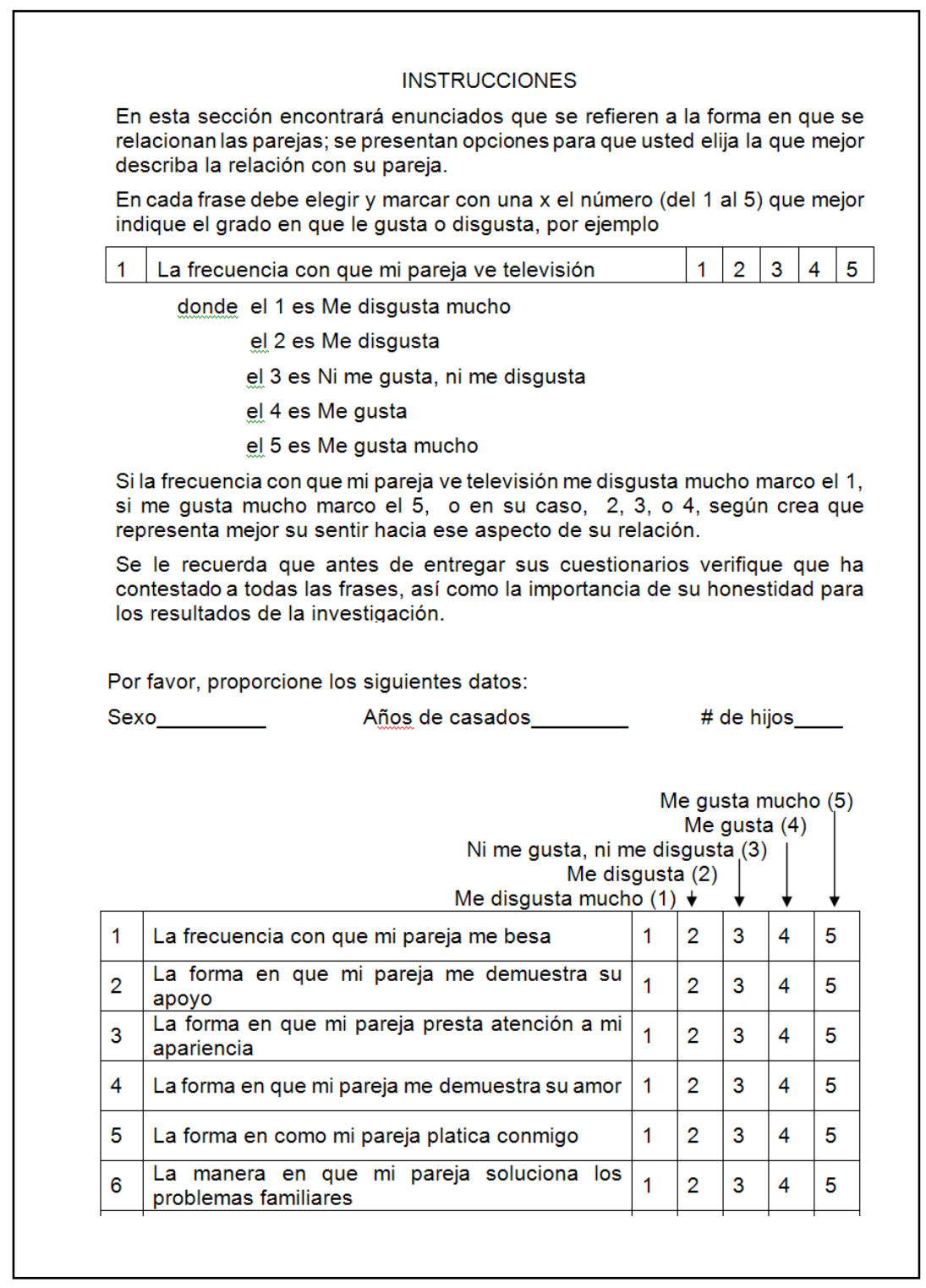

Figura 5.15. Ejemplo de un cuestionario elaborado por un grupo de estudiantes sobre el tema de satisfacción marital 
Evaluación del aprendizaje. Para evaluar el tema de la representación gráfica utiliza ejercicios o examen.

Mira lo que ha pasado allí [en la representación de datos] es que como fue en el primer semestre y sucedió de que ellos conocían una buena parte de ese material, lo que hicimos fue una evaluación, a través de un ejercicio en el salón de clase. Trabajamos en el salón de clase con un ejercicio que se les presentó, en el cual ellos tenían una serie de datos que procesaron en SPSS, vieron algunas cosas, y después tenían ellos me tenían a mí que hacer una presentación en power point de esos datos que se les había dado. Era un trabajo que era en equipo y ellos tenían que presentarme allí, esta información y se les dio inmediatamente una retroalimentación acerca de si la presentación de estos datos era adecuada o no (E1.CL.162)

Más o menos allí fue la forma en la que trabajamos. Lo que sucede es que en este curso en particular fue así. En los dos años anteriores si fue más un examen en el cual ellos tenían que obtener manualmente medidas y representarlas, decidir después si un conjunto de representaciones que se les daba eran adecuadas o no. Era un examen. En esta ocasión precisamente a través del diagnóstico que se hizo, consideré no era necesario, pero sí yo tenía que hacer una evaluación del tema (E1.CL.163)

En la Figura 5.16 se presenta un ejemplo de la presentación que hizo un grupo de estudiantes de una investigación que realizaron sobre estilos de comunicación y satisfacción marital.

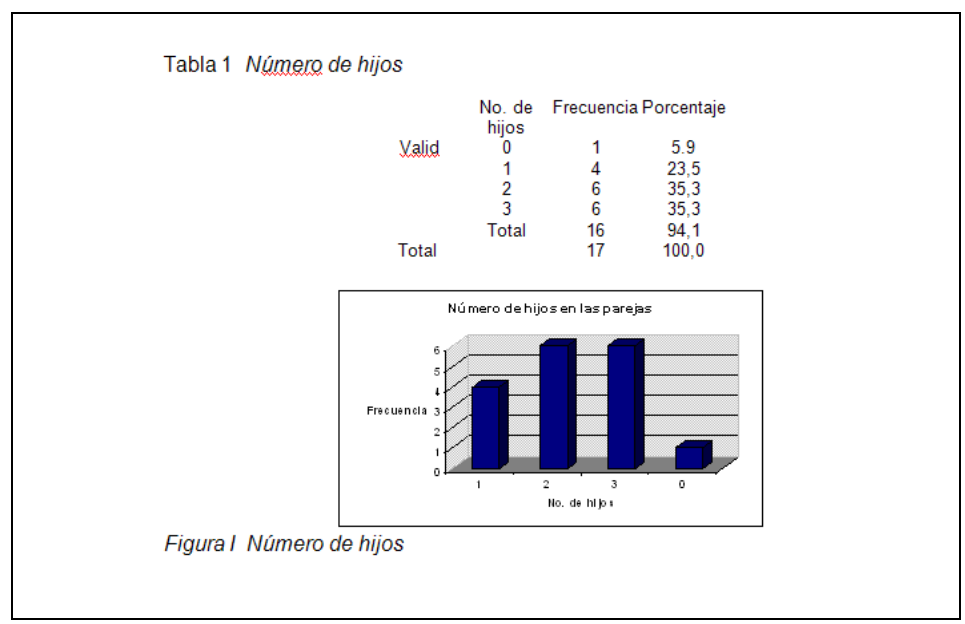

Figura 5.16. Ejemplo de ejercicio elaborado por un estudiante a partir de un ejercicio con el SPSS

Del conocimiento que tiene Luis del currículo sobre la RG, podemos afirmar que es relativamente limitado comparado con el conocimiento sobre el programa de Estadística (en lo general). Si bien la mayoría de las respuestas que da son congruentes con lo establecido en el programa de la asignatura, promueve el aprendizaje de la RG al nivel de leer entre datos, conocimientos de las características (ventajas y desventajas) y que se puedan construir o elaborar. Estudia gráficos descriptivos y categóricos y sólo uno de carácter analítico (el histograma). Si bien se preocupa para que los alumnos logren identificar representaciones confusas, inadecuadas e incompletas, e identificar los errores en su construcción, esto se hace a través del análisis de las exposiciones por parte de los 
alumnos en el salón de clases o en la sala de informática. No se encontró alguna actividad planificada y organizada para el desarrollo de los diferentes niveles cognitivos de la RG.

Cuenta con un amplio número de materiales y recursos, dentro los cuales destaca el uso de cuestionarios de contextos, donde a partir de información demográfica del estudiante se generan bases de datos reales. El diseño de cuestionarios de contexto está ampliamente recomendado para la enseñanza de la Estadística (Thompson, 1994). De estas bases de datos, Luis les solicita a sus alumnos diseñar gráficos que son revisados en la sala de informática. Asimismo, resalta los Applets que utiliza a manera de simulación de datos, aunque principalmente para explorar las distribuciones de las pruebas estadísticas.

Luis recomienda algunos libros de texto a los estudiantes orientados más hacia la Metodología que a la Estadística, lo que se explica por la orientación curricular que tiene la asignatura. Sólo se encontró un texto de Estadística que presenta una concepción de la RG como técnica de graficación exclusivamente y una secuencia lineal de pasos para aprender a construirlo según ciertos criterios. Se trata de un libro obsoleto que no contempla las aportaciones y recomendaciones curriculares en la enseñanza de la Estadística y específicamente, de la RG.

El conocimiento del currículo de la RG está estrechamente relacionado con el programa de la asignatura y no así con la concepción que manifestó sobre esta, su aprendizaje y enseñanza. Según sus concepciones acerca de la Estadísta se espera que Luis oriente el aprendizaje y enseñanza de la RG en el análisis de las relaciones (de los gráficos) en contextos reales; sin embargo, el énfasis está en el cuidado escrupuloso de la adquisición del concepto de escalas de medición y variables, así como en mostrar las características de los gráficos y poder elaborarlo. Parece que a través de los gráficos que construyen en la sala de informática (del cuestionario de contexto) y las investigaciones que hacen los alumnos, donde generan gráficos (descriptivos y categóricos), las presentaciones que exponen delante sus compañeros en clases sea suficiente para establecer las relaciones en contextos reales

Por consiguiente, Luis tiene un conocimiento del currículo de la RG limitado en relación con las recomendaciones internacionales. Si bien conoce y utiliza un conjunto de materiales y recursos para la enseñanza de la Estadística, no es así para la RG. Por ejemplo, no conoce la diversidad de recursos y materiales on-line que le pueden permitir actualizarse en el tema de la RG, y al mismo tiempo ampliar su concepción sobre ésta, de su aprendizaje y enseñanza o las investigaciones realizadas en torno a este tema, como los trabajos de Friel, Bright y Curcio (1997); Friel, Bright y Curcio (2001); Gal (2002); Monteiro y Ainley (2003); delMas, Garfield y Ooms (2005); Pfannkuch (2006); Monteiro y Ainley (2006) y Aoyama (2006 y 2007). 


\subsubsection{Conocimiento de las estrategias y representaciones instruccionales}

El Cuestionario Didáctico sobre Representación Gráfica fue uno de los instrumentos que nos permitió analizar el conocimiento de las estrategias de enseñanza específicas que utiliza en sus clases, sobre todo a partir de situaciones-problema. Las estrategias específicas se agruparon en cuatro categorías: preguntas, manipulación de datos y gráficos, proyectos de investigación y estudio de casos.

\subsubsection{Preguntas}

Una de las estrategias y representaciones instruccionales que utiliza Luis a menudo son las preguntas. Desde el primer momento en el que se trató acerca de sus concepciones, cuando hablaba de su forma habitual de dar clases menciona el uso de preguntas a partir de una situación o contexto como: 1) las situaciones que utiliza habitualmente en clase, y 2) a las situaciones-hipotéticas del cuestionario.

En el primer tipo de contexto se utilizan las preguntas como recurso para hacer pensar al estudiante y desarrollar su razonamiento estadístico, explorar los significados que subyacen en su pensamiento e inducir a que se dé cuenta de sus concepciones erróneas:

- Corroborar intuiciones y razonamientos

O sea, esta interpelación constante, de esta investigación que se les dio hoy, es "qué esperas, o sea qué es lo que podría esperarse" "pues no sé tal o tal cosa" "y si fuera por azar qué encontrarías". O sea, este proceso constante de estarles preguntando y que ellos vayan como que anticipándose a lo que pueda pasar... Lo que creo, que en un proceso precisamente así, el alumno puede más que nada corroborar que muchas de sus intuiciones, de sus razonamientos bien elaborados coinciden precisamente con lo que las herramientas le dan (E1.CL.71).

- Clarificar conceptos antes de seguir avanzando

Yo creo que precisamente lo que se está tratando de generar es ir buscando esa claridad del lenguaje y del concepto y que antes de avanzar quede bien claro en dónde estoy, cuál es mi problema ahora, y seguir en este proceso de interpelarlos, de preguntarnos, de regresar y volver a situaciones previas, para que cada vez quede claro cuál es la problemática que se nos presenta ahora. Creo que eso es muy importante y que tengo que garantizar durante todo el tiempo en clase $i s i$ ? (E1.CL.74)

- Explorar los conocimientos previos del estudiante

Esa época lo que hice fue a cercarme a gente de otras licenciaturas a preguntarles "qué era metodología", la respuesta común era "una materia que no tiene relación con nada más y que te sirve para hacer tu tesis", "qué era estadística" lo mismo (E1.CL.79)

- Analizar el contexto de una situación

Lo que iría en la técnica es poco lo que te digo: que desde el principio comenzamos [sic] de donde viene y es así como que muy cómodo, o sea el comenzar con de qué parte el cuestionario, cuál es la intención, qué se quería saber, qué se quiere representar y entonces... (E2.CL.28)

Jesús Enrique Pinto Sosa 
- Analizar las características, ventajas y desventajas de los gráficos en función de la variable y escalas de medición que se traten

Generalmente cuando estamos trabajando con esto ya tenemos varias bases de datos, entonces... comenzamos a jugar con ellos, o sea por ejemplo... "bueno vamos a sacar tal base de datos y vamos a hacer de tal variable un histograma y al mismo tiempo hacer un gráfico de tallo y hoja", "de tal variable... no sé... pon tú, ¿qué gráfico quieres hacer" porque muchas veces lo que hago con ellos es "bueno cuál se te antoja, a ver cuál [gráfico] se te antoja", "a ver bueno pues voy hacer un gráfico de pastel [circular]" . Entonces ok, "y ahora qué ventajas tiene frente a este otro que habíamos dicho primero" entonces... y es un poco ir viendo dónde es más fácil encontrar la información (E2.CL.06)

Pues como te decía, lo discutimos dentro de lo que es el tema de representación de cada escala de medición y vemos sus características. Son dos o tres sesiones en la que revisamos los gráficos (E2.CL.64)

Generalmente Luis pide a los alumnos que construyan un gráfico a partir de una variable, o bien, seleccionar un gráfico y analizar los elementos a considerar. En otras ocasiones deben construir un gráfico a partir de la escala de medición:

Pues en general lo que estamos haciendo en estas sesiones es el análisis de cada, o sea bajo... bajo esta idea de que "hoy vamos a representar la escala nominal" es bueno... "ok, vamos a representar un gráfico de áreas ... si es un gráfico de áreas entonces ¿qué tendrías que poner?" (E2.CL.32)

y preguntas como por ejemplo "si representaras algo ordinal que tendrías que adicionar" (E2.CL.33)

Generalmente lo que hacemos es que les pregunto "bueno ¿qué tipo de gráfico es?" [ellos dicen] "bueno tal", [les digo] "este gráfico, ¿cuáles son sus características?" Entonces hacemos una revisión de esas características, se mencionan las más importantes y cada una se revisa, o sea ¿está o no está esa característica allí? (E2.CL.137)

Bueno allá sí. En esa actividad lo hacemos (como te decía) a partir de la escala de medición, ¿cuáles serían las características de esa escala de medición?, ¿qué se está representando en la gráfica?, cada uno de los elementos de la gráfica ¿qué dicen de esa escala de medición?, eso es algo que hacemos siempre. En esa sesión en eso nos centramos (E2.CL.65)

\section{- Analizar los componentes estructurales del gráfico}

Generalmente cuando llegamos a ese tema lo que hacemos es: entro con escalas de medición, o sea "vamos a traba... quiero representar variables nominales" y comenzamos "¿cuáles serían las opciones?", entonces comienzan "tal gráfico, tal gráfico" entonces hacemos representaciones, "¿y de estos gráficos qué tendría?, ¿qué se tendría que poner?" "bueno tal cosa, tal cosa" (E2.CL.30)

\section{- Corregir errores}

... el tema de representación gráfica, generalmente lo que hago es más que nada corrección de errores, porque como es un tema que ya han trabajado vamos no tanto a aprender hacerlos sino a "yo ya sé hacer estos" "¿y en qué casos los haces?" [les pregunto], entonces ahorita es ponerle las características a lo que estamos haciendo (E2.CL.22) 
Generalmente es más de ir como que corrigiendo ideas (E2.CL.29)

Esta corrección se hace cuando identifica alguna dificultad o error en el estudio, y no como estrategia inicial:

La situación de contrastar directamente los tipos de gráficos me pareció que puede servir mucho más en clase, porque generalmente lo que hago es desde gráficos que ellos generan o que yo les presento. Es analizar a ese [gráfico], no necesariamente de comparación. Generalmente cuando hay algo que no se aclara es cuando comienzo a comparar. No es el elemento inicial representar la comparación (E2.CL.25)

En el segundo contexto, a partir de las situaciones-problema del cuestionario didáctico sobre representación gráfica, cuando se le pide que indique las estrategias que utilizaría para afrontar cada situación ante sus alumnos, menciona diferentes preguntas que haría a sus alumnos La Tabla 5.7 resumen las preguntas que se recogieron del cuestionario y de la entrevista en profundidad.

Las preguntas representan un instrumento valioso para desarrollar el razonamiento pedagógico del estudiante sobre el tópico de estudio. Con ellas Luis busca que el estudiante desarrolle su capacidad analítica más allá de la adquisición de definiciones y de los procedimientos a realizar. Luis utiliza las preguntas para que los estudiantes se den cuenta de las características de cada gráfico y de la naturaleza de los datos representados.

Otras de las preguntas que plantea en el cuestionario (Tabla 5.7) constituyen un segundo nivel puesto que se refieren al pensamiento cognitivo que se requiere en relación con la RG para:

- explorar los significados

- explorar las características y condiciones en la construcción de un gráfico.

- confrontar la validez de la información y su correspondencia con el tipo de gráfico

A continuación se describirá brevemente cada una de estas clasificaciones de preguntas.

La cuarta parte de las preguntas (25\%) están orientadas a explorar los significados que para el estudiante tiene cierta información de la situación-problema. Los significados estaban relacionados con el conocimiento de los valores a partir del contexto del problema.

Ejemplo de estas preguntas:

¿qué representa el tallo? (E2.CL.02)

¿qué es lo que ella quiere dar a conocer de esta información? (E2.CL.123)

¿cuánto tiempo se viaja? (E2.CL.123)

Jesús Enrique Pinto Sosa 
Tabla 5.7. Preguntas elaboradas por Luis como estrategia para responder a casos del cuestionario didáctico sobre representación gráfica.

\begin{tabular}{|c|c|c|}
\hline $\begin{array}{c}\text { C-1, ítem 1a } \\
\text { ¿Cómo ayudaría usted al } \\
\text { estudiante a comprender el } \\
\text { procedimiento para discriminar } \\
\text { entre los gráficos anteriores? }\end{array}$ & $\begin{array}{l}\text { C-3,ítem } 3 \mathrm{~b} \\
\text { Usted le entregó a sus alumnos } \\
\text { este ejercicio y les solicitó que lo } \\
\text { resolvieran ¿cómo les ayudaría } \\
\text { a resolverlo correctamente? }\end{array}$ & $\begin{array}{c}\text { C-4, ítem 4a } \\
\text { Describa la estrategia que } \\
\text { utilizaría con sus alumnos, paso } \\
\text { a paso, para ayudarles a criticar } \\
\text { y evaluar el gráfico anterior }\end{array}$ \\
\hline $\begin{array}{l}\text { A través de preguntas directas y } \\
\text { comparación le pediría que } \\
\text { dedujera qué información le } \\
\text { proporciona cada uno } \\
\text { (Cu.CL.1a.1). Por ejemplo } \\
\text { (E2.CL.01 al 9): }\end{array}$ & $\begin{array}{l}\text { No contestó en el cuestionario... } \\
\text { lo hizo en la E2 } \\
\text { No comentó preguntas en este } \\
\text { inciso... }\end{array}$ & $\begin{array}{l}\text { Establecer qué información se } \\
\text { desea (Cu.CL.4a.1). Ejemplo } \\
\text { (E2.CL.122 y 123): } \\
\text { ¿qué queremos decir al } \\
\text { utilizar un gráfico? }\end{array}$ \\
\hline $\begin{array}{l}\text { ¿qué semejanzas encontraban } \\
\text { entre los dos? } \\
\text { ¿qué pasaría si rotas el eje y } \\
\text { cambias el gráfico? }\end{array}$ & & $\begin{array}{l}\text { ¿qué es lo que ella quiere dar } \\
\text { a conocer de esta } \\
\text { información? } \\
\text { ¿cuánto tiempo se viaja? }\end{array}$ \\
\hline $\begin{array}{l}\text { ¿qué representa el tallo? } \\
\text { ¿cuáles son las características } \\
\text { de ese gráfico? } \\
\text { ¿qué datos hay allá [en el } \\
\text { gráfico]? }\end{array}$ & & $\begin{array}{l}\text { Establecer el tipo de variable } \\
\text { (Cu.CL.4a.2). } \\
\text { (E2.CL.124): } \\
\text { ¿cuáles serían las opciones } \\
\text { de tipos de gráficos a } \\
\text { utilizar? }\end{array}$ \\
\hline $\begin{array}{l}\text { ¿qué ventajas y desventajas } \\
\text { tiene cada gráfico? }\end{array}$ & & $\begin{array}{l}\text { ¿qué cosas podemos decir y } \\
\text { qué cosas no podemos decir, } \\
\text { de esa variable? }\end{array}$ \\
\hline $\begin{array}{l}\text { ¿es una variable continua o } \\
\text { no lo es? }\end{array}$ & & $\begin{array}{l}\text { Identificar el tipo de gráfico } \\
\text { utilizado (Cu.CL.4a.3). Ejemplo } \\
\text { (E2.CL.125): }\end{array}$ \\
\hline & & $\begin{array}{l}\text { ¿qué ventajas y desventajas } \\
\text { tiene ese gráfico en } \\
\text { particular? }\end{array}$ \\
\hline & & $\begin{array}{l}\text { Analizar si las líneas representan } \\
\text { los porcentajes correctamente } \\
\text { (Cu.CL.4a.4). }\end{array}$ \\
\hline & & $\begin{array}{l}\text { Que me indicaran el tipo de } \\
\text { gráfico y sus características } \\
\text { (Cu.CL.4bii.1) }\end{array}$ \\
\hline & & $\begin{array}{l}\text { ¿Cuáles son los elementos que } \\
\text { sobresalen? (Cu.CL.4bii.2) }\end{array}$ \\
\hline & & 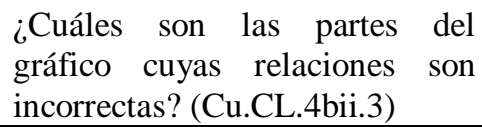 \\
\hline
\end{tabular}


La mitad de las preguntas (50\%) están orientadas a explorar las características y condiciones de la construcción de un gráfico para saber si el alumno conoce el tipo de variable, las ventajas y desventajas de cada gráfico y el grado de precisión que se quiere de este:

¿qué ventajas y desventajas tiene cada gráfico? (E2.CL.09)

¿es una variable continua o no lo es? (E2.CL.09)

¿cuáles serían las opciones de tipos de gráficos a utilizar? (E2.CL.124)

Un tercer grupo fueron preguntas para confrontar la validez de la información y su correspondencia con el tipo de gráfico; su propósito es cuestionar al estudiante, por ejemplo si un dato se podría obtener a través de otro gráfico $(\mathrm{C}-1)$, o bien, si está claro para el lector lo que representan las posiciones de los autos (C-4):

¿qué pasaría si rotas el eje y cambias el gráfico? (E2.CL.02)

¿cuáles son las partes del gráfico cuyas relaciones son incorrectas? (Cu.CL.4bii.3)

Del análisis de estas se puede deducir que para Luis es importante que "a través de diferentes preguntas directas y de comparación le pediría que dedujeran qué información le proporciona cada gráfico" (Cu.CL.1a.1). Las preguntas se pueden agrupar en: a) la información que desea (a través del gráfico), b) el tipo de variable que se trata, c) el tipo de gráfico (seleccionado) e d) identificación de los componentes estructurales del gráfico.

\subsubsection{Manipulación de datos y gráficos}

Luis hace referencia a la manipulación de datos y gráficos como recurso para enseñar la RG. El siguiente ejemplo muestra cómo a través de la manipulación intenta explorar lo que ocurre con los ejes del gráfico (C-1), así como las semejanzas y diferencias entre el TyH y el histograma:

Una de las cosas que por ejemplo cuando hemos trabajado con gráficos es pedirles un poco que manipulen con la imaginación el propio gráfico. Por ejemplo en esta clase, generalmente eso lo trabajo ya en cómputo porque podemos manejar ya con el proyector y cosas, los gráficos, por ejemplo, de repente, “¿qué pasaría si rotas el eje y cambias el gráfico?”, porque para el caso del gráfico de tallo y hoja... "o sea si lo giramos y lo dejamos en... o giramos el gráfico del histograma, ¿qué pasa? o sea ¿qué semejanzas encuentras entre los dos? ¿si?” Y en ese momento comenzar a ver qué elementos encuentran entre ambos como particulares (E2.CL.01)

Por ejemplo en el caso de este trabajo eh... tenemos hecho... porque es una duda generalmente, el gráfico de tallo y hoja es un gráfico que al principio las veces que lo presentaba no lo entienden, $o$ sea qué ventaja les da frente a uno ya conocido y que usan desde siempre que es el histograma, y al rotarlo al ver bueno... qué representa el tallo, cuáles son las características de ese, qué datos hay allá, comienzan a identificar algunas ventajas o desventajas de cada uno (E2.CL.02)

Luis hace referencia a la manipulación de los datos para generar el gráfico o bien, a la rotación de los ejes o del gráfico mismo:

por ejemplo generalmente la edad de ellos pues es un rango de tres, cuatro años, que al representarla en un histograma queda muy clara la descripción pero al presentarla en un gráfico de tallo y hoja, 
pues realmente no hay... Como son repeticiones del mismo rango, ven en el SPSS que te deja... no sé 19, 19, 0, 20, 20, 0 y te deja esto espacios, al... [interrumpe la idea]. Por ejemplo, lo que hacemos que es rotar los ejes, ponerlos uno junto al otro y demás pareciera que lo que se está generando es un gráfico de barras y te dicen "bueno por fin ¿es una variable continua o no lo es?" o sea esa clase de discusiones se pueden hacer en ese momento ¿si? (E2.CL.09)

Esta estrategia no es una actividad sistemática o habitual en sus cursos, sino circunstancial dependiendo del momento de la clase y está dirigida al análisis de la gráfica durante la práctica del SPSS. Esta estrategia necesariamente "va de la mano" de las preguntas que el profesor debe hacer a los estudiantes.

... por ejemplo "vamos a ver la escala nominal y vamos cuáles son sus características otra vez" bueno entonces "ok tales características" "bueno una primera opción sería representar con un gráfico... de pastel [circular], qué representa este gráfico", [los alumnos dicen] "tal y tal cosa" . Que primero me lo describen, qué es y entonces en ese momento de esto de la escala de medición, "qué está representado" tales cosas, tales elementos, se representan porcentajes, se representan las categorías... y se van haciendo preguntas, por ejemplo "¿qué pasaría si son más de diez sectores?", [dicen los estudiantes] "se hacen muy pequeños, se hacen muy grandes", [les diría] "si fueran menos de tantos, ¿qué pasa?" Se van haciendo esa clase de preguntas durante esa presentación... (E2.CL.66)

Por ejemplo, tomar una variable continua, una variable discreta, alguna variable nominal y comenzar a ver "vamos a representarlas" y como trabajo mucho con grupos, entonces muchas veces es "a ver qué propuesta tiene cada grupo y que hagan sus gráficas" y también les dejo esa libertad de hacerlas en el graficador de Office o hacerlas en el graficador de SPSS. Generalmente terminan haciéndolo siempre en Office porque con esta situación de que el SPSS se cambian mucho los ejes, hay que cambiar demasiadas cosas de la gráfica, muchas veces no les gusta. entonces a partir de eso "vamos a ver, la propuesta de este grupo es hacer un histograma de esta manera, ponerle... ¿qué ventajas tiene?" , [los estudiantes dicen] "bueno es que se representa la continuidad o no se representa la continuidad..." e irles haciendo preguntas muy específicas "¿qué está representado en el eje Y?, ¿qué está representado en el eje X?, ¿qué representa la altura?" o sea esta clase de preguntas directas acerca de la naturaleza del gráfico. Muchas veces aparecen por ejemplo, el eje tiene diferentes cambios de los intervalos, entonces [les digo] "vamos a ver ¿qué pasa si el incremento mínimo lo cambiamos?, ¿qué pasa si lo aumentamos?, ¿qué información se da de más?" Esto es parte de lo que jugaríamos (E2.CL.21)

En estos ejemplos, las instrucciones fueron modificar la cantidad de sectores en el gráfico circular y los incrementos de intervalos del histograma.

\subsubsection{Proyectos de investigación}

Como hemos mencionado, otra de las estrategias que usa Luis son los proyectos de investigación en pequeños grupos.

Por ejemplo, el que haya la necesidad del tiempo presencial tan marcado y las faltas de asistencias, cuando para mí hay muchas cosas [más importantes]: que es que ellos estén trabajando en el proyecto de investigación, pero que vengan a mí a decirme "bueno estas son mis dudas y aurita nos vamos a meter a la biblioteca a seguir trabajando y te vemos dentro de cuatro días con todo el proceso" a que nos veamos en el salón de clase (E1.CL.29)

Está metodología está centrada en que el estudiante desarrolle un proyecto de investigación a lo largo de la asignatura. Esto le permite vincular la teoría con la práctica, así como encontrarle sentido a lo que hace y aprender a fundamentar sus ideas. 
En el momento actual, como estoy tratando de llevarlo más hacia una metodología de proyectos, una de las situaciones es pensar a la Estadística como aquella herramienta que me va a servir para fundamentar mis conclusiones y las posibles generalizaciones que haga de mis datos. (E1.CL.93)

De hecho, esta estrategia es al mismo tiempo una forma de evaluar los aprendizajes en la asignatura:

¡Ah bueno! Allí sí hay criterios muy claros. Ellos identifican por ejemplo (de que todos estos tipos de evaluación), cuáles son parte del rubro exámenes, ejercicios y problemas; otro rubro que tienen que ver con participación activa; y el rubro de proyecto de investigación (E1.CL.152)

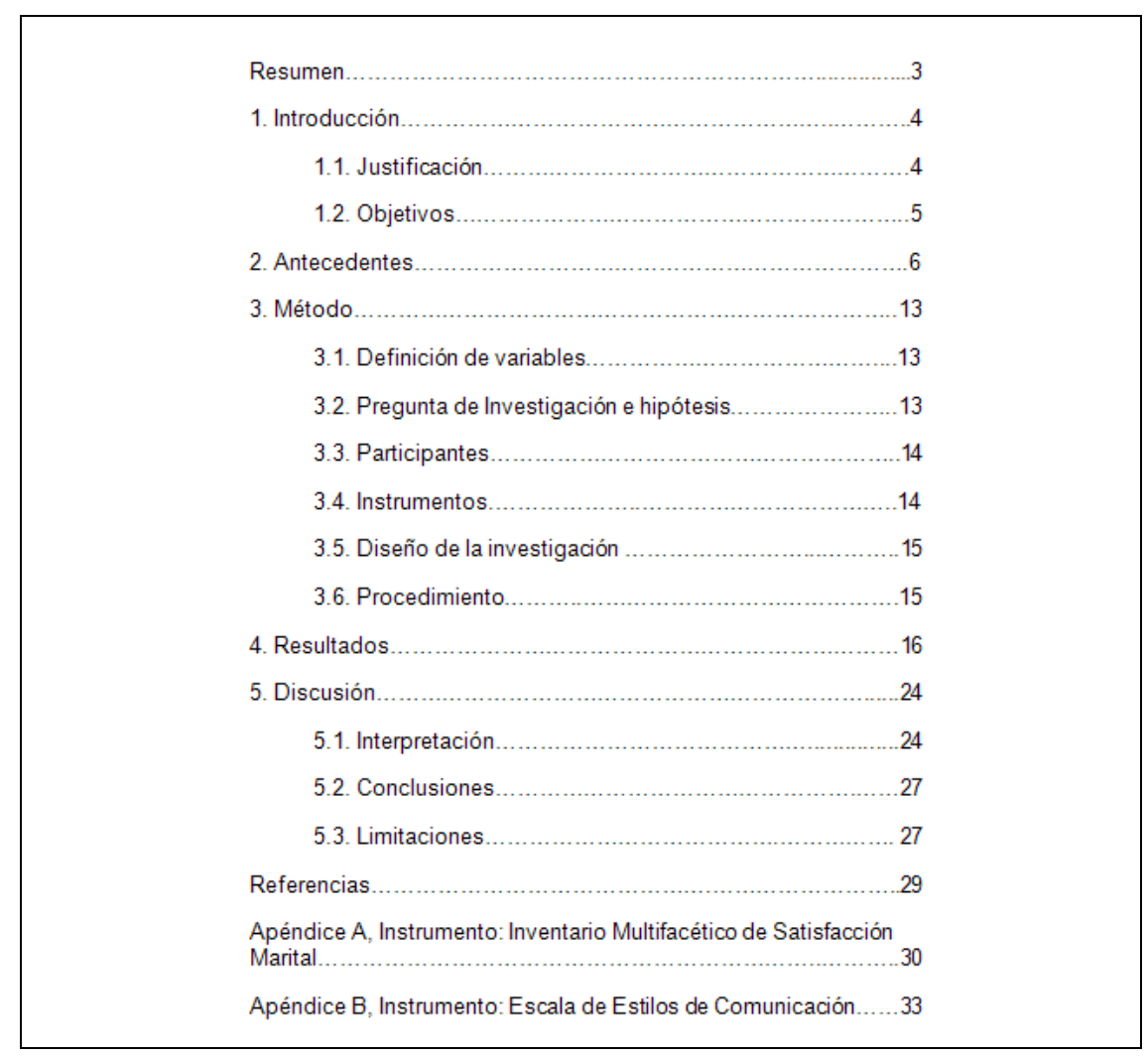

Figura 5.17. Ejemplo del índice de un proyecto de investigación

Como se puede apreciar en la Figura 5.17 las partes de un proyecto de investigación tienen estrecha relación con la información que lleva una publicación científica: problema, marco de referencia, método, resultados, discusión y conclusión.

\subsubsection{Estudios de casos}

Otra estrategia a la que hace referencia son los estudios de casos que se trabajan fuera del salón de clase. Por ejemplo: 
Les presento una situación, el efecto Mozart, de esta idea de que a través de la música clásica se mejora tu capacidad. Bueno, entonces ellos leen un caso hay información científica proveniente de journals. Tienen que leer en inglés y ellos tienen durante cuatro semanas que elaborar todo un análisis de esta información, y es una tarea que ellos saben que es durante el tiempo y no es parte específica del trabajo en clase sino que ellos puedan en clase decirme "oye tenemos una duda, de por qué dicen que es un diseño... ¡no sé! un diseño de grupo control con..." O sea, no lo vemos [en clase así] y podamos aclarar algunas cosas, pero son dudas que aparecen y que... (E1.CL.31)

Las Figuras 5.18 y 5.19 presentan el caso que hace referencia Luis: el efecto Mozart. Se puede observar que consta de tres partes:

I) se presenta una lectura con la situación problema que va acompañada de algunas preguntas iniciales para reflexionarsobre la evidencia descrita en el texto,

II) esbozo del experimento con preguntas con base en el método científico (ej. pregunta de investigación, hipótesis, variables, control de variables) y la búsqueda de reportes de investigación sobre el tema a tratar, y

III) el análisis de reportes de investigación localizados a partir de una guía de discusión que contiene algunas instrucciones y preguntas específicas a contestar.

Estas fases llevan al estudiante a contrastar los resultados de las investigaciones localizadas con la situación problema planteada al inicio. Como producto final, los estudiantes deberán elaborar un informe con las respuestas, los análisis hechos y las referencias consultadas.

Esta estrategia es utilizada por primera vez por Luis en su curso de Estadística y los estudios de casos pertenecen al Instituto Nacional para la Enseñanza a través de Estudios de $\begin{array}{lllll}\text { Casos } & \text { por la } & \text { Universidad } & \text { Búfalo }\end{array}$ (http://ublib.buffalo.edu/libraries/projects/cases/case.html).

Aquí nada más para que veas un poquito los materiales que tienen ellos [pausa, viendo en la computadora]. Estos estudios de caso no son construidos por mí, son tomados del Instituto Nacional de Estudios de Caso que mantiene la Universidad Estatal de Búfalo. Me suscribí al servicio y todo para tenerlos. Obviamente los traduzco y se le dan los créditos adecuados en todo momento, pero precisamente porque siento que es un avance muy fuerte, o sea, puedo ver cosas distintas en ellos en este momento, entonces aquí, yo espero que no esté toda la situación. Obviamente el caso está adaptado (E1.CL.131) 


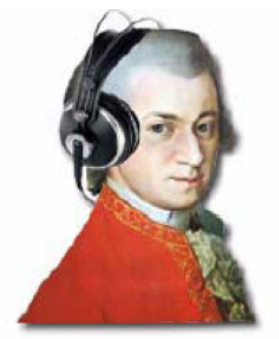

\section{EL EFECTO MOZART UN ESTUDIO DE CASO SOBRE METODOLOGÍA DE LA INVESTIGACIÓN}

Lisa D. Hager

Departamento de Psicología, Spring Hill College

Este estudio de caso fue tomado del National Center for Case Study in Science de la University at Buffalo, State University of New York. Este estudio de caso fue depositado el $16 / 03 / 2004$

PARTE I. ¿Desempeño mejorado?

"Hey Pedro!, ¿qué estás escuchando?”, pregunta Mario.

"Unos CDs de música clásica que me acabo de comprar. Se supone que deben ayudarme a mejorar mi concentración y a ser más creativo", respondió Pedro.

Con cara de extrañado Mario le respondió “¿puede hacer todo eso la música clásica?, ¿de dónde sacas esas cosas?"

.....

\section{Preguntas a esta sección}

1. ¿Qué cosas se afirman sobre los cds de música clásica de Pedro?

2. ¿Existe evidencia que soporte a estas afirmaciones sobre los cds de música clásica?

3. ¿Cómo y dónde pueden encontrar Pedro y Mario evidencia publicada que sirva de soporte a esas afirmaciones?

4. Evaluen la información que se presenta en el sitio de Internet. La tabla siguiente servirá de guía al análisis pero elaboren una respuesta integrada.

\begin{tabular}{|c|l|l|}
\hline & \multicolumn{1}{|c|}{$\begin{array}{c}\text { Características de una } \\
\text { aproximación NO científica a la } \\
\text { experiencia }\end{array}$} & $\begin{array}{c}\text { Características de una } \\
\text { aproximación no científica a la } \\
\text { experiencia }\end{array}$ \\
\hline Observación & Casual, no controlada & Sistemática, controlada \\
\hline Reporte & Sesgado, subjetivo & Sin sesgo, objetivo \\
\hline Conceptos & $\begin{array}{l}\text { Ambiguos, con significados } \\
\text { múltiples y sin aclarar }\end{array}$ & $\begin{array}{l}\text { Definiciones claras, operaciones, } \\
\text { específicas }\end{array}$ \\
\hline Instrumentos & Imprecisos, inexactos & Exactos, precisos \\
\hline Medidas & No válidas o confiables & Validas y confiables \\
\hline Hipótesis & No comprobables & Comprobables \\
\hline $\begin{array}{c}\text { Aproximación } \\
\text { general }\end{array}$ & Intuitiva & Empírica \\
\hline $\begin{array}{l}\text { Adaptado de Shaughnessy, J.B., Zechmeister, E.B \& Zechmeister, J.S. (2003) Research Methods } \\
\text { in Psychology. New York: McGraw-Hill. }\end{array}$ \\
\hline
\end{tabular}

Figura 5.18. Ejemplo del estudio de casos: el efecto Mozart. 


\section{Parte II. Esbozo de un experimento}

Después de platicar más sobre el tema y de discutirlo con el profesor de Metodología, Mario y Pedro deciden realizar un experimento para probar la efectividad de los CDs de música clásica. Realicen un esbozo del experimento que deberían desarrollar. Respondan cuando menos a las siguientes cuestiones:

1. ¿Cuál es la pregunta de investigación a la que se quiere responder?

2. ¿Cuál es la hipótesis de investigación que se quiere probar?

3. ¿Cuál es la variable independiente a probar?

4. ¿Cómo podría ser medido el efecto de la variable independiente? En otras palabras, ¿cuál es (son) la(s) variable(s) dependiente(s)?

5. ¿Qué aspectos deben controlar en la situación de aprendizaje? Mencionen como deben hacerlo. Incluyan (pero no se limiten a) lo siguiente:

a. Variables a mantener constantes

b. Eliminar el efecto de otras variables

\section{Parte III. Análisis de reportes de investigación}

\section{A. Música y desempeño en una tarea espacial}

Buscando información para su experimento, Mario y Pedro encontraron el reporte de Rauscher, Shaw y Ky (1993) llamado Music and spatial task performance publicado en la revista Nature. Lean el reporte y respondan a lo siguiente:

1. Identifiquen $\mathrm{la}(\mathrm{s})$ variable(s) independiente(s)

2. Identifiquen $\mathrm{la}(\mathrm{s})$ variable(s) dependiente(s)

3. ¿Qué aspectos del estudio fueron controlados por los investigadores? ¿Qué aspectos no controlaron?

4. ¿Cuáles fueron los resultados del estudio?

5. ¿A qué conclusiones llegan los investigadores?

6. Basado en el diseño y los resultados de este estudio, ¿creen que los investigadores pueden justificadamente llegar a esas conclusiones? ¿por qué?

7. Ahora revisen el diseño de experimento que ustedes proponen, ¿pensaron en controlar alguno de los problemas que se presentaron en la investigación de Rauscher, Shaw y Ky (1993)? Si es así, ¿cuáles?

\section{B. Tratando de demostrar algo}

En su búsqueda bibliográfica, Mario y Pedro se encontraron con un artículo de Steele, Bass y Crook (1999) publicado en la revista Psychological Science, donde se trató de replicar el estudio de Rauscher, Shaw y Ky (1993). Revisen el artículo y respondan a las preguntas 1 a 6 anteriores ahora con respecto a este nuevo artículo. Además indiquen de que modos el estudio de Steele, Bass y Crook es una mejora al estudio de Rauscher, Shaw y Ky.

Documento a entregar. Respuesta a cada una de las tres secciones, estilo APA (2001), engrapado.

\section{Elementos del documento:}

1. Portada

2. Respuestas y análisis

3. Referencias, en su caso

Figura 5.19. Ejemplo del estudio de casos: el efecto Mozart (continuación). 
Los estudios de casos pueden ser tomados de periódicos o artículos de investigación y representan una estrategia interesante para los estudiantes. Luis los define como sigue:

... son situaciones en las que tienen que analizar y discutir y ellos incluso tienen que hacer todo una... posterior, una evaluación de qué tanto se participó en la discusión, de cómo se resolvió y demás y siento que es una actividad que podría utilizar en estas situaciones, o sea decirles "bueno vamos a iniciar ahorita", por ejemplo dárselas al inicio del tema, "bueno aquí está esta actividad, el tema lo terminamos el próximo miércoles, tenemos cuatro clases para trabajarlo entonces comiencen" y conforme vamos trabajando en el salón de clase muchas de esas cosas también se van discutiendo en casa (E2.CL.116)

Para potencializar el uso de los estudios de casos, Luis se ayuda del SGA de Dokeos. La estructura que generalmente tiene cada caso es: a) lectura de la situación y contexto, b) generación de una alternativa o diseño de un breve experimento, c) análisis de reportes de investigación, recogida de datos o experimentación, d) análisis de datos y e) discusión y conclusión. Luis resume así todo el proceso:

Todo este proceso, implica ya la integración de Metodología y Estadística, porque ellos tienen que leer el reporte y decirme "bueno ¿a qué se concluyó?, o sea por ejemplo, cuáles fueron... o sea identifiquen las variables independiente, la variable dependiente, ¿qué aspectos fueron controlados por los investigadores?, ¿cuáles fueron los resultados del estudio?, ¿a qué conclusiones se llegaron?, basado en el diseño y resultados del estudio ¿creen que los investigadores puedan justificadamente llegar a esas conclusiones?". Precisamente lo que estoy tratando es que ellos, cuando estén viendo en clase que estamos trabajando con algo, digan "¡ah! en algún momento voy a poder yo leer esta información científica" (E1.CL.129)

Además, para Luis, los estudios de casos deben cumplir tres condiciones: 1) lo metodológico, 2) lo estadístico y 3) relación entre ambas. Para solicitar un estudio de casos previamente Luis ha trabajado los aspectos conceptuales y procedimentales de los contenidos estadísticos con los estudiantes.

No obstante, Luis reconoció que no cuenta con alguna actividad para desarrollar el análisis y reflexión sobre la RG. En repetidas ocasiones mencionó que las actividades que realiza no son como las del cuestionario didáctico sobre RG sino surge según las circunstancias de la clase.

No es un ejercicio propio que ellos hagan en esa clase sino que es más el análisis de la gráfica (E2.CL.67)

o sea, no es una actividad propiamente dicha de análisis como esta, sino que es basada en el nivel de medición y ya con cada uno es "ok, vamos a representar eh... la proporción de hombres y mujeres, proviene de tal pregunta, ¿nivel de medición?”. Comienza todo este análisis de qué se quería dar, pero no tengo una actividad que utilice de este tipo [de ejercicio como C-1] (E2.CL.31)

O sea, no lo he puesto nunca como una actividad específica estas tareas que me mencionas. Siempre ha sido más en la discusión [en clase], creo que no está tan formalizado tal y como me lo preguntas (E2.CL.33)

Allí siento que es una situación [el C-2] que me ha sucedido en varias ocasiones. Lo que te comentaba desde las primeras entrevistas, con todas esas preguntas me has puesto a cuestionar 
algunos nuevos ejercicios para proponer en clase, que tal vez he confiado un tanto en... en que esto aparece generalmente, no lo he propuesto como situaciones propias de la clase. O sea generalmente si al momento de que voy a cambiar de tema no ha aparecido ninguna de estas situaciones, yo las provoco en ese momento, pero no han sido presentadas con anterioridad como una situación de análisis propio (E2.CL.59)

Lo explica o ejemplifica del siguiente modo:

Voy trabajando con él...[gráfico] y si ya estamos terminando el tema y no ha ocurrido, yo lo provoco, pero tal vez el presentarlo como una situación como tal pudiera aprovechar incluso más la sesión porque tal vez... o sea veo que ya pasó 40 minutos y veo que no ha ocurrido y lo provoco, pero pude aprovechar desde el principio ese tiempo (E2.CL.59)

Luis reconoce que invierte poco tiempo en el tema de la RG y que lo que cubre del programa tiene que ver con la construcción de gráficas fundamentalmente.

porque siempre ha sido, te digo, lo hemos puesto como parte de un reporte y con sinceridad ha sido que deben representar ya sea en una tabla o gráfica esa información, pero hasta allá (E2.CL.120)

Eh... siento que pocas veces se interpreta una gráfica, o sea es y si te soy sincero es algo que también yo no he hecho con suficiente frecuencia, o sea generalmente no es algo que de la gráfica se saque [obtenga] información sino que generalmente la usamos como un resumen que está allí, pero no es de la gráfica de la cual se jala [obtiene] información. Entonces siento que allí es una de las cosas que suceden ¿no? que... que... muchas veces en texto se escribió previamente y el gráfico es un referente a algo que ya está dicho en el texto, pero no es la gráfica el punto de información ¿si? o sea y con total sinceridad siento que yo ahorita al hacer este análisis como lo estás presentando es algo que no he hecho, o sea el que la gráfica de allí [el histograma] tengamos la información (E2.CL.104)

Luis no desarrolla el nivel cognitivo de pensamiento estadístico en sus estudiantes, sino que las actividades que utiliza pertenecen parcialmente al nivel de alfabetización Estadística. Busca que los estudiantes conozcan y usen algunas técnicas básicas de graficación; organizar datos, construir y presentar gráficos (principalmente descriptivos y categóricos). No obstante, no atiende suficientemente lo relativo a la comprensión de la información estadística (comprensión gráfica) y no le concede valor a comprender e interpretar información presentada en un típico gráfico estadístico de distribución (ej. de puntos, histograma y de caja), identificar algunas formas comunes de distribución (ej. normal, sesgadas, bimodal, uniforme), distinguir entre un gráfico de barras y serie de tiempo de los histogramas, y comprender los términos relacionados con la distribución. Los elementos de la RG a nivel de pensamiento estadístico descritos en la sección 2.5.2 no los contempla.

Enseña la Estadística a partir de un limitado repertorio de estrategias, que son congruentes con su concepción hacia la asignatura: las preguntas, la manipulación de datos y gráficos, los proyectos de investigación y los estudios de casos. Sin embargo, debemos establecer diferencia entre aquellas estrategias que utiliza para su curso de Estadística (en lo general) y las directamente relacionadas con la RG. El primer grupo lo hemos denominado como estrategias genéricas y son aquellas que comentó y explicó sin hacer referencia en algún momento a la RG. Aquí se situaron: los proyectos de investigación y los estudios de casos. En el segundo grupo, las estrategias específicas, se agrupan aquellas donde 
mencionó ejemplos y usos de la RG: las preguntas y la manipulación de datos y gráficos. El análisis que a continuación presentaremos vendrá diferenciado a partir de esta clasificación.

De las cuatro estrategias y representaciones instruccionales dos de ellas son representaciones verbales: las preguntas y las manipulación de datos y gráficos; y dos concretas: los proyectos de investigación y estudios de casos (McDiarmid, Ball y Anderson, 1989). Circunstancialmente las estrategias específicas que Luis utiliza coinciden en que son de tipo verbal, mientras que las genéricas resultaron concretas. La fuente de donde se derivan las representaciones verbales es el propio Luis, es decir, las crea o construye él mismo, la mayoría según las circunstancias de la clase; mientras que las genéricas se derivan de sitios Web, periódicos y artículos de investigación.

Por otra parte, en cuanto a las forma de estas representaciones las preguntas están centradas en la interacción entre el profesor y los estudiantes, mientras que las demás representaciones se centran en el estudiante, es decir, son ellos los protagonistas o quienes se involucran activamente en actividades de construcción de los conceptos, procesos o relaciones.

Sobre los propósitos de cada una de las representaciones instruccionales:

- Las preguntas se usan para identificar información que se desea del gráfico, identificar el tipo de variable que se trate, explorar las características del gráfico, así como el contexto de la situación y analizar ventajas y desventajas de cada uno.

- La manipulación de datos y gráficos para explorar lo que ocurre con los ejes $x$ e $y$ del gráfico y las variaciones de los sectores e intervalos en los gráficos circular e histograma, respectivamente.

- El proyecto de investigación para encontrar sentido a lo que hace y vinculación de los conceptos con la práctica profesional.

- Los estudios de casos para relacionar la teoría con la práctica.

Sobre los contextos y momentos de las representaciones instruccionales usa:

- Una pregunta cuando desea corroborar intuiciones y razonamientos, clarificar conceptos, explorar antecedentes y corregir errores.

- La manipulación de un dato o gráfico cuando se encuentra en la sala de informática y los alumnos están construyendo gráficos.

- Un proyecto de investigación cuando desea vincular la metodología de la investigación con la Estadística.

- Un estudio de caso cuando está viendo el tema de estadísticos de prueba de hipótesis. 
Las estrategias específicas que utiliza Luis como representaciones instruccionales son de tipo verbal, de su propia autoría, una está centrada en la relación profesor estudiantes (las preguntas) y otra en el estudiante (la manipulación). No obstante, estas representaciones se dan según las circunstancias de la clase y las necesidades del alumno y no son actividades con una planificación anticipada. Por su parte, las estrategias genéricas que utiliza son de tipo concretas, se derivan de sitios Web, periódicos y artículos de investigación, y están centradas en el estudiante como principal protagonista. Son actividades planificadas con anticipación desde el inicio del curso.

Luis proporciona la dirección electrónica de sitios es Web especializados en estudios de casos para fines de aprendizaje y menciona el uso de periódicos aunque no presentó ningún ejemplo. Para los artículos de investigación como fuente para los proyectos de investigación recomienda las bases de datos electrónicas como marco conceptual de su investigación. Y en cuanto a los estudios de casos sugiere la lectura específica de algunos artículos.

El proyecto de investigación trata de integrar todos los contenidos vistos durante el curso y de vincular la metodología de la investigación con la Estadística. Se aborda implícitamente el análisis de la RG con el propósito de conocer si los alumnos seleccionan el gráfico y lo interpretan adecuadamente, así como si está correctamente construido. Pero el análisis es superficial, no se le da la relevancia necesaria, no tiene mucho valor en la asignación de notas del alumno y está subordinada al gráfico que decida utilizar el estudiante, que generalmente son categóricos, de una variable y exclusivamente para comunicar resultados (Figura 5.16).

Los estudios de casos se usan exclusivamente para el aprendizaje de los estadísticos de prueba de hipótesis (ej. ANOVA, $t$ de Student, chi cuadrado). No se encontró evidencia de que se aborde el estudio de la RG.

Las preguntas tienen relación con las que elaboró a partir del cuestionario didáctico de RG que fueron agrupadas en tres categorías: explorar la interpretación de los componentes estructurales del gráfico, explorar las características y condiciones en la construcción de un gráfico y desarrollar el sentido crítico en un gráfico. Entre las dos primeras categorías se encuentran el $75 \%$ de éstas.

La manipulación de datos y gráficos, es una representación que se realiza de manera circunstancial y ocasional y surge de las respuestas que Luis dio del cuestionario didáctico.

Estos resultados son hasta cierto punto contradictorios con la concepción que tiene Luis de la RG. Por un lado concibe la RG como interpretar relaciones en contextos reales pero utiliza las preguntas para explorar los significados de los conceptos previos y de las características y elementos del gráfico. $\mathrm{Si}$ bien reconoce otras tres representaciones instruccionales, dos no son utilizadas en la enseñanza de la RG y una se considera sólo a partir de las situaciones hipotéticas del cuestionario. Él mismo confirmó que se centra más en la construcción de gráficos, poco en su interpretación y los proyectos de investigación se usan para comunicar resultados. 
Por último, estas representaciones instruccionales distan mucho de los avances en materia de enseñanza de la RG. Por ejemplo, las recomendaciones de Meletiou y Stylianou (2003) para mejorar la comprensión de los gráficos; el proceso de desarrollo de los niveles cognitivos de la comprensión gráfica a través de actividades interactivas y en contextos reales de Curcio $(1989,2001)$, la información sobre técnicas gráficas generales y una lista bibliográfica sobre gráficos, principalmente de cajas y paralelos, circular, de barras y de dispersión en Pittenger (1995), la inclusión de textos actualizados con novedades recientes en cuanto a la forma de abordar el estudio de la RG, incluyendo niveles cognitivo de leer más allá de los datos y detrás de los datos de Moore (2000) y Salkind (2000), y las aplicaciones prácticas que presenta la revista Teaching Statistics dirigidas a los profesores de Estadística, por citar algunos ejemplos.

\subsubsection{Conocimiento del estudiante}

En la tercera categoría del CDCse incluye el conocimiento que tiene Luis del proceso cognitivo de los estudiantes, cómo diagnostica las dificultades y las estrategias específicas que utiliza para corregir las concepciones erróneas. Presentaremos este conocimiento en dos de sus dimensiones: a) las creencias, y b) los errores y dificultades de los estudiantes sobre la representación gráfica.

\subsubsection{Creencias}

Las creencias que Luis piensa que tienen los alumnos sobre la RG se agruparon en los siguientes apartados:

- Lo importante de la representación gráfica: lo bonito, visual, el color y tamaño

- Con los números de la RG se puede hacer lo que quieran

- Los gráficos son todos iguales

- Es información que hay que poner

A continuación explicaremos cada una.

Lo importante de la representación gráfica: lo bonito, visual, el color y tamaño. Sobre la primera creencia, Luis afirma que para los estudiantes lo más importante de la representación es "lo bonito", lo visual, el color y el tamaño. En el C-1, ante la pregunta ¿por qué el estudiante da esta explicación? Un estudiante contestó "Porque es fácil de comprender, a golpe de vista los datos se visualizan... y obtienes una conclusión más rápidamente”, Luis atribuyó su respuesta a que:

Quizá sea producto de la creencia de que una buena representación gráfica es aquella que sin recurrir a número brinda información. (Cu.CL.1ci.1)

Luis piensa que :

muchas veces que cuando se dice 'representa gráficamente', lo que se está diciendo "has un dibujo", o sea has una... alguna forma de decir lo mismo que está dicho en los números, pero sin tener que utilizar algún número". Por ejemplo, hacen referencia a que "hay más área", "hay más largo", "hay más ancho" y que eso es lo que tienes que decir, que es más grande que otra cosa. Entonces sí es una 
representación gráfica, pero por ejemplo en el caso del de tallo y hoja y el histograma en el otro [el de $\mathrm{TyH}]$ al ver números entonces la representación ya no es buena, porque no se utilizaron los referentes visuales o los referentes incluso de color (E2.CL.14)

Afirma que muchas veces lo que me dicen es que "es más fácil leer", por ejemplo, una gráfica de pastel [circular] porque "son diferentes colores y te llama más la atención", pero al "llamarte más la atención te está dando más información o te puedo engañar poniéndote un color más llamativo y haciéndote ver algo diferente a lo que realmente debieras ver" (E2.CL.15). Luis afirma que para los alumnos es más importante el tamaño del gráfico y que eligen gráficos que sean visualmente más bonitos. Según él, esto se debe a que los estudiantes no comprenden la naturaleza propia de cada elemento de la gráfica. Por ejemplo, Luis hace alusión a un ejemplo de una representación en tres dimensiones:

Por ejemplo, en alguna ocasión les encontré en ese momento en el periódico una información que traía en el Diario de Yucatán esta parte de medicina que está en la parte [sección] de Imagen: Tribuna Médica, una gráfica y cuando se las mostré decían "bueno sí, lo que pasa es que tal medicamento es el que mejor funciona". Les decía "bueno ahora voy a dibujar eso mismo sin tercera dimensión” y cuando dibujas y ves que la diferencia es mínima entre dos cosas, [les pregunto] “¿hay una ventaja de usar un medicamento y otro?" "no"[contestan los estudiantes]. ¿Qué sucede?, al no poner un referente numérico y al poner como referente la tercera dimensión pues lo que estabas viendo es que era más, te llamaba la atención, además estaba en un color más claro, los colores... En el Diario al ser en blanco y negro, los colores oscuros se veían más pequeños, o sea todo esto y entonces a lo que se iban [los estudiantes] es a brindar información más bonita y no información más fidedigna (E2.CL.17)

Sobre las atribuciones de las respuestas de los estudiantes añade que es común que responda: "porque se ve bien, se ve bonito", "me gusta cómo se ve", "porque lo único que quiero es impactar visualmente", o simplemente porque "me quedó espacio en el papel". No hacen alusión a porque "quiero dar información sobre...". Para Luis no es un criterio informacional, es un criterio simplemente perceptual.

Esto mismo se vuelve a comentar en otro momento, cuando se le pregunta sobre ¿en qué afecta esta creencia de que lo visual y “bonito” es más importante? En este ejemplo, podemos apreciar que Luis manifiesta su preferencia hacia la elección de la representación gráfica en función de la naturaleza de los datos más que la importancia de lo visual que impacta más en los alumnos.

y como no se ha visto (incluso) la naturaleza propia de cada elemento de la gráfica, cuando ellos, por ejemplo consideran que es más importante un tamaño que un indicador de la naturaleza de ese tamaño, esto hace que de pronto elijan gráficas que sean visualmente más bonitas. Por ejemplo, siempre les digo "a mí no me gustan las gráficas de tercera dimensión, rotadas y demás porque siento que allí te vas por esos elementos" entonces me dicen "pero es que es más bonito, o sea le estás dando información visual agradable a quien lo lee" (E2.CL.17)

Piensa que todos esos elementos son distractores y que al incluirlos en el gráfico "podrían llevar a no centrarse en la información principal” (E2.CL.133)

Para corregir la creencia de que en un gráfico lo más importante en lo perceptual o lo visual (colores) Luis hace alusión a discutir acerca de: a) los usos que se le da a la información y b) la ética de la información. 
Con los números de la $R G$ se puede hacer lo que quieran. Luis afirma que los alumnos piensan que los números no son datos, sino números que sirven para hacer cálculos estadísticos.

Mira una de las cosas que he visto, que es lo que siento que más problema me da a mí en clase con Estadística es una tendencia que viene de la preparatoria [bachillerato] y quizá desde la secundaria (que ahora ya desde la primaria se está haciendo), que es que se toma el conjunto de números, y el conjunto de números se les hace Estadística, pero no son datos, son números (E2.CL.10)

Esto lleva a los alumnos a "hacer lo que quieran con ellos". Están acostumbrados a que de un conjunto de 20 números se " 'saca media, mediana, moda, haz un gráfico de...' y casi como si se pudiera pasar por todos ¿no? o sea, 'haz un pictograma, haz un histograma, haz un gráfico de barras' y todo para ver si lo sabes hacer, pero no tiene sentido hacerlos" (E2.CL.11). Nuevamente Luis hace referencia al sentido del gráfico que los alumnos pueden no comprender a consecuencia de esta creencia.

Luis atribuye nuevamente esta creencia inadecuada a que los estudiantes no logran entender la naturaleza del gráfico, es decir, el significado de "esos números", el contexto de donde emergen, la forma de obtener los datos, el tipo y características de la información que arroja y la selección y características de cada tipo de gráfico.

Los alumnos creen que mientras "más matematizable [sea] la medida, mucho más elaborada, es mejor" (E2.CL.46). El se refiere a "matematizable" al cálculo de valores numéricos a partir de las fórmulas estadísticas, sin pensar en el sentido de los datos y la argumentación a cada situación. Cuanto más complicado o sofisticado sea el gráfico es mejor, mientras más datos numéricos se tengan y que éstos sean el resultado de la aplicación de una fórmula matemática o estadística es mejor.

Lo anterior, lleva a los alumnos a insertar gráficos sin saber el sentido, significado, como si fuera una moda que hay que cumplir.

Ok. Si regresamos para allá, me iría otra vez al sin sentido que era representar datos. Tú podías hacerlo con chicles, histogramas, curvas, con lo que quisieras; la cosa era que los números cayeran adentro de algo. Es a lo que llegaba, de hecho me daba cuenta este año, que ellos sabían, o sea les podía mostrar un histograma, y que me dijeran "esto es un histograma", [les preguntaba] "¿cuáles son sus características?", ok, "las barras están unidas y la altura representa esto" [contestaban], o sea, que me dijeran perfectamente qué era, y dije "ah ok, entonces ... le pregunté a la gente su estado civil y los clasifiqué en gente casada y la representé a través de un histograma", me dijeron, "está perfecto". ¿Por qué?, porque los números están cayendo en eso y iya! No hay problema, y hacían un histograma perfecto, en el sentido de "perfecto" en cuanto a que si tú lo ves dices "hay altura, hay esto, tiene todo". [Ahora que] no tiene sentido, eso es cierto. ¿Por qué? porque esa era la dificultad básica. Ellos decían, "oye y por qué no seguimos con hacer una curva ojiva, y hacer esto, y hacer aquello", les digo "¿por qué?, ¿para qué la quieres?", o sea, el hecho de que era totalmente mecánico (E1.CL.171)

Esto preocupa mucho a Luis dado que tiene que ver con el significado y la toma de decisiones y que, desde el punto de vista pedagógico, se debe considerar la Estadística como una herramienta para tomar decisiones. 
Los gráficos son todos iguales. Por ello es posible representar un mismo conjunto de datos de diferentes maneras.

Precisamente a esta misma situación de que todos los gráficos son equiva... son iguales, se puede hacer todas las variables y el hecho de que estando trabajando en un programa de cómputo, simplemente seleccionar otro gráfico y se representa. O sea mal o bien, pero se representa. Entonces los gráficos se vuelven equivalentes, o sea no hay información representada sino hay simplemente un dibujo hecho. Lo me ha sucedido de pronto [que un alumno se me me presenta diciendo] "ah mira aquí hay uno que se llama radar", [le digo] "pero pues, ¿a ver qué pasa?", [pero el estudiante dice] "pues quien sabe". Se hizo una telaraña, pero no hay información allí que se esté leyendo. Simplemente ya está representado (E2.CL.49)

Agrega que es usual que el alumno utilice programas como Excel y SPSS y elabore un gráfico obteniendo diferentes representaciones sin sentido. Explica que el alumno no tiene en cuenta la información sobre la naturaleza de los datos y desconoce las características y tipos de gráficos.

Es información que hay que poner. Finalmente, otra creencia que Luis piensa que los estudiantes tienen es que cuando se les pide que construyan un gráfico utilizan todos sin tener en cuenta que algunos pueden no ser adecuados:

Siempre era "represéntalo" [como una instrucción y hay que hacerlo], pero no qué significaba cada elemento de la gráfica. Entonces esta falta de uso real de esa información ¿si? Y lo veo, porque incluso me pasa con algunos muchachos hacia el final [del curso] en sus reportes que de pronto veo [y le digo] "oye y para qué tanta gráfica, o sea por qué pusiste tantas, o sea de dónde vienen", [el muchacho contesta] "pues es que... como en tu reporte dice que se escojan aquellas gráficas y tablas que se consideren adecuadas para resumir la información, pues pusimos todas" le digo "sí, pero era poner las que consideres adecuadas para resumir la información, o sea te voy a evaluar si escogiste adecuadamente qué poner", [me dice el estudiante] "bueno no estoy... o sea no está de más aquí están números y aquí están gráficas", [le contesto] "pues no está de más, pero o sea... imagínate si te digo que tengo un espacio mínimo que cada hoja que me des cuesta, que no la puedo presentar, ¿cómo escoges cuál?". Ese... ese elemento allí está ¿no? de no usar la información, simplemente presentarla (E2.CL.48)

Lo importante aquí es insertar tablas o gráficos como si fuera una moda, por llenar espacio, sin tener los argumentos conceptuales para hacerlo.

En síntesis, la Tabla 5.8 presenta las diferentes creencias que Luis considera que tienen los estudiantes respecto a la RG, con su correspondiente atribución. Las causas de estas creencias son principalmente el desconocimiento de la naturaleza de los datos y de los elementos del gráfico. Luis no comentó que alguna creencia sea origen didáctico.

La primera creencia coincide con Tufte (1983) y Salkind (2000) quienes afirman que los estudiantes se dejan llevar por elementos de un gráfico que no son esenciales para la representación de datos, criterios engañosos o modelos ineficientes de técnicas gráficas como, por ejemplo, software (ej. hojas de cálculo y programas gráficos) que proporciona misteriosos embellecimientos pero superfluos para la presentación de información (ej. ofrecen muchas opciones, incluyendo ejes en tercera dimensión, color, pictogramas, y otras decoraciones no esenciales; formatos gráficos que son difíciles para interpretar). A estos elementos Tufte los denomina chartjunk. Para corregir esta creencia, Pittenger (1995) 
afirma que los estudiantes necesitan aprender los fundamentos de la construcción de los gráficos usados en la ciencia

Tabla 5.8. Relación del tipo de creencias y las atribuciones que Luis conoce de los estudiantes

\begin{tabular}{|c|c|c|c|c|}
\hline Caso & Gráfico & Objetivo & Creencia & Atribución \\
\hline $\mathrm{C}-1$ & $\begin{array}{c}\text { TyH } \\
\text { e } \\
\text { Histograma }\end{array}$ & $\begin{array}{l}\text { Seleccionar, criticar y } \\
\text { evaluar el gráfico }\end{array}$ & $\begin{array}{l}\text { Lo importante de la } \\
\text { representación gráfica: lo } \\
\text { bonito, visual, el color y } \\
\text { tamaño }\end{array}$ & $\begin{array}{l}\text { No comprende la naturaleza } \\
\text { de los datos del gráfico y se } \\
\text { basan en criterios } \\
\text { perceptuales }\end{array}$ \\
\hline C-1 & $\begin{array}{c}\text { TyH } \\
\text { e } \\
\text { Histograma }\end{array}$ & $\begin{array}{l}\text { Seleccionar, criticar y } \\
\text { evaluar el gráfico }\end{array}$ & $\begin{array}{l}\text { Con los números de la RG } \\
\text { se puede hacer lo que } \\
\text { quieran }\end{array}$ & $\begin{array}{l}\text { No comprenden la } \\
\text { naturaleza de los datos, las } \\
\text { características y el sentido } \\
\text { del gráfico y el contexto }\end{array}$ \\
\hline C-2 & Barras & $\begin{array}{l}\text { Definir una variable y } \\
\text { relacionar con el tipo } \\
\text { de gráfico }\end{array}$ & $\begin{array}{l}\text { Los gráficos son todos } \\
\text { iguales }\end{array}$ & $\begin{array}{lrr}\text { Experiencias } & \text { previas } & \text { de } \\
\text { aprendizaje y falta } & \text { de } \\
\text { conocimiento de } & \text { la } \\
\text { naturaleza de los datos } & \end{array}$ \\
\hline $\mathrm{C}-2$ & Barras & $\begin{array}{l}\text { Definir una variable y } \\
\text { relacionar con el tipo } \\
\text { de gráfico }\end{array}$ & $\begin{array}{l}\text { Es información que hay } \\
\text { que poner }\end{array}$ & $\begin{array}{l}\text { Falta de uso de la } \\
\text { información del contexto y } \\
\text { del significado de los } \\
\text { elementos del gráfico }\end{array}$ \\
\hline
\end{tabular}

La segunda y tercera creencia tienen que ver con los datos, a la idea de que la representación gráfica es sólo dar un "click" en el programa de informática y "jugar" probando diferentes diseños de gráficos y que dé lo mismo utilizar uno u otro, y se atribuye principalmente al desconocimiento de la naturaleza de los datos y de sus características. Luis afirma que se puede atribuir a experiencias previas en niveles escolares anteriores pues cuando se habla de gráficos se subestima su valor y se simplifican hasta considerarlos como que "es lo más fácil del mundo", o bien, "para qué se aprenderá, si por eso existe programas informáticos". En este sentido, también los profesores son responsables de la manera como se realiza la enseñanza de la RG en el nivel básico o elemental.

La última creencia tiene que ver con la falta de contextualización de los gráficos. Aunque Luis lo atribuye al desconocimiento por parte del estudiante, tanto del contexto como de los significados de los elementos del gráfico, también tiene su origen en la manera como se enseña la RG. Esto suele ocurrir si el profesor concibe la RG como técnica de graficación y pide al alumno que simplemente organice sus datos, los tabule y los represente. Los datos no proceden de información real y no se realiza el análisis de los mismos, su interpretación y escritura. El alumno por lo tanto, considera la necesidad de incluir gráficos sin saber si son o no adecuados. 


\subsubsection{Errores y dificultades}

Tal como se hizo en el caso de Alicia, a continuación se presentan los errores y dificultades en relación ocn las diferentes situaciones-problemas del cuestionario didáctico sobre RG.

Caso 1. Gráficos: tallo y hoja e histograma. Ante la afirmación de un estudiante en el C-1 de "Me cuesta trabajo discernir entre un gráfico de y otro, diferenciar qué grafico es el más adecuado para cada situación", Luis piensa que los alumnos no consideran desde el inicio el análisis de las escalas de medición (Cu.CL.1b.2) y eso les lleva a tener dificultades para discriminar entre un gráfico y otro. En este sentido, afirma que para él:

es el punto básico de trabajo en Estadística. Precisamente de la naturaleza de ese número, de ese dato, cada escala de medición te aporta información acerca de la naturaleza de ese dato y lo que puedes hacer con él. Al momento de no hacer referencia a la escala de medición, en ese momento ya no sabes hasta dónde puedes llegar con esa información (E2.CL.13)

Lo explica a través del siguiente ejemplo:

Cada vez que trabajamos, o sea el tema que sea, hasta parece repetitivo muchas veces en clase que es "¿cuáles son las variables implicadas?", "tal y tal", "¿qué escala de medición tiene cada una?", "¿son dicotómicas, son politómicas?", "alguna actúa como independiente o dependiente", o sea tratar de hacer todo ese análisis antes de hacer cualquier cosa, para mi es básico y sí muchas veces les resulta repetitivo de que al momento de que comienzo en clase a decir "bueno, ok, tal situación..." ya comienzan ¿no? o sea "es nominal, dicotómica" "bueno ok, pero ¿por qué?, porque entonces ya puedes saber qué vas hacer con ellos" (E2.CL.13)

De hecho es uno de los temas medulares que enfatiza mucho:

Desde que iniciamos, les decía "un tema básico para mi curso son las escalas de medición y ese sí va a ser, de que espérense que hasta el último día de clase que les pregunte, esta variable qué escala de medición tiene" [enfatizando la importancia de conocer sobre las escalas de medición a lo largo del curso escolar], y me decían, "¿y para qué?, o sea ¿para qué va a servir?". Entonces cuando llegábamos a representación gráfica: "bueno tiene que ver con la escala de medición”, o sea, comenzar a darles el sentido, porque precisamente lo que pasaba es que tuve gente que podía hacer "perfectamente" todo, pero "perfectamente" mal, o sea perfectamente todo en el sentido de que no tiene sentido alguno, pero tiene todas las características, para que si tú le presentas números, los números los represente pero esos números, yo les digo siempre "para un psicólogo representan algo, y ese algo puede tener naturaleza distinta; valores uno y dos, puede significar muchas cosas", o sea, allí está el momento de trabajo fuerte en la materia (E1.CL.172)

Las escalas de medición son otra forma de clasificación de los datos que está relacionada con la de variables (cualitativas y cuantitativas) y con la de variable discreta y continua. Las escalas clasifican los datos en función de su referencia temporal, o bien, a sus propiedades métricas (ej. tiempo y unidad de medida) y pueden ser: nominal, ordinal, intervalo y de razón. Algunos autores hacen referencia a éstas usando el término variables, con lo cual se pueden encontrar textos que hacen referencia a variables nominales, ordinales, de intervalo y de razón. Para Luis, saber y comprender los datos a partir de las escalas de medición les permitirá a los alumnos comenzar a conocer la naturaleza de éstos y posteriormente ver el tipo de representación gráfica que se necesita. 
Luis le atribuye principalmente este error al profesor, dado que es esencial que a través de su enseñanza resalte la importancia y el estudio de las escalas de medición en las clases.

Caso 2. Gráfico: barras. En este caso, Luis identifica varios errores. El primero que resalta es que los alumnos no le dan sentido a los datos y no son capaces de realizar argumentación. Generalmente los alumnos le dan mucho valor al cálculo a partir de las fórmulas. Habla de este sin sentido y de "hacer por hacer" sin comprender la razón y el significado de ello. Luis lo atribuye:

Más que nada al poco uso que le damos a esta información, porque yo lo veo muchas veces incluso cuando estoy estudiando clases de otras materias (no de metodología), que lo que son las tablas, lo que son los gráficos no se leen, o sea, lo que se lee es el texto y no es información que se analice y me doy cuenta incluso cuando lo discuto en academia [de profesores] que es información poco usada, pera también de pronto se pone como información obligatoria. Lo veo incluso en las tesis que de pronto te dicen bueno es que tienes tu lista de gráficos, tu lista de figuras, tu lista de tablas, pero "para qué pusiste la misma información en la tabla que en la gráfica", [contesta el estudiante] "porque me dijeron que había que poner, poner las dos" o sea, no es nueva información, no es un resumen de información es información que hay que poner, que no se analiza y no tiene un sentido específico ¿si? (E2.CL.47)

Según él, este "poco uso" de información tiene que ver con la poca o nula importancia que se otorga a la representación gráfica desde el del profesor de Estadística, hasta los colegas u otros profesores, y de los alumnos. Si no se le concede la importancia necesaria, no se pondrá particular atención a las implicaciones que tiene en la educación estadística del alumno y por consiguiente seguirá pensando que los gráficos son sólo para "hacer, cortar y pegar" en los informes, así como en "llenar" éstos con tablas y gráficos sin sentido ni fundamento.

Otro error que señala es que los estudiantes no interpretan el significado de gráficos, particularmente de aquellas gráficos no convencionales (ej. tallo y hoja y de caja). Comenta que la interpretación es el "talón de Aquiles" del estudiante y proporciona el siguiente ejemplo:

Por ejemplo estaba el fin de semana pasada dando un curso precisamente de Estadística. Tenía un grupo de muchachos del área de la salud (unos de Nutrición y otros de Medicina) y estábamos viendo las gráficas de caja y bigote. Precisamente por ellos, porque en el área de la salud es muy utilizada por lo que son los rangos, por lo que son los percentiles y demás. Es una medida utilizada con frecuencia, y me decían "es que las vemos pero nunca las hemos interpretado" y los cuatro que estaban allá están en servicio social, es decir, ya terminaron toda su formación y están en la última parte, cuando es un gráfica realmente utilizada con sentido en la Medicina, porque representa los percentiles, representa... o sea todo lo que tiene para ellos información está allí, o sea "ii nunca la interpretamos!!" (E2.CL.48)

Luis vuelve atribuir este error a que a los estudiantes se les dice "represéntalo" (como una instrucción) y "hay que hacerlo", pero no se aborda el significado de cada elementos o de los componentes estructurales del gráfico. Es necesario que el estudiante le vea el uso real de la información del gráfico. 
Además, señala que no entienden qué es una variable, por eso la confunden con el concepto de media. Este error se identificó a partir del C-2, ante la pregunta ¿cuál cree que puede ser la causa del posible razonamiento de Diego a esta actividad? Luis contestó:

En este ejemplo, no tener claridad sobre el concepto de variable y de medidas de centralidad, en su respuesta parece indicar que la "variable" es la media (Cu.CL.2b.1)

Luis afirma que Diego puede estar confundido al escribir como variable "media de altura", parece:

Que estuviera confundiendo tal vez al concepto de variable como media y no representar a la variable altura sino querer poner nada más un rasgo de la variable y entonces como tal aclarar esto; porque como tal en ese gráfico que está él escogiendo no se representa una media, no hay ningún elemento de allí que me muestre una media. Me podría mostrar tal vez la moda, me podría mostrar tal vez la mediana, pero no me podría representar una media. Pero quizá allí lo que está como problema es el concepto de variable (E2.CL.41)

Insiste que el alumno al no tener claro el concepto de variable, decide incorporar en su respuesta la media, porque ésta puede representar para él lo más habitual, lo visto en cursos anteriores. De hecho, el tema de las medidas de tendencia central (ej. la media) es uno de los más vistos en Estadística. Por otro lado, Luis relaciona las características que deben tener una variable (discreta) para diseñar un gráfico de barras, por eso hace mención a que no se "podría representar una media" para ese tipo de datos.

Para él [Diego] en esa frase lo que está poniendo como importante más que nada, lo que está poniendo como importante, representar la media, pero no ¿la media de qué?, o sea en esa frase parece estar más... o sea mi interpretación era como que una preocupación porque [como que piensa el estudiante] "en esta gráfica tengo que representar este dato de la media", pero no la naturaleza completa de una variable, no la naturaleza completa de la altura y al no entender claramente el concepto de información de la variable, al no entender claramente que lo que se quiere representar es la altura de algo, la altura de las personas... (E2.CL.44)

Pudimos apreciar que en la respuesta que da Luis, identifica otro error por parte de los alumnos que está relacionado con entender el por qué un estudiante como Diego tiene este tipo de dificultades en la representación del gráfico, que es el relativo al desconocimiento de las características de los gráficos.

Sobre la justificación de Diego, de utilizar un gráfico de barras para representar "la media de altura", Luis afirma que "quizá está relacionada más con 'equivalencia' entre los gráficos" (Cu.CL.2b.2). Al respecto explica:

Precisamente a esta misma situación de que todos los gráficos son equivalentes, son iguales, se puede hacer todas las variables ... (E2.CL.49)

En este sentido le llamó la atención cómo Diego menciona "porque se ve bien". Esto tiene estrecha relación con la creencia de que los gráficos son todos iguales. Al alumno "le da lo mismo" elegir uno u otro indistintamente, porque piensa que lo importante es la representación en sí misma, sin entender ni importar el significado. 
Otra dificultad que tienen los estudiantes es la de distinguir cuándo se deben representar las barras separadas (gráfico de barras) y cuándo no (histograma), es decir, distinguir el "espacio" entre las barras y el histograma.

"¿Qué representa el ancho”" generalmente "no pues que no tiene ningún sentido, la puedo hacer delgada, la puedo hacer ancha, no, no pasa nada" (E2.CL.39)

La pregunta que generalmente tienen problema es la siguiente, la de "¿qué representa el espacio?" o sea dicen "se deja, ... es parte de la gráfica" "pero si se queda, si estamos... ¿por qué no ponerlas juntas?" ah entonces [dice el estudiante] "bueno es que si las pones juntas ya es un histograma", [contesta el profesor] "bueno entonces qué diferencia hay entre este que dejas los espacios y estos que no" . En ese momento que comienzas con ese cuestionamiento bueno "es que si esta es una variable que no es continua quizá lo que está haciendo es que no puedan estar juntas las categorías". Precisamente ir hacia ese punto, hacia la discontinuidad al momento de ... (E2.CL.40)

Asegura que el alumno no considera la naturaleza de los datos y las características del gráfico, por eso desconoce "qué sentido tiene dejar espacio o no entre las barras" (E2.CL.36). Remarca la importancia de que al principio (de la clase sobre RG) se comience con el estudio de todos los elementos del gráfico, su sentido y significado (E2.CL.34).

Caso 3. Gráfico: histograma y circular. En este caso se analiza la identificación del error y las atribuciones que Luis encuentra a las respuestas equivocadas de dos estudiantes (Omar y María).

El primer error que Luis identifica a partir del caso es que los estudiantes desconocen el significado de las barras del gráfico, así cuando se le pregunta ¿por qué Omar da esa respuesta? (en el C-3, inciso c) señala:

Desconoce el significado de las barras en este tipo de gráfico (Cu.CL.3ciO.1)

Sí, lo que pasa que él [Omar] está diciendo que hay siete ciudades representadas entonces lo que él está viendo cada una de las barras como un caso particular, como una ciudad particular y no como la frecuencia que tiene un porcentaje de alfabetización. El está aquí entendiendo que lo que pasó en la primera ciudad es la primera barra, lo que pasó en la segunda ciudad... entonces allí es...(E2.CL.97)

Según Luis, Omar considera “cada una de las barras como una ciudad particular” y la principal atribución es que contó las barras y atribuye esta confusión a:

En la situación no hay ningún elemento que indique cuántas ciudades son. El está diciendo que son siete ciudades, entonces al ver siete barras, infiriendo allí siete ciudades que no está dicho en ninguna parte que son siete o que es un número particular de ciudades isi? (E2.CL.98)

Luis identifica correctamente el error de Omar y también logra establecer la razón de su error (contar las barras como ciudades).

En esta misma situación-problema, Luis manifestó otro error del estudiante: confundir conceptos como caso, variable, frecuencia:

... está confundiendo el concepto de caso, de variable y de frecuencia, o sea el caso como la ciudad, la variable que sería el porcentaje de alfabetización y la frecuencia, entonces allí está... él está 
confundiendo estos tres elementos. Entonces cada barra para él es una ciudad en ese lugar (E2.CL.97)

Luis no profundiza al respecto, sólo se limitó a repetir nuevamente que "al ver siete barras, infirió siete ciudades". No obstante, su respuesta tiene clara intención de hacer notar que la variable del C-3 es "porcentaje de alfabetización" y la frecuencia es representada de otra manera, diferente a la cantidad de ciudades a la que hace alusión Omar.

Sobre la conclusión de María, Luis respondió que ella no entiende la información que representa los ejes (Cu.CL.3ciM.1) y lo justifica de la siguiente manera:

¡Ah bueno! del 45 al 50\% de las mujeres alcanzan un nivel de uno, un nivel de tres, pero aquí al hablar de la frecuencia, el decir "un nivel de..." pareciera que existen niveles de alfabetización que están dados y que cada uno de esto que está acá [señala el gráfico] aunque esté el dato de que es una frecuencia, no está usando el concepto frecuencia sino está usando este "nivel". Pareciera que es nivel de alfabetización (E2.CL.99)

por otra parte del 45 al 50\% de las mujeres eh... lo que veo aquí 45 al 50\%, pero aquí lo que se está representando es el porcentaje de alfabetización, no porcentaje de mujeres. Entonces está confundiendo aquí otra vez el concepto de lo que se está representando con los casos. Entonces ella está diciendo que lo que está aquí representado es un porcentaje de mujeres, no la variable alfabetización, eso es lo que está aquí pasando (E2.CL.100)

Según Luis, para María "pareciera que existen niveles de alfabetización”, dado que no analiza la situación y no identifica las variables y por lo tanto no es capaz de darle el significado correcto. Asimismo, María relaciona "porcentaje de alfabetización de mujeres" con el porcentaje de alfabetización de la mujer adulta porque:

Siento que un primer caso estaría en una falta de análisis de la situación, de identificar claramente cuáles son las dos variables o la variable que se está representando y cómo se está representando, que en este caso sería la frecuencia (E2.CL.101)

Y al hablar de porcentaje creo que está remitiendo inmediatamente que lo que se representa siempre son casos y no se puede representar otra cosa por medio de porcentaje. Entonces al decir "porcentaje de alfabetización de mujeres" allí está pensando que el porcentaje son las mujeres, no el grado de alfabetización (E2.CL.102)

Como podemos apreciar, Luis también hace mención a una falta de análisis de la situación del contexto y la confusión entre los casos (la cantidad de mujeres que participaron en el estudio) y la frecuencia del porcentaje de alfabetización que aparece en el histograma.

Al preguntarle por qué piensa que el estudiante (en el inciso $d$-i) elige el gráfico circular como mejor forma de representar los datos, Luis señaló que "estaría confundiendo los datos pues no se refiere al porcentaje entre personas sino al porcentaje que cada mujer ha adquirido" (Cu.CL.3di.1):

Lo que estaría pasando en esta frase del "porcentaje de la alfabetización de la mujer adulta", que es un poco lo que María estuvo pensando, habría esta confusión entre el porcentaje de mujeres y el porcentaje de alfabetización, que pensara que el circular al representar mejor al conjunto total de 
datos entonces vamos a tener a todas las mujeres representadas en un lugar, y al hacer el análisis de que realmente es, cada mujer tiene un porcentaje de alfabetización, es decir, no es en relación a otro sino es en relación a sí misma, entonces ya no habría forma de ponerlas juntas en esa situación. Entonces tendríamos que ir analizando eso, o sea, esa distinción entre los dos porcentajes (E2.CL.110).

En este caso, Luis piensa que el estudiante relaciona el gráfico circular con los porcentajes, pero en vez de fijarse en que se trata de datos que representan las posibles ciudades que participaron en el estudio, cree que se tienen los porcentajes individualizados de alfabetización de cada mujer. El error que se identifica es que no tiene claro la naturaleza de los datos para un gráfico circular.

Luis cierra el análisis del C-3, enfatizando que la clave para una situación como ésta es insistir con los estudiantes en "¿cuál es la variable que estás representando?, ¿cómo se llama?, ¿qué es lo que estás queriendo decir" (E2.CL.103), así como darle sentido real a lo que se está representado, no ponerlo como una representación estática, sin significado. Atribuye que muchos de estos errores se deben a que "pocas veces se interpreta una gráfica" en las clases de Estadística, que la RG se concibe como "un resumen que está allí" pero no se obtiene nada de la gráfica. El mismo reconoce que es algo que no ha hecho con sus alumnos (darle significado a la información del gráfico).

Caso 4. Gráfico: comunicación impresa (media graph o print graph). Un error que los estudiantes cometen al criticar un gráfico es centrarse exclusivamente en el análisis de los elementos y datos del gráfico, es decir, identifican los valores absolutos o los datos con cantidades mayores y se centran únicamente en ellos para comprender el gráfico, dejando a un lado otros factores fundamentales como el propósito, el contexto, el tipo y tamaño de datos, el tipo y complejidad del gráfico y los componentes estructurales. Luis identificó este error cuando se le preguntó en $\mathrm{C}-4$ ¿qué interpretaciones le darían los estudiantes al criticar el gráfico?:

Se basarían más en las cantidades que en el gráfico (Cu.CL.4bi.1)

O sea estas cantidades que están (el 11, 32 y 50\%) ... al interpretar y evaluar el gráfico creo que sería lo más llamativo dentro del gráfico, o sea lo que en ese momento ellos verían como dato, dirían "bueno se está dando esa información, con esa información podemos tomar conclusiones, se puede decir que el $50 \%$ tarda menos de 20 minutos en viajar". Eso llevaría a que no se evaluaran otros elementos inmediatamente, se vería como que la información está dada a través del número (E2.CL.130)

Ahora al hablar de la proporción es que precisamente al estar esta información ya dada en los números no se requeriría observar como tal la línea, no se requeriría tampoco represen... revisar el orden entre los intervalos (E2.CL.131)

En otras palabras, los alumnos hacen una lectura literal del gráfico, pero no van más allá de los datos ni lo que está detrás de ellos (ej. análisis del contexto).

Por último, Luis comentó otro error que los estudiantes pueden tener al interpretar un gráfico como el del C-4, que es hacer poco caso a los errores en el diseño del media graph. Por ejemplo, al tratarse de un media graph, Luis observa que el estudiante puede 
dejar a un lado el análisis de las proporciones de las líneas (Cu.CL.4bi.2). Expresa que el gráfico tiene errores en cuanto a que no hay una proporcionalidad en las líneas $(11 \%, 32 \%$ y $50 \%)$.

De que por ejemplo... como la línea de $11 \%$ es más pequeña de la de 32 , aunque no representa una proporción específica de 11 a 32, al ser más pequeña esté correcta ¿si? Aunque específicamente no es una línea que representa el 11\% de... dentro de esa... (E2.CL.132)

En el gráfico, Luis piensa que existe un error en las proporciones de las líneas que representan los porcentajes, debiendo estimar con otra longitud los porcentajes representados o el recorrido de los coches que aparecen.

lo que parecería que los alumnos en esta situación estarían basándose más en la información numérica más que en la información gráfica. Entonces se perdería la intención de la representación gráfica (E2.CL.126)

Piensa que el alumno da por sentado que el gráfico es correcto por el hecho de haberse publicado en algún medio de comunicación impresa, deja a un lado este tipo de análisis y se centra solamente en las cantidades representadas con un tamaño de letra mayor, que puede "llevar a no centrarse en la información principal" (E2.CL.133) y hacer que el lector tenga una apreciación equivocada o sesgada de la interpretación del gráfico.

A través de las respuestas que dio Luis en cada una de las situaciones-problemas clasificamos los errores en cuatro grupos: a) errores por ignorancia o desconocimiento de conceptos previos, b) errores de reconocimiento y comprensión de la información del gráfico, c) errores en la comprensión de conceptos y d) errores relacionados con el contexto. Como se podrá observar, una misma categoría puede ubicarse en otra, o bien, estar íntimamente relacionada con otros errores. Esto es dado que los errores y dificultades tienen como característica común que tienen que ver con el estudio de la RG a partir diferentes situaciones-problemas interconectados por preguntas que buscaban identificarlos a través de diferentes contextos y tipos de gráficos. A continuación se describen brevemente estos grupos:

a. Errores por ignorancia o desconocimiento de conceptos previos. Este tipo de errores tienen relación con la falta de conocimiento del estudiante sobre conceptos específicos que se necesitan para resolver el problema relacionado con la RG. Aquí se agruparon los siguientes:

- no consideran desde el inicio el análisis de las escalas de medición,

- no entienden qué es una variable,

- no identifica las variables,

- desconocimiento de las características de los gráficos,

- desconocen el significado de las barras del gráfico,

- no entiende la información que representa los ejes, y

- no tiene claro la naturaleza de los datos para un gráfico circular. 
Específicamente desconoce conceptos como escalas de medición, variable, características de los gráficos, significado de barra y ejes.

b. Errores de reconocimiento y comprensión de la información del gráfico. Se trata de errores relacionados con la falta de apreciación, observación y comprensión de los elementos o componentes estructurales del gráfico:

- hacer poco caso a los errores en el diseño del media graph.

Específicamente el error fue desestimar los elementos del media graph.

c. Errores en la comprensión de conceptos. Aquí se ubican aquellos que tienen que ver con errores de carácter conceptual, es decir, el estudiante tiene un concepto equivocado o inadecuado:

- distinguir cuándo se deben representar las barras separadas (gráfico de barras) y cuándo no (histograma) y

- confundir conceptos como caso, variable, frecuencia.

Específicamente, Luis identifica los siguientes conceptos: caso, variable, frecuencia, porcentaje, rectángulos discontinuos (gráfico de barras), rectángulos continuos (histograma).

d. Errores relacionados con el contexto. Se agrupan los errores relacionados con la identificación, comprensión y uso de la información del contexto de la situación de donde se originan los datos, como es el problema de investigación:

- no le dan sentido a los datos y no son capaces de realizar argumentación,

- no interpretan el significado de gráficos,

- centrarse exclusivamente en el análisis de los elementos y datos del gráfico, $\mathrm{y}$

- falta de análisis de la situación del contexto.

Específicamente se habla de información del contexto, de los significados y sentido de los datos.

Esta clasificación nos permite identificar claramente:

a) Lo que no conoce el estudiante: escalas de medición, variable, variable continua, variable discreta, características de cada gráfico.

b) Lo que no observa de los elementos del gráfico: los elementos del media graph.

c) Lo que confunde: diferencia entre caso, variable, frecuencia y porcentaje; diferencia entre los rectángulos de un gráfico de barras y del histograma. 
d) Lo que no considera del contexto: sentido de los datos, argumentación, interpretación, análisis del contexto.

Si contrastamos estos errores, en cuanto a los cuatro factores críticos que influyen en la comprensión gráfica (Friel, Curcio y Bright, 2001), Luis considera principalmente errores relacionados con el primero (los propósitos para usar gráficos) y el cuarto (las características del lector) a partir del inciso (d) que tratan de los errores relacionados con el contexto. No identifica errores que tienen que ver con las características de las tareas (descodificación visual del gráfico, taxonomía para analizar las capacidades a desarrollar en las tareas sobre graficación, niveles cognitivos, contexto del problema) y las características de la disciplina (tipo y tamaño de datos y complejidad gráfica).

De los elementos o componentes estructurales (Friel, Curcio y Bright, 2001), Luis identifica errores relacionados principalmente con el armazón (ej. ejes, escalas, coordenadas, marcas de referencia) y etiquetas (ej. categorías de las barras, frecuencia, porcentajes). No menciona o no considera errores en cuanto a especificadores (dimensiones visuales utilizadas para representar los datos) y de fondo (algún color, coordenadas y cuadro sobre el cual el gráfico puede ser sobrepuesto).

Podemos observar también que los errores que más menciona son conceptos que están relacionados con los conocimientos previos que el alumno debe tener para estudiar la RG: variable, tipos de variables, definición de variable, características de los gráficos. Asimismo incorpora errores que tienen que ver con el sentido de los datos, argumentación, interpretación, análisis del contexto.

La Tabla 5.9 nos presentan otra mirada a los errores y dificultad que Luis señaló y sus correspondientes atribuciones. Sólo en los tres primeros Luis atribuye el error al profesor y la manera como aborda la enseñanza de la RG en el aula. Los demás errores son atribuidos al estudiante. Luis argumenta que muchas veces el profesor no pone énfasis en las escalas de medición, o bien porque desconoce la relación que tiene con el programa y específicamente con la RG. Afirma que el profesor puede no estar dando el valor necesario a la RG y presenta una clase centrada en las técnicas de graficación sin abordar el análisis e interpretación. 
Tabla 5.9. Relación del tipo de errores y dificultades y las atribuciones que conoce Luis de los estudiantes a partir del cuestionario

\begin{tabular}{|c|c|c|c|}
\hline Caso & Gráfico / Objetivo & Error & Atribución(es) \\
\hline $\mathrm{C}-1$ & $\begin{array}{l}\text { TyH e Histograma } \\
\text { Seleccionar, criticar } \\
\text { y evaluar el gráfico }\end{array}$ & $\begin{array}{l}\text { 1. No consideran desde el inicio el } \\
\text { análisis de las escalas de medición }\end{array}$ & $\begin{array}{l}\text { Falta de énfasis y estrategia } \\
\text { del profesor }\end{array}$ \\
\hline \multirow[t]{5}{*}{$\mathrm{C}-2$} & \multirow{5}{*}{$\begin{array}{l}\text { Barras } \\
\text { Definir una variable } \\
\text { y relacionar con el } \\
\text { tipo de gráfico }\end{array}$} & $\begin{array}{l}\text { 2. No le dan sentido a los datos y no son } \\
\text { capaces de realizar argumentación. }\end{array}$ & $\begin{array}{l}\text { Poca importancia concedida } \\
\text { del profesor en sus clases }\end{array}$ \\
\hline & & $\begin{array}{l}\text { 3. No interpretan el significado de } \\
\text { gráficos }\end{array}$ & $\begin{array}{l}\text { El profesor enfatiza en la } \\
\text { construcción de gráficos y no } \\
\text { aborda los significados }\end{array}$ \\
\hline & & 4. No entienden qué es una variable & $\begin{array}{l}\text { Confunde la variable con el } \\
\text { concepto de media y decide la } \\
\text { media por ser conocida }\end{array}$ \\
\hline & & $\begin{array}{l}\text { 5. Desconocimiento de las características } \\
\text { de los gráficos. }\end{array}$ & $\begin{array}{l}\text { Pensar que todos los gráficos } \\
\text { con iguales }\end{array}$ \\
\hline & & $\begin{array}{l}\text { 6. Distinguir cuándo se deben representar } \\
\text { las barras separadas (gráfico de barras) y } \\
\text { cuándo no (histograma), }\end{array}$ & $\begin{array}{l}\text { No se tiene el significado de } \\
\text { los datos y las características } \\
\text { del gráfico }\end{array}$ \\
\hline \multirow[t]{6}{*}{$\mathrm{C}-3$} & \multirow{6}{*}{$\begin{array}{l}\text { Histograma y circular } \\
\text { Interpretar, describir } \\
\text { y evaluar el gráfico }\end{array}$} & $\begin{array}{l}\text { 7. Desconocen el significado de las } \\
\text { barras del gráfico, }\end{array}$ & Cuenta las barras \\
\hline & & $\begin{array}{l}\text { 8. Confundir conceptos como caso, } \\
\text { variable, frecuencia }\end{array}$ & No comprende los conceptos \\
\hline & & $\begin{array}{l}\text { 9. No entiende la información que } \\
\text { representa los ejes }\end{array}$ & Ignorancia de los conceptos \\
\hline & & 10. No identifica las variables & Ignorancia del concepto \\
\hline & & $\begin{array}{l}\text { 11. Falta de análisis de la situación del } \\
\text { contexto }\end{array}$ & $\begin{array}{l}\text { No identifica, ignora o usa } \\
\text { información del contexto }\end{array}$ \\
\hline & & $\begin{array}{l}\text { 12. No tiene claro la naturaleza de los } \\
\text { datos para un gráfico circular. }\end{array}$ & $\begin{array}{l}\text { Ignorancia de las } \\
\text { características del gráfico }\end{array}$ \\
\hline \multirow[t]{2}{*}{$\mathrm{C}-4$} & \multirow[t]{2}{*}{$\begin{array}{l}\text { Media graph } \\
\text { Criticar y evaluar el } \\
\text { gráfico }\end{array}$} & $\begin{array}{l}\text { 13. Centrarse exclusivamente en el } \\
\text { análisis de los elementos y datos del } \\
\text { gráfico. }\end{array}$ & Lectura literal de los datos \\
\hline & & $\begin{array}{l}\text { 14. Hacer poco caso a los errores en el } \\
\text { diseño del media graph. }\end{array}$ & $\begin{array}{l}\text { Se da por sentado que los } \\
\text { media graph son correctos }\end{array}$ \\
\hline
\end{tabular}


Del tipo y atribuciones de los errores, estos son diversos y pueden encontrarse en diferentes gráficos y para diferentes objetivos de aprendizaje (ej. para seleccionar, evaluar y criticar un gráfico; definir una variable y relacionarlo con el gráfico; interpretar, describir y evaluar un gráfico). No obstante, encontramos los siguientes:

- En el C-1 y C-2 hizo referencia en el desconocimiento del estudiante del concepto de variable.

- En el C-1 y C-2 la atribución que le da es por el profesor, por una creencia equivocada y por el desconocimiento del concepto de variable. Estos casos tiene que ver con la discriminación entre un gráfico y otro, y la relación variable-tipo de gráfico.

- En el C-3 se identifican mayores errores atribuibles al desconocimiento de conceptos.

- En el C-3 y C-4 se hace referencia a algunos errores referentes al contexto.

- En el TyH e histograma se resaltó el error por desconocimiento de las escalas de medición.

- En el gráfico de barras se resaltó el error por desconocimiento del concepto de variable, de las características del gráfico y la distinción de los rectángulos (del gráfico de barras y del histograma).

- En el histograma (del C-4) se habló de la confusión de varios conceptos (caso, variable, frecuencia, porcentaje, ejes) y del análisis del contexto.

- Del media graph, el error se produce por fijarse sólo en los valores que resalta el gráfico y dar por sentado que los gráficos publicados son correctos.

Los errores y dificultades encontrados por Luis coinciden con algunos identificados en la literatura:

1. interpretar el contenido de los gráficos, además de la incapacidad de procesar la información contenida en ellos de forma coherente (Batanero, 2001b),

2. interpretar gráficos en los niveles superiores (ej. leer entre datos, leer más allá de los datos y leer detrás de los datos) (Batanero, 2001b, Shaughnessy, 2007),

3. elegir escalas de representación poco adecuadas para el objetivo predeterminado (Batanero, 2001b; Wu, 2004),

4. relacionados con el título, etiquetas, especificadores y tipo de gráfico (Wu, 2004),

5. confusión entre frecuencia y valor de los datos (Wu, 2004),

6. relacionados con el uso de la información dada en el gráfico (Wu, 2004),

7. relacionados al uso del contexto, (Wu, 2004), y los

8. alumnos hacen lecturas de dato a dato privilegiando los máximos y mínimos y realizan descripciones cualitativas de cómo cambia algo aduciendo que sube o baja (Dolores y Cuevas, 2007).

Además, Luis identificó los siguientes:

- no entienden qué es una variable y la diferencia entre discreta y continua,

- desconocimiento de las características de los gráficos,

- desconocen el significado de los rectángulos del gráfico de barras, 
- no entiende la información que representa los ejes,

- no tiene claro la naturaleza de los datos para un gráfico circular,

- hacer poco caso a los errores en el diseño del media graph,

- distinguir cuándo se deben representar las rectángulos separadas (gráfico de barras) y cuándo no (histograma), y

- no le dan sentido a los datos y no son capaces de realizar argumentación.

\subsubsection{Identificación y diagnóstico del conocimiento del estudiante}

Luis utiliza dos estrategias en la identificación y diagnóstico del conocimiento del estudiante: el diálogo e interacción acompañado siempre por preguntas:

Lo que pasa es que realmente, como estamos en constante diálogo en el salón de clase, precisamente es el momento en el que estoy yo evaluando eso. ¿Por qué?, porque lo que hago es que mientras están resolviendo algo (p.e. un ejercicio), estoy interactuando con ellos, o sea, no sé, Maru "oye y, entonces, ¿cuál sería la decisión?" "tal cosa”, "pero Juan, y la hipótesis y la frase estadística, ¿cómo estaría establecida?" (E1.CL.164)

Entonces en ese momento trato de que durante las clases, durante una semana, todos hayan sido interpelados por mi cuando menos una vez. No es un proceso de que yo agarro la libreta y estoy apuntando cuantas veces, sino que trato de hacerlo en una dinámica, de tal modo que realmente que ellos sientan que estamos trabajando en conjunto. Eso es lo que yo quiero (E1.CL.165)

Con frecuencia, utiliza la interacción con sus alumnos para explorar los errores y dificultades que presentan en los diferentes tópicos que aborda en sus clases. Este diálogo e interacción es permanente durante todo el curso y sobre todo en los trabajos en equipo, el proyecto de investigación y los estudios de casos que realizan sus alumnos. Constantemente utiliza preguntas en diferentes momentos (ej. presentación de avances delante del grupo y en asesoría individual o grupal). Un aspecto positivo de estas estrategias es que siempre busca interpelar a cada alumno para explorar sobre su proceso de aprendizaje.

\subsubsection{Estrategias específicas para corregir errores y dificultades}

En cuanto a las estrategias que utiliza para corregir los errores y dificultades de los estudiantes utiliza dos: preguntas e instrucciones. A continuación presentamos los resultados más relevantes.

\subsubsection{Preguntas}

Para ayudar al estudiante a discriminar entre un gráfico y otro $(\mathrm{C}-1)$, además de utilizar "instrucciones" concretas (indicaciones verbales durante la clase) con manipulación de las bases de datos generadas de los cuestionarios, utilizaría las siguientes preguntas:

entonces a partir de eso "vamos a ver, la propuesta de este grupo es hacer un histograma de esta manera, ponerle... ¿qué ventajas tiene?" , [los estudiantes dicen] "bueno es que se representa la continuidad o no se representa la continuidad..." e irles haciendo preguntas muy específicas "¿qué está representado en el eje Y?, ¿qué está representado en el eje X?, ¿qué representa la altura?" o sea esta clase de preguntas directas acerca de la naturaleza del gráfico. Muchas veces aparecen por ejemplo, el eje tiene diferentes cambios de los intervalos, entonces [les digo] "vamos a ver ¿qué pasa 
si el incremento mínimo lo cambiamos?, ¿qué pasa si lo aumentamos?, ¿qué información se da de más?" Esto es parte de lo que jugaríamos (E2.CL.21)

En el C-2, mencionó las siguientes preguntas con el propósito de determinar si para el alumno (Diego) las dos alturas se refieren a lo mismo, así como entender a qué se refiere con esa variable:

Primero... ¿Cuál es la variable y el nivel de medición? (Cu.CL.2a.4)

¿Qué representan la altura de las barras? (Cu.CL.2a.1)

¿Qué representa el ancho de las barras? (Cu.CL.2a.2)

¿Qué representa el espacio entre las barras? (Cu.CL.2a.3)

Estas preguntas y las expresadas en el C-1, están centradas en los especificadores o los elementos que tiene el gráfico. Luis afirma que "todos los elementos dentro del gráfico tienen un sentido, tienen un significado" (E2.CL.34) y que es fundamental explorar primero cuál es éste para los estudiantes.

Entonces al preguntarles "¿qué representa la altura?" es ver la naturaleza de ese elemento, ver que quede muy claro (precisamente lo que te decía): que no es una representación bonita, es una representación resumen y que cada elemento resume algún dato (E2.CL.34)

Entonces para cada uno de los gráficos cuando lo analizamos trato de hacer preguntas específicas acerca de los elementos mínimos que deben conocer de ese gráfico en particular (E2.CL.35)

Por ejemplo en el gráfico de barras, una de las de las cosas que (me parece) siempre me encuentro que es muy claro para ellos qué representa una altura, si tiene significado o no el ancho, qué representa cada uno de los ejes, pero no la naturaleza del espacio entre las barras; o sea, qué sentido tiene dejar espacio entre las barras (E2.CL.36)

Su principal objetivo es guiar al alumno a través de estas preguntas hacia cuestiones como: si la naturaleza de la variable se mantiene al representarla, si no perdió información o si ganó información (E2.CL.37)

En el C-2 nuevamente Luis afirma que a través de las preguntas corregiría el error de Diego:

Primero creo que aquí tendría que preguntarle otra vez "¿qué quieres representar?" y ver un poco qué es lo que quiere, quiere representar la media [por ejemplo], [le contestaría] "¿la media de qué?" o [me puede decir el alumno] "quiero representar la altura", [le diría] "si vas a representar la altura... en tu respuesta decías que es la media de la altura", [el alumnos diría] "sí pero ...". O sea ver qué quiere decir él con esta respuesta de la media de la altura (E2.CL.51)

Ya después de aclarar precisamente qué es una variable, otra vez [preguntarle] "¿cuál sería la naturaleza de esa variable?, ¿dónde comienzas?, ¿dónde terminas?, o sea ¿tu altura de quiénes son?", [me pueden contestar] "bueno de los niños de primaria", eh... [les diría] "¿cuál sería tu altura mínima?, ¿tu altura máxima?, ¿qué quieres decir de ellos?" (E2.CL.52)

Después pedirle "bueno vamos a representarlo de varias maneras" y entonces pedirle, por ejemplo proyectar las tres representaciones que escojamos en ese momento y decirle "bueno en esta gráfica de 
pastel [circular], ¿qué información tienes?" entonces me dice "bueno pues que parece que el 30\% tiene algo", [les diría] "pero bueno, ¿qué información se estaría perdiendo?". (E2.CL.53)

Las preguntas están orientadas al conocimiento y significado de los conceptos y a explorar la naturaleza de los datos y los elementos o componentes estructurales del gráfico. El propósito va encaminado a aclarar los conceptos que tiene el alumno, saber qué información conoce y determinar en qué se confunde (Cu.CL.2c.3).

Cuando está recibiendo el reporte estadístico de un proyecto de investigación, en la asesoría les hace igualmente preguntas, las cuales están centradas en el significado de las variables representadas, la relación con el cuestionario (que utilizaron los estudiantes) y cuestiones de forma o estructura del gráfico (según los lineamientos de la APA):

Entonces en ese momento es cuando estamos... como lo traen impreso ya en la computadora, entonces [les dice, por ejemplo] "bueno aquí pusieron este" que... o sea yo les digo "bueno qué están diciendo acá", [ellos pueden decir] "o sea es que esto era lo que queríamos decir de la variable", [les pregunto] "el cuestionario qué dice", [ellos vuelven a contestar] "se le preguntó tal cosa", [les digo] "bueno ok, ¿lo están diciendo aquí? ¿se está representando?" y se ven incluso algunos errores del propio estilo de presentación en el manual de publicaciones [APA]. Esas son cosas que ya haríamos con cada equipo, no se haría frente al salón de clase en ese momento. (E2.CL.58)

Para corregir el error de Omar (C-3) también utiliza una pregunta: "qué representan cada barra y su altura" (Cu.CL.3ciiO.3) después de explorar qué es cada eje.

Ante la pregunta ¿qué harías ante la respuesta de un estudiante que afirma que es mejor el gráfico circular para representar los datos del histograma? Luis contestó "Aclararía lo que representa ese porcentaje" (Cu.CL.3dii.1) de la siguiente forma:

Pues precisamente haríamos este análisis ¿no? de que por ejemplo cuando estoy hablando del porcentaje de alfabetización... "¿qué es eso?... o sea es qué tanto ya sabe leer y escribir María?" "Ok, ella puede tener un nivel... bueno cuando digo que tiene $40 \%$, significa qué cosa" o sea entonces ahora es ella que tiene un $40 \%$, un $60 \%$ ique no!, ok. (E2.CL.111)

Ella ya es un todo, ahora requieres poner aquí en este gráfico si lo representarías aquí junto con las demás ¿esta información que tienes de María seguiría allá o ya la perdiste?, o sea estaríamos tratando de ver estos porcentajes (E2.CL.112)

Las preguntas que estarían dirigidas a conocer los significados de María sobre algunos elementos del gráfico.

Para cada situación-problema Luis utilizaría una gran diversidad de preguntas, no obstante, se trata de preguntas encaminadas a explorar los significados que tiene el estudiante de los elementos del gráfico, de algunos conceptos y qué haría el estudiante ante situaciones hipotéticas en la construcción del gráfico.

Además de las preguntas en ocasiones utiliza explicaciones breves a manera de integración y síntesis:

O sea ir en ese análisis de cada una e ir recordando [diciéndoles] "bueno lo que querías decir era esto, está allí o no está" y una vez que hagamos este análisis hacer una aclaración [síntesis] de "bueno este 
gráfico se utiliza mejor... se utiliza para estas situaciones, este gráfico para otras". Pero primero hacer ese análisis de qué información se está brindando (E2.CL.54)

Estas explicaciones generalmente van acompañadas de un análisis a manera de discusión con el apoyo de más preguntas.

\subsubsection{Instrucciones}

Las instrucciones que utiliza Luis como estrategia para corregir los errores del estudiante tienen diferentes modalidades:

\section{- Ejecutar o realizar la representación}

Ante la preguntas ¿qué haría para ayudar al estudiante a ver sus errores e inducirlo a aprender a discernir entre un gráfico TyH y del histograma?

Primero establecería con él qué información se pretende dar (Cu.CL.1cii.1)

Y propone el siguiente ejemplo:

Por ejemplo, tomar una variable continua, una variable discreta, alguna variable nominal y comenzar a ver "vamos a representarlas" y como trabajo mucho con grupos, entonces muchas veces es "a ver qué propuesta tiene cada grupo y que hagan sus gráficas" y también les dejo esa libertad de hacerlas en el graficador de Office o hacerlas en el graficador de SPSS. Generalmente terminan haciéndolo siempre en Office porque con esta situación de que el SPSS se cambian mucho los ejes, hay que cambiar demasiadas cosas de la gráfica, muchas veces no les gusta (E2.CL.21)

De igual modo, para que Diego (en C-2) se diera cuenta de sus errores:

Después estas preguntas lo que haría es proponerle de qué otra manera podrías representarla y pedir que buscara alguna otra opción para representar y ver si lo que él quería representar es mejor o peor expresado en ese nueva representación y otra vez hacer el análisis de qué características quedaron, qué características estuvieron fuera. E2.CL.42

Para el C-4, Luis les pediría:

Lo que haría es pedirles que ellos al final reelaboraran la gráfica, que hicieran una reelaboración de esa gráfica para ver que... y que la representaran, o sea que después del análisis, su tarea final sea la reelaboración de esa gráfica (E2.CL.144)

Dependiendo de la situación específica Luis pide al alumno que elabore la RG, intente buscar otra representación (con ayuda del SPSS o del graficador de Word), o bien, reelabore el gráfico. La idea es que "interactúe" con el gráfico o "ensaye" y así se de cuenta de qué es o no posible de hacer, qué es mejor o peor. 
- Comparación de gráficos

También en C-2 indica que para corregir el error de Diego "pondría a comparación varios gráficos (pastel, barras, histogramas)" (Cu.CL.2c.2). No especifica cómo.

- Leer, subrayar y analizar con el estudiante

En el C-3, Luis comentó sobre las estrategias específicas que utilizaría para ayudar a Omar: "Revisaría la situación de nuevo con él" (Cu.CL.3ciiO.1), y lo explica del siguiente modo (E2.CL.105):

O sea leeríamos de nuevo la situación

y en esa situación le pediría que subrayara específicamente cuál es la variable,

qué datos se tienen de esa variable,

qué cosas podríamos eliminar de esa situación que no serían importantes para representación,

que tratara él de identificar, por ejemplo aquí parece que él está dando énfasis en las ciudades, o sea si es información importante para esto representar cuántas ciudades son,

o sea este primer párrafo [primero momento] sería que analizaríamos con profundidad para ver que es lo que se está pidiendo hacer ¿no?

De igual manera lo haría con María (en el C-3) al pedirle "que revisemos lo que representa cada eje" (Cu.CL.3ciiM.1):

Sí, porque aquí lo que aparece en el caso de ella es que ella está hablando de los porcentajes y de los niveles, entonces otra vez veríamos el qué representa cada eje ¿si? (E2.CL.109)

- Observación por parte del estudiante

También comentó que otra forma de ayudar a Omar (en C-3) es "que identificara la información en cada eje" (Cu.CL.3ciiO.2). Esto tiene que ver particularmente con solicitarle al estudiante a observar lo que está representado (E2.CL.106)

\section{- Lista de verificación}

En el análisis del C-4, con el objeto de que el estudiante analice los elementos de un media graph, les pediría que hicieran una lista de verificación (check list) para corroborar si éste tiene todos los elementos y de ese modo no caer en interpretaciones equivocadas por gráficos mal diseñados.

... o sea una vez que identificaron cuál es el tipo de gráfico que ellos consideran que es, que hicieran un listado de sus características para que con ese listado de características ahora vinieran y sean como un especialista de chequeo "bueno tiene estas características" y al momento de ¿tiene estas características?, "ok, sí las tiene... pero tiene algunas que son 
incorrectas, estas que son incorrectas... ¿cuáles son?, qué... cómo se debieran corregir, qué elemen... qué información están dando adecuada o inadecuadamente" (E2.CL.136)

Tabla 5.10. Resumen de las estrategias y propósito de aprendizaje sugeridas por Luis a partir de las preguntas del cuestionario

\begin{tabular}{|c|c|c|c|c|}
\hline Caso & Gráfico/Objetivo & Preguntas del cuestionario & $\begin{array}{l}\text { Estrategia } \\
\text { sugerida }\end{array}$ & $\begin{array}{l}\text { Propósito de } \\
\text { Luis }\end{array}$ \\
\hline \multirow[t]{3}{*}{$\mathrm{C}-1$} & \multirow[t]{3}{*}{$\begin{array}{l}\text { TyH e Histograma } \\
\text { Seleccionar, criticar y } \\
\text { evaluar el gráfico }\end{array}$} & \multirow[t]{3}{*}{$\begin{array}{l}\text { ¿Qué harías para ayudar al } \\
\text { estudiante a ver sus errores e } \\
\text { inducirlo a aprender a discernir } \\
\text { entre un gráfico de TyH y de } \\
\text { histograma }\end{array}$} & Preguntas & $\begin{array}{l}\text { Determinar si ya } \\
\text { entendió cuál es } \\
\text { la variable }\end{array}$ \\
\hline & & & Preguntas & $\begin{array}{l}\text { Explorar si } \\
\text { comprendió el } \\
\text { significado de los } \\
\text { elementos del } \\
\text { gráfico }\end{array}$ \\
\hline & & & $\begin{array}{l}\text {. Instrucciones } \\
\text { (ej.construir el } \\
\text { gráfico) }\end{array}$ & $\begin{array}{l}\text { Darse cuenta del } \\
\text { error }\end{array}$ \\
\hline \multirow[t]{4}{*}{$\mathrm{C}-2$} & \multirow[t]{4}{*}{$\begin{array}{l}\text { Barras } \\
\text { Definir una variable y } \\
\text { relacionar con el tipo } \\
\text { de gráfico }\end{array}$} & \multirow[t]{4}{*}{$\begin{array}{l}\text { ¿Cómo haría para corregir el } \\
\text { error de Diego }\end{array}$} & Preguntas & $\begin{array}{l}\text { Conocer el } \\
\text { significado que } \\
\text { tiene de los } \\
\text { conceptos y los } \\
\text { datos }\end{array}$ \\
\hline & & & . Explicaciones & $\begin{array}{l}\text { Integrar y } \\
\text { sintetizar los } \\
\text { aspectos más } \\
\text { importantes }\end{array}$ \\
\hline & & & $\begin{array}{l}\text { Instrucciones } \\
\text { (ej. reelaborar el } \\
\text { gráfico) }\end{array}$ & $\begin{array}{l}\text { Darse cuenta del } \\
\text { error }\end{array}$ \\
\hline & & & $\begin{array}{l}\text {. Instrucciones } \\
\text { (ej. comparar con } \\
\text { otros gráficos) }\end{array}$ & $\begin{array}{l}\text { Darse cuenta del } \\
\text { error }\end{array}$ \\
\hline \multirow[t]{4}{*}{$\mathrm{C}-3$} & \multirow[t]{4}{*}{$\begin{array}{l}\text { Histograma y circular } \\
\text { Interpretar, describir } \\
\text { y evaluar el gráfico }\end{array}$} & \multirow[t]{4}{*}{$\begin{array}{l}\text { ¿Qué estrategias utilizarías para } \\
\text { que Omar y María analicen si su } \\
\text { razonamiento es correcto? y ¿qué } \\
\text { harías ante esta respuesta? }\end{array}$} & Preguntas & $\begin{array}{l}\text { Aclarar lo que } \\
\text { representa los } \\
\text { elementos del } \\
\text { gráfico }\end{array}$ \\
\hline & & & Preguntas & $\begin{array}{l}\text { Aclarar lo que } \\
\text { representa el } \\
\text { porcentaje }\end{array}$ \\
\hline & & & $\begin{array}{l}\text {. Instrucciones } \\
\text { (ej. leer y subrayar) }\end{array}$ & $\begin{array}{l}\text { Analizar su } \\
\text { propio } \\
\text { razonamiento }\end{array}$ \\
\hline & & & $\begin{array}{l}\text {. Instrucciones } \\
\text { (ej. revisar los } \\
\text { ejes) }\end{array}$ & $\begin{array}{l}\text { Analizar su } \\
\text { propio } \\
\text { pensamiento }\end{array}$ \\
\hline
\end{tabular}


Estas instrucciones siempre están acompañadas de preguntas para ayudar al estudiante a darse cuenta de los elementos del gráfico y de los significados que subyacen en la representación. Utiliza las instrucciones a manera de análisis de error por parte del estudiante: "deberían fijarse bien para no caer..." en errores, ya que una fuente proviene de no leer las instrucciones y no darse cuenta qué es lo que se espera que hagan.

La Tabla 5.10 presenta un resumen de las estrategias sugeridas por Luis a partir de las preguntas del cuestionario didáctico sobre la RG. Encontramos que:

- Lo común a todas las situaciones es que realice preguntas para explorar si el alumno ya entendió cuál es la variable o si ya comprendió el significado de los elementos del gráfico; así como instrucciones para que el alumno se dé cuenta de sus propios errores y el profesor analice su razonamiento.

- Utiliza la explicación para integrar y sintetizar los aspectos más importantes.

- Para corregir algún error de razonamiento del estudiante (ej. Diego, Omar o María) utiliza las instrucciones.

Utiliza las preguntas tanto como representación instruccional como para corregir errores y dificultades del estudiante de forma semejante en cuanto a los tipos de preguntas, forma, propósitos y contextos; en cambio, la estrategia de las instrucciones sólo se utilizó para la corrección de errores.

\subsubsection{En síntesis: el conocimiento didáctico del contenido de Luis}

A partir de las diferentes dimensiones estudiadas del conocimiento didáctico del contenido, a continuación se resume el CDC de Luis.

Contexto, origen y desarrollo del conocimiento. Luis es un profesor con formación de psicólogo, con un master en Psicología aplicada que imparte clases de Estadística donde estudió. Estos dos aspectos (ser psicólogo y ser docente en la Facultad donde cursó sus estudios) han favorecido el conocimiento que tiene del tipo de competencias con que debe egresar el estudiante de la carrera de Psicología, así como del tipo de aplicaciones que le son útiles para su formación. Imparte también materias que tienen cierta vinculación con la Estadística (Medición y Evaluación, y Construcción de Instrumentos) y es ayudante y asesor de proyectos de investigación tanto de la parte metodológica como la de análisis estadísticos.

Desde el momento en que empezó a impartir Estadística se propuso cambiar la mentalidad del estudiante sobre ésta buscando vincularla con la Psicología para que el estudiante le encuentre sentido. Evita enseñar como sus profesores le mostraron la Estadística: centrada en la fórmula matemática, en el cálculo sin fundamento, descontextualizada de la profesión y de situaciones reales; cuya estrategia didáctica era la lectura de textos y hacer ejercicios de carácter rutinarios. Concibe la Estadística como una herramienta que debe ayudar a entender lo que está sucediendo en la vida real, particularmente en el contexto de la Psicología. 
Luis se mantiene actualizado en torno a la enseñanza de la Estadística y los cambios que se han producido en su enseñanza, así menciona: materiales y recursos diversos (journals, Webs) y especializados en educación estadística, incorpora el estudio de la Estadística utilizando bases de datos reales para darle sentido, utiliza ejemplos contextuales, busca comprender los estilos de aprendizaje del alumno y cree en el aprendizaje situado del aprendizaje, usar la tecnología como recurso. Se interesa por lo que piensan los alumnos de la asignatura y con frecuencia les hace preguntas que le ayudan a conocer sus motivaciones y preocupaciones. Su actitud de aprender de los demás, ser autodidacta y estar abierto al diálogo y a la crítica le han ayudado a tener un estilo propio de enseñar y a mantenerse actualizado

Dos aspectos que pueden explicar el origen del conocimiento y la concepción que Luis tiene de la Estadística son que proviene de una familia de profesores con formación matemática, y que fue invitado a participar como ayudante de investigación.

Para actualizarse, le concede valor al estudio de los contenidos estadísticos, apoyándose en la consulta y discusión con colegas o expertos y realizando cursos específicos de actualización. Estos cursos están centrados exclusivamente en el contenido, no en su enseñanza. Recurre con frecuencia a la lectura y análisis de artículos de investigación (en castellano e inglés), donde encuentra ejemplos que plantea a sus alumnos de contextos de investigación aplicados al ámbito de la Psicología.

Concepción sobre la Estadística, su aprendizaje y su enseñanza. Para Luis la Estadística es una herramienta que ayuda a entender lo que está sucediendo en el entorno y en la solución de diversas problemáticas del contexto. Reconoce y respeta las diferencias individuales en cuanto a capacidades y antecedentes académicos, concediendo mucho valor al pensamiento reflexivo, a que los alumnos aprendan de sus propios errores y dificultades, así como al aprendizaje situado y a la socialización del conocimiento. Para él es importante que el estudiante aprenda a sustentar sus ideas a partir de la Estadística, entender que es una herramienta que le debe ayudar en la práctica del ejercicio profesional, en la solución de problemas y para aprender a leer e identificar información falsa y equivocada. Su concepción de la enseñanza está centrada en el que aprende, buscando relacionar la Estadística con otras asignaturas, proporcionando ejemplos contextuales de la carrera que estudian los alumnos, utilizando datos reales a través de proyectos de investigación y estudios de casos, conceptuando el aprendizaje de la Estadística unido al de la metodología de la investigación, centrado en la resolución de problemas, la utilidad de la asignatura, la interacción y atención personalizada, la interpelación a los alumnos y el trabajo colaborativo, como características fundamentales de su enseñanza.

Por consiguiente, Luis concibe la Estadística como una herramienta global centrada en la comprensión para darle sentido a la realidad. Esta concepción se relaciona con la importancia del significado y mantiene una aproximación a la creación de soluciones a problemas de la vida real. Concibe a la Estadística como una herramienta que incluye la idea de una materia aplicada que puede ser usada en contextos específicos (ej. Psicología) o de una manera más amplia (ej. una forma de comunicación). Se fundamenta en el método científico y como una forma de pensamiento crítico. 
Esta concepción le lleva a mostrar a los estudiantes un significado interno de la Estadística, es decir, percibir que su trabajo profesional está relacionado con su propio desarrollo personal y profesional; lo que conlleva que los estudiantes visualicen la Estadística como parte integral de su futuro profesional y que asuman el desarrollo de habilidades de análisis e interpretación de datos como inherentes a su vida personal y al ejercicio de la profesión.

La concepción de Luis sobre el aprendizaje de la Estadística transita entre expandir (utilizar conceptos para comprender otras áreas) y cambiar (uso de conceptos para cambiar su visión del mundo), donde es esencial comprender lo que piensa y hace el estudiante, hacerles ver el significado que tienen los datos y del mundo real a partir de éstos. Intenta que el alumno utilice la Estadística en diferentes contextos, así como ver la Estadística como una herramienta intelectual que puede ser usada para informar o resolver problemas y que su estudio les lleve a cambiar la forma como ellos ven el mundo.

A partir de esto, Luis demuestra una concepción sobre la enseñanza de la Estadística centrada tanto en anticipar las necesidades de aprendizaje del estudiante como en ser un catalizador de su "mentalidad abierta", es decir, teniendo en cuenta las características y necesidades de los estudiantes proporciona materiales y métodos para mejorar su aprendizaje. Le confiere mucha importancia a estudiar y conocer los mejores métodos para enseñar ciertos conceptos y conocer qué hacer cuando los estudiantes no comprenden ciertas ideas.

Concepciones sobre la representación gráfica, su aprendizaje y enseñanza. Luis tiene una concepción de la representación gráfica como interpretar relaciones en contextos reales, centrada en la habilidad de los lectores para comprender el significado de gráficos creados por otros o por ellos mismos, para conocer los componentes de un gráfico, responder preguntas acerca de gráficos, adquirir el sentido gráfico o el sentido de los datos. Busca que los estudiantes diseñen y analicen gráficos a partir de datos reales, explorando su uso en contextos de la vida real y de su profesión. Incluye no sólo leer, escribir e interpretar el gráfico, sino escribir y establecer relaciones o factores importantes a partir del contexto.

Sobre el aprendizaje de la RG, Luis resaltó que lo primero que se debe buscar es que lo alumnos identifiquen con claridad las escalas de medición de una variable y que la puedan representar adecuadamente según su escala, que los alumnos aprendan a leer información e identifiquen representaciones confusas o falsas de datos. Para él, un alumno ya aprendió cuando puede leer información y detectar qué información está o no fundamentada con datos empíricos. El aprendizaje de la RG está íntimamente relacionado con la interpretación de gráficos bajo ciertos supuestos sobre todo aquellos que proceden de bases de datos reales. Le concede mucho valor a la interacción y diálogo con los estudiantes, siendo ambos (profesor y alumno) corresponsables del aprendizaje.

Sobre los niveles cognitivos que desarrolla en sus alumnos, encontramos que se centra en leer entre datos y leer más allá de los datos, en la interpretación de los datos en el gráfico, comparar algunos gráficos, observar relaciones en un gráfico e interpretarlas como una presentación visual dándole significado a los elementos del gráfico en el contexto, comparación local o global de sus características y mayor atención a los especificadores, 
interpretar algunas relaciones (ej. variable-escala de medición-tipo de gráfico) e identificar algunas tendencias.

Luis manifestó una concepción de la enseñanza de la RG centrada en cuestionar las características y fundamentos de las gráficas a partir de una diversidad de preguntas para explorar los elementos del gráfico, los fundamentos de sus decisiones y la relación con el contexto de donde surgen los datos. Pide a los alumnos que construyan gráficos a partir de cuestionarios que recojan información sobre ellos mismos y que realicen proyectos de investigación sobre algún tema de la profesión. Para guiar el aprendizaje se basa siempre en la interacción con los estudiantes y en la exposición de las representaciones gráficas por equipos con la ayuda de power point o de SPSS, así como de la revisión de las gráficas de los reportes de investigación que los estudiantes entregan como producto final de la asignatura.

Su concepción de la RG y su aprendizaje, está relacionada con el de la Estadística; resalta el valor de los contextos reales y del sentido de la asignatura. Aquí nuevamente habla del sentido de los datos para que los estudiantes reflexionen sobre las interpretaciones de los gráficos, al menos de manera literal e intenta relacionarlo con los contextos a partir de discusiones en el aula. No obstante, la concepción que tiene de la RG y su aprendizaje difiere de la de su enseñanza, que se basa en lo que ocurre en el aula y en las respuestas de los alumnos. No contempla actividades específicas, planificadas previamente para desarrollar de manera gradual los niveles cognitivos de la RG. Él remarca que el análisis que hace con los estudiantes está centrado en la revisión del tipo de variables y las escalas de medición, de gráficos descriptivos o categóricos, sin el propósito de compararlos o que discriminen en uno y otro.

Esto se puede ser atribuir a dos razones: por un lado, a que posiblemente Luis piense que el "deber ser" es entender la RG como interpretar relaciones contextuales, pero la realidad de la práctica docente es diferente. Otra razón es que el significado que le da a los conceptos "contextos", "sentido gráfico" y "sentido de los datos" sea diferente al que se le da en el campo de la educación estadística. El limita el significado de contextos a determinadas aplicaciones de la Estadística a la Psicología. Cuando habla del "sentido" hace alusión específicamente a utilizar datos reales.

Aún cuando encontramos cierta relación entre la concepción de la Estadística y la $\mathrm{RG}$, percibimos que a esta última no se le concede la relevancia debida puesto que no manifiesta tener los conocimientos necesarios de acuerdo a las tendencias actuales de las investigaciones en educación estadística.

Conocimiento del currículo. Para Luis el objetivo de la asignatura es la adquisición de las bases conceptuales y metodológicas de la investigación en Psicología en que se sustenta la Estadística que incluye un fuerte contenido sobre los conceptos de ciencia, de metodología, investigación documental y estilos de redacción. Para él, lo central es que primero comprendan qué es investigar, lo segundo que vean a la Estadística como herramienta y lo tercero que no le tengan miedo. Como parte de las actividades instruccionales que utiliza están la interacción con los alumnos, la metodología de proyectos y los estudios de casos; actividades no mencionadas en el programa en extenso. 
Cuando evalúa también va más allá de lo que establece el programa, ya que incorpora la participación activa, la elaboración de un proyecto de investigación y de estudios de casos; con lo cual encontramos mucha relación con las actividades que hace en el aula.

El eje central de la asignatura gira en torno a la concepción de la relación que debe existir entre la metodología de la investigación y la Estadística, que le lleva a concebir la necesidad de desarrollar el razonamiento estadístico del estudiante a partir de la formulación de una problemática (originada de los escenarios reales de trabajo de los estudiantes) y a orientar el análisis hacia los fundamentos y validez en la toma de decisiones estadísticas.

Es preciso destacar lo que para nosotros representan los puntos clave del conocimiento de Luis sobre el currículo de Estadística que están relacionados entre sí y que pueden explicar parcialmente sus concepciones iniciales y su actuación como profesor. Lo primero es que el currículo de la carrera donde imparte clases ofrece un curso que integra la Metodología y la Estadística, concediéndole a la asignatura en un $75 \%$ de las clases el estudio de los contenidos y habilidades propias del método científico. Lo segundo es que la carrera tiene como eje transversal el aprender a investigar, es decir, los estudiantes de Psicología desde el inicio hasta el final de la carrera se habitúan a hacer investigación, por lo que la adquisición de conocimiento y habilidades de la metodología adquiere una relevancia fundamental. Por último, la tercera clave está en el poco tiempo que se le otorga al estudio de la Estadística (25\% de las clases) ya que se destina sólo 6 horas a la parte de estadística descriptiva y 9 a sesiones de trabajo en la sala de informática para el uso del SPSS.

Luis tiene un gran conocimiento sobre el currículo de la Estadística en el contexto de la carrera donde imparte clases. Coincide con los fines principales de la enseñanza de la Estadística en la formación de los alumnos que diferentes investigadores y asociaciones recomiendan en los cursos introductorios de Estadística. Sin embargo, un elemento del que no se encontró información o evidencia es la alfabetización y el desarrollo del razonamiento y pensamiento estadístico.

Su conocimiento del currículo sobre la RG es relativamente limitado comparado con el conocimiento sobre el programa de Estadística. Si bien la mayoría de las respuestas que da son congruentes con lo establecido en el programa de la asignatura, promueve el aprendizaje de la RG al nivel de leer entre datos, y se centra en el conocimiento de sus características y cuando se pueden construir. Estudia gráficos descriptivos y categóricos y sólo uno de carácter analítico (el histograma). Si bien se preocupa para que los alumnos logren identificar representaciones confusas, inadecuadas e incompletas e identificar los errores en su construcción, esto se hace a partir del análisis de las exposiciones por parte de los alumnos en el salón de clases o en la sala de informática. No se encontró ninguna actividad planificada y organizada con anticipación para el desarrollo de los diferentes niveles cognitivos de la RG.

Cuenta con un amplio número de materiales y recursos, entre los cuales destaca el uso de cuestionarios de contextos, donde a partir de información demográfica del estudiante se generan bases de datos reales y con los que sus alumnos deben diseñar gráficos que son 
revisados en la sala de informática. Asimismo, resalta los Applets que utiliza a manera de simulación de datos para explorar las distribuciones de las pruebas estadísticas.

Luis recomienda algunos libros de texto a los estudiantes más orientados hacia la Metodología que a la Estadística, lo que se explica por la orientación curricular que tiene la asignatura. Sólo se encontró un texto de Estadística que presenta una concepción de la RG exclusivamente como técnica de graficación y una secuencia lineal de pasos para aprender a construir gráficos según ciertos criterios. Un libro que no contempla las aportaciones y recomendaciones curriculares en la enseñanza de la Estadística y específicamente, de la RG.

El conocimiento del currículo de la RG está estrechamente relacionado con el programa de la asignatura y no con su concepción sobre esta, su aprendizaje y enseñanza. Parte de una concepción basada en el análisis de las relaciones de los gráficos con los contextos reales; sin embargo, el énfasis está en el cuidado escrupuloso de la adquisición de los conceptos de escalas de medición y variables, así como en mostrar las características de los gráficos para poder elaborarlos correctamente. Posiblemente Luis piensa que a través de los gráficos que construyen en la sala de informática y las investigaciones que hacen los alumnos, sean suficientes para establecer las relaciones con los contextos reales. No obstante, esto es difícil si asumimos la definición de sentido gráfico de Friel, Bright y Curcio (1997) y delMas, Garfield y Ooms (2005).

Por consiguiente, aunque Luis tiene buenas intenciones su conocimiento del currículo a partir de las recomendaciones internacionales es limitado.

Conocimiento de las estrategias y representaciones instruccionales. Luis enseña la Estadística a partir de un limitado repertorio de representaciones instruccionales, que son congruentes con su concepción de la asignatura: las preguntas, la manipulación de datos y gráficos, los proyectos de investigación y los estudios de casos. Estas representaciones fueron diferenciadas entre las que utiliza para su curso de Estadística (estrategias genéricas) y las directamente relacionadas con la RG (estrategias específicas). Las estrategias genéricas son proyectos de investigación y estudios de casos; mientras que las estrategias específicas son preguntas y manipulación de datos y gráficos.

Respecto del tipo de representaciones, dos son verbales (las preguntas y las manipulación de datos y gráficos) y dos concretas (proyectos de investigación y estudios de casos). Circunstancialmente las estrategias específicas que utiliza Luis coinciden en que son de tipo verbal, mientras que las genéricas resultaron concretas.

Sobre la fuente de donde proceden las representaciones verbales es el propio Luis, es decir, las crea o construye él mismo, la mayoría según las circunstancias de la clase; mientras que las genéricas se proceden de sitios Web, periódicos y artículos de investigación.

En cuanto a la forma de las representaciones, las preguntas están centradas en la interacción entre el profesor y los estudiantes; mientras que las demás representaciones se 
centranen el estudiante, es decir, son ellos los protagonistas o quienes se involucran activamente en actividades de construcción de los conceptos, procesos o relaciones.

Sobre los propósitos de cada una de las representaciones instruccionales: las preguntas se usan para identificar la información que se desea del gráfico, identificar el tipo de variable que se trate, explorar las características del gráfico, así como el contexto de la situación y analizar ventajas y desventajas de cada uno; la manipulación de datos y gráficos se usa para explorar lo que ocurre con los ejes $x$ e $y$ del gráfico y las variaciones de los sectores e intervalos en los gráficos circular e histograma, respectivamente; el proyecto de investigación se usa para encontrar sentido a lo que hace y la vinculación de los conceptos con la práctica profesional; y los estudios de casos se usan para relacionar la teoría con la práctica.

Sobre los contextos y momentos utiliza: una pregunta cuando desea corroborar intuiciones y razonamientos, clarificar conceptos, explorar antecedentes y corregir errores; la manipulación de un dato o gráfico cuando se encuentra en la sala de informática y los alumnos están construyendo gráficos; un proyecto de investigación cuando desea vincular la metodología de la investigación con la Estadística; y un estudio de caso cuando está viendo el tema de estadísticos de prueba de hipótesis.

Las estrategias específicas se dan según las circunstancias de la clase y las necesidades del alumno a diferencia de las estrategias genéricas que son actividades planificadas con anticipación desde el inicio del curso.

Para las representaciones que proceden de sitios Web (ej. los estudios de casos), proporciona la dirección electrónica donde se pudo constatar que es un Web especializada en estudios de casos. Sobre las representaciones que proceden de los periódicos Luis no presentó ningún ejemplo, sólo lo mencionó. De los artículos de investigación recomienda las bases de datos electrónicas para localizar y utilizar aquellos que sirvan para el marco conceptual de su investigación. Cuando se trata de los estudios de casos sugiere la lectura específica de algunos artículos de investigación.

Con el proyecto de investigación trata de integrar todos los contenidos vistos durante el curso y de vincular la metodología de la investigación con la Estadística. Sin embargo, aborda implícita y superficialmente el tema de la RG y está subordinada al gráfico que decida utilizar el estudiante, que son generalmente categóricos, de una variable y exclusivamente para comunicar resultados (de información demográfica). Por su parte, los estudios de casos se usan para el aprendizaje de los estadísticos de prueba de hipótesis.

Las preguntas que utiliza en sus clases tienen relación con las que elaboró a partir del cuestionario didáctico de RG. Luis generó una diversidad de formas de preguntar que fueron agrupadas en tres categorías: explorar la interpretación de los componentes estructurales del gráfico, explorar las características y condiciones en la construcción de un gráfico y desarrollar el sentido crítico en un gráfico. Aunque entre las dos primeras se agrupan el $75 \%$, a través de la diversificación de los tipos de actividades con los estudiantes puede desarrollar, ampliar y darle más sentido a esta técnica como 
representación instruccional. La manipulación de datos y gráficos, es una representación que se realiza de manera circunstancial y ocasional; y surge de las respuestas que Luis dio del cuestionario didáctico.

Estos resultados son hasta cierto punto contradictorios con la concepción que tiene Luis de la RG. Por un lado concibe la RG como interpretar relaciones en contextos reales, pero principalmente utiliza las preguntas como representación instruccional orientadas hacia la exploración de los significados de conceptos previos, de las características y elementos del gráfico. Aunque reconoce otras tres representaciones instruccionales, dos no son utilizadas específicamente para ayudar al alumno a aprender la RG y una la utilizaría a partir de las situaciones hipotéticas que se le plantearon a través del cuestionario. El mismo confirmó que se centra más en la construcción de gráficos, poco en su interpretación y en los proyectos de investigación para comunicar resultados.

Conocimiento del estudiante. Sobre esta dimensión del CDC nos centramos únicamente en el conocimiento que tiene Luis de las creencias, errores y dificultades de los estudiantes, a partir del cuestionario didáctico de la RG.

Sobre el conocimiento de las creencias de los estudiantes, Luis habló de cuatro: a) lo importante de la representación gráfica: lo bonito, visual, el color y tamaño; b) con los números de la RG se puede hacer lo que quieran; c) los gráficos son todos iguales; y d) es información que hay que poner. Las razones de estas creencias que tienen los estudiantes se atribuyen al desconocimiento de la naturaleza de los datos y de los elementos del gráfico. Luis no comentó que alguna creencia sea origen didáctico.

Sobre el conocimiento de los errores y dificultades de los estudiantes, encontramos un total de 14, los cuales se clasificaron en cuatro grupos:

a. Errores por ignorancia o desconocimiento de conceptos previos. Este tipo de errores tienen relación con la falta de conocimiento del estudiante sobre conceptos específicos que debió tener para resolver el problema relacionado con la RG. Aquí se agruparon los siguientes:

- no consideran desde el inicio el análisis de las escalas de medición,

- no entienden qué es una variable,

- no identifica las variables,

- desconocimiento de las características de los gráficos,

- desconocen el significado de las barras del gráfico,

- no entiende la información que representa los ejes, y

- no tiene claro la naturaleza de los datos para un gráfico circular.

b. Errores de reconocimiento y comprensión de la información del gráfico. Se trata de errores relacionados con la falta de apreciación, observación y comprensión de los elementos o componentes estructurales del gráfico:

- hacer poco caso a los errores en el diseño del media graph. 
c. Errores en la comprensión de conceptos. Aquí se ubican aquellos que tienen que ver con errores de carácter conceptual, es decir, el estudiante tiene un concepto equivocado o inadecuado:

- distinguir cuándo se deben representar las barras separadas (gráfico de barras) y cuándo no (histograma), y

- confundir conceptos como caso, variable, frecuencia.

d. Errores relacionados con el contexto. Se agrupan los errores relacionados con la identificación, comprensión y uso de la información del contexto de la situación de donde se originan los datos, como es el problema de investigación:

- no le dan sentido a los datos y no son capaces de realizar argumentación,

- no interpretan el significado de gráficos,

- centrarse exclusivamente en el análisis de los elementos y datos del gráfico, $\mathrm{y}$

- falta de análisis de la situación del contexto.

Esta clasificación nos permitió identificar:

a) Lo que no conoce el estudiante: escalas de medición, variable, variable continua, variable discreta, características de cada gráfico.

b) Lo que no observa de los elementos del gráfico: los elementos del media graph.

c) Lo que confunde: diferencia entre caso, variable, frecuencia y porcentaje; diferencia entre los rectángulos de un gráfico de barras y del histograma.

d) Lo que no considera del contexto: sentido de los datos, argumentación, interpretación, análisis del contexto.

Estos resultados nos permiten afirmar que Luis logró identificar un conjunto de creencias, errores y dificultades a partir del cuestionario didáctico. Cerca de la mitad de éstos coincidieron con los encontrados por otros investigadores. De igual modo, los errores que más menciona están relacionados con los conocimientos previos que el alumno debe tener para estudiar la RG: variable, tipos de variables, definición de variable, características de los gráficos. Fue interesante identificar errores que tienen que ver con el sentido de los datos, argumentación, interpretación, análisis del contexto.

En cuanto a la forma en que Luis identifica y diagnostica las creencias, errores y dificultades la más habitual es la interacción con sus alumnos (ej. a partir de los trabajos individuales o grupales que asigna), constantemente utiliza preguntas (en forma verbal) en diferentes momentos (ej. presentación de avances delante del grupo y en asesoría individual o grupal), y siempre busca interpelar a cada alumno para conocer su proceso de aprendizaje. Ambas estrategias se utilizan simultáneamente. 
A partir del cuestionario didáctico también averiguamos el conocimiento que tiene Luis de las estrategias para corregir determinados errores de los estudiantes: realiza preguntas para explorar si el alumno ya entendió cuál es la variable o si ya comprendió el significado de los elementos del gráfico; así como instrucciones para que el alumno se dé cuenta de sus propios errores y el profesor analice su razonamiento. En ocasiones utiliza la explicación para integrar y sintetizar los aspectos más importantes.

Por último, es preciso mencionar que Luis reconoció que no cuenta con actividades similares a las del cuestionario desarrollar la RG. Reconoce que invierte poco tiempo en el tema de la RG y que lo que cubre del programa tiene que ver fundamentalmente con la construcción de gráficas.

\subsection{ANÁLISIS INTERCASOS}

A continuación presentaremos el análisis intercaso, que nos permitirá ampliar la comprensión del conocimiento que tiene cada uno de los profesores, así como encontrar las interrelaciones entre las dimensiones del CDC y sus posibles atribuciones. Por lo tanto, centraremos más nuestra atención sobre cómo las concepciones que sobre la Estadística y la RG tiene el profesor están relacionados con el conocimiento del currículo, el conocimiento de las estrategias y representaciones instruccionales y el conocimiento del estudiante.

Para el análisis, como se mencionó en el Capítulo 4, nos apoyamos de la construcción de unas figuras que resumen a manera de descriptores clave los resultados obtenidos en cada una de las dimensiones e indicadores del CDC que estudiamos.

Estos dos profesores tienen una formación inicial diferente, una es matemática y el otro psicólogo. Alicia tiene un master en matemáticas y Luis uno en Psicología aplicada. Ambos ingresaron a la universidad por invitación y de manera circunstancial comenzaron a enseñar Estadística; Alicia con estudiantes para profesor (educadores) y Luis con estudiantes de la carrera de Psicología. La manera de asumir este compromiso fue diferente. Por un lado, para Alicia fue una sorpresa, algo inesperado y lo consideró desde un principio como un reto, con sentimientos encontrados, por un lado el temor a encontrarse con estudiantes que no saben matemáticas y por otro lado ganas por contagiarles el gusto que ella tiene por la matemática. Luis en cambio, se sintió motivado y entusiasta y ya desde antes de iniciar su curso comenzó a investigar acerca de la percepción que tienen los estudiantes hacia la Estadística; y a partir de las experiencias que tuvo como estudiante, se propuso cambiar la mentalidad del estudiantado sobre ésta. Los factores que influyeron en que Luis asumiera de este modo ser profesor de Estadistica fueron: que había sido estudiante de la misma Facultad donde enseña, proviene de una familia de matemáticos y profesores, y previamente había participado como ayudante de investigación en el área de Psicología aplicada.

En cuanto a la evolución y los cambios en la enseñanza de la Estadística, mientras Alicia piensa que no se ha modificado, Luis opinó que es el cambio ha sido "enorme". Alicia manifiesta desconocer el campo de la educación estadística, mientras que Luis conoce algunos materiales y recursos (ej. journals, páginas Web) que le han ayudado a modificar sus clases. Esto puede explicarse a partir de sus experiencias previas. Por 
ejemplo, Alicia enseña como le enseñaron sus profesores durante la carrera de matemáticas. En cambio Luis, a partir de esas experiencias y después de ser ayudante de investigación, intenta modificar el sentido y orientación de la asignatura. Por otra parte, Alicia no tiene el bagaje de conocimiento que tiene Luis sobre las teorías y procesos de aprendizaje, mientras que Luis, por la carrera que realizó maneja términos como aprendizaje situado o socialización del conocimiento. No obstante, ambos coincidieron en que no habían recibido ninguna formación para ejercer como profesores.

El origen del conocimiento de Alicia y de Luis, también se explica en función de las experiencias previas a su labor como profesores. Por ejemplo, Alicia lee y estudia libros de estadística similares a los de la carrera y recurre a colegas matemáticos para aclarar dudas conceptuales, no de enseñanza; mientras que Luis aprende de los cursos de actualización sobre contenidos estadísticos (impartidos generalmente por especialistas en estadística), preguntando a colegas sobre aspectos de contenido, preguntando y monitoreando el aprendizaje con los estudiantes y leyendo y analizando reportes de investigación que le sirven para encontrar ejemplos en contextos de la investigación en el ámbito de la Psicología. Un elemento a favor de Luis en cuanto al conocimiento que ha adquirido de la Estadística es su actitud de aprender de los demás, es completamente autodidacta, abierto al diálogo y a la crítica, y el gusto por la Estadística. Por su parte Alicia, asume una actitud positiva en el sentido de intentar hacer lo mejor que puede con sus estudiantes por medio de los conocimientos y recursos que domina, pero manifiesta en reiteradas ocasiones que desconoce cómo hacerlo mejor porque no estudió para ser docente. En ocasiones esto le causa ansiedad y le genera dudas sobre lo que debe o no hacer con sus alumnos de Educación.

Las figuras 5.20 y 5.21 nos ayudan a conocer las diferencias entre las concepciones de Alicia y Luis. Mientras Alicia considera la Estadística como una parte de las matemáticas y su centro de interés es la comprensión conceptual, Luis piensa que la Estadística es una herramienta con sentido en diferentes contextos. Alicia mantiene un estilo tradicional caracterizado por explicar y poner ejemplos que aborden los conceptos estadísticos sin mencionar los diversos contextos de aplicación de éstos. No usa recursos diferentes a la pizarra, se basa en la práctica de ejercicios tomados de los libros de texto durante las clases. Relaciona los conceptos estadísticos con determinadas aplicaciones o prototipos de ejercicios, clarificando, explicando, aclarando dudas, especialmente en situaciones inusuales o cuando el estudiante lo requiera. Por su parte Luis, mantiene un estilo más avanzado centrado en el estudiante. Utiliza como estrategias clave la interacción y el diálogo, los proyectos de investigación y los estudios de casos que le le permiten que el estudiante aplique los contenidos estadísticos. Trata de comprender las necesidades del estudiante y crear espacios de reflexión que le ayudan a razonar estadísticamente.

La visión que tiene Luis de la Estadística es fundamentalmente práctica mientras que la que tiene Alicia es matemática. Para Luis lo que importa es el significado de los conceptos y cuándo deben usarse, para Alicia es la coherencia de esos conceptos desde el punto de vista matemático. 


\begin{tabular}{|c|c|c|}
\hline \multirow[b]{2}{*}{$\begin{array}{l}\text { Sentido de la asignatura } \\
\text {. Orientación: énfasis conceptual } \\
\text {. Objetivo: conceptual de carácter } \\
\text { terminal } \\
\text {. Finalidad: informativa utilitaria } \\
\text { Palabra }(s) \text { clave: reto } \\
\text {. Expectativa: } \text { significado de la } \\
\text { Estadística y algunas aplicaciones } \\
\text {. Razonamiento estadístico: relacionar lo } \\
\text { nuevo con algo conocido }\end{array}$} & & \multirow[b]{2}{*}{\begin{tabular}{l}
\multicolumn{1}{c}{ Aprendizaje } \\
. Aprendizaje: significado relevante \\
(conceptos y aplicación) \\
. Tipo: deductivos \\
Proceso: por apropiación \\
. Tipo de agrupamiento: individual \\
. Dificultades del alumno: interpretación \\
en general \\
. Participación del alumno en la \\
programación: no participa \\
. Papel del alumno: reproduce e imita, \\
atiende y cree
\end{tabular}} \\
\hline & & \\
\hline & $\begin{array}{l}\text { Enseñanza } \\
\text { Metodología: ejercitación repetida } \\
\text {.Enfoque: exposición magistral (libro de } \\
\text { texto) } \\
\text {. Programación: oficial, prescriptiva, } \\
\text { rígida } \\
\text { Papel del profesor: transmite } \\
\text { verbalmente, dicta, reproduce, es } \\
\text { especialista en el contenido }\end{array}$ & \\
\hline & $\begin{array}{l}\text { Evaluación } \\
\text { Carácter: sumativa (proceso en función } \\
\text { del producto) y cuantitativa } \\
\text {. Criterios: criterios explícitos, } \\
\text { taxonómica, no diferenciación individual } \\
\text {. Instrumento principal: examen } \\
\text { Diagnóstico: sobre la base de los } \\
\text { contenidos impartidos con anterioridad } \\
\text {. Valoración del proceso: } \text { mediante } \\
\text { controles de los objetivos }\end{array}$ & \\
\hline Estadística & & Representación gráfica \\
\hline $\begin{array}{l}\text { Estadística como: parte de las } \\
\text { matemáticas en el análisis e } \\
\text { interpretación de datos } \\
\text {. Aproximación: aplicar } \\
\text { Foco: datos } \\
\text {. Entidad profesional: significado } \\
\text { extrínseco } \\
\text {. Aprendizaje: aplicación de métodos - } \\
\text { relacionar la teoría con la práctica } \\
\text {. Enseñanza: relacionar conceptos } \\
\text { estadísticos y guiar el aprendizaje }\end{array}$ & & $\begin{array}{l}\text { Representación gráfica como: técnica } \\
\text { de graficación } \\
\text { Aprendizaje centrado en: } \\
\text { Curcio (1989): leer datos y leer entre } \\
\text { datos } \\
\text { Garfield (2002): alfabetización } \\
\text { estadística } \\
\text { Aoyama (2006): lectura básica de } \\
\text { gráficos } \\
\text { Enseñanza: definir, explicar y dar } \\
\text { ejemplos de gráficos }\end{array}$ \\
\hline
\end{tabular}

Figura 5.20. Rasgos característicos de la dimensión concepciones sobre la enseñanza y aprendizaje de la Estadística del CDC de Alicia

Las concepciones que cada uno tiene, pueden explicarse a partir de las experiencias previas que han tenido. Alicia enseña como le enseñaron y asume que es lo que debe ser. Por su parte Luis, a partir de la interacción con profesores investigadores y a partir de su experiencia como ayudante de investigación comprendió el "deber ser" de la Estadística y busca que los estudiantes le encuentren sentido y significado a partir de contextos reales de aplicación en la carrera que estudian. 


\begin{tabular}{|c|c|c|}
\hline Sentido de la asignatura & & Aprendizaje \\
\hline $\begin{array}{l}\text { Orientación: procedimientos, conceptos } \\
\text { y actitudes } \\
\text { Objetivo: flexibles y orientativos } \\
\text { Finalidad: formativa (aprender a } \\
\text { aprender) } \\
\text { Palabra(s) clave: utilidad } \\
\text { Expectativa: investigar es fundamental, } \\
\text { interés a la estadística como herramienta } \\
\text { y una estadística accesible a todos } \\
\text { Razonamiento estadístico: formular una } \\
\text { problemática y fundamentar las ideas }\end{array}$ & & $\begin{array}{l}\text { Aprendizaje: significado relevante } \\
\text { (fundamentación) } \\
\text {. Tipo: inducción-deducción } \\
\text { Proceso: por construcción dirigida } \\
\text {. Tipo de agrupamiento: trabajo en grupo } \\
\text { y debates } \\
\text { Dificultades del alumno: "sin sentido" } \\
\text { de la Estadística y la notación } \\
\text {. Participación del alumno en la } \\
\text { programación: indirectamente a través } \\
\text { de sus reacciones } \\
\text { Papel del alumno: investiga, reflexiona, } \\
\text { cuestiona }\end{array}$ \\
\hline & $\begin{array}{l}\text { Enseñanza } \\
\text {. Metodología: resolución de problemas } \\
\text { Enfoque: investigación planificada } \\
\text { Programación: redes conceptuales } \\
\text { organizadas } \\
\text {. Papel del profesor: provoca, conduce, } \\
\text { investiga en y sobre la acción, } \\
\text { experimentador interactivo del contenido } \\
\text { y los métodos } \\
\text { Evaluación } \\
\text { Earácter: formativa-sumativa (proceso } \\
\text { y producto) y cualitativa-cuantitativa } \\
\text {.Criterios: criterios explícitos, holística, } \\
\text { diferenciación individual organizada } \\
\text {. Instrumento principal: proyecto de } \\
\text { investigación } \\
\text {. Diagnóstico: que informa la } \\
\text { elaboración y ejecución del proceso } \\
\text {. Valoración del proceso: por conjunción } \\
\text { de varios instrumentos }\end{array}$ & \\
\hline Estadística & & Representación gráfica \\
\hline $\begin{array}{l}\text { Estadística como: herramienta global } \\
\text { para desarrollar significados } \\
\text {. Aproximación: creación } \\
\text { Foco: significado } \\
\text { Entidad profesional: significado } \\
\text { intrínseco } \\
\text {. Aprendizaje: utilizar conceptos para } \\
\text { comprender más allá de la estadística - } \\
\text { para cambiar su visión } \\
\text {. Enseñanza: anticipar las necesidades } \\
\text { del alumno - catalizador de "mentes } \\
\text { abiertas" }\end{array}$ & & $\begin{array}{l}\text { Representación gráfica como: } \\
\text { interpretar relaciones en contexto reales } \\
\text {. Aprendizaje centrado en: } \\
\quad \text { Curcio (1989): leer entre datos y leer } \\
\text { más allá de los datos } \\
\quad \text { Garfield (2002): alfabetización } \\
\text { estadísitica } \\
\quad \text { Aoyama (2006): literal / racional } \\
\text {.Enseñanza: cuestionar las } \\
\text { características y fundamentos de las } \\
\text { gráficas }\end{array}$ \\
\hline
\end{tabular}

Figura 5.21. Rasgos característicos de la dimensión concepciones sobre la enseñanza y aprendizaje de la Estadística del CDC de Luis 
La concepción de cada uno justifica lo que hacen en el aula. Por ejemplo, Alicia explica, proporciona ejemplos y muchos ejercicios. La enseñanza de Luis gira en relación a la construcción de un proyecto de investigación y al análisis de estudios de casos donde se estudia la aplicación de los contenidos estadísticos. Ambas concepciones influyen de forma diferente en el significado que transmiten a sus alumnos, un significado extrínseco en el caso de Alicia y un significado intrínseco en el caso de Luis; esto marcará la concepción de lo Estadística que tendrán estos futuros profesionales (de Educación y Psicología) y el papel pasivo o activo que tendrá ésta en la solución de problemas inherentes a su práctica profesional.

La concepción de cada uno sobre la RG es igualmente diferente. Alicia la concibe más como una técnica de graficación y Luis como el instrumento para interpretar relaciones en contextos reales. Alicia piensa que el alumno debe aprender cómo construir los gráficos y centrarse en la lectura literal de los datos, cuidando los elementos o componentes estructurales que tiene. Por su parte, Luis cree que además el estudiante debe construir gráficos en contextos reales, a partir de datos reales, y que deben servir para comunicar los resultados de proyectos de investigación. Alicia sostiene que la forma de enseñar la RG es explicar, definir y dar ejemplos de gráficos; mientras que para Luis es cuestionar las características y fundamentos de los gráficos que el propio estudiante construye a partir de su proyecto de investigación. La diferencia entre ambas concepciones radica en que Alicia trata exclusivamente la representación como cualquier otro de sus temas: define, explica, da ejemplos y propone ejercicios de construcción de gráficos; mientras que Luis interpela a los estudiantes para que hagan gráficos con SPSS y junto con ellos analizar los elementos del gráfico y su utilidad en el proyecto que están realizando. Al final, los estudiantes deberán incluir aquellos gráficos necesarios para comunicar los resultados de su investigación. A pesar de esta diferencia, Luis no logra ir más allá de los contextos de las investigaciones de los estudiantes, no aborda el sentido del gráfico y el sentido de los datos como lo establece la literatura en educación estadística. De este modo, se puede afirmar que su concepción de la $\mathrm{RG}$ como interpretar relaciones en contexto reales es parcial o acomodaticia.

Las concepciones de Alicia hacia la enseñanza de la Estadística con la enseñanza de la RG son congruentes. Tal como lo hace habitualmente con los demás contenidos, de igual modo lo hace al ver el tema de la RG. Por su parte Luis, confronta su concepción de la RG con el de la Estadística y se da cuenta de que las estrategias y recursos que utiliza no las aplica del mismo modo para enseñar la RG. No cuenta con ninguna actividad previamente planificada para desarrollar el razonamiento o el pensamiento estadístico de la RG. Sólo hace referencia a la interpelación de los estudiantes.

En cuanto al conocimiento que Alicia y Luis manifiestan tener del currículo de la Estadística, encontramos que existen algunas diferencias que nos parece importante destacar. Primero que los programas que cada uno utiliza son diferentes. Alicia se basa en un programa que se imparte en un solo semestre y centrado en el contenido de temas estadísticos, mientras que Luis cuenta con un programa que une el estudio de la metodología de la investigación y la Estadística, que se imparte en dos semestres. Segundo, la carrera de Psicología tiene un eje transversal orientado a fomentar y desarrollar habilidades de investigación. Esto se refleja en muchas asignaturas que utilizan la estrategia de diseño de proyectos de investigación para desarrollar los contenidos. Por su parte, en 
Educación, si bien se podría considerar el mismo eje transversal, la realidad es que las asignaturas de metodología se imparten de forma aislada, y es allí donde se aprende a elaborar un proyecto, pero sin recoger, analizar, interpretar y comunicar los resultados. En las demás asignaturas de la carrera no se tienen evidencias de que los alumnos desarrollen proyectos de investigación.

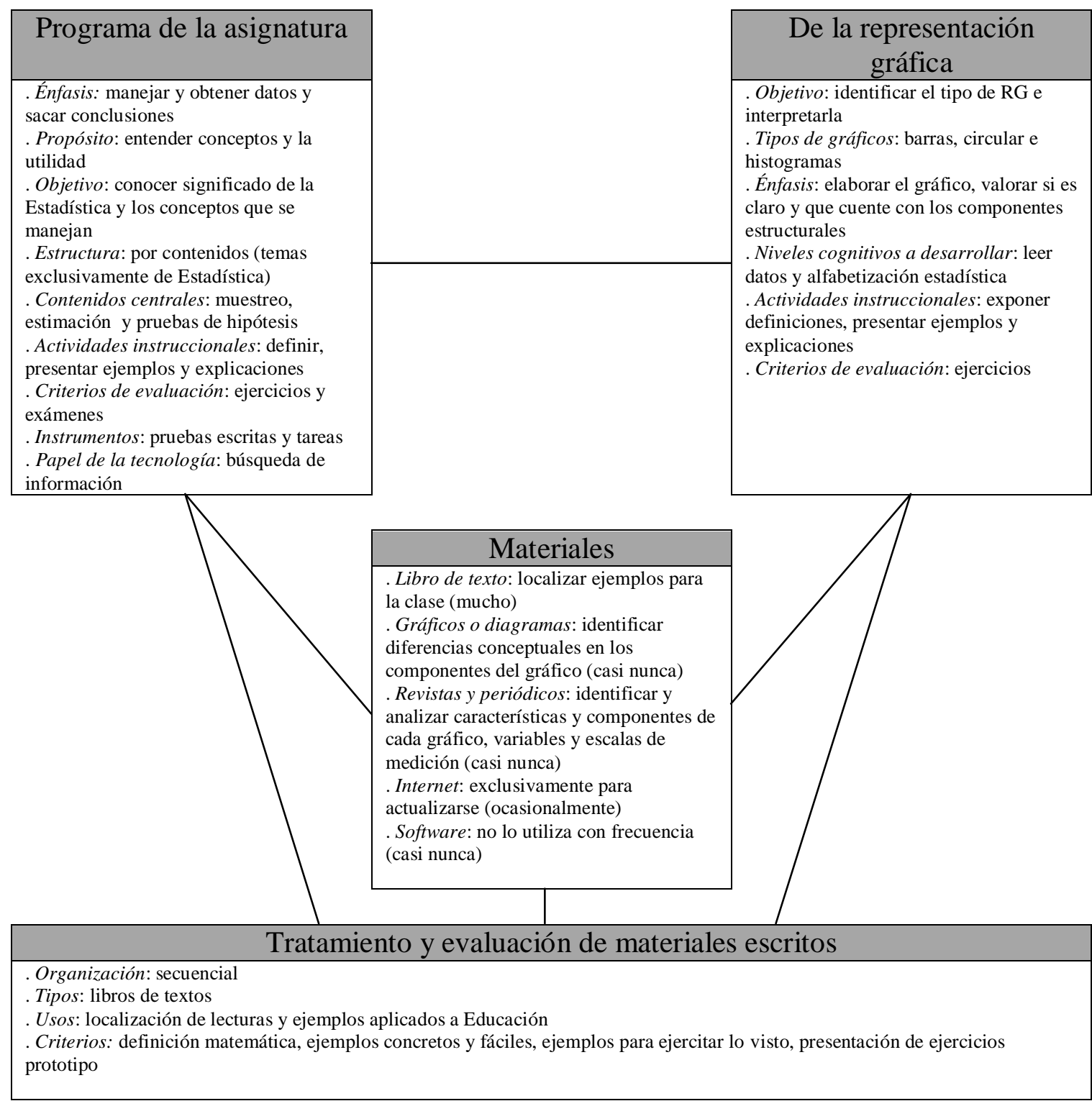

Figura 5.22. Rasgos característicos de la dimensión conocimiento del currículo del CDC de Alicia

Las Figuras 5.22 y 5.23 nos ayudan a comprender las diferencias que hay entre el conocimiento de Alicia y el de Luis, comenzando con el objetivo y propósito que cada uno le concede a la asignatura de Estadística, congruentes con la concepción de cada uno de ellos. 


\begin{tabular}{|l|}
\hline \multicolumn{1}{|c|}{ Programa de la asignatura } \\
\hline . Énfasis: la estadística como una \\
herramienta \\
. Propósito: comprender e interesarse por \\
la investigación científica, vean la \\
Estadística como herramienta y no \\
tenerle miedo \\
. Objetivo: conocer la metodología y los \\
conceptos de estadística descriptiva y \\
aplicarlos a la investigación \\
.Estructura: por contenidos (fusión \\
metodología de la investigación y \\
estadística) \\
.Contenidos centrales: nivel de \\
significancia y pruebas de hipótesis \\
. Actividades instruccionales: interacción \\
con los alumnos, metodología de \\
proyectos y estudios de casos \\
.Criterios de evaluación: exámenes, \\
tareas, participación y elaboración de \\
proyectos y casos \\
. Instrumentos: tareas, proyectos y \\
estudios de casos \\
. Papel de la tecnología: dar más \\
significado, unir lo visual con el proceso \\
reflexivo y contar con varios recursos \\
\hline
\end{tabular}

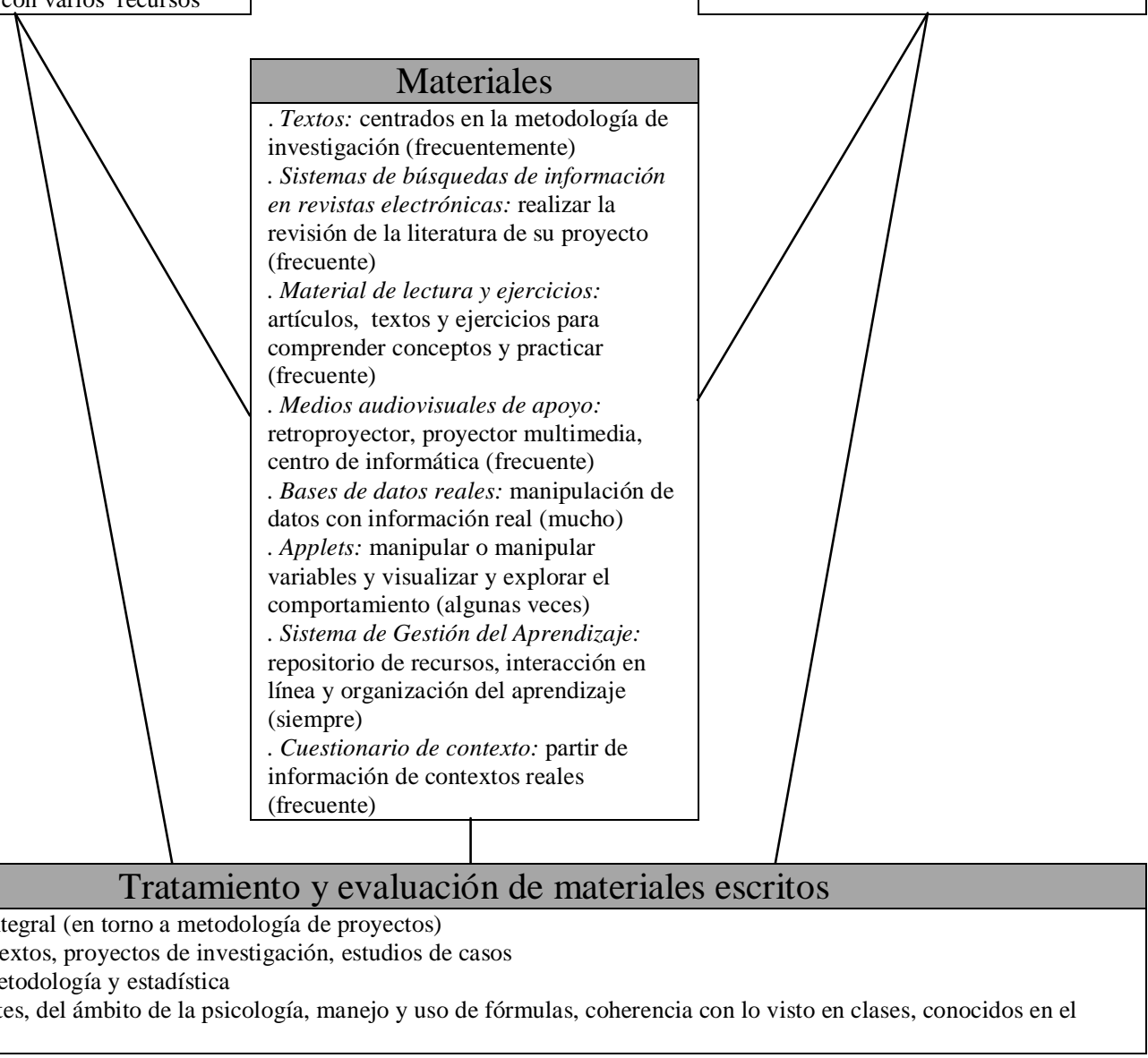

Figura 5.23. Rasgos característicos de la dimensión conocimiento del currículo del CDC de Luis

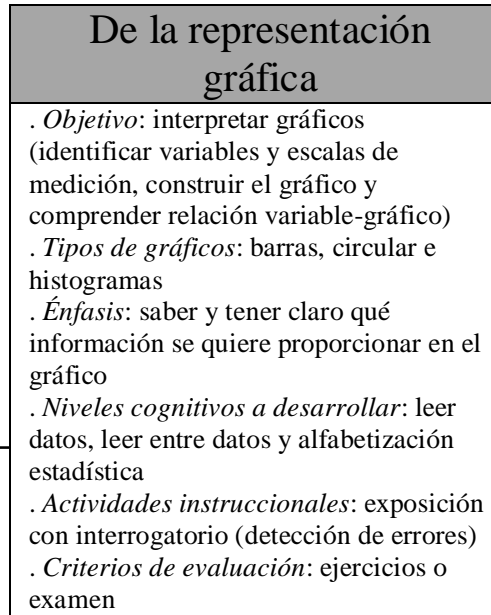

examen 
Un tercer aspecto a destacar es que en ambos programas se concede poco tiempo al estudio de la RG. Los programas estipulan de 2 a 3 sesiones de hora y media para el tema de la RG. Asimismo, los objetivos de aprendizaje señalan el énfasis, primero en la construcción de gráficos y segundo, en la interpretación. Tanto Alicia como Luis cumplen el programa y se centran en la construcción e interpretación de gráficos al nivel de leer datos y leer entre datos. Sobre la interpretación de gráficos, ambos coincidieron que se trata de manera superficial.

Sobre las actividades que utilizan al enseñar la RG, Alicia siempre mencionó el uso de ejercicio como actividad principal, con apoyo del uso de definiciones y explicaciones. Luis, a diferencia de las actividades que realiza con otros temas del programa, utiliza principalmente las preguntas para analizar las características y componentes del gráfico y su relación con los datos y el contexto de donde emergen.

Mientras Alicia utiliza como materiales principalmente ejercicios tomados de libros de texto, Luis utiliza en sus cursos una variedad de materiales que ayudan a comprender más su concepción hacia la Estadística. No obstante, al analizar los materiales de Luis sobre el tema de la RG no encontramos información específica. Pareciera, como él lo expresó, que el tema lo presenta de manera verbal-oral en la sala de informática. En ambos casos llamó la atención que los libros que utilizan para el tema de la RG son obsoletos y presentan una concepción sobre la misma como técnica de graficación exclusivamente.

El conocimiento que tienen de las estrategias y representaciones instruccionales para enseñar la RG (ver Figuras 5.24 y 5.25) es limitado. Alicia conoce y utiliza cuatro: definiciones y explicaciones, preguntas, ejemplos y ejercicios e instrucciones, mientras que Luis usa: proyectos de investigación, estudios de casos, preguntas y manipulación de datos y gráficos. Una primera distinción es que Luis utiliza dos estrategias (proyectos de investigación y estudios de casos) que le denominamos genéricas por ser utilizadas para encontrar la relación teoría y práctica e integrar los conocimientos en cada uno de los temas del programa.

Tanto Alicia como Luis utilizan las preguntas como representación instruccional, que generalmente de centran en conocer el significado que le dan los estudiantes a las variables, las escalas de medición, las características y la identificación de los elementos del gráfico. Por otra parte, las representaciones instruccionales que Alicia utiliza (ej. definiciones, explicaciones, ejercicios, instrucciones) se centran en la labor del profesor, mientras que las de Luis están más pensadas para desarrollar el trabajo activo del estudiante (ej. proyectos de investigación y estudios de casos). Aun así, respecto del tema de la RG, las estrategias que ambos utilizan están centradas en la interacción con el estudiante (ej. preguntas y manipulación de datos y gráficos). 


\begin{tabular}{|c|c|c|}
\hline $\begin{array}{l}\text { Definiciones y } \\
\text { explicaciones }\end{array}$ & & Preguntas \\
\hline $\begin{array}{l}\text { Características: exposición, dictado, } \\
\text { ejemplos prototipo } \\
\text { Momentos: cierre de un proceso } \\
\text { inductivo y al iniciar tema nuevo } \\
\text { Fuente: libro de texto } \\
\text {. Atribuciones: importancia de presentar } \\
\text { la definición matemática } \\
\text { Uso: frecuente }\end{array}$ & & $\begin{array}{l}\text { Características: orales } \\
\text { Finalidad: desarrollar razonamiento } \\
\text { estadístico, comprensión y clarificación } \\
\text { del concepto, reforzar conocimiento } \\
\text { adquirido } \\
\text {. Tipos (situaciones-problemas): explorar } \\
\text { la interpretación de los componentes } \\
\text { estructurales del gráfico, explorar las } \\
\text { características y condiciones del gráfico, } \\
\text { desarrollar el sentido crítico, } \\
\text { conocimiento propositivo para mejorar el } \\
\text { gráfico } \\
\text {.Momento: presentación del gráfico (en } \\
\text { ejercicios) } \\
\text {. Atribuciones: ayudar a comprender el } \\
\text { procedimiento, a resolver la situación, a } \\
\text { evaluar el gráfico } \\
\text {.Uso: frecuente }\end{array}$ \\
\hline & $\begin{array}{l}\text { Ejemplos y ejercicios } \\
\text { Características: actividades de } \\
\text { aprendizaje en papel después de una } \\
\text { definición del concepto } \\
\text {. Tipos: ejemplos y ejercicios } \\
\text {. Momentos: elaborar gráficos, calcular } \\
\text { valores estadísticos, interpretar gráficos } \\
\text {. Niveles cognitivos: no aplica } \\
\text {. Atribuciones: comprender los conceptos } \\
\text { y practicar } \\
\text {.Uso: frecuente }\end{array}$ & \\
\hline \multicolumn{3}{|c|}{ Instrucciones } \\
\hline $\begin{array}{l}\text { Características: indicaciones, señalamie } \\
\text { Técnicas: observación, corrección y con } \\
\text { Atribuciones: ayudar a los estudiantes a } \\
\text {. Uso: casi nunca }\end{array}$ & $\begin{array}{l}\text { s, órdenes (verbales) } \\
\text { etar información del gráfico } \\
\text { nprender situaciones de la RG }\end{array}$ & \\
\hline
\end{tabular}

Figura 5.24. Rasgos característicos de la dimensión conocimiento de las estrategias de enseñanza específicas del CDC de Alicia

Las representaciones que más utiliza Alicia para el tema de la RG son las definiciones y explicaciones, las preguntas, y los ejemplos y ejercicios; mientras que Luis utiliza las preguntas. Esto coincide con la concepción que cada uno tiene de la RG y con el reconocimiento que ambos hicieron, de que no utilizan actividades específicas para desarrollar niveles cognitivos más allá de la lectura literal de datos y leer entre datos, sus actividades están más centradas en las características de cada gráfico y el análisis y relación con el contexto (en el caso de Luis). 


\begin{tabular}{|c|c|c|}
\hline \multirow{3}{*}{$\begin{array}{l}\text { Preguntas } \\
\text { Características: orales } \\
\text {. Finalidad: corroborar intuiciones y } \\
\text { razonamientos, clarificar conceptos, } \\
\text { explorar antecedentes, analizar el } \\
\text { contexto de la situación, analizar } \\
\text { componentes estructurales (incluyendo } \\
\text { variables y escalas de medición), corregir } \\
\text { errores } \\
\text {. Tipos (situaciones-problemas): explorar } \\
\text { significados, explorar las características } \\
\text { y condiciones en la construcción del } \\
\text { gráfico, confrontar la validez de la } \\
\text { información } \\
\text {. Momento: presentación del gráfico (en } \\
\text { ejercicios) } \\
\text {.Atribuciones: desarrollar la capacidad } \\
\text { analítica del estudiantes } \\
\text {.Uso: frecuente }\end{array}$} & & $\begin{array}{c}\text { Manipulación de datos y } \\
\text { gráficos }\end{array}$ \\
\hline & & \multirow{2}{*}{$\begin{array}{l}\text { Características: modificar datos y } \\
\text { edición del gráfico } \\
\text {. Finalidad: explorar los ejes, explorar } \\
\text { las barras, comparar gráficos, } \\
\text {. Ejemplos: rotación de ejes, modificar } \\
\text { características de edición (con ayuda del } \\
\text { SPSS), modificar el tipo de gráfico } \\
\text {. Momento: exposición de gráficos por } \\
\text { parte de los alumnos } \\
\text {. Atribuciones: identificar semejanzas y } \\
\text { diferencias entre gráficos, identificar } \\
\text { errores, corroborar características, } \\
\text { analizar conceptos } \\
\text {. Uso: ocasionalmente }\end{array}$} \\
\hline & & \\
\hline & $\begin{array}{l}\text { Características: desarrollar por equipos } \\
\text { un proyecto de investigación científica } \\
\text { aplicado a la Psicología } \\
\text {. Elementos: problema, marco de } \\
\text { referencia, método, resultados, discusión, } \\
\text { referencias } \\
\text { Momento: a lo largo del curso } \\
\text { Fuente: de los alumnos } \\
\text {. Atribuciones: aplicar los conceptos } \\
\text { estadísticas en contextos de la } \\
\text { investigación en psicología (aprendizaje } \\
\text { situado) } \\
\text {.Uso: siempre }\end{array}$ & \\
\hline \multicolumn{3}{|c|}{ Estudios de casos } \\
\hline \multicolumn{3}{|c|}{$\begin{array}{l}\text { Características: situaciones-problema a partir de una contexto real con el fin de estudiar y analizar un concepto } \\
\text { Elementos: lectura de la situación y contexto, generación de una alternativa o diseño de un experimento, recogida de datos, } \\
\text { análisis de datos, discusión y conclusión. } \\
\text { Momento: después de varios temas relacionados o tipo de estadístico de prueba } \\
\text { Fuente: periódicos, revistas y páginas Webs (Universidad de Búfalo) } \\
\text { Atribuciones: integrar los conceptos vistos y aplicarlos en contextos de la psicología (aprendizaje situado) } \\
\text { Uso: siempre }\end{array}$} \\
\hline
\end{tabular}

Figura 5.25. Rasgos característicos de la dimensión conocimiento de las estrategias de enseñanza específicas del CDC de Luis

Respecto al conocimiento que tienen de las creencias de los estudiantes Alicia identificó: a) los gráficos que se ven en la escuela son los más adecuados para representar datos, b) el gráfico de barras y el histograma sirven para representar siempre algo, c) lo que el profesor hace o dice está bien y d) es difícil de entender gráficos no convencionales. Las creencias de los estudiantes que conoce Luis son: a) lo importante de la representación gráfica: lo bonito, visual, el color y tamaño; b) con los números de la RG se puede hacer lo que quieran; c) los gráficos son todos iguales; y d) es información que hay que poner. Algunas de las creencias que mantienen ambos están estrechamente relacionadas y las diferencias son sutiles, por ejemplo, Alicia piensa que para los estudiantes lo que el 
profesor dice o hace está bien, lo cual tiene relación con que Luis afirma de que es información que hay que poner a partir de lo que el profesor dice. La diferencia radica en que Alicia hace más referencia al papel del profesor, mientras que Luis habla más de cierta cultura aprendida equivocadamente, de que cuando se hace un reporte de investigación lo que importa es "llenar" de gráficos el informe.

Ambos coincidieron que algunas creencias son de origen didáctico y otras debido a las dificultades de los estudiantes al aprender la RG. Sobre el profesor, piensan que depende mucho de cómo éste presente el tema de la RG, de las actividades que haga con sus alumnos y planificar de manera anticipada lo que se quiere para dirigir apropiadamente el aprendizaje. Alicia reconoció la necesidad de conocer el proceso cognitivo del estudiante y diversos materiales y recursos para su enseñanza. Entre las dificultades del estudiante destacan las relativas al desconocimiento de conceptos que previamente deberían tener claros como: variable, tipos de variables y escalas de medición y a las características de cada gráfico.

\begin{tabular}{|c|c|}
\hline Creencias & Errores y dificultades \\
\hline $\begin{array}{l}\text { (1) Los gráficos que se ven en la escuela son } \\
\text { los más adecuados para representar datos. } \\
\text { Atribución: seleccionar gráficos en función de la } \\
\text { frecuencia con que aparece en los medios de } \\
\text { comunicación } \\
\text {. (2) Es difícil de entender gráficos no } \\
\text { convencionales. Atribución: miedo a las } \\
\text { matemáticas y a cierto bloqueo mental al ver } \\
\text { números o símbolos matemáticos o estadísticos } \\
\text {. (3) El gráfico de barras y el histograma sirven } \\
\text { para representar siempre algo. Atribución: } \\
\text { solicitar al estudiante que construya } \\
\text { exclusivamente ciertos gráficos (ej. histograma y } \\
\text { barras) para un único conjunto de datos } \\
\text { descontextualizados } \\
\text {. (4) Lo que el profesor hace o dice está bien. } \\
\text { Atribución: figura de autoridad }\end{array}$ & $\begin{array}{l}\text { (1) Errores por ignorancia o desconocimiento de } \\
\text { conceptos previos. Ejemplos: desconocimiento } \\
\text { del significado de los valores representados en los } \\
\text { gráficos, diferencia entre variable discreta y } \\
\text { continua, no estable relación entre el tipo de } \\
\text { variable y el tipo de gráfico. Atribución: el } \\
\text { profesor sólo se limita a dar la definición, } \\
\text { ignorancia del concepto, no comprende el } \\
\text { significado de variable y la naturaleza de los } \\
\text { datos } \\
\text {. (2) Errores de reconocimiento y comprensión de } \\
\text { la información del gráfico. Ejemplos: no } \\
\text { distinguen que el "intervalo" de la barra de un } \\
\text { histograma es diferente al de un gráfico de barras, } \\
\text { no toma en cuenta que las alturas de las barras } \\
\text { muestran la frecuencia. Atribución: ignorancia de } \\
\text { los elementos y características del gráfico } \\
\text {. (3) Errores en la comprensión de conceptos. } \\
\text { Ejemplos: deformación del concepto de variable, } \\
\text { confunde lo que es una variable con media } \\
\text { poblacional, la variable con la longitud de las } \\
\text { barras y las frecuencias con categorías. } \\
\text { Atribución: comprensión inadecuada de } \\
\text { conceptos } \\
\text {. (4) Errores relacionados con el contexto. } \\
\text { Ejemplos: no comprende lo que se mide a través } \\
\text { del gráfico, } \\
\text { los estudiantes consideran a quién está dirigido el } \\
\text { gráfico. Atribución: desconocimiento del contexto } \\
\text { y énfasis en técnicas de graficación }\end{array}$ \\
\hline
\end{tabular}

Figura 5.26. Rasgos característicos de la dimensión conocimiento de las creencias, errores y dificultades en el estudiante del CDC de Alicia 
Entre los errores y dificultades (ver Figuras 5.26 y 5.27), tanto Alicia como Luis lograron identificar un promedio de 14 errores, con sus correspondientes atribuciones, que están relacionados con las creencias de los estudiantes. Estos errores nos permitieron clasificarlos en cuatro apartados: 1) por ignorancia o desconocimiento de conceptos previos, 2) de reconocimiento y comprensión de la información del gráfico, 3) en la comprensión de conceptos y 4) relacionados con el contexto.

\begin{tabular}{|c|c|}
\hline Creencias & Errores y dificultades \\
\hline $\begin{array}{l}\text { (1) Lo importante de la representación gráfica: } \\
\text { lo bonito, visual, el color y tamaño. Atribución: } \\
\text { no comprende la naturaleza de los datos del } \\
\text { gráfico y se basan en criterios perceptuales } \\
\text {. (2) Con los números de la RG se puede hacer lo } \\
\text { que quieran. Atribución: no comprenden la } \\
\text { naturaleza de los datos, las características y el } \\
\text { sentido del gráfico y el contexto } \\
\text {. (3) Los gráficos son todos iguales. Atribución: } \\
\text { experiencias previas de aprendizaje y falta de } \\
\text { conocimiento de la naturaleza de los datos } \\
\text { (4) Es información que hay que poner. } \\
\text { Atribución: falta de uso de la información del } \\
\text { contexto y del significado de los elementos del } \\
\text { gráfico }\end{array}$ & $\begin{array}{l}\text { (1) Errores por ignorancia o desconocimiento de } \\
\text { conceptos previos. Ejemplos: no consideran desde } \\
\text { el inicio el análisis de las escalas de medición, no } \\
\text { entienden qué es una variable, desconocen la } \\
\text { naturaleza de los datos y las características de los } \\
\text { gráficos y sus elementos. Atribución: falta de } \\
\text { énfasis y estrategia del profesor, confunde } \\
\text { variable con el concepto de media, ignoran los } \\
\text { conceptos } \\
\text {. (2) Errores de reconocimiento y comprensión de } \\
\text { la información del gráfico. Ejemplo: hacer poco } \\
\text { caso a los errores en el diseño del media graph. } \\
\text { Atribución: se da por sentado que los media } \\
\text { graph son correctos } \\
\text {. (3) Errores en la comprensión de conceptos. } \\
\text { Ejemplos: distinguir cuándo se deben representar } \\
\text { las barras separadas (gráfico de barras) y cuándo } \\
\text { no (histograma) y confundir conceptos como } \\
\text { caso, variable, frecuencia. Atribución: no se tiene } \\
\text { el significado de los datos del gráfico, no } \\
\text { comprenden los conceptos } \\
\text {. (4) Errores relacionados con el contexto. } \\
\text { Ejemplos: no le dan sentido a los datos y no son } \\
\text { capaces de realizar argumentación } \\
\text { no interpretan el significado de gráficos, centrarse } \\
\text { exclusivamente en el análisis de los elementos y } \\
\text { datos del gráfico, no consideran la información } \\
\text { del contexto. Atribución: lectura literal de datos, } \\
\text { el profesor se centra en la construcción de } \\
\text { gráficos }\end{array}$ \\
\hline
\end{tabular}

Figura 5.27. Rasgos característicos de la dimensión conocimiento de las creencias, errores y dificultades en el estudiante del CDC de Luis

Complementando la información obtenida de los errores, los alumnos tienen cierto desconocimiento de temas, conceptos o habilidades sobre la RG:

- Lo que no conoce el estudiante: concepto de variable, variable discreta y variable continua, escalas de medición, características y componentes (elementos) del gráfico, relación variable-tipo de gráfico.

- Lo que no observa de los elementos del gráfico: los ejes, los intervalos (los de los rectángulos) del gráfico de barras y del histograma, la frecuencia, los porcentajes, los elementos del media graph, las categorías de un gráfico de barras. 
- Lo que confunde: qué y que no es una variable; diferencia entre variable y media poblacional; diferencia entre variable y longitud de los rectángulos (en el gráfico de barras); diferencia entre frecuencia, categorías y porcentajes; diferencia entre caso, variable, frecuencia y porcentaje; diferencia entre los rectángulos de un gráfico de barras y del histograma.

- Lo que no considera del contexto: propósito del gráfico, lo que se mide a través del gráfico, a quién está dirigido el gráfico, sentido de los datos, argumentación, interpretación, análisis del contexto.

Para corregir determinados errores (a partir del cuestionario didáctico), no tienen una estrategia ad hoc que les permita identificar y diagnosticar errores y dificultades. Generalmente acuden a las preguntas o a la revisión de ejercicios durante las clases. La diferencia está en que Luis aprovecha los diferentes momentos que tiene de interacción con sus estudiantes en la revisión del proyecto de investigación y los estudios de casos, y de la asesoría individual o grupal.

Las Figuras 5.28 y 5.29 resumen los puntos claves de las estrategias para corregir errores y dificultades.

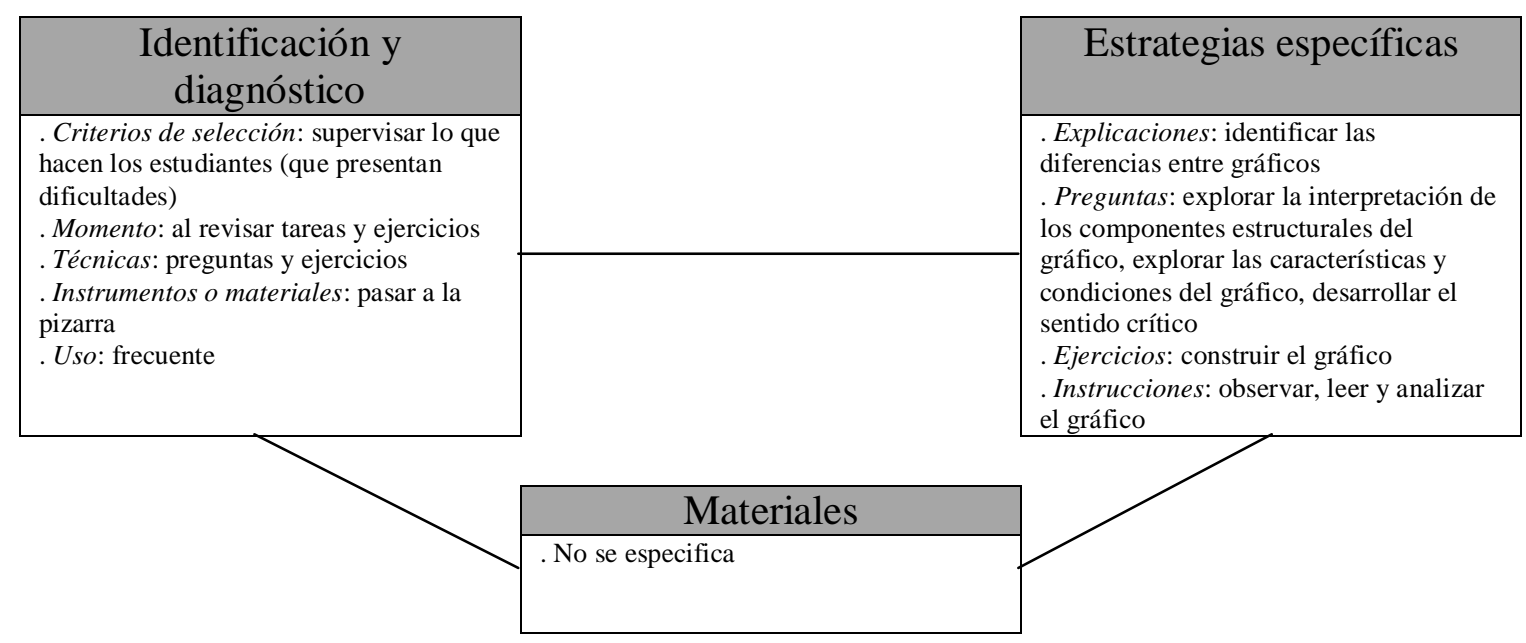

Figura 5.28. Rasgos característicos de la dimensión conocimiento de las estrategias para ayudar al estudiante del CDC de Alicia

Alicia, es congruente con su manera habitual de impartir sus clases, utiliza las mismas estrategias para corregir errores: explicaciones, preguntas, ejercicios e instrucciones; mientras que Luis utiliza las preguntas y las instrucciones. Las preguntas que ambos utilizan están centradas principalmente en clarificar conceptos, analizar las características y los elementos del gráfico. Ambos utilizan las instrucciones como estrategia 
para ayudar a los alumnos aleer, observar, subrayar y elaborar el gráfico. Ni Alicia ni Luis, consideran la elaboración, selección o uso de materiales específicos para corregir los errores y las dificultades de sus alumnos.

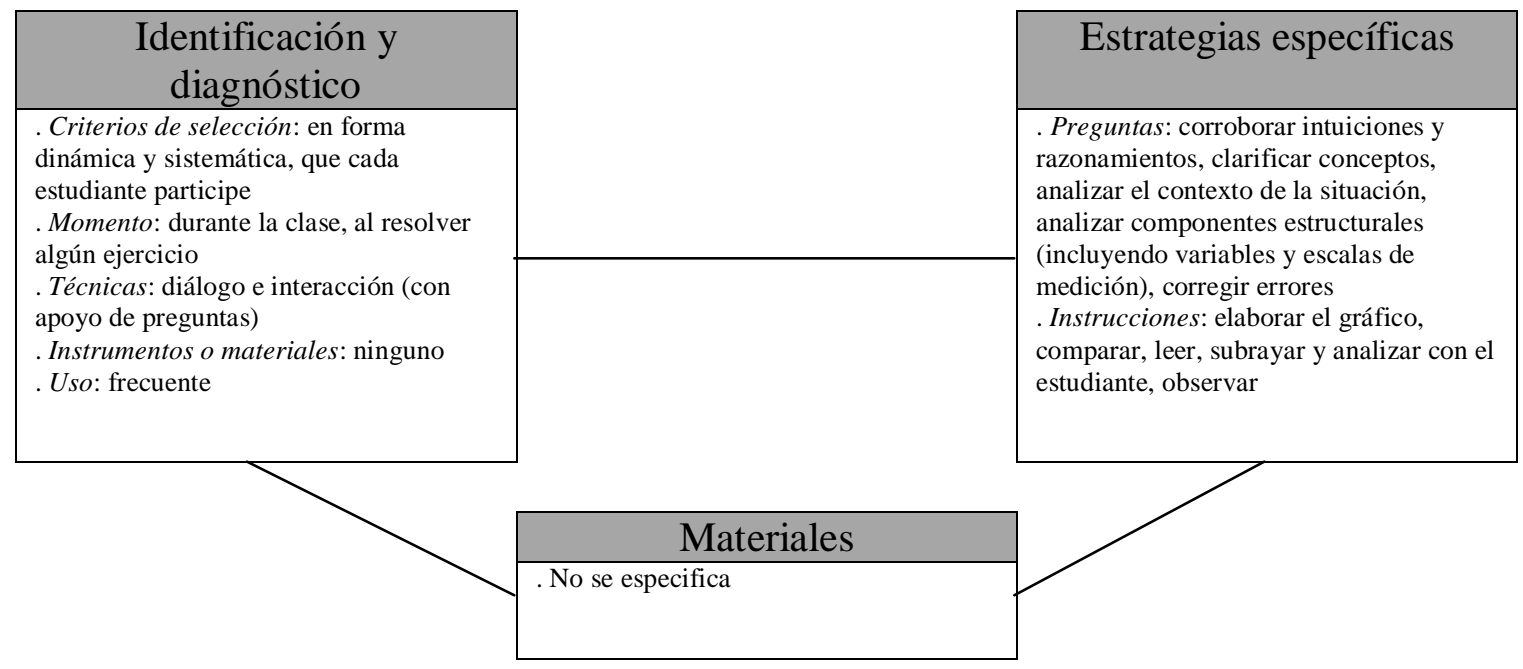

Figura 5.29. Rasgos característicos de la dimensión conocimiento de las estrategias para ayudar al estudiante del CDC de Luis

En el siguiente capítulo, se concluye el análisis y discusión de estos resultados, y se establecen las conclusiones de la investigación. 


\section{CAPÍTULO 6: Discusión y conclusiones}

En este capítulo se discuten los resultados más relevantes de la investigación, se analiza y discute acerca del conocimiento didáctico del contenido sobre la representación gráfica, la consecución de los objetivos y las hipótesis de investigación, las limitaciones identificadas, para después describir la contribución de este estudio. Al final del capítulo se presentan algunas implicaciones para futuras investigaciones y para la enseñanza de la Estadística y de la representación gráfica.

\subsection{DISCUSIÓN}

El retrato del CDC que surge a partir de este estudio está constituido por cuatro grandes áreas que parecen altamente integradas: las concepciones sobre la Estadística y la representación gráfica, su aprendizaje y enseñanza, el conocimiento del currículo, el conocimiento de las estrategias y representaciones instruccionales y el conocimiento del estudiante.

Nosotros analizamos el conocimiento profesional del profesor de matemáticas desde una perspectiva cognitiva (Llinares, 1996) cuyo interés es la identificación del contenido de los diferentes dominios de conocimiento profesional del profesor y cómo se estructura. Desde este punto de vista cognitivo el análisis tuvo como foco las creencias y conocimiento del profesor e intentó dar cuenta de su forma de conocer y de los procesos interpretativos a través de los cuales dota de significado a las situaciones en las que se encuentra y que le permiten dirigir su acción (García, 1997, en Llinares, 1999a).

Sobre las fuentes de conocimiento de los profesores, nuestros resultados coinciden con Wallece (1990) quien encontró que los profesores acuden a colegas, cursos y lecturas para construir el conocimiento. Es decir, los profesores utilizan "su propia experiencia docente y reflexión", y "el intercambio diario con colegas" como dos importantes fuentes para desarrollar los tres componentes del CDC (Fan, 1998). Tanto Alicia como Luis recurren a colegas para que les ayuden a generar, ampliar o profundizar sobre el conocimiento de la materia, específicamente en aspectos exclusivamente de contenidos.

Los dos profesores difieren en su CDC sobre el tema de la representación gráfica, particularmente sobre el conocimiento del currículo y de las representaciones instruccionales, así como del conocimiento de la materia. Se encontró que sus decisiones iniciales están estrechamente relacionadas con su forma de conocer el contenido 
matemático producto, generalmente, de sus experiencias previas que influyen en su concepción de la Estadística y de la RG (Sánchez y Llinares, 2003).

Si bien Luis tiene una concepción hacia la Estadística como herramienta, más incluyente e integral y su enseñanza se caracteriza por darle sentido y significado a los datos a partir de contextos reales, fomentando la investigación científica; su concepción sobre la RG no es así. Tanto él como Alicia enseñan la RG "demasiado formalmente con pocos ejemplos de aplicaciones reales" (Meletiou 2003), excesivamente formalizada, con poca oportunidad de diseñar experimentos, analizar datos o conectar el estudio de la RG con el desarrollo del pensamiento estadístico (Batanero, 2000).

Los resultados demuestran que los profesores tienen una imagen del concepto representación gráfica limitada y obsoleta lo cual representa un problema. Esto limita mucho los contenidos a enseñar, la forma de abordar el aprendizaje y las estrategias y representaciones instruccionales que utiliza el profesor.

La representación gráfica juega un papel importante como forma de desarrollo del pensamiento crítico del estudiante, como objeto de alfabetización de los ciudadanos y como aprendizaje necesario a desarrollar en la escuela (Friel, Curcio y Bright, 2001). Esta habilidad resulta más necesaria en la sociedad actual dado la información presentada en periódicos, revistas, reportes comerciales y en TV exigen habilidad lectora para la comprensión de gráficos (Monteiro y Ainley, 2006; Curcio, 1989). No obstante esto no se refleja ni en el currículo de la asignatura ni en el conocimiento de ambos profesores puesto que ambos le conceden poca importancia al tema.

Esto tiene importantes implicaciones en la enseñanza, dado que las decisiones pedagógicas del profesor (preguntas que ellos hacen, actividades que diseñan, sugerencias que siguen de sus estudiantes) están basadas, en parte, en el conocimiento de la materia (Even, 1993); por consiguiente, es importante que los profesores desarrollen una imagen del concepto de la representación gráfica más moderna.

La falta de contextualización en el estudio de la RG puede ser atribuible tanto a las concepciones que cada uno tiene, como al limitado conocimiento sobre el tema, sobre las representaciones instruccionales y sobre el conocimiento del estudiante. No obstante, también puede atribuirse a las características del diseño curricular de la asignatura de Estadística y concretamente al tema de la RG. Por ejemplo, la falta de un mayor desarrollo en la construcción de gráficos depende tanto de la especificidad de los objetivos, propósito, orientaciones didácticas, recursos, así como del tiempo que se le asigne para la enseñanza. Otro ejemplo que se asocia con el desarrollo cognitivo de los estudiantes, es que únicamente se trata la RG a partir de gráficos descriptivos y categóricos y del histograma.

Ambos profesores desconocen recursos, materiales y actividades actuales para el desarrollo cognitivo de la representación gráfica. Ambos utilizan o sugieren textos antiguos que fomentan o transmiten una concepción de la RG como técnica de graficación.

Las estrategias y representaciones instruccionales mantienen una estrecha relación con las concepciones que tienen tanto de la Estadística como de la RG, así como el 
conocimiento que tienen del currículo. Ambos profesores utilizan un número limitado de representaciones y las relativas a la RG no son actividades diseñadas ad hoc o ya sistematizadas, sino que se realizan en función de lo que ocurra en el aula (ej. preguntas, manipulación de datos y gráficos, instrucciones). Todas ellas se centran en clarificar dudas y reforzar el conocimiento, así como identificar las características y elementos de los gráficos. Las fuentes son los libros de textos para Alicia y las lecturas y páginas Web para Luis. En el caso de Alicia se trata de libros que utilizó durante la carrera, lo cual está relacionado con la concepción que tiene de la RG. En el caso de Luis, si bien cuenta con algunos recursos y lecturas para la enseñanza de otros temas, no es el caso de la RG.

La reforma de la educación estadística (Moore, 1997) impulsó investigaciones desde la perspectiva de la psicología educativa, la psicología cognitiva, la educación matemática y las ciencias de la educación (Garfield, 1995, en Chance y Garfield, 2002), y se ha avanzado sobre la investigación entorno al aprendizaje y enseñanza de la RG (ver Capítulo 3). Estos avances no forman parte del conocimiento de ambos profesores.

Ambos profesores lograron identificar algunas creencias, errores y concepciones, dando sus propios argumentos sobre las atribuciones a cada uno de ellos. El limitado conocimiento que tienen sobre la $\mathrm{RG}$ permite explicar el tipo de argumentos que proporcionan, por ejemplo, la mayoría están relacionados con el desconocimiento de conceptos y con las características y elementos de los gráficos. Encontramos, al igual que Even y Tirosh (1995), que algunas veces saben por qué un caso específico fue resuelto de cierta forma pero no pueden explicar qué ocurre en casos diferentes o extremos. Los datos evidencian que profesores, como Alicia, no se plantean comprender el por qué de las respuestas de los estudiantes y tienen dificultades para explicar por qué reaccionan de una forma determinada. Claramente, esto demuestra que a estos no se les ha formado para su actividad profesional, no han realizado cursos o participado en un programa de formación de profesores.

El conocimiento que tienen sobre las estrategias para corregir o modificar algún error y dificultad de los profesores es también limitado: preguntar y dar instrucciones, principalmente. Por otro lado, no consideran este conocimiento como parte de la base del conocimiento que deben tener para enseñar.

A lo largo de este estudio se ha puesto de manifiesto que no sólo las concepciones están asociadas al CDC de cada profesor, sino también otros elementos como son los conocimientos psicopedagógicos del profesor, Así, Luis incorpora en su concepción hacia el aprendizaje de la Estadística conocimiento especializado de las teorías del aprendizaje, aspectos más concretos como las diferencias individuales, el aprendizaje situado y la socialización del conocimiento. Esto incide en su manera de desarrollar sus clases, en la interacción y diálogo constante, así como en la organización de los trabajos en grupo o individuales, la discusión en grupo grande y las atención a cada estudiante realiza en diferentes momentos. Pensamos que al igual que el conocimiento de la disciplina, el conocimiento de los fundamentos psicopedagógicos tienen mucho que aportar a la práctica de la enseñanza de una materia escolar concreta (López, 1999). 
Se confirman algunas relaciones significativas, como la relación entre las concepciones de la Estadística y la RG, su enseñanza y aprendizaje y el CDC, así como entre las características del CDC y la formación inicial del profesor, las experiencias previas como estudiante, el contexto escolar, la actitud positiva del profesor hacia su formación permanente como docente, y el conocimiento del contenido a enseñar, destacando la experiencia docente del profesor como elemento diferenciador en algunos aspectos relativos a la práctica docente.

Por último, esta investigación, al igual que Escudero y Sánchez (2007), no tiene como propósito mostrar lo "bueno" o "malo" del conocimiento de los profesores, sino más bien, comprender el conocimiento que tiene, explicar los aspectos que están asociados a su construcción e integración, así como identificar diferentes características de las categorías o dominios de conocimientos y cómo estas son integradas y de qué manera influyen en su enseñanza. Por consiguiente, de manera general, las características del CDC en Estadística de Alicia, con particular atención a la RG fueron:

- su concepción sobre la Estadística está centrada en el contenido con énfasis más en la comprensión conceptual, con un marcado énfasis en el trabajo en el aula, pasar a los alumnos a la pizarra, dar explicaciones, ejemplos; basado en evaluar el aprendizaje a través de ejercicios y pruebas escritas;

- le concede mucho peso a que el alumno participe en clases, se preocupe por su propio aprendizaje y esté dispuesto a aprender;

- su concepción sobre la representación gráfica está centrada en la construcción de gráficos, es decir, en la lectura literal del gráfico, extraer información elemental y en la interpretación de los datos del gráfico;

- el objetivo de la Estadística es la comprensión de conceptos estadísticos y que el alumno aplique algunos conceptos en su práctica profesional, entendiendo por aplicaciones a los ejercicios tomado de los libros de textos dentro de algún contexto de la profesión;

- las representaciones instruccionales que utiliza en su enseñanza son las definiciones y explicaciones, preguntas, ejemplos y ejercicios, y las instrucciones; todas ellas centradas en las explicaciones, el uso de ejemplos y la ejercitación a través de prototipos similares utilizados en el aula, centrados en la construcción de gráficos;

- la mayoría de las representaciones instruccionales que utiliza son de tipo verbal, que se derivan de su propia autoría y están focalizadas en la actuación de las clases, según el momento en cuanto a lo que se necesita o pregunte el alumno;

- las definiciones y ejercicios que utiliza para enseñar la representación gráfica se derivan de los libros de textos;

- las atribuciones que le concede a las creencias de los estudiantes son más de origen didáctico;

- la forma habitual con que identifica los errores y dificultades en la RG consisten en revisar las tareas y los ejercicios de los alumnos, pasar a los alumnos a la pizarra y hacerles preguntas relacionadas con los datos del gráfico; y

- utiliza preguntas, explicaciones, ejercicios e instrucciones como estrategias para corregir errores y dificultades de los estudiantes, buscando lograr que el estudiante identifique las características y elementos del gráfico, así como construirlo. 
Por su parte, las características del CDC en Estadística de Luis, con particular atención a la RG fueron:

- concibe la Estadística como una herramienta que debe ayudar a entender lo que está sucediendo en el entorno y en la solución de diversas problemáticas del contexto;

- concede mucho valor al pensamiento reflexivo, a que los alumnos aprendan de sus propios errores y dificultades, así como al aprendizaje situado y a la socialización del conocimiento;

- busca relacionar la Estadística con otras asignaturas, proporcionando ejemplos contextuales de la carrera que estudian los alumnos, utilizando bases de datos reales, a través de proyectos de investigación y estudios de casos;

- relaciona la Estadística con el conocimiento de la metodología científica, centrado en la resolución de problemas, utilidad de la asignatura, la interacción y atención personalizada, la interpelación a los alumnos y el trabajo colaborativo;

- su concepción sobre la representación gráfica se focaliza en la interpretación de relaciones en contextos reales, centrada en la habilidad del estudiante en comprender el significado de gráficos creados por ellos mismos, conocer los componentes del gráfico y responder a pregunas acerca de gráficos; buscando que se diseñen y analicen gráficos a partir de datos reales, explorando su uso en contextos de la vida real y de su profesión;

- la enseñanza de la representación gráfica consiste principalmente en cuestionar las características y fundamentos de las gráficas a partir de algunas preguntas que exploran el conocimiento de los estudiantes sobre los elementos del gráfico, los fundamentos de sus decisiones y la relación con el contexto de donde surgen los datos;

- el objetivo de la Estadística es la adquisición de las bases conceptuales y metodológicas de la investigación de la investigación en Psicología en que se sustenta la Estadística; buscando primero, que los estudiantes comprendan qué es investigar; segundo, que vean a la Estadística como una herramienta; y tercero, que no le tengan miedo;

- los libros de textos que sugiere y utiliza están más orientados hacia aspectos metodológicos que estadísticos;

- las representaciones instruccionales que conoce y utiliza en la enseñanza de la Estadística son las preguntas, la manipulación de datos y gráficos, los proyectos de investigación y los estudios de casos; las dos primeras son específicas para la representación gráfica;

- las representaciones instruccionales que utiliza para la enseñanza de la representación gráfica son tipo verbal, que se derivan de su propia autoría y están focalizadas en la actuación de las clases, según el momento en cuanto a lo que se necesita o pregunte el alumno; orientadas más hacia la exploración de los significados de conceptos previos, de las características y elementos del gráfico;

- la atribuciones que le concede a las creencias de los estudiantes están relacionadas con el desconocimiento de éste de la naturaleza de los datos y los elementos del gráfico; 
- la forma habitual con que identifica y diagnostica las creencias, errores y dificultades es la interacción con los alumnos, con el apoyo de preguntas; y

- las preguntas y las instrucciones son estrategias que utiliza para corregir los errores y dificultades que los estudiantes presentan en el aprendizaje de la representación gráfica.

Los resultados nos permitieron también darnos cuenta que los profesores sostienen una concepción diferente sobre la Estadística que sobre la RG, su aprendizaje y enseñanza. Asimismo, presentan algunas dificultades relacionadas con la adquisición del conocimiento de algún(os) dominio(s) del CDC o de su integración. Al respecto, identificamos las siguientes dificultades:

- relacionar el conocimiento del contenido a enseñar con las representaciones instruccionales y el conocimiento del proceso de aprendizaje del estudiante;

- utilizar una variedad de recursos y materiales para la enseñanza de la representación gráfica; y

- conocer el contenido y estudio de la representación gráfica, más allá de la construcción de gráficos.

Lo anterior evidencia la necesidad de planificar, desarrollar, implementar y evaluar programas de formación de profesores con enfoques diferentes a los actuales, a la luz de la educación estadística, centrados en el desarrollo del CDC en Estadística.

\subsection{CONSECUCIÓN DE LOS OBJETIVOS DE INVESTIGACIÓN}

En este apartado analizaremos en qué medida se han alzando los objetivos que nos habíamos planteado al iniciar este trabajo:

Objetivo 1. Describir las concepciones que tienen los profesores sobre la Estadística, su enseñanza y aprendizaje y sobre la representación gráfica

En el capítulo de resultados, presentamos las concepciones de Alicia y Luis tanto sobre la Estadística, su aprendizaje y enseñanza, así como de la representación gráfica, su aprendizaje y enseñanza. Para la definición de las concepciones sobre la Estadística, nos apoyamos del trabajo hecho por Reid y Petocz (2002) y Petocz y Reid (2002) quienes hicieron una investigación fenomenográfica con estudiantes de matemáticas. En la sección 4.6.4 (del Capítulo 4) resumimos las diferentes concepciones, tanto de la asignatura, como del aprendizaje y enseñanza. Para las concepciones sobre la RG, fue necesario hacer un análisis de contenido de las definiciones y características que diferentes autores le conceden o le han dado a la representación gráfica. A partir de ahí, se elaboraron cinco concepciones sobre la RG que contemplan las aportaciones de Curcio (1989), Garfield (2002) y Aoyama (2006) y se pudo caracterizar la concepción de cada profesor sobre el aprendizaje de la RG; 
mientras que para la enseñanza, solamente identificamos el rasgo característico o el énfasis que cada profesor pone en sus clases.

Los resultados se pueden ver en la sección 5.1 .3 y 5.1 .4 (Alicia) y 5.2.3 y 5.2.4 (Luis), así como el análisis a través del intercaso en la sección 5.3.

Objetivo 2. Determinar el conocimiento acerca de la representación gráfica de los profesores de las carreras de Psicología y Educación

En la sección 5.1.5 y 5.2.5 presentamos los resultados sobre el conocimiento que tiene Alicia y Luis del currículo de Estadística y de la representación gráfica. Específicamente sobre la RG se puede ver en las secciones 5.1.5.2 y 5.2.5.2. Se obtuvo información sobre el conocimiento que cada uno tiene de los objetivos y propósitos de la RG; sobre qué aspectos del contenido enfatiza, prioriza y enseña; las actividades instruccionales que sugiere el programa y las que hace; así como las formas de evaluar y saber cómo el alumno aprendió la RG. El análisis se hizo a partir de la contrastación con lo que se ha establecido a partir de diferentes investigaciones sobre el tema, así como las recomendaciones de investigadores y asociaciones internacionales sobre la enseñanza tanto de la Estadística como de la representación gráfica.

Se relacionó la concepción sobre la $\mathrm{RG}$, su aprendizaje y enseñanza, con los conocimientos que cada uno manifestó. Este análisis puede verse en el 5.3.

Objetivo 3. Determinar el conocimiento de las estrategias y representaciones instruccionales del profesor sobre la representación gráfica en la Estadística

La fuente principal de donde surgen las estrategias y representaciones instruccionales fue el cuestionario didáctico sobre la representación gráfica.

Las secciones 5.1.6 y 5.2.6 presentan los conocimientos de las estrategias y representaciones instruccionales de Alicia y Luis respectivamente. Cada estrategia y representación instruccional se analizó en función de cinco categorías: tipo, forma, fuente, propósito, contexto y momento. Asimismo, se describieron los rasgos características de cada uno y se confronta con lo que en la realidad hace cada profesor y lo que se establece en la literatura.

En la síntesis de cada caso, sección 5.1.11 (Alicia) y 5.2.10 (Luis), se analiza este conocimiento en función de las concepciones que sobre la Estadística y la RG tiene cada uno. 
Objetivo 4. Identificar los conocimientos del profesor sobre los procesos de aprendizaje, errores y dificultades de sus alumnos en la representación gráfica en Estadística

La fuente principal de donde se obtuvo el conocimiento de las creencias, errores y dificultades de los estudiantes fue el cuestionario didáctico sobre la representación gráfica.

Las secciones 5.1.7 y 5.2.7 presentan el conocimiento que Alicia y Luis tienen al respecto. Identificamos aquellas expresiones que reflejan el conocimiento que tienen los profesores de las creencias de los estudiantes. Se hizo un análisis de cada una, con la correspondiente atribución que le otorga el profesor. Ver sección 5.1.7.1 y 5.2.7.1.

Posteriormente, del análisis de contenido de las respuestas que cada uno dio en el cuestionario y la entrevista en profundidad determinamos el conocimiento que tienen de los errores y dificultades de los estudiantes. Se presentó un análisis de cada error, con su correspondiente atribución y ejemplos. Los errores fueron clasificados en cuatro grupos: errores por ignorancia o desconocimiento de conceptos previos; errores de reconocimiento y comprensión de la información del gráfico; errores en la comprensión de conceptos; y errores relacionados con el contexto. Posteriormente, generamos una lista temas, conocimientos o habilidades de lo que no conoce el estudiante; lo que no observa de los elementos del gráfico; lo que confunde; y lo que no considera del contexto y un análisis de cada error. Al final, contrastamos estos conocimientos con lo que establece la revisión de la literatura. Ver sección 5.1.7.2 y 5.2.7.2.

El conocimiento sobre la identificación y diagnóstico se puede ver las secciones 5.1.8 y 5.2.8. Finalmente las secciones 5.1.9 y 5.2.9 presentan las estrategias que Alicia y Luis, respectivamente, usan para la corrección o modificación de determinados errores y dificultades del estudiante. Se agruparon en apartados, se describieron sus características y se contrastó con lo que en la realidad hacen los profesores en sus clases.

Finalmente, en la sección 5.3 se presenta un análisis intercaso, que nos ayudó a comprender mejor sobre el CDC de cada profesor, así como establecer relaciones entre las dimensiones y las concepciones de cada profesor. 


\subsection{HIPÓTESIS DE INVESTIGACIÓN. RESULTADOS}

En este apartado analizaremos las hipótesis de investigación establecidas a la luz de los resultados obtenidos en los diferentes estudios que componen la investigación.

Hipótesis 1. Los profesores cuya formación inicial es matemática tienen una concepción formalista hacia la enseñanza de la Estadística, es decir, conciben la Estadística como ciencia de la demostración rigurosa, basada en un lenguaje y reglas formales, con fundamentos absolutos, cuyas verdades son verificables $y$ normalmente son presentadas por el profesor, quien además enfatiza en el significado de los conceptos y la lógica de los procedimientos estadísticos

Hemos establecido en el aparatado 5.1.3 la concepción de Alicia tiene sobre la Estadística. Ella conceptúa a la Estadística como parte de las matemáticas, sin hacer referencia al campo de la educación estadística. Tiene una concepción hacia la naturaleza de la Estadística dogmático-conservador, basada en explicar y proporcionar ejemplos a los estudiantes, ligada en presentar ejemplos y ejercicios que abordan el concepto a partir de las diferentes formas de solucionar los planteamientos del tema, con una marcado énfasis en el trabajo en el aula.

Alicia concibe la Estadística como una parte de las matemáticas centrada en el análisis e interpretación de datos (Concepción 4 de Reid y Petocz, 2002) puesto que hace alusión a la comprensión, interpretación y dotar de sentido a los datos, la exploración de las diferencias entre los datos y el uso de esas relaciones para esbozar conclusiones acerca de los mismos. Las respuestas de Alicia indican una clara consciencia del material conceptual y la interpretación. Se refiere a la Estadística en términos de habilidades técnicas, conocimiento de hechos y comprensión de los conceptos estadísticos presentados en clase (Gordon, 1998).

A partir de este análisis se rechaza la hipótesis de investigación. Alicia sostiene una concepción más platonista (con énfasis en la comprensión conceptual) que formalista (centrada en la clase). Tiene una visión dogmático-conservadora, por lo que mantiene un estilo tradicional en la enseñanza de la Estadística. Esto se debe a que no ha realizado cursos de formación docente, por lo que desconoce los elementos que subyacen en en el planeamiento docente. No obstante, es congruente con la forma como le enseñaron, enfatiza la definición y significado de los conceptos y la lógica de los procedimientos. 
Hipótesis 2. Los profesores cuya formación inicial es diferente a la matemática tiene una concepción instrumentalista hacia la enseñanza de la Estadística, es decir, se concibe como un conjunto de procesos, algoritmos, reglas y prácticas, en la cual el profesor de manera preestablecida enfatiza en la enseñanza de demostraciones, reglas y procedimientos estadísticos

Hemos establecido en el apartado 5.2.3 la concepción de Luis sobre la Estadística. El conceptúa la Estadística como una herramienta que ayuda a entender lo que está sucediendo en el entorno y en la solución de diversas problemáticas del contexto. Tiene una concepción hacia la naturaleza de la Estadística pragmático-constructivista, caracterizado por tener en cuenta el contexto social, que busca desarrollar capacidades intelectuales, buscando relacionar la Estadística con otras asignaturas, proporcionando ejemplos contextuales a la carrera que estudian los alumnos, utilizando datos reales a través de proyectos de investigación y estudios de casos, conceptuando el aprendizaje de la Estadística unido al de la metodología de la investigación, centrado en la resolución de problemas, la utilidad de la asignatura, la interacción y atención personalizada, la interpelación a los alumnos y el trabajo colaborativo, como características fundamentales de su enseñanza.

Luis concibe la Estadística como una herramienta global usada para dar sentido al mundo y desarrollar significados personales (Concepción 6 de Reid y Petocz, 2002). Los estudiantes usan los métodos estadísticos para desarrollar su propio pensamiento, para crear nuevas interpretaciones de datos y de la vida, crean su conocimiento estadístico a partir del manejo de datos reales. Considera la Estadística como algo aplicado a la investigación en un área disciplinar o en la sociedad (Gordon, 1998), reconociendo tanto los alcances y limitaciones de su uso; conceptuándola como base para el método científico y como una forma de pensamiento crítico.

A partir de este análisis rechazamos también la hipótesis de investigación. Luis sostiene una concepción más constructivista (centrado en el estudiante) que instrumentalista (centrado en el contenido con énfasis en la práctica). Esto es coincidente a partir del análisis de su concepción según varios autores. Las razones pueden estar relacionadas con que proviene de una familia de matemáticos y profesores, que ha sido ayudante de investigación en Psicología aplicada y ha leído algunos referentes teóricos sobre las tendencias de la enseñanza de la Estadística. Se interesa mucho sobre las teorías del aprendizaje y para él tiene mucho valor el aprendizaje situado y la socialización del conocimiento. 
Hipótesis 3. Los profesores tienen un bajo nivel de construcción del conocimiento didáctico del contenido sobre la RG, el cual se explica en función de su concepción de la enseñanza y aprendizaje de la Estadística y de las fuentes de obtención de su conocimiento

En las secciones 5.1.10 y 5.2.10 se presenta una síntesis del conocimiento que cada profesor tiene sobre el CDC y las relaciones que encontramos con sus concepciones. El análisis intercaso (sección 5.3) reafirma la confirmación de la hipótesis de investigación.

Tanto Alicia como Luis tienen un bajo nivel de construcción del CDC sobre la RG. Esto es posible explicarlo a partir de sus concepciones. Alicia por ejemplo, enseña como le enseñaron, con una concepción hacia la RG como técnica de graficación y un estilo docente centrado en definir, explicar y dar ejemplos. La fuente de su conocimiento, particularmente libros de textos, son similares a los que habitualmente utilizó en su época de estudiante. Se actualiza a partir de lecturas y materiales similares a los que utilizó durante su aprendizaje en la carrera de matemáticas y pregunta a sus colegas exclusivamente sobre aspectos de contenidos estadísticos.

Por parte, Luis aún cuando concibe la Estadística como una herramienta, para él la RG cumple el papel de ayudar a interpretar relaciones en contextos reales, pero bajo su propia forma de entender el significado de "sentido gráfico" y "contextos", limitado al uso de bases de datos reales y el aprendizaje de la RG a partir de la construcción de gráficos generados de los proyectos de investigación de los estudiantes. Aún cuando concibe de ese modo la RG, en realidad se limita a trabajar los conceptos de variables, escalas de medición, características y elementos de los gráficos. Aunque Luis conoce algunas tendencias sobre el aprendizaje y la enseñanza de la Estadística y utiliza una diversidad de recursos y estrategias para ello, no es así cuando se trata de la RG.

Salvo el conocimiento que tienen ambos sobre algunas creencias y errores y dificultades a partir del cuestionario didáctico, tienen un limitado repertorio de representaciones instruccionales para la enseñanza de la $R G$, utilizan textos obsoletos y no planifican actividades específicas para el desarrollo de niveles de comprensión gráfica en sus estudiantes. Desconocen los avances en materia de investigación sobre el tema, así como los recursos y materiales disponibles para ello. 
Hipótesis 4. El conocimiento didáctico del contenido de cada profesor es único, construido a partir de su concepción hacia la Estadística y su enseñanza, su formación inicial, su práctica y experiencia docente, lo que le convierte en un modelo con características particulares y distintivas por profesor

En las secciones 5.1.11 y 5.2.10 se presenta una síntesis del CDC de cada profesor y en el análisis de intercaso (sección 5.3) una ampliación para la reflexión. A partir de este análisis confirmamos la hipótesis de que el conocimiento didáctico del contenido de cada profesor es único y construido a partir de su concepción hacia la Estadística y su enseñanza, su formación inicial, su práctica y experiencia docente.

Existe cierta asociación sobre la formación inicial recibida por el profesor, las experiencias previas que tuvo durante sus estudios y las concepciones que van desarrollando a partir de ésta que influyen en el CDC que desarrollan. Hay tres aspectos más que favorecen o inciden de algún modo: el contexto de la materia (ej. carrera que imparte, tipo y características de los estudiantes), los antecedentes de formación pedagógica o matemática de familiares y la actitud y disposición hacia la enseñanza de la Estadística.

Por otro lado, en el CDC intervienen además las interpretaciones particulares que cada profesor hace del contenido. Si bien, pudimos identificar algunos elementos comunes (ej. errores y dificultades), cada uno dirige su atención a determinados temas y tiene intenciones o propósitos diferentes. Cada uno puede usar algunos o muchos recursos o materiales y darles significado diferente. En ambos casos, el CDC se explica a partir de las concepciones que el profesor ya tiene sobre la asignatura y que se comenzaron a generar durante los estudios de la carrera o a través de experiencias previas como docente.

Finalmente, el CDC de un tópico específico, puede tener algunos rasgos característicos, por ejemplo, en el tema de la representación gráfica se espera que los profesores conozcan sobre algunos programas de informática específicos para su enseñanza (ej. simuladores, Applets). El CDC no es un conocimiento específico, se conjuga tanto el conocimiento del contenido a enseñar, el de las representaciones instruccionales y del conocimiento del estudiante. En la medida que cada profesor logre engranar estos podrá darle significado y sentido a la enseñanza de la RG. Ese significado y sentido generalmente es diferente en cada profesor. No obstante, la base del conocimiento para su enseñanza es similar. 


\subsection{LIMITACIONES DEL TRABAJO}

Identificamos y señalamos las siguientes limitaciones del trabajo:

A través de los instrumentos de recogida de datos que utilizamos, la investigación se centró en estudiar el conocimiento de las estrategias y representaciones instruccionales a partir del cuestionario didáctico sobre la RG, bajo determinadas situaciones-problema de enseñanza. No se logró explorar las representaciones instruccionales que cada profesor utiliza en un contexto real de clases, al enseñar la RG.

El estudio sobre el conocimiento del estudiante sólo fue de las creencias, errores y dificultades, a partir del cuestionario didáctico sobre la RG. No se pudo abarcar el estudio del conococimiento de las concepciones de los estudiantes debido a que no se logró obtener la información necesaria del profesor, o bien, incluir otros instrumentos de recogida de información.

No hemos podido indagar sobre las estrategias que utilizan los profesores para corregir o modificar las creencias, errores y dificultades que identificaron en el estudio.

El análisis de la investigación se centró principalmente en el conocimiento de las estrategias y representaciones instruccionales y el conocimiento del estudiante. Aún cuando el conocimiento del contenido a enseñar (primer componente) es parte del CDC, lo central de la investigación fueron los otros dos componentes.

El CDC se exploró sólo a partir de las entrevistas realizadas, el cuestionario didáctico sobre la $\mathrm{RG}$ y el análisis de los materiales del profesor. Las futuras investigaciones deberán incluir el estudio del CDC a partir de la práctica docente del profesor a partir de observaciones en el aula.

\subsection{CONTRIBUCIÓN Y RELEVANCIA}

Esta investigación responde a una preocupación por conocer el conocimiento didáctico del contenido de la representación gráfica de dos profesores que imparten la asignatura de Estadística en contextos diferentes al de las matemáticas, con estudiantes de Psicología y Educación. Se trata de comprender qué conocimiento tienen de la Estadística y específicamente de la representación gráfica, indagar sobre las relaciones que existen entre el conocimiento didáctico del contenido y las concepciones sobre la Estadística y la RG, así como acercarnos a identificar y explicar de qué manera se asocian a su formación recibida, al origen y fuentes de ese conocimiento y algunos otros elementos del contexto. Aún cuando en los marcos teóricos se ha hecho referencia al desarrollo de la investigación correspondiente al Conocimiento Didáctico del Contenido y de la Representación Gráfica como línea de investigación, y que cada día son más los estudios que aparecen, este trabajo tiene una contribución y relevancia importante dado que:

- No se ha hecho ningún estudio sobre el conocimiento didáctico del contenido con profesores de Estadística de educación superior, que impartan clases a estudiantes de carreras de Psicología y Educación. 
- Es una de las primeras investigaciones en México, en el campo de la educación estadística, sobre el conocimiento didáctico del contenido.

- Aporta información útil sobre la naturaleza conceptual y metodología del CDC en educación estadística, que es un constructo donde se ha hecho poca investigación y que actualmente está en desarrollo.

- Organiza y sustenta el estudio del conocimiento didáctico del contenido a partir de un Sistema de Dimensiones e Indicadores (SDI).

- No se había analizado el currículo de Estadística en este nivel y contexto de la Psicología y Educación.

- Utiliza las situaciones-problema para explorar el conocimiento de las representaciones instruccionales y del estudiante aplicado en el contexto de la Estadística y de la representación gráfica.

- Genera un conjunto de objetivos sobre el aprendizaje de la representación gráfica a nivel de pensamiento estadístico, sugerido para el nivel de educación superior.

- Genera una primera aproximación y categorización de las concepciones sobre la representación gráfica.

Concretamente, en Mérida (México) en donde se origina y desarrolla la investigación, hay una relativa ausencia de investigación que incluya el uso de situaciones de aprendizaje para profundizar en el CDC (Van, Driel, De Jong y Verloop, 2002), es decir, prevalecen estudios que investigan el conocimiento del profesor de matemáticas a partir de marcos teóricos provenientes de la pedagogía general. Este puede ser un referente del "paradigma ignorado" (Shulman, 1986b) en la investigación sobre la enseñanza de la Estadística. Contribuye a una línea de investigación sobre el conocimiento profesional del profesor de matemáticas, una línea poco reconocida y estudiada en la región sur-sureste de México. Asimismo, el campo de la educación estadística es un campo incipiente, sobre todo en esta región del país, y la tesis permite reivindicar el papel de la Estadística en la escuela, en los cursos que se imparten, en los programas de formación de profesor y particularmente profesionalizar su estudio, aprendizaje y enseñanza en educación superior. De igual manera, permite poner de relieve el valor que tiene la representación gráfica para esta asignatura y para el aprendizaje de la Estadística en general.

Po otra parte, en el campo de la educación estadística, aporta información sobre cuál es el conocimiento esencial que los profesores tienen y deben tener para enseñar Estadística (Shaughnessy, 2007), se identifican las representaciones instruccionales que utilizan los profesores y el conocimiento que tienen del estudiante en cuanto a las creencias, errores y dificultades sobre la RG. La investigación también identifica y describe un número importante de creencias, errores y dificultades que el estudiante tiene sobre la RG, los cuales sin duda sirven para el conocimiento didáctico del contenido que deben tener los profesores sobre el tema.

En este mismo sentido, la tesis obtuvo también información sobre varios problemas que preocupan actualmente en el campo de la educación estadística: 
a. conocimientos del profesor sobre las creencias, errores y dificultades de aprendizaje de los estudiantes (Shaughnessy, 2007, 1992; Batanero, 2001a y 2000),

b. conocimiento sobre cómo se enseña Estadística en contextos diferentes a la de las matemáticas (Batanero, 2000), como es el caso de la Psicología y la Educación, y

c. los conocimientos y concepciones del profesor (Shaughnessy, 1992; Batanero, et al., 2000), sobre la Estadística y la RG.

Este trabajo nos permitió comprender el CDC de dos profesores, en un tópico específico de la matemática, así como nos ayudó a identificar rasgos característicos comunes y diferentes en la forma de construir el conocimiento base para la enseñanza, lo que proporciona información útil para mejorar la calidad de nuestros programas de formación de profesores (Marks, 1990b, Even, 1990). La investigación nos aporta información sobre la inexistencia y la necesidad de programas de formación de profesores que van a enseñar Estadística, y más concretamente en lo que se refiere a la representación gráfica.

Respecto de los programas para la formación de profesores, como se comentó en el Capítulo 3, actualmente existe en México la Especialización en Estadística dirigida a personas que estén interesadas en profundizar acerca del análisis de datos y los contenidos estadísticos, sin que se incluya la vertiente relativa a la enseñanza de la Estadística. Recientemente, el programa se está revisando por lo que esta investigación puede contribuir a la modificación del programa con la creación de una especialización en la enseñanza de la Estadística.

Por otro lado, la definición y construcción del Sistema de Dimensiones e Indicadores (SDI) del CDC, permite mostrar la diversidad y amplitud de conocimiento que el profesor de matemáticas o de estadística debe tener. La lista logra recoger e identificar muchos de los constructos y conceptos que se deben estudiar o que se están estudiando en el campo de la educación matemática; con lo cual, no sólo genera una aproximación a diferentes agendas de investigación, sino que también permite conocer el énfasis y las tendencias de investigación que se han hecho en torno al CDC y así, identificar componentes, constructos o conceptos (de un tópico específico de las matemáticas) poco o nada estudiados a través de la investigación en didáctica del conocimiento del profesor de matemáticas. El SDI proporciona información útil y valiosa tanto a la generación de más investigación, como para los programas de formación de futuros profesores, profesores noveles y expertos.

La tesis logra recoger información sobre lo que ocurre con la enseñanza de la Estadística en dos instituciones que ofrecen la carrera de Psicología y Educación. Da cuenta de las dificultades que tienen dos profesores con cursos introductorios de Estadística que son diferentes en organización y estructura curricular, selección de contenidos, actividades instruccionales sugeridas, materiales, recursos y bibliografía. Esta investigación permitirá una revisión exhaustiva de los programas para modificarlos y adaptarlos a las condiciones de los planes de estudios de cada carrera. 
Un resultado relevante que no estuvo contemplado incialmente en el planteamiento de la investigación fue el hecho de que ambos profesores solicitaron autorización para utilizar los casos del cuestionario didáctico sobre la RG. Incluso, los dos coincidieron en que a través del cuestionario y las preguntas de las diferentes entrevistas, les ayudó a reflexionar sobre sus conocimientos y práctica docente. El cuestionario y las entrevistas pueden ser un recurso útil para propiciar la reflexión sobre la práctica en la enseñanza de la RG.

Finalmente, el estudio del CDC nos permitió comprender lo que los profesores conocen y piensan, y entender más, que los componentes y dimensiones del constructo están amalgamados entre sí y representan un cuerpo de conocimientos, cuyo eje central es el contenido (Shulman, 1993).

\subsection{IMPLICACIONES PARA FUTURAS INVESTIGACIONES Y PARA LA ENSEÑANZA}

Este trabajo nos ha permitido avanzar en la comprensión del CDC sobre la RG de dos profesores de estadística del nivel superior que imparten clases a estudiantes de Psicología y Educación. A continuación indicamos algunas posibles implicaciones que surgen a partir de los resultados del estudio, las cuales hemos clasificado en futuras investigaciones e implicaciones para la enseñanza.

\subsubsection{Futuras investigaciones}

Para ampliar y profundizar en el CDC sobre la RG, sugerimos por los menos cuatro futuras investigaciones:

a. Investigar el CDC de los profesores de Estadística en la práctica docente, ampliando el estudio a más profesores lo que podría revelar categorías adicionales y proporcionar mejores ejemplos. Realizar una investigación con los profesores que actualmente imparten Estadística en carreras de Psicología y Educación, en las diferentes universidades o instituciones de educación superior en Yucatán; utilizando la observación de las clases en contextos reales durante la enseñanza de la RG. Esto nos permitirá ampliar, profundizar y comprender más sobre el CDC de los profesores de Estadística.

b. Validar las concepciones obtenidas sobre la representación gráfica, su aprendizaje y enseñanza, a partir de un estudio fenomenográfico. Esta investigación deberá incluir tanto a profesores como estudiantes de Psicología y Educación. Los trabajos de Reid y Petocz (2002) y Petocz y Reid (2002) pueden servir como referentes metodológicos.

c. Estudiar el conocimiento que tiene el profesor del estudiante, de sus concepciones, creencias, errores y dificultades a partir de preguntas específicas sobre RG, explicar las atribuciones de éstas y cómo pueden utilizarlas, para corregir las respuestas inapropiadas de estos. Se sugiere utilizar la investigación acción, por ejemplo, para 
el estudio del conocimiento del profesor de las concepciones de los alumnos, que incluya no sólo la identificación y reflexión sobre las concepciones, sino la puesta en marcha de estrategias para corregir aquellas que son inadecuadas o equívocas.

d. Estudiar el CDC a partir de otras fuentes de información, como son la observación en clases, la planificación de las lecciones de clase (Chick y Pierce, 2008), la "Guía para Analizar y Evaluar la Didáctica Apropiada" (Guide to Analyse and Evaluate the Didactial Suitability, GAEDS; Godino, et al, (2008) o el modelo sobre el conocimiento estadístico para la enseñanza de Burgess (2006 y 2008). Nuestra investigación se centró en el estudio del CDC a partir de las situaciones-problemas. No obstante, en los últimos dos años han surgido nuevos hallazgos a partir de la educación estadística que pueden ayudar a estudiar el CDC desde otra perspectiva conceptual y metodológica.

\subsubsection{Enseñanza de la Estadística y de la representación gráfica}

El análisis y discusión de los resultados obtenidos en esta investigación nos permitió reflexionar sobre las implicaciones que debe tener en la mejora continua de la enseñanza y aprendizaje de la Estadística, y particularmente de la representación gráfica. Ponemos a consideración cinco primeras recomendaciones:

Primero, revisar y actualizar los programas de Estadística que se imparten en las carreras de Psicología y Educación, particularmente lo relativo a la representación gráfica. Considerar para ello las aportaciones de los autores citados en la Concepción 5 (sección 4.6.4) sobre la representación gráfica, así como las hechas por Garfield y Ben-Zvi (2008), Godino, et al (2008), la NCTM (2000), así como las recomendaciones emitadas por la American Statistical Association (ASA, 2007) en el reporte denominado Pautas para la Evaluación e Instrucción en Educación Estadística (Guidelines for Assessment and Instruction in Statistics Education, GAISE) donde se establece que todo curso introductorio de Estadística (ver sección 2.2, p.98 del Capítulo 2).

Considerar las recomendaciones que la American Statistical Association y la Mathematical Association of América (en Moore, 2000) emitieron sobre las bases en que se debe sustentar los cursos de Estadística:

1. Énfasis en los elementos del pensamiento estadístico

(a) la necesidad de los datos,

(b) la importancia de producir los datos,

(c) la omnipresencia de la variabilidad, y

(d) la medición y modelación de la variabilidad.

2. Incorporar más datos y conceptos, menos recetas y énfasis en el cálculo. Tanto como sea posible, hacer uso de la tecnología para los cálculos y construcción de gráficos. Un curso introductorio debería:

(a) darle un valor verdadero a los datos reales (no meramente ficticios, hipotéticos), provenientes de contextos reales, 
(b) enfatizar en conceptos estadísticos (ej. causa vs asociación, experimental vs observacional y longitudinal vs estudios transeccionales),

(c) trabajar con el uso de computadoras que con resetas de cálculo, y

(d) atender con igual importancia tanto las derivaciones formales como secundarias.

3. Fomentar el aprendizaje activo, a través de alternativas de clases:

(a) resolución de problemas en grupo y discusión,

(b) ejercicios de laboratorio,

(c) demostraciones basadas sobre datos generados en clase,

(d) presentaciones escritas y orales, y

(e) proyectos, tanto grupales como individuales.

O bien, Ben-Zvi y Garfield (2004) Burgess (2002), y Hawkins, Jollife y Glickman (1992), entre otros más.

Segundo, el estudio e implementación del CDC como modelo de formación de profesores plantea todavía grandes retos o desafíos en la enseñanza de la Estadística y más específicamente en Mérida (México). Dos son los primeros desafíos: 1) reconocer el valor del CDC en la formación de profesores y 2) analizar los programas de formación de profesores de matemáticas que existen, a la luz del CDC.

El primer desafío comprende el difundir el significado del CDC, las implicaciones que tiene como modelo de formación de profesores y como objeto de investigación; así como dar a conocer las experiencias de formación y de investigación en otros países.

El segundo desafío comprende incluir en el análisis de los programas de formación de profesores de matemáticas, en los diferentes subsistemas o niveles educativos, el estudio del CDC. Este análisis deberá realizarse a partir de la naturaleza y enfoque pedagógico que prevalece en el sistema educativo mexicano. Por ejemplo, a nivel bachillerato, recientemente la formación de los profesores se focaliza en el modelo por competencias. Por otro lado, se deberá contemplar el estudio del CDC en diferentes fases del desarrollo curricular: planeación, diseño, implementación y evaluación.

Tercero, la investigación nos mostró que los profesores utilizan como recurso principal para la RG los libros de textos obsoletos y centrados en técnicas de graficación. Es urgente la adquisición de material que presenta una concepción diferente que atienda a las recomendaciones sobre la enseñanza de la Estadística. Las primeras acciones deberán consistir en enviar un listado de referencias actualizada a las instituciones educativas donde se imparte la asignatura y a las instituciones formadoras de profesores, acompañado de una relación de sitios $W e b$, materiales y recursos para la enseñanza de la Estadística. Otras acciones será invitar a especialistas, autores de libros o de materiales, para actualizar o capacitar a los profesores sobre éstos.

Cuarto, utilizar el cuestionario didáctico sobre RG como instrumento para que el profesor reflexione sobre sus conocimientos y práctica docente en la enseñanza del tema. La creación de comunidades de práctica puede ser una estrategia que facilite y coadyuve en 
este sentido. Otra estrategia puede ser el apoyo de maestros asistentes (Noll, 2007) que sirvan para retroalimentar, acompañar, ayudar a profundizar, incentivar y enriquecer la reflexión.

Cinco, diseñar un programa ad hoc para la formación de los profesores sobre el CDC de la representación gráfica, que incluya el reconocimiento de las concepciones, así como el estudio de cada uno de sus componentes a partir de un modelo transformativo (Gess-Newsome, 1999), utilizando los resultados de esta investigación, considerando los resultados de otras como las citadas en el marco teórico de la RG (Capítulo 2) y las recomendaciones, publicaciones, materiales y recursos de asociaciones internacionales como la IASE (http://www.stat.auckland.ac.nz/ iase/). Como señala Espinel (2007), falta incluir temas claves relativos a las pautas para la construcción de gráficas, las dificultades y errores más frecuentes en los alumnos, algunas propuestas didácticas o materiales didácticos y nuevas modalidades de evaluación.

Como reflexión final, el trabajo que se presenta en esta tesis nos ha permitido comprender el CDC del profesor, sobre la Estadística, con particular atención en la representación gráfica. Particularmente identificamos algunos rasgos característicos del CDC y cómo el profesor organiza el conocimiento para la enseñanza. Los resultados nos permiten concluir que debemos reconocer la existencia de diferentes profesores, quienes construyen e integran diferentes aspectos de su CDC en función de su formación inicial, sus concepciones sobre la asignatura y sobre el contenido, del conocimiento del contenido a enseñar, y a partir de su propia experiencia y práctica docente. Nuestra investigación logró acercarse a entender lo que conoce cada profesor y qué hace con lo que conoce. Abre una línea de investigación específica sobre el CDC en Estadística, particularmente de profesores que enseñanza a nivel universitario en carreras del área de ciencias sociales. Será importante continuar investigando otros aspectos que permitan darnos más información, que ayude a mejorar nuestro conocimiento y comprensión del CDC en Estadística. 
414 Conocimiento didáctico del contenido sobre la representación de datos: estudios de casos

Jesús Enrique Pinto Sosa 


\section{REFERENCIAS}

Alaminos, A. (1993). Gráficos. Cuadernos Metodológicos 7. Madrid: Centro de Investigaciones Sociológicas (CIS).

American Psychological Association (APA) (2002). Publication Manual of the American Psychological Association (5a ed.). Washington, DC: Autor.

American Statistical Association (ASA). (2007). GAISE College Report. Recuperado el 12 de julio de 2008, de http://www.amstat.org/education/gaise.

An, S., Kulm, G. y Wu, Z. (2004). The pedagogical content knowledge of middle school, mathematics teachers in China and U.S. Journal of Mathematics Teacher Education, 7, 145-172.

Angulo y Vázquez (2003). Los estudios de caso. Una aproximación teórica. En R. Vázquez y F. Angulo (Eds.), Introducción a los estudios de casos. Los primeros contactos con la investigación etnográfica, (pp.15-51). Málaga: Aljibe.

Angulo, F. (1995). Proyecto docente e investigador. Cádiz: Universidad de Cádiz.

Aoyama, K. (2006). Investigating a hierarchy of students'graph interpretation. En A. Rossman \& B. Chance (Eds.). Proceedings of the Seventh International Conference on Teaching Statistics. Salvador, Brazil: International Statistical Institute. $\begin{array}{llllll}\text { Recuperado el julio de } 2008, & \text { de }\end{array}$ http://www.ime.usp.br/ abe/ICOTS7/Proceedings/PDFs/InvitedPapers/6C2_AOYA . $\mathrm{pdf}$

Aoyama, K. (2007). Investigating hierarchy of students' interpretations of graphs. International Electronic Journal of Mathematics Educations, 2(3), 298-318. Recuperado el 6 de enero de 2009, de http://www.iejme.com/032007/main.htm

Aoyama, K. y Stephens, M. (2003). Graph interpretation aspects of statistical literacy: a japanese perspective. Mathematics Education Research Journal, 15(3), 3-22.

Appleton, K. (2003). How do beginning Primary School Teachers Cope with Science? Toward and understanding of Science Teaching Practice. Research in Science Education, 33(1), 1-25.

Arkin, H. y Colton, R. (1940). Graphs: How to Make and Use Them. Rev. ed. New York: Harper \& Brothers.

Arteaga, P., Batanero, C. y Ruiz, B. (2008). Complejidad semiótica de gráficos estadísticos en la comparación de dos distribuciones por futuros profesores. Hipótesis Alternativa, 9(1), 4-5. Recuperado el 10 de marzo de 2009, de http://www.ucv.ve/hipotesis/Data/Hipotesis\%20alternativa\%20N16.pdf

Attorps, I. (2004). Secondary School Teachers' Pedagogical Content Knowledge. En M. Johsen \& A. Berit. (Eds.), Proceedings of the 28th Conference of the International Group for the Psychology of Mathematics Education (PME28) (pp.1-279). Noruega: Bergen University College. 
Attorps, I. (2006). Mathematics teachers' conceptions about equations. Disertación Doctoral no publicada, Universidad de Helsinki.

Azcárate, C. (1998). Las entrevistas en investigaciones de didáctica de las matemáticas. Análisis de algunas experiencias próximas. En J. B. Pascual (Ed.), Segundo Simposio de la Sociedad Española de Investigación en Educación Matemática (pp.29-35). Pamplona: Universidad Pública de Navarra.

Bacelar, H., Bright, G., Chadjipelis, T., Cordani, L., Glencross, M., Ito, P. y et al. (2001). What are priority areas of research in statistics education? Reactions to the paper by Batanero, Garfield, Ottaviani and Truran in SERN 1(2). Statistical Education Research Newsletter, 2(1), 3-21. Recuperado el 20 de Julio de 2005, de http://www.stat.auckland.ac.nz/ iase/serj/Newsjan01.pdf

Badillo, L.J. (2003). La derivada como objeto matemático y como objeto de enseñanza y aprendizaje en profesores de Matemática de Colombia. Disertación doctoral no publicada, Universitat Autònoma de Barcelona.

Ball, D. L. (1988). Unlearning to teach mathematics. For the Learning of Mathematics, $8(1), 40-48$.

Ball, D. L. (2005). Mathematics teaching and learning to teach project. American Educational Research Association: Annual Meeting Montreal. Recuperado el 25 de noviembre de 2005, de http://www-personal.umich.edu/ dball/

Ball, D. L. y McDiarmind, G. W. (1990). The Subject Matter Preparation of Teachers. En W. Houston (Ed.), Handbook of Research on Teacher Education (pp.437-449). New York: Macmillan.

Ball, D. L., Lubienski, S. T., y Mewborne, D. S. (2001). Research on teaching mathematics: The unsolved problem of teachers' mathematical knowledge. En V. Richardson (Ed.). Handbook of research on teaching (pp.433-456). New York: Macmillan.

Ball, D. L., Thames, M. H., y Phelps, G. (2005). Articulating domains of mathematical knowledge for teaching, Documento presentado en la American Education Research Association Conference. Recuperado el Julio de 2006, de http://wwwpersonal.umich.edu/ dball/Presentations/RecentPresentations/041405_MKT_AERA . $\mathrm{pdf}$

Bardín, L. (1986). El análisis de contenido. Madrid: Akal.

Barnett, J. y Hodson, D. (2001). Pedagogical Context Knowledge: toward a fuller understanding of what good science teachers know. Science Teacher Education, 85(4), 26-453.

Barrabí, B. y Martín, G. (2007). Características y necesidades de formación profesional de los profesores de estadística en educación superior del área social. Tesis de licenciatura no publicada, Universidad Autónoma de Yucatán.

Batanero, C. (2000). ¿Hacia dónde va la educación estadística? Blaix, 15, 2-13.

Batanero, C. (2001a). Presente y futuro de la Educación Estadística. En Jornadas Europeas de Estadística. La enseñanza y la difusión de la estadística. Instiitut Balear d'Estadística; Palma de Mallorca. Recuperado el 20 de julio de 2005, de http://www.caib.es/ibae/esdeveniment/jornades_10_01/cast/eponencies.htm\#ponenc ias

Batanero, C. (2001b). Didáctica de la Estadística. Granada: GEEUG, Universidad de Granada. 
Batanero, C. (2002). Los retos de la cultura estadística. Conferencia inaugural presentada en la Jornadas Interamericanas de Enseñanza de la Estadística, Buenos Aires. Recuperado el 15 de octubre de 2004, de : http://www.ugr.es/ batanero/articulos/CULTURA.pdf

Batanero, C., Arteaga, P. y Ruiz, B. (2009, enero). Statistical graphs produced by prospective teachers in comparing two distributions. En Sixth Conference of European Research in Mathematics Education (CERME-6) (pp. 10).

Batanero, C., Garfield, J., Ottaviani, M. y Truran, J. (2000). Research into statistical education: some priority questions. Statistical Education Research Newsletter, 1(2), 2-6. Recuperado el 25 de julio de 2005, de http://www.stat.auckland.ac.nz/ iase/serj/newsmay00.pdf

Batanero, C., Godino, J. D., y Roa, R. (2004). Training teachers to teach probability. Journal of Statistics Education, 12(1). Recuperado 31 de Agosto, 2006 de http://www.amstat.org/publications/jse/v12n1/batanero.html

Batanero, C., Godino, J. y Navas, F. (1997). Concepciones de maestros de primaria en formación sobre los promedios. En H. Salmerón (Ed.), VII Jornadas LOGSE: Evaluación Educativa (pp.301-304). Granada: Universidad de Granada,.

Baturo, A. y Nason, R. (1996). Students teachers' subject matter knowledge within the domain of area measurement. Educational Studies in Mathematics, 31(3), 235-268.

Baxter, J. y Lederman, N. (1999). Assessment and measurement of pedagogical content knowledge. En Gess-Newsome, J. y Lederman, N. G. (Eds.), Examining Pedagogical Content Knowledge: the construct and its implications for science education (pp.147-161). Dordrecht: Kluwer Academic

Ben-Zvi, D. y Garfield, J. (Ed.) (2004). The challenge of developing statistical literacy, reasoning and thinking. London: Kluwer Academic Publishers.

Bertin, J. (1973). Le Semiologie Graphique. The Hague: Mouton-Gautier.

Bigss, J. B. y Collis, K. F. (1991). Multimodal learning and the quality of intelligent behaviour. En H. Rowe (Eds.), Intelligence: Reconceptualization and Measurement (pp.57-66). Hillsdale: Erlbaum.

Blanco, L. J. (1997). Concepciones y creencias sobre la resolución de problemas de estudiantes para profesores y nuevas propuestas curriculares. Quadrante, Revista Teorica e de Investigaçao. 6(2), 45-65.

Blanco, L. J. (1998). Otro nivel de aprendizaje: perspectivas y dificultades de aprender a enseñar Matemáticas. Cultura y Educación, 9, 77-96.

Blanco, L. J., Mellado, V. y Ruiz, C. (1995). Conocimiento Didáctico del Contenido de Ciencias y Matemáticas y Formación de Profesores. Revista de Educación, 307, 427-446.

Bolívar, A. (2002). "¿De nobis ipsis silemus?": Epistemología de la investigación biográfico-narrativa en educación. Revista Electrónica de Investigación Educativa, 4 (1). Recuperado el 6 de abril de 2009, de http://redie.uabc.mx/vol4no1/contenidobolivar.html

Bolivar, A. (2005). Conocimiento didáctico del contenido y didácticas específicas. Revista de curriculum y formación del profesorado, 9(2), 1-39.

Borg, W. y Gall, M. (1979). Educational Research. An Introduction. Nueva York: Longman. 
Bowen, M. y Roth, W.M. (1998). Lecturing graphing: What features of lectures contribute to student difficulties in learning to interpret graphs? Research in Science Education, 28(1), 77-90.

Bright, G., y Friel, S. (1998b). Graphical representations: Helping students interpret data. En S. P. Lajoie (Ed.), Reflections on statistics: Learning, teaching, and assessment in grades $K-12$ (pp. 63-88). Mahwah: Lawrence Erlbaum Associates.

Brihgt, G. y Friel, S. (1998a). Students' (grades 6-8) understanding of graphs. En L. Pereira-Mendoza, L.S. Kea, T.W. Kee, y W. Wong (Eds.), Proceedings of the Fifth International Conference on Teaching Statistics (pp.656-662). Singapore: International Statistics Institute.

Bromme, R. (1994). Beyond subject matter: A psychological topology of teachers' professional knowledge. En R. Biehler, R. Scholz, R. Strässer y B. Winkelmann (Eds.), Didactics of mathematics as a scientific discipline (pp.73-88). Dordrecht: Kluwer.

Bruner, J. (1988). Realidad mental, mundos posibles. Barcelona: Gedisa.

Burgess, T. (2002). Investigating the 'data sense' of preservice teachers. En B. Phillips (Ed.), Proceedings of the Sixth International Conference on Teaching Statistics. Ciudad del Cabo, Sudáfrica: International Statistical Institute and International Association for Statistical Education. Recuperado el 25 de junio de 2005, de http://www.stat.auckland.ac.nz/ iase/publications/1/6e4_burg.pdf

Burgess, T. (2006). A framework for examining teacher knowledge as used in action while teaching statistics. En A. Rossman y B. Chance (Eds.), Proceedings of the Seventh International Conference on Teaching Statistics. Salvador, Brazil: International Statistical Institute. Recuperado el 10 de diciembre de 2007, de. http://www.ime.usp.br/ abe/ICOTS7/Proceedings/PDFs/InvitedPapers/6F4_BURG. pdf

Burgess, T. (2008). Teacher knowledge for teaching statistics throught investigations. En C. Batanero, G. Burril, C. Reading \& A. Rossman (Eds.), Joint ICMI/IASE Study: Teaching Statistics in School Mathematics. Challenges for Teaching and Teacher Education. Proceedings of the ICMI Study 18 and 2008 IASE Round Table Conference. Monterrey: ICMI y IASE.

Caballero, A. y Blanco, L. (2007, septiembre). Las actitudes y emociones ante las matemáticas de los estudiantes para maestros de la Facultad de Educación de la Universidad de Extremadura. En el Grupo de Trabajo "Conocimiento y desarrollo profesional del profesor" presentado en el XI Simposio de la Sociedad Española de Investigación en Educación Matemática, Tenerife: Universidad de La Laguna,.

Canada, L. D. (2004). Elementary preservice teacher' conceptions of variation. Disertación Doctoral no publicada, Portland State University, Oregon, EE. UU.. Recuperado el 8 de julio de 2005, de http://www.stat.auckland.ac.nz/ iase/publications/dissertations/04.Canada.Dissertati on.pdf

Carpenter, T., Fennema, E., Peterson, P. y Carey, D. (1988). Teachers' pedagogical content knowledge of students' problem solving in elementary arithmetic. Journal for Research in Mathematics Education, 19(5), 385-401. 
Carrera, E. (2002). Teaching statistics in secondary school. An overview: From the curriculum to reality. En B. Phillips (Ed.), Proceedings of the Sixth International Conference on Teaching of Statistics. Ciudad del Cabo: IASE.

Carrillo, J. (1998). Modos de resolver problemas y concepciones sobre la matemática y su enseñanza: metodología de la investigación y relaciones. Huelva: Universidad de Huelva

Carrillo, J. y Contreras, L. (1993). La identificación de las concepciones del profesor sobre la matemática y la educación matemática como claves para el diseño de estrategias de formación del profesorado. Actas de las VI Jornadas Andaluzas de Educación Matemática, 6 (pp.351-359). Sevilla: Thales.

Carrión, J. C. y Espinel, M. C. (2006). An investigations about translation and interpretation of statistical graphs and tables by students of primary education. En A. Rossman \& B. Chance (Eds.). Proceedings of the Seventh International Conference on Teaching Statistics. Salvador, Brazil: International Statistical Institute. Recuperado el 8 de abril de 2009 de http://www.ime.usp.br/ abe/ICOTS7/Proceedings/PDFs/ContributedPapers/C332.p $\underline{\text { df }}$

Castro, E. y Castro, E. (1996). Conocimiento del contenido pedagógico de los estudiantes de Magisterio sobre la estructura multiplicativa. En J. Jiménez, S. Llinares, y V. Sánchez (Eds.), El proceso de llegar a ser un profesor de primaria. Cuestiones desde la Educación Matemática (pp. 119-141). Granada: Colección Mathema.

Cazorla, I. M. y Santana, E. S. (2006). Tratamento da informação para o ensino fundamental e médio. Itabuna: Via Litterarum.

Cebulla, K. J. (2002). High school students' conceptions of correlation after instruction (Disertación Doctoral, Universidad de Iowa, 2002). Dissertation Abstracts International, 63, 4254A.

Chadjipadelis, T. (1999). Teaching teachers to teach statistics. Documento presentado en la 52nd Session of the International Statistical Institute, Helsinki, Finlandia. Recuperado el 20 de mayo de 2005, de http://www.stat.auckland.ac.nz/ iase/publications .

Chambers, J., Cleveland, W., Kleiner, B. y Tukey, P. (1983). Graphing Methods for Data Analysys. New York: Chapman and Hall.

Chance, B. y Garfield, J. (2002). New approaches to gathering data on student learning for research on statistics education. Statistical Education Research Journal, 1(2), 3841. Recuperado el 28 de junio de 2005, de http://www.stat.auckland.ac.nz/ iase/serj/SERJ1(2).pdf.

Chee, M. I. y Han, P. M. (2006). Teachers' pedagogical content knowledge in the teaching of quadrilaters. En J. Novotná, H. Moraová, M. Krátká, y N. Stehlíková (Eds.), Proceedings 30th Conference of the International Group for the Psychology of Mathematics Education: Vol. 1 (p. 305). Praga: Psychology of Mathematics Education.

Chen, W. (2004). Learning the skill theme approach: salient and problematic aspects of pedagogical content knowledge. Education, 125 (2), 194-212.

Chick, H. (2004). Representing association: Children manipulating data sets. En Proceedings of the 10th International Congress on Mathematical Education (pp. 7). Copenhagen, Dinamarca. 
Chick, H. y Pierce, R. (2008). Teaching statistics at the primary school level: beliefs, affordances, and pedagogical content knowledge. En C. Batanero, G. Burril, C. Reading y A. Rossman (Eds.), en Joint ICMI/IASE Study: Teaching Statistics in School Mathematics. Challenges for Teaching and Teacher Education. Proceedings of the ICMI Study 18 and 2008 IASE Round Table Conference. Monterrey: ICMI y IASE.

Chinnappan, M. y Lawson, M. (2005). A framework for analysis of teachers' geometric content knowledge and geometric knowledge for teaching. Journal of Mathematics Teacher Education, 8, 197-221.

Cleveland, W. (1994). The elements of graphing data. Nueva Jersey: AT\&T Bell Laboratories.

Cobb, G. (1992). Teaching Statistics. En Lynn A. Steen (Ed.). Heeding the Call for Change: Suggestions for Curricular Action (pp.2-43). Washington: Mathematical Association of America.

Cohen, L. y Manion, L. (2002). Métodos de investigación educativa. Madrid: La Muralla.

Conners, F. A., Mccown, S. M. y Roskos-Ewoldsen, B. (1998). Unique Challenges in Teaching Undergraduate Statistics. Teaching of Psychology, 25(1), 40-42.

Contreras, L. (1998). Resolución de problemas. Un análisis exploratorio de las concepciones de los profesores acerca de su papel en el aula. Disertación Doctoral no publicada. Universidad de Huelva.

Contreras, L. (1999). Concepciones de los profesores sobre la resolución de problemas. Huelva: Publicaciones Universidad de Huelva.

Cooney, T. (1994). Research and teacher education: In search of common ground. Journal for Research in Mathematics Education, 25(6), 608-636.

Cooney, T. (1999). Conceptualizing teachers' ways of knowing. Educational Studies in Mathematics, 38(1-3), 163-187.

Costamagna, A. (2001). Mapas conceptuales como expresión de procesos de interrelación para evaluar la evolución del conocimiento de alumnos universitarios. Enseñanza de las Ciencias, 19(2), 309-318.

Cox, D. R. (1997). The current position of statistics: A personal view. International Statistical Review, 65(3), 261-290.

Curcio, F. (1987). Comprehension of mathematical relationships expressed in graphs. Journal for Research in Mathematics Education, 18(5), 382-393.

Curcio, F. (1989). Developing Graph Comprehension. Elementary and Middle School Activities. Reston: National Council of Teachers of Mathematics.

Curcio, F. (2001). Developing Data-Graph Comprehension in Grades K-8. Reston: NCTM.

Curcio, F. y Artzt, A. F. (1997). Assessing students'statistical problem solving behaviours in a small group setting. En I. Gal y J. B. Garfield (Eds.). The Assessment Challenge in Statistics Education (pp.123-138). Amsterdam: IOS Press.

delMas, R. C. (2002). Statistical Literacy, Reasoning, and Learning: A commentary [Versión electrónica], Journal of Statistics Education, 10(3). Recuperado el 14 de julio del 2005, de http://www.amstat.org/publications/jse/v10n3/delmas_intro.html

delMas, R., Garfield, J. y Ooms, A. (2005). Using assessment items to study students' difficulty reading and interpreting graphical representations of distributions. En K. Makar (Ed.), Proceedings of the Fourth International Research Forum on 
Statistical Reasoning, Literacy, and Reasoning. Nueva Zelanda: Universidad de Auckland.

Denzin, N. (1979). The research act in sociology. Chicago: Aldine.

Díaz Barriga, F. (2003). Cognición situada y estrategias para el aprendizaje significativo. Revista Electrónica de Investigación Educativa, 5 (2). Consultado el 14 de diciembre de 2009 en: http://redie.ens.uabc.mx/vol5no2/contenido-arceo.html

Díaz-Barriga, F. (2004). Evaluación de programas de materia. En S. Castañeda. (Ed.), Educación, Aprendizaje y Cognición, Teoría en la práctica (pp. 123-135). México: El Manual Moderno.

Dolores, C. (2008). Las gráficas, sus usos y retos en la enseñanza y en la investigación en matemática educativa. Perspectivas docentes, 36, 51-58.

Dolores, C. y Cuevas, I. (2007). Lectura e interpretación de gráficas socialmente compartidas. Revista Latinoamericana de Investigación en Matemática Educativa, 10(1), 69-96.

Dossey, J., Halvorsen, K. y McCrone, S. (2008). Mathematics Education in the United States 2008. A Capsule Summary Fact Book written for $11^{\text {th }}$ ICME. Reston: NCTM.

Dunkels, A. (1994). Interweaving numbers, shapes, statistics, and the real world in primary school and primary teacher education. En D. Robitaille, D. Wheeler y K. Kieran (Eds.), Selected lectures from the 7th International Congress on Mathematical Education (pp. 123-135). Quebec: Les Presses.

Durand, F. E. (2003). Secondary mathematics preservice teacher's conceptions of rational numbers (Disertación Doctoral, Universidad de Oklahoma, 2003). Dissertation Abstracts International, 64(09), 3227A.

Elliot, J. (1990). La investigación-acción en educación. Madrid: Morata.

Escudero, I. y Sánchez, V. (2007). How do domains of knowledge integrate into mathematics teachers' practice? Journal of Mathematical Behaviour, 26, 312-327.

Espinel, M. (2007). Construcción y razonamiento de gráficos estadísticos en la formación de profesores. En M. Camacho, P. Flores, y P. Bolea (Eds.), Actas XI Simposio SEIEM, (pp. 99-119). La Laguna: Universidad de La Laguna.

Espinel, M. C. y Bruno, A. (2008). Algunas dificultades sobre gráficas estadísticas que perduran en los estudiantes para profesores de Primaria. Hipótesis Alternativa, 9(1), 17. Recuperado el 10 de marzo de 2009, de http://www.ucv.ve/hipotesis/Data/Hipotesis\%20alternativa\%20N16.pdf

Espinel, M. C., Bruno, A. y Plasencia, I. (2008). Statistical graphs in the training of teachers. En C. Batanero, G. Burril, C. Reading \& A. Rossman (Eds.), en Joint ICMI/IASE Study: Teaching Statistics in School Mathematics. Challenges for Teaching and Teacher Education. Proceedings of the ICMI Study 18 and 2008 IASE Round Table Conference. Monterrey: ICMI y IASE.

Estepa, A. y Batanero, C. (1994). Judgments of association in scatterplots: An empirical study of students' strategies and preconceptions. Documento presentado en el Fourth International Conference Psychology on Teaching Statistics (IV ICOTS). The National Institute of Statistics and Applied Economics: Morocco.

Estrada, A. (2002). Análisis de las actitudes y conocimientos estadísticos elementales en la formación del profesorado. Disertación Doctoral no publicada, Universidad Autónoma de Barcelona. 
Even, R. (1990). Subject matter knowledge for teaching and the case of functions. Educational Studies in Mathematics, 21(6), 521-544.

Even, R. (1993). Subject-matter knowledge and pedagogical content knowledge: Prospective secondary teachers and the function concept. Journal for Research in Mathematics Education, 24(2), 94-116.

Even, R. (2003). What can teachers learn research in mathematics education? For the Learning of Mathematics, 23(3), 38-42.

Even, R. y Tirosh, D. (1995). Subject-matter knowledge and knowledge about students a sources of teacher presentations of the subject-matter. Educational Studies in Mathematics, 29(1), 1-20.

Fan, L. (1998). The development of teachers' pedagogical knowledge: An investigation of mathematics teachers in three high-performing high schools (Disertación Doctoral, Universidad de Chicago, 1998). Dissertation Abstracts International, 59(07), 2322A.

Farías, L., y Montero, M. (2005). De la transcripción y otros aspectos artesanales de la investigación cualitativa. International Journal of Qualitative methods, 4(1). Recuperado el 16 de abril de 2006, de http://www.ualberta.ca/ iiqm/backissues/4_1/pdf/fariasmontero.pdf

Fenstermacher, G. (1978). A philosophical consideration of recent research on teacher effectiveness. En L. S. Shulman (Ed.), Review of Research in Education, 6, 157185, Itasca, IL, Peacock.

Fernández-Balboa, J. M. y Stiehl, J. (1995). The generic nature of pedagogical content knowledge among college professors. Teaching and Teacher Education, 11(3), 293-306.

Flick, U. (2004). Introducción a la investigación cualitativa. (T. Del Amo, Trad.). Madrid: Ediciones Morata, S L y Fundación Paideia Galiza. (Trabajo original publicado en 2002).

Flores, P. (1998). Concepciones y creencias de los profesores sobre las matemáticas, su enseñanza y aprendizaje. Investigación durante las prácticas de enseñanza. Granada: Mathema Colección.

Font, J. D., Godino, J. D. y D'Amore, B. (2007). An ontosemiotic approach to representations in mathematics education. For the Learning of Mathematics, 27(2), 3-9.

Fox, D. (1981). El proceso de investigación en educación. Pamplona: Ediciones Universidad de Navarra, S. A.

Friel, S. \& Bright, G. (1995). Graph Knowledge: Understanding How Students Interpret Data Using Graphs. Documento presentado en the Annual Meeting of the North American Chapter of the International Group for the Psychology of Mathematics Education, Columbus, OH, EE. UU.

Friel, S., Bright, G., Frierson, D., y Kader, G. (1997). A framework for assessing knowledge and learning in statistics (K-8). En I. Gal y J. B. Garfield (Eds.), The Assessment Challenge in Statistics Education (pp. 55-63). Amsterdam: IOS Press.

Friel, S., Bright, G., y Curcio, F. (1997). Understanding students' understanding of graphs. Mathematics Teaching in the Middle School, 3(3), 224-227. 
Friel, S., Curcio, F. y Bright, G. (2001). Making sense of graphs: Critical factors influencing. Comprehension and Instructional Implications. Journal of Research in Mathematics Education, 32(2), 124-158.

Friel, S., y Bright, G. (1996). Building a theory of graphicacy: How do students read graphs? Documento presentado en el Annual Meeting of the American Educational Research Association, New York.

Gal, I. (2002). Adult statistical literacy: meanings, components, responsabilities. International Statistical Review, 70(1), 1-25.

Gal, I. y Garfield, J. (1997) (Eds.), The AssessmentChallenge in Statistics Education Amsterdam: IOS Press.

García, M. (1994). La relación entre la conceptualización de los profesores acerca de las matemáticas, su enseñanza y aprendizaje y la resolución de problemas. Tesis de maestría no publicada [en Ciencias, Especialidad de Matemática Educativa], Centro de Investigación y Estudios Avanzados del Instituto Politécnico Nacional, México, DF.

García, M. (1997). Conocimiento profesional del profesor de matemáticas. El concepto de función como objeto de enseñanza-aprendizaje. Sevilla: Universidad de Sevilla.

García, M. (2005). La encuesta. En M. García, J. Ibáñez y F. Alvira (Eds.). El análisis de la realidad social. Métodos y técnicas de investigación (3a . ed.). Madrid: Alianza Editorial.

García, M. y Llinares, S. (1999). Procesos interpretativos y conocimiento profesional del profesor de matemáticas: reflexiones desde la perspectiva de la enseñanza como diseño. Quadrante, 8, 61-84.

Garfield, J, delMas, B. y Chance, B. (2003, agosto). The Web-based ARTIST: Assessment Resource for Improving Statistical Thinking. Documento presentado en el Symposium: Assessment of Statistical Reasoning to Enhance Educational Quality of AERA Annual Meeting, Chicago.

Garfield, J. (1995). How students learn Statistics. International Statistical Review, 65, 2534.

Garfield, J. (1996). Assessing student learning in the context of evaluating a chance course. Communications in Statistics. Theory and Methods, 25(11), 2863-2873.

Garfield, J. (2002). Web ARTIST: Assessment Resource Tools for Improving Statistical Thinking. Founded by National Science Foundation and University of Minnesota and California Polytechnic State University. Recuperado el 9 de febrero de 2005, de https://data.gen.umn.edu/artist/index.html

Garfield, J. (2003). Assessing statistical reasoning. Statistical Education Research Journal, 2(1), 22-38. Recuperado el 25 de noviembre de 2005, de http://www.stat.auckland.ac.nz/ iase/serj/SERJ2(1).pdf

Garfield, J. y Ben-Zvi, D. (2008). Developing students'statistical reasoning. Connecting research and teaching practice. London: Springer.

Garritz, A. y Trinidad, R (2004). El conocimiento pedagógico del contenido. Educación Química. 15(2), 98-102.

Garritz, A., Nieto, E., Padilla, K., Reyes, F. y Trinidad, R. (2008). Conocimiento didáctico del contenido en química. Lo que todo profesor debería poseer. Campo Abierto, 27(1) 153-177. 
Gattuso, L. y Pannone, M. (2002). Teacher's training in a statistic teaching experimentation. En B. Phillips (Ed.), Proceedings of the Sixth International Conference on Teaching Statistics, (pp. 685-692). Cape Town: International Association for Statistical Education e International Statistical Institute.

Gess-Newsome, J. (1999). Pedagogical content knowledge: an introduction and orientation. En Gess-Newsome, J. y Lederman, N. G. (Eds.), Examining Pedagogical Content Knowledge: the construct and its implications for science education (pp.3-17). Dordrecht: Kluwer Academic Publishers.

Gess-Newsome, J. y Lederman, N. G. (Eds.) (1999). Examining Pedagogical Content Knowledge: the construct and its implications for science education. Dordrecht: Kluwer Academic Publishers.

Gil, F. (2000). Marco conceptual y creencias de los profesores sobre evaluación en matemáticas. Almería: Servicios de publicación Universidad de Almería.

Gil, F. y Rico, L. (2003). Concepciones y creencias del profesorado de secundaria sobre la enseñanza y aprendizaje de las matemáticas. Enseñanza de las Ciencias, 21(2), 2747.

Gimeno, J. (1988). El curriculum: una reflexión sobre la práctica. Madrid: Morata

Giraud, G. (1997). Cooperative Learning and Statistics Instruction. Journal of Statistics Education 5(3). Recuperado el 10 de diciembre, 2009 de http://www.amstat.org/publications/JSE/v5n3/giraud.html

Gitirana, V., Guimarães, G.,_Magina, S. y Carzola, I. (2008). Construção de gráficos de coluna: abilidade de alunos e professores. Hipótesis Alternativa, 9(1), 20-21. Recuperado el 10 de marzo de 2009, de http://www.ucv.ve/hipotesis/Data/Hipotesis\%20alternativa\%20N16.pdf

Glaser y Strauss (1967). The discovery of grounded theory: Strategies for qualitative research. Chicago: Aldine.

Godino, J., Batanero, C., Roa, R. y Wilhelmi, M. (2008). Assessing and developing pedagogical content and statistical knowledge of primary school teachers through project work. En C. Batanero, G. Burril, C. Reading \& A. Rossman (Eds.), en Joint ICMI/IASE Study: Teaching Statistics in School Mathematics. Challenges for Teaching and Teacher Education. Proceedings of the ICMI Study en la ronda de mesas de conferencias.

González, M. y Pinto, J. (2006). La formación de profesores de enseñanza secundaria en España y Méjico. En J. Aymerich, y S. Vives (Eds.), Matemáticas para el siglo XXI, 22 (pp. 207-214). Castellón: Univerdad de Jaume I.

González, M. y Pinto, J. (2008). Conceptions of four pre-service teachers on graphical representations. En C. Batanero, G. Burril, C. Reading \& A. Rossman (Eds.), en Joint ICMI/IASE Study: Teaching Statistics in School Mathematics. Challenges for Teaching and Teacher Education. Proceedings of the ICMI Study 18 and 2008 IASE Round Table Conference. Monterrey: ICMI y IASE.

Goodman, N. (1968). Languages of Art: An Approach to a Theory of Symbols. Indianapolis: Bobbs-Merrill.

Gordon, S. E. (1998). Understanding students learning statistics: An activity theory approach. Disertación Doctoral no publicada, Universidad de Sydney, Australia. 
Gould, R. y Peck, R. (2004). Preparing teachers to teach statistics. En Proceedings of the 10th International Congress on Mathematical Education (8 pp.). Copenhagen, Dinamarca.

Graeber, A. (1999). Forms of knowing mathematics: What preservice teachers should learn. Educational Studies in Mathematics, 38(1-3), 189-208.

Graesser, A. C., Swamer, S. S., Baggett, W. B., y Sell, M. A. (1996). New models of deep comprehension. En B. K. Britton y A. C. Graesser (Eds.), Models of understanding text (pp. 1-32). Nueva Jersey: Erlbaum.

Grossman, P. (1990). The Making of a Teacher. Teacher Knowledge and Teacher Education. New York: Teachers College Press.

Grossman, P. y Richert, A. (1988). Unacknowledge Knowledge growth: A re-examination of the effects of teacher education. Teaching and Teacher Education, 4, 53-62.

Grossman, P., Wilson, S. y Shulman, L. (1989). Teachers of Substance: Subject Matter Knowledge for Teaching. En M. Reynolds (Ed.), Knowledge Base for the Beginning Teacher (pp. 23-36). New York: Pergamon Press.

Guba, E. G y Lincoln, Y. S. (1994). Competing paradigms in qualitative resaerch. En N. K. Denzin y Y. Lincoln (Eds.), Handbook of qualitative research (pp.105-117). Thousand Oaks, California: SAGE: publications

Guba, E. G. y Lincoln, Y. S. (1981). Effective evaluation. San Francisco, C. A: JosseyBass.

Hawkins, A., Jollife, F. y Glickman, L. (1992). Teaching statistical concepts. London:

Hawkins, D. (s. f.). Conceptual barriers encountered in teaching science to adults: An outline of theory and a summary of some supporting evidence. En M. Apelman, R. Colton, A. Flexer y D. Hawkins (Eds.), A Report of Research on Critical Barriers to Learning and understanding of Elementary Science. University of Colorado: Boulder, C.O.

Henry, G. T. (1995). Graphing Data. Techniques for Display and Analysis. Applied Social Research Methods Series (Vol. 36). London: SAGE Publications.

Hermann, B. A. y Duffy, G. G. (1989, Marzo). Relationships between teachers' conceptual understandings, teacher responsiveness and student outcomes: Two exploratory studies in teacher education settings. Documento presentado en el Annual Meeting of the American Educational Research Association, San Francisco.

Hill, H., Schilling, S., y Ball, D. L. (2004). Developing Measures of Teachers' Mathematical Knowledge for Teaching. Elementary School Journal, 105(1), 11-30.

Holmes, P. (2002). Some lessons to be learnt from curriculum developments in statistics. En B. Phillips (Ed.), Proceedings of the Sixth International Conference on Teaching of Statistics. Ciudad del Cabo: IASE.

Howald, C. L. (1998). Secondary teachers' knowledge of fuctions: Subject matter knowledge, pedagogical content knowledge, and classroom practice (Disertación Doctoral, Universidad de Iowa, 1998). Dissertation Abstracts International, 59(05), 1500A.

Huberman, M., Thompson, C. y Weiland, S. (2000). Perspectivas de la carrera del profesor. En B. J. Biddle, T. L. Good y I. F. Goodson (Eds.), La enseñanza y los profesores: Vol. I. La profesión de enseñar (pp. 19-38). Barcelona: Paidós 
Huerta, P. (1998). La entrevista clínica y los mapas conceptuales. En J. B. Pascual (Ed.), Segundo Simposio de la Sociedad Española de Investigación en Educación Matemática (pp.57-67). Pamplona: Universidad Pública de Navarra.

Hutchison, L. S. (1992). How does prior subject matter knowledge affect the learning of pedagogical content knowledge in a mathematics methods course at the preservice (Disertación Doctoral, Universidad de Washington, 1992). Dissertation Abstracts International, 54(01), 117A.

ICMI/IASE (2006). Statistics Education in School Mathematics: Challenges for Teaching and Teacher Education. En International Commission on Mathematical Instruction (ICMI)/ International Association for Statistical Education (IASE) Study. Recuperado el 26 de julio de 2007, de http://www.ugr.es/ icmi/iase_study/

Jollife, F. (1991). Assessment of the understanding of statistical concepts. In D. Vere-Jones (Ed.), Proceedings of the international conference on teaching statistics (Vol. 1, pp.461-466). Voorburg: International Statistical Institute.

Kemmis, J. (1992). Mejorando la educación mediante IAP. En M. Salazar (Coord.), La investigación-acción. Inicios y desarrollos, (pp. 175-204). Madrid: Popular.

Koelher, M. y Grouws, D. (1992). Mathematics teaching practices and their effects. En D. Grouws (Ed.), Handbook of Research of Mathematics Teaching and Learning (pp. 115-126). Nueva York: Mac Millan.

Konold, C. y Garfield, J. (1993). Statistical Reasoning Assessment. Part 1: Intuitive Thinking, Unpublished manuscript, SRRI. Amherst: University of Massachusetts.

Kosslyn, S. M. (1989). Understanding charts and graphs. Applied Cognitive Psychology. 3, $185-225$.

Kurtz, N. R. (1999). Workbook for Statistical Analysis for the Social Sciences. London: Allyn and Bacon.

Lane, F. J. (2002). An investigation of preservice secondary mathematics teachers' conceptions of probability and statistics (Disertación doctoral, Universidad de Virginia, 2002). Dissertation Abstracts International, 62(10), 3326A.

Lee, Y. y Nelson, D. (2004). A conceptual framework for external representations of knowledge in teaching and learning enviroments. Educational Technology, 2, 28-36.

Leinhardt, G. (1988). Getting to know: Tracing students' mathematical knowledge from intuition to competence. Educational Psychologist, 23 (2), 119-144.

Lesh, R., Post, T., \& Behr, M. (1987). Representations and Translations among Representations in Mathematics Learning and Problem Solving. En C. Janvier, (Ed.). Problems of Representations in the Teaching and Learning of Mathematics (pp. 33-40). Hillsdale: Lawrence Erlbaum.

Llinares, S. (1992). Los mapas cognitivos como instrumento para investigar las creencias epistemológicas de los profesores. En C. Marcelo (Ed.), La investigación sobre la formación del profesorado: métodos de investigación y análisis de datos (pp. 5795). Argentina: Cincel.

Llinares, S. (1993). Aprender a enseñar matemáticas. Conocimiento del contenido pedagógico y entornos de aprendizaje. En L. Montero y J. Vez (Eds.), Las didácticas específicas en la formación del profesorado I (pp. 377-407). Santiago de Compostela: Tórculo Edicións.

Llinares, S. (1996). Conocimiento profesional del profesor de matemáticas: conocimiento, creencias y contexto en relación a la noción de función. En J. Ponte y et al. (Eds.), 
Desenvolvimiento profesional de los profesores de matemáticas en formación (pp. 47- 82). Lisboa, Portugal: Sociedad Portuguesa de Ciencias de la Educación.

Llinares, S. (1998). La investigación "sobre" el profesor de matemáticas: aprendizaje del profesor y práctica profesional. Aula, 10, 153-179.

Llinares, S. (1999a). Intentando comprender la práctica del profesor de matemáticas. En Ponte, J. y Serrazina, L. (Ed.). Educación Matemática en Portugal, España e Italia (pp. 109-132). Lisboa, Portugal: Sociedad Portuguesa de Ciencias de la Educación.

Llinares, S. (1999b). Conocimiento y práctica profesional del profesor de matemáticas: características de una agenda de investigación. ZETETIKE, 7(12), 9-36.

Llinares, S. (2000). Secondary school mathematics teacher's professional knowledge: A case from the teaching of the concept of function. Teachers and Teaching: theory and practice, 6(1), 41-62.

Llinares, S. (2003). Contexto y práctica de formar profesores de matemáticas. Una mirada al caso de España. En M. Fandiño (Ed.), Riflessioni sulla formazione iníziale degli insegnanti di matemática: a ressegna internazionale (pp. 177-194). Bolonia: Pitágora.

Llinares, S. y Krainer, K. (2006). Mathematics (student) teacher and teacher educators as learners. En A. Gutierrez y P. Boero (Eds.), Handbook of Research on the Psychology of Mathematics Education (pp.429-459). Rotterdam: Sense Publishers B. V.

Llinares, S. y Sánchez, G. M. (1990). El conocimiento profesional del profesor y la enseñanza de las matemáticas. En C. S. Llinares y G. M. Sánchez (Eds.), Teoría y práctica en Educación Matemática (pp. 67-116). Sevilla: ALFAR.

Llinares, S., Sánchez, V. y García, B. M. (1994). Conocimiento del contenido pedagógico del profesor. Tareas y modos de representación de las fracciones. Revista de Educación, 304, 199-225.

Lloyd, G. M., y Wilson, M. (1998). Supporting Innovation: The impact of a teacher's conceptions of functions on his implementation of a reform curriculum. Journal for Research in Mathematics Education, 29(3), 248-274.

Lopes, C. E. (2006). Stochastics and the professional knowledge for teachers. En A. Rossman y B. Chance (Eds.), Proceedings of the Seventh International Conference on Teaching Statistics. Salvador, Brasil: International Statistical Institute and International Association for Statistical Education. Recuperado el 20 de julio de 2008, de http://www.stat.auckland.ac.nz/ iase/publications

López, J. (1999). Conocimiento docente y práctica educativa. El cambio hacia una enseñanza centrada en el aprendizaje. Málaga: Ediciones Aljibe.

Magnusson, S., Krajcik, J., y Borko, H. (1999). Nature, sources and development of pedagogical content knowledge. En J. Gess-Newsome y N. G. Lederman (Eds.), Examinig pedagogical content knowledge (pp. 95-132). Dordrecht: Kluwer Academic Publisher.

Makar, K. N. (2004). Devoloping statistical inquiry: prospective secondary math and science teachers' investigations of equity and fairness through analysis of accountability data. Disertación Doctoral no publicada, Universidad de Texas.

Marcelo, C. (1993). Cómo conocen los profesores la materia que enseñan. Algunas contribuciones de la investigación sobre el conocimiento didáctico del contenido. 
En L. Montero y J.M. Vez (Eds.). Las didácticas específicas en la formación del Profesorado (pp. 191-211), Santiago de Compostela: Tórculo.

Marcelo, C. (2007). Incorporación de las TICs en la formación inicial docente. Revista Enlace, un espacio de reflexión digital, 2. Recuperado el 6 de marzo de 2009, de http://www.oei.es/noticias/spip.php?article753

Marks, R. (1989). What exactly is pedagogical content knowledge? Examples from mathematics. Documento presentado en AERA Annual Conference. San Francisco, EE. UU.

Marks, R. (1990a). Pedagogical content knowledge in elementary mathematics (Disertación Doctoral, Universidad de Stanford, 1990). Dissertation Abstracts International, 51(01), 101A.

Marks, R. (1990b). Pedagogical Content Knowledge. From a Mathematical Case to a Modified Conception. Journal of Teacher Education, 41 (3), 3-11.

Martin del Pozo, M. R. (1994). El conocimiento del cambio químico en la formación inicial del profesorado. Estudio de las concepciones disciplinares y didácticas de los estudiantes de magisterio. Disertación doctoral no publicada, Universidad de Sevilla.

Marzano, R. et al. (1992). Dimensiones del aprendizaje. Manual del profesor. EEUU: McREL Mid-continent Regional Education Laboratory.

McDiarmid, G. W., Ball, D. L. y Anderson, Ch. W. (1989). Why Staying One Chapter Ahead Doesn't Really Work: Subject-Specific Pedagogy. En M. C. Reynolds (Ed.), Knowledge Base for the Beginning Teacher (pp. 193-205). Nueva York: Pergamon, Press.

McKenzie, D. L. y Padilla, M. J. (1986). The construction and validation of the test of graphing in science (TOGS). Journal of Research in Science Teaching, 23 (7), 571579.

Md, A., Hamzah, R., Ismail, H., Husain, S. e Ismail, M. (2006). Mathematics teachers' preparation program: determining the balance between mathematics and pedagogy. En J. Novotná, H. Moraová, M. Krátká y N. Stehlíková (Eds.), Proceedings of the 30th Conference of the International Group for the Psychology of Mathematics Education, Vol. 1, (pp. 297). Praga: PME

Meletiou, M. (2003). On the formalist view of mathematics: impact on statistics instruction and learning En A. Mariotti (Ed.), Proceedings of Third European Conference in Mathematics Education. Bellaria, Italy: European Research in Mathematics Education Society. Recuperado el 31 de agosto de 2006, de http://www.dm.unipi.it/ didattica/CERME3/proceedings

Meletiou, M. y Lee, C. (2002). Student understanding of histograms: A stumbling stone to the development of intuitions about variation. En B. Phillips (Ed.), Proceedings of the sixth international conference on teaching statistics: Developing a statistically literate society. Cape Town, South Africa. Voorburg: ISI.

Meletiou, M. y Stylianou, D. A. (2003). Graphical Representation of Data: The Effect of the Use of Dynamical Statistics Technological Tool. En Proceeding Sixth International Conference on Computer Bases Learning in Science (pp. 296-306). Praga: Universidad de Zilina.

Mellado, V. (1997). Preservice teachers' classroom practice and their conceptions of the nature of science. Science and Education, 6, 331-354. 
Mellado, V., Blanco, L. y Ruiz, C. (1999). Aprender a enseñar ciencias experimentales en la formación inicial del profesorado. Estudios de caso sobre la enseñanza de la energía. Badajoz: Universidad de Extremadura.

Mendonça, T., Coutinho, C. y Almouloud, S. (2006). Mathematics education an statistics education: meeting points and perspectives. En A. Rossman y B. Chance (Eds.), Proceedings of the Seventh International Conference on Teaching Statistics. CD ROM. Salvador (Bahia), Brazil: International Association for Statistical Education and International Statistical Institute.

Menelaou, M. M. (2000). Developing student's conceptions of variation: an untapped well in statistical reasoning. Disertación Doctoral no publicada, Universidad de Texas.

Merseth, K. K. (1994). Cases, Case Methods, and the Professional Development of Educators. Washington DC, EE. UU.: Clearinghouse on Teaching and Teacher Education (No. de servicio de reproducción de documentos ERIC ED 401 272)

Mickelson, W. T. y Heaton, R. (2004). Primary teachers' statistical reasoning about data. En D. Ben-Zvi y J. Garfield (Eds.), The challenges of developing statistical literacy, reasoning, and thinking (pp. 353-373). Dordrecht: Kluwer Academic Publisher.

Miles, M. B. y Huberman, A. M. (1994). Qualitative data analysis: An expanded source book. Newburi Park, CA: SAGE.

Miller, J. B. (2000). The quest for the constructivist statistics classroom: viewing practice through constructivist theory. Disertación Doctoral no publicada, Universidad de Ohio.

Monteiro, C. y Ainley, J. (2003, marzo). Developing Critical Sense in Graphing. En, Proceedings of the Third Conference of European Society for Research in Mathematics Education (pp. 1-10). Bellaria, Italy. Recuperado el 16 de noviembre de 2007, de www.dm.unipi.it/ didattica/CERME3/proceedings/Groups/TG5/TG5 monteiro cer me3.pdf

Monteiro, C. y Ainley, J. (2006). Studen teachers interpreting media graph. En A. Rossman \& B. Chance (Eds.), Proceedings of the Seventh International Conference on Teaching Statistics. Salvador, Brasil: International Statistical Institute e International Association for Statistical Education. Recuperado el 14 de abril de 2009, de http://www.stat.auckland.ac.nz/ iase/publications

Monteiro, C. y Ainley, J. (2007). Investigating the interpretation of media graphs among student teachers. International Electronic Journal Mathematics Education, 2(3), 187-207. Recuperado el 14 de abril de 2009, de http://www.iejme.com/032007/main.htm

Moore, D. (1997). New pedagogy and new content: The case of statistics. International Statistical Review, 65 (2), 123-165.

Moore, D. (2000). The basic practice of Statistics. 2d. ed. New York: W. H. Freeman and Company.

Moreira, M. A. y Novak, J. D. (1988). Investigación en Enseñanza de las Ciencias en la Universidad de Cornell: esquemas teóricos, cuestiones centrales y abordes metodológicos. Enseñanza de las Ciencias, 6 (1), 3-18.

Moreira, M.A. y Buchweitz, B. (1988).Mapas conceituais. Instrumentos didáticos de avaliaçâo e de análise de currículo. Brasil: Editora Moraes. 
Moreno, M. M. (1995). Enseñanza de las ecuaciones diferenciales a químicos y biólogos desde la perspectiva del profesor de matemáticas. Estudio de casos. Tesis de maestría no publicada, Universidad Autónoma de Barcelona.

Moreno, M. M. (2000). El profesor universitario de matemáticas: estudio de las concepciones y creencias acerca de la enseñanza de las ecuaciones diferenciales. Estudio de casos. Tesis de doctorado no publicada, Universidad Autónoma de Barcelona.

Moreno, M. M. y Azcárate, G. C. (2003). Concepciones y creencias de los procesos universitarios de matemáticas acerca de la enseñanza de las ecuaciones diferenciales. Enseñanza de las Ciencias, 21(2), 265-280.

Moreno, M. y Azcárate, C. (1997). Concepciones de los profesores sobre la enseñanza de las ecuaciones diferenciales a estudiantes de Quimica y Biologia. Estudio de casos. Enseñanza de las Ciencias, 15, 21-34.

Mosenthal, B. P. y Kirsch, S. I. (1990a). Understanding graphs and charts, Parte I. Understanding Documents, 33(5), 371-373.

Mosenthal, B. P. y Kirsch, S. I. (1990b). Understanding graphs and charts, Parte II. Understanding Documents, 33(6), 454-457.

National Council of Teachers of Mathematics (NCTM) (1991). Estándares curriculares y de evaluación para la Educación Matemática. (J. M. Álvarez y J. Casado, Trads.) Sevilla, España: Sociedad Andalusa de Educación Matemática “Thales”. (Trabajo original publicado en 1989).

National Council of Teachers of Mathematics (NCTM) (2000). Principles and standard for school mathematics. Reston: NCTM.

National Council of Teachers of Mathematics (NCTM) (2003). Principios y Estándares para la Educación Matemática (M. Fernández Trad.). Sevilla: Sociedad Andaluza de Educación Matemática "Thales".

Nicholson, J., y Darnton, C. (2003). Mathematics teachers teaching statistics: What are the challeges for the classroom teacher? En The International Statistical Institute $54^{\text {th }}$ Session. Berlin, Alemania. Recuperado el 6 de Julio de 2008, de http://www.stat.auckland.ac.nz/ iase/publications

Noll, J. (2007). Graduate Teaching Assistants' Statistical Knowledge for Teaching. Disertación Doctoral no publicada, Portland State University.

Nortes, A. (1987). Encuestas y precios. Madrid: Editorial Sintesis.

OCDE. (1999). Measuring student knowledge and skills - A New framework for assessment. Paris: OCDE Publications.

Ortiz, C. A. (1998). Entrevistas semiestructuradas, una aplicación en educación primaria. En J. B. Pascual (Ed.), Segundo Simposio de la Sociedad Española de Investigación en Educación Matemática (pp.37-56). Navarra: Universidad Pública de Navarra.

Owens, J. E. (1987). A study or four preservice secondary mathematics teachers' constructs of mathematics and mathematics teaching. Tesis doctoral no publicada, Universidad de Georgia.

Padilla, K., Ponce-de-León, A., Rembado, F. y Garritz, A. (2008). Undergraduate Professors' Pedagogical Content Knowledge: The case of 'amount of substance". International Journal of Science Education, 30(10), 1389-1404.

Pajares, F. M. (1992). Teachers' beliefs and educational research: Cleaning up a messy construct. Review of Educational Research 62 (3), 307-332. 
Peden, B. F. (2001). Correlational analysis and interpretation: Graphs prevent gaffes. Teaching of Psychology, 28(2), 129-131.

Peden, B. F. y Hausmann, S. E. (2000). Data graphs in introductory and upper level psychology textbooks: A content analysis. Teaching of Psychology, 27(2), 93-97.

Pehkonen, E. (2001). A hidden regulating factor in mathematics classrooms: mathematicsrelated beliefs. In M. Ahtee, O. Björkqvist, E. Pehkonen \& V. Vatanen(Eds.). Research on mathematics and science education (pp.11-35). Institute for Educational research. University of Jyväskylä.

Pereira-Mendoza, L., y Mellor, J. (1991). Students' concepts of bar graphs-Some preliminary findings. En D. Vere-Jones (Ed.), Proceedings of the third international conference on teaching statistics (Vol. 1, pp. 150-157). Voorburg: International Statistical Institute.

Pérez, G. (1994). Investigación cualitativa. Retos e interrogantes. II. Técnicas y análisis de datos. Madrid: La Muralla.

Peterson, P. L. (1988). Teachers' and students' cognitional knowledge for classroom teaching and learning. Educational Researchers, 17(5), 5-14.

Petocz, P. y Reid, A. (2002). How Students Experience Learning Statistics and Teaching. En B. Phillips (Ed.), Proceedings of the Sixth International Conference on Teaching Statistics, Voorburg: International Statistical Institute.

Petocz, P. y Reid, A. (2003). Relationships between student's experience of learning statistics and teaching statistics. Statistical Education Research Journal, 2(1), 3953. Recuperado el 25 de mayo de 2005, de http://fehps.une.edu.au/serj

Pfannkuch, M. (2006). Comparing box plot distributions: A teacher's reasoning. Statistics Education Research Journal, 5(2), 27-45. Recuperado el 14 de noviembre de 2007, de http://www.stat.auckland.ac.nz/ iase/serj/SERJ5(2)_Pfannkuch.pdf

Pfannkuch, M. y Rubick, A. (2002). An exploration of students' statistical thinking with given data. Statistical Education Research Journal, 1(2), 4-21. Recuperado el 23 de junio de 2005, de http://fehps.une.edu.au/serj

Pfannkuch, M. y Wild, C. (2003). Statistical thinking: how can we depelop it? En Proceedings of the $54^{\text {th }}$ International Statistical Institute Conference [CD-ROM]. Voorburg: International Statistical Institute

Pfannkuch, M., Budgett, S., Parsonage, R. y Horring, J. (2004). Comparison of data plots: building a pedagogical framework. En Proceedings of the 10th International Congress on Mathematical Education, 8 pp, Copenhagen, Dinamarca.

Pinto, J. (2008). Conocimiento del contenido pedagógico sobre la representación de datos estadísticos: estudios de casos con profesores de Estadística en carreras de Psicología y Educación. Hipótesis Alternativa, 9(1), 29-30. Recuperado el 10 de marzo de 2009, de http://www.ucv.ve/hipotesis/Data/Hipotesis\%20alternativa\%20N16.pdf

Pinto, J. y González, M. (2006). Sobre la naturaleza conceptual y metodológica del conocimiento del contenido pedagógico en matemáticas. Una aproximación para su estudio. Actas del X Simposio de la Sociedad Española de Investigación en Educación Matemática (pp. 237-255). Huesca: Universidad de Huesca.

Pinto, J. y González, M. (2008a). El conocimiento didáctico del contenido en el profesor de matemáticas: ¿una cuestión ignorada? Educación Matemática, 20 (3), 83-100. 
Pinto, J. y González, M. (2008b). Pedagogical content knowledge of a novel teacher: a case from the teaching of statistical graphical representation. En Proceedings of the 11th International Congress on Mathematical Education (ICME. Monterrey, México. Recuperado el 12 de agosto de 2008, de http://tsg.icme11.org/document/get/477

Pinto, J., Martín, G. y Barrabí, B. (2007). Estudio de necesidades de formación de profesores que imparten estadística en carreras del área social. En G. Buendía Abalos y G. Montiel Espinosa (Eds). Memorias de la XI Escuela de Invierno en Matemática Educativa (pp. 451-463). México: Red de Centros de Investigación en Matemática Educativa (CIMATE).

Pittenger, D. J. (1995). Teaching students about graphs. Teaching of Psychology, 22(2), 125-128.

Ponte, J. P., y Chapman, O. (2006). Mathematics teachers' knowledge and practices. En A. Gutierrez y P. Boero (Eds.). Handbook of reaserch on the psychology of mathematics education: Past, present and future (pp. 461-494). Róterdam: Sense.

Porter, A. C. (2002). Measuring the content of instruction: Uses in research and practice. Educational Researcher, 31(7), 13-14.

Porter, C. y Smithson, L. (2001). Defining, developing, and using curriculum indicators. Filadelfia, PA, EE. UU.: University of Pennsylvania, Consortium for Policy Research in Education.

Prawat, R. S. (1992). Teachers' beliefs aboaut teaching and learning: A constructivist perspective. American Journal of Education, 100 (3), 354-395.

Putnam, R. y Borko, H. (2000). El aprendizaje del profesor: implicaciones de las nuevas perspectivas de la cognición. En B. J. Biddle, T. L. Good e I. F. Goodson (Eds.), La enseñanza y los profesores I (pp. 219-309). Barcelona: Paidós

Reid, A. y Petocz, P. (2002). Students' Conceptions of Statistics: A Phenomenographic Study . Journal of Statistics Education, 10(2). Recuperado el 18 de noviembre de 2009 de www.amstat.org/publications/jse/v10n2/reid.html

Rico, L. (1995). Errores en el aprendizaje de la Matemática. En J. Kilpatrick, P. Gómez y L. Rico (Eds.), Educación matemática (pp. 69-108). México: Iberoamérica.

Rodríguez, G., Gil, J. y García, E. (1999). Metodología de la investigación cualitativa. Málaga: Ediciones Aljibe.

Roth, W-M. \& Bowen, G. M. (2001). Professionals read graphs: a semiotic analysis. Journal for Research in Mathematics Education, 32(2), 159-193.

Rovegno, I. C. (1992). Learning to teach in a field-based methods course: The development of pedagogical content knowledge. Teaching and Teacher Education, 8(1), 69-82.

Rubio, M. y Varas, J. (2004). El análisis de la realidad en la intervención social. Métodos y técnicas de investigación (3a. ed.). Madrid: Editorial CCS.

Russell, S. (1990). Issues in training teachers to teach statistics in the elementary school: A world of uncertainty En A. Hawkins (Ed.), Training teachers to teach statistics Proceedings of the International Statistical Institute Round Table Conference (pp. 59- 71). Voorburg: International Statistical Institute.

Saari, H. (1983). Koulusaavutusten affektiiviset oheissaavutukset. [Affective consequences of the school achievements] University of Jyväskylä. Institute for Educational Research. Publications 348.

Salkind, N. (2000). Statistics for people who (think they) hate statistics. Londo: Sage Publications, Inc. 
Sánchez, E. (1989). Un proyecto de investigación en enseñanza de la estadística. En J. Oviedo, T. Tsijli, R. Sanabria y A. Quezada (Eds.), Memorias de la Tercera Reunión Centroamericana y del Caribe sobre Formación de profesores $e$ Investigación en Matemática Educativa, (pp. 3-16). San José, Costa Rica: Universidad de Costa Rica.

Sánchez, V. y Llinares, S. (2002). Imágenes sobre las matemáticas, su enseñanza y aprendizaje en estudiantes para profesores de secundaria y tareas matemáticas escolares. Revista de Educación, 329, 443-461.

Sánchez, V. y Llinares, S. (2003). Four student teachers' pedagogical reasoning on functions. Journal of Mathematics Teacher Education, 6, 5-25.

Sandín, M. (2003). Investigación cualitativa en educación. México: Mc Graw Hill.

Schwab, J. J. (1978). The practical: translation into curriculum. En I. Westbury y N. J. Wilkof (Eds.). Joseph J. Schwab: Science, curriculum and liberal education. Selected essays. Chicago: University of Chicago Press.

Schwab, J. J. (1983). The practical four: Something for curriculum professors to do. Curriculum Inquiry, 13, 239-265.

Sfard, A. (1991). On the dual nature of mathematical conceptions: Reflections on processes and objects as different sides of the same coin. Educational Studies in Mathematics 22, 1-36.

Sharma, S.V. (2006). High school students interpreting tables and graphs: implications for research. International Journal of Science and Mathematics Education, 4, 241-268.

Shaughnessy, J. M. (1992). Research in probability and statistics: reflections and directions. En D. Grouws (Ed.), Handbook of Research of Mathematics Teaching and Learning (pp. 465-494). Nueva York: Mac Millan.

Shaughnessy, J. M. (2007). Research on statistic learning and reasoning. En F. K. Lester (Ed.). Second Handbook of Research on Mathematics Teaching and Learning (pp. 957-1049). Greenwich: NCTM.

Shaughnessy, J. M. y Bergman, B. (1993). Thinking about uncertainty: probability and statistics. En P. Wilson (Ed.), Research Ideas for the Classroom. High School Mathematics (pp. 177-197). Nueva York: MacMillan Publishing Company.

Shaughnessy, J. M., Garfield, J. y Greer, B. (1996). Data handling. En A. J. Bishop, et al (Eds.), International Hanbook of Mathematics Education (pp. 205-307). Dordrecht: Kluwer Academic Publishers.

Sherin, M. G., Sherin, B. L., y Madanes, R. (2000). Exploring diverse accounts of teacher knowledge. Journal of Mathematical Behavior, 18 (3), 357-375.

Shön, D. (1983). The Reflective Practitioner: How Professionals Thinking in Action (1a. ed.). New York: Basic Books.

Shulman, L. S. (1986a). Paradigms and research programs in the study of teaching. In M.C. Wittrock (Ed.), Handbook of research on teaching. New York: MacMillan.

Shulman, L. S. (1986b). Those who understand: Knowledge growth in teaching. Educational Research, 15 (2), 4-14.

Shulman, L. S. (1987). Knowledge and teaching: foundations of new reform. Harvard Educational Review, 57 (1), 1-22.

Shulman, L. S. (1993). Renewing the pedadogy of teacher education: the impact of subjectspecific conceptions of teaching. En L. Moreno, y J. M. Vez (Eds.), Las didácticas 
específicas en la formación de profesores (pp. 53-69). Santiago de Compostela,: Tórculo Edicions.

Shulman, L. S. (1999). Foreword. En J. Gess-Newsome, y N. G. Lederman (Eds). Examining Pedagogical Content Knowledge (pp. ix-xii). Londres: Association for the Education of Teachers in Science, Kluwer Academic Publishers.

Shulman, L. S. y Sykes, G. (1986). A national board for teaching?: In search of bold standard. Documento presentado para la Task Force on Teaching as a Profession. Nueva York: Carnegie Corporation.

Sierra, R. (1995). Técnicas de investigación sociales. Teoría y ejercicios. Madrid: Paraninfo.

Skemp, R. R. (1976). Relational understanding and instrumental understanding. Mathematics Teaching, 77, 20-26.

Smith, B. O. (1980). A design for a school of pedagogy. Washington DC: Department of Education.

Smith, D. C. y Neale, D. C. (1989). The construction of subject matter knowledge in primary science teaching. Teaching and Teacher Education, 5 (1), 1-20.

Smith, G. (1998). Learning Statistics By Doing Statistics. Journal of Statistics Education 6(3). Recuperado el 10 de diciembre de 2009 de http://www.amstat.org/publications/JSE/v6n3/smith.html

Smith, K. H. (2000). Early chilhood teachers' pedagogical content knowledge in mathematics (Disertación Doctoral, Universidad del Estado de Georgia, 2000). Dissertation Abstracts International, 61(10), 3886A.

Solanas, A., Salafranca, L., Fauquet, J. y Núñez, M. (2005). Estadística descriptiva en Ciencias del Comportamiento. Madrid: Thomson Editores.

Sorto, M. A. (2004). Prospective middle school teachers' knowledge about data analysis and its application to teaching. Disertación Doctoral no publicada, Universidad del Estado de Michigan.

Sorto, M. A. (2007). Assessing the Knowledge of Future Middle School Teachers in Statistics by Lesson Design. Documento presentado en Proceedings of the International Association of Statistics Education, Guimaraes, Portugal.

Sorto, M. A. y White, A. (2004). Statistical Knowledge for Teaching. Documento presentado en Proceedings of the 10th International Congress on Mathematical Education, Copenague, Dinamarca.

Stake, R. (1994). Case Studies. En N. K. Denzin e Y. S. Lincoln (Eds.), Handbook of Qualitative Research (pp. 236-247). London: SAGE Publications.

Stake, R. (1998). Investigación con estudio de casos. (2a. ed.). Madrid: Morata.

Swenson, K. A. (1998). Middle school mathematics teachers' subject matter knowledge and pedagogical content knowledge of probability: its relations to probability instrution (Disertación Doctoral, Universidad del Estado de Oregon, 1998). Dissertation Abstracts International, 59(02), 440A.

Tamir, P. (1988). Subject matter and related pedagogical knowledge in teacher education. Teaching and Teacher Education, 4(2), 99-110.

Taylor, S. y Bogdan, R. (1987). Introducción a los métodos cualitativos de investigación. Barcelona: Paidós. 
Thompson, A. G. (1984). The relationship of teachers' conceptions of mathematics and mathematics teaching to instructional practice. Educational Studies in Mathematics, 15 (2), 105-127.

Thompson, A. G. (1992). Teachers' beliefs and conceptions: a synthesis of the research. En D. Grouws (Ed.), Handbook of Research of Mathematics Teaching and Learning (pp. 127-146). Nueva York: Mac Millan.

Thompson, B. W. (1994). Making data analysis realistic: Incorporating research into statistics courses. Teaching of Psychology, 21 (1), 41-43.

Tufte, E. (1983). The Visual Display of Quantitative Information. Cheshire: Graphics Press.

Tukey, J. (1977). Exploratory Data Analysis. Londres: Addison-Wesley Publishing Company.

Vallecillos, A. (1996). Inferencia estadística y enseñanza: un análisis didáctico del contraste de hipótesis estadísticas. Granada: Comares.

Valles, M. (2003). Técnicas cualitativas de investigación social. Madrid: Síntesis.

Van Driel, J., De Jong, O. y Verloop, N. (2002). The development of preservice Chemestry Teachers' Pedagogical Content Knowledge. Science Teacher Education, 86, 572590.

Villarruel, F. M. (2003). Evaluación educativa. Elementos para su diseño operativo dentro del aula. Revista Iberoamericana de Educación. De los lectores. Recuperado el 21 de abril de 2005, de http://www.campusoei.org/revista/deloslectores/473Villarruel.pdf

Wainer, H. (1980). A test of graphicacy in children. Applied Psychological Measurenment, 4(3), 331-340.

Wainer, H. (1992). Understanding Graphs and Tables. Educational Researcher, 21 (1), $14-$ 23.

Wainer, H. y Thissen, D. (1993). Graphical data analysis. En G. Keren y C. Lewis (Eds.), A Handbook for data análisis in the behavioral sciences: statistical issues (pp.391457). Hillsdale: Lawrence Erlbaum Associates, Inc.

Walker, R. (1989). Métodos de Investigación para el Profesorado. Madrid: Morata.

Wallece, M. L. (1990). How do teachers know geometry? A multi-case study of secondary school geomtry teachers' subject-matter and pedagogical content knowledge (subject matter knowledge) (Disertación Doctoral, Universidad de Minesota, 1990). Dissertation Abstracts International, 51(12), 4052A.

Wanko, J. J. (2000). Going public: The development of teacher educator's pedagogical content knowledge (Disertación Doctoral, Universidad del Estado de Michigan, 2000). Dissertation Abstracts International, 62(01), 109A.

Ward, R., Anhalt, C. y Vinson, K. (2003, abril). Mathematical representations and pedagogical content knowledge: an investigation of prospective teachers' development. Documento presentado en el Annual Meeting of the American Educational Research Association (AERA) Special Interest Group (SIG), Chicago, IL.

Watson, J. M. (2001). Profiling teachers' competence and confidence to teach particular mathematics topics: The case of chance and data. Journal of Mathematics Teacher Education, 4, 305-337. 
Watson, J. M. (2005). Assessing teachers' knowledge for teaching quantitative literacy. Proceedings of the ICMI Third East Asian Conference on Mathematics Education [CD]. Shanghai, China.

Watson, J. M. y Callingham, R. A. (2003). Statistical literacy: a complex hierarchical construct. Statistics Education Research Journal, 2(22), 3-46.

Watson, J. M. y Callingham, R. A. (2008). Establishing pedagogical content knowledge for teaching statistics. En C. Batanero, G. Burril, C. Reading \& A. Rossman (Eds,), en ICMI/IASE Study: Teaching Statistics in School Mathematics. Challenges for Teaching and Teacher Education. Proceedings of the ICMI Study 18 and 2008 IASE Round Table Conference. Monterrey: ICMI y IASE.

Watson, J.M. y Moritz, J.B. (2001). Development of reasoning associated with pictographs: representing, interpreting, and predicting. Educational Studies in Mathematics, 48, 47-81.

Weintraub, S. (1967). What research says to the reading teacher. Reading Teacher. 20, 345349.

Wild, C. J. y Pfannkuch, M. (1999). Statistical thinking in empirical enquiry. International Statistical Review, 67(3), 223-265.

Wilson, S. M. y Wineburg, S. S. (1988). Peering at history through different lenses: The role of disciplinary perspectives in teaching history. Teachers College Record, 89, 525-539.

Wilson, S. M., Shulman, L. S. y Richert, A. E. (1987). 150 different ways of knowing: representations of knowledge in teaching. En J. Calderhead (Ed.), Exploring teacher thinking (pp. 104-124). London: Cassell.

Wu, Y. (2004). Singapore Secondary School Students' Understanding of Statistical Graphs. En Proceedings of the 10th International Congress on Mathematical Education, 7 pp. Copenhagen, Dinamarca. 